

$D-10$ 



\section{Halitherium Schinzi}

die fossile Sirene des Mainzer Beckens.

Eine vergleichend-anatomische Studie

von

\section{Dr. G. R. Lepsius}

Professor der Geologie und Mineralogie an der technischen Hochschule zu Darmstadt

Inspector am Grossherzoglichen Museum.

Mit zehn lithographirten Tafeln.

Abhandlungen des Mittelrheinischen geologischen Vereins

I. Band, 1. Lieferung.

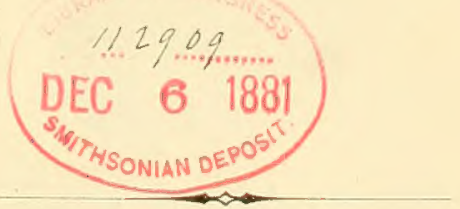

Darmstadt 1881.

In Commission bei A. Bergsträsser. 


\title{
Halitherium Schinzi
}

\section{die fossile Sirene des Mainzer Beckens.}

Eine vergleichend-anatomische Studie

\author{
Dr. G. R. $^{0^{i j}}$ Lepsius
}

Professor der Geologie und Mineralogie an der technischen Hochschule zu Darmstadt

Inspector am Grossherzoglichen Museum.

Abhandlungen des Mittelrheinischen geologischen Vereins

I. Band, 2. Lieferung.

$$
117625
$$

JUL 71882

*/THSONIAN DEPO

Darmstadt 1882. 



\section{Vor w o r t.}

In den untersten tertiären Schichten des Mainzer Beckens, den oligocänen Meeressanden, wurden bereits seit langer Zeit die fossilen Reste einer Sirene aufgefunden, welcher Kaup im Jahre 183 den Namen Halitherium Schinzi beilegte. Die Sandgruhen hei Flonheim und Cfthofen, zwei Dörfern nordwestlich von Alzey in Rheinhessen gelegen, lieferten die von Kaup, H. von Meyer, Bronn und Krauss beschriebenen Theile dieses interessanten Thieres. Einzelne Stiucke des Skelettes, hesonders Ripyenst üclie, sind nicht selten in den Meeressinden lïngs der westlichen (irenze des Mainzer Beckens von Alzey bis Kreuznach und jenseits dieser Linie in den isolirten Partien derselben Sande, welche weit die Nahe aufwärts die Rothliegenden Berge krönen.

In den letzten Jahren haben sich nun in den Sandgruben bei Alzey und Flonheim häufiger mehr oder weniger vollständige Skelette vorgefunden; es war mir möglich dadurch, dass ich mehrere Ausgrabungen selhst leitete und die zerbrechlichen Knochen aus den umhiillenden Sanden hernach

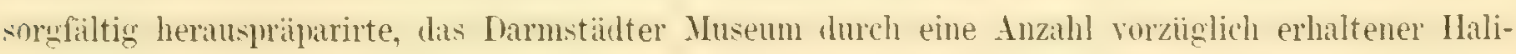
therien zu bereichern. Dieses neue treffliche IIaterial, welches gestattete, einige bisher unbekannte Theile dieses tertiüren Vorfahren der lebenden Sirenen kennen zu lemen und andre noch zweifelhafte Punkte festzustellen, gab mir die Veranlassung, die vorliegende Monographie zu schreiben.

Die Skelette des Halitherium liegen selten mehr an einem Orte in allen ihren Theilen zusammen; in der Regel fehlen die kleinen, leichteren Knochen: so fast stets die Hand- und Fingerknochen, die letzten Schwanzwirbel und der rudimentïre Oberschenkel; von dem letateren habe ich überhaupt erst fünf Exemplare erhalten kömen. Sei es nun, dass von den Sandgräbern früher diese kleinen Knnochen in den Sanden nicht beachtet, oder dass sie durch die Wellen des Mleeres, ehe die Körper in den Sand eingebettet waren, fortgespühlt, oder auch, dass sie von den zahlreichen und grossen Iaifischen des Tertiår-MLeeres mit dem Fleische verzehrt wurden. Dennoch liegen mir nun auch die 
feinsten Knnochen des Schädels und des Körpers in einer Anzahl Exemplaren so weit vollständig vor, dass ausser den Handwurzelknochen und einigen Phalangen nur noch das vordere Ende des Zwischenkiefers und das mittlere Stiick des Gaumen- und des PHugscharbeins fehlen.

Immer aber sind die einzelnen Ḱnochen des Halitherium bereits an Ort und Stelle in viele Stücke zerbrochen, entweder wohl durch den Druck der ïberlastenden Schichten, oder durch die Erderschütterungen. Es ist daher zur Erhaltung dor liopf-Knochen nothwendig, die ganzen Schädel mit den umschliessenden Sanden nach Hause zu transportiren, um dort beim Präpariren sofort jedes einzelne Stiickchen wieder ankleben zu können.

Zuweilen sind die hnochen durch Kieselsäure oder durch Kalk fest in einem Sandstein eingebacken, wo sie dam natürlich schwer ganz herauszuarbeiten sind; oder sie sind durch angehende Verwitterung sehr mürbe geworden. In der Regel aber ist die línochensubstanz treflich und vollständig erhalten: die chemische Anaḷse eines Rippenstickes ercabl die mittlere Zusimmensetzung aller Säugethier-Kinochen mit $80 \%$ phosphorsaurem und 15,5\% kohlensaurem Kalk, was nur etwa auf eine geringe Amreicherung des letzteren schliessen lïsst.

Vou den Sirenen leben jetzt noch drei Arten: die Halicore Dugong im Rothen Meere und längs der Ostküste von Afrika; Manatus senegalensis an den Miindungen der Fliisse der westafrikanischen Küste, so weit sie den Tropen angehört; und Manatus australis an der Ostküste von Süd-Amerika in Surinam und an den Mündungen des Amazonenstromes und des Orinoco. Eine vierte Art, die Rhytina Stelleri, wurde von Bering und seinen Reisegefährten im Jahre 1741 in grossen Heerden an der Küuste der Beringsinsel entdeckt; sie hielt aber die Berïhrung mit der Europäischen Kultur nicht lange aus und war bereits im Jahre 1768 vollständig ausgerottet.

Der lange walzenförmige, fette liörper, die dicke, bei der Rhytina borkenartige Haut, der gänzliche Mangel an hinteren Extremitäten und der breite Flossenschwanz, kurz die äussere Gestalt dieser Säugethiere wurde die Veranlassung, diese kleine Thiergxuppe den Walfischen im zoologischen Systeme unterzuordnen als "Herbivore Cetaceen“. Doch haben in nenerer Zeit bereits einzelne Zoologen, so Huxley, Blainville, Flower, Murie und andere gegen die Zurechnung zu den Cetaceen Einspruch erhoben und die Verwandtschaft dieser Thiere zu den Elephanten und Hufthieren hervorgehoben. Ich sehe die Sirenen als eine selbständige Thierordnung an und trenne sie völlig ab von den Cetaceen, sodass in der vorliegenden Arbeit unter dem Namen "Cetacea" nur die echten Walfische und Delphine begriffen sind, mit Ausschluss der Sirenen. Dass die Sirenen der Anatomie ihres Körperbanes nach in der That gar keine Beziehungen zu den Cetaceen, dagegen eine offenbare Verwandtschaft zu den Ungulaten zeigen, das erweist noch mehr eine genaue Untersuchung 
des Halitherium Schinzi: denu hier erlaubt vor allem der vollständige und wohl ausgeprägte Zahnapparat, dann der noch rorhandene, wenn auch schon rudimentäre Oberschenkel und die grösseren Beckenknochen, sowie das bedeutend höhere Alter des Thieres ïberhaupt, die Verwandtschaft mit anderen Säugethieren noch weiter zu verfolgen. Bei den lebenden Sirenen überwuchern die durch äussere Umstände neu erworbenen Eigenthümlichkeiten des Körperbaues natürlich noch weit mehr die von den stammverwandten Ahnen ererbten Formen, als dies bei dem tertiären Vorfahren der Fall ist.

Ich habe daher ein Hauptgewicht auf die Vergieichung des Halitherium mit den lebenden Sirenen gelegt. Es stand mir dazu das folgende Material zu Gebote: ein vollständiges Skelett von Halicore Dugong und ein Schädel derselben Art aus dem Rothen Meere, sowie ein ganzes Skelett des Manatus australis von Surinam im Darmstädter Museum. Ferner zwei Schädel von Halicore, ein Schädel des Manatus australis von Surinam und zwei Schädel des Manatus senegalensis, welche Dr. Lenz von der Mündung des Ogowe in West-Afrika mitbrachte, aus dem Berliner UniversitätsII useum; Herr Geheime Rath Professor Dr. Reichert hatte die Güte, mir diese fünf Schädel nach Darmstadt zu schicken. Professor E. von Nordenskjöld hatte die Freundlichkeit, mir für meine Arbeit eine Anzahl von ausgezeichneten Photographien zu senden, genommen nach den Skeletten von Rhytina Stelleri, welche der berühmte Umsegler Asiens aus den Sanden an der Küste der Beringsinsel ausgraben liess und auf der Vega mit nach Stockholm brachte.

Auch untersuchte ich die im Berliner Museum noch ausserdem vorhandene reiche Sammlung von Halicore- und Manatus-Schädeln und das Skelett von Halicore und einige Manatus-Schädel, welche im Senkenbergischen Institut in Frankfurt liegen.

Von gut erhaltenen Resten des Halitheriun Schinzi giebt es ausser im Darmstärlter Museum noch ein Skelett und einen Schädel im Universitäts-Museum zu Heidelberg, welche von Flonheim stammen und bereits von Krauss, Kaup und Bronn in ihren Arbeiten benutzt wurden; Herr Professor Bütschli in Heidelbery erlaubte mir freundlichst, diese Stuicke zu studiren. Endlich hatten Herr Baron de Zigno in Padua und der Director des Museums in Florenz, Professor Cesare d'Ancona, die Güte, mir werthvolle Gypsabgüsse der fossilen Sirenen aus dem Tertiär von Ober-Italien zu senden.

Die vorliegende Arbeit zerfïllt in drei Abschuitte, deren erster die Beschreibung des Skelettes von Halitherium Schinzi und die Vergleichung desselben mit den lebenden Sirenen enthält, deren zweiter sich mit den übrigen bekannten fossilen Sirenen beschäftigt, und deren dritter die Verwandtschaft der Sirenen mit andern Ordnungen der Säugethiere behandelt. 
In der vergleichenden Anatomie der Thiere herrscht leider noch weniger eine einheitliche Bezeichnungr der Organe und ihrer Theile, als in der menschlichen Anatomie: das gleiche oder doch homologe Kỉnochenstuick am Schädel der Säugethiere trägt bei den verschiedenen Autoren ganz verschiedene Namen. Nachdem num in der menschlichen Anatomie die Benennungen, wie sie Henle in seinem Handbuch der Anatomie des Menschen aufgestellt hat, meln und mehr Eingang in die Literatur gewonnen haben, bin ich in der vorliegenden Arbeit gleichfalls möglichst genau der Henle'schen Bezeichnung gefolgt; denn durch eine eingehende Betrachtung konnten fast alle Einzeltheile des Knochenbaues von Halitherium in Uebereinstimmung gelnacht werden mit den homologen Stiicken am menschlichen Skelett. Dennoch habe ich dieses Princip nicht so ängstlich durchgeführt, dass ich nicht in einzelnen Punkten aus bestimmten Gründen andere Namen genommen hätte, besonders in den Fällen, wo es darauf ankam, den Unterschied sofort im Namen zu kennzeichnen. Auch habe ich es bei der Beschreibung der Knochen versucht, die Henle'sche Ifethode anzuwenden, um so mehr, als ich einst zu Fïssen dieses Meisters anschaulicher Beschreibung gesessen habe.

Bei den mannichfaltigen Abweichungen, welche die Formen und die absoluten Maasse der Knochen nicht nur bei den verschiedenen Arten und Gattungen der Sirenen, sondern auch bei den Individuen ein und derselben Art nach Alter, Geschlecht und Eigenheit zeigen, habe ich stets die Beschreihung nach bestimmten Intividuen daturch fixirt, dass ich die Lämge des Sichädels angegreben und den Maassen als Einheit zu Grunde gelegt habe.

Die lithographische Zeichnung der zehn Tafeln verdanke ich ler kunstfertigen Hand des Herrn Architecten G. Wolff, Studirenden der technischen Hochschnle zu Darmstadt.

Darmstadt, im Juli 1881.

\section{Lepsius.}




\section{In ha l t.}

Vorwort .

I. Beschreibung des Skelettes von Halitherium Schinzi und Vergleichung desselben mit den Skeletten von Halicore, Manatus und Rhytina . . . . . . . . . . . 1 a. Der Schädel

1. Os occipitis

2. Os sphenoideum

3. Os ethmoideum

4. Os frontis

5. Os temporum et ossicula auditus

6. Os parietale.

7. Os maxillae

8. Os incisivum.

9. Os nasi .

10. Os zygomaticum

11. Os palatinum.

12. Vomer

13. Mandibula

14. Dis Gebiss

a. Dentes incisivi ossis incisivi

b. Dentes molares ossis maxillae.

c. Dentes praemolares ossis maxilla

d. Dentes molares mandibulae

e. Dentes praemolares mandibulae

f. Das Gebiss der lebenden Sirenen

15. Der Schädel im Allgemeinen

b. Die Wirbelsäule und die Extremititen

16. Columa vertebralis

17. Costae

18. Os hyoides

19. Sternum 
20. Die vordere Extremität
a. Scapula
b. Humerus
c. Ulna und radius
d. Knochen der Hand

21. Die hintere Extremität.

a. Os coxae

b. Femur .

II. Die fossilen Sirenen

1. Aus dem Mainzer Becken . . . . . . . . . . . 161

2. Aus der Umgegend von Basel . . . . . . . . . . 162

3. Aus dem Aargau . . . . . . . . . . . . . . . . . . . . 163

4. Aus Oberschwaben . . . . . . . . . . . . . . . . . . 163

5. Vou Linz an der Donau . . . . . . . . . . . . . . . . 164

6. Aus dem Wiener Becken . . . . . . . . . . . . . 165

7. Aus Bessarabien und der Krym. . . . . . . . . . . . . . . 167

8. Aus Belgien . . . . . . . . . . . . . . . . . . . . . . 168

9. Aus Frankreich . . . . . . . . . . . 168
a. Loire-liecken
. 168
b. Garonne-1Becken . . . . . . . . . . . . 170
c. Rhône-Becken . . . . . . . . . . . 174
d. Seine-Becken . . . . . . 175

10. Ans Ober-Italien . . . . . . . . . . . . . 177

a. Von Montiglio bei Turin . . . . . . . . . . . 177

b. Die Gattung Felsinotherium . . . . . . . . . 178

c. Aus den venetianischen Alpen . . . . . . . . . . . . . 179

11. Aus England. . . . . . . . . . . . . . . . . . . . 181

12. Aus Malta und Aegypten . . . . . . . . . . . . . . . . 182

13. Prorastomus sirenoïdes von Jamaica . . . . . . . . . . . . . 183

III. Uebersicht der Gattungen und Arten der Sirenen . . . . . . . . . . 18;

IV. Die Stellung der Sirenen im zoologischen System _. . . . . . . . . . . . . . 191

Erklärung der Tafeln $\mathbf{I}-\mathbf{X}$. . . . . . . . . . . . . . . . . . . . . 201 


\section{Beschreibung des Skelettes von Halitherium Schinzi und Vergleichung desselben mit den Skeletten von Halicore, Manatus und Rhytina.}

Der Knochenbau des Halitherium weist diesem tertiären Vorfalıren der jetzt lebenden Sirenen einen lang walzenförmigen, schweren Körper zu, der horizontal ausgestreckt im Wasser sich mittelst der Vorderarme langsam fortbewegte. Die etwa $2^{\mathrm{m}}$ lange aus einigen 50 Wirbeln bestehende Wirbelsäule trug vorn einen dicken Kopf, an den 19 Rückenwirbeln grosse Rippen und eine kurze vordere Extremität mit wohlausgebildeter Hand, befestigt an einem dem Brustkorbe aufgelegten Schulterblatt; ein reducirter Beclienkwochen lag nehen den plumpen Lembenwirbeln und stuitzte in einer kleinen Gelenkfläche das Rudiment eines Oberschenkels; die übrigen Theile der hinteren Extremität fehlten; die zahlreichen Schwanzwirbel waren wahrscheinlich, wie bei den lebenden Sirenen, von einer horizontal gestellten Fettlosse umgeben (Taf. VIII Fig. 91).

Der aus soliden Knnochen aufgebaute Schädel wurde von starken Nackemmuskeln aufrecht getragen, sodass er an dem kurzen Halse nicht wie bei den Walfischen nach unten herabhing, sondern durch eine schwache S-förmige Biegung der Wirbelsäule in einem halben rechten Winkel gegen die ersten Halswirbel gerichtet war; daher liegen die beiden Gelenktlïchen des Hinterhautes mehr unter-als oberhall des Hinterhauptsloches und gerale auf der Beugekante zwischen der L'nterund Hinterseite des Schädels. Der Kopf ist wie der ïbrige Körper von vorn nach linten stark verlängert; an demselben fallen sogleich die grossen Unterkiefer auf, sodann die ansehnlichen Zwischenkiefer mit den beiden Stosszähnen und die breit nach den Seiten ausgelegten Backenlinochen.

Im Gegensatz zu dem Schädelbau der Cetaceen steht der Schädel des Halitherium auf einer so hohen Stufe der Entwicklung, dass wir hei Betrachtung desselben fast überall die Topographie des menschlichen Schählels ühertragen mol die gleichen oder homologe Verhältnisse antreffen werden. Die zum Theil der Gattung zum Theil der ganzen Ordnung der Sirenen eigenthümlichen Abweichungen von dem allgemeinen Schädel-Typus der höheren Säugethiere werden wir erst nach der Beschreibung der einzelnen Schädeltheile zusammenfassen, weil in einer vorläufigen Uebersicht zuviel vorausgesetzt oder vorweggenommen werden müsste. Abgesehen davon, dass der vorliegende Schädel sich den bekamnten Gestalten der Säugethiere eng anschliesst, sollen die beigegebenen Tafeln die Anschaumg möglichst unterstiitzen und den Zusammenhang und die gegenseitige Lage der Einzeltheile an schiadel fortwährend erläutern. Wir beginnen daher sogleich mit der Beschreibung der 
Kopfknochen des Halitherium in der Reihenfolge und mit den Benennungen, wie sie Henle in seinem Handbuch der Anatomie für den menschlichen Schädel aufgestellt hat; die Vergleichung mit den drei lebenden ") Sirenen-Gattungen ziehen wir dabei sogleich heran, während wir die übrigen bekannten fossilen Arten der Sirenen und andre Säugethier-Klassen erst später in Beziehung zum Halitherium setzen werden.

\section{a. Der Schädel.}

\section{Os occipitis.}

Das Hinterhauptsbein des Halitherium nimmt einen beträchtlichen Antheil an der Bildung der Schädelkapsel und bestimmt die zum Theil eigenthiimliche Form seines Hinterhauptes; die vertikal gestellte Hinterwand des Schädels besteht fast ganz aus diesem dicken Knochen, welcher an der Unterkante der Wand nach vorn herumgebogen zugleich die Basis des Hinterhauntes abgiebt. Gerade in der Beugekante wird der Knochen durchbolnt von dem grossen foramen occipitale und der nach vorn umgebogene Grundtheil ist von den übrigen Schädelknochen isolirt durch die beiden grossen Schädelbasislöcher (foramen lacerum). Wie bei allen Säugethieren verwächst das Hinterhauptsbein des Halitherium aus vier Stïcken: dem Körper, den beiden Seitentheilen und der Schuppe. Die Gestalt und Lage dieser Theile ersieht man auf Taf. V Fig. 52 u. 53, Taf. I, Taf. II Fig. 3, Taf. X Fig. 96 u. 97.

Der Körper des Hinterhauptsbeines ist ein starker Knochen, er ist $50-55^{\mathrm{mm}}$ lang und stellt sich horizontal, also in der allgemeinen Längsrichtung des Thieres. Sein vorderer Theil ist dick und kurz, nach hinten verflacht er sich und läuft in zwei kurze, breite Aeste aus, welche den vorderen Rand des foramen occipitale bilden. Die nach vorn gewandte Fläche des Körpers ist abgerundet viereckig, beim ausgewachsenen Thiere von $30-32^{\mathrm{mn}}$ Durchmesser. Mit dieser Fläche verwächst der Körper stets fest mit dem Wespenbein-Körper: eine flache Einschniirung an der oberen Seite zwischen den beiden Körpern ist alles, was von der Naht übrig bleibt; indessen ist die Grenze zwischen beiden Knochen leicht zu erkennen dadurch, dass der Occipitaltheil schief gegen das Wespenbein anwächst, und daher ihre Obertächen an der Unterseite einen ausspringenden Winkel von $140-150^{\prime}$ bilden.

Die obere, dem Gehirnraum zugekehrte Fläche des Körpers ist ziemlich eben und glatt, gegen das foramen occipitale zu flach concav eingebogen. Die untere, im Ganzen unregelmässig ausgebogene Fläche trägt in der Mitte eine schwache Längsleiste, entsprechend dem tuberculum pharyngeum, und zu beiden Seiten je eine grosse, rauhe Ansatzfläche für den musculus rectus ca-

1) Uw nicht eine umständlichere Bezeichnung fortwährend anwenden zu mïssen, spreche ich in dieser Abhandlung auch von der Rhytina Stelleri als einer "lebenden Art, obwohl sie bereits vor mehr als 100 Jahren ausgerottet wurde; man kann sie kaum ssubfossil nennen, da wir durch Steller auch die Anatomie ihrer Weichtheile zum grossen Theil kennen. 
pitis anticus minor: ${ }^{2}$ ) Der Körper ist nicht durchbohrt. Seine freien Seiten sind stumpf abgeschnitten an den beiden grossen Oeffinungen der Schidelbasis, welche andrerseits vom Felsenbein und den Wespenbeinfligeln begrenzt werden und dem foramen lacerum und juguhre des Menschen entsprechen.

Die beiden nach hinten gestreckten Aeste des Körpers sind Hach, $7-10^{\mathrm{mu}}$ dick und spannen sich bis zu $50^{\mathrm{mm}}$ breit aus. Ihre hinteren Ränder verwachsen innig mit den Seitentheilen des os occipitis, ohne dass auch bei noch jungen Exemplaren eine Spur der Naht bliebe, und reichen bis nahe an den vorderen Rand der Condylen. Der kurze, hintere, gegen das foramen occipitale freie Rand des Körpers zwischen den Aesten ist zugeschärft; er wird von dem Zahn des Epistropleus nicht erreicht. An den beiden äusseren Seiten der Aeste springt je ein schwacher Höcker vor, dem sich die pars labyrinthica des Schläfenbeins nähert (Taf. X Fig. 96). Dieser processus intrajugularis ist bei Halicore und Rhytina nur schwach ausgebildet und entfernt sich mehr von der Pyramide des Schläfenbeins; bei Manatus aber ist dieser Fortsatz meist nicht unbedeutend und liegt der Pyramide so nahe an, dass dadurch das foramen jugulare deutlicher von dem vorderen formen lacerum abgetrennt erscheint.

Der corpus ossis occipitis der lebenden Sirenen unterscheidet sich in seiner Form nicht Wesentlich ron dem des Halitherium. IBei Halicore bleiht die Naht gesen den Wespenheinkinuer selbst bei alten 'Thieren noch sichtbar; die Nïhte der Aeste dagegen verwachsen im Alter vollständig. An dem Schädel eines jungen Dugong tragen die Aeste noch ein kleines Stiick der Condylen-Flächen. Die Naht gegen das Wespenhein rerwïchst hei Ianatus früheitig gänzlich: dagegen klaffen hei einem mir vorliegenden nicht melı jungen Schädel die Nähte der Aeste auf der Gehirnseite noch etwas, während sie aussen bereits zugewachsen sind. Die Nähte des Körpers an Schädel der Rhytina verschmelzen beiderseits völlig. Die Muskel-Ansätze des rectus capitis anticus minor treten bei den verschiedenen Sirenen-Schädeln verschierlen stark hervor: besonders gross und rauh sind sie bei der Rhytima (Taf. X Fig. 99).²)

Die Länge des Occipital-Körpers der Sirenen ist ungefähr gleich seiner Breite in den Aesten, auch bei dem abgebilileten Rhỵtina-Schïlel, während Brandt an dem ihm vorliegenden Schïdel von Rhytina eine grössere Breite fancl. $\left.{ }^{3}\right)$ Am Manatus-Schädel ist der Körper ansehnlich dünner und platter als bei Halitherium und Halicore, und ist auf der Oberseite Hach ausgeliöhlt, wie bei Rhytina. Simmntlich sind die Körper am dicksten nahe der Wespenbein-Xaht und verdünnen sich almmihlich zum Rande des foramen occipitale hin. Im Vergleich mit den breiten Seitentheilen und der Schuppe erscheint der Körper als ein dïnner Stiel durch die Ausschnitte des foramen lacerum; seine Aelmlichkeit mit einem Wirbelkörper tritt dadurch dentlicher hervor.

1) Siehe J. Mrurie. On the form and structure of the Manatee (Manatus americanus). 'Iransactious of the zoological Society of London. Vol. VIII. 1874. pag. 147. Tat. 24. Fig. 29.

$\left.{ }^{2}\right)$ Auch Blainville, Ostéographie, Vol. IV, Manatus pag. 43 erwähnt diese beiden Muskelansïtze auf der Unterseite des Körpers: „deux impressions musculaires ovales, allongées".

$\left.{ }^{3}\right)$ J. F. Brandt, Symbolae sirenologicae. Mém. de l'acad. de St. Petersbourg. VI. série, Scienc. nat. tom. V. 1810. pag. 15. 
Die partes laterales ossis occipitis von Halitherium, welche die beiden auf der Gelenkfläche des Atlas artikulirenden Condylen tragen, sind wie die andern Theile des Hinterhauptsbeines, dicke und starke Kinochen; ihre Flächen sind rauh und uneben (Taf. X Fig. 97). Sie umschliessen, unter Ausschluss der Schuppe, den grössten Theil des foramen occipitale. Während sie mit den Aesten des Körpers stets fest verwachsen sind, bleibt die lange horizontale Naht gegen die Schuppe bei den mir bekannten Schädeln von Halitherium offen, sodass unter den im Meeressande verstrenten Schädeltheilen die Occipital-Schupe mit den festgewachsenen Scheitelheinen, die Seitentheile aber mit dem Körper zusammen sich vorfinden. Die Nahtfläche gegen die Schuppe ist ganz rauh, etwas concav eingebogen und zeigt die grosse Dicke der Knochen; bei einem alten Thiere ist diese Nahtfläche $70^{\mathrm{mm}}$ lang (iiber beide Seitentheile fortgemessen) und bis $21 \mathrm{~mm}$ breit.

Die beiden Seitentheile stossen oben über dem foramen occipitale in einer bis $17^{\mathrm{mm}}$ langen Naht zusammen. Sie breiten sich zunächst flach beiderseits nach unten und seitlich aus und umfassen mit stumpfem Rande die obere Hälfte des foramen occipitale. Nach aussen und unten ziehen sich die Seitentheile in je einen starken processus jugularis ${ }^{1}$ ) aus; gerade herunter treten die beiden Gelenkhöcker, processus condyloilei, mit den grossen Gelenkflächen zu beiden Seiten des foramen occipitale hervor. Zwischen dem proc. condyloideus und dem proc. jugularis verläuft auf der Hinterseite des Schädels eine Hache Furche, fossa condylodea, die sich auf die Schädel-Unterseite herabzieht, in der Beugekante des Beins sich vertieft und in der incisura jugularis endigt. In dieser Furche und zwar gerade vor dem steilen Abfall des Gelenkhöckers anf der L'nterseite des Schädels mündet jederseits ein $4-5$ num weiter Gefässkanal, welcher innerhalb des foramen occipitale hinter dem Rand der incisuri jugularis in die Gehimhöhle anfsteigt: es ist dies der hei allen Sängethieren vorhandene Canalis hypoglossi (= foramen condyloideum auterius aut.), welcher dem zwölften Gehirnnerven, nervus lypoglossus, den Austritt aus dem Gehirn verschafft.

Der äussere Rand der Seitentheile ist unregelmässig nach aussen gekrümmt; oben an der Naht zur Occipital-Schuppe ist dieser Rand zunächst frei und bildet mit der unteren Ecke der Schuppe, dem oberen Ende des Schläfen- und Felsenbeins ein ansehnliches Loch, das foramen mastoideun; dieses Loch wurde im Leben wahrscheinlich wie bei den andern Sirenen von Knorpelmasse zum grossen Theil ausgefullt. Unter diesem freien Rande der Seitentheile fügt sich von innen her in eine thache Höhlung das hintere stumpfe Ende der Pyramide des Schlïfenheins (Felsenbein), und zwar greift der nach innen eingebogene Rand der pars jugularis ossis occipitis in eine Furche der Pyramile rauh und verzackt ein. Ein schmales Stiuck des Felsenbeins tritt daher zwischen dem Rand der Seitentheile ossis occipitis und dem Warzentheile ossis temporum an der hinteren Schädeloberfläche frei hervor. IDie beiden zusimmenstosienden Flichen der pirtes laterale's und des

$\left.{ }^{1}\right)=$ proc. paramastoideus aut. Obwohl dieser Fortsatz bei den meisten Säugethieren sehr viel grösser und auffallender geformt ist als der proc. jugularis am menschlichen Schädel, so liegt doch kein Grund vor, hier von der Bezeichnung in der menschlichen Anatomie abzuweichen, da der proc. paramastoideus animalium unzweifelhaft ein analoges Gebilde des proc. jugularis hominis ist; daher denn auch $z$. B. Claus in seinen Grundzügen der Zoologie 1871 pag. 1035 sich des letzteren Namens für den Säugethier-Schädel bedient. 
Felsenbeins sind Nahtflächen, welche niemals verknöchern; es ist diese superficies petro-occipitalis in ihrer ursprünglichen Anlage eine Gelenkfläche.

Unterhalb dieser Stelle biegen sich nun die äusseren Ränder der Seitentheile weit herab in die starken und breiten processus jugulares. Die hintere Fläche dieses wichtigen Fortsatzes ist oben glatt, unten rauh vom Sehnen-Ansatz des Zungenbeins; seine breite, etwas schief nach unten gerichtete Fläche ist höckerig und flach concav zum Ansatz des Musculus digastricus, ein Muskel, welcher zum Herabziehen des Unterkiefers bestimmt sich zugleich am processus mastoideus ossis temporum und andrerseits an dem verdickten Hinterrande des Unterkiefers inserirt (s. Murie, Manatus Taf. 21 Fig. 10).

Dhe beiden Gelenkflächen des Hinterhauptes stehen an den Seitentheilen schief von hinten nach vorn, quer iiber die rechtwinklige Kante, in welcher die vertikal gerichtete hintere Schädelfläche umbiegt zur horizontalen Schüdelbasis: sie liegen also weder auf der Hinterseite des Schädels, wie dies bei allen Cetaceen der Fall ist, noch garz auf der Unterseite, wie bei den höchsten Säugethieren, sondern ungefähr mit einer Hälfte auf jeder der beiden Seiten. Da nun der Kopf bei ruhiger Haltung horizontal steht und der Stamm des Thieres gleichfalls horizontal liegt, so muss die Axe der ersten Halswirbel in $45^{\circ}$ nach oben aufsteigen, um mit dem Atlas symmetrisch die Condylen des Kopfes zu tragen.

Die Gelenkfläche des Hinterhauptes beschreibt daher in sagittaler Richtung einen vollen Halbkreis, im Frontalschnitt ist sie fast gerade; ihre Gestalt ist ein langgezogenes Oval von $55^{\mathrm{mm}}$ grösster Länge und $25^{\mathrm{mnn}}$ grösster Breite, im Ganzen oben breiter als unten. Die beiden Flächen convergiren nach unten und rorn mit einem Winkel von $50-55^{\circ}$, so dass die Längsaxe der Gelenkhöcker sich, wie am menschlichen Schädel, auf der Unterseite des corpus ossis occipitis im tuberculum pharyngeum schneiden; beim ausgewachsenen Thier weichen die vorderen Spitzen der Condylen unter dem formen occipitale noch um $28-30^{\mathrm{nm}}$ voneinander, während ihre oberen Spitzen zu beiden Seiten des Hinterhauptsloches sich bis $62^{\mathrm{mm}}$ voneinander entfernen.

Die Fortsätze, auf denen sich die Condylen ausbreiten, sind nicht hoch, aber allseits deutlich abgesetzt; gegen das foramen occipitale fallen sie mit steiler Fläche $15^{\mathrm{mm}}$ hoch ab. Auf seiner Unterseite trägt jeder processus condỵloideus in der Richtung der Condylen-Axe einen bald stärkeren, bald schwächeren Höcker.

Das foramen occipitale ist dreiseitig: $40^{\mathrm{mm} s}$ breit und $30^{\mathrm{mm}}$ hoch, bei jüngeren Thieren etwas höher im Verhältniss zur Breite. Die untere Randfäche ist nach unten flach eingebogen und wird von den Aesten des corpus ossis occipitis gebildet; hier mindet der canalis hypoglossi. Die aufsteigenden Seiten des Loches tragen jederseits auf der Mitte ihrer Länge einen in das foramen vorspringenden Höcker. In die Naht zwischen den Seitentheilen dringt meist die obere Spitze des Hinterhauptsloches als eine flachere oder tiefere Rinne ein.

Die Occipital-Seitentheile der lebenden Sirenen weichen mehr oder weniger von denen des Halitherium ab) und mitbedingen dadurch die verschiedene Gestalt der hinteren Schädelfliiche. Am meisten stimmt Halicore in dieser Beziehung nit Halitherium überein: die auffallendste Aloweichung ist hier die, dass di squama ossis occipitis sich herabdrängt zwischen die Seitentheile und an der 
oberen Begrenzung des foramen occipitale theilnimmt, wodurch die beiden Seitentheile giinzlich von einander getrenut werden; und während die Naht gegen die Schuppe bei Halitherium mahezu horizontal verläuft, convergiren die beiden Nihte zwischen je einem Seitentheil und der Schuppe bei Halicore gegen die Spitze des foramen occipitale zu im Winkel von $130^{\circ}$. Das foramen mastoideum ist bei alten Thieren das Dugong zum Theil verknöchert und ganz verknorpelt, bei jungen Thieren ehenso weit und offen wie bei Halitherium. Der Schädel eines jungen Thieres von Halicore von $335 \mathrm{~mm}$ Schädellänge (Taf. IX., Fig. 93) hat ein foramen occipitale von $47^{\mathrm{mm}}$ Höhe und $50^{\mathrm{mm}}$ Breite, eines noch jüngeren nit $308^{\mathrm{mm}}$ Schädellänge die gleiche Höhe und Breite von $46^{\mathrm{mm}}$, während ein altes Thier mit $375^{\mathrm{mm}}$ Schädellänge (Taf. VIII Fig. 90) nur $4 l^{\mathrm{mm}}$ Höhe und $44^{\mathrm{mm}}$ Breite dessclben Loches besitzt. Auch wird in Alter die Schuppe mehr und mehr von der Begrenzung des foramen occipitale durch die Seitentheile verdrïngt. Der Canalis hypoglossi liegt randlicher und verdiunt den Knochenbogen, der ihn von der incisura jugularis trennt, zuweilen bis zur theilweisen Durchbrechung ${ }^{1}$ ).

Ianatus hat, entsprechend seinem niedrigeren Schädel, auch niedrigere Seitentheile des Occipitale: bei Halitherium ist die Höhe der Seitentheile zur Breite wie $8: 12$, bei Manatus wie $7: 16$, bei Halicore wie $8: 15$, bei Rhytina wie $8: 12$. Die Jugular-Theile treten weiter nach aussen zugleich mit dem Schläfenbein. Das Hinterhauptsloch ist nicht mehr dreiseitig, sondern oval: 51 mm weit in transversaler, $34^{m m}$ in vertikaler Richtung ${ }^{2}$ ). Dagegen ist die Schuppe wierler vom Rande des foramen occipitale durch die in einer $20 \mathrm{~mm}$ langen Naht zusammenstossenden Seitentheile ausgeschlossen, sowohl bei dem Nanatus australis von Surinam, als bei dem Manatus senegalensis vom Ogowe in West-Afrika. Der Höcker im oberen Rande des foramen occipitale fehlt. Der processus jugularis steigt meist kaum weiter abwärts als der processus condyloidens, während bei Halitherium der erstere Fortsatz stets den zweiten ansehnlich unterragt. Das foramen mastoileum ist bei Manatus besonders gross und bleibt stets unverknöchert.

In der Gestaltung der partes laterales weicht Rhytina bedeutender von den andern Sirenen ab: die Warzentheile des Schläfenbeins erreichen nicht die hintere Schädelfläche, sondern bleiben seitlich und setzen sich also vorn, nicht seitlich neben den processus jugularis an. Die Schuppe verwächst fest mit den Seitentheilen, ohne dass die Naht sichtbar bleibt, was bei den übrigen Sirenen niemals geschieht; sie scheint aber bis an den Rand des foramen occipitale zu stossen. Der processus jugularis ist nach unten wenig ausgezogen, sodass die Gelenkhöcker ihn weit unterragen. Das foramen occipitale ist oval, ähnlich wie bei Manatus.

Der Winkel, in welchem die Gelenkttächen der Condylen gegen die horizontale Lage des Kopfes gerichtet ist, bestimmt die Axenrichtung der ersten Halswirbel: eine Linie vom obersten zum untersten Ende der Condylen gezogen bildet mit der Horizontalen bei den verschiedenen Sirenen einen Winkel, der nach Art und Alter etwas verschieden ist, aber zwischen 140 und $150^{\circ}$ schwankt.

1) Cuvier, Ossements fossiles. Fol. V. 1. pag. 247: sle trou condyloïdien (foramen condyloideum anterius aut = canalis hypoglossi Henle) est très-petit et en forme d'échancrure de l'occipital latéral

${ }^{2}$ ) Krauss. Beiträge zur Osteologie des surinamischen Manatus. Archiv für Anatomie, Physiologie etc. Herausgegeb. von Joh. Miuller. Jahrg. 1858. pag. 423, giebt 43-48m an für den $₫$ Querdurchmesser des Hinterhauptsloches. 
Bekanntlich stehen die Condylen am menschlichen Schädel genau horizontal und liegen ganz auf der Unterseite des Schädels; bei den Cetaceen in vertikaler Lage auf der Hinterseite des Schädels: zwischen diesen beilen Extremen giebt es viele verschiedene Lagen der Gelenkflächen bei den iibrigen Säugethieren. Iit der Stellung der Gelenkflächen hängt auch die Lage des foramen occipitale zusammen: beim Menschen steigt die Verbindungslinie des Vorder- und Hinterrandes dieser Oeffnung schriig nach rorn an; das Hinterhauptsloch liegt demnach nicht nur ganz auf der Unterseite des Schädels, sondern schaut auch etwas nach vorn. Bei den Cetaceen umgekehrt steht das foramen occipitale auf der Hinterfläche des Schädels und zwar etwas schräg, sodass es etwas nach oben schaut. Verbindet man die Mitte des unteren mit der Mitte des oberen Randes des Hinterhauptsloches der Sirenen, so bildet diese Linie mit der horizontal getragenen Zahnreihe des Oberkiefers einen Winkel von $110-115^{\circ}$ bei Halitherium, Manatus, Rhytina und Halicore juvenis, während ein alter Halicore-Schädel $102^{\circ}$ erreicht; das foramen occipitale richtet sich demnach weit mehr nach hinten, als nach unten. Wir werden bei der allgemeinen Vergleichung der Sirenen mit den ührigen Siugethieren auf diese wichtige Stellung des Hinterhautes zur Wirhelsäule zurückiommen.

Die Schuppe des Hinterhauptsbeines von Halitherium ist ein sehr dicker Knochen ron abgerundet oblonger Gestalt von $85^{\mathrm{mm}}$ transversaler Länge und $50^{\mathrm{mm}}$ Höhe bei $20-30^{\mathrm{mm}}$ Dicke. Die Schupe steht nicht ganz vertikal, sondern mit ihrem oberen Rande etwas nach rorn geneigt und bildet den oberen Theil der hinteren SchädelHäche (Taf. V Fig 61 und Taf. VIII Fig. 87). Während die Schuppe ron den Seitentheilen ossis occipitis stets durch eine offene Naht getrennt hleibt, ist sie, sellst hei gamz jungen 'Thieren bereits fest mit dem Scheitelheine verwachsen in der sutura occipitalis: dieser verwalchsene obere Rand, in welchem die fast rechtwinklige Umbiegung der Scheitelfläche zur hinteren Schädelwand geschieht, wird sehr dick, indem hier zugleich die ossa interparietalia mit einwachsen; es liegt daher in dieser vorspringenden Kante eine der dicksten und festesten Stellen des ganzen Schüdels.

Der obere halbkreisförmige Rand der Schuppe, welcher der linea nuchae superior hominis entspricht, ragt sowohl über die äussere Fläche der Schuppe, als über den hinteren Theil des Scheitelbeins und der Schläfenbeinschuppe mit dickem Wulst hervor; ein dreieckiges Stück der Schïrlelohertlïche vor dem oberen Rande in tem Winkel der Lambdit-Naht gelegen ist wohl noch zur Schuppe hinzuzurechnen (Taf. IX Fig. 92). In der Mitte der Schuppe zieht vertikal herab die starke linea nuchae mediana; sie verschwindet auf der Fläche $10^{\mathrm{mm}}$ vor der unteren Naht. Beiderseits des oberen Endes dieser Linie erhebt sich auf dem Randwulst je ein starker, $15^{\mathrm{mm}}$ langer, vertikal gestellter Leisten, sodass der Rand der Schuppe oben in der Mitte wie mit einer kleinen Krone geschmiickt ist, der protuberantia occipitis externa (Taf. $V$ Fig. 52 und Taf. $X$ Fig. 97). An den Seiten dieser Krone befinden sich unter dem Randwulst Vertiefungen, deren rauhe Flächen den Ansatz der Kopfstrecker (musculus complexus et biventer cervicis) andeuten; auch der gebogene Randwulst ist rauh rom Ansatz der Nackenmuskeln. Der Randwulst biegt sich nach beiden Seiten nur bis zur incisura parietalis herab: hier stösst das hintere obere Ende der squama ossis temporum mit zackiger Naht von vorn her an die Occipital-Schuppe (Taf. VIII Fig. 87). Darunter endigt der Randwulst mit nach hinten vorragenden runden und rauhen Endeu und lässt das untere Stück des 
Seitenrandes der Schuppe $\left(12^{\mathrm{mm}}\right)$ nach innen eingebogen frei und glatt zum foramen mastoideum auslaufen.

Der untere Theil der Aussenfläche der Schuppe ist beiderseits der linea mediana flach eingesenkt und wölbt sich dann rechts und links schwach nach aussen. Die dem Gehirn zugekehrte Innenseite der Schuppe ist durch viele in den Knochen eindringende kleine Löcher rauh; sie ist viel niedriger als die Aussenflïche, da sie durch das breit angewachsene Scheitelbein fast die Hälfte der Schuppenhöhe verliert: heim ausgewachsenen Thier ist sie $80^{\mathrm{mm}}$ breit und nur $30^{\mathrm{mm}}$ hoch. Diese innere Fläche steht noch schräger nach vorn als die åussere (Taf. V Fig. 61) wegen der starken oberen Verdickung der Schuppe. Die verwachsene Naht gegen das Scheitelbein gielst sich hier deutlicher kund als auf der Aussenseite, da längs derselben eine scharfe und meist einige mm tiefe Rinne hinzieht, iblel welche der ganz hintere Rand der Scheitelbeine herabragt; die Nahtlinie ist flach nach oben ausgebogen mit einer geringen Senkung in der Mitte unter der spina parietalis. Parallel dieser oberen doppelt geschwungenen Linie läuft über die Mitte der Fläche eine zweite, schwächere, flache Rinne, ein sulcus transversus. Endlich zeigt sich eine mediane, schwache Leiste vertikal die beiden Furchen durchschneidend und in der Fortsetzung der starken Leiste auf der inneren Scheitelfläche, eine crista occipitalis interna.

In der Lamda-Naht auf der Gehirnseite scheidet sich meist deutlicher als auf der Oberseite ein schmales Zwickelbein aus. Bei Rhytina beschreibt Brandt (1. c. pag. 17. Taf. I u. II Fig. 1 u. 5) ossa interparietalia, welche auf der Schädeloberseite als ein dreieckiges Zwickelbein in der Lambdanaht, auf der Gehirnseite als zwei kleine Knochen erscheinen. ${ }^{1}$ )

Die Occipital-Schuppe von Halicore ist kleiner und weniger dick als bei Halitherium. Der obere Randwulst steht wenig vor, ist aber ebenso rauh durch den Ansatz der Nackenmuskeln. Die kronen-artige protuberantia externa fehlt. Die äussere Fläche ist beiderseits der linea nuchae mediana tiefer eingesenkt als beim Halitherium. Die Innentläche ist ziemlich glatt. 'Zugleich nimmt, wie erwähnt, die Schuppe an der oberen Umrandung des foramen occipitale stets theil mit einem zugeschärften Rande, der mit dem Alter des Thieres immer kiurzer wird. ${ }^{2}$ )

Iranatus besitzt eine sehr dicke Schuppe: sie steht ebenso wie bei den andern Sirenen etwas nach vorn oben geneigt; die Aussenfläche wölbt sich flach nach aussen mit schwachen Einseukungen für die Muskelansätze. Die Krone ist ausgeprigter, als bei Halicore, und breiter als bei Halitherium: am afrikanischen wie amerikanischen Manatus gegen $40^{\mathrm{mm}}$ breit, am Halitherium nur $20-22^{\mathrm{mm}}$; doch hat die Krone ihre scharfen Ränder und ilure scharf ausgeprägte Form verloren und rundet sich flach ab. Die starke crista $\mathrm{s}$. linea nuchae mediana verlängert sich meist bis an den unteren Rand der Schuppe, welcher fast niemals bis an das foramen occipitale hinabreicht. ${ }^{3}$ ) Die innere, dem Gehin zugewandte Fläche der Schuppe ist ebenso niedrig, höckrig verwachsen und

1) Ebenso A. von Nordmann, Beiträge zur Kennt. d. Knochenbaues der Rhytina Stelleri. Acta Societ. Scient. Fennicae tom. VII. 1861. pag. 9.

$\left.{ }^{2}\right)$ Siehe auch die trefflichen Abbildungen des Dugong in Blainville, Ostéographie, Manatus Taf. IV.

3) Krauss I. c. $1858 \mathrm{pag} .395$ constatirt an einem einzigen Exemplar unter vielen Janatus australis, dass die Schuppe bis fast an den oberen Rand des Hinterhauptloches einspringt. 
von Löchern durchbohrt, wie bei Halitherium; besonders tief schneidet der Sinus transversus ein. Wihrend aber die Lambda-Naht bei Halitherium und Ifalicore schon bei ganz jungen Thieren völlig verwachsen ist, bleibt dieselbe bei Manatus länger oflen und zwar verknöchert sie auf der Innenseite frïher als aussen; auch hier zeigt der Verlauf dieser Naht, dass ein kleines Stiick der Schuppe auf die Oberseite des Schälels zwischen die Scheitelbeine sich überbiegt.

Bei Rhytina verschmilzt die Schuppe frihzeitig mit den Seitentheilen, erst später mit den Scheittelbeinen. Sie ist kleiner als bei den andern Sirenen und wird vom hinteren Rande der Scheitelbeine weit überragt. Das Krönchen fehlt; aber die beiden lochartigen Vertiefungen zu beiden seiten derselben für die Insertion der Nackemuuskeln sind wohl ausgebildet (Nordmann I. c. pag. 9). Der Randwulst ist nur auf den Seiten vorhanden und gleichfalls rauh durch Muskelansätze. Sehr interessant in Bezug auf die Entwickelung der Kopfknochen von Manatus ist 'der Schädel eines Foetus, welchen schon Vrolik ${ }^{1}$ ) benutzte und den J. Murie in seiner Anatomie des Manatus bespricht und abbildet (1. c. pag. 142 Taf. 22 Fig. 16 t. 17): hier liegt die Occipital-Schuppe, einfach oval gestaltet, noch berlentend tiefer als die Scheitelbeine und nimmt die für die höheren Säugethiere gewöhnliche Stellung am Hinterhaupt ein; sie ist von den Scheitelbeinen durch eine grosse Fontanelle und von den partes laterales ossis occipitis durch Knorpelfasern getrennt; seitlich gegen die Schläfenbein-Schuppe grenzen die_hinteren Seiten-Fontanellen an.

\section{Os sphenoideum.}

Das Wespenbein des Halitherium besteht aus einem unpaaren Mittelstück, dem Körper, welcher dem Kürper des Hinterhautsbeines vorliegt und denselhen umnittelbar fortsetzt; zwei abwärts steigenden starken Flügeln, processus pterygoidei, an welchen sich die Gumenbeine ansetzen; und zwei anfwärts steigenden Fliigeln, processus temporales, als Fortsetzung der unteren Fligel. Jederseits des Körpers ist ein solcher Doppelflügel angesetzt, sodass das Wespenbein in der That die Gestalt einer Wespe nachahmt (Taf. V Fig. 60). Die horizontal nach vorn von der Basis der Temporalflügel vorstehenden zarten processus orbitales sind an dem fossilen schädel in der Regel zum grossen Theil abgebrochen und konnten nur aus den Resten ergänzt werden.

Der Körper des Wespenbeines ist ein starker länglicher Knochen, hinten an der Occipital-Naht 25-30 mm dick, nach vorn allmählich ausgespitzt und verwachsen in Boden des Siebbeins unter der lamina perpendicularis (Taf. V Fig. 56-61); seine Länge lässt sich wegen dieser innigen Verbindung mit dem Siebbein nicht genau bestimmen, sie ist bis unter die lamina cribrosa etwa $44^{\mathrm{mn}}$. An dem dicken Hinterrande verschmilzt der Körper frühzeitig mit dem corpus ossis occipitis, die Seitenflächen sind fast ganz von den Wurzeln der Flügel eingenommen, die obere Fläche liegt frei an der Basis der vorderen Gehirnhöhle und seine untere Fläche frei gegen die Choanen. Die lange Axe des Körpers ist im Schädel sagittal gerichtet; während aber der corpus

1) W. Vrolik, Bijdrage tot de Natuur-en Ontleedkundige Kennis van den Manatus americanus. Mem. Zool. Soc. Amsterdam. 1852. pl. IV Fig. 13. 
ossis occipitis bei ruhiger Haltung des Kiopfes horizontal an der Schïdelbasis verliuft, setzt sich der Wespenbein-Körper mit stumpfem Winkel ron $140-150^{\circ}$ an den Occipital-Körper an und richtet seine Längsaxe schief nach vorn aufwärts, sodass der vor der hinteren Nasenhöhle liegende Oberkiefer mit der Reihe seiner Backenzïhne die Horizontalrichtung des corpus ossis occipitis fortsetzt, das Wespenbein aber die Decke der Choanen wird. Die untere Fläche steigt dabei stärker nach oben an als die obere, sodass der Kïrper sich vorn zuschärft (Taf. V Fig. 58).

Durch diese Aufrichtung des Wespenbeins und gleichzeitige Neigung der Scheitelbeine wird die Gehirnhöhle nach vorn niedriger: die Entfernung von der Mitte des corpus ossis sphenoidei bis unter das Schädeldach beträgt $40 \mathrm{~mm}$, während das hintere Gehirn bis $64 \mathrm{~mm}$ verticale Höhe besitzt. Die ohere Fläche des Kïrpers trïgt auf der Mitte einen niedrigen Höcker, tuberculum sellae, welcher ziemlich steil mach hinten abfillt zu einer flachen Vertiefung, fossa hypophyseos, für die glandula pituitaria des Gehirns. ${ }^{1}$ ) Vor dem Sattelknopf erhebt sich die Fläche aufwärts zu einem Kamm, auf den sich der Fuss der crista galli des Siebbeins heftet. Zu jeder Seite des tuberculum sellae läuft eine Leiste nach vorn, der eine zweite parallele folgt: beide schliessen zwischen sich eine Rinne, den sulcus opticus, und gehen vorn ibber in die Wurzeln iles Orbitalflügels, welche das foramen opticum umfassen (Taf. V Fig. 57). Auf der lateralen Seite der äusseren Leiste trennt eine breite Furche den Körler des Wespenbeins von den seitlich wurzelnden Temporal-Fligeln: diese breite Furche entsteht hinten neben der spina sphenoidalis und läuft vorn sich stark vertiefend und verbreiternd, mit trichterförmiger Oeffuung unter der ala orbitalis nach aussen in die hintere Augenhöhle als fissura orbitalis superior, durch welche mehrere Gehirnnerven aus- und die Augenvenen eintreten (Taf. V Fig. 60). Zu beiden Seiten des freien hinteren Endes des Körpers steigt der sulcus caroticus herauf, der die innere Kopfpulsader dem vorderen Theil des Gehirns zuführt. ${ }^{2}$ )

Die untere Fläche des Körpers ist glatt, sie geht seitlich unmittelbar mit runder Kehle in die innere Fläche der Gaumenflügel iiber; vorn stösst sie an das Gaumenbein, doch lässt sich hier ihre Naht nicht genau feststellen, weil das dünne Gaumenbein an den mir vorliegenden fossilen Schädeln von Halitherium niemals gut erhalten ist. Die Fläche ist hinten an der zuweilen noch sichtbaren Occipital-Naht etwa $25^{\mathrm{mm}}$, vorn am vorderen Wurzelende der Gaumenflügel nur noch $15 \mathrm{~mm}$ breit und sie spitzt sich endlich zur Nasenscheidewand hin zu einem medianen Kamm, dem rostrum sphenoidale, aus.

Bricht man vom vorderen Ende des Wespenbein-Körpers das Siebbein mit der Crista galli ab, so zeigen sich vor dem Fuss der Siebplatte in seiner Spitze zwèi kleine nach oben offene Vertiefungen, zwischen denen die dünne lamina perpendicularis ihren Anfang nimmt; es ist dies das hintere blindgeschlossene Ende der immeren Nasenhöhlen, in welchen die Muscheln einsetzen.

Die alae temporales sind zwei starke, halbrunde Ḱnochenflügel, welche mit breiter Wurzel an den Seiten des Körpers festgewachsen, fast vertikal etwa bis zur halben Höhe der äusseren Seite der Schädelwand aufragen mit sagittal gerichteter Fläche (Taf. V Fig. 57 u. 60). Die

1) Siehe auch Brandt, Rhytina l. c. pag. 22 und J. Mfurie, Manatus I. c. pag. 182, Taf. 25 Fig. 33.

2) J. Meckel, System der vergleichenden Anatomie. 1831. Bd. V pag. 305. 
Wurzel ist $30^{\mathrm{mm}}$ lang, 8-10 mm dick und wird vom Körper und dem aufstrebenden Flügel abgeschnürt innen und hinten vom sulcus caroticus, vorn von der fissura orbitalis superior, welch letztere aussen etwa $20 \mathrm{~mm}$ hoch und $10 \mathrm{~mm}$ breit ist. Diese innen herlaufende Furche entfernt die Wurzel so weit rom Körper, dass die Temporalflïgel fast mehr auf der Wurzel der Gaumenfliugel aufgewachsen erscheinen (Fig. 60); aussen tritt die flach eingebogene äussere Fläche der Gaumenfligel olne Grenze auf die Wurzel der TemporalHïgel iiber, ähnlich wie am menschlichen Schädel. An einem mir vorliegenden Exemplar ist die Wurzel des Temporalflitgels nahe dem vorderen Ende von innen nach aussen durchbohrt; an den andern Schïdeln zeigt sich dieser Canalis rotundus für den Austritt des zweiten Astes des nervus trigeminus nur als eine Rinne, welche den Vorderrand der Wurzel einschneidet (s. Brandt 1. c. pag. 23).

Auf dieser Wurzel breitet sich der Temporalfliigel schuppenförmig aus, vorn mit halbrunder Umgrenzung frei nach aussen, hinten unter dem Schläfenbein imnen vorbei mit einer spitzen hinteren Endigung, (ler spina angularis. Der Flïgel ist sagittal $52{ }^{m m} \operatorname{lang}{ }^{1}$ ), in vertikaler Richtung mit Wurzel $40^{\mathrm{mm}}$ hoch und iber der Wurzelfurche $10 \mathrm{~mm}$ dick, nach oben sich verdiunnend. Die superficies cerebralis des Flïgels ist frei dem Gehirn zugewandt: sie springt mit scharfem Rande über der fissura orbitalis superior nach innen vor; hier wächst vorn der Orbitalflïgel an zum vollen oberen Abschluss der oberen Augenhöhlenspalte. Auf dieser inneren Fliiche verläuft mit knieförmiger Biegung von oben hinten nach unten vorn eine Gefässrinne, welche wohl von der arteria meningea media herrïhrt, da sie nach oben auch auf die vorderen Spitzen der Schläfenschnpe und des Scheitelbeins übertritt; sie öfnet sich nach aussen in die hintere Augenhöhle durch einen engen Kanal zwischen Temporal- und Orbital-Flügel.

Die åussere Fläche des Temporal-Fliugels ist zugleich Augenhöhlen- und SchläfengrubenFläche, da beim Halitherium durch das weit abstehende Jochbein beide Gruben zu einer einzigen vereinigt sind. Der vordere und der untere Theil der Fläche sehen frei und glatt zur Schläfengrube. Auf dem hinteren Theil der äusseren Fläche und auf dem hinteren Rande des Flügels ist die vordere Ecke der squama ossis temprum mit höckriger, nie ganz verknöchernder Nahttläche aufgewachsen (Fig. $57 \mathrm{St}$ ). Die spina angularis reicht hinter und unter der Schläfenheinschuppe bis dicht an das vordere Ende des Felsenheins. Der vordere und obere diume zackige Rand des Fliigels heftet sich oben an das Scheitelbein, vorn an den Orbitaltheil des Stirnbeins und unten mit diinner Bricke zwischen fissura orbitalis superior und foramen opticum an den Orbitalfiugel des Wespenbeins.

Dieser Orbitalflügel fehlt, wie gesagt, zum grösseren Theil an den mir bekannten fossilen Schädeln von Halitherium; nach den noch übrigen Resten und Wurzeln desselben zu schliessen, wird er seiner Gestalt nach an ähnlichsten dem Orbitalfliigel der Halicore, also ein sehr zartes, durchlöchertes Knochenstück gewesen sein und das foramen opticum unfasst, die fissura orbitalis superior oben geschlossen und spitz nach vorn in die hintere Augenhöhle am Unterrand des Orbitaltheils des

1) Wenn ohne besondere Angabe verstehen sich die Maasse fiir das ausgewachsene Thier, wie es auf den Tafeln abgebildet ist. 
Stimbeins horizontal hervorgeragt haben (Taf. V Fig. 57 u. 61); am Stirnbein haften häufig noch Reste dieses Flügels mit zackiger Naht an.

Dagegen bilden nun die beiden starken und grossen absteigenden Gaumenflugel einen Haupttheil des Wespenbeins; sie sind ungefahr spitz-dreieckig. die Spitze nach unten gerichtet, die kurze Basis festverwachsen mit der Unterseite des Körpers und mit der Wurzel der entgegengesetzt gerichteten Temporalflügel; die processus pterygoidei stehen etwas schräg nach aussen, sodass ihre Wurzeln nur $25^{\mathrm{mm}}$, ihre Spitzen $50^{\mathrm{mm}}$ im Lichten sich von einander entfernen; zugleich weichen sie in sagittaler Richtung nach hinten auseinander, sodass sie im Verein mit den Gaumenbeinen recht weite Choanen bilden. Jeder Flügel ist aus zwei Stücken zusanmengewachsen, einer medialen Knochenplatte, lamina medialis, und einer lateralen: die Verwachsungslinie beider Platten zeigt sich bei jungen Exemplaren deutlich in den vorderen und hinteren schmalen Flächen der Flügel.

Die lamina lateralis steigt nicht ganz so weit herab als die mediale, ist aber die grössere; sie wird am unteren zugespitzten Ende dick, indem sie sich mit einem Knorren nach aussen dreht; ihre Aussenfläche geht glatt in die Aussenfliche des Temporalfligels iiher. Die mediale Platte kehrt ihre glatte Innenfäche der Choane zu und endigt unten in eine stumpfe Spitze, die sich nach rückwärts etwas umbiegt und dem hamulus pterygoideus entspricht. Durch ihre Verschmelzung bilden die beiden Platten vorn eine vertiefte, schief nach hinten absteigende, schmale Fläche, in welcher der Pyramidenfortsatz des Gaumenbeins fest mit zackiger Naht eingefügt ist, fissura pterygoidea (Taf. X Fig. 96); auch zeigen sich in dieser Tahttlache mehrere (refisskaniale, die in der Xitht durch ein rundes Loch an der Wurzel des Flügels zur Chaone ausminden; ein eigener canalis vidianus fehlt den Sirenen. Ganz nahe an diesen vorderen Rand der lateralen Platte tritt das hintere Ende des Alveolartheiles ossis maxillae, getrennt durch eine schmale fissura spheno-maxillaris; ein dreieckiger kleiner Vorsprung des Vorderrandes, gerade unter der fissura orbitalis superior gelegen, streckt sich dem Oberkiefer entgegen (Taf. V Fig. 57).

In der hinteren, anfangs vertikal absteigenden, dann etwas rückwärts gebogenen Fläche des Gaumentliigels liegt eine Hache Längsfurche, die fossa pteryroidea für die Insertion des musculus pterygoideus internus; mitten in dieser Rinne mündet constant ein Gefässkanal. Oben am Körper endigt diese Hinterhante des Flügels mit einer scharfen Zacke, welche sich der vorderen Spitze der pars tympanica ossis temporum bis auf wenige mm nähert: diese Zacke, wir wollen sie spina sphenoidalis nennen (Taf. V Fig. 57), liegt an Vorderrande des grossen foramen lacerum und trennt den breiten sulcus caroticus von dem foramen ovale, welches einen tiefen Ausschnitt in den Hinterrand der Temporalthigel-Wurzel macht: das foramen spinosum ist hier mit dem foramen ovale rereinigt unter der spina angularis.

Das Wespenbein des Halitherium stösst im Ganzen an sieben andre Schädelknochen, nämlich an das os occipitis, an die Schuppe des Schläfenbeins, an Scheitelbein, Stimbein, Siebbein, Gaumenbein und Vomer; von allen sieben Knochen bleibt es durch zackige Nähte getrennt; nur mit dem Siebbein und dem os occipitis verschmilzt es innig. Das Wespenbein steht demnach mitten in den Schädelknochen eingekeilt und berührt mit den analogen Theilen dieselben Knochen, wie am menschlichen Schädel, mit alteiniger Ausmahme des Jochbeins, welches nur bei Affen und Menschen sich 
mit dem Wespenbein verbindet. In seiner ursprunglichen Anlage bestand das Wespenbein des Halitherium wahrscheinlich auch aus mindestens zwei Stïcken, dem rorderen und hinteren Keilbein; für Manatus rechnet Krauss (1. c. pag. 407) zum vorderen Theil die lamina lateralis des Gaumenflugels, die alae temporales und orbitales, zum hinteren Keilbein den corpus sphenoidale und die lamina medialis processus pterygoidei. Diese Theilung ist hei den andern Säugethieren nicht die vorherrschende, wie wir später sehen werden.

Das Wespenbein der lebenden Sirenen weicht in den wesentlichen Theilen wenig von dem des Halitherium ab. Bei Halicore ragt auf der oberen Fläche des Körpers das tuberculum sellae und die Leiste, auf welcher die crista galli des Siebbeins fusst, bei alten Thieren stark hervor; anch die fossa hypophysens vertieft sich. Die Naht zwischen Wespenbein- und OccipitalKörper bleibt bei Halicore selbst bei alten Thieren stets sichtbar und zum Theil offen, während sie bei allen andern Sirenen frühzeitig verschmilzt. Die Temporalflügel gehen aussen nicht ganz bis zur Hälfte der seitlichen Schüdelwand hinauf; ihre Wurzel ist rom Körper abgeschnürt durch die breiten Furchen, die von hinten her aus dem tief eingeschnittenen foramen ovale und dem sulcus caroticus nach vorn zur weifen fissura orbitalis superior an der Gehirnbasis hinführen. Zuweilen ist im äusseren Rande des foramen ovale noch ein besonderer Einschnitt für das foramen spinosum vorhanden unter der nach hinten gebogenen spina angularis, welche fast das Paukenbein berührt.

Die Orbitalflügel stehen am Halicore-Schädel schwertförmig spitz, horizontal und etwas schief nach aussen und vorn in die hintere Augenhihle hinein, verschliessen die trichterfürmige fissura orbitalis superior nach oben und innen und enthalten den nach vorn in eine Rinne übergehenden canalis opticus; mit ihrer oberen Fläche legen sie sich flach unter die weit herahreichenden Orbitalwände ossis frontis. Diese Flügel stossen nach allen Seiten mit zackigen Nähten an die Temporalflügel des Wespenbeins, an das Stimbein, das Siebbein und die Gaumenbeine; nur mit dem Körper des Wespenbeins verschmelzen sie frithzeitig: an dem 270 mm langen Schädel eines ganz jungen Thieres ist die zackige Naht gegen den Körper noch vorhanden; ebenso die Naht zwischen dem vorderen und hinteren Keilbein, welche gerade da, wo das Gaumenbein sich mit der lamina medialis processus pterygoilei verzahnt, quer durch den Körper des Wespenbeins läuft. Da zugleich die Nähte zwischen den faumenplatten deutlich sind, so erhellt aus diesem Schädel, dass iibereinstimmend mit Manatus, bei Inalicore der hintere Theil des Kürpers und die mediale Gumenplatte dem hinteren Kieilbein, die laterale Gaumenplatte, alae temporales und orbitales und der vordere Theil des Körpers zum vorderen Keilbein gehören.

Die beiden Platten der Gaumenfligel sind stärker gegeneinander verschoben, als bei den andern Sirenen: die lamina medialis senkt sich zu beiden Seiten der weiten Choane fast senkrecht abwärts, sehr wenig nach aussen gebogen; sie behält ungefähr die gleiche Breite von der Wurzel bis zum unteren Rande, der nach hinten in eine scharfe Ecke ausläuft. Die lamina lateralis aber biegt sich so stark neben dem Fortsatz des Gaumenbeins vorbei nach vorn, dass ihr scharfer Hinterrand in einem Winkel von $45^{\circ}$ gegen die Schädel-Horizontale ansteigt; dieser Rand endigt nach oben in eine spitze spina sphenoidalis, welche sich zwischen sulcus caroticus und foramen ovale der vorderen Spitze der pars labyrinthica des Felsenbeins entgegenstreckt. Der Prramidenfortsatz des 
Gaumenbeins schneidet eine so tiefe fissura jterygoidea ein, dass die beiden Gaumenplatten des Wespenbeins in der That nach unten auseinanderklaffen.

Bei Manatus ist der Wespenbein-Körper an der Occipital-Naht nicht im Winkel gegen den corpus ossis occinitis festgewachsen, sondern gewinnt die nach vorn aufsteigende Richtung durch allmähliche Wölbung. Der Körper ist kürzer als bei Halitherium und Halicore, da die Fortsätze der Gaumenheine grösseren Raum einnehmen und den vorderen Theil der Choanen umspannell. Auf der Gehirntliache des Körpers ragt das tuberculum sellae als eine scharfe Querleiste nach rückwärts über die tiefe fossa hypophyseos; nach vorn erhebt sich die Fläche zu einem Kamm, die crista galli tragend. Auf die sonst glatte untere Fläche treten von hinten her die heiden rauhen Muskelansitze des rectus capitis anticus minor auf den Wespenbeinkörper über; die Naht zum Occipital-Körper verschmilzt sehr-früh.

Die Wurzel der Temporalflügel stellt sich mit ihrer Fläche fast horizontal von den Seiten des Körpers nach aussen, sodass diese Flïgel sich stark nach aussen legen und die untere Fläche des Gehirns verbreitern; zugleich entsteht dadurch auf der Schädel-Cnterseite eine breite superficies infratemporalis zwischen Gaumentlïgel und Lnterkiefer-Gelenk. Die spina angularis ist bei Manatus eine rechtwinklige Ecke, nicht spitz nach hinten ausgezogen, sodass das foramen ovale nur von der in das foramen lacerum vorspringenden spina sphenoidalis angedeutet und nicht, wie bei den andern Sirenen, in den Temporalflügel eingeschnitten ist. Die Orbitalflügel sind beim Manatus dünne, schwertförmige Blätter, welche hinten und innen an der Wand der Augenhöhle liegen und den canalis opticus eine Strecke weit umschliessen. Die Gaumentliigel weichen nicht so weit wie die Temporalfligel auseinander, stehen vertikal abwirts und gleichen mehr denen ron Halitherium als von Halicore. Die mediale Platte ist dreieckig, mit der stumpfen, zweispaltigen Spitze nach unten gewandt. Die fossa pterygoidea ist kurz, sclmal und wenig tief; die spima sphenoidalis entfernt sich durch die ahstehenden Temporal-Wurzeln ziemlich weit rom kürper nach aussen, sodass das foramen ovale $^{1}$ ) auch abgedrängt wird. Der Pyramidenfortsatz der Gaumenbeine greift nicht so tief in die fissura pterygoidea wie bei Halicore. Die lamina lateralis ist wenig nach vorn und gar nicht nach aussen geneigt, weicht aber doch weit genug aus, dass neben ihr und über dem Gaumenbein noch die Keim-Alveolen des Oberkiefers in der fissura orbitalis superior Platz haben.

Das Wespenbein der Rhytina gleicht am meisten dem von Manatus: der Körper steigt als Decke der Choanen weniger steil aufwäts als bei Halicore, wesshalb die lamina perpendicularis des Siebbeins, unter welche das vordere Ende des Wespenbeinkörpers einwächst, höher wird, etwa wie bei Halitherium und Manatus ${ }^{2}$ ). Die starken und rauhen Ansätze des musculus rectus capitis anticus minor treten von hinter her iiber die Occipital-Naht auf die untere Fläche des Wespenbeinkörpers (Taf. X Fig. 99). Im übrigen ist die untere Fläche glatt und geht unmittelbar in die weit

\footnotetext{
1) Cuvier, Ossem. fossiles. vol. V.1. pag. 247: „le trou ovale est une échancrure du bòrd du sphénoide postérieur completée par la caisse $«$. Caisse = pars tympanica ossis temporum.

$\left.{ }^{2}\right)$ von Nordmann 1. c. Taf. II Fig. 1-3. Der Läugsschnitt des Wespenbeins bei Brandt 1.c. Taf. II Fig. 4n ist nicht ganz richtig in der Stellung gegen den Occipital-Körper und im vorderen Theil, der abgebrochen war nach pag. 22.
} 
auseinanler weichenden Gaumenflïgel über. Die obere Fläche enthält hinten eine tiefe Grube für die glandula pituitaria ${ }^{1}$.

Die Temporalflügel. sind durch eine flache Furche vom Körper abgesetzt, welche hinten in das tief in den Wurzelrand eingeschnittene foramen ovale ausläuft; medianwärts von diesem Ausschnitt springt scharf die spina sphenoilalis ror, ohne indess wie bei Halicore und Halitherium einer entgegenragenden Spitze des Felsenheins zu begegnen (Fig. 99). Die Wurzelflïche der Temporalflügel steht gleichfalls wie bei Minatus horizontal nach aussen ab, sodass sich spina sphenoidalis und foramen ovale ziemlich weit vom Körper entfernen. Die spina angularis biegt sich nicht nach hinten über, sondern ist stumpf abgeschnitten wie bei Manatus, berührt aber dennoch die vordere Ecke des Felsenheins. Vorn umschliessen diese Flügel nit den schwertförmigen Orbitaiflügeln die $30^{\mathrm{mm}}$ hohe und $8^{\mathrm{mm}}$ breite fissura orbitalis superior, welche zugleich das foramen rotundum enthält. Das foramen opticum ist gerade wie bei Manatus erst ein Kanal zwischen den Wurzeln der Orbitalflügel, dann eine nach vorn laufende Rinne in denselben.

Die Gaumenflügel stehen schräg mach aussen und unten auseinander (bei Manatus vertikal). Die lamina medialis endigt unten zweiköpfig und wird nur von einer schmalen und kurzen fossa pterygoidea eingefurcht ${ }^{2}$ ). Der Fortsatz der Gaumenbeine dringt nicht sehr tief zwischen die beiden Platten in die fissura pterygoidea ein. Die lamina lateralis schiebt sich seitlich vor die mediale Platte, sodass der untere Rand der Gaumenflügel von vorn nach hinten länger wird, als selbst bei Halicore.

Im Ganzen schliesst sich also das Wespenbein von Rhytina in seiner Gestalt mehr an das von Manatus als an das von Halicore und Halitherium; mit dem letzteren hat es gemein die weit auseinander sperrenden Gaumentlügel, welche bei beiden in einem Winkel ron 120-130 gegen die Horizontale abstehen, bei Minatus und Halicore aber mehr rechtwinkelig gestellt sind. Am RihytinaSchädel öffnen sich die Choanen zwischen den Gaumenflïgeln am weitesten von allen Sirenen.

\section{Os ethmoideum.}

Das Siebbein der Sirenen liegt so verborgen unter den umschliessenden Knochen im Innern des Vorder-Schädels, dass es schwer fällt, dasselhe in seine einzelnen Theile zu zergliedern; indessen hat die Verborgenheit auch wieder den Vortheil, dass die zarten Lamelleu der Muscheln sich auch an dem fossilen Schädel recht gut erhalten haben. Wir konnten daher dieses complicirte Bein des Halitherium in verschiedenen Durchschnitten vollstïndig erläutern (Taf. V Fig. 56. 58. 59). Sieht man von hinten her in die Gehimhöhle, so ist dieselbe vorn abgeschlossen durch eine viel durch-

1) Brandt l. c. Taf. II Fig. 3c. Uebrigens stehen auf dieser Zeichnung wohl durch falsche Perspective die processus orbitales (pag. 22 proc. ensiformes") und darüber die lamina cribrosa des Siebbeins $3 a$ viel zu nahe an der fossa hypophyseos. Vergl, von Nordmann Taf. I Fig. 4.

$\left.{ }^{2}\right)$ Taf. X Fig.99. Brandt 1. c. pag. 24 sagt von der fossa pterygoidea: $»$ non distincta, sed sulculo angusto parum indicata. So unbedeutend erscheint die Grube in unserer Abbildung nicht. 
löcherte Platte, die lamina cribrosa (Taf. II Fig. $4^{3}$ ). Von vorn her durch die Nase blickend (Taf. V Fig. 55), wird man eine starke vertikal absteigende Platte gewahr, die lamina perpendiculiris, und zu beiden Seiten derselben, in das Innere der Höhlen zurückgezogen, mehrere Muschelwülste und Falten, welche nach vorn und oben je ein vorspringendes Horn unter die Nasenbeine senden.

Beginnen wir mit der Betrachtung der Siebplatte, deren obere Hälfte in Fig. 4 dargestellt ist, wäbrend sie an andern Schädeln vollståndig erhalten ist. Die lamina cribrosa verschliesst das Spitzhogen-Fenster, dessen Seiten von den hinteren Rïndem der Orbitaltheile des Stimbeins, dessen Basis vom vorderen Ende des Wespenheinköpers gehildet wird; sie trennt den Gehirnram von den inneren Nasenhöhlen. Die Platte steht also mit ihrer Fläche transversal im Schädel: ihre vertikale Höhe beträgt $34-37^{\mathrm{mm}}$, ihre grösste Breite liegt an der Basis mit $32^{\mathrm{mm}}$; 'ihre Fläche steht schief von oben vorn, wo sie unter den vorspringenden stumpfen Rand der Stimbeine eingelassen ist, nach unten und hinten. Die Platte setzt sich zusammen aus zwei durchlöcherten Blättern, welche beiderseits der Medianlinie sich nach vorn gegen die Nasengänge ein wenig einstülpen; die Mittellinie ist ein nach innen gegen das Gehirn vorspringender Kamm, die crista galli, welche mit breitem Fuss weit nach hinten vorgeschohen aufsetzt iuf dem vorderen, kimmartig erhobenen Wespenbeinkörper; nach oben verliert sich der Hahnenkamm, und die Siehplatte zieht sich mit dem oberen Ende der beiden Seitenblätter in die Spitze des Bogenfensters nach vorn hinein zu dem blindgeschlossenen, kurzen foramen coecum. Die Siebplatte ist von vielen kleinen und grösseren Löchern durchbohrt, ordnungslos zu beiden Seiten der crista galli vertheilt, besonders zahlreich in der Einstülpung der Blitter, um die testchen des nervis olfactorius durchzulassen in die Muschelgänge; ich will hier gleich vorausgreifend hemerken, dlass bekimntlich die Cetaceen eines Riechnerven und der dazu gehörigen Organe entbehren.

Die lamina perpendicularis ist ein bedentender Theil des Siebbeins: diese rechtwinkelige linochenplatte von $50-.56^{\text {mm }}$ Höhe und $40-4.5^{\text {mu }}$ Länge stelit vertikal und sagittal mitten in der inneren Nasenhöhle; sie fusst auf dem vorteren Theil des Wespenbeinkürpers; verwälst mit dem dumnen Hinterrande in der Mittellinie der Siebplatte, gewissermassen als Fortsetzung der crista galli nach vorn; ihr oberer Rand legt sich etwas verbreitert unter die Nasenbeine und die sutura frontalis der Stimbeine; der Vorderrand steht frei in der Nasenhöhle, nachdem der Nasenknorpel weggefallen ist; der untere land wirl zunächst an Wespenbein ron den dünnen Blättern des Vomer umfasst, drängt sich aber alsbald mit abgestumpfter Kante frei nach unten heraus. Die lamina perpendicularis ist in ihrem hinteren Theile papierdiunn (Taf. II Fig. 4 und Taf. V Fig. 56), nach vorn wird sie immer dicker, sodass die rauhe Fläche, an der sich die knorpelige Nasenscheidewand ansetzte, in der Mitte bis $14^{\mathrm{mm}}$ breit ist; auch gegen den oberen und untereu Rand verdickt sie sich im vorderen Theil. Die Seitenflächen der Platte sind glatt und undurchbohrt.

Jederseits der lamina perpendicularis liegt in den innern Nasenhöhlen ein Labyrinth von mehreren Wiilsten und Muscheln, unter denen wir drei iihereinander liegende Partien, getrennt durch zwei grössere (rïnge, unterscheiden liönnen (Taf. Y Fig. jo): ein oberer langgezogener Inschelwulst,

1) Durch Versehen steht diese Zeichnung auf dem Kopf; sie muss umgekehrt betrachtet werden. 
welcher hinten an der Siebplatte beginnt und mit einem plattenförmigen Horn bis unter die Nasenbeine nach vorn sich auszieht; ein mittlerer dicker Wulst, der hinten an der Siebplatte durch eine diinne Knochenbrücke mit der oberen Muschel sich verbindet; endlich eine eingerollte Lamelle an Boden der Nasenhöhlen auf dem Wespenbeinkörper aufgewachsen. Die seitlich das Labyrinth umschliessende Wand, welche selbständig von der Siebplatte aus nach vorn die imnere Fläche der Orhitaltheile des Stimbeins iblerkleidet, würde der laminat papyracea hominis entsprechen, obschon sie nicht frei gegen die weiter nach vorn gerïckte Augenhöhle wird.

Die Siebplatte liegt mit ihrem oberen Theile stark verdickt unter den Stirnbeinen: daher steigen die Nasengänge zwischen den Muscheln hinter der Siebplatte im Bogen nach vorn aufwärts und biegen sich erst allmählich mit den Muscheln zum horizontalen Verlauf herum. Die lamina perpendicularis steht mit ihren lateralen Flächen ganz frei und wird nicht von den Muscheln berührt: daher bleibt, abgesehen von den beiden Gängen zwischen den Muscheln, neben der lanina perpendicularis jederseits ein freier Raum, der hinten schlitzartig eng ist und sich nach vorn mehr und mehr zur äusseren Nasenhöhle hin ïthnet, sorlass er hinten an der Siebplatte nur $15-20$ mm, vorn aber $40-45 \mathrm{~mm}$ Höhe besitzt.

Die obere Inschel (Fig. 58) beginnt vor der Siebplatte als einfacher Wulst, wird nach vorn immer höher, ohne dicker zu werden, steigt im Bogen nach oben und vorn und verlängert sich als laterale Wand der Nasenhöhle nach vorn iber die knöcherne lamina perpendicularis hinaus zu einem weit vorspringenden Blatt bis unter die Nasenbeine: diese Muschel ist daher im Ganzen 90-100 mm lang. Ihre vordere Hälfte ist aber kaum als Muschel zu bezeichnen, da sie vorn nicht mehr den oberen Nasengang ïberwölbt, sondern als ein dünnes, einfaches Blatt die inneren Flächen der Stirn- und Nasenbeine ïberzieht; ihr vorderes Ende verdickt sich und löst sich von der Nasenwand als ein selbständiges Horn. Diese unter dem Nasenbeine frei abstehende, 27-30 mohe Platte (Taf. V Fig. ō5 Cs) ist häufig abgewittert, und damn sieht man das hinten fortsetzende diunne Blatt die Nasen- und Stirnbeine mit deutlich abgesetztem Rande umziehen; die Platte ist ungefähr vierseitig, mit ihrer Fläche vertikal und sagittal gestellt: der vordere stumpfe Rand ist 24 nm lang und fällt etwas nach hinten $a b$, sodass er mit dem oberen horizontalen Rande eine Ecke vorn unter dem Nasenbein bildet; der untere Rand ist nur auf 15 mm Länge frei und läuft flach abgerundet in den vorderen Rand über. Dieses Horn ist durch einen tiefen und langen Einschnitt von den überdachenden Nasenbeinen getrennt, die Nähte sieht man bei abgewitterten Stiicken in der Fortsetzung des Einschnittes nach hinten weiterziehen.

Die beiden ansehnlichen Nasenbeine des Halitherium wurden bisher ${ }^{1}$ ) mit diesem Horn der oberen Mfuschel zusimmen failschlich als Theil des Siehbeins angesehen, wie wir unten bei Besprechung der Nasenbeine ausfuilren werden; dieselben sind von der oberen Muschel durch Nähte getrennt und stecken im Stirnbein. Zugleich mit den Nasenbeinen iiberragen die Hörner des Labyrinthes den Stimrand noch um 15-20 mm, während sie selbst von den Nasenbeinen iberragt und von oben überdacht werden.

1) Krauss, Der Schådel des Halitherium Schinzi. Neues Jahrbuch für Mineralogie etc. Jahrg. 1862, pag. 394. 
Die beiden Hörner des rechten und linken Labyrinthes bleiben von einander getrennt, vorn in den Spitzen um 17-19 mas, weiter hinten neben dem vorderen Ende der lamina perpendicularis um $18-20 \mathrm{~mm}$; ihr oberer Rand setzt sich scharf von den überdachenden und mitten zusammenstossenden Nasenbeinen ab, duch eine schmale Nahtrinne von ihnen geschieden. Auch der obere, verbreiterte Rand der lamina perpendicularis berührt die Hörner vorn nicht, sondern verschmilzt mit ihnen erst weiter hinten da, wo die Nasenbein-Wurzeln bereits im Stirnbein stecken.

Die mittlere Muschel besteht aus einem dicken, nach vorn ausgespitzten Wulst und ist, ebenso wie die untere Muschel bedeutend kürzer, als die obere; sie umfasst von unten her den oberen Nasengang. An der Vorderseite der Siebplatte beginnt sie mit einer papierdünnen, scluråg gestellten Lamelle (Fig. 56), welche an der lateralen Nasenwand angewachsen, sich nach oben und innen umschlägt, den oberen Nasengang iberbrückt und am oberen Muschelwulst eine Strecke weit (Fig. 58) festwächst. Der Nasengang zwischen diesen beiden Muscheln ist hinten an der Siebplatte sehr eng, empfängt durch dieselbe einige Canäle, erweitert sich dann nach vorn und vertieft sich nach der äusseren Seite: in seinem Lumen bilden sich zwei dünne längsgestelite parallele Lamellen und drei tiefe und schmale Furchen aus, wie die beiden Querschnitte auf Taf. V Fig. 56 und 59 veranschaulichen; wenn die Muscheln an einem verwitterten Stücke ausgebrochen sind, zeigen sich daher in der äusseren Wand der imneren Nasenhöhlen drei tiefe, sclumale, parallel von hinten nach vorn laufende Furchen, getrennt von einander durch zwei dünne Lamellen.

Die mittlere Muschel umfasst im hinteren Theile des Labyrinthes den oberen Gang vollständig als eine selı diunne Knochenlamelle (Fig. 56), welche an der oberen Muschel und an der Siebplatte festgewachsen ist; sie verdickt sich dam, nachdem sie sich von der oberen Muschel gelöst hat, nach vorn rasch zu einem breiten, schrïg nach imnen und oben gestellten Wulst, der den Boden des oberen Nasenganges abgiebt; ganz vorn endlich zielit sie sich allmählich aus zu einer Spitze, welche flach der äusseren Wand anliegt und sich in der inneren Ecke der Augenhöhle im Seitenblatt des Siebbeins verliert (Fig. 58). Die Länge dieses Muschelwulstes ist $55-60 \mathrm{~mm}$, also bleibt sein vorderes Ende ganz bedeutend hinter dem Horn der oberen Nuschel zurück. Blickt man von vorn in die innere Nasenhöhle, so sieht man in der äusseren. Wand zwischen dem flachen oberen und dem dicken mittleren Muschelwulst den tief eingesenkten oberen Nasengang mit den beiden in ihm liegenden Lamellen (Fig. 59).

Am Boden der inmeren Nasenhöhle erhebt sich endlich ein dritter Muschelwulst, meist begleitet von zwei feinen parallelen Leisten: derselbe ist hinten an der Siebplatte am stärksten und besteht hier aus einer mach imen eingerollten, am Rande stark verdickten, $7-8^{\text {mm }}$ hohen Lamelle (Taf. II Fig. 4 und Taf. V Fig. 56), welche nach vorn schnell an Höhe und Dicke abnimmt und am vorderen Ende der inneren Nasenhöhle nur als eine schwache Leiste am Borlen ausläuft. Zwischen dieser Knochenfalte und der mittleren befindet sich ein enger, mittlerer Nasengang, an der inneren und unteren Seite der ersteren ein dritter Gang; beide Gänge sind gleich hinter der Siebplatte scharf markirt und communiciren, wie der obere Gang, durch Oeffnungen in der lamina cribrosa mit dem Gehirnraum, nach vorn aber sind sie weit geöffnet und verflacht durch die Kleinheit des unteren Wulstes. 
Der obere lange Wulst mit seinem Horn und der mittlere dicke Wulst sind wohl ohme Schwierigkeit der Concha superior und media zu vergleichen. Ob aber der untere, tief in das innere der Nassenhöhle zurückgezogene untere Wulst das eigentliche Muschelbein, concha inferior, reprïsentirt, dïrfte zweifelhaft sein. Keiner der erwähnten Autoren berührt die Frage, betreffend die untere Muschel der Sirenen. Bei den übrigen Säugethieren liegen die Muschelbeine allgemein an der inneren Fläche des Oberkiefers, gewöhnlich auch zugleich des Gaumenbeins, als gewundene mit der Wölbung nach inuen gerichtete línochen, die melr oder weniger weit nach innen in die Nasenhöhle ragen und den Umfang derselben bedeutend vergrössern (Meckel 1. c. II. 2. pag. 552). Zum Beispiel bei den mit den Sirenen verwandten Tapiren sind die unteren Muscheln stark entwickelt und reichen unter den Aesten des Zwischenkiefers nach vorn fast bis an das foramen incisivum, während sie hinten die Choanen uiberspannen, welche bei den Sirenen ganz offen in die vordere Nasenhöhle ausmiinden. Trotzdem lassen sich diese aufgeblähten Muscheln der Tapire noch mit denjenigen des Halitherium vergleichen, wie wir unten ausfïhren werden; das Labyrinth der lebenden Sirenen dagegen reducirt sich weit mehr, was auf eine riickläufige Entwicklung dieser Organe schliessen lässt. Der untere Nuschelwulst des Halitheriun ist innig verwachsen mit dem zum Siebbein gehörigen Boden der inneren Nasenhöhle, welcher wiederum dem vorderen Keilbein-Körper fest verbunden ist; die Naht zwischen beiden Knochen ist kaum nachzuweisen.

Das lamellöse Labyrinth liegt demnach im Schädel des Halitherium weit in das Innere der Nasenhöhlen zurückgezogen; nach vorn laufen die Muscheln in einfache Wülste aus und endigen, mit Ausnahme des oberen Hornes, ehe sie die Choanen und die vordere Nasenhöhle erreichen. Von den übrigen Schädelknochen stossen an das Siebbein vor allen das Stimbein, welches dasselbe von drei Seiten her umfasst und von ihm durch mehr oder weniger sichtbare, geschlossene Nähte getrennt ist; die Nasenbeine, welche ron dem vorderen Blatt der oberen Huschel von innen und unter her überzogen werden; das Wespenbein und der Vomer.

Von den lebenden Sirenen stimmt in der Bildung des Siebbeins mit Halitherium eher Manatus und Rhytina als Halicore uiberein.

Am Manatus-Schälel springt die crista galli des Siebbeins als ein scharfer Kamm gegen das Gehirn vor, fusst unten mit der Siebplatte schmal und spitz auf der Oberseite des vorderen Keilbein-Körpers und verliert sich nach oben in einer rhombischen Fläche, welche zwischen die absteigenden Stirnbeine eingekeilt ist. Dieser obere Theil der Siebplatte ist ganz glatt und kaum durchbohrt, während er bei Halitherium und Halicore viele Löcher zeigt, obschon die Nasengänge erst unterhalb desselben ansetzen. Die scharfe obere Spitze der Siebplatte zieht sich wenig oder gar nicht ein zu einem foramen coecun. Darunter stiilpen sich die durchbolnten Platten beiderseits der crista galli sackförmig nach vorn ein gegen die Nasengänge. In Ganzen ist die Siebplatte bei einem Schädel des Manatus australis von $340^{\mathrm{mm}}$ Länge, 43 num hoch und $34 \mathrm{~mm}$ an der breitesten Stelle. Am Manatus senegalensis vom Ogowe drủcken die Stirnbeine die Spitze der Siebplatte mehr, als bei den anderu Sirenen nach hinten und unten vor, sodass das foramen coecum verschwindet und die Spitze abgeschnitten wird. Die lamina perpendicularis verkürzt sich bei Manatus sehr und zieht sich nach innen unter den bereits zurückgewichenen Stimrand zuriick: ihr oberer Rand beriihrt das 
Stimbein gar nicht mehr, besonders bei Manatus senegalensis entfernt er sich weit von demselben; der untere Theil des vorderen, rauhen Randes, an den sich die knorpelige Scheidewand ansetzt, springt zwischen den Vomer-Blättern weiter nach voru vor, sodass er an einem Exemplar des Manatus australis den Stirmrand überragt (doch weit getrennt und unter ihm). ${ }^{1}$ ) Der Unterrand der lamina perpendicularis wird an einem mir vorliegenden Schädel von Manatus australis aus Surinam von den beiden Blättern des Vomer völlig unschlossen; bei einem andern surinamischen bleibt, wie bei Halitherium und Halicore ein Schlitz von 23 mä Länge und 3,5 mm grösster Breite (vorn); die beiden Manatus vom Ogowe zeigen einen sehr schmalen, kurzen Schlitz; Krauss giebt an ${ }^{2}$ ), dass an allen ihm bekinnten Schädeln von Manatus australis der Vomer den Unterrand der perpendiculitren Platte völlig umschliesse. Es ist dies wieder ein Beispiel von der Unbeständigkeit kleiner Merkmale an verschiedenen Schädeln ein und derselben Art, welche mehr noch als bei andern Thierspecies hier bei den Sirenen sich zu erkennen giebt; das Individuum erlaubt sich eben stets kleine Abweichungen vom Körperbau seiner Art und leitet dadurch neue Arten ein.

Die Muscheln des Labyrinthes sind bereits stärker bei Manatus reducirt, als bei Halitherium, lassen sich aber noch auf die lomologen Theile beziehen: die obere Muschel besteht aus einem flachen Wulst, welcher nach vorn ein liurzes, poröses, zugespitztes Horn aussendet; diese beiden Hörner überragen vorn den zurückgezogenen Stirnrand, ohne die bier" getrennten kleinen Nasenbeine an Länge zu übertreffen. Im Ganzen ist der obere Muschelwulst $65-72 \mathrm{~mm}$ lang, steht völlig frei neben den Stirnbeinen und annähernd vertikal mit seiner Fläche und endigt vorn in eine oder mehrere Spitzen; sein Inneres ist von lockerer, spongiöser Structur. Der untere Theil des oberen Horns biegt sich mit breiter Fläche so weit nach unten und hinten zurück, dass er an dem kurzen dicken, mittleren Muschelwulst anstösst, ja zuweilen an ihn anwächst; dadurch erscheint der obere Nasengang, der wie bei Halitherium tief in die Seitenwände eingefurcht mehrere Falten zeigt, nach vorn blindgeschlosșen, ähnlich wie im Labyrinth des menschlichen Schädels. An einem Schädel von Manatus australis löst sich vom mittleren Muschelwulst vorn eine kleine Knochenplatte los, die vorgerïclit den dïnnen Blätern des Craumenbeins und Oberkiefers anliegt. Der Boden der inneren Sasenhöhlen zieht sich hereits bei Manatus. im Verhältniss zu Halitherium, ausehnlich nach hinten zuriek und verkiirzt sich so stark, dass für eine untere Muschel, in der Weise ausgebildet, wie bei Halitherium, kaum Platz bliebe; es zeigen sich an diesen Stellen nur einige kurze, durchlöcherte Lanellen ron unbeständiger Form.

Das Siebbein von Rhytina hat von Nordmann beschrieben ${ }^{3}$ ): die dreilappige Gestalt der lamina cribrosa weist auf die Verwandtschaft mit Manatus; die foramina cribrosa durchbohren am zahlreichsten die Platte in den vertieften Theilen zu beiden Seiten der crista galli; ein foramen

$\left.{ }^{1}\right)$ Krauss, Müller's Archiv etc. 1. c. pag. 408 giebt an, dass von acht Schädeln des Manatus australis an zweien die perpendiculäre Platte den Stirnrand überragte, bei den übrigen aber sehr kurz war, besonders bei den jungen Thieren.

2) Müiller's Archiv etc. 1858 pag. 408 und wiederholt Neues Jahrb. etc. 1858 pag. 526.

$\left.{ }^{3}\right)$ v. Nordmann 1. c. pag. 12 Taf. I Fig. 4 und Taf. II Fig. 2.3. Siehe auch Brandt 1. c. pag. 19 Taf. II

Fig. 4. 6. 7. 
coecum scheint zu tehlen und wird auch ron Brandt nicht erwähnt. Da die Rlytina uiberhaupt die grösseste Art unter den Sirenen war, erscheinen auch alle ihre Theile grösser: die Siebplatte ist bei ihr $78^{\mathrm{mm}}$ hoch und $73^{\mathrm{mm}}$ breit; dennoch bewahrt sie dasselbe Grössenverhältniss zum Schädel, wie die andern Sirenen, nämlich etwa wie 1:8 in ilırer Höhe zur Länge des Schädels. Die Siebplatte stützt sich anch bei Rhytina mit ihrem unteren Rande auf den Förper und die Orbitalfligel des Wespenbeins.

Die perpendiculïre Platte der Rhytina ist ansehnlicher entwickelt, als bei Ianatus: sie besitzt nach Nordmann bei $600 \mathrm{~mm}$ Schädellïnge $96^{\mathrm{mm}}$ Höhe und $24^{\mathrm{mm}}$ grösste Dicke (bei Halitherium dem Verhältniss entsprechend $56^{\mathrm{mm}}$ Höhe bei $344^{\mathrm{mm}}$ Schädellänge). Die Aelmlichkeit der Muschelbildung mit derjenigen ron Halitherium ersieht man bei Nordmann 1. c. Taf. II Fig. 2 und 3 und aus seinen Worten pag. 12: „Zu beiden Seiten der Scheidewand liegen die Muscheln, an welchen man den oberen und unteren Fortsatz unterscheiden kann, beide sind indessen unter sich und anf der unteren Fläche mit dem Kieilbein rerwachsen und bilden ein Convolut von wulstförmigen Platten. Der obere Fortsatz, an die Wand des mittleren Stirngewölbes sich legend, ist eine lange, vorn $56^{\mathrm{nm}}$ breite, nach innen convexe Platte; sie begrenzt den inneren Rand des Nasenbeines, umfasst von unten die Basis des processus orbitalis (ossis froutis) und reicht mit ihrem vordersten, nach innen gekelurten Zipfel uiber den Stirnrand weit herror" (siehe unsre Taf. X Fig. 98). "An ihrer imeren und unteren Fläche ist sie ausgehöhlt und geht dann, getrennt durch eine von innen nach vorn sich streckènde knöcherne Scheidewand, oder vielmehr eine andre Muschel, in den andern, unteren, kürzeren Fortsatz ïber, welcher mit einer flachen und dïnnen spatelförmigen Spitze endet und von der perpendiculïren Scheilewand durch eine tiefe, nach vorn sich erweiternde Höhlung geschieden ist". Der hinten dicke Wulst der mittleren Muschel endigt also wie bei Halitherium vorn in eine Spitze, welche sich dem unteren Rande der absteigenden Stimtheile anlegt. Die obere Muschel ist ähnlich derjenigen von Manatus, doch ist das Horn ansehnlicher, wenn auch schon bedeutend reducirt gegen das von Halitherium. Die letzte kleine Falte am Boden der Nasenhöhle bei ron Nordmann Taf. II Fig. 3 e. rechts, scheint das vordere Ende eines kleinen dritten Wulstes zu sein; denn Brandt l. c. pag. 20 nimmt eine solche untere Yuschel an: „nec non sub concha secunda tertiam concham infimam, parvam, brevissimam, secunda concha fere dimidio breviorem, conchulis duabus brevibus, involutis instructam inveni". Doch spricht sich Brandt nicht dartiber aus, ob er in dieser dritten Muschel den Rest eines eigentlichen Muschelbeines sieht.

Der vordere Theil des Siebbeins von Halicore ist stärker verkümmert, als bei den anderen Sirenen. Die lamina cribrosa dagegen ist älmlich gestaltet: dieselbe sitzt in einem Fenster, welches geradeso spitzbogenförmig ist, wie bei Halitherium; sie hat in einem Sclädel von 335 mm Länge die Höhe von $47^{\mathrm{mm}}$ (genau die Höhe des foramen occipitale an demselben Schädel) und die Breite ron $37^{\mathrm{mm}}$, während das alte Thier von $375^{\mathrm{mm}}$ Schädellänge nur $44^{\mathrm{mm}}$ Höhe und $33^{\mathrm{mm}}$ Breite der Siebplatte besitzt, gerade wie auch die Grösise des foramen occipitale im Alter abnimmt (siche oben pag. 6). Daher denn bei dem alten Thiere die lamina cribrosa stärker gewölbt ist und die crista galli schärfer gegen das Gehirn rorspringt, als hei den jungen Dunong-Schädeh. Ausserdem sitzt mitten auf der crista galli des alten Schälels eine kleine honochemase auf. nicht unähnlich einem wirklichen kleinen 
Hahnenkamm, mit der Spitze nach abwårts gerichtet und nur mit einer 2 mm grossen Flïche des $11^{\mathrm{mm}}$ langen Randes an Jem Mediankamm der Siebplatte festgewaclsen. Dieser kleine, fast isolirte dreieckige Schnabel der crista galli fehlt bei den andern mir bekannten Sirenen-Schädeln und wirl auch von keinem Autor erwähnt ${ }^{1}$ ); dennoch diurfte er wohl die eigentliche crista galli sein, die bekanntlich selbständig ossificirt als Rest des septum interorbitale der Vögel und Reptilien, und der Siebplatte anwächst. Der hintere, schräg absteigende scharfe Rand dieses dreieckigen, platten Schnabels ist $16^{\mathrm{mm}}$ lang, der untere schräg nach rorn und oben ansteigente $10^{\mathrm{mm}} ;$ die $2^{\text {mm }}$ kleine Anwachsstelle liegt am unteren Ende der vorderen, sonst freien Kante. Entweder war dieses an dem einen Schädel isolirte Knockenstück bei den andern Schädeln gar nicht vorhanden oder es ist mit dem Nediankamm des Siebbeins verwachsen - was nicht wahrscheinlich, da es gerade ein altes Thier ist, an dem diese Nase erhalten blieb - oder es war noch nicht mit der Siebplatte verwachsen und ging bei der Maceration verloren. In Uebrigen habe ich stets den medianen Kamm der lamina cribrosa, welcher oben am foramen coecum beginnt und unten auf dem Wespenbein fusst als "crista galli" bezeichnet.

Der obere Theil der Siebplatte von Halicore ist weniger durchlöchert als die unteren, etwas eingestiilpten Seitenblätter, und zieht sich mit der Spitze zu einem foramen coccum ein, welches bei ganz jungen Thicren noch weit geöfnet bleibt. Die lamina cribrosa ist von grösserer Dicke, als bei den andern Sirenen, und auf der vorderen Fläche mit vielen Höckem besetzt; diese Fläche wird hier ïber den Muscheln unter dem Stimrand sichtbar, weil dic inneren Nasenhöhlen bei Halicore überhaupt sehr kurz sind und daher frei daliegen.

Die lamina perpendicularis ist wenig entwickelt: an dem jungen Schädel von $335^{\text {mm }}$ Länge ist der untere, horizontale Rand derselben nur $37^{\mathrm{mm}}$ lang von vorn nach hinten; nach oben aber hat dieselhe kaum einige Ausdehnung und weicht schnell der knorpeligen Scheidewand; der knöcherne Theil beginnt erst auf der Mitte der Siebplatte und läuft $40 \mathrm{~mm}$ weit direct nach unten zwischen die Vomer-Blätter hinein, welche durchbrochen werden. Das Innere der Platte ist von spongiöser Structur.

Das Labyrinth liegt selır reducirt und mit einigen unregelmässig gestalteten Lamellen vor dem unteren Theil der Siebplatte und den absteigenden Wünden des Stirnbeins an: ein oberes, 25-30 mo langes Horn weist kaum noch einige Aelnlichkeit mit dem grossen Horne des Halitherium auf; darunter stehen noch zwei ganz diinne, verschiedenartig durchbrochene kleine Muschelblätter zwischen zwei kurzen Höhlen, welche melı in die Choanen als in die vordere Nase blicken; ein eigentlicher Boden fehlt dem Labyrinthe, sodass es kaum von den Choanen abgeziunt erscheint. Zugleich tritt der Stirnrand am Halicore-Schädel weit nach hinten zuruick und bedeckt nur den kleinsten Theil der Nasenhöhle; dagegen erweitert sich die vordere Nasenöfinumg bedeutend und wird von den stark entwickelten desten des Zwischenkiefers im weiten Bogen umfasst (Taf. IX Fig. 93).

Demnach besitzt Halitherium die stärkste Entwicklıng des Siebbeins und besonders des Labyrinthes; älinlich demselben ist das Siebbein der Rhytina, reducirter dasjenige des, Manatus und am meisten verkïmmert am Schärlel der Halicore.

2) Nur Blainville's Zeichner zeichnet auf Taf. IV Manatus, Ostéogr. III, in dem Medianschnitt eines Dugong eine ähnliche scharf vorspringende, aber breit angewachsene crista galli. 


\section{Os frontis.}

Die Stirnbeine bilden zusammen mit den Scheitelbeinen das schmale, langgezogene Schädeldach des Halitherium; sie verbreitern sich nach vorn zu zwei auffallenden, grossen Augenfortsätzen, welche die solide Decke der Augenhöhle abgeben und senden vertikal abwärts zwei Temporal-Wände zum Schutz der inneren Nasengänge. Da die kräftigen Stirnbeine fest miteinander verbunden und mit dem Siebbein ausgefuilt sind, erhalten sie sich fossil in gutem Zustande. Die Frontalnaht zieht gerade über die Mitte der oberen Schädelfläche in sagittaler Richtung vom Stirnrand bis in den spitzen Winkel zwischen die processus parietales; vor ihrem hinteren Ende biegt sie häufig etwas nach rechts aus, als ob sie hier ein kleines Zwickelbein in der Stirnfontanelle ru umgehen hätte, wie ein solches bei Manatus öfters auftritt.") Die sutura frontalis bleibt anch an den Schädeln alter Thiere stets sichtbar, verknöchert im Innern und zeigt innen eine rauhe, zackige Nahtfläche, aussen etwas klaffend einen ziemlich glatten Rand; beim ausgewachsenen Thiere von 350 mm Schädellänge erreicht diese Naht eine Lünge von $104^{\mathrm{mm}}$, von welcher Länge die hinteren $31^{\mathrm{mm}}$ von den schräg anfwachsenden Scheitelbeinen oberflächlich bedeckt werden. Die Nahtfläche ist rom im dïnnen Stimrand ganz niedrig, nach hinten nimmt sie mehr und mehr an Höhe zu durch wachsende Dicke der Stirnbeine, sodass sie über der Siebplatte $25^{\mathrm{mm}}$ hoch ist (Taf. V Fig. 61). Zu beiden Seiten der Frontalnaht sind die Stirnbeine rechts und links ziemlich symmetrisch gestaltet.

Während die Stimbeine sich hinten zusammenziehen und einen oblongen Querschnitt von $60 \mathrm{~mm}$ Höhe und $50 \mathrm{~mm}$ Breite besitzen (Taf. II Fig. 4 und Taf. V Fig. 56) breiten sie sich nach vorn allmählich flach aus, sodass die äusseren Ecken der processus orbitales sich bis $167^{\mathrm{mm}}$ von einander entfernen (Taf. V Fig. 55). Ein hervorstechendes Merkmal des Schädeldaches von Halitherium sind die beiden hohen, scharfen, in der Mitte leistenförmigen Kanten, welche den lineae temporales hominis entsprechen und im vorliegenden Falle besser als cristae temporales zu bezeichnen sind; sie beginnen auf den Scheitelbeinen vor dem Rande der squama ossis occipitis, laufen nach vorn in geschwungener Linie durch die processus parietales und treten auf die Stirnbeine über, wo sie sich vorn in den Orbitalfortsätzen verlieren; diese crista temporalis kenuzeichnet die Grenze und liegt auf der Beugekante zwischen ler horizontalen Scheitelfläche und den fast vertikal abfallenden Schüfenwänden des Schädels (Taf. I Fig. 1 und Taf. IX Fig. 92).

Wir unterscheiden an jedem Stirnbeine: die obere horizontale facies frontalis, den processus orbitalis, die seitliche facies temporalis, eine dem Gehirn zugekebrte facies cerebralis und eine innere, ausgehöhlte facies ethmoidalis.

Die obere Fläche ist über beide Stirnbeine hin dreiseitig: die kürzere, vordere Linie ist der Stirnrand oder margo nasalis, die beiden längeren, nach hinten spitz zusammenlaufenden Seiten werden von den beiden nach vorn divergirenden cristae temporales, sowreit sie auf dem Stirnbein

1) G. von Jäger, Osteolog. Bemerkungen iiber MIanatus americanus, Nora Acta Acad. Natur. Curios. Vol. 24 und Krauss, Müller's Archiv. 1. c. pag. 397. 
liegen, begrenzt. Der Stimrand wird im Ganzen zwischen den beiden Orbitalfortsätzen $67^{\mathrm{mm}}$ lang; er ist nicht gerade, sondern mehr oder weniger doppelt geschwungen (Taf. V Fig. 50), bei jungen Exemplaren stïrker geschwungen als bei alten; in der Mitte läuft er stets spitz nach vorn zu einem kurzen Stachel jederseits der sutura frontalis aus, damn schwingt er im Bogen nach aussen und hinten zurück und biegt wieder nach vorn, um hinter dem eingelagerten Stirnfortsatz des Zwischenkiefers in den processus orbitalis überzugehen. Unter diesem diumen Stimrande wachsen die breiten Nasenbeine heraus, deren mediane Naht die sutura frontalis nach rorn fortsetzen; diese Nasenbeine Stecken, wie wir unten ausfihren werden, mit ziemlich langen, lamellösen Wurzeln in dem Stirnbein: in Folge davon liegen unter dem Stimrand jederseits zwei tiefe und breite Gruben, beim ausgewachsenen Schädel jede etwa 35 - $40 \mathrm{~mm}$ tief und 30 mm breit, deren Flächen aus feinen Lamellen und engen Falten zur innigen Verbindung mit den Wurzeln der Nasenbeine bestehen; unter diesen Gruben tritt daher ein zweiter Stirnrand uber der imneren Nasenhöhle heraus (Taf. V Fig. 50 Sn), auf dem die Nasenbeine ruhen; dieser untere Stimrand ist ein homologes Gebilde zu dem processus nasalis ossis frontis am menschlichen Schädel, da hier die Nasenbeine auf diesem F'ortsatz und gleichfalls mit gefurchter Nahttläche aufruhen und dariiber in vertiefter Grube in die Stirnbeine einwachsen.

Die obere Fläche der Stimbeine ist schwach nach aussen gewölbt, sowohl in transversaler, als in sagittaler Richtung; zwei ganz Hache Kanten ziehen von hinten nach vorn mitten über jede Hälfte; melrere Gefäss-Eindriicke und -Löcher lassen sich auf der Fläche bemerken. Von hinten her schieben sich die beiden spitzen processus parietales der Scheitelbeine bis $65 \mathrm{~mm}$ weit auf die Stimbeine, sodass die zackige Kronennaht zweispitzig bis auf das halbe Stimbein vorläuft und in der Mitte weit zuriickweicht in den Winkel zwischen jenen beiden Fortsätzen (Taf. IX Fig. 92).

Die processus orbitales ${ }^{1}$ ) ossis frontis sind beim Halitherium ganz besonders stark entwickelt (Taf. I Taf. II Fig. 3. 4. 5 und Taf. V Fig. 50): beim ausgewachsenen Thiere werden sie ireieckig, beim jungen (Taf. II Fig. 5) sind sie mehr beilförmig. Als ein dicker und breiter Knnochen gab dieser Fortsatz den darunter befindlichen Augen ein sicheres Dach. Zwei solide Ecken sendet derselbe aus, eine mach vorn neben das obere Ende des Zwischen- und Oberkiefers, eine nach aussen, die sich mehr oder weniger dem Jochbein und dem Jochfortsatz des Schläfenbeins nähert. Die vordere Ecke ist rund etwa 18 man dick; bei jungen Thieren bleibt sie allseits frei, bei alten aber legt sie sich medianwïrts dicht an die Stimfortsïtze des Ober- und Zwischenliefers mit rauher Fläche an und verwächst mit ihnen allmählich. Die äussere Ecke ist weniger dick, bei jungen Thieren stumpf $110-115^{\circ}$, bei ausgewachsenen spitzer $80-90^{\circ}$ und streckt sich mehr dem Jochhein entgegen, von dem es aber immer noch 10-20 mm getrennt bleibt, sodass die Augenhöhle frei mit der Schläfengrube communicirt. Der stumpfe und rauhe Rand zwischen den beiden Ecken läuft schräg von innen vorn nach hinten aussen und wird $55^{\mathrm{mm}}$ lang. Der hintere Rand steht am alten Schädel genau transversal, wird $37^{\mathrm{mos}}$ lang und geht im Bogen in die Temporalfä̈che über. An

$\left.{ }^{1}\right)$ Entsprechend dem proc. zygomaticus ossis frontis Henle; diesen Namen können die Fortsätze nicht gut erhalten, weil sie sich wohl dem Jochbein aähern, aber dasselbe nicht erreichen. 
der medialen Seite grenzt der Orbitalfortsatz an das Nasenbein und die aufgelegten Aeste des Zwischen- und Oberkiefers. Die untere und obere Fläche des Fortsatzes sind schwach concav eingebogen, indem der mediale Theil desselben bis $28^{\mathrm{mm}}$ und die äussere Ecke etwas sich verdicken. Die Grenze gegen das übrige Stirnbein zieht man am besten von der obersten Spitze des Zwischenkieferastes nach dem Winkel zwischen dem Hinterrand des processus orbitalis und der facies temporalis; diese Linie wird $30-34 \mathrm{~mm}$ lang.

Die absteigenden Temporalwände des Stimbeins stehen im rechten Winkel abgebogen gegen die Stimfläche; auf der Beugekante wulstet sich die crista temporalis auf und verläuft vorn in der oberen Fläche der Orbitalfortsätze; sie bieten nach aussen glatte, etwas von oben nach unten gewölbte Flächen von $40-50 \mathrm{~mm}$ Höhe und $50-60 \mathrm{~mm}$ sagittaler Länge dar. Der untere Rand verläuft horizontal vou vorn nach linten, ist zackig als Nahtfläche gegen den Orbitalfliggel des Wespenbeins, gegen $60 \mathrm{~mm}$ lang und erreicht mit dem vorderen Ende die Spitze der mittleren Muschel des Siebbeins; die Naht sowohl gegen das Siebbein als gegen das Wespenbein bleibt bei allen Schïdeln sichthar, da der Rand des Stirnbeins ein wenig nach aussen von der Naht absteht. Nach oben verdicken sich die Temporalwände schmell zu herleutender Stïrke; sie umfassen daher innen einen scharf nach oben zulaufenden Raum, in dem das Siebbein nud die inneren Nasenhöhlen Platz nehmen.

Die hintere Fläche der Stirnbeine zeigt oben die rauhe Nahtfläche gegen das Scheitelbein: dieselbe ist eigentlich die Fortsetzung der oberen Stirnfläche, nur dass sie sich abwärts biegt und die Scheitelbeine sich schräg auflagern (Taf. II Fig. 4 und Taf. V Fig. 50 Sc). Mit dem übrigen Theil schliessen hier die dicken Stimbeine mit der darunter befindlichen Siebplatte das vordere Ende des Gehirns flach ab. Diese Gehirnfläche der Stirnbeine ist verhältnissmässig klein; sie liegt wie ein Halbmond über der Siebplatte mit den abwärts gerichteten Hörnern auf dem Orbitalflügel des Wespenbeins aufgesetzt (Taf. V Fig. 56); mitten durch den Halbmond geht die Stirnnaht, welche auf dieser Seite stets offen klafft mit glatten Rändern; der obere, grössere Theil der Fläche steht bei jungen Thieren ganz schräg von oben hinten nach unten vorn und läuft oben in der Mitte zugespitzt nach hinten; beim ausgewachsenen Schädel wird die Fläche ein wenig steiler und höhlt sich mehr aus, sodass sie die Gehirnfläche der Scheitelbeine unmittelbar fortsetzt (Taf. V Fig. 61). Von hinten werden die Stirnbeine auch auf der Schädelseite von dem dïnnen Rande der Scheitelbeine und unten von den Temporalflügeln des Wespenbeins von aussen her umfasst.

Die Stirnbeine der lebenden Sirenen werlen im Verhältniss zum Halitherium weit schmïchtiger, besonders zieht sich der margo nasalis zwichen den diumeren processus orbitales nach hinten zurück; doch weichen Manatus und Rhytina im Ganzen weniger ab vom Halitherium in der Bildung der Stirnbeine, als dies bei Halicore der Fall ist. Da das Schädeldach der lebenden Sirenen iiberhaupt breiter ist, als das von Halitherium, so rücken auch bei Manatus die beiden Schläfenkanten weiter auseinander, obschon bei manchem Nanatus australis-Schädel diese Kanten sich in der Mitte bis auf $15-20$ män nähern. Die verschiedene Form der Temporalkanten bedingt auch eine srössere oder geringere Breite der oberen Stirnflïche: an dem Taf. IX Fig. 95 abgebildeten Manatus australis von Surinam laufen die scharfen Schläfenkanten einander fast parallel und in einer Entfernung von 50-55 $\mathrm{mm}$; ebenso an einem andern mir vorliegenden surinamischen Schädel. Am Ma- 
natus senegalensis rom Ogowe ist das Schädeldach noch schmaler, die Temporalkanten verlaufen ziemlich parallel und auf dem Stirnbein in einer Entfernung von $45-50 \mathrm{~mm}$. Die Temporalkanten stehen dabei viel weniger stark nach oben hervor, als bei Halitherium.

Indem die Nasenbeine bei Manatus bedeutend reducirt sind und sich nicht mehr in der Medianlinie berihren, verbält sich der Stirnrand auch etwas anders, als bei Halitherium: zwischen den seitlich gelegenen, sackförmigen Gruben, in welchen die Nasenbeine im Stimbein stecken, bleibt ein freier, ausgefranster Stirnrand von $20 \mathrm{~mm}$ beim surinamischen Manatus frei über der inneren Nasenhöhle übrig (Taf. IX Fig. 95), welcher sich bei der afrikanischen Art noch auf 15 mm verkïrzt, nicht weil hier die Nasenbeine grösser wären, im Gegentheil, sie sind kleiner, als beim australis, sondern weil die Stirn überhaupt schmaler wird. In sagittaler Richtung erreicht das Stimbein des Manatus australis eine Länge von $80^{\text {mm }}$ (ohne die Orbitalfortsätze); dasjenige des Manatus senegalensis wird ansehnlich länger und besitzt an einem Schädel vom Ogowe $110^{\mathrm{mm}}$ längs der sutura frontalis gemessen. Die Stirntläche von. Manatus senegalensis wird demnach lang gezogen und schmal, während sie bei Halitherium breit dreiseitig war. Die Frontalnaht bleibt bei Manatus in der Regel sichtbar und ist besonders in der hinteren Hälfte vielfach verzahnt; an ihrem hinteren Ende trifft sie an jungen Schädeln häufig auf ein Zwickelbein, welches bei alten Exemplaren völlig verwächst. Die zackige lironennalit stösst in einem weniger scharfen Winkel auf die sutura frontalis, weil die processus parietales mehr voneinander weichen und kïrzer sind, als bei Halitherium.

Während bei Halitherium die Orbitalfortsätze mit sehr breiter Wurzel an die Stirnbeine ansetzen, ist diese Brücke bei Manatus bedeutend schmaler, sodass sich die Fortsätze mehr vom Körper der Stirnbeine isoliren: bei beiden Manatus-Arten verengt sich die Wurzel auf $13-15 \mathrm{~mm}$. Die Fortsätze selbst nehmen gleichfalls an Breite ansehnlich ab gegen Halitherium; in ihrer Form variiren sie nach Art und Alter: die vordere Ecke zieht sich schärfer und länger nach vorn aus; an dem Exemplar Taf. IX Fig. 95 hat der Fortsatz $70^{\mathrm{mm}}$ in sagittaler und 40 mm in transversaler Richtung; ungefähr dieselben Längen haben die afrikanischen Manatis. Die äussere Ecke reicht bald mehr bald weniger weit hinüber zum Jochbein bis zur gelegentlichen Berührung beider Knochen. ${ }^{1}$ ) Die äusseren Ecken beider Orbitalfortsätze entfernen sich von einander an dem Schäde! von Manatus australis Taf. IX Fig. 95 um $145^{\mathrm{mm}}$, an einem andern mir vorliegenden Schädel derselben Art um $112^{\mathrm{mm} 2}$ ), bei zwei Manatus senegalensis um 141 und $142 \mathrm{~mm}$; je weiter diese Entfernung, um so mehr nähert sich der Fortsatz dem Jochbein, und die Knochen streben sich entgegen durch kleine Auswïchse und stärkere Biegung der betreffenden Stücke. Bei dem ahgebildeten Manatus steht der Fortsatz nur um $10 \mathrm{~mm}$ vom Jochbein entfernt (Taf. IX Fig. 94). Da bei Halitherium der processus orbitalis ossis frontis zwar sehr gross ausgebildet ist, aber doch stets entfernt bleibt vom Jochbein, so könnte man in der gelegentlichen Vereinigung beider Knochen bei Manatus

\footnotetext{
1) Einen solchen Manatus senegalensis, an welchem der Orbitalfortsatz des Stirnbeins an das Jochbein und den processus zygomaticus đes Schläfenbeins stösst und sich diese Knochen gegeneinander aufwulsten, bildet Blainville ab, Ostèogr. Manatus Taf. III; auch von einem Manatus australis erwähnt Krauss, Müller's Archiv 1. c. pag. 399 diese Verwachsung.

$\left.{ }^{2}\right)$ Krauss giebt für dieselbe Entfernung 95-138 mon an.
} 
eine Entwicklung erkennen in der Richtung, diese Schïleltheile in gleicher Weise, wie bei andern Säugethieren, zu verbinden. Zugleich bestrebt sich Manatus durch stärkere Rundung der unteren Fläche des Orbitalfortsatzes und des vorderen Theiles des Jochbeines der Orbita eine kreisrunde und allseits geschlossene Form zu geben.

An dem medialen Rande des processus orbitalis wächst am Manatus-Schädel der Stirnfortsatz des Oberkiefers mit starken Zähnen und Zacken ein in voller Länge des Randes, während der Zwischenkieferast nicht verwächst, zuweilen sogar liaum anliegt; die kleinen Nasenbeine bleiben hinten an der Wrurzel des Fortsatzes liegen, ohne vorzuragen an die Seite desselben und ohne festzuwachsen. Diese Abweichungen rom Halitherium-Schädel hängen zusammen mit der allgemeinen stärkeren sagittalen Streckung des Manatus-Schädels.

Die absteigenden Temporal-Wände der Stirnbeine sind von der Schläfenkante an sofort ein wenig concav nach innen eingebogen, wodurch die innen gelegenen Nasengänge und das Siebbein eingeengt werden. Die untere hintere Ecke dieser Wände steckt unter dem Temporalfluigel des Wespenbeins; der untere Rand steht mit gezackter Naht auf den diinnen Orbitalfligeln desselben Beines und vorn auf der zarten Knochenlamelle, welche dem Gaumenbein angehört und den Raum gegen den Oberkiefer schliesst; zwei oder drei Löcher in diesem Blatte gestatten bei Manatus eine freie Communication zwischen der Augen- und Nasenhöhle, während bei Halicore an dieser Stelle eine sehr weite, grosse Oeffnung bleibt, da ein solches Gaumenblatt ebenso wie bei den anderen Sirenen fehlt und der Oberkiefer weiter entfernt liegt von dem Orbitalfortsatz.

Die Stimbeine der Rhytina sind ziemlich flach ausgebreitet und gross. Die auf den Scheitelbeinen vorhandenen Temporalleisten sind kaum angedeutet auf der Stirntläche. Die sutura frontalis klafft aussen ein wenig mit glatten Rändern und wird im Ganzen 130 mm lang; in der Tiefe der Naht wachsen die beiden Stirnbeine mit rauhen und lamellösen Flächen zusammen (Brandt 1. c. Taf. II Fig. 4). Die Kronennaht bildet mit zackigen Rändern einen nach hinten einspringenden Winkel, ähnlich wie bei Manatus und weniger spitz als bei Halitherium, da die processus parietales nicht sehr weit nach vorn vorspringen. "Einige Zwickelbeine" liegen nach v. Nordmann in der Stirnfontanelle.

Die processus orbitales setzen mit breiter Wurzel an das Stimbein, wie bei Halitherium; doch sind sie nicht dreieckig gestaltet, sondern spatelförmig, sodass der mediale Rand annähernd dem hinteren Rande parallel verläuft. Die äusseren stumpfen Ecken bleiben weit entfernt vom Jochbeim; sie spannen sich im Ganzen $202 \mathrm{~mm}$ voneinander an einem Schädel von $590 \mathrm{~mm}$ (v. Nordmann 1. c. pag. 30). Wegen dieser Breite bleibt auch der Stirnrand zwischen den Orbitalfortsätzen $50 \mathrm{~mm}$ lang und endigt frei über der Nasenhöhle; unter ihm ragen die Hörner der oberen Muschel des Siebbeins hervor (Taf. X Fig. 98).

Die absteigenden Temporalwände des Stimbeins biegen sich wie bei Manatus flach concav nach innen ein; sie sind sowohl in vertikaler, als in sagittaler Richtung verkiirzt im Verhältniss zu Halitherium, sodass ähnlich wie bei Halicore eine grosse Oeffnung zwischen ihnen und dem Oberkieferbeine frei bleibt (Taf. X Fig. 100). 
Die Stirubeine der Halicore sind gegen diejenigen der übrigen Sirenen sehr reducirt: der Stirnrand weicht zwischen den langen, schmalen Orbitalfortsätzen weit zuruick, sodass die Stirnfläche verhältnissmässig klein ist; an einem Dugong von $335 \mathrm{~mm}$ Schädellänge ist die Frontalnaht $60^{\mathrm{mm}}$ lang, die Stimfläche $70 \mathrm{~mm}$ breit. In der Mitte des Stirnrandes springen zwei Fortsätze jederseits der Naht meistens stärker vor, als bei dem auf Taf. IX Fig. 93 abgebildeten Exemplar. ${ }^{1}$ ) Die Linie des Stirnrandes, die Wölbung der Stirnfläche und die Länge und Breite derselben sind an verschiedenen Schädeln, besonders von verschiedenem Alter sehr variabel: an einem jungen Schädel von $310^{\mathrm{mm}}$ Länge ragt der Stirnrand mit starken Mittelspitzen weit über das verkiimmerte Labyrinth vor, wölbt sich nach oben flach convex aus und ist in der Mitte der Frontalnaht mit einer unregelmässig gestalteten Oeffnung durchbrochen, welche schrigg nach vorn vor der Siebplatte in die innere Nasenhöhle mündet; es ist dies kein Gefässkanal, sondern nur die vordere noch offene Spitze der Stirnfontanelle, wie man aus den noch sichtbaren Nähten der Zwickelbeine dahinter erkennt. An dem alten Schädel der. Halicore dagegen von $375^{\mathrm{mm}}$ Länge ist die Stirntäche stark concav eingedrückt, solass die scharfen Seitenkanten hoch über die Fläche emporragen; der Stimrand ist ohne Spitzen und nach hinten flach gebogen.

Sehr merkwürdig ist es nun, dass auf dem hinteren Theile der oberen Stirnfläche bei Halicore, wie es scheint wicht selten, jederseits der Frontalnaht eine melı oder weniger starke, rundIiche Knochen-Apophyse aufragt, gerade an der Stelle, wo die Knochenzapfen für die Hörner der Wiederkäuer sich befinden. Der von Rüppell eingefangene und beschriebene, weibliche Dugong besitzt diese beiden auffallenden Fortsätze besonders stark (1. c. Abbildung Fig. 4 u. 5 und pag. 107): "höchst merkwürdig sind zwei konische Erhabenheiten, deren stumpf zugerundetes Ende nach vorn und aussen zu gerichtet ist, und die sich in der Mitte jedes Schenkels des Stimbeins befinden; sie erinnern unwillkürlich an die Knochenkerne der gehörnten Wiederkäuer". An diesem Schädel in Frankfurt habe ich in Bezug auf diese Gebilde folgende Maasse genommen: jeder Fortsatz hat einen horizontalen Durchmesser von $10-11 \mathrm{~mm}$ und eine Höhe von $10^{\mathrm{mm}}$; nach vorn fallen sie steiler ab, als nach hinten, wo sie über die Kronemnaht fort in das Scheitelbein flach verlaufen; ihre immeren Ränder entfernen sich von einander um $27 \mathrm{~mm}$, ihre äusseren um $55^{\mathrm{mm}}$; im Innern der Stirnbeine entspricht keine Vertiefung dieser äusserlichen, glatt abgerundeten Erhebung. Mir liegen vier Schädel von Halicore vor von verschieden alten Thieren: an jedem sind diese beiden Apophysen wahrzunehmen, wenn auch weniger stark erhöht, als bei dem Dugong des Dr. Rüppell; auf der Zeichnung Taf. IX Fig. 93 sind dieselben nicht so deutlich, als in natura. Sogar an einem mir vorliegenden Schädel von Manatus senegalensis vom Ogowe treten an den gleichen Stellen, nur entsprechend den langgezogenen Stirnbein etwas weiter mach rorn entfernt ron der Kronemnaht, ganz

1) Dr. E. Ruippell. Beschreibung des im rothen Meere vorkommenden Dugong. Abhandl. des Mus. Senkenberg. Bd. I. Frankfurt. 1833. In dieser vortrefflichen Abhandlung, welche wenig bekannt zu sein scheint, da sie nirgends citirt wird, ist fälschlich auf Taf. VI Fig. 5 der grössere Theil der Stirnfäche als Nasenbein gezeichnet. Ich habe das im Senkenberg'schen Institut zu Frankfurt befindliche Thier daraufhin untersucht und gesehen, dass die Nähte an dieser Stelle nicht vorhanden sind. Ueber die Nasenbeine von Halicore siehe unten. 
ähnliche, niedrige Apophysen hervor; an den andern Schädeln von Manatus und auf den Stirnbeirien von Halitherium ist nichts analoges zu entdecken.

Keiner der andern Autoren, als Rüppell, erwähnt dieser Ansätze zur Hornbildung, obwohl G. Cuvier (Oss. foss. tom. V Taf. 19 Fig. 7) diese kurzen Zapfen an einem Halicore-Schädel in höchst auffallender Weise gezeichnet hat; bei Cuvier Taf. 20 Fig. 2 fehlen sie einem andern Halicore-Schïdel, und auch Blainville's berihmter Zeichner deutet nichts dergleichen an. Auch rom Rhỵtina-Schädel ist ähnliches nicht bekannt. So scheint dieser Ansatz zur Geweihbildung eine neue Erwerbung besonders von Halicore zu sein.

Die Orbitalfortsätze des Stirnbeins ragen am Halicore-Schädel sehr schmal und mit rauher, fast knorriger Oberfläche weit nach rorn, ansehnlich länger als die Stirnfläche. Entfernt man die hoch aufsteigenden Stirnäste des Zwischenkiefers, so verbreitern sich die Orbitalfortsåtze um das Doppelte, da sie unter dem Zwischenkiefer eine breite, lamellüse Ansatzfliche demselben darbieten. Die äussere Ecke der processus orbitales ragt sehr wenig nach aussen und bleibt daher weit getrennt vom Jochbogen. Nach vorn zieht sich der Fortsatz weit vor zu einer Spitze, welche sich am Stirnfortsatz des Oberkiefers vorbei bis zum oberen Ende des Jochbeins erstreckt und aussen rom knorrigen Thränenbein bedeckt wird (Taf. IX Fig. 93).

Die absteigenden Temporalwände der Stirnbeine von Halicore sind mehr oder weniger stark nach innen concar eingebogen; sie sind hinten an der Naht gegen Scheitelbein und Temporalfügel des Wespenbeins ziemlich hoch, erniedrigen sich aber nach vorn sehr schnell bei kurzer sagittaler Erstreckung. Die Oeffnung gegen den Oberkiefer ist daher weit, obschon sich die Orbitalfortsätze etwas nach unten herabbiegen (Taf. VIII Fig. 90).

Das Stirnbein der Sirenen variirt demnach in seiner Gestalt nach dem Alter der Thiere und nach der Art in ziemlich reiten Grenzen; im Vergleich mit dem Stirnbein des Halitherium verschmälert sich dasselhe Bein am Manatus-Schädel nicht unbedeutend, verkiurzt sich bei Halicore in sagittaler Richtung und gewinnt zwei Apophysen auf der Stirnflïche, verbreitert sich bei Rhytina; von allen Theilen des Stirnbeins verändern sich die Orbitalfortsätze am stärksten sowohl bei den verschiedenen Arten als an verschiedenen Individuen.

Von Muskeln setzen sich am Stimbeine der Sirenen an: der musculus temporalis an der linea temporalis; der musculus levator labii superioris alaeque nasi und der musculus pyramidalis nasi inseriren sich an dem medialen Rande der Orbitalfortsätze über dem Stirnaste des Zwischenkiefers. (J. Murie l. c. pag. 148 Taf. 21 Fig. 8 und 12).

\section{Os temporum et ossicula auditus.}

Das Schläfenbein des Halitherium erfüllt jederseits den hinteren Theil der Schädelseite; es fügt sich mit zackigen Nïhten hinten an die Schuppe und die Seitentheile des Os occipitis, oben an das Scheitelbein und vorn an den Temporalthigel des Wespenbeins, während sein unterer und innerer 
Rand frei gegen die Oeffnung an der Schïdelbasis, das grosse foramen lacerum, sieht und vom corpus ossis occipitis auf $10-20^{\mathrm{mm}}$ entfernt bleibt. Mit einer schmalen Fläche nimmt das Schläfenbein an der Bildung der hinteren Schädelwand Theil. Tach aussen erstreckt sich der starke und am Schädel sogleich in die Augen fallende Jochfortsatz.

Die Wichtigkeit dieses bedeutenden Schädeltheils wird dadurch erhöht, dass das Schläfenbein den wohl ausgebildeten Gehör-Apparat enthält.

Das Schläfenbein des Halitherium (und der Sirenen überhaupt) zerfällt in zwei von einander getrennte Abtheilungen, welche wir daher auch getrennt behandeln wollen: 1. Der Schuppentheil, pars squamosa, bestehend aus der Schuppe, squama, und dem an ihr festgewachsenen processus zygomaticus; an der Schuppe sitzt hinten der Warzentheil, pars mastoidea, mit dem processus mastoideus. 2. Die Pyramide, pyramis (Felsenbein, os petrosum aut.), aus zwei in der Anlage getrennten Theilen zusammengesetzt: dem Felsentheil, pars petrosa, welcher das Gehörlabyrinth enthält, und dem Paukentheil, pars tympanica (annulus tympanicus). Unter dem Paukenring und an dem Felsentheil liegen die drei kleinen Gehörknöchelchen, malleus, incus und stapes, weiche wir im Anschluss an den Paukentheil behandeln wollen. (Taf. II Fig. 6-10. 12. 13. und Taf. V Fig. $39-45$.)

Die Schuppe des Schläfenbeins ist ein flügelförmig ausgebreiteter Knochen, dessen äussere Fläche glatt ist und in den processus zygomaticus ausläuft und dessen immere Fläche oben sich stark gerieft den ahsteigenden Wänden der Scheitelbeine auflegt. unten halbingelförmig ausgehoihlt die Pyramide umfasst.

Der obere Theil der Schuppe theilt sich in zwei halbrunde Knochenplatten, von denen die hintere und grössere gerade aufwärts steigt und mit ihrem Hinterrande seitlich der Schuppe des os occipitis anliegt; der vordere Bogen ruht vorn mit zackiger Naht aussen auf dem Temporaltligel des Wespenbeins. Am ausgerwachsenen Thier ist die Schuppe $90^{\mathrm{mm}}$ lang und $70^{\mathrm{mm}}$ hoch.

Die Schuppe zieht sich nach aussen an ihrem unteren Theile aus zu einer 10-15 mm dïnnen und in sagittaler Richtung $47-50{ }^{\mathrm{mm}}$ langen Knochenbrücke, an welcher der processus zygomaticus angewachsen ist (Taf. V Fig. 39a). Diese Brïcke ist gegen $30^{\mathrm{mm}}$ breit (transversal), steht bei ruhiger Haltung des Kopfes mit ihrer Längsaxe schräg von unten vorn nach hinten oben, und trägt auf ihrer Unterseite die Gelenkfläche für den Unterkiefer (Taf. II Fig. 13). Der vordere Rand der Brïcke ist gerale transversal gerichtet und geht nach rorn in die crista infratemporalis der ala temporalis ossis sphenoidei iiber, der hintere Rand zieht sich nach hinten auf der Schuppe als Kante ans, welche über der flachen Einsenkung gegen den Warzentheil zur incisura parietalis verläuft. Die untere Fläche der Wurzel des Jochfortsatzes zeigt auf dem vorderen Theile die flach von rechts nach links concave Gelenkfläche fuir den Unterkiefer: diese Gelenkfläche ist $35^{\mathrm{mm}}$ lang in transversaler und $27 \mathrm{~mm}$ breit in sagittaler Richtung; sie liegt nicht in einer Pfanne, sondern ragt eher etwas nach unten vor, indem sich limter ihr eine lange schmale Grube über die Fläche zieht; im Vergleich mit dem menschlichen Schälel artikulirt also der" Unterkiefer nur auf dem tuberculum articulare, nicht in der fossa mandibularis (s. glenoidea aut.). Hinter der erwähnten Grube erhebt sich 
eine scharfe Kante, weiche sich aut dem Unterrande der Schuppe ïber dem äusseren Gehörgange zu einem rauhen Knoten verdickt. ${ }^{\text {) }}$

Der Jochfortsatz des Schläfenbeins ist ein sehr starkes, weit nach aussen vorspringendes Knochenstück von prismatischer Gestalt. Beim ausgewachsenen Thier wird er $120^{\mathrm{mm}}$ lang von vorn nach hinten gemessen, $45^{\mathrm{mm}}$ hoch und $10-20 \mathrm{~mm}$ dick. Seine Aussenfläche (Taf. II Fig. 3) ist glatt, schwach gewellt, nach vorn spitz zulaufend, hinten abgerundet. Der obere Rand des Fortsatzes ist leicht nach oben ausgebogen, der untere mehr gerade und schärfer als der obere. Vorn legt sich der Jochfortsatz unverwachsen auf das spitze, hintere Ende des Jochbeins auf mit $10^{\mathrm{mm}}$ breiter Fläche (Taf. VIII Fig. 87). Die Unterseite des Fortsatzes ist rauh und wellig zum Ansatz des sichèrlich recht grossen Kammuskels, musculus masseter, der hauptsïchlich den schweren Unterkiefer emporziehen musste und dessen vordere Lagen sich an das Jochbein inserirten. Die innere gegen die Schläfengrube schauende Fläche des Fortsatzes ist glatt und schwach convex.

Der bedeutend entwickelte Jochfortsatz des Schläfenbeins bewirkt hauptsächlich die grosse Breite des Schädels der Sirenen (siehe Taf. I und IX Fig. 92): am ausgewachsenen HalitheriumSchädel entfernen sich die äusseren Flächen dieser Fortsätze von einander um volle $200^{\mathrm{mm}}$ bei $344 \mathrm{~mm}$ Lünge des ganzen Schädels. So stark entwickelte Jochfortsätze besitzt kein andres Säugethier; am ehesten noch die Pachydermen, besonders Rhinoceros.

Der Warzentheil des Schläfenbeins ist beim Halitherium ein solider Knochen, der sich, als unmittelhare Fortsetzung des hinteren Theiles der Schuppe mach unten, aussen dem Felsentheil auflegt und in den starken processus mastoideus endigt. Die Grenze gegen den Schuppentheil ist angedentet durch eine flache Rinne, welche sich schräg von der incisura parietalis herunterzieht zur Gehöröffnung. Der Warzentheil steht als eine regelmässig vierseitige kurze Säule vertikal an der hinteren und unteren Ecke zwischen der Seiten- und Hintertläche des Schädels: seine äussere Fläche bietet rauhe Kanten und niedrige Wellen dar; von der incisura parietalis bis zum unteren Ende des Warzenfortsatzes ist sie $73 \mathrm{~mm}$ lang und ist etwa $22^{\mathrm{mm}}$ breit. Die Kante, mit welcher der Warzentheil die Grenze zwischen Hinter- und Seitenwand des Schädels bildet, dreht sich etwas von oben am foramen mastoideum auf der hinteren Schädelwand beginnend seitlich herab bis in die äussere Spitze des processus mastoideus. Die hintere Fläche sieht auf die Schädellhinterseite und ist flach von oben nach unten eingefurcht. Die innere Seite wölbt sich wie die Schuppe halbrund zur Aufnahme des Felsentheils; oben liegt sie mit freiem Rande bis zur incisura parietalis an dem offenen foramen mastoideum. Unter diesem Schädelloch lässt der Warzentheil ein kleines Stiick des Felsentheils zur Hinterseite des Schädels herausschauen; unten legt er sich mit zackiger Nahtfläche an den processus jugularis ossis occipitis. Die vordere Seite des Warzentheils ist oben mit dem Schuppentheil vereinigt, unten bietet sie eine runde Fläche als knöcherne Hinterwand dem äusseren Gehörgang dar: hier steht in einer schwachen Vertiefung der breite hintere Fuss des Paukentheiles frei auf. während der vordere Fuss desselben am Felsentheil stets anwächst.

$\left.{ }^{1}\right)$ Auch am menschlichen Schädel ist an dieser Stelle hinter der Gelenkgrube des Unterkiefers ein kleiner Knoten und ein unbenanter Kamm (Henle I. c. pag. 146). 
Das dicke untere Ende des Warzentheils ist der processus mastoideus: es ist dies eine rauhe rundliche Apophyse von $20-25^{\mathrm{mm}}$ Durchmesser und $5-10^{\mathrm{mm}}$ Höhe, wenn man diesen Fortsatz da beginnen lässt, wo sich der. Warzentheil frei macht von dem neben angewachsenen processus jugularis ossis occipitis. Nach Analogie des lebenden Manatus lätten sich an diesen hervorragenden dicken Knoten der musculus digastricus, welcher durch Hebelbewegung das hintere Ende des Unterkiefers aufwärts, das vordere abwärts zieht, und der musculus sterno-mastoideus befestigt (s. Murie, 1. c. Taf. XXI Fig. 9.10). Da bei den Sirenen die Kaumuskeln stark entwickelt sind, um den schweren Unterkiefer zu bewegen, so treten auch deren Ansïtze an den Schïdelknochen stark hervor.

Die Pyramide des Schläfenbeins bleibt, wie bei den meisten Säugethieren getrennt von dem Schuppentheil, verwächst aber mit dem Paukentheil; indessen liegt die Pyramide innen an der Schuppe so nahe an und wird von den überhängenden Rändern der Schuppe so fest gehalten, dass bei den gut erhaltenen fossilen Halitherien heide Theile des Schlifenbeins stets imnigr verbunden bleiben, und eher in Stiicke zerbrechen, als sich von einander lösen; erst eine tiefgreifende Verwitterung bewirkt die Trennung.

Die Pyramide ist ein ansehnlich grosser Knochen, von kugeliger Gestalt, der an der Unterseite des Schädels frei in das weite foramen lacerum und in die Gehirnhöhle hineinsieht. Beim ausgewachsenen Thier ist die sagittale und transversale Länge fast gleich gross und beträgt $55^{\mathrm{mm}}$; die vertikale Dicke ist etwa $50 \mathrm{~mm}$. Die Pyramide besteht aus dem dicken Felsentheil, der das Gehörlabyrinth enthält, und dem Paukentheil, einem lateralwärts offenen Ringe, in welchem das Trommelfell ausgespannt war. In der Paukenhöhle zwischen Pauken- und Felsen-Theil liegen die drei ansehnlich grossen Gehörknöchelchen (Taf. V Fig. 41 und 45).

Der Felsentheil ist ein solider kugeliger Knochen, welcher medianwärts in die Gehirnhöhle zwei hinter einander liegende starke Auswüchse sendet: diese Auswiichse sind von einander getrennt durch einen tiefen, schmalen Einschnitt, der sich nach unten in die Paukenhöhle zieht, auf der oberen Fläche des Felsentheils undeutlich wird und um die Aussenfläche desselben als seichte Furche herumläuft. Durch solche Einschniirung entstehen zwei Hälften: eine vordere kleinere 20 mm und eine hintere dickere $35^{\mathrm{mm}}$ lange (in sagittaler Richtung gemessen). Die obere Fläche des Felsentheils bildet eine flachwellige Ebene, als Boden des hinteren Gehirns von der dura mater ïberzogen; die untere Fläche ist ausgehöhlt als Decke der Paukenhöhle; die bintere Fläche ist dreiseitig und dringt mit schmalem Streifen zwischen dem Warzentheile der Schlifenschupre und den Seitentheilen des os occipitis frei hinaus auf die Hinterseite des Schädels; die äussere Fläche ist nierenförmig rund, ziemlich glatt mit vielen kleinen Höckern und Narben besetzt und liegt in dem halbkugeligr ausgehöhlten Schuppentheile verborgen.

Die vordere kleinere Hälfte des Felsentheils steckt lateral- und vorwärts mit kugeliger Oberfläche soweit im vorderen Theil der Schuppe, dass etwa ein Drittel derselben von scharfen, vorspringenden Kanten der bier ziemlich dicken Schuppe umfasst wird; diese Hälfte des Felsentheils sitzt daher am festesten ${ }^{1}$ ); an den beiden auf Taf. II Fig. 6 and 7 abgebildeten Pyramiden ist

1) Am menschlichen Schädel bleibt hier vorn trotz der Verwachsung noch von der ursprïnglichen Trennung zwischen Pyramide und Schuppe die fissura petro-squamosa übrig. 
kaum die Naht gecren die Schupe wahrzunehmen. Ein freier mit Knorpel und Fett ausgefiulter Zwischenraum, wie bei den Cetaceen, ist weder bei dem Halitherium noch bei den andern Sirenen vorhanden. Nach innen läuft die vordere Hälfte des Felsentheils in einen Wulst von ovalem Querschnitt und in eine stumpfe Kante vom $17 \mathrm{~mm}$ Jänge aus: die rordere Ecke dieser Kante ist abgerundet und tritt sehr nahe der spina angularis des Temporal-Fliugels des Wespenbeins, welcher sich hier unter den vorderen Ausläufer der Schläfenschuppe mit zackiger Nahtfliche unterlegt. Die hintere Ecke der Kante springt weiter als die vordere nach innen vor und endigt spitz: an dieser Stelle wichst mit einer papierdiunnen $6^{\text {mm }}$ langen Knochenbrücke die eine Zacke des vorderen Hornes des Paukentheils fest, und zwar liegt die Ehene der Knochenbriicke horizontal; die Verwachsung findet an der schmalen Hinterseite des Felsentheil-Wulstes dicht unter der Spitze statt. Die Unterseite dieser Vorder-Hälfte des Felsentheils ist ausgebancht und dient als Decke der Paukenhöhle: an ihr ruht der dicke Kopf des Hammers mit dem Ambos darüber. Unter der dünnen Knochenbricke zwischen dem vorderen Felsen-Wulst und dem vorderen Horn des Paukentheils und über dem Hammer hin tritt eine schmale Spalte, etwa $6^{\mathrm{mm}}$ lang und $3^{\mathrm{mm}}$ breit von der Unterseite des Schädels in die Paukenhühle ein, wo sie auf den Steigbiigel zu sich richtet; diese Spalte ist die fissura petro-tympanica Ifenle (s. Glaseri ant.), welche mehrere Gefässe hindurchtreten liisst; sie erweitert sich nach aussen trichterförmig.

Nach hinten zieht sich die Unterseite dieser vorderen Felsenhälfte tief zurïck und bildet mit der hinteren Hälfte eine schmale und tiefe Rinne im Grunde der Paukenhöhle: in die Mitte dieser Rinne ragt der processus brevis des Ambos mit feiner langer Spitze hinein.

Die hintere grössere Hälfte des Felsentheils besitzt eine sehr flächenreiche, wulstige Gestalt. Die obere Fläche derselben (Taf. V Fig. 41) ist oblong mit $50^{\mathrm{mm}}$ Länge und $21-22^{\mathrm{mm}}$ Breite und ist schief von binten aussen nach vorn innen gestellt. Eine breite und tiefe Furche trennt das innere glatte Drittel der Fläche von dem äusseren wulstigen Theil: diese Furche, sulcus superior petrosus, führt zum inneren Gehörgang, meatus auditorius internus; hier tritt durch ein rundes Loch der nervus acusticus in das Felseubein zum Gehörlabyrinth ein. Weiter vor entliisst der sulcus superior petrosus unter einer dünen linochenbriicke den nervus facialis in die Paukenhöhle. Das Loch fiir den nervus acusticus liegt $13^{\mathrm{mm}}$ vom Hinterrande der pars labyrinthica des Felsenbeins entfernt; $4^{\mathrm{mm}}$ vor demselben öffnet sich der verhäitnissmässig weite $(3-3,5 \mathrm{~mm})$ runde Durchgang für den nerrus facialis, in welcher Oeffnung die obere Felsen-Furche nach vorn endigt. Da innerhalb des sulcus superior petrosus in Felsentheil Schnecke, Vorhof und Bogengänge des GehörLabyrinthes sich befinden, bricht der starke Wulst, welcher als dickes Ende der pars labyrinthica des Felsentheils in die Gehirnhöhle nach innen hineinragt, hier in dieser Furche leicht ab (Taf. II Fig. 6 und 7).

Lateralwärts von der Felsen-Furche erhebt sich die obere Fläche des Felsentheils zu einer wulstigen Hervorragung, unter der an ihrem hinteren Rande eine schmale, $6-7^{\mathrm{mm}}$ lange, horizontal gestellte Spalte, der aquaeductus vestibuli, eindringt (Taf. V Fig. 81 Av). Eine zweite wulstige Hervorragung folgt weiter mach aussen auf der oberen Flïche und endigt mit scharfer und spitzer Eche noch $10^{\text {ma }}$ vor dem Ansatz der Schuppe des Schläfenbeins; diese eigenthuimliche $11^{\text {mn }}$ lange 
und $5^{\mathrm{mm}}$ hohe, nach hinten steiler als nach vorn abfallende Nase besitzt keines der Felsenbeine der drei lebenden Sirenen. Im übrigen sieht dieses wulstige Stück der oberen Felsenbein-Fläche, gerade wie bei den andern Sirenen, so aus, als wenn es nicht ein ursprünglicher, sondern ein später aufgewachsener Theil des Felsenbeins wäre, sowohl durch seine ganze Erhebung über die übrige Oberfläche, als besonders durch die lange, sich als Furche fortsetzende Spalte des aquaeductus vestibuli.

Die hintere Fläche des Felsenbeines bauscht sich im lateralen Theile stark convex aus, zeigt am oberen Rande die oben erwähnte Nase, daneben die Wasser-Spalte des Vorhofs und zieht sich nach innen in einen scharfen Rand zusammen, der dem Labyrinth-Wuste angehört. Ehe das laterale Ende dieser Fläche frei nach aussen tritt an die hintere Schädelseite, bemerkt man eine ansehnliche, höckerige Einsenkung, in welche der Rand des processus jugularis der Seitentheile ossis occipitis einbeisst (Taf. X Fig. 97).

Die untere Fläche der pars labyrinthica ist zunächst durch eine horizontal stehende, scharf vorspringende knochenleiste in zwei Theile getheilt: liese Leiste begimnt medianwirts in dem dicken Wulstende des Labyrinththeils mit einem starken Buckel, in dem der erste Schneckengang liegt, und der dem promontorium im mittleren Ohr des Menschen entspricht; (der Buckel ist sogleich beiderseits durchbohrt: hinter der Leiste öffnet sich nämlich die fenestra cochleae s. rotunda, vor derselben die fenestra vestibuli s. ovalis in die Paukenhöhle. Zum runden Fenster hin zieht sich die Oberfläche des Knochens von hinten her allmählich flach, zuletzt als breite Furche einwärts; das Fenster selbst ist ansehnlich gross $\left(3^{\mathrm{mm}}\right)$ und führt zur scala tympanica der Gehör-Schnecke. Das ovale Fenster liegt versteckt unter dem dicken Endwulst der pars labyrinthica vor der erwähnten vorspringenden Leiste, es bildet ein Rechteck mit abgerundeten Winkeln von 3,5-4 ${ }^{\mathrm{mm}}$ Länge in schiefer Richtung von vorn aussen nach hinten innen, und $2,5-3^{\mathrm{mm}}$ Breite; dieses Fenster wird von dem Tritte des Steigbügels geschlossen und führt in den Vorhof des Gehör-Labyrinthes.

Dieser vordere Theil der unteren Fläche der pars labyrinthica, in dessen medianem Ende das ovale Fenster sich öffnet, biegt sich stark concav ein, zieht sich tief nach vorn und aussen zurïck und bildet die hintere und obere Wand des mittleren Gehöramms, in den sich die Gehörknöchelchen einlagern. Der mittlere Ohrraum dringt nach aussen tief in die Schliffenschuppe ein, welche dadurch an dieser Stelle, über dem dicken margo tympanicus so dünn wird, dass ein geringer Grad von Verwitterung hier bald die Schuppe durchbohrt; bei Halicore ist diese Stelle stets durchbohrt, und schaut daselbst ein Stïckchen Felsenbein nach aussen zur Schädelseite heraus.

Vor der mittleren Paukenhöhle spannt sich der ansehnliche Paukentheil aus. Dieser nach aussen nicht ganz geschlossene dicke Knochen-Ring ist sowohl vorn als hinten mit dem Felsentheil durch diume Brïcken verwachsen, während er frei der pars mastoidea der Schläfenschuppe anliegt. Die Ebene des Paukentheils ist die gleiche wie die des in ihm ausgespannten Trommelfells und steht ungefähr horizontal im Kopfe, innen und hinten ein wenig nach unten gesenkt, sodass der äussere Gehörgang nach unten stark aushiegen musste. um die Schallwellen in gerader Richtung auf das Trommelfell zu führen; in der That constatirt auch S. Murie (1. c. p. 188) eine "S förmige Biegung" des äusseren $80^{\mathrm{mm}}$ langen Gehörganges in seiner Anatomie des Manatus americanus. 
Der Paukentheil des Halitherium besteht aus einem dicken, spitzen Kopf, der medianwärts gegen das foramen lacerum gerichtet ist, und sendet zwei ansehnliche Hörner nach aussen, die das Trommelfell umspannten. Wie bei den andern Sirenen entsteht am Paukenring weder nach innen eine bulla ossea noch mach aussen eine knöcheme tuba. Der Kopf hat einen elliptischen Querschnitt. ist $19-20^{\mathrm{mm}}$ hoch und $15^{\mathrm{mm}}$ dick; nach oben rundet er sich platt ab und stellt diese Seite dem Labyrintb-Wulst entgegen, in einem Abstand von nur $4^{\text {mum }}$; unten zeigt er zwei schwache Buckel, und beiderseits läuft er mit abgerundeten Kanten in die Hörner aus. Die knotige Spitze wendet sich schief nach vorn, ragt weit in das foramen lacerum vor und kommt mit der vorderen, abgeflachten Seite sehr nahe der hinteren nach oben gewendeten Spitze der Gaumentligel des Wespenbeins (Taf. X Fig. 96). An dieser Seite des Kopfes des Paukenringes zieht sich aus dem Innern der Paukenhöhle hinter der fissura petro-tympanica entlang his nahe an die Spitze des Patukentheils eine ausgerundete, längsgestreifte $3^{\mathrm{mm}}$ weite Furche, welche auf das Wespenbein nach vorn übersetzt und zwischen Kö̈rler und Gaumenflügel des Wespenbeins auf die Schäilelbasis hinanstritt; diese Furche dürfte für die arteria carotis interna sein, welche bei Manatus aus der Halsgegend aufsteigend hinter dem Wespenbein vorbei in die Paukenhöhle dringt, hier umbiegt nach vorn und oben und auf der oberen Seite des corpus ossis occipitis durch einen Schlitz der dura mater zur Gehimbasis gelangt (J. Nurie 1. c. pag. 176 Fig. 30 und 36).

Das vordere Horn des Paukentheils ist viel kürzer als das hintere und theilt sich in zwei Arme, welche die fissura petro-tympanica umgeben: der vordere Arm setzt sich durch die erwähnte Knochenbrïcke mit der vorderen Spitze des Felsentheils in Verbinlung. Der hintere Arm ist $6-7^{\text {num }}$ lang und verwächst mit dem processus longus (s. folii) des Hammers; dieser Arm des Paukenringes zeigt mehrere Längsfalten, von denen die hinterste frei an dem Kopf des Hammers endigt und mit den vorderen Falten und der Ansatzstelle eine tiefe Rinne bildet: diese Rinne ist im Ganzen (auf Paukentheil und Hammer) $10^{\mathrm{mm}}$ lang, $2^{\mathrm{mm}}$ breit und $1-2^{\mathrm{mm}}$ tief, sie läuft in eine Vertiefung auf dem Hammer aus; in derselben hätte nach Analogie der Halicore und anderer Säugethiere als Fortsatz des processus longus des Hammers der knorpelige processus Meckelii gelegen, der nach der Innenseite des Unterkiefers hinüberzieht; die erwähnten scharfen Längsfalten anf der Unterseite dieses Horns in und neben der grösseren Furche scheinen Reste der Befestigung des Knorpels zu sein. An den mir vorliegenden Schädeln von Halicore ist der processus Meckelii auf eine verhältnissmässig lange Strecke verknöchert, resp. der processus longus des Hammers sehr verlängert. ${ }^{2}$ ) Die Anwachsstelle zwischen Paukentheil und Hammer ist bei Halitherium $4-5^{\text {nmm }}$ breit, sehr dünn und vertikal gestellt.

Das hintere" Horn des Paukentheils hat eine Länge 'von etwa $38^{\mathrm{mm}}$, setzt $11^{\mathrm{mm}}$ breit und $8^{\mathrm{mm}}$ dick am Kopf an, verdünnt sich allmählich bis $\mathrm{zu} 4^{\mathrm{mm}}$ und endigt mit einem grossen, platten Fuss, der sich ohne Verwachsung flach an die Vorderseite des processus mastoidens der Schläfenschuppe aufsetzt. Am hinteren Rand besitzt das Horn eine scharfe Kante, die sich am Kopfe fort-

1) Siehe auch M. Claudius, das Gehörorgan von Rhytina Stelleri, in den Mém. de l'acad. imp. des scienc. de St. Petersbourg, VII série, tome XI Nr. 5. 1867, pag. 9 und Taf. I Fig. 2 und 3. 
setzt. Der Fuss ist $18^{\mathrm{mm}}$ lang (in transversaler Richtung), $10^{\mathrm{mm}}$ breit und $4-6^{\mathrm{mm}}$ dick; seine Ebene liegt transversal im Schädel; die hintere Fläche ist etwas rauh und fïgt sich dem processus mastoideus mit oder ohne Vertiefung an; die vordere Fläche zeigt den gleich zu erwähnenden Falz fiir das Trommelfell. Der obere scharfe Rand des Fusses ist in $12-13^{\mathrm{mm}}$ Länge mit einem kurzen Fortsatz der hinteren Felsenbein-Hälfte fest verwachsen. Dieser Fortsatz ragt noch über dem Fuss des Paukentheils kurz vor und trägt hier eine auffallende, $4-5^{\mathrm{mm}}$ grosse, rauhe Vertiefung mit scharf vorspringenden Rändern: es ist dies der processus styloideus, an den sich das knorpelige ligamentum stylo-hyoideum hefestigt und das Zungenbein hängt; unter dem rauhen Ansatz. des Ligamentes schneidet eine breite Furche in das hintere Horn des Paukentheils ein, welche die Verdünung dieses Hornes verursacht. Bei den andern Sirenen findet sich dieser processus styloideus in ähnlicher Weise.

Die beiden Hörner des Paukentheils entfernen sich mit ihren freien Enden um 11 mm von einander; in diese Luicke dringt von oben her der Hammer mit seiner scharfen Kante vor (Taf. $\mathrm{V}$ Fig. 45). Das ovale Lumen, welches der Paukentheil grösstentheils umfasst, liegt wie gesagt, mit seiner Ebene ziemlich horizontal: es hat vom freien Ende des hinteren Horns zum inneren Rande des Kopfes, also transversal gemessen, einen Durchmesser von $16 \mathrm{~mm}$ und sagittal in den Mitten der beiden Hörner einen solchen von 11-12 wa. Nach unten, zum äusseren Gehörgang hin, erweitert sich das Lumen ein wenig, oben ist es am engsten. Im Kreise herum zieht nun an der inneren Seite des Paukentheils rom vorderen Horn unter dem Kopf durch bis fast an die freie Spitze des hinteren Hornes eine breite Rinne oder ein Falz, dessen unterer Rand scharf, dessen oberer flach abgerundet ist; der Falz ist am schärfsten längs des hinteren Hornes und zwar $2-3^{\mathrm{m} n}$ breit und $1-2^{\text {nn }}$ tief; in diesem Falz lag das Trommelfell, an das sich von oben her die scharfe Kante des manubrium mallei anlegte.

Da nun der Paukenring lateralwärts auf 11 mm offen ist, so musste hier das Trommelfell entweder auf dem hier tief eingeschnittenen Rande des Warzentheils (margo tympanicus) entlang gehen, oder ohne eine knöcherne Unterlage zwischen den Enden der Paukenhörner ausgespannt sein. Die erstere Annahme ist nicht wahrscheinlich: denn erstens sieht man keine Rinne oder Kante auf dem Rande des Warzentheils, und solam ist die Entfernung von den Enden der Hörner bis zu gemanntem Rande eine beträchtliche: es bliebe hier ein Raum von etwa $10^{\mathrm{mm}}$ Durchmesser, fast so gross wie das Pauken-Lumen; auch stellt sich der Fuss des hinteren Hornes in spitzem Winkel frei ab von der Wand des Warzentheils ${ }^{1}$ ).

Von den drei Gehörknöchelchen ist der Hammer der grösseste (Taf. V Fig. 44, Taf. II Fig. 8 und 9): er besteht aus einem dicken runden Köpfchen von $11^{\mathrm{mm}}$ Durchmesser und zwei Fortsätzen, dem manubrium und dem processus longus. Die beiden Fortsätze streckt der Hammer nach unten and innen; auf seiner oberen kugeligen Fläche trägt er eine dreieckige Erhebung und eine runde Fläche, beide zur Gelenkung mit dem Ambos. Das manubrium mallei hat nicht die Form

1) Claudius, Gehörorgan der Rhytina 1. c. p. 8, wo die Verhältnisse in dieser Beziehung ähnliche sind wie bei Halitherium. 
eines Stieles, sondern ist eine dünne Knochenplatte von etwa $12^{\mathrm{mm}}$ Länge und $5-6^{\mathrm{mm}}$ Höhe, welche mit der einen langen Kante verdickt am Köpfchen sitzt und die andere lange Kante von Papierdiume nach unten kehrt zur Anlage an das Trommelfell. Wahrscheinlich lief diese TrommelfellKante des manubrium nach innen gegen den Paukentheil in eine Spitze aus, wie bei Halicore; wenigstens zeigen die mir vorliegenden Hämmer alle an dieser Stelle eine kleine Bruchfläche. Diese Spitze wiirde etwa dem Griff am Hammer des menschlichen Schädels und das obere dickere Ende der wenigstens $13 \mathrm{~mm}$ langen Kante dem gleichfalls dem Trommelfell anliegenden processus brevis entsprechen. Die freie Kante des manubrium ist in der Ebene des Trommelfells ein wenig kreisförmig gebogen, sodass das Trommelfell nach aussen gegen den äusseren Gehörgang etwas convex vorspringen musste, wie das auch J. Murie beim Manatus americanus pag. 188 erwähnt.

Der processus longus steht nach vorn kurz ab rom Köpfchen, ist $7-8 \mathrm{~mm}$ lang, verwächst an seinem inneren Rande mit dem vorderen Horn des Paukentheils und zeigt vor dieser Brücke die Furche und rauhe kleine Ansatzfläche für seinen knorpeligen Fortsatz, den processus Meckelii. Gerade wie am menschlichen Schädel verwächst also der processus folii mit dem Paukenring an der unteren Wand der fissura petro-tympanica (Taf. II Fig. 12).

Der tiefen Furche, welche das manubrium vom processus folii tremnt, entspricht eine weniger tiefe und breite Furche auf der Oberseite des Köpfchen: in dieser Furche steht ein zweiflächiger Gelenk-Kégel, an seiner Basis am Kopf $3^{\mathrm{mm}}$ dick, welcher seine kleinen ( ${ }^{\mathrm{mn}}$ Durchmesser) in $90^{\circ}$ gegeneinander gestellten. runden Gelenktlichen den beiden kleinen Gelenken des Ambos darhietet. Vor diesem Kegel, also auf der Seite des Köpfchens, von der unten der processus folii ausläuft, befindet sich noch eine $3^{\text {mm }}$ grosse, ebene, runde Gelenkfläche, welcher eine gleiche Fläche auf dem vorderen dicken Ende des Ambos entspricht.

Der $A \mathrm{mbos}$ liegt mehr versteckt als der Hammer über demselben im Innern und an der Decke der Paukenhöhle (Taf. V Fig. 43). Der Körper, corpus incudis, ist von oben nach unten abgeplattet, $10^{\mathrm{mm}}$ lang und $3,5-4^{\mathrm{mm}}$ dick; vorn $6^{\mathrm{mm}}$ breit, wird er nach hinten schmäler und endet hier in dem 2-3 ${ }^{\mathrm{mm}}$ dicken, runden, seitlich umgebogenen langen Schenkel. In der Mitte der Unterseite erheben sich zwei kurze Fortsätze, deren jeder eine runde $2^{\mathrm{mm}}$ grosse Gelenkfläche trägt. Diese beiden Gelenkfliichen stehen in $90^{\circ}$ gegeneinander und umfassen den kurzen Gelenkkegel des Hammers. Ausserdem befindet sich aber vor den Gelenkfortsätzen, gleichfalls auf der Unterseite des Ambos eine grössere ovale Gelenkfläche; Hammer und Ambos sind also durch drei in verschiedenen Ebenen stehende Flïchen mit einander recht fest eingelenkt. Die Oberseite des Ambos ist ziemlich eben, schwach wellig, ohne Auswiichse.

Nach aussen und oben in die enge Furche der Paukenhöhlen-Decke sendet der Ambos den spitzen kurzen Schenkel, crus breve s. posterius, aus, der sich auch am menschlichen Schädel mit seinem zugespitzten Ende in einem Grübchen in der Wand der Paukenhöhle hefestigt. An der Basis ist dieser $6^{\mathrm{mm}}$ lange Schenkel $4,5 \mathrm{~mm}$ breit; die feine Spitze bricht in der Regel ab, doch fand ich sie noch bei einem Exemplar, dem die Gehörknöchelchen sonst fehlten: in der engen Furche an der Decke der Paukenhöhle war diese Spitze, 3 mm lang mit einer runden Bruchfläche von 1,5 mm, stecken geblieben. Der andere Schenkel, crus longum s. descendens, ist rund, $3-4^{\mathrm{mm}}$ dick, streckt sich 
medianwärts gegen die Hinterwand der Paukenhöhle und wendet sein 2,5 mn dickes, etwas abgeschuirtes Ende umgebogen schief nach oben und hinten: hier trägt das aufgebogene Ende die runde, ebene $2 \mathrm{~mm}$ grosse Gelenkfläche für den Steigbügel. Der Ambos hat seine grösste Länge von $12 \mathrm{~mm}$ in der Richtung des langen Schenkels.

Der Steigb ügel endlich ist ein geradegestreckter, mitten durchbohrter Knochen von $10 \mathrm{~mm}$ Länge, der zwischen dem Ambos und der fenestra ovalis des Labyrinthes stelit (Taf. V Fig. 42 und Taf. II Fig. 8). SeineEbene ist im Schädel schief von aussen-unten nach oben-innen und von vornunten nach hinten-oben gerichtet. Am ovalen Fenster ist er am dicksten: abgerundet rechteckig hat der Tritt, basis stapedis, eine Länge von $5 \mathrm{~mm}$, eine Breite von $3,5 \mathrm{~mm}$, mit etwas in das Fenster hinein ausgewölbter Fläche; rings un den Tritt ist durch Punkte und durch schwache Vorragung ein zweiter Rand angedeutet, bis zu welchem derselbe im Felsenbein steckt. Vom Tritt an nimmt der Steigbügel eine rundere Gestalt an und wird allmählich ein wenig spitzer, sodass seine runde Gelenkfläche am Ambos nux $2^{\mathrm{mm}}$ Durchmesser besitzt. Die beiden Schenkel, crura stapedis, sind geradegestreckt; das Loch zwischen ihnen ist rund, innen 1 mm im Durchmesser, nach aussen beiderseits durch abgerundete Ränder etwas weiter; es liegt entweder gerade in der Mitte nach beiden Richtungen, und verdünnt jeden Schenkel bis zu $1-1,5$ mm, orler es verdünnt den einen Schenkel bis auf $0,6^{\mathrm{mm}}$ und lässt den andern $2^{\mathrm{mm}}$ dick; in einem Falle liegt das Loch auch 1 num weiter vom Ambos als vom ovalen Fenster ab.

Das Gehör-Labyrinth ist leider bei Halitherium nicht vollständig zu studiren, da die Knochensubstanz so spröle ist, dass genaue Durchschnitte nicht gelingen. Bei einem abgebrochenen Endwulste der pars labyrinthica ist der Boden des Vorhofs, schwach concav und $5^{\text {ma }}$ gross, sowie der Eingang zur Schnecke sichtbar geworden. Die Schnecke selbst sitzt in dem Wulst, der sich über der Leiste zwischen den beiden Fenstern erhebt. An einem andern Bruchstiick sieht man ein Stiick der Treppe. Ein drittes Bruchstück legt einen grossen Theil des Vorhofs frei und einen der drei bogenförmigen Kanäle: der Vorhof ist $2,5-3 \mathrm{~mm}$ hoch und etwa 5 mm lang; auf der vorderen Seite sieht man den 1,6 mm weiten Eingang zur Schnecke münden. Der freiliegende Bogen ist 9/4 eines Kreises von $4^{\mathrm{mm}}$ Radius; er hat eine Weite von $0,5-0,7^{\mathrm{mm}}$ und ist von oben nach unten comprimirt. Das Lumen des Kanals ist mit Substanz ausgefültt, während daneben das Stück eines zweiten Bogens offen geblieben ist; seine Ehene liest annähernd horizontal in der soliden Substanz des Felsenbeins lateralwärts von der Ebene der Fenster und des meatus auditorius internus: es ist dies der äussere oder horizontale Bogengang.

$\mathrm{Zu}$ erwähnen ist noch, dass analog dem Manatus wahrscheinlich das weite foramen lacerum an der Schädelbasis eingenommen wurde von einem memhranüsen Eustachischen Sack, der die Halitherieu befähigte, im Wasser Schellwellen aufzunehmen und durch die Paukenhöhle direct auf die fenestra cochleae s. rotunda zu leiten. Die tuba Eustachii mindete am hinteren Theil der Basis des Wespenbeins neben dem Gaumentligel in die hintere Choane. Keinesfalls kann hei Halitherium die Rede sein von so ausgedehnten Erweiterungen der tuba Eustachii wie bei den Cetaceen, da für solche lufthaltigen Räume liein Platz zwischen den festgeschlossenen Schädelknochen des Halitherium vorhanden ist. 
Manatus, Rlıytina und Halicore besitzen ein Schläfenbein, welches sowohl in seinem Felsentheil und Gehör-Apparat, als in dem Schuppentheil etwas von dem eben beschriebenen des Halitherium abweicht.

Die Schuppe bei II anatus ist im Ganzen dünner, als bei Halitherium; die beiden bogenförmigen Platten, welche sich ohen auf die ahsteigende Wand des Scheitelheins legen, weniger kräftig und kleiner. Vorn greift der Temporaltiigel des Wespenbeins mit tiefer Naht-Grube in die Schupre und zwar gerade da, wo nach aussen die breite Briicke zum Jochfortsatz aufsitzt, sodass die Schuppe an dieser Stelle am solidesten gebaut ist. Die Jochfortsatz-Brïcke ist stärker, als bei Halitherium: $45^{\mathrm{mm}}$ lang in sagittaler Richtung, etwa $20 \mathrm{~mm}$ breit und 10-20 $\mathrm{mm}$ dick. Die Gelenkfläche für den Unterkiefer an der Unterseite der Brücke steht genau tunnsversal mit 28 mm Länge auf einer hervorragenden, $12 \mathrm{~mm}$ breiten Leiste, die durch eine tiefe und lange Grube (fossa glenoidea) dahinter noch mehr markirt wird. Der Jochfortsatz ist in der Regel bedeutend dicker, als bei Halitherium, sonst aber ähnlich gestaltet; vorn endigt er breit mit etwa $20 \mathrm{~mm}$; an einem Schädel des Manatus australis von $340 \mathrm{~mm}$ Länge ist er $112 \mathrm{rm}$ lang, über dem tuberculum articulare $47^{\mathrm{mm}}$ hoch, vorn an der Spitze $17^{\mathrm{mm}}$ dick; an andern Schädeln von Manatus wird der Fortsatz noch weit dicker, schwillt schwammig auf und enthält viel Knorpelsubstanz. Das Jochbein reicht an der Unterseite dieses Fortsatzes hedentend weiter nach hinten, als bei Halitherium: nämlich bis an die Gelenkfläche des Unterkiefers, während er bei jenem mit viel dünnerem Aste kaum bis zur Mitte des Jochfortsatzes reicht; doch giebt es Schädel rom Manatus australis, bei denen der Jochbein-Ast auch nur bis zur Mitte des Jochfortsatzes des Schläfenbeins reicht (siehe unten, Jochbein).

Der Warzentheil von Manatus ist bedeutend kleiner und schwächer, als bei Halitherium; die incisura parietalis an dem foramen mastoideum ist kaum eingeschnitten; die Kante, welche von hier direct himunter in den Warzenfortsatz an der äusseren Schädelseite hinabläuft, steht zwar schäxfer hervor, ist aber halb so schmal, als bei jenem und schlägt sich nach vorn etwas uiber. Der processus mastoidens reducirt sich bei Manatus auf eine lange, schmale Fläche, an der sich der hintere Kaumuskel, musculus digastricus, ansetzt, ohne dass der Kinochen nach unten sich zu einem freien Fortsatz auszieht; daher ragt hier der processus jugularis weiter nach unten vor, als der processus mastoideus. Die innere halbkugelfïmige Aushöhlung für den Einsatz des Felsentheils zeigt ziemlich glatte Flichen, auf denen ron der ursprünglichen zackigen Verbindung nur schwache Wellen und unbedeutende Höcker übrig geblieben sind.

Die Pyramide des Manatus ist verhältnissmässig grösser, als die von Halitherium: besonders vergrössert sich die vordere Hälfte des Felsentheils und der Paukentheil. Der Felsentheil des auf Taf. IX abgebildeten Schädels von $340^{\mathrm{mm}}$ Länge hat im Ganzen von vorn nach hinten eine Länge von $65^{\mathrm{mm}}$ und ragt mit dem Labyrinthwulst $67^{\mathrm{mm}}$ breit durch das foramen lacerum bis dicht an den corpus ossis occipitis. Die vordere Hälfte des Felsentheils ist $45^{\mathrm{mm}}$ lang und bis $31 \mathrm{~mm}$ dick, also viel ansehnlicher, als bei Halitherium. An seiner kugeligen Aussenfläche zeigt sie stärkere Runzeln und Löcher, als die entsprechende Gegenfläche der Schuppe. Die Knochenbrïcke von der Spitze dieser Hälfte zum Paukentheil ist solider: fast $10^{\mathrm{mm}}$ lang und bis $4 \mathrm{~mm}$ dick. Die hintere Hälfte des Felsentheils ist ähnlich gestaltet, wie bei Halitherium: nur die Nase auf der Oberseite fehlt; 
der Schlitz des aquaeductus vestibuli ist aussen $11^{\mathrm{mm}}$ lang, zieht sich aber bald im Innern des Felsenbeins zu einem dünnen Kanal zusammen, der im Ganzen $16 \mathrm{~mm}$ lang ist und $2 \mathrm{~mm}$ lateralwärts vom meatus auditorius internus in den Vorhof mündet. Das runde, $2 \mathrm{~mm}$ weite Loch für den Durchgang des nervus facialis ist von einer diinnen Knochenbrïcke ïberspannt und befindet sich $4,5 \mathrm{~mm}$ vor dem inneren Gehörgang.

Der Paukentheil des Manatus hat einen dick aufgeschwollenen Kopf, ein sehr kurzes vorderes, dagegen ein $24^{\mathrm{mm}}$ langes hinteres Horn. Die Ebene desselben steht schief $\left(45^{\circ}\right)$ nach innen und unten, während sie bei Halitherium mehr horizontal stand; (laher ragt der Paukentheil hier mehr heraus auf der unteren Schädelseite, und uiberlässt es der pars labyrinthica das foramen lacerum zu fuillen (Taf. IX Fig. 94). Der Kopf des Paukentheils ist nicht spitz, sondern rund, $35 \mathrm{~mm}$ lang (sagittal) und 18 mm dick (vertikal). Torn setzt sich der liopf des Paukentheils fast olme abgesetztes Horn direct an die vordere Spitze des Felsentheils; die Verwachsung mit dem Hammer geschieht mittelst einer ganz kleinen, düunen Spitze, sodass beide Knochen leicht sich trennen. In der fissura Glaseri bei einem mir vorliegenden Exemplare des Nanatus australis findet sich an der hinteren Wand ein 2-3 $\mathrm{mm}$ grosses Knochenstückchen als Rest des processus Meckelii.

Das hintere Horn des Paukentheils streckt sich in weitem Halbkreis um das $17 \mathrm{~mm}$ weite Lumen herum und trägt an der inneren Seite einen scharfen Falz für das Trommelfell. Der Fuss dieses Horns ist durch die breite Furche des stylohyal-Knorpels weniger abgeschnürt als bei Halitherium: er ragt ausserdem so weit.gegen den margo tympanicus der Schläfenschuppe vor, dass ein Ansatz des Trommelfelles an diesem Rande nicht möglich ist. Die Oeffnung zwischen den Hörnern beträgt volle $20 \mathrm{~mm}$ und riickt wegen der Verkïrzung des vorderen Hornes weiter nach vom und imnen. Der processus styloideus ist in der Regel etwas grösser als bei Halitherium: seine ranhe $5 \mathrm{~mm}$ grosse Ansatzfläche für den Knorpel ragt $6-7 \mathrm{~mm}$ auf der vorderen Hälfte des Felsentheils empor an der Seite des Pauken-Horns.

Die Gehör-Lünöchelchen sind denen von Halitherimm ähnlich, doch hedeutend grösser. Besonders der Hammer streckt sich bis zu $20^{\mathrm{mn}}$ Länge (sagittal) und $13^{\mathrm{mm}}$ Dicke; während die ManubriumPlatte an der Wurzel zum Köpfchen nur $\delta^{\mathrm{mm}}$ Länge hat, zieht sie sich frei nach oben aus und endigt nicht in eine Spitze, wie bei Halicore, sondern mit einer quer zur Schneide gestellten ovalen Fläche von $6^{m m}$ Höhe und $4 \mathrm{~mm}$ Breite, welche sich an die innere Seite des dicken PaukentheilKopfes frei anlegt; das manubrium wird dadurch im ganzen 18 mm lang, von denen auf die etwas gebogene Schneide 13,5 mom kommen, und liegt fester am Paukenring an. Ein Knötchen an der hinteren Seite des Hammer-Köpfchens und ein Auswuchs an der Oberseite desselben fehlten hei Halitherium. Ebenso wie das vordere Horn des Paukentheils hier stark reducirt ist, beschränkt sich auch der processus longus s. folii des Hammers anf eine kaum hervorragende Ecke, sodass das dicke Köjpfchen des Hammers unmittelbar an die vordere Kante des Paukentheil-Kopfes anwächst. Die Beweglichkeit des Hammers diirfte bei Manatus geringer sein, als sie bei Halitherium gewesen ist. 'Die runde Gelenkfläche neben der dreiseitigen zum Ambos hat $6^{\mathrm{mm}}$ Durchmesser. Der Ambos sendet in die Tiefe der Spalte, welche an der Decke der Paukenhöhle die vordere und hintere Felsenhälfte trennt, einen langen diimnen Schenkel, crus breve, dessen feine Spitze beim Herausuehmen des Ambos aus 
der Paukenhöhle abbricht, da sie festgeklemmt ist. Die runde Gelenkfläche auf dem umgebogenen crus longum hat $3^{\mathrm{mm}}$ Durchmesser. Der Steigbiigel gleicht ziemlich genau dem des Halitherium: die Durchbohrung scheint auch meist ein wenig excentrisch zu stehen. ${ }^{1}$ )

Das Gehör-Labyrinth habe ich an einem der mir vorliegenden Felsenbeine von Manatus australis (Taf. IX) aufgebrochen und finde darin die folgenden Verhältnisse: die fenestra vestibuli S. ovalis, von 5,6 mm langem und 3,6 mm kurzem Durchmesser, erweitert sich sogleich zu einem Vorhof von 10-11 $\mathrm{mm}$ Lïnge (in sagittaler Richtung), 5-6 $\mathrm{mm}$ Tiefe und $3-4$ mn Höhe; die Flächen des Vorhofs sind glatt und schwach gewölbt. Der Vorhof zeigt an seinem Ende oben ein rundes Loch von $2^{\mathrm{mm}}$ Durchmesser, mit dem die scala vestibuli der Schnecke beginnt. Die papierdünne lamina spiralis, welche diese Oeffinung der scala vestibuli hinten ungiebt, schliigt kuxz auf die Decke des Vorhofs über und hat an diesem Rande eine Länge von 5 ma. Die lamina spiralis trennt zugleich den Vorhof von der fenestra cochleae s. rotunda vollständig. Dagegen communiciren die beiden Treppen frei mit einander, da die lamina spiralis sich nicht von der Spindel bis an die äussere Schneckenwand hiniber spaunt, sondern einen Zwischenraum von $0,5-1 \mathrm{~mm}$ frei lässt; diesen freien Raum zwischen beiden Trepnen überspamnte aber eine Haut, deren Ansatz an der Wand durch eine feine Knochenleiste angegeben ist. ${ }^{2}$ )

Das runde Fenster hat eine Höhe von 6,5 und eine Breite von $4,5 \mathrm{~mm}$, es ist oval, die unteren Ecken zugespitzt; eine seichte und breite Furche läuft auf der Aussenseite des Felsentheils so auf das Fenster $z u$, dass in der Verlingerung ihrer Axe die scala cochleae beginnt; auch von der Seite her ziehen sich zwei schmale, etwas gewundene Furchen in das Fenster hinein. Auf die Innenseite der fenestra rotunda schlïgt sich das Spiralblatt $3-5^{\mathrm{mm}}$ breit ïber. Die Schnecke macht fast $1^{1 / 2}$ Windungen, hat eine Höhe von 6,5 mn und besitzt noch in der Hälfte der ganzen Windung ein Lumen von 3,5 Weite; die Windungs-Ebene liegt ungefähr sagittal und vertikal im Schädel, die Spitze der Schnecke richtet sich medianwärts.

Von der Oberseite des Felsentheils dringt in den Nabel der Schnecke hinein der meatus auditorius internus: er endigt blindgeschlossen mit zwei Gruben, deren Böden vielfach durchbohrt sint zum Durchlass der Aestchen des nervus acusticus.

1) Gegenbaur, Grundzüge der vergleichenden Anatomie, 1870, erwähnt pag. 776, dass der Steigbiigel beim Amerikanischen Manatus, wie bei den Einhufern und Wiederkäuern, in der fenestra ovalis festgewachsen sei. Gegenbaur gibt die Quelle dieser Beobachtung nicht an und ich finde dieselbe von keinem andern Autor wiederholt. Jedenfalls ist dies bei den mir vorliegenden Exemplaren nicht der Fall: der stapes schliesst zwar hermetisch das ovale Fenster, liegt aber frei in demselben und fällt daher beim Maceriren von selbst heraus. Die mir bekannten Autoren stimmen auch hiermit überein, und J. Murie erklärt in seiner Anatomie des Manatus americanus ausdrücklich 1. c. pag. 188: in beiden Fällen war keines der Ohrknöchelchen verwachsen weder mit dem Felsennoch mit dem Paukentheil.»

$\left.{ }^{2}\right)$ Claudius 1. c. p. 11 sagt, dass die knöcherne Spiralleiste sobwohl sehr dïnn werdend, zur äusseren Schneckenwand hinitber reiche»; und fäht fort: wes wird wohl bei vollkommen macerirten Exemplaren eine schmale Spalte regelmässig vorhanden sein, indem der schmale Knochensaum abbricht, sobald er nicht mehr von IVeichtheilen, die ihn umgeben, gestittat. wird.» An meinem Exemplar ist die bleibende Spalte von so gleichmässigen Rändern der knöchernen Spiralleiste eingefasst, dass eine völlig knöcherne Ueberbrïckung kaum vorausgesetzt werden kann. Da Claudius p. 12 wegen der voliständig knöchernen Spiralleiste den Sirenen ein schwächeres Gehör zuschreibt, weil eine Knochenleiste schwerer als ein Membran schwinge, so wäre es gut, wenn dieser Punkt an frischen Exemplaren von Manatus oder Halicore nochmals untersucht würde. 
In den Vorhof münden ausserdem die drei bogenförmigen Kanäle, canales semicirculares ossei: die Kanäle sind $0,4-0,5 \mathrm{~mm}$ weit, etwas abgeplattet oval; jeder Bogen liegt in einer wenig erhobenen Spiralebene. Der zunähst der Paukenhöhle gelegene Bogen steckt in dem schwachen Wulst über den beiden Fenstern in amnähernd horizontal gestellter Ebene, und entspricht dem äusseren Bogengang des Menschen, canalis semicircularis s. horizontalis externus; er muindet an der Decke des Vorhofs, vorn in einer ziemlich scharf abgesetzten Ampulle von 1,6 mm Durchmesser, hinten Ampullen-los; beide Oeffnungen liegen $7 \mathrm{~mm}$ weit von einander entfernt und sind verbunden durch eine 1 meite, wenig tiefe Furche, die an der aufgewölbten Decke des Vorhofs hinläuft; er ist etwas kuirzer als die beiden andern Bogen und hat einen Radius von 3,4 $\mathrm{mm}$.

Der obere Bogengang, canalis semicircularis s. superior transversalis, beginnt vorn an der Decke des Vorhofs mit einer runden Ampulle, die dicht neben derjenigen des äusseren Bogens und zwar lateral-vorwärts vor diesem mündet. Die Ebene dieses Bogens liegt annähernd vertikal von oben nach unten und sagittal von vorn nach hinten; der Bogen ist etwas länger als der äussere, hat einen Radius von etwa $3,5^{\mathrm{mn}}$ und mündet nach drei Viertel seines Verlaufes in den hinteren Bogengang, ehe er den Vorhof wieder erreicht hat. Da also seine hintere Oeffnung mit der des hinteren Bogens gemeinsam ist, so liegen seine beiden Oeffnungen an der Decke des Vorhofes $8^{\mathrm{mm}}$ von einander entfernt und sind verbunden durch eine Furche, welche sich mit der Furche des äusseren Bogens in der Hälfte ihres Verlaufs einigt.

Der dritte hintere Bogengang, canalis semicircularis S. posterior longitudinalis, ist der längste: er ist etwa $17^{\mathrm{mm}}$ lang und beschreibt drei Viertel eines Kreises von $4^{\mathrm{mm}}$ Radius; die eine Oeffnung befindet sich in der hintersten Ecke des Vorhofes, wie alle Oeffnungen an der Decke desselben gelegen, und erweitert sich zu einer 1,6 weiten Ampulle. Die vordere Mündung ist ampullenlos und liegt an der lateralen Seite der Vorhof-Decke, dicht unter der Einmündung des aquaeductus vestibuli. Die Ebene des hinteren Bogenganges steht schief von vorn innen nach hinten aussen und schief von oben innen nach unten aussen, doch in beiden Richtungen nur etwa $25^{\circ}$ von der vertikalen und horizontalen abweichend. Die drei Bogengänge stehen demnach alle über dem Vorhof, in dem harten Felsenbein und mühden an der Decke desselben mit drei Ampullen und zwei einfachen Oeffnungen, ähnlich wie beim Menschen; auch befindet sich die Schnecke unter dem Vorhof und den Bogengïngen, etwas nach innen zu grelegen: dic Gehörknöchelchen sitzen lateralwärts des inneren Ohres in der Paukenhöhle. Die ganze Pyramide erfüllt das weite foramen lacerum zum grossen Theil und lasst nur nach vorn-imnen einen sichelförmigen Raum frei gegren das Wespenbein und den corpus ossis occipitis.

Noch will ich aus der Anatomie des Manatus von J. Murie einige Punkte betreffend den Gehör-Apparat hervorhehen: die äussere Gehör-Oeffnung mündet ohne Muschel als ein 2 mm enges Loch $105^{\mathrm{mm}}$ ) hinter dem Auge. Der äussere Gehörgang ist eng, cordel-artig, faserig, $80 \mathrm{~mm}$ lang mit einer S-förmigen Biegung; das Trommelfell ist eine elliptische, etwas dicke Membran. Die weite

3) An einem jungen Thiere gemessen. 
Eustachische Röhre communicirt mit der Paukenhöhle gerade vor dem Stylohyal-Knorpel. Murie sagt, dass an seinen beiden Exemplaren von Minatus atustralis keines der Gehörnöchelchen mit dem Pauken- oder Felsen-Theil verwachsen war. Bei zwei mir vorliegenden Pyramiden derselben Art ist, wie gesagt, der Ambos an einer kleinen Stelle am Paukentheil festgewachsen; leicht kann diese schwache Verbindung ganz authören. Die individuellen Verschiedenheiten sind ja überhaupt bei den Sirenen ziemlich bedeutend und betreffen oft wichtige Theile.

Das Schläfenbein von Rhytina schliesst sich in seinen Formen am nächsten an dasjenige des Manatus an (Taf. X). Die Schuppe gleicht der von Halitherium. Am Warzentheil fällt besonders die Breite (von vorn nach hinten) des processus mastoideus auf: die vordere knotige und rauhe Ecke für den Ansatz des musculus digastricus trennt sich scharf von einer flach concaven Ausbreitung des Knochens nach hinten zur Anlehnung an den processus jugularis ossis ossipitis; dadurch wird die Gehimhöhle nach hinten verlängert, was in der Seitenansicht (Taf. X Fig. 100) deutlich wird: das kurze Hinterhaupt des Hilitherium und der Halicore (Taf. VIII) streclit sich nach hinten bei Manatus (Taf. IX Fïg. 94) und noch mehr bei Rhytina. Die incisura parietalis, welche bei Halitherium deutlich abgesetzt den oberen Theil des Hinterrandes des Schläfenbeins zwischen Schupre und Warzentheil einschneidet, fehlt den andern drei Giattungen der Sirenen; nur das ansehnliche, im Leben nit Fasern erfiillte foramen mastoideum ist vorhanden. Die weite Spalte, welche von Nordmann 1. c. pag. 11 erwähnt, zwischen Schläfen- und Hinterhauptsbein von $108^{\mathrm{mm}}$ Länge und $19^{\mathrm{mm}}$ grösster Breite befindet sich unter diesem foramen und dient dazu das Felsenbein hier auf die Schädelhinterseite von innen her herausschauen zu lassen.

Der grosse Jochfortsatz besteht aus derselben schwammig-porösen Knochensubstanz wie bei Manatus; diejenigen von Halitherium und Halicore sind viel dichter und weniger dick. Bei dem auf Taf. X abgebildeten Schädel von Rhytina Stelleri, dessen ganze Länge 625 mm beträgt, ist der Jochfortsatz $190 \mathrm{~mm}$ lang (von Nordmann Taf. II Fig. I nur $160^{\mathrm{mm}}$ bei $590 \mathrm{~mm}$ Schädellänge), also im Verhältniss zur Schädellänge wie 100:329; bei Manatus $100: 315$, bei Halicore 100:288 und bei Halitherium $100: 280-290$.

Dadurch dass das auffallend grosse Jochbein tief nach unten hinabhängt, wird der Jochfortsatz gleichfalls aus der mehr horizontalen Lage, die er bei Halitherium und Manatus besitzt, nach vorn schief herabgezogen und steht zum Scheitelrand in einem Winkel von $25^{\circ}$, das ist noch etwas schiefer als bei Halicore; es wird dadurch das Augenhöhlenloch vergrössert.

Die Pyramide des Schläfenbeins von Rhytina sieht man auf Taf. X Fig. 99 das grosse foramen lacerum zum Theil ausfüllen; wahrscheinlich war auch hier diese weite Oeffnung an der Schädèlbasis unterfangen von einem membranösen Eustachischen Sack, wie bei Manatus. Unsere Abbildung zeigt, dass der Paukeming mit seiner Ebene fast vertikal nach unten gerichtet ist, wie bei Manatus und Halicore, während er bei Halitherium beinahe horizontal steht. Das vordere Ende des Felsentheils senkt sich ausser in die Schliffenschupe auch noch in den Temporalfligel neben der sjina angularis des Wespenbeins ein. Nach hinten innen erscheint die stark aufgeblähte pars labyrinthica des Felsenbeins. Eine genaue Beschreibung des Gehörapparates von Rhytina besitzen wir von M. Claudius 1. c. Ich will nur hervorheben, dass der Knochenwulst der pars labyrinthica an dem von Claudius abge- 
bildeten Stück auf ler unteren Seite viel weniger dick ist, ais an dem Nordenskjöld'schen Exemplar (Taf. X. Fig. 99); er ist ähnlich dem von Manatus gestaltet. Der sagittale Durchmesser des Felsentheils ist $80 \mathrm{~mm}$, derselbe bei Claudius $86 \mathrm{~mm}$. Auch die iibrigen auf pag. 13 angegebenen Maasse von Claudius beweisen, dass ihm ein Felsentheil von einem noch grösseren Exemplar von Rhytina als das auf Taf. $\mathrm{X}$ abgebildete vorlag. Das rauhe Ansatz-Grübchen für den Stylohyal-Knorpel hinter dem hinteren Fuss des Paukenringes liegt auf einem línochenfortsatz, del noch stärker als bei Manatus nach unten ausgezogen ist. Die Grösse des Labyrinthes ist hervorzuheben; die Form der Fenster, des Vorhofs, die Lage und Weite der Bogengänge ist bis ins einzelne ganz aualog dem Bate des Manatus; der obere und hintere Bogen haben einen langen gemeinschaftlichen Schenkel wie bei Manatus. Dagegen setzen sich die Ampullen hei Manatus ziemlich scharf ah, wihrend Claudius pag. 10 sagt: "die Ampullen sind wenig entwickelt und nicht so scharf abgesetzt, wie bei vielen Såugethieren, welche in der Luft hören."

An dem von Claudius untersuchten Felsenbein, dessen zugehöriger Schädel wie gesagt etwas grösser gewesen sein mag, als der auf Taf. $\mathrm{X}$ abgebildete, hatte das runde Fenster eine Weite von $7: 8^{\mathrm{mm}}$, das ovale von $6: 9^{\mathrm{mm}}$, der obere Bogen eine grösste Höhe von $5^{\mathrm{mm}}$, der horizontale Bogen von $6^{\mathrm{mm}}$ und der hintere von $9 \mathrm{~mm}$.

Was endlich das Schlifenbein von Halicore anbetrifft, so zeigt der Schuppentheil keine besonderen Abweichungen (Taf. VIII Fig. !0). Der Warzentheil ist schwächer als bei Halitherium, aber noch nicht soweit reducirt als bei Manatus; die breite, concave Fläche hinter dem processus mastoileus, die wir bei Rhytina fanden, bleiht ehenso klein. wie hei Halitherium. Das Schläfenbein liegt hier wanz auf der Seite des Schädels, während bei Halitherium der Warzentheil mit zur Bildung der hinteren schädelHäche beiträgt: das lange foramen mastoideum iffnet sich daher nach der Seite des Schädels, nicht wie bei Halitherium nach hinten; dieses Loch wird anselınlich erweitert durch Ausbauchung der Seitentheile und der Schuppe ossis occipitis nach hinten. Darunter sieht man ein Stück des Felsenheins freiliegen. Ueher dem Eingang zum Ohr schneidet ein tiefer halbrunder Ausschnitt in die Schuppe; er ist nach vorn begrenzt durch einen stark vorragenden linochenfortsatz, der eine rauhe Fläche zum Ansatz von den vorderen Fasern des musculus digastricus trägt; es entsteht dadurch ein unten offener äusserer knöcherner Ohrkanal, der direct auf die runde Oeffnung des Paukenrings zuführt. Der Jochfortsatz der Schuppe zeigt die Eigenthiumlichkeit, dass seine hintere Spitze sich nach innen umbiegt und einzieht gegen eine schmale Vertiefung, in der bei alten und jungen Exemplaren von imnen her das Felsenbein durch die diune Schuppe mit kleiner Fläche nach aussen herausschaut, was bei den andern Sirenen niemals der Fall ist (bei Halitherium nur bei starker Verwitterung der Schuppe). Der Jochfortsatz ist dick, schwammig, steht weit rom Schädel ab und trägt an seiner Unterseite die Gelenkfläche für den Unterkiefer, welche bei alten Thieren sich zu einem kurzen Gelenkfortsatz erhebt.

Die Pyramide steht fest in dem Schuppentheil und liegt mit ziemlich glatter Fläche in der Höhlung der Schuppe, sodass zwischen heiden hnochen kein Platz für ein Polster von Bindegewebe oder gar für eine Fettablagerung, wie bei den Cetaceen, bleibt. Der Paukentheil steht mit seiner Ebene ziemlich vertikal nach unten; er ist lange nicht so dick, wie bei Manatus, sondern ähnlich 
gebildet, wie bei Halitherium. Das manubrium mallei ist wie erwähnt sehr lang, läuft nach unten in eine schlanke Spitze aus, die sich in einer Falte des Trommelfelles birgt. Der Hammer ist fest mit dem vorderen Horn des Paukenringes verwachsen. An den mir vorliegenden Exemplaren von Halicore-Schädeln wächst als ein Fortsatz des processus longus des Hammers in der Rinne an der Vorderseite des Paukentheils ein knöcherner Stal) an, dessen Spitze dem Gelenkast des Unterkiefers entgegen schaut: es kann dieser Stab nur eine weitere Verknöcherung des Meckel'schen Knorpels

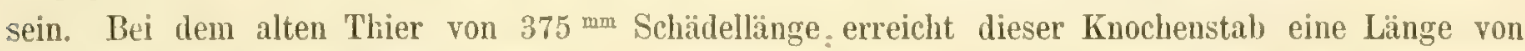
$18^{\mathrm{mm}}$ und eine grösste Breite von $5^{\mathrm{mm}}$; seine Spitze ist auf $2-3^{\mathrm{mm}}$ weit frei vom Paukentheil abgebogen. Meines Wissens verkn̈̈chert der Meckel'sche Knorpel bei keinem andern Sïugethier bis zu solcher Litnge; der processus longus mallei reicht mittelst dieses Knochenstabes durch die Glaser'sche Spalte bis weit auf die Aussenseite des Paukentheils. ${ }^{3}$ )

Der Ambos liegt in der Deckenspalte der Paukenhöhle ziemiich fest geklemmt und ragt mit dem kurzen Schenkel tief in dieselbe hinauf. Der Steigbuigel passt genau in das grosse ovale Fenster; hier zeigt er einen etwas abgesetzten Rand, der den glatten Kopf des Steighügels umgiebt.

Das Labyrinth ist ähnlich gebaut wie das bei Manatus beschriebene: der Vorhof ist bei dem jungen Halicore-Schädel von $335 \mathrm{~mm}$ Länge, wie bei dem alten von $375^{\mathrm{mm}}$ Länge in gleicher Weise $10^{\mathrm{mm}}$ lang und 2-4 mo hoch; die Ampullen der Bogengänge setzen von den letzteren nicht so scharf ab wie bei Manatus. Der aquaeductus vestibuli mündet nach aussen mit weiterer Oeffinung als bei Manatus und Halitherium: seine Mündung ist hier $8^{\mathrm{mm}}$ hoch und $2-3^{\mathrm{mm}}$ breit, während sie bei den andern Sirenen eine enge Spalte bleibt.

Claudius macht es in seiner Arbeit wahrscheinlich, dass die Sirenen beim Untertauchen in das Wasser keine Schallwellen mehr durch directe Vermittelung des Trommelfelles und die Reihe der Gehörknöcheichen in das ovale Fenster und den Vorhof empfingen, sondern dass die Schallwellen durch die Schwingungen der Schädelknochen, wie bei den echten Cetaceen, zum Theil durch die Paukenhöhle in das runde Fenster, zum andern Theil durch den festgewachsenen Hammer auch in die Gehörknöchelchen ühergeleitet wurden; es würde dann der Eustachische Sack wie ein Resonanzboden zur Verstärkung des Schalles gedient haben. Da der Hammer fest mit dem Paukenring und dieser mit dem Felsentheil verwachsen, der kurze Schenkel des Ambos fest eiugeklemmt ist in die Deckenspalte der Paukenhöhle und die Gehörknöchelchen sehr dick und stark gebaut sind - viel plumper als bei allen andern Säugethieren - und endlich der lange, selrr enge äussere Ohrkanal nur eine $2^{\text {ma }}$ grosse Oeffnung besitzt, so können die Sirenen in der Luft jedenfalls nicht so gut als im Wasser hören; sie werden ja auch als wenig scheue Thiere geschildert, besonders Steller’s Rhytina; sie unterscheiden sich dadurch wesentlich von den scharf hörenden Phocen. ${ }^{2}$ )

1) Bei Cuvier, Ossem. foss. tome V T'af. XX Fig. 13 ist der knöcherne Rest des Meckel'schen Knorpels an der Vorderseite des Paukentheils der Halicore gezeichnet; im Text beschreibt Cuvier den Obrapparat des Dugong nicht.

$\left.{ }^{2}\right)$ Leider konnte J. Murie an dem von ihm anatomisch untersuchten Manatus americanus keine Beobachtungen über den Bau des inneren Obr-Apparates macheu, da die Injection missglückte, I. c. pag. 188. 


\section{Os parietale.}

Das Scheitelbein des Halitherium ist der solide Deckknochen der Gehirnhöhle; er besteht in seiner Anlage aus zwei Scheitelbeinen, deren Naht (sutura parietalis s. sagittalis) stets so imnig verwachsen ist, dass selten eine Spur derselben wahrzmehmen ist. Die Form der vereinigten Scheitelbeine ersieht man ausser auf den andern Tafeln am besten aus Fig. 51, 60 und 61 auf Taf. V: lang gestreckt von hinten nach vorn sendet das Scheitelbein nach vorn zwei spitze Zacken auf das Stirnbein über und nach unten zwei absteigende Wände, die sich mit dünnem Rande hinter die Schläfenbeine und den Temporalflügel des Wespenbeins mit zackiger Nalitfläche anlegen; es verwächst an der breiten und sehr dicken Hinterseite mit der Schupe des Hinterhauptsheines zu einem Kinnchen; man findet daher das Scheitelbein beim Ausgraben aus dem Sande stets vereinigt mit der Hinterhauptsschupe, getremnt ron den uibrigen Schüdelknochen mit abgebrochenen spitzen, die auf dem Stirnbein zuriickbleiben.

Was dem Schädel des Halitherium ein eigenthümliches Aussehen giebt, das sind die beiden scharf vorspringenden langen Knochenleisten, welche auf der Oberseite des Schädels von hinten an der oberen dicken Querkante des Hinterhaupts beginnend sich nach vorn auf die Stimbeine ziehen und hier in den breiten Orbitalfortsätzen des Stirnbeins verlaufen: es sind dies die beiden Kanten, in denen das Schïdeldach umbricht gegen die Seitenwände des schïdels, also die lineae temporales (s. semicirculares ossis parjetalis), also die Linien, welche die Schläfengruben von dem Schädeldach trennen. Da diese Linien bei den Sirenen zu mehr oder weniger stark vorspringenden Leisten oder Kanten werden, wollen wir sie hier als cristae temporales bezeichnen. Jede dieser beiden Kanten beginnt hinten unmittelbar ïber der höchsten Zacke der Schläfenbein-Schuppe da, wo sich das Scheitelbein an die squama ossis occipitis anlegt und zieht dann mehr oder weniger bogenförmig geschwungen nach vorn, am stärksten erhoben in den vorderen Spitzen des Scheitelbeins.

Die Lage der beiden Kanten gegen einander variirt: an dem auf Taf. I und IX abgebildeten Schädeldache entfernen sich die Kanten hinten an der Hinterhauptsschuppe um 60 mo, convergiren dann nach vorn, bis sie nach einem Verlauf von $70 \mathrm{~mm}$ in der Mitte des Scheitelbeins sich auf $4-5 \mathrm{~mm}$ nïhern; und divergiren endlich, nachdem sie auf das Stimhein ibergetreten, in den heiden Spitzen des Scheitelbeins bis zu 76 m. An diesem ausgewachsenen Exemplill sind die beiden Kanten demmach ziemlich stark einwärts geschwungen. Die Querschnitte Fig. 60 und 56 Taf. V sind ron diesem spitzköpfigen Halitherium genommen. Bei andern verlaufen sie gerader: ein eben so grosser Schädel, als jener, lässt die heiden Kanten hinten am Hinterhauptshein un $67^{\mathrm{mm}}$ anseinandertreten; in der vitte des Schädel-

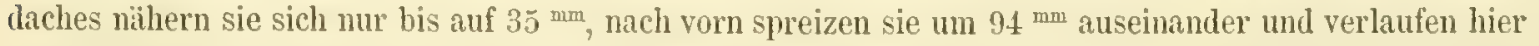
in die äussere Ecke der Stirnfortsåtze, bei einer totalen Länge von $170 \mathrm{~mm}$. Es sind dies die beiden Extreme der mir bekannten Schädel. Bei einem dritten ebenso grossen Schädel nähern sich die beiden Kanten bis auf $26^{\mathrm{mm}}$, bei einem vierten auf $20^{\mathrm{mm}}$, einem fünften auf $18^{\mathrm{mm}}$ etc. Wir wollen hier gleich bemerken, dass die Halitherien aus dem Wiener Becken, aus Frankreich und Italien, welche wir später zu besprechen haben, in dieser Beziehung dieselben Unterschiede darbieten, nur 
dass sie meistens zu den breithöpfigen Halitherien gehüren, während die rheinhessischen häufiger spitzköpfige Thiere gewesen sind; die lebenden Sirenen haben alle ein breites Schädeldach. Bekanntlich ist der Schiidel der Tapire noch weit spitzer und schïrfer, als bei Halitherium. Die Scheitelbeine des Halitherium sind in der Oberwand sehr dick: mit einer Fläche von $60-70 \mathrm{~mm}$ Breite und $25^{\text {mm }}$ Höhe wächst das Scheitelbein an die vordere und obere Hiilfte der Hinterhauptsschuppe an und zwar so fest, lass oben keine deutliche Spur der sutura occipitalis (s. lambloidea) unten aber eine mehr oder weniger tiefe Rinne bleibt, an welcher der Rand der Stimbeine überragt. Der Hinterrand der Scheitelbeine ist auf der Unterseite einfach flach geschwungen, beiderseits etwas abwärts gebogen. In der Mitte des Rand hängt eine krüftige Spitze, spina parietalis interna, nach unten gegen das Gehirn herab und setzt sich in einer allmählich verlaufenden Kante nach vorn fort gerade auf dem Unterrande der Pfeilnaht. Inden zugleich die Dicke des Scheiteldaches beiderseits dieser Kante abnimmt, entstehen zwei grosse flache Höhlungen, in welche sich die oberen Theile der beiden Hemisphären des Gehirns hineinlegen. Die herabhängende Kinochenkante der Scheitelbeine setzt sich nach vorn fort in die crista galli, welche zugleich die beiden kurzen bulbi olfactorii scheidet. An diese herabhängende Kante des Scheitelbeins und die crista galli setzt sich die falx cerebri der dura mater an, um die beiden Hemisphären des Vorderhirns in der incisura longitudinalis zu trennen. Die am hinteren Ende der Kante vorspringende Ecke und der quer anstossende, vortretende bintere Rand des Scheitelbeins senken sich in die fissura, welche J. Murie in seiner Anatomie des Amerikanischen Manatus fissura parieto-occipitalis nennt, eine Fissur, die wohl der fissura centralis s. Rolandi des Menschen entsuricht. Dem tiefen Einschnitt zwischen cerehrum und cerebellum kommt keine protuberantia occipitalis interna oder gar ein knöchernes tentorium cerebelli, wie bei den Carnivoren, von der inneren Wand der Hinterhauptsschuppe entgegen.

Auf der Oberseite ist der Hinterrand der Scheitelbeine stumpfwinklich nach vorn eingezogen, da die Schuppe ossis occipitis hier vor dem Krönchen noch eine kurze dreiseitige Fläche zwischen die Scheitelbeine nach rorn einschiebt. Die Lambda-Naht ist ihrem Namen entsprechend ja auch bei andern Säugethieren nach vorn und in der Mitte spitzwinklich gestaltet.

Ein oder zwei kleine ossa interparietalia geben sich beim Halitherium-Schädel kund einerseits auf der Oberfläche durch ein schwach ungrenztes dreckiges Knochenstïck, welches im Winkel der Lambda-Naht zwischen die Scheitelbeine einspringt (siehe Taf. V Fig. 51) und andererseits auf der Unterseite durch ein orler zwei runde, deutlich abgesetzte Knochensticke, welche sich gelegentlich ziemlich weit beiderseits in der Rinue zwischen Scheitelbein und Occipital-Schuppe als schmale Knochenstreifen entlang ziehen: an dem Schüilel Taf. I erreicht das abgesetzte eingeschaltete Knochenstück auf der Unterseite des Schädełdaches eine Länge von $85^{\mathrm{mm}}$, bei einer Breite von $2-4 \mathrm{~mm}$. Bei Manatus scheint auch in der Regel ein Zwickelbein vorhanden zu sein (Krauss 1. c. p. 397); bei Halicore kann ich keine Spur davon entdecken, finde es auch nicht erwähnt; dagegen ist an dieser Stelle das Schüdeldach der Halicore stets ron einem ansehnlichen Gefässloch durchbohrt, welches bei den übrigen Sirenen nicht vorhanden ist.

Nach vorn sendet das Scheitelbein des Halitherium zwei je 50-60 mm 'lange Spitzen aus, welche mit zackiger Nahtflïche auf der hinteren Oberseite des Stimbeins aufwachsen (Taf. V Fig. 50 
und 51); wir wollen diese sehr eigenthümlichen Zacken des Scheiteibeins processus frontales nennen. Da in diesen Spitzen zugleich die Temporallinien verlaufen, erscheinen sie als zwei hohe und dicke hunochenleisten zwischen der eingesenkten Oberfliche und den vertikal absteigenden Seitenwänden des Stirnbeins aufgelagert. Isetrachtet man deu ganzen Schädel von oben (Taf. I und Taf. IX Fig. 92), so erscheint die hintere Fläche des Stimbeins als eine spitze nach hinten zwischen die Scheitelzacken einspringende Winkelflitche, ohwohl sich dieselbe eigentlich in voller Breite des Schädeldaches unter die Scheitelbeine unterschiebt (vergl. Fig. 50 und 51). Jeder processus frontalis hat an seinem hinteren Ende etwa die vertikale Dicke von $10^{\mathrm{mm}}$ und spitzt sich nach vorn allmählich aus. In dem Winkel zwischen den Zacken entsteht in der Regel ein höckriger und knotiger Randwulst des Scheitelbeins, etwas erhaben iiber die sutura frontalis, als ein verwachsener Rest der Stirnfontanelle. Durch Auswitterung der Nähte zeigt sich bei jungen Exemplaren leicht ein bis in die Gehirnhöhle dringendes Loch (vergl. Krauss, Neues Jahrb. 1862 p. 393).

Die vordere Nahtfläche der Scheitelbeine unter dem Ende der Zacken ist in der Mittellinie bis $25 \mathrm{~mm}$ hoch und zwar in der schiefen Richtung, in welcher dieselbe über das Stimbein rauh uiberwächst (Fig. 61) und hat eine horizontale Breite von $42 \mathrm{~mm}$; zugleich ist sie von rechts nach links flach eingebuchtet. Die vertikale Dicke der Scheitelbeine erreicht vorn in der Temporal-Kante 23 mn .

Die Seitenwände der Stirnbeine steigen nicht vertikal, sondern mehr oder weniger flach nach aussen convex nebogen abwiirts; bei den spitzküpfigen Thieren (siehe den Querschnitt Fig. 60 Taf. V) ist naturlich die Ausbiegung eine stärkere als bei den breitscheiteiigen, doch richten sie sich auch bei diesen nicht vertikal, sondem schief mach aussen und unten. Aus dem dicken Scheiteldache gehen die Seitenwände ebenso dick hervor und verringern ihre Wandstärke nach abwärts mehr und mehr, sodass der zackige Unterrand derselben ganz dünn ist; dieser Unterrand ist nicht gerade, sondern läuft unregelmässig breitzackig von vorn nach hinten in ungefihr horizontaler Richtung. Von aussen her legt sich auf die vordere und untere Ecke der Seitenwand ein kleines Stück des Oberrandes der Temporalfluigel des Wespenbeins (Fig. 60 und 61) und dann nach hinten an Höhe zunehmend die grose Schlifenheinschuple: hesonders hinten vor der Hinterhauptsschuppe greift das Schliffenhein hoch hinauf his an die Tumlonalkante und bedeckt die ganze seitenwand rles Scheitelbeins mit einer vielgefurchten, bis 35, wu hohen und ehenso breiten Nahtfläche (vernl. Fig. 39 auf Taf. V). Da demnach die Seitenwände des Scheitelheins zu imnerst der andern Deckknochen der Schädelkapsel bleiben, so sieht man iunen an der Seite der Gehirnhöhle den Unterrand des Scheitelbeins frei iiber dem Felsenbein verlaufen (Ansicht Taf. I Fig. 61).

Was die Dimensionen des Scheitelbeins anbetrifft, so hat dasselbe bei einem ausgewachsenen Thier von $350 \mathrm{~mm}$ Schädellänge seine grösste Breite von $75^{\text {mon }}$ in der hinteren Hälfte seines Unterrandes; vorn unter dem Ansatz der Stirnzacken eine Breite ron $57 \mathrm{~mm}$; die Entfernung zwischen den Spitzen der Zacken auf der Stirnfläche erreicht $70 \mathrm{~mm}$; die ganze Lïnge des Scheitelbeins ist $155 \mathrm{~mm}$ und die Länge der Pfeilnaht 85 min.

Die Form und Grösse der Gehirnhöhle vom Halitherium erkennt man am besten an den Längsschnitten Fig. 61 und 58 und am Querschnitt Fig. 60 auf Taf. V, deren Zeichnungen alle im halben Massstah genommen sind. Die grösste Breite des (iehirmraums lag demmach nahe der Hinter- 
wand über den Felsenbeinen mit $75 \mathrm{~mm}$ (bei $344^{\mathrm{mm}}$ Schädellänge); die grösste Länge an der Unterseite des Gehirns vom bulbus olfactorius, der sich ein wenig in die Siebplatte einstuilpte (Fig. 58), bis zum inneren Rande des foramen occipitale, mit $105 \mathrm{~mm}$; die grösste Höhe etwa in der Mitte und unter den beiden Höhlen des Scheitelbeins mit 75 m. Die Kapacität des Gehirnraumes beim ausgewachsenen Halitherium ist möglichst genau berechnet nahezu $200 \mathrm{cbcm}$.

Die lange, schmale Form der Scheitelbeine des Halitherium verkiurzt sich ansehnlich bei den lebenden Sirenen, und giebt diese Verkiirzung und Verbreiterung der Scheitelbeine dem Schädeldache ein wesentlich abweichendes Aussehen. Während die Länge der Pfeilnabt bei Halitherium ein volles Viertel der Schädellänge ausmacht, ist dieselbe für Halicore ein Fünftel bis ein Siebentel, für Rhytina ein Sechstel, für Manatus australis 1/8-1/9 und bei Manatus senegalensis ist das Scheitelbein so stark verkürzt, dass es nur $1 / 10-1 / 12$ der Schädellänge beträgt. Mit der Verkürzung der Scheitelbeine geht Hand in Hand eine Verbreiterungs derselben und zugleich eine Abnahme der Länge und Zunahme der Breite des Gehirnraumes: das Verhältniss der Länge zur Breite des Gehirnraums ist nämlich $16: 10$ bei Halitherium, $15: 10$ bei der jungen Halicore, $14: 10$ bei der erwachsenen Halicore und $13: 10$ bei Manatus australis.

Die stakken Temporalkanten des Halitherium verflachen sich und rücken auseinander bei den andern Sirenen, die langen Zacken, welche das Scheitelbein auf das Stimbein vorsendet, werden mehr und mehr verkïrzt, der spitze Winkel zwischen diesen Zacken weicht einer breiten Ausbuchtung, kurz die Veränderung der Gestalt der Scheitelbeine ist grösser, als diejenige der andern Schädelknochen.

Am Schädel der jungen $\mathrm{Halicore}$ überragen die beiden Temporalkanten fast gar nicht das flache Schädeldach; am höchsten erheben sich hier die beiden oben erwähnten Knochenbuckel auf dem Stirnbein, welche wie Ansätze zu einem Geweih erscheinen. Dieser Schädel hat eine Totallänge von $335 \mathrm{~mm}$ und eine Breite in den Jochbogen von $203^{\mathrm{mm}}$; die vollständig verwachsene Pfeilnaht des Scheitelbeins ist $62 \mathrm{~mm}$ lang. Die Breite des Scheitelbeins an der noch wenig verwachsenen Lambdanaht ist $57^{\mathrm{mm}}$; die grösste Breite desselben von $89^{\mathrm{mm}}$ liegt am Unterrand in der Nitte der Naht zur Schlifenheinschuple. Die Temporalkanten nähern sich nur bis auf $54^{\text {mm; }}$ die Spitzen der processus frontales entfernen sich um $71 \mathrm{~mm}$. Die grösste Länge der Scheitelbeine (mit den Fortsätzen) ist $92 \mathrm{~mm}$, also nur um $3^{\text {mm }}$ mehr als die grösste Ibreite: bei der atusgewachsenen Halicore betriggt das Verhïltniss von Lünge zur Breite des Scheitelheins genau ebensoviel 92:89, obwohl der Schüdel eine Totallänge von $375^{\mathrm{mm}}$ (gegen 335 des jungen) und eine Breite von $222^{\mathrm{mm}}$ (gegen 203) besitzt; während also die andern Knochen des Schädels hedentend in die Linge wachsen, bleibt das Scheitelbein im Wachsthum stehen, oder ist hei der jungen Halicore relativ gross. Dasselhe Verhältniss beträgt bei Halitheriun 20:10, bei Rhytina 12,4:10, bei Manatus australis 10,8:10 und Manatus senegalensis 11,6:10. Uebrigens variirt die Länge des processus frontalis bei allen Sirenen, besonders bei Manatus ziemlich stark; das eigentlich charakteristische liegt in der Verkuirzung der Sutura parietalis, das heisst in der Zurückdrängung uni weiteren Ausbuchtung der suturi coronalis. Die processus frontales des Scheitelbeins erscheinen bei Halicore von oben gesehen länger als von der Seite: denn die Seitenwände des Scheitelbeins gehen weiter nach vorn als die Pfeilnaht. Da nun die Fortsätze, welche 
bei dem jungen Schädel nicht wie bei Halitherium als Knochenleisten nach oben hervorspringen, sondern im Gegentheil flach concav eingebogen sind, sich wenig weit nach vorn auf das Stirubein auflegen (Taf. IX Fig. 94), fällt die ganze vordere Hälfte der Temporalkanten auf das Stimbein; sie ragen hier stark hervor, wie wir gesehen haben, und laufen in die schmalen Orbitalfortsätze über. Bei der Breite der horizontalen Oberfliche des Seheitels fallen die Seitenwände steil ab von der Temporalkante, ja sind aussen flach concav eingebogen, während sie bei Halitherium stets convex waren.

Die innere Fläche der Scheitelbeine gestaltet sich bei Halicore ebenso wie bei Halitherium, nur dass durch die grössere Breite derselben die Oberfläche des Gehirns breiter sein konnte, und demnach entsprechend kürzer. Eigenthümlich ist, dass an zwei mir vorliegenden Schädeln von Halicore das Scheitelbein gerale an seiner dichsten Stelle von oben nach unten durch ein Gefässloch durchbohrt ist, welches auf der Gehirnseite gerade in der spina parietalis interna mündet; es liegt dieses Loch also gerade am Ende der Pfeilnaht. und dürfte das dahinter übrigbleibende Knochenstiick wohl einem verwachsenen os interparietale angehören.

Auf dem Scheitelbein von Rhytina schwingen sich die Temporalkanten wieder stärker nach innen: das Schädeldach wird dadurch schmäler und nähert sich hierin mehr dem Halitherium. Aber diese Kanten erheben sich fast gar nicht iiher die Oberfläche und verlieren sich auf dem Stirnbein (von Nordmann pag. 16): sie weichen an der sutura occipitalis um 120 mn auseinander (an dem Schädel Taf. X Fig. 97 von 600 mm Länge), nähern sich in der Mitte des Scheitelbeines bis auf 43 mm und weichen in den Spitzen desselben auseinander um $60 \mathrm{~mm}$.

Auf unserer Abbildung erscheint am Ende der Pfeilnaht ein dreieckiges os interparietale. Brandt, Symb. Siren. p. 17 sagt, dass das an der Aussentläche einfache Zwickelbein an der Innenseite aus zwei kleinen Ḱnochenstücken bestehe (Brandt, Taf. II Fig. 5) und nimmt daher zwei ossa interparietalia an. Brandt crwähnt weder eine spina parietalis interna noch eine crista longitudiualis auf der Innenseite des Scheitelbeins, und nach seiner Abbildung Taf. II Fig. 5 scheinen solche zu fehlen; auch von Nordmann sagt nichts darüber.

Abweichend von den andern Sirenen erhebt sich an der Hinterkante des Schädeldaches von Rhytina das Scheitelhein über die Schupe des Hinterhauptsbeines (Taf. X Fig. 100): bei Halitherium erhob sich der Oberrand der squama ossis occipitis mit seinem Krönchen ansehnlich über den an seiner Vorderseite angewachsenen Hinterrand des Scheitelheins. Manatus erhebt seine Hinterhauptsschuppe noch etwas höher ïber den Hinterrand des Scheitelbeins, zu dem eine ansehnliche Senke hinüberfihrt. Dagegen rundet Halicore die Querkante des Hinterhauptes fast völlig ab, sodass die Hinterhauptsschuppe mit ihrem Oberrand nach voru geneigt etwa in gleicher Höhe in das Scheitelbein iibergeht. Und bei Rhytina endlich wächst der Oberrand der Schuppe mit deutlichem Absatz unterhalb des Scheitelbeines an.

Das Scheitelbein von Manatus zeichnet sich dadurch aus, dass die sutura coronalis zwischen den processus frontales tief nach hinten sich zurückzieht, sodass das Scheitelbein in der Richtung der Pfeilnaht sehr verkürzt wird. An einem mir vorliegenden Manatus australis beträgt die Länge der sutura parietalis $39 \mathrm{~mm}$ bei $340 \mathrm{~mm}$ Schädellänge. Die Pfeilnaht wird auch von hinten her verkürzt, da die squama ossis occipitis auf der Oberseite des Schädels vor dem Krönchen mit einer vorn 
stumpfwinkeligen glatten Fläche von $15^{\text {num }}$ sagittaler Länge zwischen die Scheitelheine einspringt (Taf. IX Fig. 95). Daher ist die Länge der Scheitelbeine in der Temporalnaht $91 \mathrm{~mm}$. Die processus frontales des Scheitelbeins springen gegen die Seitenwände desselben nur wenig nach vorn vor auf der Temporalkante, während ilure Spitzen sich vom Beginn der Pfeilnaht um 52 mn entfernen. Die Temporalkanten sind rund abgeflacht, ohne nach oben über die Scheiteltläche vorzuragen; sie laufen ziemlich parallel zu einander in $45-57^{\mathrm{mm}}$ Entfernung. Wir sehen also auch hier den eigenthümlichen Charakter des zugeschärften Schädeldaches vom Halitherium mit seinen geschwungenen, starken Temporalkanten abgeschwächt zu einem flachen Dach mit runden Seitenkanten. Die sutura occipitalis ist an meinen Exemplaren often; sie scheint erst in höherem Alter zu verwachsen (z. B. Blainville, Manatus pl. III).

Die Breite des Scheitelbeins an der sutura occipitalis beträgt $90^{\circ} \mathrm{mm}$ : hier schiebt sich ein schmaler Knochenstreifen des Scheitelbeins seitlich heraus, um sich breit hinter der aufsteigenden Schläfenbeinschuppe an den geradgestreckten Vorderrand der squann ossis occipitis anzulegen (Fig. 95). Die Seitenwände fallen hinten convex, rorne concav ab, und erreicht das Scheitelbein an ihrem unteren Rande die Breite von $90^{\mathrm{mm}}$ (am oheren vorderen Rand der Schlïfenschuppe). Seine grösste Höhe besitzt das Scheitelbein über der Ecke, wo squama ossis temporum und ala temporalis ossis sphenoidei an ihm zusammenstossen, mit $51 \mathrm{~mm}$.

Der Manatus senegalensis verkürzt die Oberfläche der Scheitelbeine noch mehr, sodass die Schädeldecke nur zum fïnften Theil von diesem Knochen gebildet wird; die Pfeilnaht an dem von Blainville 1. c. Taf. III abgebildeten Schädel von $375^{\mathrm{mn}}$ Länge ist nur $30^{\mathrm{mm}}$ lang, während die Länge der Scheitelbeine längs der Temporalkanten $120 \mathrm{~mm}$ beträgt: so tief sind die Scheitelbeine vorn ausgebuchtet. Es ist, als hätte der Rückzug des Stirurandes iiber der weiten Nasenöffnung auch das Scheitelbein weiter und weiter nach hinten gedrückt.

Auf die hochgewölbten Scheitel- und Stimbeine des Manatus-Foetus (s. Murie Taf. 22 Fig. 16 und 17) haben wir bereits oben hingewiesen; relativ sind hier die Scheitelbeine bedeutend grösser, als beim ausgewachsenen Ianatus, da ihre sagittale Länge $26^{\mathrm{mm}}$ ist, ihre Höhe am Vorderrand $20 \mathrm{~mm}$ bei einer Länge des Schädels von $70^{\mathrm{mm}}$ und einer Höhe (ohne Unterkiefer) von $35 \mathrm{~mm}$. Am Foetus wirl der Raum zwischen den Scheitelbeinen auf dem rundgewölbten Scheitel durch eine lange Fontanelle, fonticulum frontalis und occipitalis zusammen, eingenommen; daher die unregelmässigen Verwachsungsnarben auf dieser Fläche beim erwachsenen Manatus. Es wird wohl auch bei Halitherium der dreieckige Raum zwischen dem Oberrand der squama ossis occipitis und den Scheitelheinkanten gröstentheils durch Verwachsung von Zwickelheinen, welche aus der Verknöcherung der Occipital-Fontanelle entstanden, ausgefüllt worden sein. Bei jungen Manatis zeigt sich häufig noch das Zwickelbein der Stirnfontanelle (Krauss, Manatus 1858, p. 398).

Was die Nähte der Scheitelbeine anbetrifft, so verwächst bei allen Sirenen die sutura parietalis schon bei jungen Thieren vollständig. Die sutura occipitalis bleibt bei Manatus am längsten offen, bei Rhytina und Halicore wåchst sie etwas fríher zu; aber bei Halitherium ist sie bei sehr jungen Thieren schon nicht mehr sichtbar: hier bildet daher squama ossis occipitis und os parietale stets eine einzige dicke Schaale. Die sutura coronalis bleibt bei allen Sirenen auch in hohem Alter sicht- 
bar, doch verwachsen die Nahtzacken besonders an den processus frontales fest miteinander; ebenso verhäIt sich das kurze Stiuck Naht zwischen Scheitelbein und Temporalfiigel des Wespenbeins, sutura sphenoidalis. Die lange Naht gegen die Schläfenschuppe ist dagegen stets mehr oder weniger offen: hier legen sich ja auch ziemlich grosse Nahttlïchen aufeinander. Beim Halitherium fallt daher stets das Schläfenbein in der Nahttläche ab vom Scheitelbein.

\section{Os maxillae.}

Das Oberkieferbein ist bei den Sirenen lang gestreckt und nimmt einen ansehnlichen Antheil an der Bildung der Gesichtsknochen, obwohl es weren der hervorragenden Grisse des Zwischenkiefers weniger als bei andern Säugethieren die Form des Gesichtes bestimmt. Bei Halitherium liegt der Oberkiefer zum grossen Theil unter dem Stimbein; nach vorn biegt er sich herab, um mit breiter Fläche den Boden der äusseren Naseuhöhle zu bilden und mit dem aufgebogenen Seitenrande die aufsteigenten Aeste des Zwischenkiefers zu tragen; nach der Seite legen sich die grossen, Hachen Jochfortsïtze aus, welche sich am Jochbein inseriren und zum Theil den Boden der Augenhöhle bilden. Ueber dem weiten foramen infraorbitale erstreckt sich der Stirnfortsatz linauf in die Ecke zwischen Nasenbein und processus orbitalis ossis frontis. Der Alveolartheil endlich stützt sich mit seinem hinteren Ende auf das Gaumenbein und dringt mit demselben in die fissura orbitalis unter den Gaumenflügel des Wespenbeins (Taf. V Fig. 37. 38 und Taf. X Fig. 96).

Da sich von oben her noch der Vomer auflegt, so tritt das os maxillae des Halitherium in Verbindung mit 7 Schädelknochen, nämlich mit dem Stirnbein, dem Nasenhein, dem Thränenbein. dem Gaumenbein, dem Jochbein, dem Ptlugscharbein, dem Zwischenkiefer; von den letzten 4 Kinochen ist es durch oftenbleibende Nähte getrennt, mit den ersten drei verwächst es mehr oder weniger fest; dem Wespenbein kommt das hintere Ende iles Alveolartheiles selrr nahe. Die Lage des Oberkiefers im Gesicht ist derartig, dass etwas weniger als die halbe Länge desselben vor dem vorderen Ende des Stirnbeins nach vorn hervorragt, die andre Hälfte unter dem Stimbein liegt: die Verhindungslinie der heiden Orbitalspitzen des Stirnheins fallt gerade vertikal über die Linie zwischen dem ersten Molar und ersten Prämolar. Die sagittale Länge des Oberkicfers beträgt bei einem ausgewachsenen Thier $160-170^{\mathrm{mm}}$, von denen etwa $90^{\mathrm{mm}}$ unter, $70^{\text {man }}$ vor dem Stirnbein sich befinden. Der hintere Rand des Orbitalfortsatzes ossis frontis steht gerade über dem hintern Rande des Jochbeinfortsatzes ossis maxillae. Bei Manatus australis dagegen liegen von dem $170^{\mathrm{mm}}$ langen Oberkiefer $120^{\mathrm{mm}}$ unter, und nur $50^{\mathrm{mm}}$ vor dem Stimbein; und beim Manatus senegalensis vom Ogowe verkürzt sich der vordere Theil des Oberkiefers so weit, dass von der ganzen Länge von $170^{\mathrm{mm}}$ nur 25-30m vor das Stirnbein fallen. Für Halicore besteht in dieser Beziehung so ziemlich das gleiche Verhältniss, wie für Halitherium, nur dass der Oberkiefer im Ganzen verhältnissmässig sich verkürzt.

Der Oberkiefer ist so flach, dass ein Zahnfortsatz nicht von ihm sich abtrennt, vielmehr die Alveolen direct im Körper des Beines stecken; dagegen sondern sich die andern Fortsätze hinreichend scharf $\mathrm{ab}$, um einen processus frontalis, einen processus zygomatico-orbitalis, und 
einen processus palatinus zu unterscheiden. Der Körper des Oberkiefers hat eine untere breite Fläche der Mundhöhle zugewandt, eine obere als Boden der Augenhöhle und eine mediale Fläche, den Boden der Nasenhöhle. Die untere Fläche enthält die Alveolen der Backenzähne und ist daher in dieser Strecke sehr rauh und porös, durchlöchert von zahlreichen Gefäss-Oeffinungen, die zu den Zahnwurzeln herantreten; ein gemeinsamer, grösserer Gefäss-Kanal für diese Zälne ist nicht vorhanden, vielmehr durchbohren viele einzelne kleine Löcher die oberen Flächen des Körpers. Bei einem alten Thier ist der Alveolar-Rand am breitesten da, wo der hintere Theil des Jochbein-Fortsatzes nach aussen die Zahnflïhe fortsetzt: hier befinden sich breite Scheidewände zwischen den drei grossen W'urzeln des zweiten und dritten Backenzahnes und heiderseits wulsten sich die äusseren Linochenrinder auf (Taf. III Fig. 1 und 22). Die drei Alveolen des letzten (vierten) Backenzahnes liegen in dem schmalen hinteren Stücke des Körpers und öffnen sich daher gewöhnlich nach aussen, die Oberwände des Knochens durchbrechend. Nach vorn spitzt sich der rauhe Zahnrand zu und enthält die Alveolen des dreiwurzeligen ersten Backenzahnes und hintereinander je eine Alveole der drei einwurzeligen falschen Backenzähne; gewölnnlich sind die vordersten Alveolen bereits mehr oder weniger zugewachsen, da die Prämolaren friih ausfallen; auch die Alveolen des ersten Molaren verwachsen nach dem Ausfall dieses Zahnes. Gerade wie am Unterkiefer bleibt der Zahnrand auch vor den Backenzähnen rauh und Gefäss-reich; nach innen erhebt sich derselbe mit hohem, etwas ïberhängendem Rande über der bis $12^{\mathrm{mm}}$ tiefen und $10-15^{\mathrm{mm}}$ breiten Rinne des Gaumenfortsatzes (Taf. III Fig. 22).

Die den Borlen der Nasenhöhle bildende obere Fläche des Körpers ist vorn ziemlich glatt, flach ausgebreitet und mit dem vorderen Theil des Oberkiefers abmïrts gebogen: ganz vorn taucht sie unter den üherragenden Zwischenkiefer und zieht sich zusammen zu einer Rinne (canalis incisirus), welche sich in das foramen incisivum öfnet; nach Analogie des Manatus würden hier die Jacobson'schen Organe des Riechapparates aus der Nasen- in die Mundhöhle übergetreten sein. Weiter hinten, unter den Stirnfortsätzen legt sich der unpaare Vomer mit seinem Vordertheil in einer Länge von $65^{\mathrm{mm}}$ und einer grössten Breite von $26^{\mathrm{mm}}$ so auf die Oberseite des os maxillae auf, dass die mehr orler weniger verwachsene Jaht zwischen den heiden Hälften des Oberkiefers grösstentheils ron demselben bedecht wird. Da die Oberseite des os maxillae von vorn nach hinten flach gewölbt ist, so legt sich auch der Vomer mit derselben Wölbung auf; die Nahtfläche für den Vomer ist rauh (viele Knochenlamellen liegen uibereinander) und ist seitlich durch einen schwach vortretenden Rand gegen die ibrige Fläche des Oherkiefers abgesetzt. Hinter dem geschlossenen Ende des aufgewachsenen Vomer treten die beiden Alveolar-Aeste des Oberkiefers auseinander, beiderseits das Gaumenbein umfassend. Die mediale Fläche des Alveolartheiles des Oberkiefers dreht sich gegen die vordere Nasenfläche allmählich abwärts, sodass sie hinten annähernd vertikal gerichtet liegt, als mediale Knochenwand der Zahnwurzeln der letzten Molaren.

Die Orbital-Fläche des Oberkiefers ist grösstentheils horizontal gerichtet; sie wird ansehnlich gross durch die den Sirenen eigenthümliche breite Auslage des processus zygomatico-orbitalis. Die Fläche ist ziemlich eben, von vielen einzelnen Gefisslöchern durchbolhrt; nach hinten läuft sie aus in die allmählich in vertikale Richtung übergehende äussere Alveolar-Wand der letzten 
Molaren; nach vorn wird sie der Boden des weiten Unteraugenhöhlenloches, über welchen sich der Bogen des Stirnfortsatzes nach oben wölbt. Ein scharfer Grat trennt in der ganzen Länge des Oberkiefers die Nasen- von der Orbital-Fläche: derselbe trägt hinten über dem letzten Backenzahn Spuren des Ansatzes vom Gaumenbein; davor liegt er frei gegen die lange ()effnung zwischen Augenund Nasenhöhle, eine Oeffnung, welche bei Manatus zum grossen Theil durch das nach vorn verlängerte Gaumenbein geschlossen ist. Weiter nach vorn erhebt sich der Grat zu einer ansehnlich dicken Scheidewand, welche den Stirnfortsatz trägt und das grosse foramen infraorbitale begrenzt: diese Scheidewand ist der Länge nach (von hinten nach vorn) durchbohrt durch einen ziemlich weiten canalis alveolaris, welcher vom Boden der Augenhöhle hindurchführt durch den vorderen Theil des Oberkiefers in den Zwischenkiefer hinein und dizu diente, die Stosszähne des Zwischenkiefers zu ernähren: dieser Kanal beginnt hinten mit einer Oeffnung von $7^{\text {mn }}$ Durchmesser im Unteraugenhöhlenloch und endigt vorn in der Nahtrime des Zwischenkiefer-Astes, wälrend seines Verlaufes im Oberkiefer 45-50 $\mathrm{mm}$ lang; er ist an jedem Oberkiefer leicht zu finden, ebenso wie er an derselben Stelle bei Manatus und Halicore zu sehen ist: die ansehnliche Weite dieses Kanales lässt schon auf das Vorhandensein der Stosszähne schliessen, deren Existenz Irrauss bestritt.

Die bereits erwähnte starke Auslage des Oberkiefers nach der Seite in dem dicken processus zygomatico-orbitalis lïst die Tendenz des Sirenen-Schälels erkemen, nicht nur nach vorn (wie die Gesichtsknochen der Wale), sondern auch nach der Seite sich auszudehnen: es entsteht dadurch der breite Boden der Augenhöhle, die Weite des foramen infraorbitale und die ungewöhnliche, glatte, $30^{\text {mm }}$ breite, ganz unbenutzte Fläche auf der Unterseite neben den drei ersten Molaren, welche das Jochbein so weit nach aussen drängt. Der Ansatz des Jochbeins am Oberkiefer entfernt sich bis zu $37^{\mathrm{mon}}$ vom dritten Molaren; er geschieht an einer rauhen Nalitfläche von $20^{\mathrm{mm}}$ Höhe und $42^{\mathrm{mm}}$ Länge. Das Jochbein biegt sich damn nach vorn hinauf zum Stirnfortsatz des Oberkiefers und ist an diesem olne Unterbrechung mit schmaler Kante angewachsen ('Taf. V Fig. 38).

Das Unteraugenhöhlenloch ist bei keinem Säugethier so gross, wie bei den Sirenen: bei einem ausgewachsenen Halitherium ist es oval, $17^{\mathrm{mm}}$ auf $13^{\mathrm{mm}} \mathrm{im}$ Durchmesser; es ist rings umschlossen vom Oberkiefer; nur am vorderen und oberen Rande grenzt ein kleines Stück des Zwischenkiefer-Astes an das $23-25^{\mathrm{mm}}$ lange Loch. Durch das foramen infraorbitale traten die Gesichts-Adern und -Nerven aus und gaben in Innern des Loches, gerade wie beim Mlenschen, Zweige ab an den vorhin beschriebenen ansehnlichen Alveolar-Kanal des vorderen Theils des Ober- und Zwischen-Kiefers.

Ganz eigenthimlich ist der processus frontalis des Oberkiefers bei Halitherium gestaltet: die beiden linochenwände jederseits des foramen infriorbitale, welche mit ihren Flächen sagittal gerichtet stehen, tragen als Schlusstiick oben. einen dicken Knorren, der sich nach rückwärts überlegt und spitz hincinragt in die Ecken zwischen den Orbitalfortsatz des Stimbeins und das Nasenbein. An einem ausgewachsenen Thier ist der Stirnfortsatz des Oberkiefers ohne die Seitenwände des Unteraugenhöhlenloches $23^{\mathrm{mm}}$ dick (transversal) und $45^{\mathrm{mm}}$ lang (vom vorderen oberen Rand des foramen infraorbitale bis zur obersten Spitze im Stirnbein, Taf. V Fig. 38).

Der aufsteigende $\boldsymbol{A}$ st des Zwischenkiefers liegt mit seiner unteren scharfen Kante in einer tiefen, rauhen Rimne, welche vom vorderen Ende des Oberkiefers an dessen Aussenkante hinläuft: 
in ihr muinden viele Gefïsslöcher und der erwähnte canalis alveolaris für den Zwischenkiefer. Diese Rinne hört auf am Stimfortsatz des Oberkiefers medianwärts vom foramen infraorbitale: hier tritt der Zwischenkiefer-Ast über auf die Oberseite des Stirnfortsatzes und breitet sich anf derselben flach aus. Diese Ansatzflizche dez Zwischenkiefers auf dem Stirnfortsatz des Oberkiefers ist völlig runzelig und gefurcht, und zwar laufen die scharfen Runzeln oder Leisten ungefithr einander parallel von vorn nach hinten oder da die Fläche bei rubiger Kopfhaltung schief steht, schrïg von vorn unten nach hinten oben. Der Zwischenkiefer bedeckt die ganze rauhe Oberfläche des Stirnfortsatzes (Taf. IX Fig. 92) und haftet vermöge der Ansatz-Leisten zuweilen so fest, dass beide Knochen nur schwer von einander zu trennen sind, gerale wie bei den lebenden Sirenen.

Noch fester und durch ähnliche Zapfen und Leisten verbunden wächst der Stirnfortsatz in das Stirnbein und Nasenbein hinein; auf Taf. V Fig. 55 sieht man die innere Nase von vorn mit ahgeschnittenem Stirnfortsatz des Oherkiefers und oberstem Ende des Zwischenkiefers; es ist diese Zeichnung die genaue Copie eines trefflich erhaltenen Oberkopfes unsrer Sammlung: man sieht, dass das Nasenbein unten herumgreift unter das spitze Ende des Maxillar-Stirnfortsatzes und dass dann auf dem letztern das obere Ende des Zwischenkiefers aufliegt. Wegen der schwachen Verbindung des Ober- und Zwischenkiefers in ihren beiden Stirnfortsitzen brechen sie gewöhnlich an der durchschnittenen Stelle von dem Oberkopf ab.

Unter dem Stirnfortsatz und an seiner hinteren Seite, sowie unmittelbar über dem foramen infraorbitale schneidet regelmässig eine glatte Hohlkehle ein: dieselbe läuft rom inneren Augenwinkel horizontal unter dem Stirnfortsatz des Oberkiefers $20^{\text {mim }}$ lang herum und tritt durch einen auffilligen Einschnitt in der Scheidewand, welche Orbital- und Nasenhöhle trennt. in die Nase ïber; es kann diese Furche nur der Thränenkanal sein, der sonst dem Halitherium fehlen würde. Ganz in derselben Weise findet sich diese Rinne bei Manatus, während sie bei Halicore nur angedeutet ist.

Die nach aussen gekehrte Seite des Stirnfortsatzes verbreitert sich als Aussenwand des foramen infraorbitale ansehnlich nach vorn und trïgt am Unterrande die schmale Ansatzfläche für das Vorderende des Jochbeins. Seitlich auf dieser Aussenfläche des Stirnfortsatzes ist an einem mir vorliegenden Stuicke ein $15^{\mathrm{mm}}$ hoher und ebenso langer platter Ḱnochen angewachsen, der wohl das Thränenbein sein dürfte: denn derselbe liegt, gerade wie bei den lebenden Sirenen und den Säugethieren überhaupt, am Stirnfortsatz des Oberkiefers aussen an, vor dem Vorderende des Orbitalfortsatzes des Stirnbeins und hinter und über dem ungebogenen Vorderende des Jochbeins im Orbitalring; dieses Thränenhein ist nicht vollständig, da es vorn abgebrochen ist; es ist undurchbohrt und trägt an der Aussenseite eine Vertiefung; es liegt gerade neben und über dem Thränentanal, denselben begrenzend nach aussen und oben gegen die Orbita. An andern Stücken befindet sich an der Stelle des Thränenbeins nur eine rauhe Ansatzfliche; dasselbe scheint also, gerade wie bei Halicore, meist lose aufgelegt gewesen zu sein und leicht abzufallen.

Endlich haben wir noch den Gaumenfortsatz des Oberkiefers zu erwähnen: es ist dies eine schmale dünne Linochenleiste, welche sich ron den Körpern jedes Oberkiefers medianwärts zur Mittelnaht (ein Theil der sutura palatina mediana) erstreckt und die Gaumenplatte nach vorn bis zum foramen incisivum fortsetzt. Diese $84^{\mathrm{mm}}$ langen Gaumenleisten wölben sich mit dem Oberkiefer von 
hinten nach vorn; sie endigen hinten an der Quernaht des Gaumens (sutura palatina transversa) etwa neben der Lücke zwischen erstem Molaren und erstem Prämolaren. An dem vorderen Ende klaffen die Gaumenfortsätze ein klein wenig von einander, sodass von dem foramen incisivum ein feiner Spalt nach hinten zwischen die Oberkiefer eindringt. Die sutura incisiva, die Naht, mit welcher die Spitzen der Oberkiefer vorn endigen gegen den absteigenden Theil des Zwischenkiefers, ist etwa $16^{\mathrm{mm}}$ lang jederseits des formen incisivum und greift mreyelmissig Zackig in die lockere Knochenmasse des 'Zwischenkiefers ein.

Die Oberseite der Gaumenfortsätze befindet sich mit der Nasentläche der Körper in einer Ebene; dagegen entsteht durch die sehr verschiedene Dicke beider Theile an der Unterseite des Oberkiefers eine tiefe Rinne, welche wir bereits oben erwähnten. In diese Rimne münden constant zwei Gefässlöcher (Taf. X Fig. 96); sie ist innen glatt, wälırend der Rand der Zahnlücken rauh und mit vielen kleinen Poren durchbohrt ist. Diese Rauheit des zahnlosen Kieferrandes deutet vielleicht darauf hin, dass bereits Halitherium auf diesem vorderen Theil des Oberkiefers, auf dem Zwischenkiefer und auf der schrägen, rauhen Fläche des Unterkiefers eine zum Abrupfen und Zermalen der harten Algen-Nahrung geeignete hornige, zottige Epidermis hesass, wie die lebenden Sirenen; es wäre eine solche Verhärtung der Epidermis der Anfang zu der Bildung einer vollständigen Zahnplatte, wie sie die Zwischen. und Lnterkiefer von Rhytina bedeckte. Die auffallend rauhe und porise Fläche am Unterkiefer von Halitherium spricht hesonders fur diese Annahme; dagegen spriche etwa die tiefe und breite Rinne auf der Unterseite des Oberkiefers: indessen ist eine solche Rinne in gleicher Weise bei Halicore vorhanden und hier sehen wir, dass der zottige Theil der Pflaster-Epidermis erst am vorderen Ende derselben beginnt, sodass wesentlich nur die breite \%wischenkieferFläche von ihr bedeckt wird.

Der Oberkiefer von Manatus schliesst sich am nächsten an den von Halitherium an; eine weitere Entwickelung in derselben Richtung zeigt der (oberkiefer von Rhytina; dagegen weicht dieses Bein bei Halicore von dem eben betrachteten in seiner Bildung beträchtlich ab.

Der vollständigeren Bezahmung von Manatus entspricht ein seln langer Alveolar-Theil des Oherkiefers: die letzten Keimzïhne sitzen in einer Kinochentasche, welche mach hinten eindringt in die breite fissura orbitalis und sich also zwischen Gaumenbein, Temporal- und Orbital-flügel des Wespenbeins hineinschiebt. Die äusseren Knochenwände der Alveolen sind besonders in dem hinteren Theile des Oberkiefers hïutig durchhrochen, sodass die Zahnwurzeln resp. die Zahnkeime sichthar werden. Die Backenzähne sind alle dreiwurzelig und zwar stehen die Wurzeln regelmässig so im Kiefer, dass eine breite Wurzel sagittal innen, die andern beiden aber mit ihrer Fläche transversal gerichtet aussen lieren; bei Halitherium weicht der letzte Backenzalm stets von dieser Wurzelstellung ab. Je weiter nach vorn, un so mehr wachsen die Alveolen zu, sodass die ersten Backenzähne einfach durch Verwachsen der Alveolen abgestossen werden; zugleich wird, wie es scheint, die Substanz der Zahmwurzeln resorbirt: der erste Backenzahn, welcher vorhanden ist, hat in Folge dessen meist ganz kurze Wurzeln ïber bereits zugewachseneu rauhen Alveolen. Diese Verwachsung der Alveolen von Manatus ist gewissermassen ein Vorstadium zum gïnzlichen Verschwinden der Alreolen und der 
Zithne bei Rlytina. Eine Andeutung dieses Entwicklungsganges sehen wir schon in Verwachsen der Prämolar-Alveolen bei Halitherium.

Die breite Fläche, welche bei Halitherium durch Auslage des processus zygomatico-orbitalis entsteht, verkürzt sich bei Manatus von vom nach hinten ansehnlich, sodass der vordere freie Rand derselben (Unterrand des foramen infraorbitale) mit dem ersten Backzahn, bei Halitherium mit dem dritten Prämolaren in gleicher Linie liegt, und rom Hinterrand derselben Fläche nur $34^{\text {nin }}$ entfernt ist, dagegen bei einem Halitherium von gleicher Kopfgrösse 62 mw (Taf. X Fig. 96). Die veränderte ('estalt des Jochbeins hängt damit zusammen: das Jochbein wölbt sich stärker um die Augenhöhle und liegt mehr anf, als aussen an dem Oberkiefer-Fortsatz. Rhytina zeigt dieselbe Gestaltung des Jochbein-Fortsatzes, wie Manatus.

Die Gaumenplatte verändert sich bei Manatus in der Richtung ihrer veränderten Function: bei dem gänzlichen Ausfall der Prämolaren zieht sich der Zahnrand zu einer scharfen Kante jederseits zusammen; in der Mitte flacht und breitet sich die rauhe Fläche der Gaumenfortsätze aus ohne eine tiefe Rinne: schon bei Manatus ist der ganze vordere, wenig absteigende Theil des Oberkiefers mit einer zottigen, hornigen Kruste bedeckt, welche dann bei Rhytina eine wellige Zahmplatte wird. Die Gaumenfortsïtze rom Oberkiefer des Manatus erstrecken sich weit nach hinten: das Gaumenbein setzt erst neben dem vierten Backenzahn hinten an dem Oberkiefer an, bei Halitherium bereits in der Linie zwischen dem ersten Molaren und ersten Prämolaren. Auf der rauhen vorderen Fläche des Oberkiefers von Yanatus erscheinen ausser den zahlreichen Poren einige grössere Gefisslöcher, welche nicht mit verwachsenen Alveolen zu verwechseln sind. Das foramen incisivum, welches auch bei Manatus fast ganz im Zwischenkiefer liegt, sendet rückwärts eine schmale, $15 \mathrm{~mm}$ lauge Spalte zwischen die Oberkiefer hinein: dahinter schliesst sich zackig die lange Gaumemmaht.

Ein wesentlicher Unterschied im Schädelbau von Halitherium und Manatus besteht darin, dass bei letzterem der aufsteigende Ast des Zwischenkiefers weder den Stirurand noch die Nasenbeine erreicht, vielmehr noch ein $15^{\mathrm{mm}}$ langes Stück des Stirnfortsatzes des Oberkiefers frei neben dem Orbitalfortsatz des Stirnbeins hervortreten lisst. Es ist diese Bildung bei allen mir vorliegenden Manatus-Schädeln dieselbe und hängt wohl mit dem Rückzug des Stirnrandes zusammen. Die Art der Befestigung der drei Knochen in einander ist eben so innig wie bei Halitherium: lange Zacken springen vom Oberkiefer-Fortsatz in den Orbitalfortsatz des Stimbeins hinein, wïhrend der Zwischenlieferast kaum das Stimbein berührt und allein auf der runzeligen Fliche des processus frontalis ossis maxillae festgewachsen ist. Der Manatus senegalensis vom Ogowe in West-Afrika hat mit seinem reducirten Zwischenkiefer auch einen kleineren Stimfortsatz des Oberkiefers: der letztere legt sich als eine schmale Knochenplatte dem Stimbein an; die obere Spitze des Zwischenkieferastes bleibt bei diesem Afrikiner noch um volle $30^{\mathrm{mm}}$ von dem Vorderende des Nasenbeins entfernt bei einer Schädellänge von $340 \mathrm{~mm}$.

Bei Manatus australis von Surinam ist der Thränenkanal breit unter dem Stirnfortsatz des Oberkiefers durchgefuhrt aus dem inneren Augenwinkel in die Nasenhöhle; vom Thränenbein ist nur eine dünne Lamelle iibrig, welche am Anfang des Thränenkanals in der Orbita aussen dem Stirnfortsatz des Oberkiefers platt anliegt. Beim afrikanischen Manatus ist die Wind zwischen Augen- 
und Nasenhöhle fast ganz geschlossen: nur der Thränenkanal durchbohrt dieselbe und eine unregelmässige Oeffnung nahe hinter demselben.

Rhytina schliesst sich in der Bildung der Gaumenfläche des Oberkiefers mehr an Manatus an, während die Form des Stirnrandes und die Zwischenkiefer-Befestigung an demselben zu Halicore hinuiberfuhrt (Taf. X Fig. 98-100). Das Gaumenbein setzt erst sehr weit hinten an die Gaumenfortsätze des Oberkiefers an; das foramen incisivum liegt ganz im Zwischenkiefer. Der zahnlose Rand ist ziemlich breit und glatt, die rauhe Fläche für die Zahnplatte beginnt erst auf dem vordersten Theile des Oberkiefers und liegt grösstentheils an Zwischenkiefer. Die Brücken zum Jochbein sind rerhältnissmässig noch schmaler (von rorn nach hinten) geworden, als bei Manatus, sodass eine sehr grosse Oeffnung zwischen dem Alveolartheil des Oberkiefers einerseits und dem Jochbein und Jochfortsatz des Schläfenbeins andrerseits an der Schälelunterseite entsteht (Taf. X Fig. 99).

Der Stirnfortsatz des Oberkiefers wird auf der Schädeloberseite ganz vom ZwischenkieferAst rerdeckt, wie bei Halitherium und Halicore, abweichend rom Hanatus. Der Stimrand berührt sich mit dem Zwischenkiefer und enthialt eingekeilt das Nasenbein; die langen Hörner des Siebbeins erseheinen imnen neben dem Stirnfortsatz des Oberkiefers, weitrorragend in die Nasenhöhle (Fig. 98). von Nordmann gibt in seiner Abhandlung über Rhytina an (p. 16), dass zwei 7 mm weite canales alveolares aus dem foramen infraorbitale durch den Oberkiefer in den Zwischenkiefer vordringen, also gerade wie bei den andern Sirenen, obwohl weder bei Rhytina noch bei Manatus Stosszähne vorkommen; sodann sagt derselbe Autor daselbst: "das innere Gefuige des Oberkiefers besteht aus einer grossen Anzahl von diinnen und breiten auf einander geschichteten Krnochen-Lamellen oder Platten, die von Gefïsskanälen durchbohrt sind." Dieselbe lamellöse línochenstructur beohachtet man am Oberkiefer von Halitherium und Halicore und zwar liegen die Lamellen ungefähr parallel der Gaumenfläche.

Der Oberkiefer von Halicore ist verhältnissmässig kürzer, als der der übrigen Sirenen: wie denn ïberhaupt hier eine Verkiurzung, resp. Verbreiterung des Schädels zu beobachten ist. Der Alveolar-Theil ist dick aufgetrieben, sodass die ungespaltenen breiten Zahnwurzeln niemals seitlich zum Vorschein kommen; zugleich dringt die Keimtasche des letzten Backenzahnes nicht unter den Gaumentlügel des Wespenbeins, vielmehr trennt das (aumenbein beide Knochen. Die einfachen Alreolen sind für die langen Zähne sehr tief; bei einem alten Thiere öffien sie sich auch nach oben, sodass die Zahnwurzeln von der Nasenhöhle her sichtbar werden. Die Gaumenplatte senkt sich zu breiter Rinne ein zwischen den vorstehenden Zahnrändern: diese Rinne ist im Leben bedeckt mit einer knorpeligen Haut, welche nach vorn in die dicke, papillöse Kauplatte der rauhen Fläche des Zwischenkiefers übergeht. Nahe der Quernaht des Gaumenbeins durchbohren mehrere Gefässlöcher den Gaumen bis in die Choanen hinein.

Die Foramina infraorbitalia sind bei Halicore am grössten: da zugleich die Scheidewand zwischen Augen- und Nasen-Höhle fortfällt, so entsteht eine sehr weite und lange Oeffnung zwischen dem Stirnbein und dem Oberkiefer (Taf. VIII Fig. 90). Damit fehlt die Ursache, einen besonderen Thränenkanal auszubilden: in der That an der Stelle, wo bei den übrigen Sirenen sich eine Hohl- 
kehle im Knochen für diesen Kanal vortindet, ist auch boi jungen Exemplaren kein besonderer Kanal vorhanden. Dagegen ist das Thränenbein von Halicore grösser als bei den Verwandten: ein platter, aussen knorriger, undurchbohrter Knochen liegt dem oberen Ende des Jochbeins und dem Stirnfortsatz des Oberkiefers aussen an: bei dem Halicore-Schädel von $335^{\mathrm{mm}}$ ist das Thrïnenbein eine dïnne Platte von $38^{\mathrm{mm}}$ Länge und $30^{\mathrm{mm}}$ Breite, von oben nach unten um die andern Knochen herumgewölbt; auf der Aussenflache des Thrïnenheins stehen drei Knorren, welche an dem alten Thiere noch gröber, als bei den jungen werden. An zwei jungen Schädeln der Halicore von Querimba in Mozambique sind die Thränenbeine viel kleiner, als an jenen aus dem rothen Meere. Die Thränenbeine der jungen Halicore fallen leicht ab; auch bei dem alten ist die Verbindung mit Jochbein und Oberkiefer keine sehr feste, da die Ansatzfläche ziemlich glatt ist.

Die Verwachsung des Oberkiefers am Orbitalfortsatze des Stirnbeins und am Jochbein ist eine sehr vollkommene: nimmt man den bedeckenden Zwischenkiefer fort, so erscheinen die vielfachen Lamellen, Zacken und Runzeln, mit denen die genannten Schädelknochen hier ineinander greifen.

An den stark abwärts gebogenen vorderen Theilen des Oberkiefers sind die aufsteigenden Aeste des Zwischenkiefers nicht wie bei Halitherium und Manatus in einer Rimne befestigt, sondern sie liegen in breiter Fläche dem Oberkiefer auf, mit den zahlreichen Knochenlamellen desselbeu so wenig verwachsen, dass hei jungen Thieren der Zwischenkiefer mit geringer Miihe abzuheben ist. Diese Ansatzflichen ragen nicht ïber den mittleren Nasenboden hervor; daher erscheint der Oberkiefer von Halicore nach Abhebung der Zwischenkiefer als ein breiter, platter Knochen. Auch die sutura incisiva ist daher länger als bei den Verwandten. Diese Verbreiterung des Oberkiefers entspricht der bedeutenden Entwicklung des mit Stosszähnen bewaffneten Zwischenkiefers.

\section{Os incisirum.}

Der Zwischenkiefer des Halitherium nimmt wie bei den andern Sirenen durch seine Grösse einen bedeutenden Antheil an der Gesichtsbildung des Schälels: er bestelıt aus einem langen schmalen aufsteigenden Stirnast. welcher sich über den Oberkiefer hinauflegt bis zum Stirn- und Nasenbein; und einem breiten ahsteigenden Theile, welcher die Stosszähne enthält. Die beiden Stirnäste umfassen die weite Nasenöffnung und stossen vor derselben in einem mehr oder weniger scharfen Winkel zusammen, um mit zwei dicken Wülsten in den Alveolartheil überzugehen: die beiden absteigenden Theile sind in der Vittellinie ihrer ganzen Lïnge nach durch eine rauhe Nahtfläche (sutura incisiva mediana) verbunden (Taf. III Fig. 14 und 16, Taf. V Fig. 46 und 54, Taf. VIII Fig. 87, Taf. IX Fig. 92, Taf. X Fig. 96).

Der processus frontalis reicht von dem Wulst vorn in schräger Richtung nach hinten und oben 105-110 mm lang bis hinauf in die hinterste Spitze, welche sich dem Stirnbein an- und dem Nasenbein auflegt (Taf. IX Fig. 92). Der obere Rand des Astes ist glatt abgerundet, der untere scharfkantig. Der dicke Wulst vorn bildet einen stumpfen Winkel von $110-120^{\circ}$, in welchem sich 
der auf- und absteigende Theil des Zwischenkiefers treffen; er ist das solideste und dickste Stück des os incisivum und seine rechte und linke Hälfte fügen sich in einer $26^{\mathrm{mm}}$ breiten Nahtfläche zusammen. Von hier aus treten die beiden Aeste auseinander, um sich um die Nasenöffnung sanft geschwungen herumzulegen. In der Mitte ihrer Länge werden die Aeste bis $10^{\mathrm{mm}} \mathrm{schmal}$; erst da, wo sie dem Stirnfortsatz des Oberkiefers aufliegen, breiten sie sich flach bis zu 22 ma aus, um dann rasch sich über dem Nasenbein auszuspitzen. In vertikaler Richtung sind die Stirnäste vorn am dicksten, etwa $40 \mathrm{~mm}$, und gehen hier unmittelbar in die Alveolartheile über; nach hinten nelmmen sie gleichmässig bis zur Spitze an Dicke ab. Mit ihrem Unterrande fügen sich die Stirnäste scharfkantig in die erwähnte seitliche Rinne des Oberkiefers, bis sie sich auf dem Stirnfortsatz des letzteren in breiterer Fläche mit vielfachen Runzeln und Leisten inseriren. Das obere Ende endlich ruht flach mit glatter Fläche auf dem Nasenbein in der Einsenkung, welche sich für diesen Theil des Zwischenkiefers im Nasenbein und neben dem Orbitalfortsatz des Stirnbeins gebildet hat (Taf. V Fig. 48 und 55). Die Verbindung mit dem Oberkiefer ist durch die scharfe zackige Kante des Astes und die Runzeln auf dem Stirnfortsatz des Oberkiefers eine ziemlich feste, sodass beide Stiicke zuweilen noch zusammenhängend im Meeressande gefunden werden. Auch uber dem Nasenbein ist das obere Ende fest genug eingekeilt, dass es niclıt selten vom übrigen Zwischenkiefer abbricht und am Oberkopf neben dem Stirnbein sitzen bleibt; ein solches abgebrochene Ende des Zwischenkiefers hat Kaup in seinen Beiträgen Taf. II Fig. 2 abgebildet und Krauss, Neues Jahrb. f. Min. 1858 p. 527 , fälschlich als Nasenbein gedeutet und auf Taf. XX als solches bezeichnet.

Die breiten absteigenden Theile des Zwischenkiefers sind deswegen von Wichtigkeit, weil sie die beiden Stoss- oder Schneidezähne enthalten. Leider sind die Knochenwände dieser Theile durch ihre poröse Structur, durch das ansehnliche foramen incisivum und durch die grossen Alveolen der Stosszähne so dünn und zerbrechlich, dass es mir noch nicht gelungen ist, dieselben vollständig zu erbalten. Auf Taf. III Fig. 16 ist ein Stück abgebildet, welches noch das obere Ende der Alveole und die Gefässkanäle des Stosszahnes zeigt; die beiden Stosszähne Fig. 15 und 16 sind mit dem Zwischenkiefer Fig. 14 zusammen gefunlen. Der Alveolartheil setzt mit breiter, etwas schief von vorn nach hinten und aussen gerichteter Fläche an den vorderen Wulst des Stirnastes an in einer Dicke, welche $10^{\mathrm{mm}}$ nicht überschreitet. Die äussere Fläche ist glatt, mit vielen kleinen Poren durchbohrt; sie lässt vorn eine schmale Fläche neben der sutura incisiva mediana durch eine Kante abgesondert. welche oben an den Wülsten $10^{\text {mm }}$ breit sich nach unten bei einer Länge von $45^{\mathrm{mm}}$ ausspitzt; diese kleine Flïche ist rauh, wïhrend sie bei den lebenden Sirenen weniger deutlich hervortritt und wie die Seitenflächen glatt ist.

Da der untere Theil des Zwischenkiefers von Fig. 16 abgebrochen ist, erscheinen an der Oberfläche drei grosse Gefässkanäle von 2-4 Wn Weite; dieselben treten in dem inneren Winkel an der Unterseite des Zwischenkiefers vereinigt in einen 5-6 ${ }^{\mathrm{mm}}$ weiten Kanal wieder heraus und finden ihre Fortsetzung zunïchst in der Seitenrimne, dann im Innern des Oberkiefers; wir sahen oben diesen Gefässkanal des Zwischenkiefers münden in der medianen Fläche des foramen infraorbitale. Es ist wohl kein Zweifel, dass diese Kanäle der Ernährung des Stosszahnes und des unteren Theiles des Zwischenkiefers dienten; sie sind in derselben Ausbildung bei Halicore, reducirt bei Manatus vor- 
handen. Krauss läugnet in seiner Abhandlung (N. Jahrb. 1862) die Existenz der Stosszähne bei Halitherium, obschon Bronn in einer daran anschliessenden Notiz dieselben vertheidigt; die Stosszähne, welche meistens zusammen mit dem Schädel des Halitherium gefunden werden, hielt Krauss für die Zühne „eines andern Cetaceum“. Obschon an den Originalen zu Lirauss' Abbildungen, welche in Heidelherg sind, wie gewöhnlich die Zwischenkiefer zur Hälfte abgebrochen sind, so ist doch, wie schon Bronn hervorhebt, der Boden der Alveolen noch zu sehen, und sind ausserdem die drei grossen Gefïsscanäle vorhanden, welche auf eine Fortsetzung des Zwischenkiefers hinweisen.

Endlich hat der Sandgräber Ph. Krämer während des Druckes dieser Arbeit wiederum einen vollständigen Schädel in seiner Sandkaute zu Flonheim gefunden, an welchem in dem besser erhaltenen Zwischenkiefer die Alveolen der Stosszähne noch $40 \mathrm{~mm}$ tief vorhanden sind; daneben lagen die beiden Stosszähne. Es kann demnach kein Zweifel meln sein, dass das Halitherium einen lang herunterhängenden Zwischenkiefer und in demselben zwei Stosszähne besessen hat; und zwar haben alle mir hekannten Schädel Stosszïhne gehabt. sodass dieselben wahrscheinlich sowohl den männlichen als den weiblichen Thieren zukamen.

An dem Stück Taf. III Fig. 16 ist die hintere Seite der Stosszahn-Alveole bis auf $24^{\text {nmm Länge }}$ und $9^{\mathrm{mm}}$ Breite erhalten: sie zeigt die rauhe und poröse Structur aller Alveolen.

Die mediane Fläche des Alveolartheils zeigt vorn die rauhe Nahtflïche: an dem abgebildeten Stück Fig. 16 ist sie noch $80^{\mathrm{mm}}$ lang, oben am Wulst $28^{\mathrm{mm}}$ breit (sagittal gerichtet), sie wird weiter abwärts bis $19^{\mathrm{mm}}$ schmal und nimmt dann wieder bis $26^{\mathrm{m} m}$ am abgebrochenen Ende zu (Taf. V Fig. 55). Hinter dieser Tahttläche liegt oben die halbrunde, länglich gezogene Zwischenkieferhöhle (sinus incisivus), welche das vordere blindgeschlossene Ende der zwischen den Oherkiefern liegenden Nasenhöhle darstellt: die Hälfte der Höhle, welche in jedem Zwischenkiefer liegt, ist 40-50 mm lang, $15-18 \mathrm{~mm}$ breit (sagittal) und 10-12 $\mathrm{mm}$ tief. Dieser sinus incisivus öffnet sich mach hinten in einem schmalen $35^{\text {mm }}$ langen foramen incisivum in die Mundhöhle (Taf. X Fig. 96). Unter der Zwischenkieferhöhle erscheint eine glatte, flach eingewölbte Fläche, welche frei gegen innen geöthnet die Fortsetzung der Gaumenfläche des Oberkiefers bildet. Am hinteren rauhen Rande des absteigenden Alveolartheiles legte sich oben die vordere Spitze des Oherkiefers an; doch ist bis jetzt nicht genau zu bestimmen, wie tief der Oberkiefer hier herabreichte und wie vielen Antheil er an der Lmrandung des foramen incisivum nahm, da diese Theile an allen mir bekannten Schideln zerbrochen sind. Aus demselhen Gruncle lisst sich nicht feststellen, ob ansser der grossen Alveole im Zwischenkiefer noch kleine oder rudimentäre Alveolen weiterer Schneidezähne vorkommen.

Die Zwischenkiefer von Halicore zeigen eine Fortentwicklung in der Richtung derjenigen von Halitherium: sie schwellen noch stäker an und enthalten bedeutend grössere Stosszähne; wïhrend bei Rhytina mit den anderen Zähnen auch die Stosszähne verschwinden und bei Manatus eine Reduction dieser Knochentheile sich anbahnt.

An dem Schädel einer ausgewachsenen Halicore (Taf. VIII Fig. 19) ist der Zwischenkiefer nüchst dem Unterkiefer der grösseste Knochen und bestimmt die eigenthümliche Gesichtsform. Die Stirnäste werden grösser und breiter als bei Halitherium; zugleich schwingen sie sich im Bogen um die breite Nasenöfnung (Taf. IX Fig. 98). Auf dem platten Oberkiefer inseriren sie sich nicht mehr 
mit schmaler Kante, sondern legen sich breit auf und befestigen sich mit zahlreichen Lamelien auf demselben: die lamellöse Structur des Ober- und Zwischenkiefers zeigt sich, wenn man beide von einander trennt; die dïnnen Knochenlamellen liegen annähernd horizontal, sodass sie an den Beugestellen der Kinochen gequert werden. Bei der Breite der Stimiste inserirt sich auch das Jochbein mit vielen Zacken und Runzeln an ihrer Unterseite, weiterhinauf der Oberkiefer und endlich das Stirnbein in der gleichen Weise. Die Spitze der Stirnäste ruht in einer langen, schmalen Grube im Stirnbein neben den weitvorgestreckten schmalen Orbitalfortsätzen.

Der absteigende Alveolartheil des Zwischenkiefers ist gross und aufgebläht zu einem schwammig-lamellösen Knochen. An der Innenseite steigt der Oberkiefer breit bis zur Hälfte der Fläche herab und wächst mit seinen Lamellen ziemlich fest in diejenigen des os incisivum. Die Zwischenkieferhöhle endigt in einem schmalen, kleinen foramen incisivum, das zur Hälfte im Ober-, zur andern Hälfte in Zwischenkiefer liegt: bei alten männlichen Thieren wird durch die starke Entwicklung der Stosszihhe das formen im Zwischenkiefer stark zusammengedriickt und rerkleinert, es bleibt dann mehr auf den Spalt im Oberkiefer besclränkt. Die sutura incisiva mediana ist eine grosse breite Fläche, von unzähligen feinen Poren durchbohrt; sie verwächst auch im Alter wenig, ja klafft nach unten zwischen den Stosszähnen etwas auseinander.

Der ganzen Länge nach ist der dicke absteigende Theil des Zwischenkiefers von einer Alveole durchbohrt, in melcher auch bei weiblichen Thieren Stosszälne erzeugt werlen (s. Riüpell l. c. p. 104). Bei jungen Thieren erscheint vor dieser grosen Alveole eine zweite, ganz an der äussersten Spitze des Zwischenkiefers gelegen: dieselbe ist bei einem Schädel von $290 \mathrm{~mm}$ Länge noch $55^{\mathrm{mm}}$ tief, während die beiden Stosszähne noch weit im Knochen stecken; in dieser Alveole fand ich bei einem noch jüngeren Schädel einen $23 \mathrm{~mm}$ langen Zahn (siehe unten), also den ersten, bald ausfallenden Schneidezahn. Die zweite Alveole verwächst allmählich; bei dem alten Thiere Taf. VIII Fig. 90 ist nichts mehr von derselben zu sehen. Dagegen erhält sich stets eine grössere Gefüssöffnung an der inneren Seite des Stosszalmes in der Spitze des Zwischenkiefers, welche mit mehreren andern, höher oben auf der Innenseite mïndenden Kanälen sich in Knochen vereinigt und in einen grösseren Kanal in den Oberkiefer eintritt, um endlich wie bei Halitherium und den andern Sirenen im foramen infratorbitale zu münden. Die innere rahe Fliche des Zwischenkiefers in der Iundspalte wird bedeckt von einer hornigen, paprillisen Epidemis, welche nach imen auf den Gaumen ïhergeht und sich bis zwischen die Backenzähne hineinzieht. Die äussere Fläche des Zwischenkiefers ist glatt abgerundet.

Der Zwischenkiefer von Rhy tina gleicht am meisten demjenigen von Halicore sowohl in seiner Gestalt und Grösse als in seinem Ansatz und Auflagerung auf dem Oberkiefer, am Jochbein, auf dem Nasen- und an dem Stirnbein; doch sind die aufsteigenden Aeste etwas schmaler und weniger stark um die Nasenhöhle gekriimmt (Taf. X Fig. 98). Die Alveolartheile steigen zwar sehr weit nach vorn hinunter, sind aber lange nicht so aufgebläht als bei Halicore, weil eben die Stosszähne im Innern nicht zur Entwickelnng gelangen, obschon die Alveolen der Schneidezähne rorhanden sind; daher entbehren die Zwischenkiefer der sehr dicken Wülste, wie sie Halicore an der Oberseite der Alveolartheile vor der Vilsenüffnung entwickelt. IDie innere, der Mundspalte zugekehrte Fläche der 
Zwischenkiefer trägt die Hornplatten, welche der Rhytina bei dem Mangel an Zïhnen zur Zerreibung der harten Algen-Nahrung dienten: zu diesem Zwecke wird die Fläche von noch zahlreicheren Gefïsslöchern durchbohrt, als bei Halicore; dieselben dürfen nicht für Alveolenreste gehalten werden (Taf. X Fig. 99). Das foramen incisivum geht weiter als bei den andern Sirenen nach unten zwischen die Zwischenkiefer hinab, als eine ansehnliche und lange Spalte und wird von der Spitze des Oberkiefers kaum erreicht.

Der Zwischenkiefer von Manatus australis verhält sich etwas anders als der von Manatus senegalensis: bei dem ersteren (von Surinam) reichen die schmalen Stirnäste nicht bis an den Stirnrand, sondern lassen zwischen ihrem oberen Ende und demselben noch ein kurzes Stück des Oberkiefer-Astes an der Schïdeloberfliche erscheinen (Taf. IX Fig. 95); die Nasenheine werden auch nicht bedeckt vom Stimast des Zwischenkiefers, ja kaum erreicht. Die Stimäste sind dünner als die von Halitherium, inseriren sich mit der scharfen Unterkante ebenfalls in einer schmalen Rimne des Oberkiefer-Randes und greifen mit Zacken und Spitzen in den Stirnfortsatz des Oberkiefers ein, ohne an dem anliegenden Orbitalfortsatz des Stimbeins befestigt zu sein. Beim afrikanischen Manatus legen sich die Stirnäste des Zwischenkiefers noch platter und dünner zu beiden Seiten der Nasenüftnung auf den Rand des Oherkiefers und spitzen sich an der inneren Seite der Orbitalfortsïze des Stirnbeins aus, sodass sie noch $30^{m}$ von dem Nasenbein und $50^{\mathrm{mm}}$ von dem Stirnrande entfernt bleiben; dem Stirnfortsatz des Oberkiefers liegen sie flach innen an, ohne das breite Polster, welches sie bei Halitherium und Halicore stiitzt. Die Alveolartheile des Zwischenkiefers sind noch stärker bei dem afrikanischen als bei dem amerikanischen (Taf. IX Fig. 93) verkürzt: kaum dass dieselben herabhängen vor der Mundspalte. Das foramen incisivum ist bei Manatus senegalensis verhältnissmässig grösser als bei den andern Sirenen und wird hinten auf eine längere Strecke begrenzt vom Oberkiefer, während der Manatus australis ein kleineres foramen incisivum besitzt, welches nur mit feiner Spalte zwischen die Oberkiefer-Aeste eindringt. Auch bei Manatus ist die Gaumen- und Zwischenkiefertlïche mit einer papillüsen Hornhaut belegt, welche grössere Dicke als bei Halicore erreicht.

\section{Os masi.}

Mit Recht hebt von Nordmann in seiner Abhandlung über Rhytina hervor, dass die Untersuchungen über die Nasenbeine der Sirenen zu den interessanteren Gegenständen der vergleichenden Anatomie gehören. In den Werken von G. Cuvier, Blainville, Stannius, Rüppell und Krauss finden sich sehr von einander abweichende Angaben über die Nasenbeine von Manatus und Halicore. Doch kann jetzt kein Zweifel mehr darüber bestehen, dass Manatus und Rhytina rudimentäre Nasenbeine besitzen, während Halicore eimes solchen Beines vollständig enthehrt. Gegenüber diesem Verhalten der lebenden Sirenen ist es von um so grösserer Bedeutung, dass Halitherium noch ein wohlausgebildetes Nasenbein aufweist, welches keineswegs als rudimentär zu bezeichnen ist, vielmehr sich nach Grösse, Gestalt und Lage unmittelbar den Nasenbeinen der andern Säugethiere 
anschliesst. Wir haben bereits erwähnt, (lass Krauss, Kaup ${ }^{1}$ ) folgend, das abgebrochene obere Ende des Zwischenkiefer-Astes fälschlich für das Nasenbein erklärt, dagegen das wirkliche Nasenbein für einen Theil des Siebbeins gehalten hat ${ }^{2}$ ), obschon Bronn eine richtige Auffassung des Nasenbeins bereits angebahnt hatte ${ }^{3}$.

Das Nasenbein des Halitherium ist ein flach ausgebreiteter Schildknochen, welcher die vordere Oeffnung der inneren Nasengïnge ïberdacht und mit langer, lamellöser Wurzel in dem Stirnbein eingewachsen ist; die beiden Nasenbeine stossen in der Mittellinie zusammen in einer Naht, welche die sutura frontalis nach vorn fortsetzt (Taf. IX Fig. 92 und Taf. V Fig. 48, 49, 55, 58 und 59).

Bei dem ausgewachsenen Thier ist jedes Nasenbein $70-80^{\mathrm{mm}}$ lang, von welcher Länge weniger als die Hälfte frei vor dem Stirurande vorragt, der übrige Theil in dem Stimbein innesteckt. Die grösste Breite jedes Nasenbeines liegt am Stirnrand mit etwa $40 \mathrm{~mm}$; die Dicke wird $15-17 \mathrm{~mm}$. Die beiden Yasenbeine biegen ihre Flächen derartig, dass sie in ter Vitte neben der medianen Naht. wenig, dann stärker nach den Seiten und unten abfallend die Nasenöffuung halbkreisförmig überwölben und endlich wieder ansteigend der inneren Seite der Orbitalfortsïtze des Stirnbeins anwachsen. Durch diese doppelte Biegung entsteht an der Obertliche jedes Nasenbeins in der Mitte ein convex nach oben ausgebogener Theil, der glatt ist und frei bleibt bis zum Rande des Stirnbeins, und jederseits ein concav eingebogenes Stiick, auf welches sich erst der jrocessus frontalis des Oberkiefers, dann der Stirnast des Zwischenkiefers auflegt. An der Grenze zwischen beiden Theilen erhält das Nasenbein meist eine stumpfe Kante, die den Rand des Zwischenkiefer-Astes begleitet.

Die untere Fläche der Nasenbeine bleibt in der Mitte zunächst ganz frei über der Nasenoffnung, da hier sowohl der untere Rand des Stimbeins (Taf. V Fig. 50), als das Siebbein unterbrochen ist und die limina perpendicularis ossis ethmoidei im Hintergrunde bleibt; dieses freie Stuick der Fläche ist wenig gewölbt, im Ganzen 18-20 mm breit und gegen $40^{\mathrm{mm}}$ lang bis zum Einsatz im Stirnbein. Dam zeigt sich eine mehr oder weniger scharfe Kante. an der die Naht und die obere Grenze der concha superior des Labyrinthes hinläuft. Von lieser Kante an überzieht das Siebbein mit diunnem Blatt die Unterflïche der Nasenheine, deren Dicke zugleich durch stärkere Biegung der Fläche zunimmt. Hier wächst nun aus dem Blatte des Siebbeins frei heraus das vordere Horn der oberen Muschel und legt sich fast vertikal stehend dem Nasenbeine von innen her an, ohne dasselbe nach vorn an Länge zu ïberragen; man sieht bei angehender Verwitterung den abgebrochenen Rand des Siebbein-Blattes die untere, schrïg gestellte Fläche der Nasenbeine überziehen. nachdem das freie Ende des Hornes abgefallen ist. (Taf. V Fig. 55 und 58). Weiter nach der Seite schiebt sich die Unterfläche in den Orbitalfortsatz des Stirnbeins hinein: an dieser Stelle erscheinen bei gut

$\left.{ }^{1}\right)$ J. Kaup, über Halitherium in seinen Beiträgen zur näheren Kenntniss der urweltlichen Säugethiere, zweites Heft, Darmstadt 1855. In dieser ersten, ziemlich mangelbaften Beschreibung des Halitherium hat Kaup, pag. 16, die oben angegebene unrichtige Auffassung des Nasenbeines zuerst ausgesprochen.

${ }^{2}$ ) In beiden bereits citirten Beiträgen zur Kenntaiss des Halitherium, Neues Jahrb. 1858 pag. 519 . und 1862 pag. 385.

3) Bronn bezeichnet nämlich in der Lethaea geognostica Taf. 48 Fig. 9a das wirkliche Nasenbein richtig mit nas", nasale; doch erwähnt er nichts darüber im Text und erhebt in der Bemerkung uiber Halitherium im Anschluss an Krauss' Abhandlung, Neues Jahrb. 1862, pag. 416, keinen Einspruch gegen die ron Kaup und Krauss gewachte falsche Deutung. 
erhaltenen Stücken die Ränder des Siebbein-Blattes und des Stirnbeins zu beiden Seiten eines schmalen, frei nach unten in die Augenhöhle sehenden Streifens der unteren Flïche des Nasenbeins.

Der vordere scharfe Rand der Nasenbeine ist gleichfalls doppelt geschwungen: in der Mitte nach hinten tief eingebuchtet, zieht er sich nach aussen und unten weit nach vorn vor mit gleichmässiger Rundung und tritt dann gestreckter nach den Seiten an den Orbitalfortsatz des Stimbeines heran. Der grössere Theil des Randes ist frei; nur unter dem Zwischenkiefer-Ast verwächst er innig mit dem processus frontalis ossis maxillae. Die Linie des Vorderrandes und damit die Gestalt der Nasenbeine ist an verschiedenen Individuen recht verschieden: in Fig. 92 Taf. VIII ist eine tiefere Bucht in der Mitte vorhanden, als auf Taf. V Fig. 49; oft bricht oder wittert der diinne Rand ab, sodass nur die dickeren Theile der Nasenbeine iibrig bleiben.

Die Nasenbeine stossen stets in der Mittellinie auf eine ziemlich lange Strecke zusammen und verwachsen miteinander in einer zackigen immer erkennbaren Naht; die Länge dieser medianen Naht ist etwa balb so gross, als die ganze Länge jedes Nasenbeins, da sowohl vorn in der erwähnten Bucht als hinten in den Wurzeln die Nasenbeine auseinander treten.

Der grössere Theil der Nasenbeine steckt fest verwachsen in den Stirnbeinen mit langen, lamellösen Wurzeln. Ich entdeckte diese Wurzeln zuerst an dem Schädel eines jungen Thieres, welcher so angewittert war. dass auf der Oberseite der obere Stirnrand und unter den Nasenbeinen der untere Stirnrand und die Seitenblätter des Siebheins weit zuriickgezogen die zum grossen Theil frei gewordenen Wurzeln der Sasenbeine umranden: auf der Oberseite werden die zahlreichen Lamellen und Zapfen sichtbar, mit denen die Nasenbeine in das Stimbein und in dessen Orbitalfortsatz fest eingelassen sind, während unten in der offenen inneren Nasenhöhle das Nasenbein mit fast glatten Flïchen sich tief in den oberen Muschelwulst des Siebbeins einsenkt, ganz allmählich nach hinten zugespitzt. Die Zerfaserung in Wurzellamellen findet demnach an der Ober- und Seitenfläche des Nasenbeins viel weiter vorn statt, als an der Unterseite, wo die Wurzeln erst am hinteren spitzen Ende des Beines ansetzen. Diese Beobachtung macht man an allen Schïdeln, bei denen die dünnen Theile des Stirn- und Siebbeins von den Nasenbein abgeblättert sind; zwischen den Nasenbeinen und dem dium uiberziehenden Blatt des Siebbeins ziehen stets einige Grefässe von hinten nach vorn, deren verzweigte Eindrücke auf der sonst glatten Unterseite der Nasenbeine sich abzeichnen. Eine von diesen Gefissrinnen ist vielleicht der sulcus ethmoidalis zur Aufnahme des nervus ethmoidalis.

An vollkommen erhaltenen Schädeln umfassen die beiden Ränder des Stirnbeines, der obere und untere, die Nasenbeine derartig, wie ich es durch die beiden punktirten Linien 1 und 3 auf Taf. V Fig. 49 angegeben habe: wenn man mit dieser Figur das nebenstehende Stimbein Fig. 50 vergleicht, ist leicht zu erkennen, dass die Linie 1 den oberen, 3 den unteren Stirnrand andeutet. Ich habe schon oben erwähnt, dass im Verhältniss zum menschlichen Schädel der untere Stirnrand des Halitherium dem processus nasalis ossis frontis hominis entspricht, da derselbe die Nasenbeine trägt; auch dass die Nasenbeine am menscllichen Schädel und mehr oder weniger bei den meisten Säugethieren sich mit flachem Auswuchs in das Stirnbein einsenken; doch findet sich freilich eine so tiefe Einsenkung der Nasenteine in das Stimbein, wie bei dem Halitherium. bei keinem andern Säugethier. 
In die beiden Einsenkungen an der Oberfläche der Nasenbeine neben den Orbitalfortsätzen des Stirnbeins (Taf. I Fig. 1 und Taf. II Fig. 3) wächst der Stirnfortsatz des Oberkiefers mit fester Wurzelverbindung ein und legt sich das obere flache Ende des Zwischenkiefer-Astes frei auf: gerade wie bei den andern Säugethieren verbindet sich der Stirnfortsatz des Oberkiefers mit zackiger Naht mit dem Orbitalfortsatz des Stimbeins, greift aber unter dem Zwischenkiefer herum zum Nasenbein und verwächst auch mit diesem (Taf. II Fig. 5). Der Zwischenkiefer-Ast breitet sich als obere Knochenlage so in der Bucht der Nasenbeine aus, dass er allseits über den unterliegenden Fortsatz des Oberkiefers hinausgeht und demnach sowohl dem Nasenbein als dem Stimbein, aher olne Verwachsung, auf- oder anruht. Auf Taf. V Fig. 49 habe ich mit der punktirten Linie 2 den medianen Rand des Zwischenkiefer-Endes auf der Oberfliche des Nasenbeins angedeutet; in der Ansicht der inneren Nase von vorn Fig. 55 sieht man noch besser die Auflagerung des Zwischenkiefer-Astes auf dem Nasenhein im Durchschnitt gezeichnet. Das allgemeine Bild der Nasenbeine und des Zwischenkiefers gibt Taf. IX Fig. 92 und Taf. VIII Fig. 87.

Die Nasenbeine des Halitherium überwölben demnach den mittleren Theil der weiten Naseniffnung als solide Deckknochen, stossen in einer längeren medianen Naht zusammen, verwachsen mit. lamellösen Wurzeln im und am Stirnbein, sowie mit dem Stirnfortsatz des Oberkiefers. werden von dem dünnen Seitenblatte des Siebbeins von unten her zum Theil überkleidet und sind überlagert von dem Stimaste des Zwischenkiefers. In allen diesen Merkmalen weicht folglich das Nasenbein des Halitherium nicht bedeutend von demjenigen anderer Säugethiere ab.

Dagegen treffen wir bei den lebenden Sirenen eine wesentliche Umgestaltung der Nasenbeine an, welche als die weitere consequente Fortentwickelung der beim Halitherium bereits eingeleiteten Abweichungen vom Säugethier-Typus zu erkennen ist.

Ein Zweifel daran, ob Manatus überhaupt Nasenbeine besässe, konnte wohl nur dadurch entstehen, dass meistens nur die Skelette der Manatis in die Hände der Zoologen gelangten: die kleinen rudimentïren Nasenbeine des Manatus liegen nämlich frei über der Nase, ohne miteinander oder mit einem andern Knochen verwachsen zu sein; daher fielen sie beim Maceriren gewöhnlich mit den Sehnen und Yuskeln $a b$ und gingen unbeachtet verloren. Doch hatten schon Cuvier und Stannius richtig die Nasenbeine am Manatus erkannt und auch Blainville hat trotz einigen Widerspriichen und Unklarheiten über diesen Punkt im Texte auf seiner Taf. III an dem einen Schäde! eines Manatus senegalensis das rechte Nasenbein richtig abgebildet. Krauss hat in seiner citirten Arheit über Manatus vom Jahre 1858 das Nasenbein des Manatus australis hinreichend genau beschriehen: es liegt an derselben Stelle am Schädel, wie beim Halitherium, nur dass es ganz bedeutend an Gestalt und Grösse reducirt ist.

An einem mir vorliegenden Schädel des Manatus senegalensis vom Ogowe mit $337^{\mathrm{mm}}$ Länge ist das rechte Nasenbein erhalten: ein vertikal stehendes glattes Knochenstück von 20 mm Höhe und $3-4^{\mathrm{mm}}$ Dicke steckt mit seinem hinteren, zugespitzten Ende in einer Tasche, welche zwischen dem Stirnbein und dem oberen Muschelwulst nach hinten in die obere Aussenwand der inneren Nase eindringt. Die laterale Seite des Knochens liegt mit der ganzen Fläche lose dem processus orbitalis des Stimbeins an; die mediane Seite sieht zum grossen Theil frei mit welliger Oberfliche in die 
innere Nasenhöhle, da der obere Muschelwulst des Siebbeins nur den unteren Rand des Nasenbeins umfasst. Die grüsste Länge des Nasenbeins liegt in sagittaler Richtung mit $34^{\mathrm{mm}}$. Der vordere

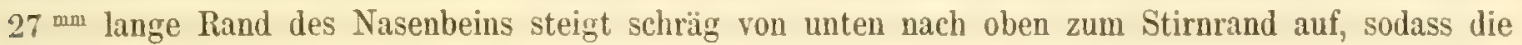
obere Kante des im Ganzen dreieckigen Knochens nur $26^{\mathrm{mm}}$, die untere aber $34^{\mathrm{mm}}$ lang ist. Zugleich biegt sich die obere Ecke des Nasenbeins um einige mm weiter nach innen, als die untere, vordere Ecke, ein schwacher Rest davon, dass einst (beim Halitherium) diese Knochentafel die innere Nase ganz überwölbte und mit dem linken Nasenbein in der Mitte zusammenstiess. Das Nasenhein dieses Manatus senegalensis ist gerade so lang, als das Horn der oberen Siebbein-Ifuschel; es scheint aher nach Krauss nnd Blainville, dass bei einigen Exemplaren der beiden Manatus-Arten die Nasenbeine noch etwas weiter nach vorn gingen und zugleich nach vorn spitzer wurden, als dies bei dem mir vorliegenden Schädel der Fall ist. Der gefranste Stirnrand zwischen den beiden Nasenbeinen ist an diesem Manatus senegalensis nur $16^{\mathrm{mm}}$ lang und überdacht demnach allein die inneren Nasengïnge. An den übrigen mir vorliegenden Manatus-Schädeln fehlen die Nasenbeine stets; doch ist an allen die Tasche zwischen dem Stirnbein und dem Horn der Siebbein-Muschel vorhanden zum Zeichen, dass an diesen Stellen die Yasenbeine sassen und beim Maceriren ausgefallen sind. ${ }^{1}$ ) Manatus unterscheidet sich vom Halitherium wesentlich dadurch, dass der Stirnast des Zwischenkiefers niemals das Nasenbein erreicht, wie wir oben gesehen haben.

Die Nasenbeine der Rhytina Stelleri scheinen nach der Beschreibung derselben durch Brandt und von Nordmann ${ }^{2}$ ) nur wenig von den eben beschriebenen Nasenbeinen des Manatus abzuweichen: ein unregeImissig dreieckiger, rudimentärer Knochen von $38^{\mathrm{mm}}$ Höhe steckt mit seinem hinteren Ende fest in dem Stirnbein, wird seitlich vom processus orbitalis des Stimbeins und unteninnen von dem oberen Muschelwulst begrenzt; die sagittale Länge des Nasenbeins, soweit es innen frei über dem Siebbein erscheint, betrïgt $45^{\mathrm{mm}}$ bei einer Schädellänge von $600 \mathrm{~mm}$; die Nasenbeine der Rhỵtina sind noch weiter von einander getrennt, als bei Manatus, da überhaupt die innere Nasenöfnungr verhältnissmïswig breiter wird. Der Stirnast des Zwischenkiefers bedeckt das Nasenbein von oben her vollständig (Taf. X Fig. 98).

Dass der Halicore Dugong ein Nasenbein in der Regel abgeht, dürfte kaum zu bezweifeln sein: an allen mir bekannten Halicore-Schädeln habe ich unter dem Stirnast des Zwischenkiefers vergebens nach einem solchen Bein gesucht. Nur an dem Schädel eines ganz jungen Thieres, den ich aus dem Berliner Museum erhalten habe, von etwa $250 \mathrm{~mm}$ Länge $^{3}$ ), erscheint in der Ecke, in welcher Stirnbein, processus frontalis 0ssis maxillae und Zwischenkiefer-Ast an der Wand der inneren Nasenhöhle zusammenstossen, ein kleiner, dreieckiger, durch offene Nähte isolirter Knochen von

1) J. Murie erwähnt den ,diminutive nasal bone" nur l. c. pag. 201. Auf der Tafel 26 Fig. 38 sind die Nasenbeine verhältnissmässig gross gezeicbnet; ïbrigens steht in dieser Figur die Bezeichnung "Na*, nasale, nicht am richtigen Platz oder der Verbindungsstrich mit dem Nasenbein fehlt.

2) Brandt, Symb. Sirenol. pag. 38, Taf. II Fig. 8, und von Nordmann l. c. pag. 14, Taf. II Fig. 2 und Taf. V Fig. 4.

${ }^{3}$ ) Das Hinterhauptsbein ist an diesem Schädel abgeschlagen, daher dieses Maass nicht genau angegeben werden kann. 


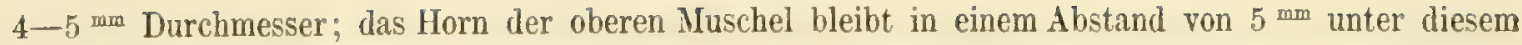
Knöchelchen stehen; wie tief dieses zweifelhafte Nasenbein in das Stirnbein eindringt, kann ich nicht sagen, weil ich diesen Schädel nicht verletzen darf. Da dieser Knochen an der Stelle auftritt, wo er nach Analogie der andern Sirenen erwartet werden kann, und derselhe an jeder Seite an genau dem gleichen Ort und von gleicher Form erscheint, so ist immerhin einige Wahrscheinlichkeit vorhanden, dass dieser kleine Knochen den letzten Rest des Nasenbeins vorstellt. An den Schädeln älterer Thiere wäre dann dieses Nasenbein mit dem Stimbein verwachsen. Krauss') hat am HalicoreSchädel keine Spur eines Nasenbeines auffinden können. Dass Riippell an der Halicore, welche er aus dem Rothen ILeere mithrachte und im Senkenhergischen Institut in Frankfurt aufstellte, irrthümlich den vorderen Theil des Stimbeines am Stirnrande für das Nasenbein hielt, habe ich bereits oben erwähnt (pag. 28); er wurde getiuscht durch Fasern, welche der musculus pyramidalis nasi auf der Stirnfläche zurückgelassen hat.

\section{Os zygomaticum.}

Das Jochbein des Halitherium ist ein platter Knochen von rhombischer Gestalt, welcher nach vorn einen schmalen, langen Fortsatz unter die Orhita. nach hinten eine Spitze unter den processus zygomaticus ossis temporum sendet: jener Ausläufer ist als processus orbitalis, dieser als processus malaris zu bezeichnen, während sich das Mittelstïck als der eigentliche körper des Beines darstellt. Die äussere Fläche des Jochbeins wendet sich frei mit schwach welliger Oberfläche der Wange zu, die innere Fläche trägt auf ihrer vorderen Hälfte die runzelige Nahtfläche für den Ansatz des Oberkiefers; das Schläfenbein legt seinen Fortsatz ohne feste Verbindung auf das hintere Ende des Jochbeins (Taf. III Fig. 17 a, b und c, Taf. V Fig. 40, Taf. VIII Fig. 87 und Taf. IX Fig. 92).

Das auf Taf. III Fig. 17 abgebildete Jochbein gehört einem jüngeren Thier an; es wird noch grösser und erreicht die Länge von $145^{\mathrm{mm}}$, der Körper wird $52 \mathrm{~mm}$ lang, $44^{\mathrm{mm}}$ hoch und $13 \mathrm{~mm}$ dick; sein oberer Rand ist 10-12 ma dick und flach abgerundet, nach vorn geht er breit in den Orbitalfortsatz über, nach hinten stüsst er mit einer schärferen oder stumpferen Ecke wider das vordere Ende des Schläfenbein-Fortsatzes. Diese obere Ecke des Körvers (tuberositas frontalis) entspricht dem processus frontalis des Jochbeins am menschlichen Schïdel und bei andern Säugethieren: sie streckt sich nur wenig der äusseren Ecke des processus orhitalis ossis frontis entagegen und bleibt von derselben immer ziemlich weit entfernt, sodass die Orbita hinten nicht geschlossen ist. Der hintere Theil des oberen Randes wird platt gedrïckt von dem Schlïfenbeinfortsatz, der hier aufliegt: diese schmale Rand-Fläche ist auf dem Körper zunächst an der tuberositas frontalis mit $10 \mathrm{~mm}$ am breitesten und spitzt sich nach hinten bei einer Totallänge von $61^{\mathrm{mm}}$ auf dem processus malaris aus. Beide Hälften des oberen Randes stehen in der tuberositas frontalis im stumpfen Winkel gegeneinander.

1) Neues Jahrb. 1858 I. c. pag. 523. 
Der untere Theil des Körpers steigt weiter nach unten hinab und schärft sich zu in zwei Rändern, welche sich rechtwinkelig in der tuberositas malaris schneiden. An diese untere rauhe Ecke und an den unteren Theil der Aussenfläche des Körpers setzten sich die Fasern des musculus masseter externus an; doch werden die Ansatzstellen der Muskeln niemals so rauh und wulstig, wie bei alten Halicore-Schädeln, deren schwerer Unterkiefer dem Muskel noch mehr zu tragen gab. Tom Jochfortsatz des Oberkiefers wird die tuherositas malaris nicht erreicht, sodass dieselbe frei steht; sie bleibt ziemlich weit nach aussen entfernt von den Backenzähnen und liegt etwa in gleicher Linie mit der Lüicke zwischen dem dritten und vierten Molaren.

Die mediale Seite des Körpers zeigt zu zwei Drittel ihrer Grösse eine ziemlich glatte, freie Oberfläche; erst auf dem hinteren Drittel heftet sich die ganze Breite des processus zygomaticus ossis maxillae an und verbindet sich durch feine Lamellen und Runzeln so fest mit dem Jochbein, dass beide Ḱnochen sich in der Nahttläche schwer ganz von einander lösen lassen und z. B. an dem Jochbein Taf. III Fig. 17 b und $c$ ein Stück des Oberkiefers hängen geblieben ist. Da der Jochfortsatz des Oberkiefers hinten am dicksten ist und nach vorn mit diinner Brücke zum Stirnfortsatz desselben Beines hinüberleitet, so spitzt sich auch die rauhe Nahtfläche des Jochbeines nach vorn um die Orbita herum bald zu dem dünnen Innenrande des processus orbitalis ossis zygomatici zu (Fig. 17b).

Dieser letztgenannte Fortsatz schwingt sich mit schwacher Biegung um den unteren Rand der Augenhöhle mit doppelt gebogener, $20-23^{\mathrm{mm}}$ breiter, $2-4^{\mathrm{mm}}$ dicker Fläche: sein vorderes Ende verdickt sich zu $10^{\mathrm{mm}}$ und wächst mit rauhem Rande sowohl vorn als innen an den Stirnfortsatz des Oberkiefers an. Im Ganzen erreicht der processus orbitalis eine Länge von $75^{\mathrm{mm}}$; bei dieser Länge biegt er sich als Unterrand der Orbita soweit aufwårts, dass sein vorderes Ende 50 mm über der Wurzel an Körper liegt. Die grosse transversale Breite des Fortsatzes bei Halitherium und den lebenden Sirenen ist besonders auffallend; bei keinem anderen Säugethiere wird die Orbita von so breiten Linochenrändern umfasst und tritt dadurch so weit seitlich aus dem Schädel heraus, als bei den Sirenen. Bei seiner geringen Dicke gleicht der processus orbitalis mehr dem analogen Theil am Jochbein des Manatus, als der Halicore, nur die Befestigung an dem Oberkiefer ist in so fern eine andere, als der Orbitalfortsatz bei Manatus sich flach auf den Oberkiefer-Fortsatz oben auflegt, wihrend er bei Halitherium mit sehr dünnem Rande an die laterale Kante des processus zygomaticoorbitalis maxillae anwächst (Fig. 38 und 40).

Der processus malaris legt sich in seiner ganzen Länge unter die Kante des Schläfenbeinfortsatzes und zwar glatt und frei an, sodass die Gegenflächen niemals weder mit zackiger Naht sich mit eimander verzahnen, noch verwachsen, noch sich umfassen. Die Länge des Fortsatzes ist verschieden: Fig. 17 ist das diinne Ende abgebrochen und ebenso ist Fig. 40 gezeichnet; er wird ansehnlich länger: z. B. an einem alten Schådel von $370^{\mathrm{mm}}$ Länge, reicht er fast am ganzen Unterrande des Schläfenbeinfortsatzes entlang mit $65^{\mathrm{mm}}$ Länge; dieses os zygomaticum wird daher im Ganzen $185^{\mathrm{mm}}$ lang, wovon $45^{\mathrm{mm}}$ auf den rhombischen Körper und $75^{\mathrm{mm}}$ auf den processus orbitalis kommen. Der Molarfortsatz verdünnt sich von seiner Wurzel am Körper an rasch zu einem runden, $15^{\mathrm{mm}}$ dicken Knochenstabe, der vor seinem hinteren Ende ein wenig an Dicke zunimmt. 
Gefässdurchbohrungen zeigt das Jochbein nicht. Wenn die Gestalt des Jochbeines schon bei verschiedenen Individuen von Halitherium wenn auch nicht wesentlich variirte, so thuen dies die Jochbeine der lebenden Sirenen noch weit melı; doch gleicht das Jochbein von Manatus noch am meisten demjenigen der tertiären Art; stärker weichen diejenigen von Halicore und Rhytina ab.

Bei Manatus wird der Körper breiter und höher; er gewinnt eine grössere, sehr rauhe, zuweilen zackige tuberositas frontalis, welche gelegentlich, besonders bei Manatus senegalensis, dem Stimbeinfortsatz wulstig anliegt, sodass sie dadurch zum richtigen processus frontalis ossis zygomatici wird und die Orbita völlig schliesst (z. B. Blainville, Manatus Taf. III rechts oben). Der Knochenrand der Augenhöhle wird noch breiter, als bei Halitherium: damit erhält auch der processus orbitalis des Jochbeins eine grössere transversale Breite. Das Ange des Manatus ist ungewöhnlich gut durch seinen starken Knochenring geschützt. Dass der Angenfortsatz mit ganzer Breite dem dünen, seln weit ausgelegten processus orbitalis maxillate ohen aufliegt, statt wie bei Halitherium aussen an demselben anzuwachsen, habe ich bereits bemerkt. Mit seinem oberen Ende stösst der processus orbitalis an das undurchbohrte, kleine Thränenbein, ohne den Fortsatz des Stirnbeins und ohne den Ast des Zwischenkiefers zu erreichen. Der Wangenfortsatz wird bei Manatus auch bedeutend stärker, als bei Halitherium; doch wechselt seine Form sehr: bald ist er mehr stabförmig, bald gewinnt er eine anselnnliche verticale Höhe und grössere Dicke; auch seine Länge variirt; doch streckt er sich stets ganz frei unter den aufgetriebenen Jochfortsatz des Schläfenbeins. Das Taf. IX Fig. 94 abgebildete Jochbein von Manatus australis ist verhältnissmässig klein und zierlich, und gleicht daher dem Jochbein des Haiitherium mehr, als bei andern Manatis. Das os zygomaticum des Manatus senegalensis scheint in der Regel grösser zu sein und stärkere Fortsätze zu tragen, als beim Manatus australis: an einem afrikanischen Schädel von $350 \mathrm{~mm}$ Länge ist das Jochbein $185 \mathrm{~mm}$ lang; sein Körper $70^{\mathrm{mm}}$ hoch und $60^{\mathrm{mm}}$ lang; der processus malaris $50^{\mathrm{mm}}$ und der processus orbitalis $75^{\mathrm{mm}}$ lang, der letztere lalbkreisförmig gebogen. Der Nahtansatz des Oberkiefers ist weiter nach vorn geriickt, als bei Halitherium, sodass die Schläfengrube vergrössert wird; es hängt mit dieser Verïnderung zusammen, dass der processus coronoideus mandibulae sich bei Manatus weit nach vorn neigt und also bei der Kaubewegung des Unterkiefers vorn in der Schläfengrube mehr Raum brauclit (Fig. 95).

Halicore hat im Verhältniss zu Halitherium sein Jochbein stark umgewandelt: der ganze Knochen ist aufgeschwollen, legt sich weit nach unten aus und trägt dicke Wulste und Knnorren zum Ansatz der Kau- und Lippenmuskeln (Fig. 90); dafür ist er der sagittalen Länge nach verhältnissmässig verkürzt (wie der Halicore-Schädel überhaupt), besonders der processus malaris reicht nur noch bis zur Hälfte des processus zygomaticus ossis temporum nach hinten. Ansehnlich verdickt und vergrössert ist der processus orbitalis, welcher der Orbita nach vorn und unten einen solchen soliden Rand bietet, wie er bei keinem andern Säugethier vorkommt. Das obere Eude des processus orbitalis wird aussen frei bedeckt von dem platten, undurchbohrten Thränenbein (siehe oben pag. 59) und umfasst ein Stück des Zwischenkiefer-Astes; endlich stösst es weit zurïckgebogen noch gerade an den stark nach vorn verlängerten processus orbitalis ossis frontis, was weder bei Halitherium noch bei Manatus der Fall ist. Der Körper des Jochbeins ist ebenso dick und gross geworden und 
wird stark nach abwärts gezogen durch den musculus masseter, dessen Ansatz eine grosse wulstige Fläche an der Unterseite des liörpers bewirkte; der schwere Unterkiefer der Halicore bedurfte eben sehr kräftiger Kaumuskeln. Die ganze Länge des Jochbeins beträgt, bei einem jungen HalicoreSchädel von $335^{\mathrm{mm}}$ Länge, $155^{\mathrm{mm}}$, von welchen etwa $50^{\mathrm{mm}}$ auf den Wangenfortsatz, $65^{\mathrm{mm}}$ auf den processus orbitalis und $40^{\mathrm{mm}}$ auf den Körper zu rechnen sind. Die Ansatzfläche des Jochbeins an den processus zygomaticus ossis temporum hat sich entsprechend der Verdickung des Knochens verbreitert und verkiurzt.

Das os zygomaticum der Rhytina schliesst sich nach seiner Form durchaus an dasjenige der Halicore (Fig. 100): der processus malaris liegt frei unter der vorderen Hälfte des Schläfenbeinfortsatzes; der Körper ist stark nach unten durch den Kaumuskel herabgezogen und bleibt mit der wulstigen tuberositas frontalis ebensoweit vom Stimbein-Fortsatz entfernt, wie bei Halicore. Der Orbital-Bogen legt sich ebenfalls dick und knorrig unten und vorn um die Augenhöhle; nur erreicht dieser Fortsatz weder den processus orbitalis ossis frontis, noch den Ast des Zwischenkiefers. Auf der runzeligen Fläche, welche auf Fig. 100 zwischen dem oberen Ende des Jochbeins und dem Stirnbein-Fortsatz zu sehen ist, wird wohl das Thränenbein aufgesessen haben; dasselbe ist bei Rhytina noch unbekannt geblicben.

Wir sehen demnach, dass das verhältnissmässig noch kleine und schlanke Jochbein des Halitherium sich ansehnlich vergrössert bei Manatus, und zwar bei Manatus senegalensis noch mebr als bei Manatus australis; dass es bei Halicore ganz bedeutend an Stärke gewinnt, und dass Rhytina hierin der Halicore folgt. Die Verbindung mit den eigentlichen Schädelknochen geschieht nur am Fortsatz des Schläfeubeins und zwar ohne jede Verwachsung oder Verzahnung, in der Regel mit zwischengeschobenem Knorpelpolster. Dagegen wird das Jochbein der Sirenen mit den Gesichtsknochen verzahnt und zwar mit dem Oberkiefer bei allen Sirenen. mit dem Ast des Zwischenkiefers nur bei Halicore; bei der letzteren stösst auch der processus orbitalis an den gleichbenannten Fortsatz des Stirnbeins, während bei Janatus die bei höheren Säugethieren gewöhnliche Verbindung der tuberositas frontalis mit der äusseren Ecke des processus orbitalis ossis frontis gelegentlich rorkommt. Die ungewöhnlich kräftige Entwicklung der Kau- und Lippenmuskeln, welche sich zum Theil an das Jochbein anheften, hat das bedeutende Wachsthum dieses Gesichtsknochens wohl hauptsächlich zur Folge gehabt.

\section{Os palatinum.}

Das Gaumenbein ${ }^{1}$ ) des Halitherium ist lang und schmal und besteht aus einem verticalen linteren, und einem horizontalen vorderen Theil, die unter einem rechten Winkel verbunden sind,

1) An den meisten Schädeln des Halitherium finden sich nur zerbrochene Reste der dỉnnen Gaumenbeine, weil dieselben die Schädelknochen verbinden mit den Gesichtsknochen und also gerade da sitzen, wo die fossilen schädel in der Regel auseinanderbrechen. Neuerdings wurde indessen in Flonheim ein Schädel aufgefunden, an dem die Ganmenbeine ganz vollständig erhalten sind; bis jetzt der einzige. Danach ist das, was ich oben im Vorwort pag. II über das Gaumenbein gesagt habe, zu verbessern. In unsrer Fig. 96 fehlt das mittlere Stück des Gaumenbeins. Auf Taf. $V$ konnte ich das Gaumenbein noch nicht wiedergeben. 
wie bei den meisten Süugethieren; die pars perpendicularis füllt die Lücke zwischen dem Wespenbein und dem Oberkiefer, ihre rechte und linke Hälfte sind durch die Choanen von einander gretrennt; die pars horizontalis bildet das hintere Stück des Gaumengewölbes als Fortsetzung der Flïchen des Gaumenfortsatzes des Oberkiefers, ihre rechte und linke Hälfte stossen in der Gaumennaht zusammen; eine spitz nach vorn zulaufende fissura palatina spaltet beide Gaumenbeine von einander.

Die pars perpendicularis streckt nach unten und schief nach aussen einen kegelförmigen processus pyramidalis und liegt mit diesem Fortsatz an der Vorderseite der dicken processus pterygoidei ossis sphenoidei, befestigt an demselben mit vielen Lamellen und Runzeln; längs der Mitte dieser Hinterseite des Gaumenbeins zeichnet sich eine Lamelle aus, welche tiefer als die andern in die sonst wenig beim Halitherium markirte incisura pterygoidea eindringt (siehe oben pag. 12). Mit der vorderen, schrïg nach aussen gerichteten Flähe setzt sich dieser absteigende Theil des Gaumenheins an das hintere Ende des Alveolartheiles ossis maxillae fest an, sodass das Ende des Oberkiefers nicht seitlich an dem Gaumenbein vorbei in die fissura orbitalis superior eindringt (wie hei Manatus), sondern unter und vor der Augenspalte stehen bleibt.

Nach oben drängt sich die pars perpendicularis in den engen, schmalen Raum ein, welcher zwischen dem oberen Rande des Alveolartheiles einerseits und dem Unterrande des processus orbitalis ') ossis sphenoidei andrerseits ülorigbleibt: nach hinten als ein Theil der Decke der fissura orbitalis superior erstreckt sich ein Ausläufer, processus sphenoidalis, bis an den Kïrper des Wespenbeins, nach vorn ein zweiter, processus orbitalis, welcher sich auf dem Alveolartheil des Oberkiefers verzahnt und unter dem Orbitalflïgel des Wespenbeins als ein schmaler, kurzer Streifen im IIntergrunde der Augenhöhle und unter dem canalis opticus erscheint. Die processus orbitales sowohl ossis palatini als ossis sphenoidei endigen vorn mit den absteigenden Wänden des Stimbeins weit vor dem Hinterrande des processus frontalis maxillae, sodass eine weite, von vorn nach hinten langgezogene Oeffnung unter den Orbitalfortsätzen des Stimbeins übrig bleibt, in welcher lie Augenhöhle frei mit der Nasenhöhle communicirt (siehe Fig. 87); bei Manatus ist diese Oeffnung zum grossen Theil geschlossen, bei Halicore wird sie noch weiter geöffnet.

Ein $2^{\text {mm }}$ weiter Gefässkanal durchbohrt die Naht zwischen der pars perpendicularis des Gaumenbeins und dem hinteren Ende des Alveolartheils maxillae schräg von innen oben nach unten aussen; es ist dies wahrscheinlich das foramen pterygo-palatinum für die vasa und nervi pterygopalatina.

Die pars perpendicularis ist an diesem $370^{\mathrm{mm}}$ langen Schädel $45^{\mathrm{mm}}$ hoch und $10-15^{\mathrm{mm}}$ breit; die unteren Spitzen der processus pyramidales rechts und links weichen un 90 mm auseinander; die Ränder der oberen Theile entfernen sich zu beiden Seiten der Choanen nur um 35 mm und im Uebergang zu der pars palatina zwischen den letzten Molaren um $17^{\mathrm{mm}}$ von einander.

1) An demselben Schädel, an welchem die Gaumenbeine zuerst sich vollständig fanden, sind auch die processus orbitales ossis sphenoidei zum ersten Male ganz erhalten (siehe oben pag. 11); sie sind genau so gestaltet, wie ich sie nach den an andern Schädeln vorhandenen Resten Taf. V Fig. 57 ergänzt hatte. Der canalis opticus läuft an ihrer äusseren Fläche als offene Rinne noch etwas weiter nach vorn; an dem untereu Rande der Orbitalfligel setzen sich die Gaumenbeine fest an. 
Das untere Ende des processus pyramidalis zeigt in gleicher Weise, wie das Ende der Gaumenflügel des Wespenbeins, die rauhen, vertieften Ansitze der musculi pterygoidei.

Die pars horizontalis des Gaumenbeins ist einfacher gestaltet: eine $8-10 \mathrm{~mm}$ breite, wagerecht gestellte, 2-3 diinne Knochenplatte schliesst sich hinten an die pars perpendicularis, verzahut sich lateral mit $4-5^{\mathrm{mm}}$ hoher Nahtfläche mit dem Alveolartheil des Oberkiefers, vorn in der sutura palatina transversa mit dem Gaumenfortsatz maxillae und medialwärts vorn in der sutura palatina sagittalis mit dem andern Gaumenbeine; hinten innen begrenzt die Gaumenplatte frei den Gaumenschlitz, der als eine vordere Fortsetzung der Choanen grelten kamn: wïhrend bekanntlich bei dem sagittal rerkïzten Gesichtstheil des Menschen die far's horizontalis ossis palatini nach hinten gegen die Choanen die spinae nasales posteriores aussendet, spalten sich die Gaumenheine der meisten Säugethiere (bei ihren nach vorn gezogenen Gesichtsknochen) von einander auch in den partes horizontales; der Gaumenschlitz (fissura palatina) läuft nach vorn spitz aus am hinteren Ende der sutura palatina sagittalis: die Spitze der fissura dringt bei den verschiedenen Sïugethieren verschieden weit nach vorn vor, oder mit andern Worten die partes horizontales sind meln oder weniger tief ron einander gespalten. Bei Halitherium ist der Gaumenschlitz ziemlich lang, nämlich vom Hinterrande des Gaumenbeins an gerechnet dringt er $71^{\mathrm{mm}}$ weit nach rorn, während die sutura palatina sagittalis noch $40^{\mathrm{mm}}$ lang bleibt; er endigt bei dem alten Schädel von $370^{\mathrm{mm}}$ Länge in der Höhe der Mitte des vorletzten Molaren, bei etwas jüngeren Thieren um eine halbe Zahnlänge weiter nach vorn. Die sutura palatina transversa ist zackig, $19^{\mathrm{mm}}$ lang und steht in der Höhe des ersten Molaren, fast in einer Linie mit der Liicke zwischen dem ersten Molaren und ersten Prämolaren.

An der unteren Seite der Wurzel der horizontalen Gaumenplatte verläuft eine Furche, welche hinten an der Vorderseite des senkrechten Theiles entsteht; sie setzt nach vorn fort in die beiden tiefen, scharf ausgeprïigten Rimen, welche heiderseits des Gaumengewölbes hinlaufen und dieses von den erhabenen Zahmrïndern des Oberkiefers abtremnen (siehe oben pag. 53 und 56, und Fig. 22 und 96$)$.

Die sagittale Länge des ganzen Gaumenbeins an dem $370 \mathrm{~mm}$ langen Schädel beträgt $108^{\mathrm{mm}}$, von welchen $92^{\mathrm{mm}}$ auf die Länge der pars horizontalis kommen.

Bei den lebenden Sirenen verkürzen sich die Gaumenbeine ganz bedeutend: bei Manatus wohl desswegen, weil die Oberkiefer mehr Platz einnehmen durch die Vermehrung der Zahl der Molaren, und bei Halicore, weil dieselbe iberhaupt ihre Gesichtsknochen mit Ausnahme des Zwischenkiefers verkïrzt.

Bei Manatus zeigt sich die pars perpendicularis ziemlich viel vergrössert gegen diejenige bei Halitherium: ihre glatten medialen Fliichen zu beiden Seiten der Choanen gehen weit nach vorn, setzen sich oben an das Siebbein und an den Vomer mit Nähten ab und senden noch weiter nach vorn ein dünnes Blatt, vertical gestellt, welches den Raum zwischen Oberkiefer, Orbitaltügel des Wespenbeins und Stirnbein fast ganz ausfüllt; nur einige unregelmässige, mehr oder weniger grosse Oeffnungen in diesem Knochenblatt, das man mit der lamina papyracea vergleichen könnte, gestatten der Xasen- mit der Augenhühle zu communiciren. Diesem langvorgestreckten Blatt wächst eine gleiche linochenlamelle von unten entgegen, die oben in der Mittellinie des Alveolartheiles 
maxillae entsteht; besonders bei Manatus senegalensis ist diese Lamelle des Oberkiefers lioch und lang, solass die Oeffnung zwischen Nasen- und Augenhöhle in ihrer vorderen IIälfte von der MaxillarLamelle, in der hinteren von dem Fortsatz des Gaumenbeins fast ganz geschlossen wird.

Eine weitere Eigenthümlichkeit des wagerechten Theiles ist die, dass die obere Randfäche des processus pyramidalis die lieimtasche des Oberkiefers halbkreisförmig umgibt und ziemlich dicht unter den über ihr sich vorschiebenden Molarkeimen steht; die Keimtasche ragt bei Manatus eben tief in die hintere Augenspalte, um den Zahmrand für die vielen Molaren möglichst zu verlängern, und danach hat sich auch das Gaumenbein zu richten.

Der processus pyramidalis ist kräftig und wird von den beiden Blättern der Gaumentlügel auch nicht viel mehr unfasst als bei Halitherium.

Der wesentlichste Unterschied liegt in der starken Verkürzung der pars horizontalis und der fissura palatima; hei Manatus australis ist dieselbe noch länger, als beim afrikanischen Manati, weil dieser mehr Molaren als jener, also auch einen längeren Oberkiefer entwickelt. An dem Fig. 94 und 95 abgehildeten Schärlel des australis von 340 mm Länge wird das ganze Gaumenbein 65 mm lang, ron welcher Lïnge dem horizontalen Theil etwa $35^{\text {mm }}$ zuzurechnen sind; die sutura palatina sagittalis ist nur $25^{\mathrm{mm}}$ lang; die Gaumenspalte ist ganz kurz, und kömen auf sie eigentlich nur $6^{\mathrm{mm}}$ gerechnet werden, da der hintere, weit offene, halblireisfömige Raum mehr der unteren Umrandung der Choanen (dem concaren margo posterior hominis) entspricht; eine kleine vorspringenle Ecke zwischen diesem weit ausgeschweiften Rande ider Gaumenbeine und der engen fissura palatina verleiht dem ganzen Rande cine schön geschwungene und zierlich getheilte Linie. Die beiden Theile der Gaumenplatte sind hinten $24 \mathrm{~mm}$ breit und spitzen sich zu der schmalen sutura palatina transversa vorn zu; die Nühte zam Oberliefer sind zackig. bei diesem Schïdel endigt die Gaumenspalte vorn hinter dem fünften Molaren; noch zwei Molaren folgen in der Keimtasche. Die sutura transversa liegt noch um zwei Molaren weiter nach vorn.

Bei Manatus senegalensis ist der horizontale Theil noch kürzer und schmächtiger; das Gaumengewölbe wird fast in seiner ganzen Länge von dem Oberkiefer gebildet. Die pars horizontalis ist bei einem Schädel von $325^{\mathrm{mm}}$ nur $34^{\mathrm{mm}}$ lang, die sutura sagittalis nur $10^{\mathrm{mm}}$; die enge, $11^{\mathrm{mm}}$ lange Gaumenspalte lïuft vor bis hinter den siebenten Molaren (hinter ihm folgen noch drei Kreime), um einen Molaren weiter vor die kurze sutura transversa. Die partes horizontales zusammen sind hinten 10, vorne $4-5^{\mathrm{mm}}$ breit; die ganze Entfernung zwischen den letzten Molaren beträgt eben nur 17 man, woraus eine ganz ungewöhnliche Schmalheit des Gaumengewölhes folgt; der Schädel des Manatus ist eben im allgemeinen ausserordentlich schmal, nur die starke seitliche Auslage des Jochbogens verbreitert den Kopf.

Am Schädel der Halicore reducirt sich die pars perpendicularis bedeutend: in die fissura pterygoidea legt sich ein schmächtiger processus pyramidalis tief hinein. Der processus orbitalis bleibt ganz kurz und lässt den Unterrand des processus orbitalis ossis sphenoidei nach vorn über die Hälfte seiner Länge ganz frei; da auch der Alveolartheil des Oberkiefers auf seiner Oberseite keine Orbital-Lamelle entwickelt, so öffnet sich bei Halicore der auffallend weite Raum zwischen Augen- und Nasenhöhle, auf welchen wir wiederholt hinwiesen. 
Die pars horizontalis wird an dem Schädel Fig. 93 von $335^{\mathrm{mm}}$ Schädellänge etwa $45^{\mathrm{mm}}$ lang, die sutura sagittalis $33^{\mathrm{mm}}$. Die Gaumenspalte ist kurz und weit geöffnet; sie endigt vorn bei diesem jungen Schüdel vor dem letzten Mlolaren, bei dem alten von $375^{\mathrm{mm}}$ Schïdellïnge am hinteren Theil des $30^{\mathrm{mm}}$ langen letzten Molaren. Die beiden Seiten der Gaumenplatten zusammen werden bei dem jungen Schädel $13^{\text {mm }}$ breit.

Das Gaumenbein der Rhytina ist verhältnissmässig noch reducirter, als dasjenige der Halicore (Fig. 99) ${ }^{\mathbf{1}}$ ). Die processus pyramidales sind schmächtig, weichen sehr weit von einander, sodass eine sehr weite Choane entsteht. Die processus orbitales scheinen ganz zu verkümmern: denn man sicht auf unsrer Abbildung, dass der Raum zwischen dem Gaumenbein und der Wurzel des OrbitalHlïgels ossis sphenoilei ganz offen bleibt; noch dazu ist der zahnlose Alveolartheil des Oberhiefers ganz niedrig und bleibt daher weit unter der fissura orbitalis superior stehen; die Oeffnung zwischen Nasen- und Augenhöhle wird damit noch grösser als bei Halicore.

Die Gaumenspalte verkïrzt und erweitert sich noch mehr als bei Halicore; die partes horizontales bleiben an dem Schädel von Brandt noch kiirzer als bei demjenigen, welcher unserer Abbildung zu Grunde liegt.

Die Gaumenbeine der Sirenen verbinden sich durch zackige Nähte mit dem Wespenbein, dem Siebbein, dem Vomer und dem Oberkiefer, also mit denselben Schädelknochen, wie beim Menschen, wo nur noch die den Sirenen abgehende untere Muschel hinzutritt. Das Halitherium besitzt die grössesten Gaumenbeine und das breiteste (raumengewölbe; lei Manatus dehnt sich der wagerechte Theil mehr aus, während sich der horizontale Theil stark rerkïrzt; bei Halicore und Rhytina reduciren sich die Gaumenbeine nach allen Richtungen.

\section{Vomer.}

Das Płlugscharbein erscheint bei Halitherium als ein sehr schmaler Knochen, dessen dïnne Blätter hinten die knücherne Nasenscheidewand unfassen; er streckt sich weit nach vorn und legt sich mit einem schmabelartigen, breiten processus maxillaris oben auf den Gaumentheil des Oberkiefers. Leider ist dieser zarte Knochen an allen mir bekannten Schädeln so weit fortgebrochen, dass nu das vordere und hintere Ende gelegentlich uibrigbleiben (Fig. 5); ich habe auf Taf. V Fig. 87 das mittlere Stück ergånzt. Bei dem Schädel von 370 mm Länge ist der ganze Vomer etwa 120 mm lang, vorn gegen $30^{\mathrm{mm}}$ breit und hinten $25^{\mathrm{mm}}$ hoch gewesen. Die beiden alae vomeris sind sehr dünn, liegen hinten dicht an den lateralen Wïnden der lamina perpendicularis ossis ethmoidei und begleiten die knorpelige Nasenscheide nach vorn, an Höhe allmählich abnehmend. Die breite, nach oben offene Rinne des processus maxillaris hat dickere Wände. Da der Gaumentheil des Oberkiefers in sagittaler Richtung convex nach oben gebogen ist, so folgt der Fortsatz des Vomer dieser Biegung. Die untere Seite des processus liegt mit rauher Nahtfläche auf dem Oberkiefer, umgeben von einem niedrigen Wulste des letzteren. Die aufliegende Fläche des Vomer ist in der sagittalen Mittellinie

$\left.{ }^{1}\right)$ Brandt. Symb. Siren. I, c. pag. 25. Taf. I Fig. 1 und 3, Taf. III Fig. 1. 
$65^{\mathrm{mm}}$ lang und quer dazu in der Mitte $22 \mathrm{~mm}$ breit; sie läuft vorn und hinten spitz zu. Die Länge des die Nasenhöhle frei überbrückenden unteren Randes des Vomer beträgt etwa 40 mm.

Die Höhe des Pflugscharbeins nimmt nach vorn fortdauernd ab: die vordere Spitze des Vomer erreicht das hintere Ende des foramen incisivum, also auch die sutura incisiva des Oberkiefers.

Das Pfugscharbein des Manatus australis wird fast ebenso lang, wie dasjenige des Halitherium, sollass seine vordere scharfe Spitze meistens den Hinterrand des foramen incisivum erreicht. Aber es ist weit niedriger, als bei der tertï̈ren Sirene, und seine Kinochenwände hleiben viel dünner; besonders die Rinne des langen, schmalen processus maxillaris ist schmächtiger. Die Ansatzflïche dieses Fortsitzes wird bei einer Schïlellänge von $340^{\mathrm{mm}} 90^{\mathrm{mm}}$ lang, also bedeutend lïnger als bei Halitherium; daher ist die freie Bruicke des Vomer um ebensoviel kürzer, und die alae vomeris sinningen sofort von der knöchernen Nasescheidewand auf den Oberkiefer iber. Rings um die Ansatzfliche entwickelt der Oberkiefer ebensolche Randwulste, wie bei Halitherium.

Der Vomer der beiden mir vorliegenden Schädel des Manatus senegalensis verkürzt sich bedeutend gegen denjenigen des australis: er besteht eigentlich nur aus den beilen alae; der processus geht fast ganz verloren und wird nur aus einigen durchbrochenen Knochenlamellen gehildet, die hinten auf dem Oberkiefer liegen, weit entfernt von dem foramen incisivum. Bei dem Schïrlel von $325^{\mathrm{mm}}$ Länge ist der ganze Vomer nur $60^{\mathrm{mm}}$ lang und hinten $10^{\mathrm{mm}}$ hoch.

Bei Halicore verkürzt sich zwar das Pflugscharbein ebenso wie bei Manatus senegalensis, aber es hehïlt doch solide Wände und entwickelt einen richtigen processus maxillaris (Taf. XI Fig. 93). Bei diesem abgebildeten Schädel von $335^{\mathrm{mm}}$ Länge wird der vomer $75^{\text {mm }}$ lang, hinten $14 \mathrm{~mm}$ hoch und vorn in der Mitte der Rinne $22^{\mathrm{mm}}$ breit. Da bei Halicore der kurze Oberkiefer in der sagittalen Richtung stark gebogen ist, so liegt der processus maxillaris nur in einer Strecke von $40 \mathrm{~mm}$ der maxilla auf; er wird von wulstigen Rändern derselben in seiner hinteren Hälfte umfasst. Ebenso wie dies bei den andern Sirenen in der Regel der Fall ist, treten die beiden Blätter des vomer an ihrem Unterrande auseinander, sodass die knöcherne Nasenscheidewand zur Choane durchschauen kann (siehe oben pag. 20). Das Pflugscharbein der Rhytina ist weder Brandt noch von Nordmann bekannt und scheint auch dem Schädel unserer Abbildung zu fehlen.

\section{Mandibula.}

Taf. IV. Taf. VIII Fig. 87.

Bei Betrachtung des Schälels vom Halitherium fällt sogleich die unverhältnissmässige Grösse des Unterkiefers auf: Die Dicke des Körpers, die flache Aushreitung der Aeste, das starke Kinn mit seiner eigenthümlichen, schräg nach vorn abfallenden Ǩinn-()berfläche geben dem Unterkiefer eine besondere Gestalt. Die beiden Hälften dieses Knochens vereinigen 'sich vorn in einer grossen Fläche: die Symphyse hat beim ausgewachsenen Thiere eine sagittale Länge von $75^{\mathrm{mm}}$, eine Höhe von $50^{\mathrm{mm}}$; sie verknöchert im Alter zum grossen Theil, nur unten bleibt sie eine offene, aber enge, bis $20^{\mathrm{mm}}$ tiefe Fuge; auf der ganzen Aussenseite bleibt sie durch eine Rinne angedeutet, nur im Innenwinkel verwischt sich ihre Spur vollständig. Die beiden Hälften des Unterkiefers stehen 
symmetrisch ${ }^{3}$ ) zu einander und convergiren nach vorn in einem Winkel von $40^{\circ}$, vorn spitz, nicht abgerundet zusammenstossend. Die Entfernung zwischen den beiden Gelenkköpfen (an den medialen Rïnlern gemessen) beträgt $130^{\mathrm{mm}}$ bei $350^{\mathrm{mm}}$ Schïlellänge; die Hinterränder der Kieferüste weichen noch um $15^{\mathrm{mm}}$ jederseits weiter auseinander, wïhrend die Kieferwinkel sich nur um $90^{\mathrm{mm}}$ von einander entfernen.

Die Knochenstructur des Unterkiefers ist wie bei alleu Knochen-des Halitherium eine durchaus dichte, nicht die gewöhnliche, poröse Structur der meisten Såugethiere.

Jede Unterkiefer-Hälfte hat beim erwachsenen Thier von $350^{\mathrm{mn}}$ Schädellänge eine sagittale Länge von $240^{\mathrm{mm}}$, ihre grösste Dicke in der Mitte des Körpers mit $32^{\mathrm{mm}}$, ihre grösste Höhe im Gelenkkopf mit $150^{\mathrm{mm}}$, also sehr bedeutende Dimensionen. Die grösste Fläche jeder Hülfte steht genau vertical, wie auch aus der linken Hälfte der Fig. 32 zu ersehen ist; der Gelenkkopf und der Oberrand des Kriähenfortsatzes, welcher in Fig. 30 vollständig erhalten, während er bei Fig. 31 verletzt ist, stehen vertical über dem Unterrand des Astes.

Jede Hälfte besteht aus einem mittleren, horizontal gestreckten Theile, dem Körper, einem vorderen, nach unten gebogenen Linntheile und dem flachen, ausgebreiteten Aste, welcher die transversal gestellte Gelenkfläche und den processus coronoideus trägt. Der Körper ist etwa $100^{\mathrm{mm}}$ lang, $50^{\mathrm{mm}}$ hoch und hat einen elliptischen Querschnitt, dessen grösste Breite näher dem abgerundeten Unterrande liegt. Der obere, horizontale Zahnnrand enthält vier Paar bis $25^{\text {mm }}$ tiefe Alveolen für die vier zweiwurzeligen Molaren und vor denselben drei Alveolen für drei einwurzelige Prämolaren; vor der Alveole des dritten (vordersten) Prämolaren geht der Zahnrand ohne Lücke in den schräg nach unten abfallenden Zahurand des Kinutheiles über. Der Zahurand des Kürpers ist im Ganzen schmäler und hat steilere Seiten, als der processus dentalis des Oberkiefers; er nimmt nach hinten an Breite zu, sodass sich die Knochenwände des letzten Molaren in transversaler Richtung bis $20^{\mathrm{mm}}$, diejenigen des ersten Molaren nur $10^{\mathrm{mm}}$ von einander entfernen. Die Septa zwischen den Alveolen haben verschiedene Dicke und Länge: die Prämolaren stehen am weitesten auseinander; an dem Unterkiefer der Taf. IV bleibt zwischen $p^{2}$ und $p^{2}$ eine Brücke von 4 mm und zwischen $p^{2}$ und $\mathrm{p}^{3}$ eine solche von $\mathrm{S}^{\mathrm{mm}}$; in den letzten beiden Stücken läuft der Zahnrand nach oben ziemlich scharf zu. Die Alveolen und Septen stehen vertical im Knochen; nur die Wurzeln des letzten Molaren stehen etwas schief nach vorn oben geneigt.

Die laterale Fläche des Körpers ist nach aussen stark convex ausgebogen und glatt abgerundet. In ihrem vorderen Stück münden bereits einige der foramina mentalia, welche wir sogleich beim Kinntheile besprechen werden. Die mediale Fläche desselben ist flach eingebogen; sie trägt keine sichtbaren Spuren des sich hier ansetzenden musculus mylohyoideus $\%$. Der Unterrand des Körpers ist breit und glatt abgerundet.

J) Am Unterkiefer Fig. 32 ist, wie man aus Fig. 30 sieht, der rechte Ast abgebrochen gewesen und in dem Meeressande durch natïrliche Verkittung schief angefügt worden. Die linke Hälfte des Unterkiefers Fig. 32 zeigt die richtige Stellung aller Theile.

") J. Murie, Manatus pag. 150. Taf. 24 Fig. 30. 
Zum Kinntheil rechne ich das zur Seite der Symphyse liegende Stück des Unterkiefers. Die Zahnrïnder beider Kinntheile vereinigen sich nicht vorn im IIalblireis gebogen, sondern laufen, mit den Innensciten dicht verwachsen, parallel zu einander schräg nach vorn abwärts und stehen gegen den horizontalen Zahnrand des Körpers im Winkel ron $140^{\circ}$. Dieser schräge Zahnrand eines Kinntheiles ist $75^{\mathrm{mm}}$ lang, an dem oberen Ende der Symphyse $12^{\mathrm{mm}}$, am unteren $9^{\mathrm{mm}}$ breit; er ist unregelmässig vertieft, von sehr poröser Knochenstructur und enthält sehr viele kleine Gefïssmündungen. Im oberen Ende dieses Zahnrandes erscheinen bei dem Lnterkiefer Taf. IV jederseits zwei hintereinanderliegende, $15^{\mathrm{mm}}$ tiefe Alveolen, deren Oeffnungen kreisrund und $4-6^{\mathrm{mm}}$ weit sind; das Knochenseptum zwischen beiden ist nur $2^{\mathrm{mm}}$ dick; die Axe der beiden Alveolen ist ein wenig nach vorn geneigt. In diesen Alveolen haben jedenfalls zwei einwurzelige Zähne gesteclit, die wir nicht kennen; wie wir unten ausführen werden, ist es wahrscheinlich ein vierter Prämolar und ein Eckzahn, beide früh ausfallend, gewesen. An andern Unterkiefern sind diese Alveolen in der Regel schon mehr verwachsen. In dem übrigen, porüsen Theil des Kinnzahmrandes haben, nach Analogie der lebenden Sirenen zu schliessen, jedenfalls rudimentïre Schneidezähne gesessen, welche frïhzeitig ausfielen oder absorbirt wurden; die Alveolen derselben sind in der porösen Kinochenstructur der Fläche bereits zu stark obliterirt, un noch dentlich erkennbar zu sein. Die mir vorliegenden Unterkiefer scheinen drei Paar obere, breit und flach ausgehöhlte Alveolen und ein Paar untere, nach unten gerichtete Alveolen aufzuweisen, hïtten demnach, wie Halicore, vier Par rudimentïrer Schneidezähne besessen.

Für die Vergleichung mit anderen Säugethier-Typen muss hervorgehoben werden, dass der $190 \mathrm{~mm}$ lange Unterkiefer eines jungen Thieres mit ca. $270^{\mathrm{mm}}$ Schädellünge ${ }^{1}$, die eigenthümliche, schräg abfallende Symphysen-Fläche der alten Thiere noch nicht besitzt: hier stossen die beiden incisiven Zahmränder nicht mit breiter Flïche, sondern mit nach vorn fast scharfen Kanten zusammen. In dem oberen Theil der Symphysenrïnder üfthen sich zwei kleine, runde Alveolen, eine dritte mehr verwachsene darüber; dahinter folgen auf dem horizontalen Zahnrande des Körpers drei hreite, wenig tiefe Zithnlager für die drei Prämolaren-Keime, endlich hinten je zwei grosse Alveolen für die zweiwurzeligen ersten beiden Molaren. Leider ist von allen Zähnen dieses Unterkiefers nur ein abgekatuter Molar gefunden worden. Doch ist auch bei erwachsenen Halitherien die Symphysen-Fläche noch lange nicht so gross, breit und flach ausgebildet, wie bei den lebenden Sirenen und ist derartig gestaltet, dass von einem Lederbelag, wie bei Halicore und Manatus, oder gar von einer Hornplatte, wie bei Rhytina, hier nicht die Rede sein kann. Das erwachsene Halitherium befindet sich in Bezug auf dic Entwicklung der eigenthümlichen Symphysenfliche der lehenden sirenen noch in einem Vorstadium: beide incisiven Zahnränder des ausgewachsenen Halitherium zusammen haben oben eine Breite von $33^{\mathrm{mm}}$, unten von $18^{\mathrm{mm}}$, und eine Länge von $60-70^{\mathrm{mm}}$; in oberen Theile fällt

$\left.{ }^{1}\right)$ Der Oberkopf dieses Thieres ist schlecht erhalten, stimmt aber der Grösse und dem Alter nach mit dem jungen Heidelberger Schädel ïberein, dessen Unterkiefer fehlt; diesen Heidelberger Oberkopf bildete Krrauss, Neues Jahrb. 1862 Taf. VII ab: er enthält zwei Mlolaren, die Alveolen eines dritten Molareo und zwei Prämolaren (siehe unten die Besprechung des Gebisses). 
von der Breite von $33^{\mathrm{mm}}$ noch ein Stïck von $7-9^{\mathrm{mm}}$ fort, welches der klaffenden Symphyse angelört (Fig. 32). Es kamm daher bei Halitherium von einer besonderen Kimnfläche noch kamm gesprochen werden, sondern nur von einem etwas verbreiterten, nach abwärts ausgezogenen incisiven Zahnrande.

Der schräg nach hinten und unten ziehende Unterrand der Symphyse bildet mit dem schräg nach vorn und unten abfallenden Oberrand derselben einen Winkel von ca. $80^{\circ}$; er entspricht dem in derselben Richtung verlaufenden äusseren und unteren Symphysenrande anderer Säugethiere.

Die Kinntheile entwickeln beiderseits der unteren Ecke der Sympliyse zwei dicke, glatt abgerundete wulstige Ränder (Fig. 31), welche den Unterrand des Unterkiefers vorn auffallend herabziehen. Die beiden Wulste werden von einander getrennt durch die an dieser Stelle etwas klaffende Symphyse; sie sind homolog den beiden Hälften der spina mentalis anderer Säugethiere (z. B. Tapir).

Auf der Innenseite der Symphyse verwächst bei alten Thieren die Fuge zwischen den beiden Kieferhälften vollständig. Hier entsteht eine ausgerundete Hohlkehle (Fig. 32), eine tiefe fossa digastrica, in deren oberen Theilen jederseits die etwas vertieften rauhen Ansätze der vorderen Bäuche des musculus digastricus an allen Unterkiefern erhalten sind.

An den schwach concav eingebogenen Aussenflächen der Kinntheile öffnen sich die foramina mentalia, welche die Irïndungen des weiten, durch den ganzen Körper durchziehenden canalis mandihularis sind und verschiedene Gesichts-Nerven und -Arterien austreten lassen. Die grösste Oeffnung des canalis mandibularis liegt gerade in der Verlängerung der Längsaxe desselben und befindet sich etwas iỉer der Mitte der Aussenfläche des Kinntheils, gerade unter der Beugeecke zwischen dem incisiven und dem molaren Zahnrande. Das Lumen dieser Oeffnung ist verschieden weit, in der Regel grösser, als an dem Kiefer Fig. 31: ungefähr kreisrund hat sie einen Durchmesser von 10-12 $2^{\text {mnx }}$. Ihr äusserer Knochenrand ist scharf, nach hinten rund ausgebogen. Längs der medialen Knochenwand schneiden zwei oder drei Gefässkanäle ein, welche zuweilen halb geschlossen sind; ein stets ausgeprägter biegt sich beim Austritt aus der Oefinung mach unten und enthielt wohl eine Arterie, welche besonders der Ernähırung des stark muskulösen Unterkinnes diente ${ }^{1}$ ). Hinter dieser grössesten Oeffnung des canalis mandibularis treten aus der Seitenwand des Kinntheiles und des Körpers noch weitere 5 oder 6 kleinere Kanäle aus, welche kurze Nebenäste des Kieferkanales sind. Diese Oeffnungen sind $2-4^{\mathrm{mm}}$ weit und münden nach aussen etwas oberhalb des innen liegenden canalis manlihularis: sie vertheilen sich unregelmäissig auf der Fläche, doch liegen sie meist hinter einander auf einer 30-40 langen Strecke. Yeist hat auch bei diesen Oeffnungen das austretende Blutgefäss eine offene Rinne von 5-10 mm Länge in der medialen Knochenwand hinterlassen.

Der canalis mandibularis durchzieht den Kiefer von hinten nach vorn in der Richtung der Längsaxe des Körpers so gerade, dass man durch seine ganze Långe hindurch sehen kann: man bemerkt dabei eine schwache Krümmung des Kanals nach oben und nach innen. Das Lumen des Kanals bleibt durchgängig $10-12^{\mathrm{mm}}$ und ist von ungefähr kreisrundem Querschnitt; seine Länge

2) J. Murie beschreibt 1. c. pag. 149 genau die stark entwickelten Lippen- und Kinn-IIuskeln des Manatus; auch bei Halitherium dürfen wir bereits diese Entwicklung voraussetzen. 
erreicht beim ausgewachsenen Thier, dessen letzter Holar bereits zur Hälfte der Lirone abgekaut ist, $125^{\mathrm{mm}}$ bei Totallänge des Kiefers von $240^{\mathrm{mm}}$. Ausser den erwähnten Seitenästen, welche der Kanal im vorderen Theil seines Verlaufes nach aussen sendet, zweigen sich kleinere Kanäle von ihm ab nach oben und bringen die Nerven und Ernährungsgefässe den Zahnalveolen zu; ganz vorn nahe vor der Hauptmïndung entsendet der canalis mandibularis schräg nach oben vorn in den Kinochen hinein einen $3^{\mathrm{mm}}$ weiten Kanal, dessen Aeste in dem porösen incisiven Zahnrande beiderseits der Symphyse ausmünden. Die hintere Oeffnung des canalis mandibularis ist $13-15^{\mathrm{mm}}$ weit und liegt unter und hinter den Wurzeln des letzten Molaren an der medialen Wand der Kieferäste. Die unverhältnissmässig grosse Weite des Lumens und der Oeffinungen des canalis mandibularis gibt zu erkennen die ansehnliche Entwicklung, welche üherhaupt der Unterkiefer des Halitherium nimmt, und im Besonderen das starke Auswachsen der Unterlippe und ihrer Muskeln, welche offenbar durch die Schwierigkeit hervorgerufen wurde, die harte und zähe Pflanzen- (Algen u. a.) Nahrung am Meeressrestade ohne Beihilfe andrer Orwane als der Iippen abzurupfen. Wie wir daher ohen pag. 58 bei Besprechung des Oberkiefers hervorhohen, dass der canalis infraorbitalis ein grösseres Lumen besässe, als bei jedem andern Såugethier, so haben wir ihier das Gleiche zu constatiren für den canalis mandibularis: hesonder's die vordere Oeffnumg des Kanals ist weiter und die Tehenöffnungen zahlreicher, als bei allen andern Säugethieren, und zwar aus dem angegebenen Grunde der hervorragenden Entwicklung der Lippen-Muskeln und -Häute.

Der Ast des Unterkiefers ist eine Hach ausgebreitete Knochentafel von etwa 100 mm Länge, $120^{\mathrm{mm}}$ Höhe und $5-10^{\mathrm{mm}}$ Dicke. Die ïussere Fläche (Fig. 31) ist leicht gewellt und zeigt besonders in der oberen Hälfte schräg nach vorn und unten verlaufende Streifen und Furchen, den Eindrïcken der Bündel des musculus masseter. Der hintere Rand des Astes ist etwa von Zahnhöhe an bis unten zum angulus mandibulae halbkreisförmig geschwungen und ansehnlich verdickt und rauh für den Ansatz der hinteren Bäuche des musculus digastricus. Besonders am oberen Ende unter dem schmäleren Hals des processus condyloideus ist der Hinterrand wulstig verdickt bis zu 20 mm (transversal gemessen); gelegentlich wird sogar eine Knochenecke vom Wulste medialwärts ausgezogen, offenbar durch den Zug des Kaumuskels ').

Die Innentläche des Astes ist flach concav eingebogen und gleichfalls bedeckt von schräg laufenden Furchen, welche hier vom musculus digastricus herrühren. Ausser dem Hinterrande fällt sogleich in die Augen eine nach innen wulstige Verdickung des Randes über und vor dem angulus mandibulae; ja gelegentlich erscheint der Rand über der Kieferecke nach innen so wcit umgeschlagen, dass eine Apophyse entsteht, welche an den eigenthümlichen Fortsatz an derselben Stelle des Unterkiefers der Marsupialien, der Nager und der laubthiere erinnert, ohne natürlich denselben homolog zu sein. Durch diesen vorspringenden Rand bildet sich eine breite Furche,

1) Zur starken Apophyse entwickelt sich diese Kuochenecke bei dem Unterkiefer des Halitherium Veronese, welchen Ach. de Zigno beschreibt und abbildet im Vol. 21 der Nem. del Istituto veneto, Venezia 1880. Siehe dariber unten. Auch beim Kameel ist an der gleichen Stelle am Unterkiefer eine Apophyse. 
welche vorn und oben mit der Oeffnung des canalis mandibularis beginnt und schräg nach unten und hinten zum angulus mandibulae hinabzieht ${ }^{1}$ ).

Eine starke Knochenbriicke baut sich üher die Keimtasche der Nolaren und über den Ausgang des canalis mandibularis, von oben nach unten langgestreckt, auf der vorderen Hälfte der medialen Fläche des Astes heraus: unter dieser Brícke, welche der lingula mandibulae Henle am menschlichen L'nterkiefer homolog ist, entsteht eine schmale Oeffnung, in verticaler Richtung 35 mm lang, transversal 7-10 mm breit, deren untere Hälfte dem Lumen des Kieferkanals angehört und in deren oberer Hälfte die Keimtasche, resp. nach dem Aufhören der Zithnentwicklung die Alveolarwand des letzten Molaren sichtbar wird. Auch diese lange Oeffnung und die starke Kinochenbrücke darüber sind Eigenthimlichkeiten des Sirenen-Unterkiefers, welche wir bei einigen andern Säugethieren (z. B. beim Tapir) nur in beschränktem Maasse wiederfinden; bei den meisten Säugethieren ist das hintere Ende des molaren Zahmrandes von dem Ausgang des canalis mandibularis getrennt und liegt weit vor demselben.

Der processus condyloideus erhebt sich mit geradem Hinterrande als oberster Ausläufer des Astes derartig über der breiten Fläche desselben, dass sein Gelenkkopf nicht den hintersten Punkt des Astes bildet, sondern etwas vor dem linteren Rande des Astes steht. Auf der medialen Fläche des Astes ziehen zwei niedrige Falten schrïg zum Gelenkfortsatz hinauf. Der Gelenkliopf hat eine glatte Oberfliche und ist sicherlich überknorpelt gewesen; er ist von abgerundet oblonger Gestalt mit $25 \mathrm{~mm}$ transversalem und $13-15^{\mathrm{mm}}$ sagittalem Durchmesser; seine lange Axe ist transversal gestellt, mit dem medialen Ende nach rückwärts abweichend (Fig. 32 linke Tieferhälfte). Von vorn nach hinten wölbt sich die Gelenkflïche in gedrückten Bogen von 140² die Biegung in transversaler Richtung ist geringer. Wir haben oben pag. 30 die Fläche am os temporum kennen gelernt, auf welcher der Gelenkkopf des Unterkiefers zu gleiten lat: da diese Fläche stets ansehnlich breiter (in transversaler Richtung) ist als der Gelenkkopf des Unterkiefers, so ist es wahrscheinlich, dass der Lnterkicfer auch seitliche Bewegungen ansfïhren liomte, was zun Zerreiben der Pflanzenfasern durch die Molaren von Vortheil sein musste. Ueber der incisura mandibulae ragt der processus condyloideus wenig hervor (Fig. 30): dieser flache Ausschnitt ist eben kaum $10^{\text {mm }}$ tief (gemessen unter der Verbindungslinie der Höhe beider nebenliegenden Fortsitze) und etwa 30 mm lang; der Knochenrand des Ausschnittes verdickt sich zum Gelenkkopf hin.

Der processus coronoideus ist auffallend niedrig und in sagittaler Richtung lang gezogen (in Fig. 30 ist er ganz unverletzt): er ist um $7-8$ miedriger als der Gelenkfortsatz, wenn der angulus mandibulae und die unterste Kinnecke auf einer ebenen Fläche aufstehen und damit auch der Zahmrand der Backenzähne horizontal steht. Bei den lebenden Sirenen und bei allen andern Säugethieren ist der Kirïhenfortsatz immer höher als der Gelenlfortsatz, und um so höher je stärker das Gebiss in Anspruch genommen wird; denn je höher der Krähen- über dem Gelenk-Fortsatz emporragt, um so effectvoller ist die Hebelwirkung der am processus coronoideus angreifenden Kau-

1) Diese Furche und der wulstige Rand kommt in der Zeichnung Fig. 30 nicht genug zum Ausdruck, besonders da die Knochenbrücke über dem Ausgang des canalis mandibulae weggebrochen ist. 
muskeln. Beim Halitherium Schinzi konnte also der musculus tempornlis trotz der grossen Schläfengrube nicht kräftig entwickelt sein; obgleich bei dem Manatus der processus coronoideus ansehnlicher, wenn auch nicht viel höher als bei Halitherium ist, constatirt doch J. Murie auch für Мanatus einen schwachen musculus temporalis' ${ }^{1}$ ). Furchen der Muskelansätze sieht man besonders auf der Aussenseite der breiten Fläche des processus coronoideus: beim ausgewachsenen Halitherium wird der Krähenfortsatz $45-50^{\mathrm{mm}}$ lang in sagittaler Richtung; seine Dicke ist $2-5 \mathrm{~mm}$. Der höchste Punkt seines Randes liegt gerade vor der incisura mandibulae; von da an fallt der Rand unregelmässig geschwungen nach vorn abrärts und geht endlich in die scharf ausgebildete linea obliqua steil hinab bis auf die Aussenfläche des corpus. Auf der medialen Seite der linea obliqua breitet sich der Krnochen aus bis zum vorderen Rande der Kunochenbriicke, welche sich über die Keimtasche spannt (Fig. 32): es entsteht dadurch hinter und über dem vierten Molaren eine flache Hohlkehle, cavum buccinatorium, in welcher ein Theil des bei den Sirenen stark entwickelten musculus buccinator ansetzt; dis obere dicke Linde dieses Muskels entspringt an der bei den Sirenen gleichfills auffallend grossen Fläche an der Unterseite des processus zygomatico-orbitalis ossis maxillae, von welcher Fläche ich oben pag. 54 fålschlich gesagt habe, dass sie unbenutzt bliebe ${ }^{2}$ ). Es diürte demnach bei den Sirenen der buccinator einigermassen die mangelhafte Function des temporalis beim Aufwärtsziehen des schweren Unterkiefers ergänzen; immerhin ist anch hier wieder daran zu erimnern, dass wir es mit Wasserthieren zu thun haben, deren Knochen bereits vom Wasser ein wenig getragen werden, sodass diejenigen Iuskeln, welche den Zweck haben, die Organe des Kürpers aufwärts zu ziehen, schwächer entwickelt sind, als die abwärts bewegenden Muskeln.

Bei den lebenden Sirenen ist der Unterkiefer des Manatus noch am ähnlichsten dem des Halitherium, wenn auch bedeutend mehr in die Länge gestreckt und also verhältnissmässig niedriger. Der Lnterkiefer von Halicore ist im Gegentheil gedrungener, kürzer und höher geworden als der des Halitherium. Der Unterkiefer der Rhytina endlich schliesst sich mehr an denjenigen der Halicore an, wenn er auch durch den gänzlichen Mangel an Zähnen und durch Erwerbung der grossen Kauplatte umgestaltet und formloser wird (Fig. 90. 94. 100).

Bei Manatus ist der Körper und Kinntheil des Unterkiefers viel gerader gestreckt als bei Halitherium: besonders biegt sich die untere Kinnecke nicht so weit abwärts. Dadurch wird auch die Lage der incisiven Zahnfläche weniger steil, der ganze Kinntheil niedriger. Der noch junge Schädel des Manatus australis ron $340^{\text {mun }}$ Länge Fir. 94 hat einen Unterkiefer ron $233^{\mathrm{mm}}$ sagittaler Länge, also das gleiche Verhältniss wie bei Halitherium: aber der Ast besitzt im Gelenkfortsatz eine Höhe von $124^{\mathrm{mm}}$, im Krähenfortsatz von $131 \mathrm{~mm}$, und der Kinntheil hat eine Höhe von $70^{\mathrm{mm}}$ (gegen $150^{\mathrm{mm}}, 143^{\mathrm{mm}}$ und $80^{\mathrm{mm}}$ bei einem Halitherium derselben Schädel- und Unterkiefer-Länge); die Innenrïnder der Gelenkköpfe weichen um $134^{\mathrm{mn}}$, die anguli mandibulae nur um $68^{\text {mm }}$ auseinander, woraus herrorgeht, dass die Aeste des Manatus australis stark nach unten convergiren, während sie

1) J. Murie 1. c. pag. 151: ses sei in Bezug auf den temporalis bemerkt, dass, im Verhältniss zur Grösse der Knochen und dem Rauminhalt der Schläfengrube, derselbe dünn ist und bedeckt mit einer grossen Masse Fett.

$\left.{ }^{3}\right)$ Siehe über die starke Entwicklung des buccinator bei Manatus, J. Murie 1. c. pag. 150 . 
bei Manatus senegalensis ebenso steil stehen wie bei Halitherium. Bei einem Manatus senegalensis vom Ogowe von $340^{\mathrm{mm}}$ Schädellänge ist der Unterkiefer $230^{\mathrm{mm}}$ lang, $143^{\mathrm{nm}}$ hoch im Gelenkkopf, $153^{\mathrm{mm}} \mathrm{im}$ processus coronoideus und nur $64^{\mathrm{mm}}$ hoch im Kinntheil; die Gelenkköpfe sperren auseinander um $130^{\text {mun }}$, die etwas nach innen umgebogenen Ränder der anguli mandibulae um $90 \mathrm{~mm}$. Die flachen Astflächen des Unterkiefers des Manatus senegalensis stehen im Ganzen vertical gerichtet wie bei Halitherium. Körper und Kinntheil strecken sich noch gerader aus beim afrikanischen, als beim amerikanischen Manatus, solass man durch den weiten canalis mandibularis ganz gerade hindurchsehen kann. Ein weiterer Unterschied zwischen den beiden Manatus-Arten liegt darin, dass die incisiven Zahnflächen verschieden gerichtet und gestaltet sind: bei gleicher Länge der Unterkiefer ist diese poröse Fläche bei Manatus australis $75^{\mathrm{mm}} \mathrm{lang}$, sie ist oben $28^{\mathrm{mm}}$, in der Mitte $37 \mathrm{~mm}$, unten $22 \mathrm{~mm}$ breit und ist von hinten nach vorn abwärts gleichmässig flach convex ausgebogen. Bei Manatus senegalensis geht die Fläche von dem ersten Molaren direct nach vorn vor mit sehr geringer Abwärts-Biegung, fällt erst zuletzt mit starker Verschmälerung vertical ab: der obere geradgestreckte Theil hat eine Länge von $40 \mathrm{~mm}$, der untere vertical gerichtete von $18 \mathrm{~mm}$, also im Ganzen $58^{\mathrm{mm}}$; die Breite der Fläche ist oben $36^{\mathrm{mm}}$, in der Mitte $41^{\mathrm{mm}}$ und am unteren

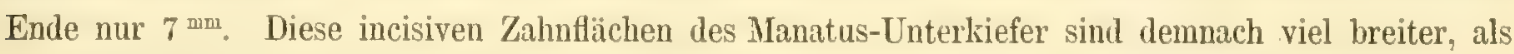
bei Halitherium, sie sind auch ebener und haben ein dickes, zottiges Knorpelpolster getragen.

Der molare Zahnrand des Manatus-Unterkiefers ist durch die Vermelnung der Anzahl der Backenzähne bedeutend länger geworden, als bei Halitherium. Die Molaren haben nicht nur den prämolaren Zahnrand besetzt, sodass der erste Molar dicht hinter der incisiven Zahnfläche steht, sondern drängen auch den Alveolarrand rückwärts gegen den Ast; desshalb fällt der Vorderrand des processus coronoideus nicht mehr steil nach vorn ab, läuft vielmehr tief eingeschnitten nach hinten hinein: đaher entsteht die eigenthimliche Beil-fömige Gestalt des Krrähenfortsatzes. Dieser processus lehnt sich weit nach vorn über, zuweilen soweit, dass unter ihm noch fünf Molaren liegen. Die Form des processus coronoideus wechselt im Einzelnen bei verschiedenen Individuen, und weicht auch bei den beiden Arten so ab, dass bei Manatus australis die Basis des Beiles meist kürzer ist, als die vordere Kante (die Schneide), während bei Manatus senegalensis beide Längen ungefähr gleich sind ${ }^{3}$ ).

Die Ansatzspuren des musculus temporalis sind bei Manatus kräftiger ausgebildet, als bei Halitherium: die vordere untere Ecke des beilförmigen Fortsatzes ist gewöhnlich nach aussen vorgezogen und etwas umgeschlagen; starke Furchen und auf der medialen Fläche auch Ecken und Kanten hedecken den processus coronoideus. Das obere Enle des Fortsatzes ragt gewönnlich 5-10 mm über den processus condyloideus empor. Durch die energischere Auslage des processus coronoideus

1) Siehe Krauss, Manatus 1. c. 1858 pag, 410. Ich finde bei den mir vorliegenden Schädeln diesen Unterschied und also die Ansicht von Gray bestätigt, wodurch nicht ausgeschlossen ist, dass zuweilen bei Manatus australis die gleiche Gestalt des Krähenfortsatzes wie bei Manatus senegalensis vorkommt. Wohl kaum bei einer andern Gruppe der Säugethiere variiren ja so sehr die Knochenformen im Einzelnen bei verschiedenen Individuen, wie gerade bei den sirenen. 
nach vorne wird auch die incisura mandibulae in der sagittalen Richtung länger und erscheint daher flacher ausgeschnitten. Der Gelenkkopf steht in derselben Richtung, wie bei Halitherium.

Der Zahnrand erlangt bei Manatus senegalensis stets eine grössere Länge, als bei der amerikanischen Art, weil jener 10, dieser nur 8 Molaren erzeugt: der Alveolarrand ist bei gleicher Länge der Unterkiefer $100^{\mathrm{mm}}$ lang bei Manatus australis, $120 \mathrm{~mm}$ bei Manatus senegalensis. Dazu ragt die dünnwandige Keimtasche bei Manatus stets unter der Knochenbrücke und über dem Ausgang des canalis mandibularis nach hinten herror, beim senegalensis weiter, als beim australis. Eine so auffallend lange und sichtbar nach hinten heraustretende Keimtasche, in der zuweilen zwei, ja drei Molarkeime stecken, wie bei Manatus findet sich hei keinem andern Säugethiere; am ähnlichsten sind diese Verhältnisse noch bei den Pachydermen.

Die mandibula der Halicore nimmt sehr viel grössere Dimensionen an, als diejenigen des Halitherium und des Manatus (Taf. VIII Fig. 90). Der Kinntheil verlängert sich bedeutend nach unten, der incisive Zahnrand wird eine lange und breite Fläche; der processus coronoideus spitzt sich aus und strebt höher nach oben. Dem Schädel eines jungen, wahrscheinlich weiblichen Thieres von $340^{\mathrm{mm}}$ Länge kommt ein Unterkiefer zu von $215^{\mathrm{mm}}$ Länge, gemessen vom Hinterrand der Aeste zur vorderen Symphysen-Ecke; die Höhe dieser mandibula, bei horizontal stehendem molaren Zahnrande, beträgt $205^{\mathrm{mm}}$ (gegen $150 \mathrm{~mm}$ bei Halitherium und $130 \mathrm{~mm}$ bei Wanatus von gleicher Scliädellänge); die Höhe des Astes im processus coronoideus ist $160 \mathrm{~mm}$, im processus condyloidets $140 \mathrm{~mm}$; die Höhe des Kinntheils $125^{\mathrm{mm}}$ (gegen $80^{\mathrm{mn}}$ bei Halitherium und $70^{\mathrm{mm}}$ bei Manatus). Die bedeutende Höhe des ganzen L'nterkiefers folgt also wesentlich aus dem almorm grossen Kinntheil. Die Grösse der mandibula des alten Schädels von $375^{\mathrm{mm}}$ Länge ersieht man aus Fig. 90.

Die incisive Zahnfläche fällt schräg nach vorn ab mit $120^{\circ}$ gegen den Molar-Rand: sie wird bei dem Unterkiefer von $215^{\mathrm{mm}}$ Länge $95^{\mathrm{mm}}$ lang; oben ist sie $34^{\mathrm{mm}}$ breit, in der Mitte $55^{\mathrm{mm}}$, unten verschmälert sie sich bis auf $20 \mathrm{~mm}$. In der im übrigen ebenen Fläche liegen oben dicht unter einander drei Paar incisive Alveolen, deren jede einen Durchmesser von $14-16^{\mathrm{mm}}$, eine Tiefe von 8-11 $\mathrm{mm}$ hat; unten steht ein viertes Paar, $20 \mathrm{~mm}$ entfernt vom dritten, deren Höhlungen nach unten schauen, als ob zwei nach unten gerichtete Stosszähne darin Platz greifen sollten, und von denen jede $20^{\mathrm{mm}}$ lang in verticaler Richtung, 8-9 mm breit in transversaler Richtung wird. Die Böden der Alveolen bestehen aus feinzerfaserter, ganz poröser Knochensubstanz und gestatten vielen Gefässen den Austritt. Auch der übrige Theil der Fläche, besonders der untere Theil wird von Gefässen durchbohrt. In den Alveolen findet sich in der Regel keine Spur mehr von den früh absorbirten, rudimentären Schneidezilhnen. Ueber diese rrosse incisive Fläche hreitete sich eine dicke Konorpelplatte, als ein Vorstadium der Hornkauplatte von Rhytina.

Der Körper der mandibula hat bei Halicore auch an Höhe ganz bedeutend zugenommen. Der molare Zahnrand beherbergt nur in seiner hinteren Hälfte, vier bis sechs, im Alter nur zwei Cylinder-Zähne (sielıe unten das Gebiss); diese Backenzähne haben sehr lange Wurzeln: desswegen und bei der Höhe des Körpers überhaupt liegt der Zahnrand bedeutend höher über den canalis mandibularis, als hei Halitherium und Manatus. Die vordere Hälfte des Zahnrandes, in der Länge von $40^{\mathrm{mm}}$ bei $215^{\mathrm{mm}}$ Kieferlänge, ist durch den Mangel der Prämolaren und Caninen ein scharfer 
Knochenrand, also eine lange Zahnluicke, wie sie weder bei Halitherium noch bei Manatus vorhanden ist.

Der canalis mandibularis besitzt ein sehr weites Lumen, $15^{\mathrm{mm}}$ bei $215^{\mathrm{mm}}$ Kieferlänge. Vorn mündet er in einer einzigen grossen Oeffnung auf dem vorderen Theil des Körpers, also früher als bei den beiden andern Sirenen; er ist in Folge dessen auch kürzer und wird bei $215 \mathrm{~mm}$ Kieferlänge nur $45^{\mathrm{mm}}$ lang (gegen $120^{\mathrm{mm}}$ bei Halitherium und $80-90 \mathrm{~mm}$ bei Manatus). Vor dem foramen mentale schmeiden in die Knochenwand vier his fünf grosse Gefässkanäle, nach unten, vorn und oben ausstrahlend.

Die Aeste des Unterkiefers von Halicore weichen nicht so stark ab von denen des Halitherium: nur der processus coronoideus zieht sich länger und spitzer nach oben aus, bis $30 \mathrm{~mm}$ den processus condyloideus iiberragend. Hat doch auch Halicore bedeutend schwerer zu heben an seinem Unterkiefer als Halitherium. An der mandibula von $215^{\mathrm{mm}}$ Länge entfernen sich die Gelenkköpfe um $120^{\mathrm{mm}}$, die Hinterränder der Aeste um $160^{\mathrm{mm}}$ und die anguli nur um $45^{\mathrm{mm}}$ von einander. Das foramen mandibulae ist sehr gross und liegt direct unter der Alveole des letzten Molaren.

Die enorme Entwicklung des Kinntheils, des Körpers und des canalis mandibularis, sowie die gleichen Verhältnisse am Zwischenkiefer der Halicore weisen darauf hin, dass diese Sirene bereits in ̈̈lhnlicher Weise, wie Rhytina, vorwiegend den vorderen Theil seiner Mundspalte zum Abrupfen und Zermalmen der Pflanzennahrung (hauptsäichlich Seealgen) gehraucht und diesem Zwecke die betreffenden Organe möglichst anzupassen sucht.

Den Unterkiefer der Rhytina sehen wir auf Taf. X Fig. 100 vor uns; A. von Nordmann beschreibt denselben in der citirten Abhandlung pag. 16. Bei einer Schädellänge von 590 ram wird die mandibula $374^{\mathrm{mm}}$ lang und $270 \mathrm{~mm}$ hoch (im processus coronoideus); im Verhältniss zur Schädellïnge entspricht diese Länge derjenigen der Halicore, ist etwas geringer als bei Halitherium und Manatus; in der Höhe ist der Manatus-Unterkiefer am niedrigsten, es folgt Halitherium, dann Rhytina, endlich Halicore als der höchste, da sich die Höhe der mandibula zur Länge derselben verhält bei Manatus wie $10: 19$, bei Halitherium wie $10: 16$, bei Rhytina wie $10: 14$ und bei Halicore wie 10:10 (bei alten Schädeln der Halicore wird der Unterkiefer sogar etwas höher als er lang ist, z. B. bei dem Fig. 90 abgebildeten).

Die incisive Zahnfläche fällt in flachem Bogen wenig steil nach vorn ab und geht nach hinten ohne eine trennende Kante in den zahnlosen molaren Rand uber; sie wird bekanntlich bedeckt von der dicken, hornigen Kauplatte, welche nicht auf den moliten Zahmrand übergreift. Die Lïnge der incisiven Fläche beträgt bei $590^{\mathrm{mm}}$ Schädellänge $146^{\mathrm{mm}}$, die grösste Breite $65^{\mathrm{mm}}$, ein Verhältniss, welches ungefähr dem des Manatus australis entspricht, während Halicore eine relativ längere und breitere Fläche besitzt. Alveolen oder gar rudimentäre Schneidezähne sind bis jetzt unter der Kauplatte des Unterkiefers der Rhytina nicht gefunden worden; dieselben würden auch wohl höchstens am fötalen Schädel zu finden sein.

Das einzige foramen mentale mündet bei Rhytina noch weiter hinten als bei Halicore, sodass der canalis mandibularis sehr kurz wird: er ist nåmlich $85^{\mathrm{mm}}$ lang bei $374^{\mathrm{mm}}$ Länge der mandibula. Bei dem Mangel der Backenzähne liegt der canalis mandibularis auch bedeutend höher im Körper, als 
bei Halicore; der Kinntheil biegt sich lange nicht so weit herab, als bei jenem. Der Hinterrand des Astes faillt ansehnlich steiler zum angulus mandibulae ab, als bei den andern Sirenen, wodurch die sagittale Länge der Astfläche relativ verkürzt wird.

Der processus coronoideus ragt $30-40 \mathrm{~mm}$ über den Gelenkkopf empor und ist ähnlich gestaltet wie derjenige der Halicore: sein Vorderrand fällt steil ab, etwas nach vorn geneigt, ist nicht tief nach hinten ausgeschnitten, wie bei Nanatus; von Nordmann zeichnet diesen Fortsatz sehr spitz nach oben auslaufend, etwas nach hinten übergekrümmt (1. c. Taf. II Fig. 4), während derselbe auf unsrer Abbildung Fig. 100 oben stumpf abgeschnitten erscheint. Zu bemerken ist, dass der Gelenkkopf sehr wenig über die incisura mandibulae emporragt, und dann nicht wie bei den andern drei Sirenen transversal langgezogen, sondern abgerundet ist und eher in sagittaler Richtung etwas verlängert erscheint. Der Gelenklkopf würde danach besser eine seitliche Gleitung der Kiefer an einander vorbei gestatten, als dies bei den quergestellten Gelenkköpfen der andern Sirenen der Fall sein kann: der zahnlose Mund der Rhytina musste auch mehr eine zermahlende, horizontale Bewegung, als eine zerbeissende, verticale ausfübren.

Die Unterkiefer der vier Sirenen-Gattungen weichen demnach mehr von einander ab, als dies bei den andern Schälelknochen im Allgemeinen der Fall ist, ein Umstand, welcher sich daraus erklären diurfte, dass die mandibula frei und ohne Behindermong anliegender Knochen sich am besten dem Beduirfniss des raseher als alle andern Organe sich umwandelnden Gebisses anpassen komnte.

\section{Das Gebiss.}

Wir werden zuerst die beiden Schneidezähne des Zwischenkiefers, welche ihrer Form nach als Stosszähne zu bezeichnen sind, zu betrachten haben, dann die vier Molaren und die Prämolaren des Oberkiefers; endlich die Bezahnung des Unterkiefers. Das Gebiss der lebenden Sirenen wollen wir hernach gesondert behandeln, da es sich seh" wesentlich von dem des Halitherium Schinzi unterscheidet.

\section{a. Dentes incisivi ossis incisivi.}

Taf. III Fig. 15. 16, und Taf. VIII Fig. 87.

Die beiden abgebildeten Stosszähne gehören ein und demselben Individuum an, welches im Januar 1877 in dem Meeressaud bei Flonheim gefunden wurde; von allen Stosszihnen, die ich keune, sind diese am besten erhalten und die grössesten. Der vollständige Zalın Fig. 16 hat eine Länge von $90^{\mathrm{mm}}$, von denen $13-16^{\mathrm{mm}}$ auf die Schmelzkrone, die uibrigen $\mathrm{mm}$ auf die lange und verhältnissmässig dicke Wurzel kommen. Da die Spitze der Krone abgekaut ist, dürfte der Zahn eine Länge von $95 \mathrm{~mm}$ erreicht haben. Die Krone ist bekleidet mit einer glänzenden, dunkelgrauen Schmelz(Emaille-) Lage, welche an der abgekauten Fläche eine Dicke von 1 mm aufweist. Der Schmelz ist glatt ohne Runzeln; nur an dem kaum abgeschnürten Hals verfliesst er rauh und unregelmässig hegrenzt auf die Wurzel. Die Krone stellt eine einfich kegelförmige Spitze dar, ein wenig seitlich comprimirt, sodass die Basis des Kegels eine Ellipse von 10 auf $12^{\mathrm{mm}}$ Durchmesser ist. Die abgre- 
kaute Fläche an der Spitze zeigt eine geringere Compression mit einem Durchmesser von $5-6 \mathrm{~mm}$; der Schmelzrand steht ein wenig üher das mittlere Dentin-Rund hervor. Die Krautläche steht bei diesen Zälnnen fast normal zur Längsaxe des Zahnes, nur wenig nach vorn geneigt; ein andrer Stosszahn unsrer Sammlung ist stärker abgekaut, bis auf die Hälfte der lírone und zeigt eine schief nach hinten - also dem Munde zugewandte Kaufläche von ähnlicher elliptischer Rundung.

Die Wurzel der beiden abgebildeten Stosszähne schrvillt zunächst vom Hals aus nach oben an mit starker seitlicher Compression, sodass der Querschnitt der Wurzel an der stärksten Stelle 20 auf $13^{\text {nm }}$ beträgt. Weiter nach oben nimmt die Wurzel wenig an Dicke ab mit schwach welliger und rauker Oberfläche; das Ende der Wurzel trägt mehrere kleine Höcker und Längsrunzeln, denen sich wohl die aus (len Nahrungscanälen austretenden Gefässe anlegten (Fig. 16). Auch auf der stärksten Anschwellung der Wurzel erscheinen schwache Längsrunzeln.

Im Ganzen besitzt der Stosszahn eine doppelte, schwache Biegung: in der Richtung von oben nach unten derartig, dass die mediale (dem zweiten Stosszahn zugekehrte) Seite ganz gerade, die laterale Seite dagegen nach aussen schwach gekrünmt ist; und zweitens ist die Längsaxe des Zahnes auch ein wenig von vorn nach hinten gebogen, sodass die vordere Seite stärker als die hintere gekrümmt ist. Bei dieser Stellung würde die Biegung des Stosszahnes ungefihr den äusseren Flächen des Alveolartheils des Zwischenkiefers gefolgt sein.

Aelnnliche Stosszähne hat Kaup abgebiłdet in seinen Beiträgen Taf. I Fig. 9-13, von denen die letzten beiden noch ihre Spitzen erhalten haben; der Zahn Fig. 13 erreicht eine Länge von $100 \mathrm{~mm}$. Interessant ist der Keim eines Stosszahnes, den ich Gelegenheit hatte in der Heidelberger Universitäts-Sammlung zu sehen ${ }^{2}$ ). Dieser Zahn hat eine Dicke von $8^{\text {mm }}$ und eine Länge von $35^{\text {mm }}$, von welcher Länge 16-19 mm auf die schwarze Schmelzkrone kommen; die Wurzel ist hohl und hat einen sehr dümnen scharfen Rand; die Höhlung geht konisch in den Zahn hinein und endigt in der Höhe des unteren Randes der Krone. Der Zahn lag jedenfalls noch in der Alveole verborgen, da seine Spitze unversehrt ist. Da alle andern mir bekannten ${ }^{3}$ ) Stosszihlhe des Halitherium solide Wurzeln besitzen, so scheint die Schliessung der Wurzel bereits frủh zu geschehen, und der Zahn bei dem Austritt aus der Alveole eine solide Wurzel zu haben, gerade wie die Backenzähne.

Das cavum dentis, welches der Länge nach durch den ganzen Zahn hindurchgeht, hat einen unregelmässig oblongen Querschnitt: ich fand ihn in der Mitte der geschlossenen Wurzel eines halbangekauten Stosszahnes von $80^{\mathrm{mm}}$ Länge mit einem Durchmesser von 3 zu $1,7^{\mathrm{mm}}{ }^{2}$ ). Der canalis

1) Krauss, Neues Jahrbuch für Min. 1862. Taf. VII Fig. 7 bildet diesen Keimzahn des Halitherium Schinzi als den Zahn seines andern jungen Cetaceums" ab. Dieser Zahn ist mit dem Schädel des jungen Thieres, den Krauss Taf. VII abbildet, zusammen gefunden worden. Es bedarf wohl nach dem oben pag. 60 und hier Gesagten des Beweises nicht mehr, dass wir hier in der That den Keim eines Stosszahnes vom Halitherium vor uns haben, besonders wenn wir ihn mit denselben Zähnen der Halicore vergleichen.

2) Das Innere des Raumes war zierlich ausgekleidet mit feinen durchsichtigen Arragonit-Nadeln.

$\left.{ }^{3}\right)$ Während des Druckes dieser Arbeit wurde in Flonheim der Schädel eines jungen Thieres gefunden, in dessen wohlerhaltenem Zwischenkiefer die beiden Stosszähne sassen: jeder Stosszahn ist 64 mm lang, wovon $16-20 \mathrm{~mm}$ auf die kaum angekaute Schmelzkrone kommen; ihre Wurzeln sind hohl am Ende: die konische 0effnung ist $15 \mathrm{~mm}$ tief und zwischen den scharfen Rändern 9 auf $11 \mathrm{~mm}$ weit. 
radicis mündet mit enger Oeffnung an der Spitze oder seitlich neben der Spitze aus. Die Zahnsubstanz ist sehr dicht, stets dunkelbraun gefärbt und glänzend; mit der Lupe ist eine concentrische Schaalung und eine sehr feine radiale Strahlung der canaliculi dentium leicht wahrnehmbar.

Die dentes incisivi des Halitherium stellen demnach ein Zwischenstadium dar zwischen dem echten Schneidezahn und dem Stosszahn, wie er sich bei Halicore und den Proboscidiern zeigt: denn unähnlich diesen besitzen jene noch eine Schmelzkrone und eine geschlossene Wurzel, entbehren des Cementes; ihr Wachsthum ist hegrenzt. Iagegen fehlt ihnen der Charakter des schneidigen, von vorn nach hinten comprimirten Schneidezahns; auch ist die Wurzel weit stïrker entwickelt, als dies bei echten Schneidezähnen der Fall ist. Mit dem Wachsthum der Wurzel hängt wohl die bedeutende Aufblähung des Aveolartheiles des Zwischenkiefers zusammen. Da wir von dem letzteren keine vollstïndigen Exemplare besitzen, lïsst sich auch nicht entscheiden, ob noch Alveolen für andre Schneidezähne vorhanden waren; letzteres ist immerhin wahrscheinlich, sowohl als ein allgemeiner Säugethier-Charakter, als besonders desswegen, weil Halicore noch einen zweiten, früh ausfallenden Schneidezahn besitzt.

Von den Zähnen des Oberkiefers wollen wir zuerst die echten, damn die falschen Backenzähne betrachten, da uns die ersteren besser bekannt sind als die letzteren.

\section{b. Dentes molares ossis maxillae.}

Taf. III Fig. 18-20 und 22. 24. 26.

Das Halitherium Schinzi besitzt in jeden Oberkiefer vier dreiwurzelige Backenzähne, welche von vorn nach hinten an Grösse und Complication zunehmen. Die Backenzähne des Halitherium sind echte Höckerzähne, obenhin betrachtet ähnlich den Höckerzïhnen der Suiden; durch Abkaumg erhalten sie eine blumenblatt-artige Zeichnung, analog den Zïhnen des Hippopotanus. Dadurch dass die vorleren Molaren des Halitheriun sehr früh hervorhrechen und bereits im Gebrauch sind, wenn die Prïmolaren noch im Knochen versteckt liegen, kennen wir bis jetzt nur Oberkiefer, an denen die beiden vorderen Molaren fast bis zur Hälfte der Kronen abgekaut sind. Wir thuen daher gut, bei Besprechung der Backenzïhne des Inlitherium in beiden Kiefern beim letzten Molaren zu heginnen und nach vorn weiterzugehen.

Der letzte Molar $\left(\mathrm{m}^{4}\right)$ des Oberkiefers ist abgebildet auf Taf. III Fig. 18a. b als Keimzahn mit offener Wurzel, Fig. $20 \mathrm{im}$ ersten Beginn der Benutzung gleichfalls mit offener Wurzel, Fig. 24 und 26 von ein und demselben Oberkiefer ${ }^{1}$ ) etwas stärker abgekaut mit drei geschlossenen Wurzeln und im Oberkiefer Fig. 22 stark abgenutzt mit drei sehr kräftigen Wurzeln. Wie man sieht, ist dieser letzte Molar der grösseste von den Backenzähnen des Oberkiefers: seine frische Krone (Fig. 18a.b) hat eine sagittale Länge von 29 mm, ihre grösste transversale Breite liegt im

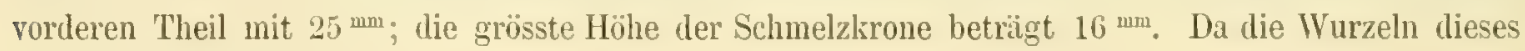

$\left.{ }^{1}\right)$ Diesen Oberkiefer bildete Kaup in seinen Beiträgen Heft 5 Taf. V Fig. 1 ab. 
Zahnes im Alter des Thieres bis $36^{\mathrm{mm}}$ lang werden, erreicht der Zahn eine Gesammthöhe von $52 \mathrm{~mm}$. Auf der unverletzten Krone zählt man bis zu 22 kleine und grosse Höcker: dieselben ordnen sich so an, dass zwei Hauptreihen von je drei grossen Höckern zu beiden Seiten, vorn und hinten, von dem tief transversal durch die Mitte einschneidenden Thale liegen. Die vordere Hauptreihe wird vorn begleitet von einer niedrigen Reihe kleiner, dicht aneinander gestellter Höcker, welche sich an den grossen medialen der drei Hügel der Hauptreihe dichter anschliessen als an den lateralen. Ebenso sind der hinteren Hügelreihe hinten sechs grössere und kleinere Höcker angeschlossen, welche im Verein mit den drei Haupthügeln rings im Rund eine ansehnlich tiefe Grube umstehen. Ausserdem zeigt sich in dem transversalen Hauptthal auf der medialen Zahnseite am Rande der Krone ein breiter, meist mitten gekerbter Schmelz-Zipfel ').

Die drei Hügel der vorderen Hauptreihe sind die höchsten und stärksten Höcker des Zahnes. Von ihnen ist der mediale am dicksten und längsten und an seiner frischen Spitze ein wenig gekerbt; er ist von den beiden andern Höckern tiefer abgetrennt als von der vorderen Nebenreihe, sodass beim Ibkauen seine Insel schneller verschmilzt mit den ersten Höckern der Nebenreihe, ais mit seinen beiden Genossen (Fig. 24. 26. 22). Von den drei Hügeln der hinteren Hauptreihe ist auch wieder der laterale der ansehnlichste; der mittlere schliesst sich dichter an den medialen als an den lateralen Höcker an. Die hintere Nebenreihe schliesst sich bei den beiden zusammengehörigen Zälnen Fig. 18a. b. derartig an die Hauptreihe, dass zunächst nehen und hinter dem lateralen Haupthöcker ein starker, aber $3^{\mathrm{mm}}$ niedrigerer Höcker steht, dann drei kleine Höcker folgen und endlich ein $7^{\mathrm{mm}}$ langer Höcker den Abschluss bildet, der in eine transversal gestellte Schneide, nicht wie die andern Höcker in eine Spitze ausläuft.

Die beiden medialen Höcker der Hauptreihen sind in sagittaler Richtung über doppelt so lang als in transversaler Richtung breit, und sind bedeutend weniger tief von einander geschnitten durch das mittlere Thal, als die beiden lateralen Höcker derselben Reihen; ferner breiten sie sich gegen den Hals zu immer breiter aus, nur dem Mittel-Zipfel noch einen Platz auf dieser Seite der Krone einräumend; zudem fallen sie mit bedeutend flacherer Böschung gegen den Hals zu ab, als die Höcker der lateralen Zahnseite. Durch alle diese Merkmale erscheint die Innenwand der Zahnkrone geschlossener als die Aussenwand, welche sowohl tief von dem Hauptthale als mehrfach von Furchen zerschinitten ist.

An den letzten Molaren anderer Oberkiefer finden sich zum Theil um die hintere Grube herum nicht so viel Nebenhöcker als bei den oben beschriebenen; sogar variirt Anzahl und Grösse dieser Höcker auf der rechten und linken Seite ein und desselben Oberkiefers: z. B. an dem von Kaup l. c. Taf. I Fis. 1 abgelbildeten Oberkiefer fehlt rechts der erste grosse Nebenhöcker der lateralen Zahnseite, der links nur als eine kleine Warze angedeutet ist (unsre Fig. 24 und 26); auch ist hier die

$\left.{ }^{1}\right)$ Auf den Abbildungen tritt dieser Mittel-Zipfel nicht scharf genug hervor, am deutlichsten noch bei Fig. 26 links auf der inneren Seite. Es dürfte geeignet sein, schon hier darauf hinzuweisen, dass ein solcher Zipfel oder Warze am medialen Eingange des Hauptthales zwischen den beiden medialen Hïgeln sich bei den meisten Ungulaten findet; diese Warze wächst zur Säule aus bei den Boviden und Equiden. 
Grube durch eine tiefere Furche nach aussen offener, wodurch die Gruppirung der hinteren Vebenhöcker derjenigen der vorderen Molaren ähnlicher wird.

Die Hügel der vorderen Hauptreihe sind die höchsten: sie werden daher zuerst abgekaut (Fig. 24 u. 26); es entstehen zwei runde kleine Inseln aus den beiden lateralen Hïgeln, und eine nach vorn auswezogene Insel aus dem medialen Hauptzapfen und den höchsten vorderen Vebenhöckern. Dann folgen die Höcker ler hinteren Hauptreilıe; endlich die hinteren Nebenhöcker. Die Abmutzung erfolgt wie bei allen Molaren des Oberkiefers an der medialen Seite stärker als auf der lateralen (umgekehrt am Unterkiefer); zugleich geht sie hei diesem letzten Molaren hinten schneller als vorn, sodass ein solcher Zahn eines mir vorliegenden alten Thieres vorn noch mit einem $5-7^{\text {mm }}$ hohen Schmelzreste umgeben und in der hinteren Hälfte bis zur halben Wurzel abgekant ist; es erscheinen daher die Kanäle der Zahnwurzeln auf der Kaufläche. Der glänzende, dunkelgraue Schmelz ist an den letzten Molaren eine $2-3^{\mathrm{mm}}$ dicke Lage; da die Zähne aber einfach (dentes simplices), heine schmelzfaltigen (dentes complicati) sind, also der Schmelz nicht zwischen das Dentin eindringt, und da auch jede Spur von Cement fehlt, so werden die Tíronen der Backenzähne des Halitherium verhältnissmässigr rasch durchgekaut, sodass wie erwïhnt die Krrnnen der ersten Molaren bereits stark abgekaut sind, ehe die Prämolaren vorbrechen.

Die Wurzeln der Keimzähne sind wie immer hohl mit scharfem Rande: die Hügrelreihen prägen sich als Hache Vertiefungen, das Haupthal und die hintere Grube als Erhöhungen aus im Innern der breit offenen Wurzel; anfänglich lassen sich sogar je drei spitze Vertiefungen erkennen, welche den sechs Hïgeln der beiden Hauptreihen entsprechen, ein Beweis, dass diese Reihen sich vor den beiden Nebenreihen auszeichnen; auch sind die beiden medialen Löcher die weitesten und tiefsten. Durch Ausfüllung und Abschnürung entstchen zugleich mit dem Herausichieben des letzten Molaren anfangs drei starke Wurzeln, von welchen eine die ganze mediale Breite des Zahnes, mit ihrer Fläche in sagittaler Richtung gestellt, einnimmt, die beiden andern an der lateralen Seite je unter den Haupthügeln stehen. Diese Stellung der Wurzeln haben z. B. die Zähne Fig. 24 und 26, und ist die gleiche Stellung, wie sie die übrigen Molaren des Oberkiefers besitzen.') Aber beim späteren Weiterwachsen des Zahnes tritt weitere Theilung und eine Verschiebung der Wurzeln des letzten Ioluren ein: die hintere laterale Wurzel nimmt stark an Breite zu, stellt ihre Flïche transrersal und drångt so die mediale Wurzel nach vorn, sodass sie auch auf der medialen Seite des Oberkiefers erscheint. meist zum Theil offen aus der Innochenwand hervorschauend; zugleich schuirt sie sich in der Mitte und am Ende mehr oder weniger zu zwei Wurzeln ab; zuweilen ist noch eine zweite Theilungsfurche angedentet. Auch die beiden vorderen Wurzeln reigen meist eine oder zwei Theilungsfurchen: indessen bilden sich nur an den Wurzelenden netre Abschnürungen, Es entsteht also hier aus dem ursprünglich dreiwurzeligen ein. mehrwurzeliger Molar im Verlauf des Lebens ein und desselben Individuums. Durch das später zu erwähnende Vordrängen der Zähne stellen sich die Wurzeln des letzten Molaren mehr und mehr schräg von vorn nach hinten.

1) Diese Stellung der Zahnwurzeln am Oberkiefer ist auch diejenige, welche bei den Ungulaten (z. B. beim Tapir) die ursprüngliche ist. Siehe unten. 
Die vorderen Molaren werden bei analogem Grundplan der Höckervertheilung je weiter nach vorn um so einfacher, d. h. um so geringer wird die Anzahl der Nebenhöcker. Doch besitzt keiner der vorderen Molaren den Schmelzzipfel im medialen Anfang des Hauptthales. Die beiden Hauptquerreihen zu je drei Zapfen, ron denen der mediale der grösseste ist, und je eine vordere und hintere Nebenreihe bleiben jedem Molar. Die hintere, mehr oder weniger durch Nebenhöcker rings geschlossene Grube des letzten Molaren wandelt sich zu einer lateralwärts abfallenden Furche, wie diejenige Furche, welche die vordere Nebenreihe von der vorderen Hauptreihe trennt: wir erhalten auf diese Weise den vierhöckerigen lateralen Rand und zwei breite Höcker am medialen Rand der Írone bei den vorderen Molaren; die beiden Nebenreihen schliessen sich nahe an die medialen Hauptzapfen an, während sie tiefer abgeschnitten sind durch Furchen von den lateralen Hauptzapfen.

Aus dieser Vertheilung der Höcker auf den vorderen Molaren lässt sich leicht die blumenblattartige Zeichnung ihrer Kaufächen erklären, wie sie auf der Tafel III zu sehen ist: die Inseln der Hauptreihen rerschmelzen an der medialen Zithnseite eher mit den Insehn der Nebenreihen, als auf der lateralen Seite. Die Abnutzung geht wie gesagt auf der medialen Seite der Molaren des Oberkiefers rascher vor als auf der lateralen: daher ragen die beiden lateralen Haupthöcker immer bedeutend über die übrige Kaufläche hervol.

Die Kŕrone des vorletzten Molars $\mathrm{m}^{3}$ (Fig. 18. 19.22) wird $22^{\mathrm{mm}}$ lang, $23^{\mathrm{mm}}$ breit und $16^{\mathrm{mm}}$ hoch, gegen $29: 25: 16^{\mathrm{mm}}$ des letzten MLlars. Bei den vorderen Molaren kann die Höhe der frischen Krone nicht mehr genau angegeben werden, weil sie zu stark abgekaut sind; doch ist dieselbe geringer als bei den letzten Molaren. Das Verhältniss der sagittalen Länge zur transversalen Breite der Kronen ist bei $\mathrm{m}^{2}=19: 20$ und bei $\mathrm{m}^{1}=17: 18$, wobei jedoch zu bemerken ist, dass die Länge bei diesen Zälınen durch die Abreibung am Nebenzahn etwas verkürzt wird. Im Ganzen sind die Kronen der drei ersten Molaren ziemlich gleich lang und breit, also abgerundet quadratisch, wïhrend der letzte bedeutend in die Länge gezogen ist; es geschieht dies dadurch, dass $\mathrm{m}^{4}$ als der letzte Zahn nach hinten freien. Spielraum hat, daher sich in die Länge streckt und die zahlreichen hinteren Nebenhöcker entwickelt.

Jeder der drei vorderen Wolaren hat drei Wurzeln, von denen eine medial steht und mit seiner breiten Fläche sagittal gerichtet ist, während die beiden andern lateral und je unter einer Zahnhälfte liegen, sollass. sich das Hauptthal der Krone in die Einschnïrung zwischen heide Wurzeln verlängert.

Den Molaren des Oberkiefers vom Halitherium eigenthümlich ist die Erscheinung, dass die hinteren Zähne im Verlauf des Lebens des Thieres sich nach vorn vorschieben, sodass der vorderste Molar $\mathrm{m}^{1}$ mit seinen Wurzeln schliesslich ganz aus dem Knochen herausgedrängt wird und ausfällt; dies letztere geschieht zu einer Zeit, wo die Krone von $\mathrm{m}^{2}$ schon fast ganz abgekaut ist und die Wurzeln desselben zum Theil resorbirt sind. Die Vorschiebung kann am besten beurtheilt werden nach der Stellung der Molaren zum hinteren Rande des processus zygomatico-orbitalis des Oberkiefers: bei Schädeln junger Thiere liegt dieser Knnochenrand noch etwas vor der Lücke zwischen $\mathrm{m}^{2}$ und $\mathrm{m}^{3}$ (z. B. Fig. 18); bei etwas älteren Thieren trifft dieselbe Linie auf den dritten Molaren 
(Fig. 22) und bei ganz alten Thieren, wo $\mathrm{m}^{2}$ bereits fehit und seine Alveolen zum Theil zugeschoben und verwachsen sind, erreicht der vordere Rand des letzten Molaren fast die Höhe jenes Knochenrandes. Daher stehen die Wurzeln aller Molaren bei alten Thieren stets schräg von vorn nach hinten gerichtet im Oberkiefer.

\section{c. Dentes praemolares ossis maxillae.}

Taf. III Fig. 18. 23. 25a. b, Taf. V Fig. 38 und Taf. X Fig. 96.

Die Prämolaren des Oberkiefers weichen sehr wesentlich in ihrer Form von den Molaren $a b$; das Halitherium gehört daher in die Klasse der Heterodonten. Die meisten Oberkiefer, auch diejenigen alter Thiere, zeigen vor dem ersten Molaren zwei hintereinander liegende, weite, einfache Alveolen, in welchen zuweilen noch zwei einwurzelige Prämolaren $p^{1}$ und $p^{2}$ stecken ${ }^{1}$ ). An manchen Oberkiefern findet sich etwas weiter vorn eine dritte einfache, meist verwachsene Alveole; an einem Schädel der Heidelherger Sammlung passte in diese vorderste Alveole ein kleiner einwurzeliger dritter Prämolar, welcher mit dem Schädel zusammen gefunden wurde ${ }^{2}$ ).

Es liegen mir sechs angekaute und drei frische Prämolaren des Ober- und Unterkiefers vor, von denen einer Taf. III Fig. 23, ein zweiter Taf. III Fig. 25 und die drei frischen Taf. IV Fig. 27. 28. 29 abgebildet sind. Der Zahn Fig. 23 ist ein einzeln gefundener von Flonheim, auf welchen Kaup im Jahre 1838 den Namen Pugmeodon Schinzi gründete (Neues Jahrb. für Mincral. 1838 pag. 319 Taf. II Fig. C 1.2); derselbe ist von Kaup als „erster oberer linker Backenzahn des Halitherium Schinzi“ auf der Etiquette bezeichnet. Der Zahn Fig. 25 steckt noch in der Alveole vor dem ersten Molaren des Oberkiefers und wurde mit dem ganzen Oberkiefer von Kaup, Beiträge Heft 5 T'af. V Fig. $1^{3}$ ) abgebildet. Dieser Zahn ist also sicher der linke $p^{x}$ des Oberkiefers. Den noch nicht abgekauten Prämolar Fig. 27 bildete Kaup, Beitrïge Heft 2 Taf. I Fig. 14 ab, den Fig. 28 daselbst Heft 5 Taf. V Fig. 3 und den Zahn Fig. 29 daselbst Heft 5 Taf. V Fig. 4 ab.

Der Schådel der Heidelberger Sammlung, welchen Krauss im Neuen Jahrb. 1862 beschrieb, enthält die drei Prämolaren im Oberkiefer Taf. X Fig. 96, von welchen Prämolaren der vorderste ${ }^{3}$ nicht im Kiefer festsass, aher mit dem Schädel gefunden wurde. in die Alveole passt und wohl auch nach Grösse und Forn richtig als $p^{3}$ angenommen wird; ausserdem wurden mit demselben Schädel (nach Bronn's Etiquette) zwei einwurzelige Prämolaren gefunden, welche $p^{1}$ und $p^{3}$ des rechten Unterkiefers sein dürften; $p^{1}$ derselben hat Krauss, 1862 Taf. VI Fig. 10 abgezeichnet. An dem jüngeren Schädel der Heidelberger Sammlung, welchen Krauss daselbst Taf. VII abbikdete, brechen

1) Wir zählen die Prämolaren von hinten nach vorn, die Molaren von vorn nach hinten, eine Zählweise, welche als sebr geeignet jetzt mehr und mehr gebräuchlich wird.

$\left.{ }^{2}\right)$ Dieser $\mathrm{p}^{3}$ wurde von Krauss 1. c. 1862 Taf. VI Fig. 2 und 7 und auf unsrer Taf. X Fig. 96 abgebildet.

3) Und bereits vorher im Neuen Jahrb. für Min. 1856 pag. 19 von Kaup besprochen und photolithographisch Taf. I abgebildet. 
aus dem Oberkiefer links eben zwei Prämolaren $\mathrm{p}^{2}$ und $\mathrm{p}^{2}$, rechts nur $\mathrm{p}^{2}$ hervor, stecken noch im Knochen und liegen schief sagittal im Kiefer, sodass ihre Spitzen sich nach hinten und unten richten. Ein Unterkiefer-Fragment aus Kilipstein's Sammlung bildete Kanp, Beiträge Heft II Taf. I Fig. 18 al): zwei einwurzelige Zïhne, welche hohle Wurzeln besitzen, stecken in den vorderen beiden Alveolen; Kaup hält sie fälschlich für Milchzïhne. Endlich shizzirt Kaup, Beiträge Heft V Taf. V Fig. 2 eine rechte Unterkiefer-Hälfte mit drei Molaren (der vierte liegt nach pag. 31 „noch als Keim tief im Kiefer") und dem ersten Prïmolaren $\mathrm{r}^{\prime}$. Leider sind diese beiden Unterkiefer nicht mehr vorhanden. Dies ist das mir bekannte Material zur Entzifferung des Prämolar-Gebisses von Halitherium Schinzi: es sind im Ganzen 20 verschiedene Prämolaren, die zum Theil dem Ober-, zum Theil dem Unterkiefer angehören und welche 8 einzeln gefundene, 12 noch in den Kiefern befestigte Zähne umfassen. Ich habe desswegen diese Angaben über das vorhandene Material gemacht, weil die Prämolaren in Gestalt und Grösse sämmtlich von einander verschieden sind, sodass sich die Beschreibung auf bestimmte Funde beziehen muss.

Alle Prämolaren besitzen, ausser einem einzigen, der zrreiwurzelig ist, nur eine Wurzel, und zwar eine ziemlich lange und runde Wurzel; dieselbe durchbohrt zuweilen die obere Knochenwand des Oberkiefers, z. B. bei $p^{2}$ Taf. II Fig. 5. Jedem Prämolar kommt ein hoher, am Ende spitzer Hauptzapfen zu, aus dessen steilen Seiten einige kleine Schmelzzipfel wachsen; den Fuss des Hauptzapfens umgibt ein vielzapfiger Schmelzkragen, welcher nur auf der lateralen Seite der Krone ganz fehlt. Die Wurzel ist an ihrem Ansatz an der Krone bedeutend schmäler als der Schmelzkragen, sodass der Hals durch starke Abschnürung von der Krone scharf getrennt ist. Die Wurzeln bleiben so lange offen, bis die Zahnkrone völlig aus dem Knochen heraus ist und abgekaut zu werden beginnt.

Der erste Prämolar $\mathrm{p}^{1}$ des linken Oberkiefers ist Taf. III Fig. $25 \mathrm{a} . \mathrm{b}$ von oben und von der Seite abgebillet. Die Schmelzkrone ist etwa zur Hälfte abgekaut und zwar schief von aussen nach innen, sodass die Krone auf der lateralen Seite $8^{\mathrm{mm}}$, auf der medialen $3^{\mathrm{mm}}$ hoch ist; sie hat eine sagittale Länge von $12 \mathrm{~mm}$, eine Breite von $10 \mathrm{~mm}$. Der Hauptzapfen trägt eine runde Kaufläche, welche sich nach hinten fast vereinigt mit der kleinen Insel eines Nebenzapfens; hinter diesem Nebenzapfen folgt ein niedriger kleiner Höcker, noch nicht angekaut, welcher auf dem Schmelzkragen sitzt; ein ähnlicher kleiner Höcker erhebt sich vorn auf dem Schmelzkragen, ohne durch einen zweiten mit den Hauptzapfen verbunden zu sein. Ein vierter Nebenhöcker endlich sitzt lateralwärts, verbindet den Schmelzkragen mit dem Hauptzapfen und ist bei der Schiefe der Kaufläche bereits mit einer concaven Insel versehen. Rings herum um den unteren Rand der Krone läuft ein Schmelzkragen, vielfach eingekerht, welcher nur auf der steil abfallenden Lateralseite des Hauptzapfens auf eine Strecke von $5^{\mathrm{mm}}$ oder $1 / 7$ seines Umfanges unterbrochen ist; an allen Stellen, wo ein Nebenhöcker fehlt, ist der Schmelzkragen durch Grübchen vom Hauptzapfen getrennt. Die Krone von $\mathrm{p}^{8}$ besässe also: einen Hauptzapfen, einen Schmelzkragen, und zwischen beirlen: zwei Nebenhöcker hinten, einen vorn und einen lateralwärts. Die Wurzel dieses Zahnes (siehe Fig.'25b) ist einfach, solid, $15^{\mathrm{mm}}$ lang, am Hals $8^{\mathrm{mm}}$ dick; ihr unteres Ende ein wenig nach innen umgebogen, da dasselbe auf der Oberseite des Oherkiefers herausschaut. Der erste Molar des Oberkiefers, in welchen 
dieser $p^{1}$ gehört, ist stark abgekaut und mit seinem vorderen Rande unter die von ihm etwas abgeschliffene Krone des $\mathrm{p}^{1}$ untergeschoben; trotzdem steht $\mathrm{p}^{1}$ in seiner Alveole ein klein wenig schief von 'hinten nach vorn gerichtet ${ }^{1}$ ) und seine Kaufläche liegt bis $\mathrm{zu} 7^{\mathrm{mm}}$ höher als diejenige von $\mathrm{m}^{1}$, sodass $\mathrm{m}^{1}$ nicht mehr abgekaut, sondern nur mit seinen Wurzeln aus dem Kiefer herausgedrängt werden kounte. In derselben Weise sehen wir an dem von Kaup, Beiträge Heft 5 Taf. V Fig. 2 abgebildeten Unterkiefer den ersten Prämolaren hoch über dem ersten Molaren hervorragen.

Betrachten wir nun andre Prämolaren, von denen es sicher ist, dass sie $\mathrm{p}^{1}$ des Oberkiefers sind, so sehen wir an dem Taf. X Fig. 96 abgebilden $\mathrm{P}^{1}$, dass er in der Anzahl und Lage der Nebenhöcker dem oben beschriehenen, welcher in dem rechten Oberkiefer derselhen Abbildung gezeichnet ist, ziemlich gleich kommt, nur dass er etwas weniger tief abgekaut ist, sodass der mediale Nebenhöcker noch nicht durch eine Insel hervortritt; ausserdem ist sein Schmelzkragen etwas stärker gekörnt und seine Krone kleiner, nämlich nur 10 mu lang und ebenso breit; seine Krone ist am lateralen Rand $8^{\mathrm{mm}}$ hoch. Der Prämolar Taf. III Fig. 23, nach welchem Kaup die später wieder eingezogene Gattung Pugmeodon schuf, ist wahrscheinlich nicht $\mathrm{V}^{\prime \prime}$ des Oberkiefers, sondern $\mathrm{p}^{\prime}$ 'des linken Unterkiefers: denn seine Kautlïhe neigt sich etwas schief ron innen nach aussen, eine Eigenschaft, welche den Unterkiefer-Zähnen zukommt.

Der frische p' steckt im Oberkiefer des jungen Schädels, welchen Krauss l. c. 1862 Taf. VH abgehildet hat; er las noch ganz in der Alveole verborgen, sodass Bronn die Zahnüfnung kiinstlich erweiterte (daselbst pag. 406). Er ist im allgemeinen ïhnlich dem frischen Prämolaren des Unterkiefers unserer Taf. IV Fig. 28: seine ,etwa $11^{\mathrm{mm}}$ hohe Krone ist von der des vorderen Zahnes $\left(\mathrm{p}^{2}\right)$ hauptsächlich durch den grossen, mit vielen Höckerchen besetzten Zahnkranz, der etwa \%/s des Umfangs einnimmt, verschieden, aber auch durch die Spitze, die nach ihrer richtigen Lage von aussen nach innen zusammengedrickt und am hintern Rand mit einem, am vorderen mit drei Höckern besetzt ist" (Krauss 1. c. pag. 406). Diese Nebenhöcker sind nicht die oben beschriebenen zwischen Hauptzapfen und Schmelzkragen, sondern sind Schmelzzipfel auf den Seiten des Hauptzapfens selbst.

Den zweiten Prämolaren $p^{2}$ kennen wir nur nach dén beiden Heidelberger Schädeln, welche Krauss abbililete; $\mathrm{p}^{2}$ des linken Oberkiefers ist nach dem älteren Heidelberger Stück auf unsrer Taf. X Fig. 96 eingezeichnet: dieser Zahn besitzt eine $24^{\mathrm{mm}}$ lange, vorwärts gekrümmte, solide Wurzel. Seine Krone ist $10^{\mathrm{mm}}$ lang und fast $9^{\mathrm{mm}}$ breit (gegen $12^{\mathrm{mm}}$ und $10 \mathrm{~mm}$ von $\mathrm{p}^{1}$ ); sie ist, wie diejenige der andern Molaren, schief nach innen zu abgekaut, aber noch nicht so weit wie $\mathrm{p}^{1}$ desselben Kiefers: daher ist neben dem Hauptzapfen lateralwärts noch die kleine Insel eines Nebenzipfels übrig. Von den Nebenhöckern auf dem vielfach gekerbten Schmelzkragen ist der an

1) Dass dem Vordrängen der Molaren nach vorn durch die Prämolaren »wenigstens auf einige Zeit Halt geboten wird«, wie das Kaup, Beiträge Heft 5 pag. 31 annimmt, ist wohl so zu verstehen, dass $\mathrm{m}^{1}$ eher aus dem Kiefer gedrängt wird, als $\mathrm{p}^{1}$, der viel später gewachsen ist uad also fester sitzt. In der That finden sich in alten Oberkiefern dic Wurzeln von $\mathrm{m}^{1}$ bereits zugewachsen, während die Alveole von $\mathrm{p}^{1}$ noch ganz offen und tief ist. 
der Hinterseite der Krone gelegene der stärkste, welcher den beiden hinteren Nebenhöckern von $p^{2}$ entspricht; dieser Nebenhöcker ist aber noch ebenso wenig wie die andern abgekaut.

Im frischen Zustande besitzt $\mathrm{p}^{2}$ einen konisch zugespitzten Hauptzapfen, welcher an der lateralen Seite seiner etwas einwärts geneigten Spitze, etwas unterhalb dieser, einen kleinen Schmelzzipfel oder spitzen Nebenhöcker trägt ; der Schmelzkragen mit seinen Kerben fehlt diesem jungen Zahn noch, und hat er also eine ähnliche Gestalt mit dem auf unserer Tafel IV Fig. 27 abgebildeten, welcher ebenfalls noch eine hohle Wurzel besitzt. Diese Zwei-Zipfeligkeit des unverletzten Hauptzapfens scheint allen Prämolaren des Halitherium eigenthümlich zu sein; da nun auch an den steilen Seiten des Haupthöckers Zipfel in verschiedener Höhe und in der Anzahl von drei bis vier hervorwachsen, so küunte man einen Prämolaren mit einer reducirten und in die Höhe ausgezogenen Hügelreilhe eines Molaren vergleichen, indem man die Nebenreihen dieser dem Schmelzkragen der Prïmolaren gleich stellt: wenigstens diurfte diese Anschauung der einzige Versuch sein, die Prämolaren mit den Molaren zu vergleichen, so auffallend bedeutende Unterschiede zeigen die Formen dieser beiden Zahngattungen beim Halitherium.

Der dritte Prämolar des Oberkiefers $p^{3}$ lässt sich mit Sicherheit nachweisen nur an dem alten Heidelberger Schädel; Krauss beschreibt ihn 1. c. 1862 pag. 405 (Abbildung daselbst Taf. VI Fig. 7 und auf unsrer Tafel X Fig. 96) folgender Maassen: „er ist kaum halb-mal so stark als der zweite, hat eine $20^{\mathrm{mm}}$ lange, etwas rickwärts gekrümmte Wurzel und eine $5^{\mathrm{mm}}$ hohe Krone von fast $6^{\text {mm }}$ Durchmesser, aussen mit dem runden Schmelzring der abgekauten Spitze, innen mit zwei kleinen Höckern, wovon der vordere auf ein ganz kleines Feldchen abgekaut ist, der hintere etwas niederer liegt und an seiner hinteren Seite noch ein kleines Höckerchen hat." Seine Krone bestelt also aus einem Hizuptzapfen und drei Nebenhöckern, welch letztere auf dem schmalen Schmelzkragen liegen. Ein frischer dritter Prämolar ist mir nicht bekannt, da es noch ungewiss ist, ob der Zahn Taf. IV Fig. 27 in den Ober- oder Unterkiefer gehört.

Bemerkenswerth ist der Umstand, dass die beiden Prämolaren, welche an dem jungen Heidelberger Schädel noch in den Alveolen liegen, schief von hinten nach vorn gelagert sind, sodass die Längsaxe der Zähne nicht vertical im Kiefer steht, sondern schräg und zwar etwa in $45^{\circ}$ gegen die Obertläche des Kiefers gerichtet ist. Ich kann mir diese abnorme Lage nur so erklären, dass an der Oberfläche des vorderen Theiles des Oberkiefers (umgekehrt als im hinteren Theil desselben) während des Wachsthums ein stärkerer Druck von vorn nach hinten stattfand als in der Tiefe des Knochens, wo die Zahnpapille sich entwickelte. Ein solcher Druck oder Zug muss auch vorhanden gewesen sein: denn durch das bedeutende Wachsthum des Zwischenkiefers und seiner Stosszähne wurde, je älter das Thier, der vordere Theil des Oberkiefers um so stärker herabgebogen; wir sehen auch diese stärkere Biegung an allen alteren Oberkiefern, die jüngeren sind weit gerader gestreckt. Durch die zunehmende stärkere Biegung aber entsteht an der Unterseite des Oberkiefer ein Schub nach hinten, an der Oberseite ein Ziehen nach vorn: durch diese Bewegung mussten die Milchzähne allmählich schief nach hinten gerichtet gestellt werden und ebenso die in den Alveolen der Milchzähne entstehenden Prämolaren schief nach hinten und unten liegen. Erst der Gegendruck der nach vorn schichenden Molaren richtete die Prämolaren gerade auf: daher die eigenthümliche Interschie- 
bung des $\mathrm{m}^{1}$ unter die Krone von $\mathrm{p}^{1}$ und die starke seitliche Abreibung aller Backenzähne gegeneinander an ihrem Vorder- und Hinterrande ${ }^{1}$ ).

Während nun alle bisher bekannten Prämolaren des Halitherium nur eine einzige Wurzel hatten, ist neuerdings in einem gut erhaltenen Schädel von $370^{\text {mm }}$ Länge im rechten Oberkiefer ein halbabgekauter erster Prämolar aufgefunden worden, welcher zwei Wurzeln besitzt\%). Seine Schmelzkrone besteht wie gewöhnlich aus einem grossen Zapfen und sechs kleinen, rings um diesen gestellten Höckern; die Krone ist sagittal $10^{\mathrm{mm}}$ lang, transversal $8^{\mathrm{mm}}$ breit und noch $5-6 \mathrm{~mm}$ hoch. Die ganze Wurzel ist $24^{\mathrm{mm}}$ lang; der Hals ist noch einfach, aber beiderseits gefurcht, erst $5 \mathrm{~mm}$ unter der Krone spaltet sich die Wurzel in zwei runde, unten spitz zulaufende, 4-5m dicke Wurzeln. Es ist dieser zweiwurzelige Prämolar von ganz besonderer Wichtigkeit desswegen, weil er berweist, dass die Sirenen einer Stammreihe mit.zweiwurzeligen Prämolaren angehören, was ja auch aus allen übrigen Eigenschaften des Halitherium zu schliessen ist. Die Reduction auf eine Wurzel ist bei den Prämolaren des Halitherium die Regel; bei den lebenden Sirenen geht die Reduction so weit, dass Prämolaren gänzlich fehlen.

Demnach sind die drei Prämolaren und der Stosszahn als dentes unicuspidati und in der Regel uniradiculati, die vier Molaren dagegen als dentes multicuspidati und triradiculati zu bezeichnen.

Die MIilchzähne des Halitherium kennen wir leider noch nicht: es wäre interessant, aus ihrer Form zu erkennen, ob auch für sie das Cuvier'sche Gesetz gilt: „c'est une règle générale que les molaires de lait participent dans tous les animaux de la forme compliquée des arrière-molaires, plus que ne le font les molaires de remplacement; et la raison en est bien simple, c'est que les molaires de lait doivent en partie remplir les fonctions des arrière-molaires, qui n'exsistent pas toutes encore" (Cuvier, Ossem. foss. Tom I pag. 288). Da an dem jungen Schädel des Halitheriun, an welchem die Prämolaren noch in den Alveolen liegen, bereits der erste Molar ausgefallen ist und die zwei folgenden schon angekaut sind, so brechen die Molaren schon hervor, ehe die Milchzähne ansgefallen sind, sodass die letzteren weniger lange \%eit die Functionen der echten Backenzilhne zu erfuillen hatten, als dies bei andern Säugethieren der Fall ist, wo die Molaren zumeist erst später herauswachsen. Aus dieser schwächeren Function könnte man vielleicht schliessen, dass die dentes decidui des Halitherium eine geringere Aehnlichkeit mit den Molaren geliabt haben.

Jedenfalls waren die Milchzähne auch einwurzelige Zähne: denn an dem erwähnten jungen Schädel der Heidelherger Sammlung ist an den Stellen, wo die beiden Prämolaren ehen hervorbrechen wollen, je eine Alveole eines ausgefallenen Milchzahns vorhanden: die Alveole des ersten Milchzahns d steht nahe vor den drei Alveolen des ausgestossenen ersten . Molaren, nur 2 mm von der vorderen lateralen Alveole desselben entfernt; die Alveole des $d^{2}$ zeigt sich auf jeder Seite des Oberkiefers 7 mm vor der ersten. Von der Alveole eines dritten Milchzahnes ist an den jungen Schädeln keine Spur zu

$\left.{ }^{1}\right)$ An dew Oberkiefer, welchen Kaup, Beiträge Heft 5 Taf. V Fig. 1 abbildete, ist die Krone von $\mathrm{m}^{\text {" }}$ unter diejenige des $p^{1}$ geschoben und beide an der Berïhrung stark abgerieben, trotzdem entfernt sich das Ende der Wurzel von $\mathrm{p}^{1}$ von dem Ende der vorderstee Wurzel von $\mathrm{m}^{1}$ um $20 \mathrm{~mm}$, sodass also beide Zähne gegeneinander im Ureieck stehen; $p^{1}$ ist dabei immer noch etwas schief nach hinten gerichtet.

2) Derselbe befindet sich im Darmstädter Museum. 
entdecken; immerhin ist es wahrscheinlich, dass auch $\mathrm{p}^{3}$ der Nachfolger eines $\mathrm{d}^{3}$ war. Dagegen erscheint an demselben jungen Schädel der Heidelberger Sammlung in jeden Oberkiefer 10 ma vor dem zweiten Prämolaren eine Alveole, welche sich schief nach rückwärts in den Kiefer einbohrt; es kann diese Alveole keinesfalls diejenige von $d^{3}$ sein, weil sie zu weit nach vorn liegt: denn $p^{3}$ wäre nach dem alten Schädel zu urtheilen von $p^{2}$ nur etwa $3-4$ mm entfernt gervesen. Diese vorderste Alveole kann einem frülı ausfallenden, später nicht ersetzten vierten Milchzahn oder vierten Prämolaren angehört haben, wie dies bei Equus und Hippopotamus vorkommt; oder, was wegen der schief nach rom gerichteten Stellung des Zahnes wahrscheinlicher ist, einem früh ausfillenden lleinen Lückenzahn (Eckzahn der Tapire und Equiden) angehört haben, wie ein solcher den meisten Ungulaten eigenthïmlich ist. Unter der letzteren Annahme würde die Formel für die Zähne des Oberkiefers vom Halitherium lauten:

1 inc. (? 1 can.) 3 präm. und 3 dec. 4 mol.

im Ganzen demnach 12 Zähne in jedem Kiefer, von denen aber höchstens 8, meistens nur 7 oder weniger auf einmal im Gebrauch waren.

Die Zahnreihe des Oberkiefers hat folgende Längen: beim ausgewachsenen Thiere nehmen die dicht an einander geschobenen vier Molaren eine Länge von $76^{\mathrm{mm}}$ ein, was etwa $14^{\mathrm{mm}}$ weniger ist als die Längen der einzehen frischen Molaren zusammengerechnet, weil die starke Vorschiehung der Zähme eine ansehnliche seitliche Abreibung der Kíronenränder zur Folge hat. Am jungen Schädel, in dessen Oberkiefer der letzte Molar noch in der Alveole steckt, beträgt dieselbe Länge $60 \mathrm{~mm}$. Doch sind natülich diese Längen etwas verschieden bei verschiedenen Exemplaren; auch verschieden, je nachdem man misst, da die Molaren auf ihrer lateralen Seite breiter als auf der medialen sind und in einer mehr oder weniger stark nach aussen gebogenen Reihe stehen: ich habe stets die mittlere sagittale Axe der Zähne gemessen. Die beiden ersten Prämolaren $p^{1}$ und $p^{2}$ stehen immer so dicht aneinander, dass sie sich gegenseitig abreiben, während $p^{3}$ wie gesagt nach dem einen bekannten Falle isolirt steht: die ganze Länge der Zahnreihe von $\mathrm{m}^{4}$ bis $\mathrm{p}^{3}$ beträgt nach Taf. $\mathrm{X}$ Fig. 96 gegen 106 m. An Breite wie an Länge nehmen die Backenzähne von vorn nach hinten gleichmåssig zu.

\section{d. Dentes molares mandibulae.}

Taf. IV und Taf. VIII Fig. 87.

An unserm auf Taf. IV abgebildeten, gut erhaltenen Unterkiefer sehen wir die vier grossen, zweiwurzeligen Molaren, die vorderen in verschiedenen Stadien der Abkaung, den letzten noch in der Alveole versteckt mit offener Wurzel. Wie am Oberkiefer werden auch hier die Kronen der vorderen Molaren früh abgenutzt, und wir thun daher gut, unsre Betrachtung wieder mit dem letzten Molaren zu beginnen.

Der letzte Molar $\mathrm{m}^{4}$ des Únterkiefers ist Taf. IV Fig. $32 \mathrm{a}$. b. als Alveolarzahn mit fertiger Krone, aber begonnener Wurzel dargestellt. Seine Krone hat eine sagittale Länge von 35 mm, eine grösste Breite (vorn) von $20 \mathrm{~mm}$, grösste Höhe (ebenfalls in den vorderen Zapfen) von $19 \mathrm{~mm}$; 
ihre dunkelgraubraune, mit feinen Längsrunzeln bedeckte, glänzende Schmelzlage schneidet an dem etwas eingeschnürten Halse nicht in gerader, sondern in auf- und absteigender Linie ab, so zwar, dass die hellbraune Wurzel unter den vorderen Zacken um $2-5^{\mathrm{mm}}$ frïher beginnt als am hinteren Zahntheile. Die Krone hesteht aus drei hintereinander liegenden Zapfenreihen, von denen die vorderste die höchste, dif hinterste die niedrigste ist. Die heiden vorderen Reihen zeigen je zwei kegelförmige Hauptzapfen, welche durch ein etwas niedrigeres, vielgekerbtes Joch verbunden werden, ${ }^{1}$ ) während die hinterste Reihe aus drei dicken Zapfen gebildet wird.

Interessant für die Entwickelung des $\mathrm{m}^{4}$ ist ein mir vorliegender, ganz junger Keim dieses Zahnes, an welchem noch die Schmelzlage fehlt; hier besteht der Zahn einfach aus fünf Zapfen, von denen vorn zwei und in der Mitte zwei noch eng mit einander verbunden sind, während der isolirte letzte Zapfen erst eine Kerbung zeigt, in welcher die Dreitheilung dieses Zapfens später vor sich gehen würde: wir haben demnach den vielhöckerigen letzten Molaren auf eine fünfzaptige und noch weiter auf eine dreizapfige Krone zurückzuführen; daher enthält dieser lieim fünf Kanäle in len Kapfen und fünf Vertiefungen in der innen noch zum Theil hohlen Krone. Die beiden Thäler zwischen den drei Hügelreihen schneiden tief quer durch die Krone, viel tiefer als die geringeren Einschnitte zwischen den einzehnen Höckern jeiler Reihe. Die vorderste Reihe des Zahnes Fig. 32a. b hat eine transversale ${ }^{2}$ ) Länge von $20^{\mathrm{mm}}$, eine sagittale Breite von $12^{\text {max }}$. Ein kegelförmiger, etwas von vorn nach hinten comprimirter Hauptzapfen stelt am Vorderrand der Krone und trägt zwei, durch Kerbung entstandene kleine Spitzen; ein zweiter, etwas niedrigerer dicker Zapfen steht am lateralen Rande der Krone, etwas schief nach hinten rom ersten geriickt und mit seiner Doppelspitze um $8^{\mathrm{mm}}$ vom ersten Zapfen entfernt. Beide Zapfen sind verbunden durch ein Schmelzjoch, welches durch Kerbung in 6 schmale Falten, jede mit einer kleinen Spitze versehen, von vorn nach hinten zerschnitten ist; dieses Zwischenjoch hat eine Länge von $5 \mathrm{~mm}$. Da diese Höckerreihe schief von vorn aussen nach hinten innen gerichtet ist, und dieselbe steil nach aussen, flacher nach innen abfaillt, so entsteht auf ihrer Innenseite eine breite, runzelige Fläche, welche zu dem medialen Theile des ersten Thales abfällt; gegen den medialen Rand der Krone wird diese Fläche hegrenzt von einem nierlrigen, sagittal in die Iänge grezogenen, gekerbten Nebenhöcker, der sich an den Fuss rles vorderen Haupthöckers anschliesst.

Die zweite oder mittlere Hauptreihe der Krone von $\mathrm{m}^{4}$ steht genau transversal gerichtet und macht daher noch mehr als die erste Reihe den Eindruck eines gekerbten Querjoches. Ein kegelförmiger, seitlich etwas comprimirter Hauptzalfen steht auf der merlialen, ein ebensolcher auf der lateralen Seite der Krone; beide sind verbunden durch eine niedrigere Jochbriicke, deren trans-

1) An diesen beiden Hauptreihen des letzten Molaren, und am deutlichsten an der mittleren Reihe tritt eine Querjochung der Zapfenreihen des Halitherium scharf hervor, schärfer als bei allen andern Zähnen; ebenso wie es wahrscheinlich ist, dass die sämmtlichen Zahnformen der Ungulaten, auch die Höckerzähne der Suiden, sich aus einfachen Querjochen (in der Weise der Jochzähne von Lophiodon und Tapir) der voreocãnen Stammeltern entwickelt haben, so diirfte auch dieser an $\mathrm{m}^{4}$ des Unterkiefers und der andern Molaren hervortretende Jochtypus auf eine Abstammung des Halitherium von zygodonten Vorfahren weisen (siehe unten im vergleichenden Theil).

2) Diese Richtungen beziehen sich stets auf die Stellung des Organes am Körper des Thieres. 
versal gerichtete Schneide in 5 -6 schmale, sagittale kleine Falten oder Runzeln gekerbt ist; an $\mathrm{m}^{4}$ der rechten Kieferseite (Fig. 32) wächst die medialste dieser Kerbfalten zu einem kleinen Zapfen aus. Die letzte Hügelreihe bildet den Abschluss der Krone nach hinten und enthält drei einfache kegelförmige, dicke Zapfen, deren Spitzen nicht in einer geraden, sondern in einer nach hinten gebogenen Linie liegen; der grösseste und dickste von ihnen ist der mediale Zapfen, an dessen Vorderseite (im rechten Kiefer Fig. 32) ein kleiner Nebenzipfel durch Kerbung entstehen kann. Die hintere Seite dieser drei Zapfen fällt steil ab, die vordere in die mitten vertiefte Furche etwas flacher mit runzeliger Oberfläche.

Der Unterkiefer Fig. 32 ist von einem besonders kräftigen Thier: dies zeigt sich auch darin, dass der letzte Molar desselben drei bis vier Zapfen der hintersten Reihe aufweist, wåhrend dieser Zahn in andern Unterkiefern und auch auf den Abbildungen von Kaup, Beiträge Taf. I Fig. 17a und 20a meistens nur zwei Zapfen der letzten Reihe besitzt. Es zeigt sich auch hierbei, dass die Formen der Organe, verfolgt man sie bis ins Einzelne, bei verschiedenen Individuen derselben Art, ja bei ein und demselben Individum (bei symmetrischen Organen) niemals constant sind; sonst gaibe es keine Art-Varietäten, keine Fortentwicklung und keine Uebergänge von einer verwandten Art zur andern; gerade bei zeitlich sich rasch verändernden Thierreihen, zu denen auch die Sirenen gehören, finden sich in dieser Beziehung die meisten Formverschiedenheiten.

Vergleicht man diese unverletzte Krone des $\mathrm{m}^{4}$ des Unterkiefers (Md $\mathrm{m}^{4}$ ) mit derjenigen des $\mathrm{m}^{4}$ im Oberkiefer ( $\mathrm{Ix} \mathrm{m}^{4}$, Taf. III Fig. 18a. b), so erweisen dieselben durchaus verschiedene Formen: Md $\mathrm{m}^{4}$ ist bedeutend schlanker gebaut, $\mathrm{d} . \mathrm{h}$. seine Zapfen sind verhältnissmässig höher, als

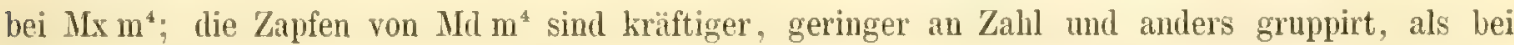
$M \times \mathrm{m}^{4}$; die mediale Seitenwand ist weniger geschlossen, als bei Mx $\mathrm{m}^{4}$. Wollte man die Zapfenreihen beider Zähne auf einander beziehen, so würde die Vorderreihe von $M d \mathrm{~m}^{4}$ der ganzen vorderen Hälfte der Krone von $\mathrm{Mx} \mathrm{m}^{4}$, die zweite Reihe jenes der hinteren Hauptreihe dieses, und also die

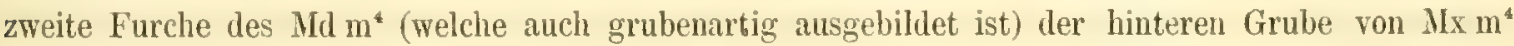
entsprechen; dann würde dem $\mathbf{M d} \mathrm{m}^{4}$ die vordere Nebenreihe (eine Art Schmelzkragen) des $\mathbf{M x ~ m}{ }^{4}$ fehlen. eine Pirrallele, deren Richtigkeit dadurch bestïtigt wird, dass an dem vorletzten Molaren des Unterkiefers $\left(\mathrm{Nd} \mathrm{m}^{3}\right.$ ) sich ein solcher vorderer Schmelzkragen, wie er dem Md $\mathrm{m}^{4}$ stets fehit, immer einstellt, wenn auch in reducirterer Gestalt als bei den Molaren des Oberkiefers. Da wir nun andrerseits sehen, dass die hinterste (dritte) Zapfenreihe bei MId $\mathrm{m}^{4}$ und die hinteren Nebenzapfen bei Mx $\mathrm{m}^{4}$ und bei den andern Molaren sich eng an die zweite Hauptreihe anschliessen, so hätten wir die vielhöckerigen Molaren des Halitherium abzuleiten von einer Stammform, deren Molaren zwei einfache Querjoche besassen ').

An der noch offenen Wurzel des Taf. IV Fig. 32 a abgebildeten letzten Molaren des Unterkiefers läšst sich die Art des Wachsthums der Zahnwurzeln gut beobachten: der scharfe Rand der

1) Analog der Entwicklung der Ungulaten-Holaren; auch darin ähnlich, dass die ursprünglichen beiden Querjoche sowohl bei den Ungulaten als hier beim Halitherium lïnger im Unterkiefer, als im Oberkiefer ihre Form bewahrten. 
offenen Wurzel schniirt sich zuerst unter dem vorderen Querthal der Kirone quer ab durch rasch zunehmende Faltung. sodass ein tiefer schmaler Raum in der ersten Zapfenreihe und ein grösserer langer unter der zweiten und dritten Zapfenreihe entstehen ${ }^{1}$ ). Sodann legt sich der scharfe Wurzelrand in mehrere schmale Falten, welche transversal gerichtet sich dicht aneinander legen und eine Tiefe von $6-10^{\mathrm{mm}}$ erreichen. Da bei ausgewachsenen Zälınen diese Nebenfalten der Wurzelwand nicht mehr vorhanden sind, müssen sie später ganz ausgefültt werden; immerhin ist diese Querfaltung der Zahnwurzel in einem frühen Stadium des Wachsthums von Wichtigkeit: denn wir sehen durch dieselbe Querfaltung bei den Suiden (Phacochoerus) und den Proboscidiern allmählich aus den dentes simplices die dentes complicati und schliesslich die dentes compositi hervorgehen.

Die geschlossene Wurzel des $\mathrm{m}^{4}$ des Unterkiefers ist sehr kräftig: unter der ersten Hügelreihe der Krone steht eine $32 \mathrm{~mm}$ lange, $8-17^{\mathrm{mm}}$ breite und $5-8^{\mathrm{mm}}$ dicke Wurzel, deren Ebene transversal gestellt ist; ihre hintere Fläche ist der Länge nach flach ausgehöhlt. Den ganzen übrigen Theil der Krone trïgt eine dicke, dreiechige Wurzel, deren schmale Seite sich nach hinten wendet: sie ist $29^{\mathrm{mm}}$ lang und unten stumpf abgeschnitten. Die an den äusseren Flächen beider Wurzeln auftretenden Furchen gelangen nicht, wenigstens bei den mir vorliegenden Exemplaren, zur Ahschnürung einer dritten oder vierten Wurzel.

Der letzte Molar des Unterkiefers wird, wie alle Zähne desselben, schief von innen oben nach aussen unten abgekaut und zugleich flach concav ausgerundet, sodass lie medialen Zacken über der blumenblattartigen Kaufäche hedeutend vormgen. Auf Taf. IV Fig. 35 ist ein halbahgekiuter $\mathrm{m}^{4}$ abgebildet: man sieht, dass dieser Molar in der hintersten Höckerreihe die Insel eines dicken lateralen Zapfens und danehen einen einzigen medialen Zapfen, nicht zwei mediale wie Fig. $32 \mathrm{~b}$ besitzt.

Der vorletzte Molar des Unterkiefers Md ms ist an dem Unterkiefer Taf. IV Fig. 30-32 noch nicht viel abgekaut. Zwar habe ich Fig. 34 einen Backenzahn abgebildet, den ich in der Erläuterung der Tafel für den $\mathrm{m}^{3}$ erklärt habe; derselbe ist aber wegen seiner Kleinheit wohl der zweite, und der abgekaute kleine Zahn Fig. 33 der erste Molar. Der Molar des Unterkiefers Fig. 32 hat eine $23^{\mathrm{nm}}$ lange und $19^{\mathrm{mm}}$ transversal breite Krone bei einer grössten Höhe von $16^{\mathrm{mm}}$ gegen $33: 20: 19^{\mathrm{mm}}$ des $\mathrm{Md} \mathrm{m} \mathrm{m}^{4}$. Zwei Haupthöckerreihen stehen transversal und einander parallel, etwas schief nach hinten und aussen gerichtet; auch hier scheinen zwei starke Höcker durch ein gekerbtes Querjoch verbunden gewesen zu sein. Die beiden medialen Zapfen fallen medialwärts sehr steil, fast senkrecht $a b$, während die lateralen flacher nach aussen abdachen. Das Querthal zwischen beiden Zapfenreihen ist beiderseits tief und breit mit einigen Runzeln versehen, in der Mitte weniger tief eingeschnitten: daher vereinigen sich die Inseln der beiden Reihen bereits bei halber Abkaung der Krone (Taf. IV Fig. 36) ${ }^{2}$ ).

An der hinteren Seite der Krone steht nicht wie bei $\mathrm{m}^{4}$ eine dritte Höckerreihe, sondern ein Talon hervor, ein schief nach hinten abstehender dicker Fortsatz, ähnlich demjenigen, welchen

1) Auch dieser Umstand beweist die engere Verbindung der zweiten mit der dritten Zapfenreihe des $M d \mathrm{~m}^{4}$, im Gegensatz zur ersten Zapfenreihe.

${ }^{2}$ ) Laut der Etiquette von Kaup's Hand wurde das Genus Halitherium naich diesem Zahn Fig. 36 von Kaup aufgestellt. 
im Kleinen alle Unterkiefer-Molaren des Manatus besitzen. Dieser starke Talon ist meist in zwei oder drei niedrige Höcker gekerbt; er ist bedeutend niedriger als die beiden Zapfenreihen und ist von der zweiten getrennt durch eine Furche, die sich merlialwärts grubenartig vertieft und verbreitert. Die vordere Seite der Krone zeigt am Rande des lateralen Hauptzapfens eine Kerbe als Rest der Furche, welche eine vordere kleine Nebenreihe abschnürt, wie solche den vorderen Molaren des Unterkiefers und in grösserem Masstabe den Molaren des Oberkiefers zukommt.

Der zweite Molar des Unterkiefers liegt uns in einem kaum angekauten Exemplar Taf. IV Fig. 34 vor; trotzdem bereits die Abnitzung beginnt, ist die Wurzel dieses Zahnes noch so weit offen, dass auch die Krone noch halb ausgehöhlt ist. Die Krone hat eine sagittale Länge von $19 \mathrm{~mm}$, eine Breite von $15 \mathrm{~mm}$, eine grösste Hőhe von 13 mm (gegen 33:20:19 des $\mathrm{m}^{4}$ und 23:19:16 (les $\mathrm{m}^{3}$ ); die Aehnlichkeit der Krone dieses frischen Zahnes mit den Molaren des Manatus tritt besonders deutlich zu Tage: zwei Haupt-Querreihen, Joch-ähnlich, werden von einander durch ein tiefes Querthal getrennt; nach hinten steht ein kräftiger, gekerbter 'Talon ab; am lateralen Rande der Vorderseite der Krone schneidet eine kleine Furche eine Schmelzfalte ab, deren transversal gerichtete Schneide viermal eingekerbt ist. Die vordere Hauptreihe hesteht aus zwei liegelförmigen Zapfen, welche eng verbunden sind durch eine breite Schmelzhriicke; der Kamm dieser Querreihe ist 9 nm lang und genau transversal gerichtet. Die erste Reihe ist mit der zweiten durch eine ziemlich hohe Brücke verbunten, welche das Thal in der Mitte durchsetzt; von der scharfen Höhe dieser sagittalen Brïcke zieht sich das Thal jederseits tief und runzelig steil abwärts. Die zweite Hauptreihe zeigt gleichfalls zwei Ǩegelzapfen, deren Spitzen wenig höher sind als das beide verbindende Joch: daher nimmt diese Reihe besonders deutlich die Gestalt eines typischen Querjoches an, was wir auch bei Md $\mathrm{m}^{4}$ zu bemerken hatten; die Länge ihres Kammes beträgt $8^{\mathrm{mm}}$. Der Talon wird durch eine tiefe, runzelige Furche von der zweiten Querreihe abgeschnitten; durch Einkerbung erhïlt er einen breiten medialen, und einen schmåleren lateralen niedrigen Höcker. Die beiden lateralen Hauptzapfen dieses Zahnes sind bereits ein wenig abgekaut; durch weitere Abnutzung erhält der zweite Molar, wie die übrigen Backenzähne, eine blumenhlattartige Katuläche, und zwar fliessen zuerst die Inseln der beiden Hauptreihen ineinander, erst später vereinigt sich die Insel des Talon mit ihnen. Durch den engen Staul der Molaren reiben sich diese Zähne geveneinander so stark ab, dass schliesslich hinten die Schmelzlage des Talon und vorn die kleine Schmelzfalte gänzlich verschleissen.

Die Wurzel des zweiten Molaren ist zweitheilig; jede der beiden Wurzeln ist von vorn nach hinten comprimirt und auf der zugewandten Seite breit-längsgefurcht. Die Wurzeln werden $28 \mathrm{~mm}$ lang, $14^{\mathrm{mm}}$ breit und $9^{\mathrm{mm}}$ dick; ihre Enden sind in transversaler Richtung $4-5^{\mathrm{mm}}$ lang und oft nach innen ein wenig umgebogen. Jede Wurzel besitzt einen Zahnkanal, welcher am Halse der Wurzel eine transversale Länge von $2,5 \mathrm{~mm}$ und eine Breite von $0,8 \mathrm{~mm}$ aufweist; dieser Kanal war an einer abgebrochenen Wurzel noch offen. Wie bei allen Molaren geht die Theilung der Wurzeln bis nahe unter die Krone.

In dem Unterkiefer Taf. IV steht an jeder Seite ein kräftiger zweiter Molar: die Krronen sind hier soweit abgekaut, dass der hintere Talon fast ganz mit der Kaufäche der zweiten Höckerreihe verbunden ist. Die Schmelzlage ist, je grösser der Zahn, um so dicker: der dritte Molar hat 
daher einen Schmelz von etwa $2^{\text {mm }}$, der zweite nur von $1^{\mathrm{mm}}$ Dicke; in den Thaltiefen wird der Schmelz etwas dicker; niemals dringt er zwischen rlas Dentin ein. ${ }^{1}$ )

Den ersten Molar des Unterkiefers Md $\mathrm{m}^{2}$ sieht man Taf. IV Fig. 31 und 32 in stark abgenutztem Zustand und Fig. 33 etwas weniger abgekaut. Der letztere Zahn hat eine sagittale Länge von $15 \mathrm{~mm}$, welche ohne die Abreibung am vorderen und hinteren Rande sich auf $16^{\mathrm{mm}}$ erhöhen würde; eine Breite bis zu $13^{\mathrm{mm}}$; die Krone hat im vorderen medialen Zapfen noch eine Höhe von $7^{\mathrm{mm}}$ und dürfte $10^{\mathrm{mm}}$ Höhe gehabt haben. Demnach verhalten sich die vier Molaren in der

$\begin{array}{lllll}\text { Länge: } & \mathrm{m}^{1}=16^{\mathrm{mm}} & \mathrm{m}^{2}=19^{\mathrm{mm}} & \mathrm{m}^{3}=23^{\mathrm{mm}} & \mathrm{m}^{4}=33^{\mathrm{mm}} \\ \text { Breite: } & \mathrm{m}^{1}=13^{\mathrm{mm}} & \mathrm{m}^{2}=15^{\mathrm{mm}} & \mathrm{m}^{3}=19^{\mathrm{mm}} & \mathrm{m}^{4}=20^{\mathrm{mm}} \\ \text { Höhe der Krone: } & \mathrm{m}^{1}=10^{\mathrm{mm}} & \mathrm{m}^{2}=13^{\mathrm{mm}} & \mathrm{m}^{3}=16^{\mathrm{mm}} & \mathrm{m}^{4}=19^{\mathrm{mm}}\end{array}$

gemessen an den frischen Lronen; die ganze Reihe der Molaren rrreicht demnach eine sagittale Länge von $91 \mathrm{~mm}$, eine Länge, welche derjenigen der vier Molaren im Oberkiefer (die Länge der frischen Kronen zusammengerechnet) genau gleich kommt.

Id $\mathrm{m}^{2}$ Fig. 33 besitzt zwei transversale Hauptreihen, deren Inseln sich in der Mitte fast berühren, weil das Querthal zwischen ilnen in der Zahmmitte von einer Schmelzbrücke durchsetzt wird, wie dies auch bei den andern Molaren mit Ausnahme des letzten der Fall ist. Der nach hinten schräg abstehende Talon ist schwicher als bei $\mathrm{m}^{2}$ und wird mitten in zwei niedrige Höcker gekerbt. An der Vorderseite der Kirone ist die starke Abreibung des Schmelzes (durch den ersten Prämolaren) hemerkenswerth, welche auch die kleine vordere Schmelzfalte zum Theil eroriffen hat. Die Schmelzlage dieses Zahnes erreicht kaum eine Dicke von 1 mm.

Die zweitheilige Wurzel des ersten Molaren wird $25^{\mathrm{mm}}$ lang, $12^{\mathrm{mm}}$ breit und $5^{\mathrm{mm}}$ dick. Doch beginnt dieselbe, noch ehe $\mathrm{m}^{4}$ aus der Alveole herrorgebrochen ist, bereits resorbirt zu werden, wie an $\mathrm{m}^{1}$ der Fig. $31 \mathrm{zu}$ sehen ist; aus der andern Kieferhälfte desselben Unterkiefers Fig. 30 und 32 ist $\mathrm{m}^{2}$ schon gänzlich abgervorfen und die Alveolen beginnen $z u$ verwachsen. Das starke Vorschieben der Molaren, wie wir solches in Oberkiefer beobachteten, ist im Unterkiefer kaum zu bemerken: nur der letzte Molar steht, wenn er ausgewachsen ist, mit seinen Wurzeln etwas schief nach hinten. Der Unterkiefer des Halitherium hat auch lange nicht eine so bedeutende Umwandlung durchgenacht, wie der Oberkiefer, welcher durch den stark vergrösserten Zwischenkiefer umgestaltet wurde; im Zusammenhang damit mögen auch dic Molaren des Unterkiefers melı als diejenigen des Oberkiefers die Jochform'der Stammverwandten bewahrt haben.

\section{o. Dontes praemolares mandibulae.}

Von den Prämolaren des Unterkicfers wurden fest im Knochen sitzend meistens nur Wurzeln, selten vollständige Zähne gefunden; nur das von Kaul, Beitrïge Heft 2 Tif. I Fig. 18 abgebildete Unterkieferfragment aus der Klipstein'schen Sammlung zeigt zwei Prämolaren in den Alveolen. Ausgefallene Prämolaren liegen mir mehrere vor, welche zwar den Prämolaren des Oherkiefers sehr ähnlich

$\left.{ }^{1}\right)$ Was z. B. bei den Suiden, bei Rhinoceros und Hippotamus der Fall ist. 
sehen, aber im angekauten Zustande dadurch leicht von diesen zu unterscheiden sind, dass sie wie alle Backenzähne des Unterkiefers schief von imnen nach aussen abgekaut worden, umgekehrt wie die Zähne des Oberkiefers; die Stellung des Prämolar im Kiefer ist damit fixirt, dass der Hauptkegel auf der lateralen Zahnseite nicht von Nebenhöckern ungeben wird.

Was die Anżahl der Prämolaren des Unterkiefers anbetrifft, so haben wir oben (pag. 78) bemerlit, dass der Unterkiefer Taf. IV jederseits vor dem ersten Molaren zwei tiefe und frische, vertical stehende Alveolen, dann weiter vor eine kleine verwachsene Alveole und endlich am Beginn der rauhen Kinnfläche zwei grosse, ganz frische, etwas schief nach vorn gerichtete Alveolen aufweist. Die drei hinteren Alveoleı sind sicher von drei, den Prämolaren des Oberkiefers entsprechenden einwurzeligen Prämolaren eingenommen worden; die beiden Alveolen, jede mit einem Durchmesser von 5 mm, vorn an dem oberen Ende der Kinnfläche möchte ich am ehesten einem vierten Prämolaren und einem Eckzahm ${ }^{1}$ ) zuweisen: denn die sehr früh ausfallenden Schneidezähme der Kïmfläche lassen keine so grossen, frischen und bis $17^{\mathrm{mm}}$ tiefen Alveolen zurïck.

Als erster Prämolar ist wohl sicher der von Krauss l. c. 1862 Taf. VI 10 a-c abgebildete Zahm iler Heidelberger Sammlung anzusehen; Krauss beschreibt ihn daselbst pag. 410 : „er ist etwas grösser als der dritte $\left(=p^{t}\right)$ des Oberkiefers, hat eine $21^{\mathrm{mm}}$ lange, solide Wurzel und eine $8^{\mathrm{mm}}$ hohe, $11^{\mathrm{mm}}$ lange und $9^{\mathrm{mm}}$ breite Krone von ähnlicher Gestalt und Abnutzung wie dieser; seine aussen glatte Hauptspitze zeigt ein lïngliches, schief von immen nach aussen abgekautes Feld, mit welchem innen und in gleicher Höhe ein ganz kleines verwachsen ist, an dessen hinterer Seite und ebenfalls in gleicher Höhe ein ganz kleines verwachsen ist, zu dessen hinterer Seite und ebenfalls in gleicher Höhe sich zwei Höcker mit etwas grösserem Feldchen hinter einander anschliessen; vor der Hauptspitze, aber nicht ganz so hoch, liegt ein dicker etwas abstehender Höcker, der noch nicht angekaut ist; der innere Zahnkranz besteht aus einem grossen und einem kleinen Höcker." Dieser Zahn hesitzt demnach einen kegelförmigen, an der Spitze wohl chemals zweizipfeligen Hauptzapfen und um den Fuss dieses Kegels herum, mit Unterbrechung von $5^{\mathrm{mm}}$ an der lateralen Seite, einen Kranz von fünf niedrigen Höckern; dieser Kranz unterscheidet sich von dem Schmelzkragen der Prämolaren des Oberkiefers durch eine weniger geschlossene Gestalt: er gleicht mehr einem Kranz aneinander gereihter kleiner Perlen. Daher möchte ich die beiden frischen Prämolaren unserer Tafel IV Fig. 28 und 29 nicht wie Kaup es that, für Prämolaren des Unterkiefers, sondern für solche des Oberkiefers halten ${ }^{2}$. Dil noch lieine unbenutzten Primolaren im Unterkiefer festsitzend gefunden wurden, fehlt uns die Kenntniss der Form ihrer Spitze.

Zwei halb abgekaute erste Prämolaren des Unterkiefers liegen mir vor, welche sich durch andre Vertheilung der Nebenhöcker ron dem Heidelberger Md $P^{2}$ unterscheiden: die Lrrone des einen

1) van Beneden, Bull. de l'acad. roy. des sciences de Belgique. 1871. pag. 176 sỉeht den obersten von den vier rudimentären Zähnen in der Kinnfäche der Halicore gleichfalls als einen caninen an.

${ }^{2}$ ) In der Erklärung unserer 'Tafel IV bin ich noch Kaup's Dentung (nach den mit seiner Hand geschriebenen Zetteln) gefolgt; wie gesagt, ist bei der grossen Veränderlichkeit in der Form der Prämolaren des Halitherium nicht mit Sicherheit festzustellen, ob diese Zähne Fig. 28. 29 in den Oberkiefer wirklich genören, so lange als nicht unverletzte Prämolaren fest sitzend im Unterkiefer aufgefunden werden. Dieselben Zähne batte Kaup bereits abgebildet in seinen Beiträgen Heft 5 Taf. V Fig. 3. 4. 
linken derselben hat eine sagittale Länge von $10,5 \mathrm{~mm}$, eine Breite von $9^{\text {mm }}$ und eine Höhe von $5-6$ mo. Der Hauptzapfen ist von ziemlich rundem Querschnitt, schief von innen nach aussen abgekaut: hinter ihm an dem vom ersten Molaren stark abgeriebenen Rande liegen zwei kleine, kaum benutzte Nebenhöcker; medialwärts zwei etwas grössere Nebenhöcker, von denen der eine eben angekaut ist; am vorderen Zithnrand liegen drei Höcker dicht neben einander, welche gleichfalls kleine Inseln zeigen. Der Hauptzapfen ist also hier umgeben von einem Kiranze ron sicben Nebenhöchern, von denen die beiden medialen die dicksten sind; der laterale Rand des Hauptzapfens ist glatt und frei von Nebenhöckern. Die Wurzel dieses Zahnes ist $20^{\mathrm{mm}}$ lang und zeigt nahe dem spitzen Ende die Mündung des Zahnkanals.

Der andere erste Prämolar befindet sich in demselben Stadium der Abnützung und zeigt dieselbe Erhaltung, wurde auch zugleich mit dem eben beschriebenen gefunden, sodass er wohl demselben Unterkiefer, aber der rechten Kíeferseite angehörte; sein hinterer Rand ist ebenso durch den ersten Molaren abgerieben, wie bei jenem. Seine Irrone ist $10^{\mathrm{mm}}$ lang, $8^{\mathrm{mm}}$ breit und $6^{\mathrm{mm}}$ hoch. Der schief nach immen algekaute Hauptząfen ist lateralwirts glatt und frei von Höckern; medial zeigt sich linten ein Nebenhöcker und getrennt von diesem durch eine $2^{\mathrm{mm}}$ breite glatte Fläche eine Gruppe von vier Nebenhöckern, welche eine kleine Gruhe umschliessen; ein ganz kleiner fünfter Höcker sitzt aussen an dem grössesten jener vier. Von diesen sechs Nebenhöckern tragen erst zwei kleine Inseln, welche an einem Punkt bereits in die Kaufläche des Hauptzapfens fliessen.

Der von Kaup, Beiträge Heft 2 Taf. I Fig. 18a abgebildete Zahn, welcher in dem nebengezeichneten L'nterkiefer-Fragment steckt, ist meinem erst heschriebenen sehr ähnlich: der Hauptzapfen wird umkränzt ron sieben Nebenhöekern, von denen sich drei vorn. zwei dickere medialwärts und zwei kleine hinten gruppiren. Die ganze halb abgekaute Krone ist nach der Leichnung von Kaup $10^{\mathrm{mm}}$ lang, ebenso breit und hoch $\left.{ }^{1}\right)$.

Als $z$ weiten Prämolaren können wir nur den Zahn mit Sicherheit erkennen, welcher neben dem ersten in dem oben erwähnten Lnterkiefer-Fragment der Kipstein'schen Sammlung steckt und von Kaup abgebildet ist. Zwar erklärt Kaup in seinen Beiträgen Heft 2 pag. 13 sowohl diesen Zahn als den danebenstehenden ersten Prämolaren für Milchbackenzälme; indessen gilht er keinen Berreis für seine Ansicht. Vielmehr haben wir oben gesehen, dass dieser $p^{1}$ in Form und Grösse genau mit den andern $p^{1}$ übereinstimmt. Von dem vorderen kleinen Zahn sagt Kaup: „er ist an der Aussenseite ron dem oberen $\left(\lambda \mathrm{xp}^{2}\right)$ bis zu seinem Ernïhrungskanal durchgeschliffen und zeigt nur an der hinteren Wand zwei spitze warzenähnliche Ansätze. Er ist schief von vorn nach hinten gerichtet." Später sagt Kaup, dass die Wurzel dieses Zahnes vollständig hohl sei, was sie freilich nach der Zeichnung wenigstens im oberen, sichtbaren Theil nicht ist, wo im Gegentheil der durchgeschnittene Nahrungskanal der soliden Furzel erscheint. Leider kann nichts weiteres iiber diesen Zahn aus der Abbildung entnommen werden.

1) Kaup bildet noch einen ersten Prämolaren im Unterkiefer sitzend ab in den Beiträgen Heft 5 'Taf. V Fig. 2; im Text pag. 31 sagt er leider fast gar nichts darüber. Das Stück ist in unserm Museum nicht vorhanden. Der Prämolar erscheint nach der Abbildung von aussen nach innen schief abgekaut, was auf einen Prämolaren des Oberkiefers deuten würde. 
Ob der etwas abgeriebene Prämolar auf unserer Taf. IV Fig. 27 in den Unter- oder Oberkiefer gehört, ist noch nicht festzustellen, wie oben bemerkt: er sieht dem frischen Mx $\mathrm{p}^{2}$ des jungen Schädels der Heidelberger Sammlung ähnlich. Auf jeder der drei Seiten besitzt er zwei kleine Warzen übereinander: medial sitzt dieses Par nahe unter der ein wenig angekauten Spitze des Zahnes; etwas tiefer rückt das vordere Paar; noch tiefer und am Rand der Schmelzkrone befindet sich das Paar der Hinterseite; die laterale Kronenseite ist wie stets an den Prämolaren glatt. Die Wurzel ist rund, solide und unten abgebrochen; in ihrer Mitte erscheint ein kleiner runder Nahrungskanal. Kaup (Beiträge Heft 2 pag. 14 Taf. I Fig. 14) hielt diesen Zaln für $p^{2}$ des Unterkiefers.

Vom dritten Pråmolaren des Unterkiefers kemnen wir nichts als die Alveole. Ebensowenig wie beim Oberkiefer können wir von Milchbackenzähnen des Unterkiefers berichten; für diese Zälne sind nicht einmal Alveolen mit Sicherheit nachzuweisen; doch waren sie jedenfalls gerade wie im Oberkiefer vorhanden, in der Anzahl von zweien, dreien oder vieren. Von etwaigen Eckzähnen und von den Schneidezähnen des Unterkiefers wurde uns auch nichts erhalten. Wie gesagt, kann ein früh ausfallender Eckzahn nach den Alveolen des Unterkiefers Taf. IV Fig. 32 vorhanden gewesen sein, zusammen mit einem vierten Prämolaren. Ueber die Anzahl der Schneidezähne haben wir hereits oben (mandibula pag. 78) erwähnt, dass sich in der löcherigen Kinntliche Spuren von den Alveolen der Schneidezähne schwer verfolgen lassen; es diurften vier früh resorbirte Schneidezähne anzunehmen $\operatorname{sein}^{1}$ ).

Die ganze Reihe der vier Molaren, der drei Alveolen der Prämolaren und der beiden vordersten Alveolen in dem Unterkiefer Taf. IV hat eine Länge von $137^{\mathrm{mm}}$, von welcher Länge 91 mm auf die Molaren fällt. Die Zahnformel für den Unterkiefer des Halitherium wäre demnach:

$$
\text { ? } 4 \text { inc. ? } 1 \text { can. (? 4-) } 3 \text { praem. } 4 \text { mol. }
$$

Und für Ober- und Unterkiefer zusammen (die fraglichen Zähne eingeklammert):

$$
\frac{1}{(4)} \frac{(1)}{(1)} \frac{3}{3} \frac{4}{4}=21 \text { Zähne. }
$$

\section{f. Das Gebiss der lebenden Sirenen.}

Vergleichen wir nun dieses immerhin ziemlich vollkommene Gebiss des Halitherium mit demjenigen der drei lebenden Sirenen, so werden wir eine bedeutende Veränderung bei Manatus

1) Hier ist daran zu erinnern, dass Stannius beim neugeborenen Manatus fünf Alveolen von Schneidezähnen in der Kinnfläche des Unterkiefers und darïber noch einen sechsten Schneidezahn aufgefunden hat (Beiträge zur Kenntniss der amerikanischen Manati's. Rostock 1845). Berücksichtigt man nun, dass bei Halicore und jedenfalls auch bei Halitherium nur vier Schneidezähne im Unterkiefer vorhanden waren, und eine Vermehrung ihrer Anzabl bei dem in dieser Beziehung retrograden Manatus nicht wahrscheinlich ist, so dürte vielleicht der fünte und sechste von Stannius als Schneidezahn angesehene Zahn des jungen Manatus den beiden Zähnen des Halitherium entsprechen, deren Alveolen im Unterkiefer Taf. IV sich zeigen und welche wir für einen vierten Prämolaren und einen Eckzahn erklärten, besonders da der sechste Zahn nicht mehr auf der Kinnfläche liegt. Auch P. Gervais, Zool. et Paléont. générales I pag. 184 erwähnt, dass er bei eiuem jungen Manatus vom Amazonas fuiof Paar Alveolen auf der Kinnfläche fand, analog denen der Halicore. Daselbst gibt auch Gervais an, dass sein Ilalitherium Guettardi im Unterkiefer fünf Alveolen für einwurzelige Zähne vor $m^{1}$ besässe (also etwa 4 Prämolaren und 1 Eckzahn) und 4 Alveolen auf der Kinnfäche (siehe unten darüber). 
zı constatiren haben, eine starke Vereinfachung des Gebisses bei Halicore, und den Mangel aller Zähne bei Rhytina.

Was zunächst Na natus anbetrifft, so besitzt derselbe eine Reihe wohlausgebildeter Molaren, während die ïbrigen Zahngattungen bein ausgewachsenen Thiere ganz fehlen '). Bei neugeborenen Manatus aber zeingt sich im Zwischenkiefer ein rudimentïrer Schneidezahn, kleine Alveolen für sechs Schneidezähne in der porösen Kinntläche des Unterkiefers und ein Prämolar (nach Stannius); alle diese Zähne werden, wie die Schneidezähne im Unterkiefer der Halicore, früh gänzlich resorbirt, und ihre Alveolen verwachsen vollständig.

Die Molaren des Manatus erweisen die Eigenthümlichkeit, dass die vorderen abgenutzten Zähne durch Schub der hinteren Molaren nach vorn aus dem Kiefer herausgedrückt werden, wobei gleichzeitig eine theilweise Resorption der Wrurzeln des abzuwerfenden Zahnes stattfindet. Am hinteren Ende der Kiefer befinden sich in der langen Keimtasche gewöhnlich mehrere frische Zähne, welche allmählich nach vorne geschoben werden. Diese Eigenthümlichkeit der durch Nachschub ersetzten Molaren theilt Manatus bekanntlich mit den Proboscidiern; dieselbe begriundet indessen keinen wesentlichen Unterschied zwischen diesen Thieren und den andern Säugethieren: denn z. B. bei den Ungulaten schiebt sich gleichfalls ein Iolar hinter dem andern horizontal im Kiefor vor, nur dass das Wachsthum der Backenzähne überhaupt schon mit dem dritten Molaren aufhört; Halitherium brachte es auf vier Molaren. Elcphas und Mastodon bekanntlich auf sechs Molaren. Manatus entwickelt in seinen Kiefern noch mehr Molaren als der Elephant. Indessen findet man eben wegen des Ausfallens der vorderen und des Nachwachsens der hinteren Backenzähne bei den Autoren verschiedene Angaben über die Anzahl der Molaren des Manatus: Owen, Odontography pag. 371, gibt dem Manatus australis 9 Molaren, dem Manatus senegalensis deren $10 \mathrm{im}$ Ganzen; F. Cuvier, des dents des Mammiferes pag. 236, dem Manatus australis 8 Molaren; P. Gervais, Mammif. II pag. 312 für Manatus 8-9 m; de Blainville, Man. pag. 69, 10-12 m; Clauss, Zoologie p. 1071, 8-10 m; J. Murie für den von ihm anatomisch untersuchten Manatus australis pag. 143 gibt an: 5 angekaute Molaren, ein sechster im Hervorbrechen begriffen, und noch drei Keime in der Zahntasche, also $9 \mathrm{im}$ Ganzen. Krauss (J. Müller's Archiv 1862 pag. 422) nimmt ein immerwährendes Nachschieben der MIolaren während des ganzen Lebens des Thieres an: nach dieser Ansicht müssten in Ganzen eine Anzahl von mindestens 20 Molaren nach und nach hervorwachsen, was allen bisherigen Beobachtungen widerspricht ${ }^{2}$ )

$\left.{ }^{1}\right)$ Dass Manatus nur Molaren besitzt, kann gewiss nicht mit 0wen, Odontography pag. 372 ein *cetaceous character genannt werden; es liegt hier keine homologe Zahnentwicklung, nicht einmal eine analoge vor, wie wir unten ausfïhren werden; die Cetacea sind stets monophyodont gewesen, Manatus gehört zu einer diphyodonten Stammreihe und ist selbst, wenigstens in der Jugend, noch diphyodont. Demnach kann die Zahnentwicklung beider Reihen gar nicht mit einander in Beziehung gesetzt werden.

3) Krauss kommt zu dieser Ansicht durch die falsche Voraussetzung, dass ein Zahn im Kiefer eines jungen Thieres dieselbe Gro̊sse haben müsse, als derselbe Zahn eines alten Thieres: „vergleicht man den letzten Backenzabn eines jungen Thieres mit dem ersten eines alten, so ist dieser viel grösser als jener, sodass wenigstens eine ganze Zahnreilue gebildet und hinausgeschoben sein muss, bis diese Zähne die gleiche Grösse erreicht habenк. Krauss vergisst, dass ebenso wie alle andern Organe und Knochen des Thieres während des 
Die mir vorliegenden Manatus-Schädel zeigen die folgende Anzahl der Molaren: a. Manatus australis von Surinam I (Taf. IX Fig. 94) hat fünf Molaren in Benutzung, von denen der erste fast ausgestossen ist mit halb resorbirten Wurzeln und fast ganz zugewucherten Alveolen; der sechste bricht eben hervor und ein siebenter steckt noch in der Keimtasche über dem Gaumenbein: ebenso im Unterkiefer, nur tritt hier noch eine kleine halb verwachsene Alveole vor dem ersten Molaren auf, in welcher sich wohl der früh ausgefallene, einwurzelige Prämolar befaud. Schädel II von Surinam hat 6 Molaren in Benutzung, von denen der erste noch nach vorn gedrängt steht und eben herausgeschoben wird; der 7. ist hervorgebrochen, 8 bricht hervor und 9 steckt noch in der Keimtasche. Dieser Schädel gehört einem älteren Thier als I an, daher dieser 9, jener nur 7 Molaren besitzt. b. Manatus senegalensis vom Ogowe I hat im Oberkiefer links 6 in Benutzung mit einer verwachsenen Alveole vor dem ersten, links 5 in Benutzung mit zwei Alveolen vor dem ersten Molaren, von welchen Alveolen die erste zwei, die zweite drei halbverwachsene Wurzellöcher zeigt; ein 8. Molar bricht hervor, und zwei liegen noch in der Keimtasche; in Unterkiefer sind links 6 in Benutzung und vor dem ersten eine halbverwachsene, zweiwurzelige Alveole, rechts 5 in Benutzung mit Alveolen für zwei zweiwurzelige Molaren davor; ein achter Molar ist links hervorgebrochen, rechts bricht er vor; 9 und 10 bilden sich noch in der langen Zahntasche. Schädel II besitzt im Oberkiefer rechts sieben Molaren in Benutzung, von denen der erste schief nach vorn steht mit stark angefressenen Wurzeln ${ }^{1}$ ); der achte ragt kaum mit seinen Spitzen aus der Alveole, und der neunte und der erst kleine zehnte sind Keimzähne; links ist der erste Molar bereits ausgestossen, dann folgen sechs Molare in Benutzung, der achte schaut lalb aus dem Knochen und 9 und 10 stecken in der Keimtasche; im Unterkiefer ist die rechte Reihe um eine halbe Zahnlänge weiter nach vorn gerückt als links, wo die Alveole für den ausgefallenen ersten Molaren noch weiter klafft als rechts; dann folgen sechs angekaute Zähne und drei Keimzähne.

Auch nach diesen Schädeln scheint es demnach, wie die Melirzahl der Autoren angibt, als entwickele Iruntus senegalensis eine grössere Anzahl Molaren, als Manatus australis; es dürften jenem 10, diesem 9 Molare im Ganzen zukommen, nicht mehr.

Die Form der Krone der Molaren des Manatus gleicht noch derjenigen des Halitherium: nur sind die kronen bedentend kleiner und die Zapfen weit schmächtiger; statt der kräftigen, nach hinten rasch an Grösse zunehmenden Backenzähne des Halitherium finden wir bei Manatus Molaren mit niedrigen Kronen, welche von vorn nach hinten dieselbe Grösse und dieselbe Form beibehalten. Um so interessanter ist die Vergleichung der Molaren beider Thiere; sie sind einander ähnlich, aber nicht mehr gleich.

Obschon die Kiefer des Manatus australis von denen des Manatus senegalensis etwas abweichen, wie wir oben gesehen haben, so sind die Zähne beider Arten doch ganz gleich; da auch die Back-

Lebens und bei fortwährendem Gebrauch derselben fortwachsen, so auch dỉe Zähne grösser werden und also ein und derselbe Zahn beim alten Thiere absolut grösser ist als beim jungen. Auch P. Gervais, Zoologie et Paléontologie gẻnérales pag. 184 gibt fälschlich an, dass Manatus Molaren en nombre indéterminé * besässe.

1) Die Resorption dieser Wurzeln verläuft von aussen nach innen, während z. B. bei den Milchzähnen des Menschen die tieferen Schichten der Wurzel früher schwinden als die oberflächlichen (Henle, Anatomie II pag.97). 
zähne des Oberkiefers unter sich gleiche Grösse1) und Form haben und die Zülne des Unterkiefers ehenfalls einanler gleichen, so haben wir nur zwei Molaren zu beschreiben, um atle Backzïhne der Gattung Manatus kemnen zu lernen.

Die Schmelz-Tírone der Molaren des Oberkiefers zeigt eine abgerundet quadratische Basis von $14-15^{\mathrm{mm}}$ Seite; sie ist durch ein tiefes Quertial in zwei transversal gestellte Höckerreihen zerschnitten, denen sich vorn und hinten je ein niedriger gekerbter Schmelzkragen anschliesst. Das Querthal schneidet verhältnissmässig tiefer durch die Krone als das entsprechende Thal bei Halitherium und es ermangelt der Längsbrücke in der Mitte, sodass die Zähne in der Regel eher ausfallen, als der Schmelz der Thalsohle durchgekaut ist: die Almutzung ergiebt daher hier zwei parallele, lange und schmale Inseln, nicht eine einfache, blumenblattartige Zeichnung, wie bei Halitherium.

Die vordere Höckerreihe besteht aus drei Höckern, welche durch gekerbte Schmelzbruicken verbunden sind zu einem transversal gestellten Kamm; der mediale Höcker ist auch hier, wie bei Halitherium, der grösseste und fillt flacher und breiter nach dem Kronenrande hin ab, als der etwas schwächere laterale Höcker. Der mediale, im frischen Zustande spitz kegelförmige Höcker wird 8-9 moch, von dem Schmelzrande über dem Zahnhalse an gerechnet; es ist dies zugleich die grösste Höhe der Krone iiberhaupt. Der Kamm dieser Reihe wird $7 \mathrm{~mm}$, ihre Basis bis $16^{\mathrm{mm}}$ lang. Parallel dieser Hauptreihe und getrennt von ihr durch eine lange, wenig tiefe Querfurche verliuft an der Vorderseite der Krone ein halb so hoher Schmelzgrat, mit seiner schwach gekerhten Kammlinie ein wenig nach vorn ausgebogen.

Die zweite Höckerreihe zeigt auch meistens drei kegelförmige Zapfen, von denen der mediale wieder der breiteste ist; doch ragt gelegentlich ein vierter Höcker aus den verbindenden Schmelzbrücken selbständig hervor. An der hinteren Zahnseite schliesst sich der hintere gekerbte Schmelzgrat näher an diese Reihe an, als die vordere Nebenreihe an die erste Hauptreihe, und umgibt im Halbrund eine kürzere, Gruben-artige Furche, hinter und neben den Höckern der zweiten Hauptreihe gelegren. IDese beiden secundïren Schmelzkïmme haben sich aus den Nebenreihen der Molaren des Halitherium reducirt, gerade wie die Hauptreihen im verkleinerten Masstabe die kräftigen Zapfenreihen des Halitheriam wiederspiegeh. Durch das tiefer geschnittene Querthal erscheinen die Molaren im Oherkiefer des Manatus noch mehr wie Zühne mit zwei Querjochen, als das bei Halitherium der Fall war, noch dazu da hier die Hauptkämme genau in transversaler Richtung laufen.

Die Mx in des Manatus werden sämmtlich unterstützt von drei platten Wurzeln, von denen die eine die mediale Zahnseite eimnimmt und mit ihrer Flïche sagittal gestellt ist, die beiden andern auf der lateralen Seite transversal gerichtet sind; wie ich schon oben (pag. 90) bemerkte; kommt diese Wurzelstellung auch allen $\mathrm{Mx} m$ der älteren Ungulaten $\mathrm{zu}$, und ist dieselbe hier bei Manatus regelmässiger als bei Halitherium. In der Keimtasche, welche in die fissura orbitalis superior ziemlich tief eindringt, liegen die Keimzähne so gerichtet, dass ihre Krone nicht nach unten, sondern

1) Owen, Odontography pag. 371 gibt an, dass die Molaren gleichmässig nach hinten an Grösse zunehmen; doch ist dies nur insofern der Fall, als die vorderen Molaren durch Abreibung der Seiten ihrer Kronen allmählich etwas kürzer werden. 
medialwärts und ihre hohlen Wurzeln lateralwärts schauen, sodass sie also beim Vorschieben aus dieser horizontalen in eine verticale Stellung allmählich umwenden.

Die Molaren des Unterkiefers von Manatus sind die verkleinerten und schwächeren Abbilder der vorderen $\mathrm{Ml} \mathrm{m}$ von Halitherium: die Kronen sind durchschnittlich $15^{\mathrm{mm}}$ lang, $11^{\mathrm{mm}}$ breit und bis $9^{\mathrm{mm}}$ hoch. Zwei Haupthöckerreihen stehen genau transversal und werden durch ein tiefes Querthal getrennt von einander; jede Reihe besitzt zwei vorragende Zapfen, welche durch einen gekerbten Kamm verbunden sind. Schräg nach hinten steht von der zweiten Reihe ein breiter Talon ab, der verhältnissmiissig stäker entwickelt geblieben ist, als die Hanptreihen und wie ein kleines accessorisches Querjoch ausgebildet ist ${ }^{3}$ ); eine lange Querfurche, ebenso tief wie das Hauptthal in die Krone eingeschnitten, scheidet den Talon von der zweiten Reihe ab. Der Kamm des Talon ist gekerbt, seine Seiten ebenso runzelig wie die Flächen der Haupthöcker. An der vorderen Zahnseite fehlt, ebenso wie bei Halitherium, ein Schmelzrand; doch findet sich an allen Molaren an der vorderen, lateralen Ecke des Schmelzrandes eine kleine Nebenfurche, welche wir auch bei den vorderen Ma m des Halitherium constatirten: sie ist jedenfalls der Rest eines in der Stammreihe vorhandenen vorderen Schmelzkragens, wie er z. B. an den Mid m der älteren Ungulaten stets auftritt.

Jeder Md $\mathrm{m}$ besitzt zwei platte Wurzeln, deren Flächen transversal gestellt sind; als abnorm finde ich bei zwei nebeneinander stehenden Molaren eines Unterkiefers von Manatus australis aus der lateralen Wurzelbasis zwischen beiden Hauptwurzeln eine kleine, runde Nebenwurzel hervorgewachsen, welche hohl und $3-5^{\mathrm{mm}}$ lang ist. Die Wurzeln der Molaren des Manatus sind im Verhältniss zu der niedrigen Schmelzkrone recht lang: an den Md m werden sie $18^{\mathrm{mm}}$ lang. Die Enden der Wurzeln sperren sich transversal auseinander, und die hintere Wurzel gabelt sich dabei in der Regel.

Die Abkauung der Molaren geschieht nicht wie bei Halitherium in einer schräg nach aussen und unten abfallenden Ebene, sondern mehr in horizontaler Fläche: trotzdem werden aber gerade wie bei Halitherium die Mdm stärker an der lateralen, die Mxm stärker an der medialen Seite abgenutzt, und zwar desswegen, weil hier bei Manatus die Molaren nicht mehr genau vertical im Kiefer stecken, sondern schräg, und zwar die $\mathrm{Mx} m$ nach aussen, die Mrd m nach innen schräg gerichtet. Bei der schärferen Jochform der Kronen werden ausserdem die Höckerreihen der Mx m meistens an der Hinterseite ihrer Kämme, diejenigen der Mtl m an der Vorderseite derselben zuerst abgeschliffen, gerade wie dies bei den echten Jochzähnen der älteren Ungulaten der Fall ist.

Während dem erwachsenen Manatus alle andern Zähne ausser den Molaren fehlen, bildet sich bei demselben durch Erhärtung und Verhornung von Papillen der Mundschleimhaut ein zottiges, diches Linoryelpolster auf der porösen, schräg nach vorn abfallenden Fläche des Zwischen- und Oberkiefers und auf der Kinnfläche des Unterkiefers; da diese Knochenflächen grösser und besonders länger sind bei Manatus australis, als bei Manatus senegalensis, so wird auch jede der beiden Hornlagen grösser bei jenem, als bei diesem: denn die Knochenflächen sind bis zu ihren Rändern ganz von der zottigen Hornhaut bedeckt. Die genaue anatomische Beschreibung dieser verhärteten

1) Aehnlich dem Talon am letzten Molar des Unterkiefers von Lophiodon. 
Schichten der vorderen Mundspalte findet sich bei J. Murie, 1. c. pag. 164 Taf. 22 Fig. 18. 19. Bei dieser Gelegenheit meint J. Murie, dass auch Halitherium bereits ähnliche Hornhäute hesessen haben mag; ich habe schon oben (pag. 56 und 78) bemerkt, dass dies nach der Structur der betreffenden Knochenfächen bei Halitherium nur in beschränktem Maasse der Fall gewesen sein kann: die tiefe und breite Gaumenrinne lässt dem vorderen Theil des Oberkiefers nur einen schmalen Zahnrand übrig, und die wenig breite, bei jungen Thieren sogar ziemlich scharfe Kiinnflüche des Unterkiefers enthält auch bei alten Thieren noch tiefe Alveolen: weder oben noch unten sind demnach grössere Flächen vorhanden, auf denen sich eine Kauplatte hïtte ausbreiten können; doch ist es wahrscheinlich, dass der Prozess der Verhornung durch Verhïrtung der Papillen der Schleimhaut bei Halitherium bereits eingeleitet war. Bei Halicore ist die Verhornung in der Muudspalte etwa ebenso weit vorgeschritten, als bei Manatus; die grundlegenden Kunochenflächen werden bei alten Thieren sehr gross ${ }^{1}$ ). Rhytina Stelleri besass bekanntlich auf den grossen Flichen des Zwischen- und Unterkiefers je eine starke Hornplatte mit breiten Querrippen auf der Oberfliche, welche bei gänzlichem Mangel aller Zïhne allein die Nahrung zerraspelten.

Halicore geht einerseits durch die Entwicklung grosser Stosszälne über Halitherium weit hinaus, andrerseits reducirt sie ihre Molaren noch weit stärker als Manatus. Der Dugong besitzt in jedem Zwischenkiefer zwei Schneidezähe, von denen der vordere früh resorbirt wird. Der bereits öfters erwähnte, mir vorliegende Schüdel von 250 mm Länge, einem ganz jungen Thiere angehörig, trägt im Zwischenkiefer zwei hintereinander liegende Alveolen, zwischen welchen die Kinochenbrïcke $2-3^{m m}$ dick ist; die erste Alveole ist $26^{m m}$ tief, in der Längsrichtung schwach gekrummt, am Ausgang kreisrund mit $6^{\mathrm{mm}}$ Durchmesser. In dieser Alveole des linken Zwischenkiefers steckt noch der erste Schneidezahn: er besteht nur aus Dentin, ist $23^{\mathrm{mm}}$ lang, in der Mitte $3^{\mathrm{mm}}$ dick bei kreisrundem Querschnitt, in der Längsaxe schwach nach vorn gekrummt; das Ende der Wurzel ist hohl; die Spitze ist bis auf $4^{\mathrm{mm}}$ Länge unregelmässing durch Resorption angefressen. In der zweiten Alveole dahinter, welche eine Tiefe von etwa $60^{\mathrm{mm}}$ und am Ausgang einen Durchmesser von $7^{\mathrm{mm}}$ zeigt, liegt der $40^{\mathrm{mm}}$ lange, an seiner Spitze mehrfach gekerbte Keimzahn des bleibenden incisor. Der letztere ersetzt also nicht den ersten Schneidezahn durch verticales Herausschieben, sondern liegt in einer eigenen von der ersten vollständig durch Knochen getrennten Alveole und zwar neben und hinter dem gleichzeitig vorhandenen ersten Schneidezahn. Fs ist daher nicht richtig, wenn Owen, Odontography pag. $36 t$ den ersten Schneidezahn für einen fruih ausfallenden Milchzahn hïlt: denı ein Ersatzzahn entwickelt sich in derselben Alveole, in welcher der Milchzahn wuchs, benutzt zum Theil die gleichen hildenden Organe wie sein Vorginger und verschmilzt sein Periost mit dem Perinst. des Milchzahnes. Der erste Schneidezahn der Halicore ist vielmehr eben solch ein rudimentärer,

$\left.{ }^{1}\right)$ Küppell l. c. pag. 103 sagt über die Hornhäute in der vorderen Mundspalte der Halicore: *ihre knorpelige Oberfäche ist mit ganz dicht zusammenstehenden kleinen Cylindern sammetartig besetzt und hat längs der Medianlinie eine lanzettförmige Auskerbung. Diese Auskerbung ist auch auf der Hornhaut des Unterkiefers bei einem mir vorliegenden Manatus australis, ebenso wie bei unserer Halicore, vorhanden. Uebrigens wäre es sehr winschenswerth, dass eine anatomische Beschreibung der Halicore, wie diejenige des Manatus von J. Murie, von einer berufenen Feder gemacht wïde. 
frïh resorbirter Schneidezahn, wie derjenige des Manatus und die vier Schneidezähne des Unterkiefers des Dugong ').

Die zweiten Schneidezähne der Halicore entwickeln sich beim månnlichen Geschlecht zu zwei starken, $6-7^{\mathrm{tm}}$ aus dem Zwischenkiefer vorstehenden Stosszähmen; im Kïiefer der weiblichen Thiere ist der Stosszahn gleichfalls von ansehnlicher Grösse, wächst aber kaum aus dem Knochen vor und kann also nicht als Waffe benutzt werden ${ }^{2}$ ). Die ausgewachsenen Stosszähne sind cylindrisch, unten allmählich lonisch zur dicken Spitze verlaufend; an einem mir vorliegenden alten männlichen Schädel von $375^{\mathrm{mm}}$ Länge erreicht jeder Stosszahn im Ganzen eine Länge von $175^{\mathrm{mm}}$, am hohlen, inneren Ende eine Dicke von $50^{\mathrm{mm}}$ und am Austritt aus dem Knochen noch eine Dicke von $40^{\mathrm{mm}}$; etwa 50 mm Länge des Zahnes wird aus dem Zahntleisch hervorgestanden haben. Die hervorstehenden Theile der Stosszähne sind vorn an der lateralen und an der hinteren Fläche abgenutzt und glänzend glatt gerieben; die in der Alveole steckenden Theile des Zahnes sind schwach längsgefurcht. Dats Dentin der Stosszähne besitzt eine sehr dichte Structur, viel dichter als dasselbe der Stosszähne der Elephanten, und ebenso dicht wie bei den Hauern des Hippopotamus. Das im Knochen steckende Ende des Stosszahnes ist tief konisch ausgehöhlt, sodass der Zahn während des Lebens des mïnnlichen Thieres fortdanernd nachwachsen liomnte; bei den weiblichen Thieren schliesst sich die Wurzel, der Zahn hört auf zu wachsen, und bleibt in der Alveole verborgen. Das spitze Ende der Stosszähne der weiblichen Thiere wird noch von einer diumen Schmelzlage überzogen, ein Rest der dicken Email-Schicht beim Halitherium. Dagegen erhält sich an den Stosszähnen der männlichen Thiere nur ein geringer Rest der Schmelzlage; statt dieser überzieht eine dicke Cement-Schicht die Aussenfläche des vorbrechenden Zahnes.

Interessant für die Vergleichung ist der Umstand, dass die Spitzen der jungen, noch in den Alveolen verborgenen Stosszähne der Halicore aus mehreren Zapfen zusammengesetzt sind. Jede Spitze ist im Ganzen abgerundet dreikantig; die eine Seite ist länger als die beiden andern, sodass die Spitzen mehr bilateral erscheinen, und wendet sich schräg nach innen hinten in der Alveole; die dicke Scliärfe des Zahmes besteht aus drei dicht nebeneinander liegenden Zapfen, welche durch zwei kleine Gruben getrennt werden; von jeder Grube zieht sich eine lange schmale Furche an der Innenseite der Spitze ent]aug; der mittlere der drei Zapfen ist der höchste und stärkste. An der

1) Es ist leicht möglich, dass dieser erste Schneidezahn der Halicore in andern Fällen gar nicht oder nur theilweise resorbirt wird, das Zahnfleisch durchbohrt und ausfällt; z. B. weist die Abbildung in Owen, Odontography Taf. 92 darauf hin. Die Wurzel schliesst sich dann wohl meistens, ehe der Zahn ausfält. Einen gleicben ersten Schneidezahn, welcher früh ausfällt, besitzt bekanntlich der Elephant; auch bei diesem bat er eine eigene Alveole, sitzt vor dem auswachsenden zweiten Schneidezahn (Stosszahn) und darf daher ebenfalls nicht als Milchzahn bezeichnet werden.

2) Dr. Rüppell in der citirten Arbeit beschreibt ein frisch getödtetes, weibliches Thier aus dem rothen Meer, und sagt pag. 104: »innerhalb der Maxillarknochen des von mir hier beschriebenen weiblichen Individuums. fanden sich zwei lange, konische, cylindrische, etwas gekrümmte Zähne; bei alten Männchen und selbst den Weibchen sollen diese Zähne aus dem Zahnfleisch bei Zoll lang hervorstehen«. Ich habe mich durch Untersuchung der in Frankfurt aufbewahrten Rüppell'schen Halicore überzeugt, dass die beiden Stosszähne im Zwischenkiefer vorhanden sind (siehe oben pag. 62). Owen, Odontogr. pag. 364, gibt an, dass die Stosszähne weiblicher Thiere niemals das Zahntleisch durchbohrea. 
lateralen Seite der Zahnspitze schneidet eine vierte Furche ein, welche von einer kleineren Falte begleitet wird. Diese Gestalt der jungen Spitze des Stosszahnes erinnert einerseits an den bilateralen Typus eines echten Schneidezahns, andrerseits an die Furchen und Zapfen der Packenzähne. Beim Vorstossen der Zähne aus den Alveolen wachsen sich die Furchen der Spitzen aus und verschwinden ganz durch Abreibung. Leider kennen wir die Stosszähne vom Halitherium nicht in einem so jungen Stadium, dass wir eine Seitlichkeit oder eine Furchung der Spitze nachweisen kïnnten. Der jüngste Stosszahn ist der oben erwälnte im Heidelberger Museum mit offener Wurzel; derselbe hat bereits eine lange Schmelzhaube und besitzt eine glatte, konische Spitze; nach den jungen Zähnen von Halicore dïrfen wir wohl auf eine Furchung der Spitze bei Halitherium in einem noch jüngeren Stadium schliessen.

Hinter dem zweiten Schneidezalın folgt die flach ausgehöhlte Fliche des Zwischenkiefers und der scharfe Rand des Oberkiefers, beide ohne jede Spur von Zähnen und bedeckt von der dicken, zottigen Mundschleimhaut. Erst seitlich hinter dem grossen foramen infraorbitale erscheint die Reihe der Backenzähne.

In allen Handbüchern wird angegeben, dass Halicore Dugong im Ganzen fünf Molaren besitze ${ }^{1}$. Es kommen aber gelegentlich bei Halicore sechs Backenzähne vor, wie aus einem mir vorliegenden Schädel zu ersehen ist. Dieser Schädel ist 310 mm lang; die Alveolen der ersten resorbirten Schneidezähne des Zwischenkiefers sind noch völlig erhalten, nicht verwachsen; daneben liegen

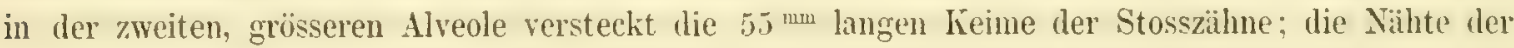
Kopfknochen sind noch alle offen, kurz es gehört der Schädel noch einem jungen Thiere an. Im Oberkiefer dieses Schädels stecken je fünf abgekaute Cylinder-fürmice Backenzälne, linter dem letzten ist die Keimtasche geöffnet für den Keim eines letzten sechsten Backenzahnes, welcher nicht eine cylindrische Stiftgestalt erhält, sondern die in Mitten zusammengeschnïrte Schleifenform, nach Art einer Sanduhr gebildet. Im Unterkiefer desselben Schïdels sind rier abgekate Stift-Backenzïhne vorhanden, vor dem ersten eine noch $11^{\mathrm{mm}}$ tiefe runde Alveole für den ausgefallenen ersten Stiftzahn; und hinter dem letzten ahgenutzten liegt in jeder Keimtasche ein hohler Keimzilnn des sechsten Backenzahnes, welcher ein vollständiger Zapfenzahn, wie ein Molar des Halitherium ist.

Auch ein zweiter mir vorliegender Schädel eines jungen Thieres zeigt im Unterkiefer vier Backenzälne und vor dem ersten zwei Alveolen für zwei weitere, bereits ausgefallene Molaren. Dagegen fehlt einem ganz jungen Schädel von $250^{\text {mm }}$ Länge der erste von den sechs Backenzïhnen im Oberkiefer gänzlich, im Unterkiefer aber ist er vorhanden: er ist aber hier unter der Mundschleimhaut stecken geblieben und seine hrone ist zur Hiilfte durch Resorption abgefressen, soliass es scheint, als könne dieser Zahn gänzlich resorbirt werden, ehe er durchbricht. Es deutet vielleicht dieser Umstand, dass der erste Backenzahn bei Halicore bald ausgewachsen mitbenutzt wird,

1) Owen, Odontography pag. 367. P. Gervais, Mammifères II pag. 312. Fr. Cuvier, dents des mammifères pag. 238. Claus, Zoologie pag. 1071 etc. Alle diese Autoren geben auch übereinstimmend an, dass diese fünf Molaren niemals gleichzeitig in Gebrauch seien, was ebenfalls nicht für alle Fälle richtig ist; 0wen sagt p. 367: the five molar teeth are never simultaneously in use. 
bald resorbirt wird, ehe er vorbricht, bald ganz fehlt, darauf hin, dass dieser erste einwurzelige Stiftzalın ein Rest der Prämolaren des Halitherium ist, obschon er offenbar keinen Milchzahn als Vorgänger gehabt hat.

Bei den andern mir bekannten Halicore-Schädeln sind nur fünf Backenzähne vorhanden, was mit der oben citirten Angabe der Autoren übereinstimmt.

Im frischen, unbenutzten Zustande und bei ganz jungen Schädeln sind die Backenzähne der Halicore Zapfenzihlne und gleichen viel mehr den Molaren des Halitherium, als die Molaren des Manatus denjenigen des Halitherium. Es ist dieser Umstand ganz besonders zu betonen, weil die abgenutzten, cylindrischen Stiftzähne der Halicore so gänzlich abweichend erscheinen von der Gestalt der homologen Zähne des Halitherium. In dem Vergleich der jungen und alten Backenzähne der Halicore mit den Molaren des Halitherium ist die eigenthümliche Umwandlung von wohlausgebildeten Ungulaten-artigen Zühnen zu solchen ungefügen cylindrischen Stiftzähnen, welche den Zähnen mancher Edentaten (Bradypoda) ähnlich sehen ${ }^{1}$ ), wohl zu beachten und lehrreich auch für andre nicht mit den Sirenen verwandte Thiergruppen.

Der erste Unterschied zwischen den Molaren der Halicore und des Halitherium besteht darin, dass die Schmelzlage der letzteren den lebenden Abkömmlingen gänzlich abhanden gekommen ist und statt derselben das Dentin von einer mit dem Alter des Thieres an Dicke zunehmenden Schichte von Cement überkleidet wird. Es darf gleich hier hervorgehoben werden, dass derselbe Vorgang der Cement-Erwerbung bei den Ungulaten ${ }^{2}$ ) ganz allgemein verbreitet ist: die älteren Ungulaten der Tertiär-Zeit haben nur Dentin und Schmelz, die jüngeren erwerben sich die Cementbekleidung dazu, freilich in der Regel ohne dass die Schmelzlage ausfällt.

Die Krone der jungen und frischen Molaren setzt sich ebenso wulstig ab von dem eingeschnürten Hals, wie die Schmelzkronen des Halitherium. Erst später verdeckt die zunehmende Ablagerung des Cementes alle Ungleichheiten und wandelt den Zahn um zu einem einfachen Cylinder.

Die Kronen der érsten beiden Backenzähne des Oberkiefers im Schädel von 310 mm Länge, hinter welchen noch vier Molare folgen, sind so stark abgekaut, dass ihre ursprüngliche form nicht mehr zu erkennen ist: die Kaufläche des ersten hat einen runden Querschnitt von $4^{\text {mn }}$ Durchmesser; seine ganze Höhe ist $16-17^{\mathrm{mm}}$. Der zweite Zahn ist mehr abgerundet vierseitig von $6-7 \mathrm{~mm}$ Seite. In dem jungen Schädel von $250^{\mathrm{mm}}$ Länge sitzen im Oberkiefer drei Backenzähne, von denen der letzte noch gar nicht, die beiden ersten so wenig abgekaut sind, dass man die Gestalt ihrer Zapfenkronen noch gut erkennen kann; ich möchte diese drei Zähne für die 3.4.5. Backzähne des Schädels von

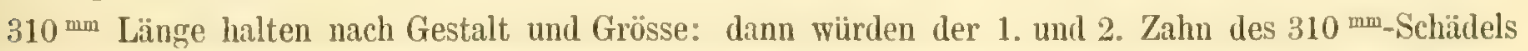

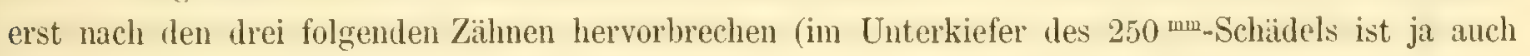
noch ein dünner Stift von $3^{\mathrm{mm}}$ Durchmesser vor den drei ausgewachsenen Backzähnen vorhanden). Dieses Verhältniss der Zahnfolge wäre das gleiche wie bei Halitherium: das heisst, der erste und

1) Es ist dieser Vergleich mit den Edentaten-Zähnen natürlich nur ein analoger, kein homologer.

2) Und bei den Proboscidiern ebenfalls: den Mastodonten fehlt das Cement, welches die Elephanten so reichlich erworben haben. 
zweite Zahn des $310^{\mathrm{mm}-S c h a ̈ d e l s ~ w u ̈ r d e n ~ d i e ~ P r a ̈ m o l a r e n ~} \mathrm{p}^{\mathrm{t}}$ und $\mathrm{p}^{2}$ des Halitherium sein und die vier nachfolgenden Backzïhne entsprächen den vier Molaren des Halitherium (was der Form und Grösse der Kronen nach passen würde). Es wäre diese Beziehung auch in sofern wahrscheinlich, als im Allgemeinen die Backzähne von Halicore eine Vereinfachung ihrer Form und Structur gegeniiber den gleichen Zähnen des Halitherium bekunden, während, wenn wir die sechs Backenzähne der Halicore alle als Molaren betrachten, gegeniiber den vier Molaren des Halitherium eine Vermelirung der Anzahl eingetreten wäre.

Der erste Backenzalnn des jungen Thieres mit 250 mm Schädellänge, den wir also als $\mathrm{m}^{1}$ ansehen wollen, hat eine Krrone von $9-10^{\mathrm{mm}}$ sagittaler Länge und $6-7^{\mathrm{mm}}$ transversaler Breite; die Krone besteht aus zwei Hauptzapfenreihen, transversal gestellt, getrent durch ein Querthal, welches ebenso wie bei Halitherium in der Mitte eine geringe Tiefe hat, während dasselbe bei Manatus fast die ganze hrone durchschneidet. An der Vorderseite der Krone lässt eine kleine Furche eine schwache Nebenreihe erkennen; an der Hinterseite lässt sich eine solche Reihe wegen der Abkaung nicht mehr nachweisen. Die Höhe der Krone beträgt $3-4^{\mathrm{mm}}$. Die Kautläche erscheint blumenblatt-artig, während dieselbe bei älteren Thieren durch gänzliche Abkaung der lirone und durch Vercementirung inmer kreisrunder wird. Die Wurzel dieses $\mathrm{m}^{1}$ ist einfach, aber viel diinner, als die Krone, mit einem Querschnitt von 5-6 ${ }^{\mathrm{mm}}$ Durchmesser. Der zweite Molar ist noch weniger abgekaut: die Krone ist $11^{\mathrm{mm}}$ lang, $7-8^{\mathrm{mm}}$ breit und $4-5^{\mathrm{mm}}$ hoch; die Sohle des Querthales ist erst auf ihrer mittleren Brücke angekaut, sodass die Zweitheilung der Krone, wie bei Halitherium hervortritt. Die hintere Nebenfalte ist durch eine stärkere l'urche deutlich abgesetzt. Die Zweitheilung der Krrone zeigt sich auch noch auf der einfachen Wurzel durch schwache Furchung angedeutet. Der

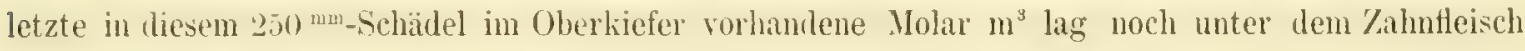
verborgen: die Krone ist $12 \mathrm{~mm}$ lang, vom $9^{\mathrm{mm}}$, hinten $7^{\mathrm{mm}}$ breit; die vordere Hälfte der Krone ist $9^{\mathrm{mm}}$, die hintere $8^{\mathrm{mm}}$ hoch. Die vordere Hälfte besteht aus zwei Hauptzapfen, von denen der eine grössere lateral, der andre medial gestellt ist; die Spitzen der kegelförmigen Zapfen nähern sich bis auf $1 \mathrm{~mm}$. Vor diesen beiden Spitzen befinden sich zwei kleine Gruben, um welche sich mehrere kleine Höcker unregrelmässig wruppiren; einige Furchen ziehen zwischen den Höckern bis zum Kronenrande hinab. Für $\mathrm{m}^{4}$ ist in diesem Oberkiefer wohl eine zur fissura orbitalis superior hin offene Keimalveole, aber noch kein Keimzahn in derselben vorhanden.

Im Unterkiefer dieses $250^{\mathrm{mm}}$-Schädels stecken drei Zapfen-Molaren und ein einfacher, kreisrunder Prämolar davor, dessen Krone durch Resorption angefressen ist und von der Mundschleimhaut bedeckt war. Die Krone des ersten Molaren ist zweigetheilt, $10^{\mathrm{mm}}$ lang, $6^{\mathrm{mm}}$ hreit; des zweiten $11^{\mathrm{mm}}$ lang und $7-8^{\mathrm{mm}}$ breit; des dritten $11^{\mathrm{mm}}$ lang und $8-9^{\mathrm{mm}}$ breit. Die beiden ersten Molaren haben neben den beiden Hauptreihen je zwei Nebenfalten; an der Hinterseite des dritten steht durch eine tiefe Furche abgetrennt ein niedriger, $4 \mathrm{~mm}$ breiter, höckeriger Talon schräg nach hinten ab. Die einfachen Wurzeln dieser Md m sind durch seitliche Furchung dentlicher zweigetheilt als diejenigen der $\mathrm{Mx}$.

Die Kronen aller dieser Molaren werden nur von einer sehr dünnen Cement-Schicht überkleidet, welche sich bei der Benutzung des Zahnes braun färbt; bei älteren Thieren nimmt die 
Dicke des Cementes bedeutend zu und wird das Cement, soweit der Zahn aus dem Fleische vorragte, dunkelbraun bis schwarz gefärbt.

Der letzte Molar $\mathrm{m}^{\star}$ der Halicore ist in etwas älteren Schädeln noch oft unbenutzt und in seiner Zapfenform zu sehen: die Zapfen legen sich viel dichter aneinander als bei Halitheriun, uncl die vorderen Zapfen schieben sich bedentend höher herauf, als die hinteren, sodass dieser Weisheitszahn der Halicore im frischen Zustande sich eher konisch zuspitzt, als seine Zapfen wie bei Halitherium flach auseinander breitet. Im Oberkiefer besteht die Krone des $\mathrm{m}^{4}$ aus zwei vorderen, dicht aneinanderliegenden Hauptzapfen, welchen sich vorn mehrere Nebenzapfen dicht anlegen; dann schneidet ein Querthal wenig tief durch die Krone; es folgen die zwei, ebenfalls dicht zusammenstehenden Hauptzapfen der zweiten Reihe, und endlich hinter einer zweiten, nur lateral offenen Querfurche ein bis zwei kleine Nebenzapfen, tief unter dem Niveau der Hauptzapfen. Die Krone eines solchen, noch unbenutzten $\mathrm{m}^{4}$ ist $12-13^{\mathrm{mm}}$ lang und oben in den Zapfen nur $5-6{ }^{\mathrm{mn}}$ breit; die Ränder der hohlen Wurzel sperren sich auseinander. In alten Schädeln wächst dieser vierte Molar derartig in die Länge und Breite, dass sein Querschnitt bei einem Schädel ron 375 mu Lünge $30^{\mathrm{mm}}$ lang, vorn $12 \mathrm{~mm}$, hinten $10^{\mathrm{mm}}$ breit geworden ist; zugleich schnürt er sich brillenförmig in der Mitte in transversaler Richtung zusammen bis zu $8^{\mathrm{mm}}$ Breite. Die vorderen Molaren behalten einen mehr oder weniger kreisrunden Querschnitt.

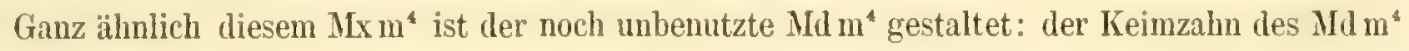
von einem Schädel mit $310^{\mathrm{mm}}$ Läuge besteht aus einer düunen Dentin-Haube und ist innen bis in die Zapfen hinein hohl; seine obere Hälfte (die Krone) ist mit einer ganz diinnen Cementschicht fast vollständig ïberkleidet. Der Zahn hat im Wurzelrande eine Länge von $13 \mathrm{~mm}$, eine grösste Breite von $10^{\mathrm{mm}}$, und hat seine grösste Höhe in den vorderen Hauptzapfen mit $15 \mathrm{~mm}$. Vorn an den beiden vorderen Hauptzapfen lehnen sich ein bis zwei kleine Nebenzapfen an, durch kleine Gruben und Furchen von jenen getrennt. Hinter dem Querthal stehen zwei Zapfen der zweiteu Reihe: sie sind um $2-3^{\mathrm{mm}}$ niedriger als die ersten Hauptzapfen und können zu einem dicken Zapfen verschmelzen; endlich schmiegen sich hinten an die zweite Hauptreihe zwei niedrige Xebenzipfel an.

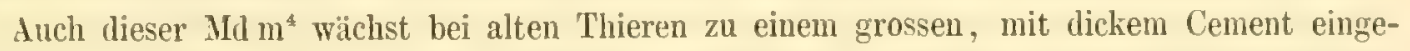
hiillten Brillenzihn ${ }^{8}$ ) aus: in dem alten $375^{\text {un }}$ langen Schädel hat der Querschnitt des Zalhnes eine Länge von $25^{\mathrm{mn}}$, vorn eine Breite von $14^{\mathrm{mm}}$, hinten von $11^{\mathrm{mm}}$, in der eingeschniirten Mitte von $8^{\mathrm{mm}}$; der Querschnitt seiner Wurzel ist ansehnlich länger und breiter.

Auch die Wurzeln der Backenzähne der Halicore haben im Vergleich mit Halitherium eine interessante Umwandlung erfihren: die selur langen, einfachen Wurzeln haben sich nïmlich eine tiefe, konische Höhlung für die Pulpa erworben, von welcher aus der Zahn in dem Maasse nachwächst, als er oben abgekaut wird. Bei den ersten Backenzähnen schliesst sich diese offene Wurzel bald, und die Zähne fallen dann aus; die Wurzel des vordersten Zahnes ist sogar in der Regel durch Resorption etwas angefressen, wie bei Halitherium. Dagegen schliessen die hinteren Backenzälme ilne Wrurzeln ent-

1) Owen vergleicht die Form dieser Zähne mit einem horizontal liegenden Stundenglas oder Sandubr. 
weder erst sehr spät oder gar nicht; der letzte Molar behält immer eine offene Wurzel und wächst also fortdauernd mach. Diese Terhältnisse bezichen sich auf den Ober- wie auf den Unterkiefer: bei dem alten Schädel von $375^{\mathrm{mm}}$ Länge hat der letzte Molar des Unterkiefers an der abgekauten Oberfläche eine sagittale Länge von $22^{\mathrm{mm}}$; der ganze Zahn (also eigentlich nur Wurzel, da hier die Krone längst weggekaut ist) ist $60 \mathrm{~mm}$ hoch; er ist schwach längsgefurcht und durch concentrische Anwachsstreifen quergerunzelt. Der Zahn ist zweitheilig im Querschnitt und erinnert dadurch an die beiden Wurzeln der Mo m des Halitherium; diese Brillengestalt hat auch die konisch in die Wurzel $20^{\mathrm{mm}}$ tief eindringende Pulpenhöhle, deren Zahnrand scharf ist.

Ebenso wie die lebenden Ungulaten sich vor den älteren tertiären Vorfahren dadurch auszeichnen, dass sie offene Zahnwurzeln und permanent fortwachsende Molaren sich erwarben, so hat auch Halicore permanent fortwaclsende Backenzühne gegenüber den beim Austritt des Zahnes geschlossenen Wurzeln der Molaren des Halitherium und damit einen Vortheil vor der Stammform gewonnen.

Wir sehen ausserdem, dass die Molaren der Halicore im unbenutzten Zustande zwar ein verkleinertes, aber doch ein ännliches Abbild der Molaren des Halitherium sind; der Schmelz ist verloren gerangen, für ihn tritt das weniger halthare Cement ein: die zwei- und dreifachen Wurzeln der Molaren des Halitherium sind hei Halicore zu einfachen Cylinder-Wurzeln reducirt; die Zapfen und Furchen der jungen Zähne werden rasch abgekaut oder verdeckt durch die mit dem Alter des Thieres sich rerdickente Cement-Schicht. In den Kiefern der alten Thiere functioniren schliesslich nur noch $\mathrm{m}^{3}$ und $\mathrm{m}^{4}$, die vorderen Backenzïhne sind ausgefallen. Zur besseren Zerkleinerung der Pflanzennalhung, als sie mit diesen acht restlichen Stiftzähnen möglich ist, bildet sich schon bei Halicore durch Verhürtung der Papillen der Schleimhaut ein zottiges, dickes Knorpelpolster in der vorderen Mundspalte aus.

Diese hornige Platte verdeckt vollständig die acht Alveolen, welche sich in der schrägen Kinnfläche des Unterkiefers stets vorfinden; diese Alveolen sind, wie wir oben (pag. 84) hervorgehoben, merkwurdig weit bei geringer Tiefe: die Kinochensubstanz ihrer Wände ist stark zerfasert und porös, und lässt zahlreiche Gefïsskanäle austreten. In diesen Alveolen liegen zuweilen noch spitze Zïhnchen mit diimner, hohler Wurzel, deren Krone meist durch Resorption angefressen ist; in dem untersten Alveolen-Paar stehen diese rudimentären Zähne steil nach unten gerichtet, in den oheren drei Paaren heliebig gerichtet, zuweilen verkrümmt. Diese Zähnchen sind als verkünmerte Schneidezähne anzuselıen; das unterste Paar wiirde etwa den Stosszähnen des Dinotherium zu vergleichen sein. Es ist auffallend, dass diese Alveolen der Md i bei Halicore schärfer ausgeprägt sind, als bei Halitherium, während doch offenbar die IId i bei letzterem bereits ebenso rudimentär waren, wie bei Halicore; ganz junge Manatis rom Amazonas zeigten fün Paar Alveolen auf der Kinnfläche des Unterkiefers, aher heim ausgewachsenen Manatus ist gar keine Spur mehr davon zu sehen; noch weniger natürlich bei Rhytina. Dagegen enthält der Unterkiefer der Halicore nichts mehr von jenen beiden Alveolen des Halitherium, welche wir einem $\mathrm{p}^{4}$ und einem Eckzahn zuschrieben.

Rhytina endlich entbehrt aller Zähne und entwickelt auf den beiden schräg abfallenden 
Flïchen der vorderen Mundspalte je eine dicke, mit Querrippen versehene Hornplatte' ${ }^{1}$ ). Wiihrend also Manatus versuchte durch weitere Entwicklung der Molaren der Stammform seine Kauwerkzeuge zu verbessern, reducirte im Gegentheil Halicore das Zahnsystem des Halitherium, und ging Rhytina in der Richtung der Halicore noch weiter durch gänzliche Abgerwöhnung aller Zähne. Desswegen gleichen die Molaren der Halicore denjenigen des Halitherium mehr als dieselben Zähne des Manatus den letzteren, weil Halicore nur eine Reduction, Manatus aber eine Fortentwickiung der Molaren der Stammform vornahm.

\section{Der Schädel im Allgemeinen.}

Die eigenthümlichen Charaktere des Halitherium-Schädels, das heisst seine Abweichungen ron dem allgemeinen Schädeltypus der Säugethiere, lassen sich etwa folgender Maassen zusammenfassen. Durch die weit wach vorn ragenden Gesichtsknochen und die Streckung der Hirnschale erscheint der Schädel des Halitherium in sagittaler Richtung stark verlängert: indessen wird der Schädel im Ganzen dadurch verbreitert, dass die kräftigen Jochbogen weit nach den Seiten ausspringen. ${ }^{2}$ ) Die stark entwickelten Schädelkanten trennen die einzehnen Regionen am Schädlel deutlich von einander. Die untere Fläche des Schädels (Taf. X Fig. 96) wird scharf umgränzt hinten von der Beugekante des os occipitis, welche einen Winkel von fast $90^{\circ}$ besitzt; dann vom Unterrande des os temporum; seitlich von den Rändern des breit ausgelegten processus zygomaticus und des os zygomaticum; rorn breitet sich der Oberkiefer flach aus, überhängt von dem ver]ingerten Zwischenkiefer. Indem die horizontal gestellten Theile des corpus ossis occipitis, die facies glenoidea ossis temporum und besonders das os maxillae dem Schädel einen breiten und ziemlich planen, horizontalen Boden verleihen, wird diese ebene Basisfläche unterragt von verschiedenen starken Knochenfortsätzen und durchbrochen von ansehnlichen Lücken: besonders fallen hier ins Auge die grossen, dicken, steil nach unten gerichteten processus pterygoidei ossis sphenoidei (Fig. 60); wir können daher auf einen kräftig entwickelten musculus pterygoideus schliessen, welcher den gleichfalls kräf-

1) Ueber die Structur der Hornplatten der Rhytina siehe Brandt, Mém. de l'Acad. de St. Petersbourg. Six. sẻrie. Sciences mathẻm. tome II. 1833. pag. 103. und Brandt, Symbolae Sirenologicae, daselbst tome V. 1849 pag. 49 ff. An letzterem Orte bemerkt auch Brandt pag. 37, dass neugeborene Thiere der Rhytina wahrscheinlich rudimentäre Schneidezähne besessen haben, welche wie bei Manatus resorbirt wurden. Die beiden Gruben, welche sich auf unserer Tafel X Fig. 99 an der Spitze des Zwischenkiefers deutlich zeigen und bei allen Rhytina-Schädeln vorhanden sind, dürften wohl sicher obliterirte Alveolen zweier resorbirter Schneide- oder rudimentärer Stosszähne sein. Gegen diese Annahme spricht es nicht, dass Brandt in diese Gruben ausmïndende Gefässkanäle aufgefunden hat (pag. 37 oben); denn solche Kanäle mïssen ja auch fïr die Zähne vorhanden gewesen sein und konnten später zur Ernährung der Kauplatte verwendet werden.

3) Der grösste mir vorliegende Schädel vom Halitherium hat von der Spitze des Zwischenkiefers an bis zu den Condylen eine Länge von $370 \mathrm{~mm}$, eine Breite in den Schläfenfortsätzen von $210 \mathrm{~mm}$, eine Höhe (ohne den Unterkiefer) von $135 \mathrm{~mm}$, wobei der noch um $40-45 \mathrm{~mm}$ tiefer als die Gaumenflügel herabhängende Zwischenkiefer nicht gerechnet ist; die auf Taf. VIII-X abgebildeten Schädel gehören, nach den Zähnen zu urtbeilen, etwas jüngeren Thieren an und sind daher etwas kleiner. Ein Schädel, dessen Oberkiefer noch alle vier Molaren und zwei Prämolaren besitzt, hat eine Lä̀ge von $355 \mathrm{~mm}$, eine Breite von $188 \mathrm{~mm}$ und eine Höhe von $124 \mathrm{~mm}$. 
tigen, doppelten musculus masseter unterstiitzte beim Aufziehen des Unterkiefers. Sodann erreichen die nach unten ragenden processus jugularis und mastoideus eine sehr bedentende Grösse und tragen breite, höckerige Ansïtze des musculus digastricus und stemo-mastoideus; vorwiegend der processus jugularis ist hei Halitherium viel stärker entwickelt als bei anderen Säugethieren und selbst stärker als bei den lebenden Sirenen. Die tuberositas malaris des os zygomaticum ragt nicht viel weiter nach unten vor als bei andern Säugethieren mit wohl entwickeltem Jochbein; bei den lebenden Sirenen aber hat der musculus masseter das Jochbein bedeutend stärker nach unten lierabgezogen.

Von den Schädelbasislöchern ist das foramen lacerum zwar gross und entfernt demnach das os temporum ziemlich weit rom corpus ossis occipitis; aber es ist doch nicht viel grösser, als bei den Siugethieren, welche ebenfalls keine bulla ossea besitzen, z. B. beim Tapir; zudem wird dieses Loch zum grossen Theil ausgefült durch die pyramis (Fig. 96), welche in allen ihren Stücken recht ansehnlich entwickelt ist; die verhältnissmässig grosse pars tympanica schwillt bei Manatus noch stärker an, als bei Halitherium. Die breite pars labyrinthica stösst fast an den corpus ossis occipitis, sodass das foramen lacerum in einen vorderen Theil und in (inen hinteren (foramen jugulare) getheilt wird, wie am menschlichen Schädel.

Die Choanen öffnen sich an der Schädelbasis mit einer einzigen Oeffnung, da die Nasenscheidewand resp. der vomer sich nicht mit dem os palatinum verbindet, sondern dasselbe überspringt und sich der Oberseite des os maxillae auflegt. Die Choanen sind bei Halitherium nicht besonders weit geüfnet, erst bei Halicore und Rhytina weiten sie sich aus. Die fissura palatina ist vorhanden: sie ist viel schmäler und spitzer, als bei den lebenden Sirenen, und sie reicht nach vorn bis zur Mitte des vorletzten Molaren beim ausgewachsenen Thiere. Das Gaumenbein ist selır lang gestreckt und diun: die Streckung desselben folgt aus der allgemeinen Verlängerung der Gesichtsknochen nach vorn.

Ganz besonders gross erscheint an der basis cranii die untere Schläfengrube, da sich der Jochbogen weit über sie spannt, wenn auch freilich lange nicht so weit als bei den Carnivoren. Wie die meisten Veränderungen am Schädel der Säugethiere von der Lmwandlung des Gebisses herriihren, so darf wohl auch die Stïke des Jochbogens in seinen beiden Theilen, dem os zygomaticum und dem processus zygomaticus, zurïckgeführt werden auf die starke Entwicklung des an der unteren Seite des Jochbogens angehefteten, doppelten musculus masseter: je weiter sich die Ansatzlinie entfernt von dem Unterkiefergelenk und je stärker dieselbe von den Knochen unterstützt wird, um so kräftiger kann der masseter beim Anziehen der mandibula wirken; im Vergleich mit den Carnivoren haben die Sirenen noch mehr durch liriftige Entwicklung der Stützknochen, als durch seitliche Entfernung des Jochbogens den angedeuteten Zweck zu erreichen gesucht.

Im vorderen Theil der Schädelbasis öffnet sich unter dem herabgebogenen Zwischenkiefer das foramen incisivum: dieses lange und schmale Loch liegt bei Halitherium fast ganz im os incisivum, nur ein feiner Spalt dringt rückwärts zwischen die Enden des os maxillae, gerade wie bei Manatus; bei Halicore betheiligt sich der Oberkiefer etwas mehr an der Umrandung des foramen incisivum, bei Rhytina gar nicht.

Von kleineren an der Schädelbasis mündenden Gefässlöchern ist der $4-5^{\text {mm }}$ weite canalis 
hypoglossi im os occipitis zu erwälnen. Der canalis rotundus ist selten ein geschlossener Kanal, meist eine Rinne an der Wurzel der ala temporalis; neben demselben liegt ein breiterer Ausschnitt an Stelle des foramen orale; eine flache Furche nehen dem corpus ossis sphenoidei nimmt die arteria carotica auf. Der canalis vidianus (in der Wurzel des Gaumenflügels) fehlt dem Halitherium und den andern Sirenen.

Yon den an der Basis sichtbaren Knochennähten bleiben alle offen, mit Ausnalume derjenigen Naht, welche die Körper ossis occipitis und ossis sphenoidei trennt: diese Naht verwächst bei alten Thieren vollstïndig. Ausserdem zeigt das os sphenoideum zwischen seinen verschiedenen Theilen auch bei jungen Thieren keine Nähte mehr, während an jungen Schädeln von Halicore und Manatus noch nicht verwachsene Nühte beweisen, dass der hintere Theil des Körpers und die mediale GaumenHhigel-Platte dem hinteren Keilbein, die laterile Gaumentlügel-Platte, alae temporales und orbitales und der vordere Theil des Körpers dem vorderen Keilbein angehören.

Die Hinterwand des Schädels steht bei Halitherium fast im rechten Winkel gegen die basis cranii, nur ein wenig nach vorn geneigt (Fig. 61 und 87); quer über die Beugekante zwischen beiden Theilen stellen sich die Gelenkfächen im Winkel von $110-115^{0}$ gegen die Horizontale, sodass der Kopf gegen die ersten Halswirbel aufrecht, nicht herabhüngend getragen wurde. Auch gegen die Seiten und die Decke des Schädels ist die Hinterwand durch scharfe Kanten abgetrennt: an den Seiten ist es die dicke Aussenkante der pars mastoidea, welche die Grenze bildet; oben der halblreisförmige Rand (linea nuchae superior) der squama ossis occipitis mit seinem eigenthümlichen Krönchen in der Mitte, der protuherantia occipitis externa (Fig. 97). Die Hinterwand wird zusammengesetzt von den stärksten Knochentheilen des Schädels, und zwar betheiligen sich an der Bildung dieser Fläche: die partes laterales und squama ossis occipitis, die Hinterseiten der partes mastoideae ossis temporum und ein Streifen der pars petrosa pyramidis. Die Nähte zwischen diesen sieben Knochenstiicken bleiben sämmtlich auch bei alten Thieren offen.

An der Umgrenzung des foramen occipitale betheiligt sich die squama ossis occipitis nicht; sie bleibt vielmehr ziemlich weit entfernt über demselben. Das Loch selbst ist dreieckig gestaltet, die lange Basis nach unten gekehrt.

Zwischen Warzen- und Felsentheil einerseits und der Schuppe und den Seitentheilen des Hinterhauptsbeines andrerseits öfnet sich das lange, schmale foramen mastoideum, am lebenden Thiere wahrscheinlich mit Faser- und Knorpel-_lasse verschlossen. Die auffallende Grösse dieser Oeffnung hei den Sirenen erklärt sich wohl aus der Verbreiterung der hinteren Schädelkapsel, hinter welcher die Verbreiterung der squama und der partes laterales ossis occipitis zurückblieb; bei Manatus und Halicore klafft das foramen mastoideum noch mehr auseinander.

Charakteristisch sind die stark ausgeprägten Gruben und Höcker zu beiden Seiten der protuberantia occipitis externa für den Ansatz der Kopfstrecker und die beiderseitigen Rauheiten für den Ansatz der Nackenmuskeln: alle diese Muskeln waren jedenfalls stark entwickelt, um den schweren Schädel wagerecht zu halten und aufwärts zu bewegen. Lateralwärts des processus condyloideus schneidet eine fossa condyloidea erst flach, dann tiefer in das os occipitis und läuft auf der basis cranii aus in der incisura jugularis. 
Die Seitenflächen des Halitherium-Schädels sind besonders auffallend verändert durch den stark vergrösserten processus zygomaticus ossis temporum, durch den grossen herabgebogenen Alveolartheil des os incisivum und - wenn wir den Unterkiefer hinzunehmen - durch die Breite des Astes und die Inicke des Kinntheils der mandibula (Fig. 87). Der processus zygomaticus ist trotz seiner Vergrösserung nicht porös in seinem Innern, sondern von derselhen dichten Structur, welche die Sirenen-Ḱnochen üherhaupt auszeichnet; erst bei seiner noch stïrkeren Auftreibung am ManatusSchällel wird er schwammig. Dagegen ist der processus alveolaris ossis incisivi selır locker gebaut und von vielen Gefässkanälen durchzogen; er ist durch das starke Wachsthmm zweier Schneideoder Stosszähne so anselnulich aufgetrieben worden: bei Manatus, welcher die heiden Stosszähne der Stammform verkïmmern lässt, zieht sich das os incisivum wieder bedeutend zusammen, während es durch die grösseren Stosszähne der Halicore noch mehr aufgeblasen wird.

Der Unterkiefer biegt die Symphyse abwärts, sodass die incisiven Zahnrånder, dicht neben einander gelegt, schrïg nach vorn hinablaufen und zugleich in die Länge gezogen werden. Dieser Abbiegung des oberen Randes folgt die untere Seite des Kimes, in Folge dessen der Kinntheil bei Halitherium bereits ansehnlich erhöht ist, wenn auch noch bedeutend weniger als bei Halicore. In beiden Fällen hat sich die Symphyse des Unterkiefers wohl nur umgewandelt, um dem lang herabgezogenen Zwischenhiefer eine Gegenfläche zu bieten; indirect hängt diese Veründerung also auch mit der Entwicklung von Stosszithnen zusammen. Ebenso verbreitert sich der Mandibula-Ast wohl zu dem Zwecke, um den Kaumuskeln eine grössere Ansatz-Flïche zu verschaffen und so der Länge, Schwere und dem vorderen Abbiegen des Unterkiefers erfolgreicher entgegen wirken zu kümnen. Die Weite des canalis mandibularis und die zahlreichen und grossen foramina mentalia erklären sich aus der stïkeren Benutzung der Weichtheile an Kinn und den Lippen, welche zum Abrupfen der Nahrung besonders muskulös und dicklıäutig ausgestattet und wahırscheinlich mit starken Borsten besetzt waren.

Das Schädeldach und die vorn angesetzten Gesichtsknochen zeigen charakteristische Eigenthiumlichkeiten in den beiden starken cristae temporales, in den breit ausliegenden processus orbitales ossis frontis und in der weiten knöchernen Nasenöffnung mit der besonderen Anordnung der umgrenzenden Schädelstïcke (Fig. 92). Im Vergleich mit den lebenden Sirenen ist das Schädeldach in den cristae temporales stark zugeschärft nach oben und sonach die Oberfäche des Gehirnraums besonders schmal (Fig. 60); es scheint diese Spitzköpfigkeit ein Erhstück der Vorfahren des Halitherium zu sein: denn bei den Nachkommen verbreitert sich das Schädeldach mehr und mehr und die lineae temporales treten weiter auseinander. Yon den Temporalleisten steigen die Seitenwände des Schädels nahezu rechtwinklig gegen das Schärleldach, ein wenig nach aussen vonvex ab; bei den lebenden Sirenen richten sich diese Wände noch steiler abwärts und sind stellenweise concav eingebogen. Die Stärke der cristae temporales und des processus orbitalis erinnert an die gleichen Verhältnisse am Schädel der Carnivoren; doch ist es bei diesen die kräftige Entwicklung des musculus temporalis, welchem die Knochentheile zur Stïtze dienen, wührend derselbe Muskel wenigstens hei Manatus gerade sehr schwach entwickelt ist. Es erscheint daher die Grösse der processus orbitales bei Halitherium mehr als ein seitliches Ausweichen dieser Knochenstücke, bewirkt durch die Verbreiterung der Nasenöffinung und der Kiefer, welche von den Fortsätzen des Stirnbeins umfasst 
werden miissen. Bei den lebenden Sirenen reducirt sich die Breite der processus orbitales, sie sperren aber noch weiter auseinander.

Die starke Erweiterung der Nasenhöhle bewirkt nun nicht etwa, dass die åusseren Nasenlïcher sehr gross gewesen wären, im Gegentheil sind die letzteren bei Manatus auffallend klein: zwei kurze, halbkreisförmige Spalten liegen am vorderen Ende zweier enger und langer Kianïle, welche die dicken Häute und Muskeln bis zur Nasenhöhle durchbohren (J. Murie l. c. pag. 186 Taf. 26 Fig. 37). Vielmehr scheint die Yerbreiterung der knöchernen Nasenhöhle und zugleich der Riuckzug der ossa nasi daher zu rühren, dass die Zwischenkiefer ihre Aeste höher hinaufschoben und weiter auseinander sperrten und so eine festere Grundlage suchten für die Thätigkeit der sich mehr und mehr entwickelnden Stosszähne: daher gehen die processus frontales ossis incisivi bereits bei Halitherium hoch hinauf und breiten sich Hach aus auf dem Oberkiefer, den Nasenbeinen und am Stirnbein; sie schwingen sich aber noch nicht so weit zu beiden Seiten herum und werden nicht so kräftig und breit, wie bei Halicore, bei welcher die mächtig anwachsenden Stosszähne eine noch stärkere Veränderung des os incisivum bewirkten. Bei Manatus verkümmern die Stosszïhne wieder und daher verringert sich die Stärke der processus frontales ossis incisivi: das vordere Ende der Aeste zieht sich ganz zurück vom Stirnrand, lässt auch den processus frontalis ossis maxillae zum Theil unbedeckt und erreicht nicht mehr das Nasenbein. In demselhen Naasse als der Zwischenkiefer, resp. die Stosszähne an Grösse zunehmen, wird das os nasi reducirt: bei Halitherium sind die Nasenbeine noch ein breites Schild über der hinteren Nasenhöhle und stossen beide Theile in langer Naht zusammen; sie sind aber mit ihrer hinteren Huilfte schon tief in den Stirnrand hineingeschoben; bei Manatus liegen bereits die ossa nasi entfernt ron einander, sie sind schmal geworden, haben aber noch eine ansehnliche Länge. Rhytina besitzt noch einen kleinen verkümmerten Rest der Nasenbeine, und Halicore, deren Zwischenkiefer-Aeste an stärksten entwickelt sind und der festen Unterlage am meisten belürfen, entbehrt derselben gänzlich. Die dicken Haut- und Muskellagen mussten bei Halicore den Schutz der Nasenhöhle übernehmen. Wir haben also bei den Sirenen eine :ihnliche Entwicklung des Zwischenkiefers und der Nasenbeine, wie bei den Proboscidiern, hei welchen die Erwerbung der mächtigen Stosszähne in gleicher Weise rückwirkte auf die Gestaltung der knöchernen Nasenhöhle.

Durch die Verbreiterung der Nasenhöhle oder vielmehr der sie umgrenzenden Fortsätze des Zwischen- uud Oberkiefers werden auch die Augenhöhlen auseinander gedrängt; die Augen entfernen sich bei Halitherium am wenigsten weit von einander, bei Manatus und Rhytina mehr, bei Halicore am meisten; zugleich wird die Orbita bei Halicore stark nach vorwärts und abwïrts gezogen durch die bedeutende Entwicklung des Jochbeins.

Gleichzeitig mit der stärkeren Entwicklung der Gesichtsknochen verkürzt sich der ganze Schädel der lebenden Sirenen ansehnlich im Vergleich mit dem des Halitherium: die sagittale Länge und die verhältnissmässige Schmalheit des Schädeldiches beim Halitherium kommt besonders darin zum Ausdruck, dass die Decke des Gehirnraumes, das os parietale, bei dieser tertiären Sirene doppelt so lang ist im Verhältniss zu seiner Breite, als es bei den drei lebenden Sirenen der Fall ist (pag. 49); besonders auffallend ist die Kürze der sutura parietalis bei Manatus und Halicore. Im gleichen 
Maasse verkürzt, resp. verbreitert sich der Gehirnraum, sodass die Länge zur Breite desselhen bei Halitherium 16:10, hei Halicore $14: 10$, bei Manatus australis $13: 10$ und bei Manatus senegalensis 11: 10 beträgt. Noch stärker wird die sagittale Länge der Nasengånge und der Muscheln durch die Grösse der Nasenhöhle oder vielmehr der Zwischenkiefer rerküzt und reducirt: Halitherium besitzt mehrere wohlentwickelte Inuschelwiilste; die obere Muschel mit ihrem Horne erreicht eine Länge von $100 \mathrm{~mm}$. Bei Janatus sind die Yuscheln löcherige Knochenplatten, welche mur noch zum Theil die regelmässige Anordnung der Halitherien-Muscheln erkennen lassen: lie obere Muschel ist noch am stärksten entwickelt und wird $70 \mathrm{~mm}$ lang (bei gleicher Schädellänge); Nasengänge und Muscheln liegen noch woh]geschiitzt, tief zuriickgezogen unter dem Stimbein. Bei Rhytina ist das os ethmoideum ähnlich ausgebildet, wie bei Manatus. Dagegen hat bei Halicore die äussere Nasenhöhle die innere soweit verdrängt und reducirt, dass die geringen Knochenhlätter der Muscheln frei am vorderen Theil der Siebplatte liegen, ohne überdacht zu werden von dem ganz zurückgezogenen Stirnrand; das Horn der oberen Muschel zeigt kaum noch Aelnlichkeit mit dem des Halitherium und wird nur $25-30 \mathrm{~mm}$ lang. Eine wohlentwickelte Siebplatte trennt am Schädel der Sirenen den Gehirnraum von den Nasengängen und gestattet, vielfach durchbohrt, den Riechnerven den Durchgang zur Nase.

Von den Knnochennähten an der Oberseite des Schädels verwächst die sutura parietalis schon bei ganz jungen Thieren aller Sirenen vollståndig; da zugleich die sutura occipitalis im Alter gänzlich zugewachsen ist und os occipitis und os parietale die stärksten hvochen des Schädels sind, so kommt den Sirenen ein ausserordentlich fester Hinterkopf zu, im Gegensatz zu der dimmwandigen Schädelkapsel der Cetaceen. Dagegen bleibt die zackige sutura coronalis anch im hohen Alter der Sirenen sichtbar, ebenso wie die sutura frontalis. Mit selr zahlreichen Zacken und Lamellen befestigen sich die Gesichtsknochen unter sich und an den medialen Rändern der processus orbitales ossis frontis. Dagegen fehlt sowohl bei Halitherium als bei Manatus und Rhytina eine feste Verbindung zwischen dem Zwischenkiefer und dem Nasenhein; bei Halitherium legt sich das obere Ende des Zwischenkiefer-Astes ganz frei und platt auf die Nasenbeine auf. Dieser Umstand kann als Beweis dafuir gelten, dass die Sirenen sich von einer Thierreihe abzweigten, bei welchen der Zwischenkiefer vollständig getrennt vom Nasenbein vorn am Oberkiefer lag und seinen Ast erst allmählich im Laufe der Entwicklung hinaufgeschoben hat bis auf das Nasenbein. In der Form, in welcher der Zwischenkiefer bei den Sirenen auftritt, erscheint er durchaus als ein Belegknochen und entwickelt daher keine eigentlichen Knochennähte, sondern zerfasert nur seine Flïchen an den Berührungsstellen mit andern Knochen, sodass er immer von seiner Unterlage mehr oder weniger leicht abgehoben werden kann.

Alle die wesentlichen Veränderungen, welche wir beim Schädel des Halitherium im Verhältniss zım allgemeinen Schädeltypus der Säugethiere und bei den lebenden Sirenen im Verhältniss zum Halitherium erkennen können, lassen sich schliesslich zurückfuhıren auf die Umwandlung des Gebisses dieser Thiere: zwei Schneidezähne des Zwischenkiefers entwickelten sich zu Stosszähnen; damit wurde die Vergrösserung und die Herabbiegung des Alveolartheiles des Zwischenkiefers bewirkt; der dadurch beschwerte Zwischenkiefer verlängerte seine Stiutzen nach hinten bis an den 
Stirnrand und vergrïsserte so die Nasenhöhle. Diesen veränderten Verhältnissen des Zwischenkiefers passte der Unterkiefer seine Gestalt an; dieser wurde daher schwerer beweglich und rief stärkere Stützen seiner Muskeln in dem vergrösserten Jochfortsatz des Schlïfenbeins und den Jochbeinen hervor. Zugleich treten die Lippen als Hülfsorgane des Gebisses auf und bedingen daher grössere Gefïsskanäle und breitere Flächen für den Ansatz ihrer Muskeln. In allen diesen Beziehungen sehen wir die beim Halitherium eingeleitete Entwickelung fortschreiten bei Halicore, dagegen im Ganzen gehemmt bei Manatus und rückschreiten bei Rhytina. Daher erscheint uns der Unterschied im Schïdelbau bei Halitherium und Halicore grösser, als bei Halitherium und Manatus. Nur den Backenzälmen versuchte Manatus eine weitere Entwickelung zu gehen und musste daher zu diesem Zwecke seinen Oberkiefer verlängern; zugleich stellen sich die beiden molaren 7ahmreihen der rechten und linken Seite sehr nahe nebeneinander: wenn schon das Gaumengewölbe bei allen Sirenen ansehnlich verschmälert erscheint im Verhältniss zu dem anderer Süugethiere, so ist dies in erhöhtem Maasse bei Manatus der Fall, bei welchem iiberhaupt der Schädel, wemn man von dem Jochbogen absieht, ganz ungewöhnlich schmal geworden ist. Rhytina endlich scheint wesentlich nur dem einen Anstoss der Stammform gefolgt zu sein, den vorderen Theil der IIundspalte zur Gewinnung und Zerkleinerung der Nahırung umzuwandeln; demn die verhärteten Schleimhäute der übrigen Sirenen wurden hier zu starken Horn-Kauplatten entwickelt.

Die übrigen Functionen, welche ihren Sitz im Kopfe haben, verlangten keine wesentlichen Umgestaltungen der Schädelknochen: der Gehirmraum, die Oeffnungen für den nervus olfactorius, für den nervus opticus und für andere Nerven, der Gehörapparat sind vollkommen ausgebildet und erweisen keine bedeutenden Abweichungen in Gestalt und Lage von den homologen Stücken am Schädel eines typischen Säugethieres.

Wie bei allen andern Thieren wandeln sich die Zähne am schnellsten um, sich der Nahrung anpassend: sie erlangen dalurch eine besondere Wichtigkeit zur Bestimmung der Gattung und der Art; aber sie sind aus demselben Grunde weniger geeignet der vergleichenden Anatomie zu dienen, als die in ihrer Form conservativeren und zugleich charakteristischen Schädelknocben.

\section{b. Die Wirbelsaiule und die Extremitaten.}

\section{Columna vertebralis.}

Die Wirbelsäule des Halitherium besteht aus 7 Halswirbeln, 19 Rückenwirbeln, an welche sich 19 Rippen anhängen, 2 Lendenwirbein, 1 Sacralwirbel, mit welchem der Beckenknochen durch Knorpel-Bänder verbunden war, und mindestens etwa 25 Schwanzwirbeln, im Ganzen also aus 54 Wirbeln $^{1}$ ).

1) Die Wirbelsäule Taf. VIII Fig. 91 habe ich zeichnen lassen nach Kaup's Abbildung, 1. c. Taf. VII, welche nach einem von Kaup im Darmstädter Huseum aufgestellten Skelette mit mehreren Ergänzungen hergestellt wurde. Nach späteren Funden von vollständigeren Skeletten ist die obige Beschreibung gemacht und bedarf 
Da der Körper des Thieres im Wasser horizontal ausgestreckt sich fortbewegte, so standen alle Wirhel mehr oder weniger vertical und transversal mit ihren grössten Flächen'). Die Abweichungen von der horizontalen Richtung der Wirbelsäule beziehen sich auf die Hals- und Rückenwirbel, da in diesen Theilen die Wirbelsäule des Halitherium schwach S-fürmig gebogen war und zwar derartig, dass die Halswirbel nach vorn und oben sich erhoben, dann zwischen den Schulterblättern ein tiefster Punkt der Wirbelsäule lag und endlich sich die Rückenwirbelsäule nach oben ein wenig convex ausbog. Die Länge der vollständigsten Wirbelsäule beträgt: $13^{\mathrm{cm}}$ für $7 \mathrm{Halswirbel,} 100^{\mathrm{cm}}$ für 19 Rückenwirbel und $90^{\mathrm{en}}$ für 17 vorhandene lumbo-caudal-Wirbel; dazu können noch $20^{\mathrm{cm}}$ für die fehlenden 11 letzten Schwanzwirbel gerechnet werden. Die ganze Wirbelsäule dieses Skelettes hätte demnach eine Länge von $223^{\mathrm{cm}}$ gehabt; dazu kommt die Länge des Schädels mit $37^{\mathrm{cm}}$, sodass das Skelett die Länge von $2^{m} 60$ besessen hätte. Da dieses Skelett einem alten Thiere mit Stosszähnen zugehört hat, so diurfte diese Länge von andern Skeletten um nicht viel übertroffen werden ${ }^{2}$ ). Das lebende, ausgewachsene Halitherium mag daher mindestens die Länge von $3^{\mathrm{m}}$ gehabt haben.

Von den Halswirbeln ist der Atlas ein starker Ring mit dicken kurzen Querfortsätzen ${ }^{3}$ ). Ein Atlas von Alzey ist noch grösser als der von Kaup abgebildete, er hat eine transversale Länge von $135^{\mathrm{mm}}$, eine verticale Höhe von $78^{\mathrm{mm}}$ und eine grösste Dicke (sagittal) von $40^{\mathrm{mm}}$. Das foramen vertebrale hat eine Höhe von $48^{\mathrm{mm}}$ und einen transversalen Durchmesser von $40^{\mathrm{mn}}$; diese Oeffnung ist nach unten halhkreisfürmig; in der Mitte springen die inneren Ränder der fossa articularis posterior

danach die Wirbelsäule der Fig. 91 einiger Verbesserungen. In der Zeichnung ist die (wenn auch seltenere) Anwachsung des dritten Halswirbels an den Epistropheus dargestellt; doch kommen die andern vier freien Halswirbel dahinter nicht deutlich heraus. Die beiden ersten Lendenwirbel der Zeichnung müssen fortfallen; denn der Wirbel mit dem grössten, stark heruntergebogenen Querfortsatz ist der Sacralwirbel, vor welchem nur zwei Lendenwirbel und zwar mit dicken und langen Querfortsätzen vorausgehen. Die ganze Reihe der Schwazwirbel ist an keinem der mir bekannten Skelette erhalten, ein Theil fehlt inmer; am meisten Schwanzwirbel besitzt das im Hainzer Museum jüngst aufgestellte Skelett, nämlich 14 Schwanzwirbel, zu welchen wenigstens noch 11 fehlende hinzuzurechnen wären; Fig. 91 sind nur 21 statt 25 Schwanzwirbel gezeichnet. Wahrscheinlich trugen noch mehr Wirbel Hämapophysen als auf der Abbildung. Die Form der Wirbel ist in der Zeichnung hinreichend gut wiedergegeben.

1) Da beim Menschen die Wirbel horizontal stehen, so passen die Henle'schen Bezeichnungen der Wirbeltheile nicht immer; ich habe dieselben daher nach der verticalen Stellung der Wirbel bei den Säugethieren verändert: z. B. statt tuberculum anterior und posterior hominis wird es heissen tub. inferior und superior animalium; fossa articularis superior $=$ fos. art. anterior; fossa articularis inferior $=$ fos. art. posterior; fossa articularis posterior $=$ fos. art. superior etc. etc. Dabei ist auf die Biegungen der Wirbelsäule der Säugethiere nicht Rücksicht genommen, sondern jeder Wirbel, auch die Hals- und Schwanzwirbel, vertical, die ganze Wirbelsäule horizontal stehend gedacht.

$\left.{ }^{2}\right)$ Allerdings erreicht ein mir vorliegender Schädel von Alzey die Länge von fast $40 \mathrm{~cm}$ und gehörte zu demselbeu wohl ein nocb längerer Körper als dem oben erwähnten; alle andern Schädel sind aber kleiner, $35-37 \mathrm{~cm}$ lang.

3) Der Atlas ist abgebildet von Kaup, Beiträge Heft II Taf. VI Fig. 1 a. b. G. Cuvier, Oss. foss, tom. V Taf. 19 Fig. 12a. b gibt die Zeichnung des Atlas eines Halitherium vom Layon, Maine et Loire, und bemerkt zu demselben im Texte pag. 269: »la vertẻbre fossile que nous représentons, aurait bien pu être prise pour un atlas humain, surtout dans les temps, ou l'on prétendait toujours que les os fossiles venaient de géants. Elle né différerait presque de notre atlas que par la grandeur etc. In der That besteht eine auffallende Aehnlichkeit zwischen dem menschlicheo und dem Sirenen-Atlas, nur dass dieser grösser und stärker ist; beide zeigen eben die einfachste Form, in welcher dieser Beugewirbel am besten seine Functionen erfüllen kann. Es ist dies wieder ein Beispiel, wie der gleiche $Z$ weck oft eine grosse Aehnlichkeit des einen oder andern Organes hervorruft bei l'hieren, die gar nicht mit einander verwandt sind. 
etwàs nach innen ein, sodass die Sonderung des halbrunden eigentlichen Rückenmarksloches von dem oheren viereckigen Ausschnitt im Wirbelkörper für den Zahn des Epistropheus angedeutet ist. Die fossa articularis superior für die Gelenlifläche am Zahn des Epistropheus ist scharf ausgeprägt, rund mit 20 mm Durchmesser. Lnter dieser Gelenkfliche ragt das tuherculum inferior mit starkem kurzen Fortsatz. nach binten über. Der Querfortsatz steht noch $25^{\mathrm{mm}}$ ziemlich horizontal, ein wenig abwärts geneigt vom Wirbel ab; er ist dick und rund mit 25-30 mm Querdurchmesser; aussen trägt er eine grosse, rauhe Ansatzfliche für die Kopfstrecker. Das foramen transversarium durchhohrt den Querfortsatz nicht in der Mitte von vorn nach hinten, wie beim Menschen; vielmehr umkreist der Kanal der arteria vertebralis die massae laterales und durchbohrt den Knochen randlich dreimal: ein Loch von $2-3 \mathrm{~mm}$ Durchmesser befindet sich am unteren Rande der Wurzel des Querfortsatzes, ein zweites am vorderen Rande derselben, ein drittes am vorderen Rande der Wurzel des arcus superior; häufig sind die dünnen Brücken über den Löchern offen; einmal ist das mittlere foramen transversarium durch eine feine linochenbrücke in eine mediale kleinere und in eine laterale grüssere Oeffinung getheilt ${ }^{1}$ ), die eine wohl für die Arterie, die andere für die Vene.

Die fossa articularis anterior ist recht gross: $50 \mathrm{~mm}$ lang, von denen etwa $30^{\mathrm{mm}}$ auf $\mathrm{dem}$ arcus inferior, 20 an der Wurzel des arcus superior liegen; sie ist fast halbkugelförmig gestaltet und besitzt erhabene, scharfe Ränder; in ihrer Mitte erscheint ein mehr oder weniger tiefes Grübchen. Ich habe oben pag. 5 auf die Stellung der Condylen am Hinterhaupt hingewiesen; ihre Lage ist der Art, dass die ersten Halswirbel hei ruhiger, horizontaler Haltung des Kopfes in nicht viel weniger als $45^{\circ}$ gegen die Horizontale schräg nach vorn oben aufsteigen mussten. Die Sirenen erheben also den Tiopf über die Halswirbelsäule, lassen nicht wie die Cetaceen den Kopf nach vorn unten herunterhängen; daher fehlt den letzteren die S-fürmige Biegung der Wirbelsäule, welche im Ganzen nur einfach convex nach oben ausgebogen ist.

Der Epistropheus ist dem menschlichen weniger ähnlich als der Atlas: der Zahn ist verhältnissmässig kurz und klein, der Körper dick, der Bogen mit starker Kappe versehen. Der zu dem oben beschriebenen Atlas zugehörige Epistropheus ist $88^{\mathrm{mm}}$ hoch, $78^{\mathrm{mm}}$ breit (im Kürper) und mit dem Zahn $58^{\mathrm{mm}}$ tief in sagittaler Richtung; der Zahn ist nur $20^{\mathrm{mm}}$ lang und 15 min dick. Die Synchondrosen-Fläche des Körpers gegen den dritten Wirbel hat eine transversale Länge von $48 \mathrm{~mm}$ eine verticale Höhe von $31 \mathrm{~mm}$. Das foramen vertebrale ist $35^{\mathrm{mm}}$ lang (transversal) und $26 \mathrm{~mm}$ hoch. Der Bogen hat schwache Stiitzen, während sein oberes Stïck eine dicke, nach vorn etwas überhängende Kappe bildet: die Mittelnaht der Kappe ist in sagittaler Richtung $38^{\mathrm{mm}}$ lang; nach hinten zeigt die Kappe nur wenige rauhe IIuskelansïtze, ohne iiberzuhängen. Der processus articularis posterior liegt wie gewöhnlich an den Seitentheilen des Bogens, welche durch die tief eingeschnittenen Gruben, die den Gelenkfortsatz des dritten Wirbels aufnehmen, stark verdümnt sind; die Gelenkfläche sieht schräg nach unten und aussen. Das foramen transversarium befindet sich an der lateralen Seite des Körpers gleich hinter dem äusseren Rande der grossen vorderen Gelenkfläche; es ist aber nicht rings geschlossen und von zwei kurzen Zacken eingefasst.

3) Wie das auch im foramen transversarium hominis vorkommt, siehe Henle, Anat. pag. 47. 
Hinten an den Epistropheus ist nun zuweilen der dritte Halswirbel zum Theil angewachsen: einen solchen Doppelwirbel hat Kaup 1. c. Taf. VI Fig. 2 abgebildet. Die Verwachsung ist folgender Iaassen beschaffen: der Körper des dritten Wirbels steht ganz frei bis auf ein kurzes Stiick in der Mitte des oberen Raudes, wo sich derselbe mit dem Kiörper des Epistropheus verbindet; im übrigen sind die beiden Körper $4-5^{\mathrm{mm}}$ von einander entfernt. Die Querfortsätze des dritten Wirbels bleiben frei und biegen sich nach hinten ab. Die processus articulares und die Gelenkflächen sind vollständig

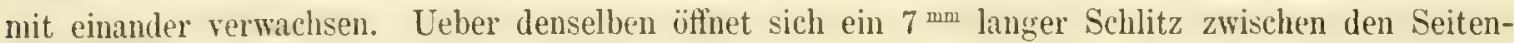
theilen der Bögen; oben ist das Mittelstiick des Bogens des dritten Wirbels auf eine Strecke von 50 min innig mit der Kappe des Epistropheus verwathsen. Es bleiben also auf jeler Seite zwischen den Bögen zwei foramina intervertebralia offen.

Bei den andern mir bekannten Halitherien bleibt der dritte Halswirbel ganz frei hinter dem Epistropheus; doch ist jene Verwachsung von grossem Interesse, weil bekanntlich Manatus in der Regel nur sechs Halswirbel besitzt und zwar den zweiten mit dem dritten Wirbel verschmilzt.

Der Körper des dritten Halswirbels ist $30^{\mathrm{mm}}$ hoch (in verticaler Richtung); oben $11-12^{\mathrm{mnu}}$, unten $14-17^{\mathrm{mm}}$ dick (sagittal). Wir beobachten bei allen Halswirheln, dass der liörper nach unten sich verdickt; es hängt dies damit zusammen, dass die Halswirbelsäule nach unten convex durchgebogen ist, um den liopf aufrecht tragen zu können. Der transversale Durchmesser des Körpers beträgt $50^{\mathrm{mm}}$, wozu die je 20 m langen Querfortsätze hinzukommen. Das formmen transversarium wird rings vom Querfortsatz umschlossen und ist rund mit $5^{\mathrm{mm}}$ Durchmesser. Das foramen vertebrale ist $30^{\mathrm{mm}}$ hoch und $40^{\mathrm{mm}}$ breit. Der ganze Wirbel ist mit dem Bogen $80^{\mathrm{mm}}$ hoch. An dem freien dritten Wirbel sind beide, die vorderen und hinteren processus articulares, an den Seitentheilen der Bögen wohl ausgebildet.

Die nächsten Halswirbel nehmen an transversaler Breite immer mehr zu: der vierte ist mit den Querfortsätzen $115^{\mathrm{mm}}$ breit und $90^{\mathrm{mm}}$ hoch, der fünfte ist $120^{\mathrm{mm}}$ breit und $100 \mathrm{~mm}$ hoch, der sechste ist $125^{\mathrm{mm}}$ breit und $107^{\mathrm{mm}}$ hoch, der siebente $130^{\mathrm{mm}}$ breit und $110^{\mathrm{mm}}$ hoch. Die Körper bleiben dabei ungefihr gleich gross; aber Bögen, Querfortsätze und foramina vertebralia wachsen. Zugleich entwickeln die Querfortsütze einen Fortsatz nach unteu, welcher an Stärke zunimnt und an seiner Lnterseite eine rauhe Ansatzfliche für Muskeln trïgt. Das foramen transversarium ist in jedem Querfortsatz rings geschlossen und wird immer grösser, sodass sein Durchmesser beim sechsten Halswirbel $9-10^{\mathrm{mm}}$ beträgt. Der Bogen bleibt eine dünne Spange, entfaltet in der Ebene des Körpers; spitzt sich aber nach oben mehr und mehr zu, sodass rier siebente Wirbel bereits einen 20 mu hohen Dorn erhält. Während am sechsten Halswirbel die heiden Apophysen des Querfortsatzes weit auseinander streben und der untere sich stark nach unten biegt, fehlt im siebenten Halswirbel das foramen transversarium gauz und der einfuche Querfortsatz streckt sich wieder horizontal vom Kürper ab, mit starker tuberositas am wulstigen Ende. Der Körner dieses letzten Halswirbels wird gelegentlich recht dünn, meist aber behält er die Dicke von $10-15^{\mathrm{mm}}$, wie die andern Halswirbel, und ist zugleich unten dicker als oben.

Die erste Rippe stiitzt sich entweder nur auf den ersten Rückenwirbel, oder aber setzt ihr Köpfchen ein in die Synchondrose zwischen jenem und dem siebenten Halswirbel; dann zeigt der 
Kö̈rper dieses Halswirbels eine Hälfte der Gelenlifläche, gelegentlich nur auf der einen Seite, auf der andern nicht. Doch stemmt sich der Höcker der ersten Rippe natürlich nur an den Querfortsatz des ersten Ruickenwirbels.

Die Reihe der Rückenwirbel besteht wie gesagt aus 19 Wirbeln, deren Höhe und Breite wenig, deren sagittale Dicke bedeutend von vorn nach hinten zunimmt. Die Querfortsätze, welche an den ersten Rïckenwirbeln noch horizontal abstehen, richten sich mehr und mehr schräg nach oben, im Winkel von $45^{\circ}$ vom Wirbel abstehend; sie werden auch allmählich kürzer und dicker. Zugleich rïcken sie mit ihrer Wurzel höher am Wirbel hinauf, sodass sie, die anfangs seitlich am Körper standen, bald zu Seiten des foramen vertebrale die Seitenstiutzen des Bogen verdicken: sie werden von den dicker und grösser werdenden Rippen nach oben gedrängt. Das foramen vertebrale besitzt in den ersten Wirbeln ein grosses Lumen; nach hinten wird es immer niedriger. Die Verkleinerung des Rückenmarkloches wird wesentlich bewirkt durch die bedentende Entwicklung des Dornfortsatzes: dieses Mittelstück des Bogens ist bei den ersten Rückenwirbeln noch eine kurze, schmale Spitze, welche von langen Seitenstützen getragen wird. Allmählich aber vergrössert sich der Dornfortsatz so stark, dass der ganze Bogen fast allein aus diesem einfachen Stuick besteht: die Wurzeln des dicken Dornfortsatzes schliessen sich unmittelbar an die aufwärts gredrängten Querfortsätze an. Zugleich verlängert sich der Dorn in sagittaler Richtung je weiter nach hinten in der Reihe um so mehr, sodass die spitzen Dornen der ersten Wirbel an den hinteren Wirbeln 40 - $50 \mathrm{~mm}$ breite (sagittal), vorn zugeschärfte, hinten $10-15 \mathrm{~mm}$ dicke (transversal) Platten von $60-70 \mathrm{~mm}$ verticaler Höhe werden. Endlich legen sich die Dornen immer mehr nach hinten über: während sie auf den ersten Wirbeln fast vertical über dem Körper stehen, sind sie auf der hinteren Hälfte der Rückenwirbel etwa in $50^{\circ}$ gegen die vertical stehende Ebene des Körpers nach hinten geneigt.

Die vorderen und hinteren Gelenke liegen an allen Rückenwirbeln, wie immer, vorn und hinten an der Wurzel des Bogens; je weiter nach hinten, um so mehr tritt ein spitzer processus articularis hervor: an den letzten Rückenwirbeln ist er am längsten und zwar 25-30 mm lang.

Am Körper des ersten Rückenwirbels zeigen sich entweder auf jeder Seite anderthalb Gelenkpfannen, nämlich am Vorderrande neben der Synchondrose zum siebenten Halswirbel eine ganze Pfanne für das Köpfchen der ersten Rippe und hinten an der Synchondrose zum zweiten Rückenwirbel eine halbe Pfanne für die zweite Rippe; oder es ist auch vorn nur eine halbe Pfanne vorhanden, in welchem Falle das Köpfchen der ersten Rippe in der Synchondrose und halb am Hinterrande des siebenten Halswirbels steckte. Die folgenden Wirbel tragen stets zwei halbe Gelenkpfannen, da die Rippenköpfchen sich in die Synchondrosen setzen: die fossae costales dieser Wirbel sind ungefilhr lireisrund (die Synchondrose mitgerechnet) mit 20-26 "m Durchmesser, immer gerade eine Hïlfte auf einem Wirbel. Die letzten sieben Riickenwirbel aber besitzen jeder nur mehr eine volle Pfamne, da die Köpfchen vom vorderen Raude des Körners allmählich ganz auf die Seite des Köryers rücken: beim letzten (19.) Wirbel ist die fossa costalis gerade bis zur Mitte des Körpers vorgerückt.

Demnach gehören zu den 19 Rückenwirbeln auch 19 Rippen. 
Die fossa transversalis für den Rippenhöcker liegt an der Unterseite jedes Querfortsatzes. An den hinteren Wirbeln nähert sich die fossa costalis mehr und mehr der iber ihr liegenden fossa transversalis: die letzten vier Wirbel haben eigentlich nur eine einzige Gelenkfläche auf der Seite des Körpers, da beide Pfannen in einander übergehen; bei dem letzten Wirbel sind beide Pfannen in eine ungefäh kreisrunde zusammengeschmolzen, welche gerade in der Mitte der Körperseite am Ende eines ganz kurzen Querfortsatzes liegt: das heisst bei der letzten Rippe stehen capitulum und tuberculum dicht bei einander, sodass sie am Wirbel nur eine, statt vorher zwei Gelenkpfannen erzeugen.

Von den vier ersten, dem 16. und dem letzten Rückenwirbel eines erwachsenen Thieres mit $370^{\text {min }}$ Schädel- und etwa $2{ }^{\text {m }} 60$ Skelett-Länge will ich noch die Maasse angeben: der erste Riickenwirbel ist $135^{\mathrm{mm}}$ breit (transversal), $110^{\mathrm{mm}}$ hoch (vertical) mit Dorn; der Körper ist $35^{\mathrm{mm}}$ hoch und $17 \mathrm{~mm}$ dick (sagittal); das foramen vertebrale ist $40^{\mathrm{mm}}$ hoch, $30^{\mathrm{mm}}$ breit; der Dorn ist $35 \mathrm{~mm}$ hoch; der Querfortsatz ist $36^{\mathrm{mm}}$ lang und $20^{\mathrm{mm}}$ dick.

Der zweite Wirbel ist ansehnlich grösser als der erste: $150 \mathrm{~mm}$ breit; $140 \mathrm{~mm}$ hoch, von denen $35^{\mathrm{mm}}$ auf die Höhe des Körpers, $40^{\mathrm{mm}}$ auf die des foramen vertebrale und $65^{\mathrm{mm}}$ auf die Dornlänge kommen; dlas foramen ist $35^{\mathrm{mm}}$ breit; der Querfortsatz ist $42^{\mathrm{mm}}$ lang und $35^{\mathrm{mm}}$ dick; der Körper ist $26 \mathrm{~mm}$ dick.

Der dritte Rückenwirbel ist $145^{\mathrm{mm}}$ breit und $155^{\mathrm{mm}}$ hoch; der Körper ist $40^{\mathrm{mm}}$ hoch und $30^{\mathrm{mn}}$ dick; das foramen ist $30^{\mathrm{mm}}$ hoch, der Dorn $85^{\mathrm{mm}}$ hoch; der Querfortsatz $35^{\mathrm{mm}}$ dick.

Der vierte Riickenwirbel ist $140^{\mathrm{mm}}$ breit und $145^{\mathrm{mm}}$ hoch; der Körper ist $35^{\mathrm{mm}}$ hoch und $35^{\mathrm{mal}}$ dick; das foramen ist $25^{\mathrm{mm}}$ hoch, der Dorn $85^{\mathrm{mm}}$ hoch; der Querfortsatz $45^{\mathrm{mm}}$ dick.

Der sechzehnte Rückenwirbel hat die folgenden IIasse: der Körper ist $80^{\mathrm{mm}}$ breit (bei den ersten Rückenwirbeln $50-60 \mathrm{~mm}$ breit), während die scitlich über ihm gelegenen Querfortsätze dem Wirbel nur eine Gesammtbreite von $114 \mathrm{~mm}$. geben; dabei ist der Körper $60 \mathrm{~mm}$ dick geworden. Das foramen vertebrale ist nur $20 \mathrm{~mm}$ hoch und $25^{\mathrm{mm}}$ breit, also sehr verengt. Der Dorn ist $70^{\mathrm{mm}}$ hoch und ist statt tler früheren Spitze eine lïngsgestellte Platte geworden mit $42 \mathrm{~mm}$ sagrittaler Länge. Der processus articularis anterior ist $25^{\mathrm{mm}}$, posterior $20^{\mathrm{mm}}$ lang in sagittaler Richtung.

Der letzte, neunzehnte Rückenwirbel ist 120 ma breit, von welcher Breite nur je 20 ma auf

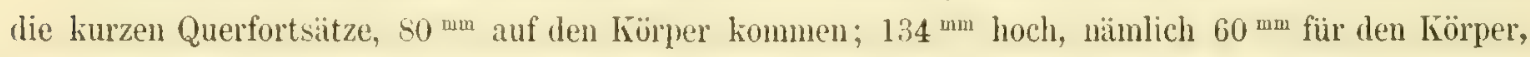
der oben herzfürmig durch eine Furche des foramen vertebrale eingeschnitten wird, wie die hinteren Rückenwirbel alle, nur $1 \mathrm{~s}-20^{\mathrm{mm}}$ für das foramen vertebrale und $56^{\mathrm{mm}}$ für den Dorn, welcher gerade in die Höhe steht, vorn einen scharfen, oben einen flach convexen Rand, hinten eine $10-15 \mathrm{~mm}$ breite Furche besitzt und eine sagittale Länge von $50-55^{\mathrm{mm}}$ erreicht. Der vordere processus articularis steht $25^{\mathrm{mm}}$ vom Bogen $\mathrm{ab}$ und wird an der Wurzel 18-20 mm dick, der hintere Gelenkfortsatz ist kleiner, etwa $15^{\text {mm }}$ lang. Der Körper wird $56^{\mathrm{mm}}$ dick (sagittal).

An den letzten sechs Rückenwirbeln werden die Dorn-Platten sagittal am längsten von allen und stehen mit ihren vorderen und hinteren Kanten fast vertical über dem Wirbelkörper, während die mittleren und vorderen Rückenwirbel-Dornen sich stark nach hinten überlegen (bis $50^{\circ}$ gegen die Verticale). 
Die ersten vier Rückenwirbel tragen wie die Halswirbel auf der Oberseite ilırer Querfortsätze rauhe Muskelansïtze, die folgenden haben glatte Oberflïhen derselben Theile. Auch die breiten Seitenflïchen der so starken Dornen zeigen keine tuberositas, nur die Kanten derselben scheinen bei den meisten Wirbeln rauh zu sein durch Ansatz von Sehnen.

Die Lendenwirbel erbalten durch ihre langen und dicken Querfortsätze eine ganz eigenthïmliche Gestalt: während der letzte Riiclienwirbel gerade die kiurzesten Querfortsätze besitzt und daher in transversaler Richtung nur $120 \mathrm{~mm}$ breit wurde, erreicht der erste Lendenwirbel mit seinen Fortsätzen eine transversale Länge von nicht weniger als $345 \mathrm{~mm}$. Es ist dies der transversal längste Wirbel von allen; von demselben an nach hinten nimmt die Breite der Wirbel wieder regelmässig ab, sodass der zweite Lendenwirbel $325^{\mathrm{mm}}$, der dritte $300^{\mathrm{mm}}$, der erste Schwanzwirbel $250 \mathrm{~mm}$, der zweite $230^{\mathrm{mm}}$, der dritte $210^{\mathrm{mm}}$, der zehnte $100^{\mathrm{mm}}$, der dreizehnte $90^{\mathrm{mm}}$ etc. breit werden ${ }^{1}$ ).

Der ausserordentlich grosse Querfortsatz des ersten Lendenwirbels sitzt mit breiter Wurzel an der oberen Hälfte der Seite des Körpers, ist $130 \mathrm{~mm}$ lang, $53-60 \mathrm{~mm}$ in sagittaler und $20 \mathrm{~mm}$ in verticaler Richtung dick; er richtet sich vom Kürper ah ein wenig nach hinten mit der ersten Hälfte seiner Länge und biegt dann mit schwacher Krümmung seine Enden nach vorn; ausserdem hängt er mit ganzer Länge etwas nach unten, sodass sein Ende in gleicher Höhe mit der Unterkante des Körpers zu stehen kommt. Das Ende des Querfortsatzes ist stumpf abgeschnitten und trägt eine $30^{\mathrm{mm}}$ sagittal und $20 \mathrm{~mm}$ vertical lange rauhe Fläche zum Ansatz von Bandmasse. Der Körper dieses Wirbels ist ebenso herzförmig durch die Furche des foramen vertebrale oben eingeschnitten, wie die letzten Rücken- und die folgenden lumbo-caudal-Wirbel; unten ist er cylindrisch und glatt; seine Höhe beträgt $60 \mathrm{~mm}$, seine Breite $85 \mathrm{~mm}$, seine sagittale Dicke $55^{\mathrm{mm}}$. Das foramen vertebrale ist niedrig, $35-40 \mathrm{~mm}$ breit und $15-20 \mathrm{~mm}$ hoch. Der Dorn ist eine starke Platte, wie bei den letzten Rückenwirbeln, von $45^{\mathrm{mm}}$ Höhe und $55^{\mathrm{mm}}$ sagittaler Länge; seine Wurzel ist $20^{\mathrm{mm}}$ breit; alle seine Kanten, auch die hintere, sind zugeschärft; die vordere und hintere Kante stelsen vertical gerichtet.

Der zweite Lendenwirbel ist dem ersten sehr ähnlich, er ist nur etwas kürzer: nämlich $325^{\mathrm{mm}}$ lang; dabei $122^{\mathrm{mm}}$ hoch und zwar der Kö̈per $57^{\mathrm{mm}}$, das foramen vertebrale $15-17^{\mathrm{mm}}$, der Dorn $50 \mathrm{~mm}$ hoch; der Körper ist $80^{\mathrm{mm}}$ breit und $62^{\mathrm{mm}}$ dick; das foramen vertebrale ist sehr niedrig, vorn unter den grossen Gelenkfortsätzen $30 \mathrm{~mm}$, hinten zwischen den Gelenkgruben $40 \mathrm{~mm}$ breit. Der Dorn steht gerade über dem Körper als eine $60^{\mathrm{mm}}$ lange (sagittal) Platte; seine obere Kante ist halbkreisförmig ausgebogen, die hintere hinte steht vertical ülser dem Kürver und in gleicher Ebene mit der Hinterfläche des Körpers, während die vordere Kante um 20-30 mm hinter der Vorderfläche des Körpers aufsitzt, sodass vorn Platz für die grossen vorderen Gelenkfortsätze bleibt. Der processus articularis anterior ist $28 \mathrm{~mm}$, posterior nur 10-12 mm lang; die vorderen Gelenkfortsätze jedes Wirbels greifen immer unter die hinteren Gelenkfortsätze des vorhergehenden Wirbels und stehen in einer mehr oder weniger tiefen Grube unter den letzteren. Jeder Querfortsatz ist $122^{\mathrm{mm}}$ lang,

1) Alle Wirbelmaasse sind an dem Skelett von 2 m 60 Länge genommen, welches Ostern 1881 in Flonheim gefunden und im Mainzer Museum aufgestellt ist; der Schädel desselben ist $37 \mathrm{~cm}$ lang. 
$50 \mathrm{~mm}$ in sagittaler, $25^{\mathrm{mm}}$ in verticaler Richtung dick; er ist flach nach vorn concav eingebogen und hängt nach den Seiten so weit abwärts, dass sein Ende noch 10-12 mm die Unterkante des Körpers unterragt; sein Ende ist stumpf abgeschnitten und trägt eine rauhe, zuweilen vertiefte Endfläche von $45^{\mathrm{mm}}$ sagittalem und $10-15^{\mathrm{mm}}$ verticalem Durchmesser für den Ansatz von Bandmasse.

Der dritte Lendenwirbel entwickelt die dicksten Querfortsätze: er ist $300^{\mathrm{mm}}$ lang, wovon $80^{\mathrm{mm}}$ auf die transversale Länge des Körpers und $110^{\mathrm{mm}}$ auf jeden Querfortsatz kommen. Der Körper ist dabei $57^{\mathrm{mm}}$ hoch und $55-57 \mathrm{~mm}$ dick. Das foramen vertebrale ist $15 \mathrm{~mm}$ hoch und $30-35^{\mathrm{mm}}$ breit. Der Dorn ist $55^{\mathrm{mm}}$ hoch, $53^{\mathrm{mm}}$ sagittal lang und $12-20^{\mathrm{mm}}$ transversal breit. Die vorderen processus articulares sind $30-35 \mathrm{~mm}$ lang, die hinteren kaum hervorragend, da die Gelenkflächen mehr und mehr in die Gelenkgruhe am hinteren Rande der Dornwurzeln rïcken. Der Querfortsatz ist an seiner Wurzel am Körper $37-40^{\mathrm{mm}}$, in der Mitte seiner Länge $28^{\mathrm{mm}}$, am dicken Ende $45-50 \mathrm{~mm}$ dick in verticaler Richtung bei $50^{\mathrm{mm}}$ sagittaler Breite; sein Ende ist quer alggeschnitten und trägt eine sehr rauhe, wulstige Endfläche von $40-50^{\mathrm{mm}}$ Durchmesser. Die Querfortsïtze, deren Wurzeln an der oheren Hältte der Körperseite entspringen, biegen sich in ganzer Länge soweit nach unten, dass ihre Enden um $30-32 \mathrm{~mm}$ tiefer als die Unterkante des Körpers herabreichen. Die Querfortsätze keines andern Wirbels sind so weit abwärts gebogen, sind so dick und tragen so grosse Ansatztlïchen an den Enden, als diejenigen dieses dritten Lendenwirbels. Berücksichtigt man zugleich, dass bei Halicore der Beclienknochen mittelst Kinorpelband am Querfortsatz des dritten Lendenwirbels hängt, so wird es wahrscheinlich, dass dieser dritte Lendenwirbel des Halitherium als Sacral-, die beiden vorhergehenden allein für vichtige Lumbal-Wirbel zu halten sind. Wenn nun auch möglicherweise das Linorpelband des Beckenknochens sich getheilt und sich auch an die Querfortsätze der beiden ersten oder nur des zweiten Lumbal-Wirbels angeheftet hätte, so wird doch jedenfalls der dickste Knorpelstrang an den dritten Lendenwirbel gegangen sein, weil dieser sowohl die grösste Ansatzfäche trägt, als am stärksten heruntergebogen ist. "Der nächst folgende Wirbel ist schon ein Schwanzwirbel, denn sein Körper zeigt am Rande der hinteren Synchondrosen-Fläche die Gelenkpfannen für das erste Paar Hämapophysen. Wir nehmen daher an, dass Halitherium zwei vertebrae lumbales und eine vertebra sacralis besass und dass vorwiegend oder allein an dem letzteren Wirbel der Beckenknochen mittelst Knorpelband aufgehängt war.

Die Querfortsätze der Schwanzwirbel nehmen vom ersten an gleichmässig an Länge und Dicke $a b$, ebenso wie die andern Theile derselben. Der Querfortsatz des ersten Schwanzwirbels ist $85^{\mathrm{mm}}$ lang (der ganze Wirbel $250^{\mathrm{mm}}$ transversal lang), an der Wurzel $50-52 \mathrm{~mm}$, am Ende $55^{\mathrm{mm}}$ sagittal breit und $22^{\mathrm{mm}}$ vertical dick: also ziemlich breite und platte Fortsätze, schon viel kürzer als diejenigen der Lendenwirbel. Der Querfortsatz trägt am Ende eine rauhe, $50^{\mathrm{mm}}$ lange und $25^{\mathrm{mm}}$ hohe Ansatzfläche ${ }^{1}$ ); sein Ende reicht nicht unter die Unterkante des Körpers herab. Der Körper ist $80^{\mathrm{mm}}$ lang, $60^{\mathrm{mm}}$ hoch und $53-55^{\mathrm{mm}}$ dick. Der Dorn bildet eine ähnliche Platte wie auf den Lendenwirbeln: er wird $50 \mathrm{~mm}$ hoch, $47 \mathrm{~mm}$ sagittal lang und $10-17 \mathrm{~mm}$ breit. Die Dornen der

1) Auch die Querfortsätze der Schwanzwirbel von Halicore und Manatus tragen solche rauhen Endfächen, an welchen sich ebenso wie an den Lendenwirbeln Knorpelbänder anheften. 
lumbo-caudal-Wirbel sind zwar an ihrem Hinterrande nicht so dick, als die der cervical- und dorsalWirbel, aber doch immer etwas dicker als an dem stets scharfen Vorderrande. Das foramen vertebrale ist $15^{\mathrm{mm}}$ hoch und $25^{\mathrm{mm}}$ breit. Die processus articulares anteriores werden $40^{\mathrm{mm}}$ lang und $20^{\mathrm{mm}}$ dick und sperren mit ihren Spitzen um $45^{\mathrm{mm}}$, an den Wurzeln nur um $12^{\mathrm{mm}}$ auseinander; die posteriores sind wie bei allen Schwanzwirbehn nicht mehr processus, sondern fossae articulares.

Die folgenden 14 Schwanzwirbel gleichen diesem ersten vollkommen, nur werden sie nach allen Richtungen hin immer kleiner; ihre Querfortsätze werden immer schmächtiger und biegen sich immer mehr mit ihren Enden nach hinten. Der zweite Schwanzwirbel hat mit den Querfortsätzen eine transversale Länge von $230 \mathrm{~mm}$, eine verticale Höhe von $120 \mathrm{~mm}$ mit dem Dorn; zugleich ist der Körper sagittal $58^{\mathrm{mm}}$ dick. Der dritte hat in diesen drei Maassen 210:115:50 mm; der vierte 190:110:50; der fünfte 170:105:50 (das foramen vertebrale desselben ist $20 \mathrm{~mm}$ breit und $10 \mathrm{~mm}$ hoch); der zehnte Schwanzwirbel 100:80:40. Der Querfortsatz des zelnten Wirbels steht so an der Seite des Körpers, dass er vor seiner Wurzel einen Raum von $7-8^{\text {mm }}$ frei lässt (welchen Raum der nach hinten ragende Querfortsatz des vorhergehenden Wirbels beuutzt) und sein zurückgebogenes Enle die hintere Fliche des Körpers um 12 m hinterragt. Der dreizehnte Schwanzwirbel ist 90 m lang, $55 \mathrm{~mm}$ hoch und sein Körper $35 \mathrm{~mm}$ dick. Der vierzelhnte Wirbel fehlt an diesem Skelett; doch wird er noch einen niedrigen Dorn besessen haben.

Dagegen vom fünfzehnten Schwanzwirbel an fällt der Dorn fort: der Wirbel besteht nur aus dem Körper, welcher auf den ersten Wirlohn noch einen oben offenen canalis vertebralis zeigt, und aus den Querfortsïtzen. Die letzteren sind anfangs etwas länger als diejenigen des 12-14. Wirbels und strecken sich gerade horizontal rom Körper nach aussen, ohne sich nach hinten zurückzubiegen. z. B. ist der siebzehnte Schwanzwirbel $95^{\mathrm{mm}}$ transversal lang, also länger als der dreizehnte, aber nur in den Querfortsïtzen; der Körper ist kleiner geworden, nämlich $40 \mathrm{~mm}$ breit, $28 \mathrm{~mm}$ hoch und $24-25^{\mathrm{mm}}$ dick. Der canalis vertebralis ist auf diesem Wirbel noch vorhanden; auch zeigt der Körper auf seiner Unterseite Ansatzflächen der Hämapophysen.

Sowohl der canalis vertebralis, als die fossae hämapophyseos werden den letzten Schwanzwirbeln gefehlt haben; nur die processus transversi werden bis auf den letzten, kleinsten Wirbel ausgehalten haben, wie dies bei Halicore der Fall ist. Doch wurden die letzten Schwanzwirbel des Halitherium, wie gesagt, noch nicht aufgefunden.

Während nun die Körper der Rücken- und Lenden-Wirbel eine ziemlich glatte, cylindrische Unterseite zeigen, finden sich an den Körpern der Schwanzwirbel die rauhen Gelenkitlächen für den Ansatz von V-fümigen unteren Bogenstiucken. Diese Hämapophysen sitzen mit ilıren oberen dicken Enden frei in den Synchondrosen zwischen zwei Schwanzwirbeln und hängen nach unten; sie hinterlassen an den Ründern der Wirbelkörper kleine Gelenkflïchen, welche meistens etwas vorstehende Ecken oder kleine Gelenkfortsätze erzeugen: wir sehen daher auf der Unterseite jedes Schwanzwirbels vier kleine Gelenkhöcker am Rande der Synchondrosen stehen; am ersten Schwanzwirbel deren nur zwei und zwar natürlich am hinteren Rande. Zugleich liufen zwei parallele Furchen in sagittaler Richtung über die Unterfläche des Körpers, die vorleren Gelenkhöcker mit den hinteren beiden ver- 
bindend. In diesen Furchen lagen die Gefässe, welche längs der Unterseite der Wirbelsäule zwischen den beiden Platten der Hämapophysen durchgingen.

Die Hämapophysen des Halitherium sind zwei V-förmig aneinander und sagittal gestellte dünne Knochenplatten; da die vorderen grösseren Paare immer getrennt von einander gefunden werden, so waren sie in ihrem Unterrande wohl nur durch Synchondrose verbunden, während die beiden Stücke der kleineren Hämopophysen der hinteren Schwanzwirbel öfters 'mit einander verwachsen sind; niemals aber wachsen sie an die Wirbelkörper fest. Eine grössere HämapophysenPlatte der vorderen Schwanzwirbel hat eine verticale Länge von $55 \mathrm{~mm}$; ihr oberes Ende ist $30 \mathrm{~mm}$ sagittal breit und hat einen halbkreisförmigen oberen, rauhen Gelenkrand. In der Mitte hat die $5-8^{\mathrm{mm}}$ dünne Platte durch concav eingebogene Seitenränder nur $24^{\mathrm{mm}}$ sagittale Breite. Der untere Rand ist $44^{\mathrm{mm}}$ lang, ist flach nach unten ausgebogen und zeigt innen die rauhe Gelenkfläche für die Verbindung mit der Gegenplatte. Ob das erste Hämapophysen-Paar anders gestaltet war, als die übrigen, wie bei Halicore und Manatus, ist mir nicht bekannt, da ich weder dieses Paar jemals an seinem Platze hinter dem ersten Schwanzwirbel fand, noch auch Knochenstucke kenne, welche etwa als erstes Hämapophysen-Paar gedeutet werden könnten. Von den oben beschriebenen V-förmigen Doppelplatten liegen mir aber eine ganze Reihe vor.

Die Wirbelsäule der lebenden Sirenen weicht nicht wesentlich von derjenigen des Halitherium ab. Im Ganzen verlängern sich die einzelnen Wirbel des Manatus, mit Ausnahme der Halswirbel, wie ja anch dessen Schädel schmaler und linger wird als der des Halitherium; umgekehrt verkïrzen sich die Wirbel der Halicore. Die Lïngenmansse beider heweisen diese Veränderung: die Wirbelsäule einer Halicore von $335^{\mathrm{mm}}$ Schädellänge erreicht eine Länge von $1^{\mathrm{m}} 83$ und enthält dabei 61 Wirbel, während rin Manatus von etwa gleichem Alter und 340 mn Schïldellïnge eine Wirbelsäule von $2^{\mathrm{m}} 12$ Länge besitzt, welche sich nur aus 51 Wirbeln zusammensetzt.

Die Halswirbel fügen sich nicht dieser Regel, sondern zeigen eine eigene Entwickelung: man hat hei Halicore an allen bisher beschriehenen Skeletten stets 7 Halswirbel gezählt, niemals ist cine Verwachsung derselben constatirt; es kïnnte dieselbe erwartet werden, weil offenbar die Sirenen die Tendenz haben, den dritten Halswirbel an den zweiten anwachsen zu lassen: denn bei Halitherium kommt, wie wir gesehen haben, zuweilen diese Verwachsung vor und bei Manatus ist sie die Regel. Die siehen Halswirbel jenes oben erwihnten Halicore-Skelettes haben zusammen eine Länge von $7,5 \mathrm{~cm}$, die sechs Halswirbel des Manatus eine solche von $8^{\mathrm{cm}}$, des Halitherium von $13 \mathrm{~cm}$, wobei zu bemerken ist, dass das Skelett des letzteren im Ganzen grösser wird als das der beiden ersten. Der Atlas der Halicore ist etwas dünner und grösser, als der des Halitherium: $120^{\mathrm{mm}}$ transversal, $80^{\mathrm{mm}}$ vertical; das foramen vertebrale ist $50^{\mathrm{mm}}$ transversal und $40^{\mathrm{mm}}$ vertical weit und wird durch eine starke Sehne gequert, welche den unteren Zahnraum abtrennt vom oberen Rückenmarksloch. Der Epistropheus und die übrigen Halswirbel sind ebenso gestaltet, wie bei Halitherium; die letzteren besitzen niedrige dünne Bögen: die foramina transversa der ersten zwei Wirbel sind nach aussen offen, der folgenden drei geschlossen im herabgebogenen Querfortsatz; dem letzten siebenten Halswirhel fehlt ein Querloch. Die 19 Rüickenwirhel der Halicore sind im ganzen ebenso gebildet wie bei Halitherium, nur etwas höher: und zwar ist das foramen vertebrale höher 
geworden, sodass die Dornen auf höheren Seitentheilen stehen; auch sind die Wirbel zierlicher gebaut. Das Köpfchen der ersten Rippe steckt zwischen dem siebenten Hals- und ersten Rüickenwirbel; an den letzten zehn Rückenwirbeln liegt die fossa costalis vorn an jedem einzelnen Körper, nicht melr in der Synchondrose; bei dem letzten, neunzehnten Riickenwirbel endlich verfliessen die fossa costalis und die fossa transversalis in eine einzige Pfanne, welche in der Mitte der Körperseite fast ohne Querfortsatz steht.

Während der 19. Rückenwirbel der Halicore eine transversale Länge von $76 \mathrm{~mm}$ zeigt und eine verticale Höhe von $110^{\mathrm{mm}}$, wovon $40^{\mathrm{mm}}$ auf den Körper, $23^{\mathrm{mm}}$ auf das foramen vertebrale und $47^{\mathrm{mm}}$ auf den Dorn kommen, erreicht der erste Lendenwirbel durch die langen Querfortsätze eine transversale Länge von $300 \mathrm{~mm}$; jeler Querfortsatz ist $115^{\mathrm{mm}}$ lang, am Körper $40^{\mathrm{mm}}$, am Ende $15^{\mathrm{mm}}$ sagittal breit und 8-12m vertical dick; am abgestumpften Ende sitzt an unserm Exemplar noch der Rest eines Ḱnorpelbandes. Die ebenso langen Querfortsätze der nächsten Lendenwirbel sind am Ende nicht spitz, sondern $30-35^{\mathrm{mm}}$ sagittal breit: am vierten Lendenwirbel hängt noch verbunden durch ein knorpeliges Band der Beckenknochen (Fig. 88); es ist dieser Wirbel allein demnach als Sacral-Wirbel zu betrachten; sein Querfortsatz ist $80^{\mathrm{mm}}$ lang und hat eine Endfläche von $35 \mathrm{~mm}$ Länge und $10^{\mathrm{mm}}$ Höhe für den Ansatz des Bandes.

Da nun erst zwischen dem sechsten und siebenten lumbo-caudal-Wirbel das erste Paar Hämapophysen hängt, so ist der auf den Sacral-Wirbel folgende Wirbel noch als ein fünfter Lendenwirbel oder als ein vierter lumbaler zu bezeichnen. Erst mit dem sechsten Wirbel beginnen die 31 vorhandenen Schwanzwirbel, welche bis zum letzten Querfortsätze entwickeln. An den letzten 14 Schwanzwirbeln fehlen die oberen Bögen, auch die Rïckenmarksfurche verschwindet bald. Die Querfortsätze biegen sich anfangs nach hinten, vom 17. an stellen sie sich gerade ab, endlich biegen sie sich an den letzten Wirbeln etwas nach vorn.

Zwischen dem sechsten und siebenten lumbo-caudal-Wirbel hängt ein von den übrigen in Gestalt sehr abweichendes Hämapophysen-Paar: zwei düme, freie, unten spitz zulaufende, $35^{\text {mm }}$ lange Knochenstïbe setzen sich oben mit $25^{\mathrm{mm}}$ sagittal breitem Gelenk in die Synchondrose; sie sehen aus, wie zwei kleine, rudimentäre Rippen. Vom zweiten Paar an sind es die gewöhnlichen V-förmigen Hïmapophysen-Platten, unten fest mit einander verbunden, oben mit Gelenk befestigt; diese sehen den Hïmapophysen des Halitherium sehr ähnlich; unsre Halicore besitzt 16 Paare derselben.

Am Atlas des Manatus ist der Querfortsatz der rechten Seite mit einem 3-4 ${ }^{\mathrm{mm}}$ weiten foramen transversum durchbohrt; der andern Seite fehlt dasselbe. Der Epistropheus hat einen verhältnissmässig dicken Körper: nämlich mit dem sehr kurzen $\left(10^{\mathrm{mm}}\right)$ Zahn $38^{\mathrm{mm}}$ sagittale Dicke bei $70^{\mathrm{mm}}$ transversaler Breite und $74^{\mathrm{mm}}$ verticaler Höhe (Halicore $35^{\mathrm{mm}}$ Dicke mit $17 \mathrm{~mm}$ langem Zabn, $70^{\mathrm{mm}}$ Breite und $80^{\mathrm{mm}}$ Höhe). Der etwas dicke Körper ist aber auch das einzige Merkmal, welches darauf hindeutet, dass der dritte Halswirbel mit dem Epistropheus vollständig verwachsen ist; dass dies der Fall ist, schloss schon J. Murie (l. c. pag. 137) aus anatomischen Gründen, und ist wohl nun dadurch festgestellt, dass die Verwachsung des zweiten und dritten Halswirbels öfters bei Halitherium vorkommt, ein Umstand, welcher jedenfalls die Tendenz dieser Verwachsung als vorhanden bei den Sirenen anzeigt. Dass Theile des dritten Halswirbels bei einzelnen Individuen 
von Manatus wirklich vorkommen, scheint nicht sicher constatirt zu sein: z. B. wird die Angabe von de Blainville, dass ein Manatus australis des Leidener Museums sieben Halswirbel besitze (1. c. Manatus pag. 49 und auf Taf. V gezeichnet), von J. Murie, welcher dasselbe Skelett untersuchte, dementirt (l. c. pag. 137). Doch bleiben die Angaben der sieben Halswirbel von Sir E. Home und Leuckart bestehen; es wïre ja möglich, dass die beiden Halswirbel bei einzelnen Exemplaren wenig oder gar nicht verwachsen sind.

Das Köpfchen der ersten Rippe sitzt in der Synchondrose zwischen dem sechsten Halswirbel und dem ersten Rückenwirbel. Unser Skelett enthïlt siebzehn Rückenwirbel, zwei Lendenwirbel (ohne Hämapophysen) und 26 Schwanzwirbel; die Reihe der 17 Rückenwirbel ist 89 m, die beiden Lendenwirbel $12^{\mathrm{cm}}$ und die 26 Schwanzwirbel $103^{\mathrm{cm}}$ sagittal lang. An andern Skeletten werden 22-26 Schwanzwirhel angegehen. Alle Wirbel sind im Verhältniss zu Halitheriun und Halicore in sagittaler Richtung verlängert. Dahei sind die Rückenwirbel breit; die Dornen niedrig, klein, gerade in die Höhe stehend und durch die Länge der Wirbel weiter von einander getrennt, als bei jenen.

Die beiden Lendenwirbel und die ersten Schwanzwirbel haben sehr grosse Querfortsätze: der letzte (17.) Rückenwirbel hat $87^{m}$ transversale Länge, der erste Lendenwirbel 220 mm, der zweite $300 \mathrm{~mm}$, der erste Schwanzwirbel $315^{\mathrm{mm}}$, der zweite ebensoviel; von da ab nimmt diese Länge regelmässig nach hinten ab. Die letzten 12 Caudal-Wirbel besitzen keine Bügen und die letzten 8 auch keine Querfortsätze mehr. Der zweite Lendenwirbel kann als sacralis angesehen werden, da sein Querfortsitz durch ein Ligament mit dem rudimentären Beckenknochen verbunden ist (J. Murie 1. c. pag. 140). Bei Manatus wird also die Anzahl aller vier Kategorien von Wirbeln verringert, dagegen die sagittale Länge jeles Wirbels, mit Ausnahme der Halswirbel, vergrössert im Verhältniss zu Halitherium und Halicore: es gibt Manatis, welche nur 47 Wirbel haben, höchstens werden es 51, während Halitherium mindestens 54 Wirbel und Halicore 59-61 Wirbel besitzen.

Von den 12 Paar Hämapophysen besteht das erste Paar wieder wie bei Halicore aus zwei isolirten Knochenstäben: jeder Stab ist $80^{\mathrm{mm}}$ lang, oben am Gelenk $20 \mathrm{~mm}$ sagittal breit, nach unten spitz und dünn zulaufend. Diese Rippen-artigen Hämapophysen biegen sich nach hinten dem zweiten Paar entgegen. Die übrigen Hämapophysen setzen sich zusammen je aus zwei dünnen Platten, welche sich V-förmig aneinanderlegen und bei jungen Thieren sich bei der Maceration von einander trennen.

Für die Wirbelsåule der Rhytina gibt zwar von Nordmann 6 Hals-, 17 Rücken-, 1 Lendenund 34 Schwanzwirhel an $^{1}$ ), indessen müssen diese Zahlen nach Nordmann's eigenen Angaben rerbessert werden. Den siebenten Wirbel hïlt ron Fordmann trotz „einer grossen Aehnlichkeit mit dem sechsten Wirbel" für den ersten Riuclienwirbel, weil „seine Querfortsïtze nicht durchbohrt sind und auf seiner hinteren Fläche, für den Ansatz des ersten Rippen-Pares Gelenkflächen sich befinden";

1) Steller sagt ron den Wirbeln: svertebrae in universum 60 sunt; 6 colli, 19 dorsi, 35 caudae. Costarum verarum 5 paria, spuriarum $12 \%$. Diese 17 Rippen stehen im Widerspruch zu den 19 Ruickenwirbeln. Siehe die Anmerkungen 3 und 5 auf der folgenden Seite. 
diese beiden Eigenschaften kommen aber, wie wir gesehen haben, gerade dem letzten Halswirbel der andern drei Sirenen zu: denn derselbe entbehrt des foramen transversum, und das Köpfchen der ersten Ripue sitzt stets in der Synchondrose zwischen dem letzten Hals- und ersten Riickenwirbel "). Den fraglichen Wirbel hat von Nordmann Taf. III Fig. 7 abgebildet: es kann kein Zweifel sein, dass derselbe der letzte Halswirbel ist ${ }^{2}$ ). Rhytina besass demnach sieben, nicht sechs Halswirbel, wie Halicore.

Zweitens gibt von Nordmann an, dass sechs Wirbeln weder Rippen noch Hämapophysen zukommen: wir haben also sechs Lendenwirbel, wenn diese Angabe richtig ist ${ }^{3}$ ). Trotzdem rechnet Nordmann nur den ersten der sechs als Lendenwirbel, weil "es auf keinen Fall zulässig ist, sechs Lenden-Sacralwirbel für ein dem Dugong und Manatus so nahe stehendes Thier anzunehmen". Um so weniger können die fünf Wirbel zu den Schwanzwirbeln gerechnet werden, als die ersten der sechs Lendenwirbel gar nicht mal die längsten Querfortsätze besitzen, sondern der vierte ${ }^{4}$ ) der transversal längste Wirbel zu sein scheint; bei den andern Sirenen nahmen aber die Schwanzwirbel regelmässig vom ersten an nach hinten an transversaler Länge $a b$.

Rhytina hat demnach 7 Hals-, 17 Rücken-, 6 Lenden- und 29 Schwanzwirbel, im Ganzen also 59 Wirbel nach Nordmann, während nach den Angaben von Steller zwei Lenden- und 35 Schwanzwirbel, also im Ganzen 61 Wirbel vorhanden waren ${ }^{5}$ ). Im Allgemeinen gleichen die Wirbel in ihrer Form sehr denen der Halicore, während sie natürlich viel grössere Dimensionen annelımen; im Text

j) Auch bei den meisten andern Säugethieren entbehrt der letzte Halswirbel eines foramen transversum und trägt an dem Hinterrande seines Körpers eine halbe Gelenkpfanne für die erste Rippe.

$\left.{ }^{2}\right)$ Auf der Photographie, welche mir E. von Nordenskjöld von dem in Stockholm aufgestellten Skelett der Rhytina Stelleri schickte, sind gleichfalls fünf freie Halswirbel hinter dem Epistropheus zu sehen. Von der Beschreibung der auf der Vega mitgebrachten Skelette werden wir noch manchen Aufschluss über die Osteologie der Rhytina zu erwarten haben.

${ }^{3}$ ) Da Steller die Hämapophysen kannte: sos latum planum figura Lamdae Graecorum und angibt, dass alle 35 Schwanzwirbel solche unteren Apophysen gehabt hätten, Nordmann aber an dem ibm vorliegenden Rhytina. Skelett vicht mehr die Hämapophysen selbst, sondern nur ihre Ansatztlächen unten an den Wirbelkörpern constatirt, so liegt die Annabme nahe, dass vielleicht die Ansatzflächen an den vorderen Schwanzwirbeln an Nordmann's Skelett nicht mehr gut erhalten waren. Dann hätten wir mit den weiteren, unten erwähnten Korrectionen der Steller'schen Angabe: 17 Rücken-, 2 Lenden- und 35 Schwanzwirbel. Indessen enthält die Steller'sche Beschreibung in der That zuviel Ungenaligkeiten oder Fehler, un seine Angaben vor denen anderer Forscher als massgebend hinstellen zu können.

4) von Nordmann gibt für die transversale Länge des ersten Lendenwirbels $484 \mathrm{~mm}$, für den vierten $612 \mathrm{~mm}$; von den andern erwähnt er nicht die Maasse.

5) Welcher von den Leudenwirbeln etwa als sacralis anzusehen wäre, ist bis jetzt noch nicht festgestellt: Steller ist der einzige, welcher die Verbindung des Beckenknochens mit den Wirbeln beobachtete; er sagt darüber: »loco ossis innominati coxae duo ossa, utrimque unum magnitudine et forma ulnam sceleti bumani referentia, ac fortissimis ligamentis ex una parte vertebrae 35 ex altera ossis pubis junguntur . Brandt 1. c. pag. 98 und Nordmann pag. 6 corrigiren beide die Zahl 35 als Druckfehler in 25 . Diese Verbesserung hat viel fïr sich, ist aber natürlich unsicher; es wäre dann mit Brandt anzunehmen, dass Steller zu seinen 17 Rippen-tragenden Wirbeln auch die beiden folgenden Lendenwirbel, von denen der zweite der sacralis wäre, mit zu seinen 19 Kückenwirbeln rechnete. Der Rhytina wïrden demaach nach Steller's corrigirten Angaben zukommen: 17 Rüeken-, 1 lumbal-, 1 sacral- und 35 Schwanzwirbel. 
gibt Nordmamn nicht die ganze Länge der ihm vorliegenden Wirbelsäule an, nach seiner Zeichnung hätte dieselbe eine Länge von $4^{\mathrm{m}} 65$ gehabt $\left.^{\mathrm{P}}\right)$.

Vergleichen wir die Wirbelsäulen der vier Sirenen mit einander, so kamen dem Halitherium 54 Wirbel zu auf eine Länge der ganzen Säule von $2^{\mathrm{m}} 23$; dem Manatus $47-51$ auf eine Länge von etwa $2^{\mathrm{m}}-2^{\mathrm{m}} 12$; der Halicore 59-61 Wirbel auf etwa $1^{\mathrm{m}} 80-1^{\mathrm{m}} 95$ der ganzen Säule; der Rhytina nach von Nordmann 59 Wirbel mit $4^{\mathrm{m}} 65$, nach Steller 61 Wirbel mit vielleicht $6^{\mathrm{ns}}$ Länge. Halitherium, Halicore und Rhytina besassen sieben Halswirbel, Manatus in der Regel deren nur sechs. Der Gestalt nach sind die Wirbel des Halitherium die dicksten, der Rhytina die grössesten, der Halicore die kürzesten, des Manatus die långsten und zierlichsten. Die Wirbel aller Sirenen sind sämmtlich wahre Wirbel, das heisst keiner ist mit dem andern verwachsen, mit der einzigen Ausnalıme, dass der zweite und dritte Halswirbel zuweilen bei Halitherium, in der Regel bei Manatus mit einander verwachsen. Die Wirbelsäule der Sirenen zeichnet sich aus durch den langen, horizontal ausgestreckten, vielwirbeligen Schwanztheil, durch die starken Querfortsätze der Lendenwirbel, durch die verhältnissmässig kleinen Dornen der Wirhel und durch die sehr kurze Reihe der Halswirbel. Alle diese Eigenthümlichkeiten sind darauf zuriickzuführen, dass diese Thiere, ebenso wie alle andern Theile ihres Körpers, so auch die Wirbelsäule anpassten ihrer Bewegung und ihrem Leben im Wasser.

\section{Costae.}

Die Rippen des Halitherium besitzen eine so auffallende Dicke und Grösse, dass man versucht ist, zu glauben, dieselben wären durch Infiltration fremder Stoffe nachtrïglich in den Meeressanden aufgequollen und versteinert; dazu ist die Structur derselben eine so dichte und der Bruch so glïnzend, dass man an Verkieselung denkt. Indessen kommt die dichte Structur fast allen Knochen der Sirenen zu. Sodamn müssten durch Infiltration doch die verschiedenen Rippen ein und desselben Thieres und noch mehr diejenigen der Skelette verschiedener Fundorte in verschiedener Weise verändert scin, was nicht der I'all ist: nicht nur alle in Rheinhessen und an der Nahe gefundenen Halitherien. auch die von Linz an der Donau, die aus dem Elsass, die französischen und italienischen haben dieselben ungewöhnlich dicken und schweren Rippen. Iazu sind die Küpfchen und Höcker der Rippen passend zu den Wirbeln. Endlich hahe ich eine chemische Analyse eines Rippenstiickes von einem Halitherium von Alzey machen lassen, wie ich in dem Vorwort erwähnte, und dieselbe hat keinerlei Verïnderung in der Zusinmmensetzung des Knochens constatirt, obschon diese Rippen fest in einem Kieselsandstein eingebettet ligen. Auf dem Bruch dunkelbraun und glianzend wurde die Rippe fast vollständig in Salzsïure aufgelöst; der kleine Rest bestand aus Sandkörnchen, die an der Oberfläche der Rippe hafteten und den geringen Gehalt an Kỉeselsïure in der Analyse erklïren. Das specifische Gewicht betrug bei $15^{\circ} \mathrm{C} 2,96$. Die Farbe des Pulvers war braun. Die Analyse ergab die folgende Zusammensetzung:

1) Mit dem Schädel von $59 \mathrm{~cm}$ Länge wäre das ganze Skelett $5 \mathrm{~m} 24$ lang gewesen, demnach ein sehr kleines und nach den unverwachsenen Gelenkköpfen der vorderen Extremität auch ein sehr junges Thier: denn Steller gibt als Länge der Rhytina, allerdings mit den Weichtheilen, 7 m 80 an. 


$$
\begin{array}{rl}
\mathrm{Si} \mathrm{O}^{2} & =0,133 \\
\mathrm{Al}^{2} \mathrm{O}^{3} & =0,138 \\
\mathrm{Fe}^{2} \mathrm{O}^{3} & =0,441 \\
\mathrm{C} \mathrm{O}^{2} & =6,813 \\
\mathrm{SO}^{3} & =1,217 \\
\mathrm{P}^{2} \mathrm{O}^{5} & =36,333 \\
\mathrm{CaO} & =51,460 \\
\mathrm{MgO} & =0,253 \\
\mathrm{H}^{2} \mathrm{O} \text { und organ. Subst. }=3,200 & 99,988
\end{array}
$$

Spuren von $\mathrm{Mn} \mathrm{O}, \mathrm{Ka}^{2} \mathrm{O}, \mathrm{Na}^{2} \mathrm{O}, \mathrm{Cl}$, Fe.

Diese Stoffe sind wahrscheinlich in folgender Weise vertheilt:

$\begin{array}{lrr}\text { Sand (in } \mathrm{H} \mathrm{N}^{3} \text { unlöslich) } & =0,133 \\ \text { Phosphorsaurer Kalk } & =77,392 \\ \text { Kohlensaurer Kalk } & =15,484 \\ \text { Schwefelsaurer Kalk } & 2,069 \\ \text { Phosphorsaure Magnesia } & 0,552 \\ \text { Phosphorsaure Thonerde } & =0,327 \\ \text { Phosphorsaures Eisenoxyd } & =0,831 \\ \text { Wasser und organische Substanz }= & 3,200 \\ & 99,988\end{array}$

Es scheint demnach die ursprüngliche Zusammensetzung der Rippe nicht verändert zu sein, denn die obige Analyse entspricht ungefähr derjenigen der Knochen der meisten Säugethiere. Die dichte Structur und die Dicke der Rippen beruht demnach auf keiner Umwandlung der Knochensubstanz, sondern ist die auch den lebenden Sirenen eigenthümliche, natïrliche' Art und Gestalt derselben ${ }^{1}$ ).

Das Halitherium besitzt an jeder Seite 19 Rippen, von denen nur die ersten etwas abgeplattet sind, die andern einen, wenn auch nicht ganz lireisrunden, so doch einen breit-elliptischen Querschnitt zeigen. Die Rippen standen, wie es scheint, sehr nahe beieinander, sodass die Intercostalräume ungewöhnlich schmal waren: denn bei einer durchschnittlichen sagittalen Dicke von $45^{\text {mam }}$ nehmen die 19 Rippen dicht aneinandergeschlossen eine Flïche von $85^{\mathrm{cm}}$ sagittaler Länge ein, während die 19 Rückenwirbel eine Säule von $100^{\mathrm{cm}}$ Länge bilden; allerdings strecken sich die letzten Rippen nach hinten. Auch habe ich die Dicke der Synchondrosen bei der Länge von $100^{\mathrm{cm}}$ kaum gerechnet, da ich die Wirbel ziemlich dicht aneinander gelegt hatte; doch kann dieselbe nicht viel mehr ausmachen, da die processus articulares doch aufeinander passen müssen. Demnach war die Brusthöhle des IIalitherium durch

1) Siehe unten die chemische Analyse einer Rippe des Halitherium von Lioz an der Donau; dieselbe zeigt fast die gleiche Zusammensetzung, was ebenfalls ein Beweis für die unveränderte Substanz der Knochen ist. 
die dicken, dicht aneinander liegenden Rippen selrr gut geschützt vor Angriffen von aussen. Doch kann dieser Schutz kaum ein Grund sein für die auffallende Dicke der Rippen.

Die capitula sind bei den ersten Rippen wohlausgebildete, zweillichige Köplfchen, abgeschnürt durch einen schlanken, langen Hals von dem hohen tuberculum; daher zeigen die ersten Rippen ziemlich grosse foramina costo-transversaria. Je weiter nach hinten, um so dicker wird Kopf und Hals, um so kürzer die Entfernung zwischen capitulum und tuberculum und um so unbedeutender tritt der Höcker hervor. Die hintersten Rippen besitzen kaum noch einen Hals, und an der letzten Rippe verschmilzt Köppfchen und Ilöcker in einer rauben Gelenkfläche, welche an letzten Rückenwirbel auf einem ganz kurzen Querfortsatz angeheftet war. Ich erwähnte bereits bei den Wirbehn, dass die Mehrzahl der Rippen ihren Kopf in die Synchondrose setzt, welche vor dem Querfortsatz liegt, an den sich der Höcker stützt, wie das bei den meisten Säugethieren der Fall ist ${ }^{1}$ ); daher steckt die erste Rippe zwischen dem letzten, siebenten Hals- und dem ersten Rückenwirbel.

Die Längen der Rippen nehmen bis zur sechsten zu; dann bleiben sie $60-63^{\mathrm{cm}}$ lang und $4-5^{\mathrm{cm}}$ dick; von der fünfzehnten an nimmt die Länge wieder ab. Am äusseren Rande herumgemessen vom Köpfchen bis zum Ende besitzen die Rippen des $2^{\mathrm{m}} 60$ langen Skelettes eine Lünge von: $26^{\mathrm{cm}}$ der ersten und $15^{\mathrm{cm}}$ in der Sehne gemessen; zweite Rippe $36^{\mathrm{cm}}$ im äusseren Bogen und $24^{\mathrm{cm}}$ in der Sehne; die dritte 44 und 27 ; die vierte 53 und 32 ; die fünfte 60 und 38 ; die sechste 63 und 44; die fünfzehnte 53 und 42 ; die sechzehnte 48 und 40; die siebzehnte 45 und 40 ; die vorletzte 35 und 30 ; die letzte 20 und $18^{2}$ ).

Die erste Rippe des Halitherium ist ungewöhnlich stark verbreitert; ich habe eine solche auf Taf. VII Fig. 78 und ihre wohlausgeprägten Kiöpfchen Taf. VI Fig. 70 abgebildet: man sieht den hohen Höcker und den stumpfen Winkel, angulus costae, ausserhalb desselben ziemlich nahe gerïclit dem tuberculum. Das foramen costo-transversarium ist bei der Länge des dünnen Halses hier ziemlich gross, nämlich $25^{\mathrm{mm}}$ lang und $10^{\mathrm{mm}}$ hoch. Die breite Fläche der Rippe steht im Körper schräg von vorn innen nach hinten aussen und hängt zugleich gerade herunter, sodass sie den Brustkasten vorn beschützt. An ihrem Ende sieht man die grosse rauhe Ansatzfläche für den Brustbeinknorpel. An der inneren Fläche der Rippe steigt von oben nach unten mit Biegung nach aussen ein $7-10^{\mathrm{mm}}$ breiter und $100^{\mathrm{mm}}$ langer Gefässkanal herab, in welchem wohl die Aorta subclavia lag ${ }^{3}$ ).

Die unteren Enden der beiden ersten Rippen entfernten sich mit ihren medialen Ecken an dem Skelett von $2^{\mathrm{m}} 60$ Länge um $19^{\mathrm{cm}}$ von einander, ihre Köpfchen um $5^{\mathrm{cm}}$; sie ragten wenig schräg nach aussen, da der Winkel im angulus costae etwa $105^{\prime \prime}$ beträgt.

Das breite Brustbein ragte mit seinem vorderen freien Theil hoch herauf in den Zwischenraum zwischen die beiden ersten Rippen, da sich deren Knorpel erst am hinteren Theil des vorderen Brustbein-Stickes anhefteten, gerade wie bei den lebenden Sirenen und den meisten Säugethieren

1) Meckel I. c. II. 2. pag. 297. Nur die Cetaceen machen von dieser Regel eine Ausnahme, da bei ihnen jeder Wirbel nur eine Rippe trägt und zwar auf der hinteren Seite des Körpers; der Höcker der Rippe legt sich an den Querfortsatz des nächstfolgenden Wirbels.

2) Taf. VI Fig. 71 ist die letzte Rippe eines ganz jungen Thieres.

s) J. Murie, Manatus pag. 176 und Fig. 30. 
überhaupt. Wahrscheinlich waren die nächsten drei Rippen auch noch durch Kinorpelbänder am Brustbein befestigt, da dieselben an ihren Enden grössere rauhe Ansatzflïchen tragen, als die fulgenden; Halitherium besåsse demnach vier wahre und 15 falsche Rippen.

Die Biegung der Rippen ist eine verschiedene. Bei allen tritt der angulus costae deutlich hervor und ist in demselben die Biegung jeder Rippe am stïrksten; die meisten Rippen verbreitern sich auch in dem angulus und zeigen demnach daselbst einen nach aussen und oben gerichteten schmalen Grat. Die vorderen Rippen werden fast nur einfach in einer Fläche gebogen; die hintersten beiden strecken sich auch einfach gebogen nach hinten. Die mittleren aber zeigen eine doppelte Biegung, gerade wie beim Menschen, sowohl nach unten, wie die vorderen und hintersten, als mit ihrem unteren Theil wach hinten, sodass die Rippen in der Weise einer flachen Schraubenlinie sich krümmen ').

Die Rippen der lebenden Sir en en sind viel dünner als diejenigen des Halitherium, dabei werden die Rippen der Halicore und der Rhytina zwar flacher als bei Halitherium, aber nicht so breit und platt als die des Manatus. Ihre innere Knochenstructur ist sehr dicht ${ }^{2}$ ), doch ist bei genauerer Betrachtung eine Diploë deutlich zu unterscheiden, was bei den fossilen Sirenen nicht der Fall ist. Ihre erste Rippe wird bei weitem nicht so breit als bei Halitherium ${ }^{3}$ ); bei allen drei Gattungen setzt sie ihr Köpfchen in die Synchondrose zwischen den letzten Hals- und den ersten Rückenwirbel, sodass der erstere Wirbel auch in der Regel an dem Hinterrande seines Körpers eine halbe Gelenkpfinne zeigt. Die folgenden Rippen stützen ebenfalls ihre capitula in die Synchondrosen, erst die letzten stehen seitlich an nur einem Wirbelkörper. Der letzten Rippe fehlt regelmässig der Höcker, welcher mit dem Kö̈pfchen in ein Stück verschmolzen ist; der Querfortsatz dieses letzten Rückenwirbels ist ebenso unbedentend wie bei Halitherium.

Die erste Rippe der Halicore unsres Skelettes von $2^{\mathrm{m}} 16$ Länge ist längs ihrer äusseren Kante $16^{\mathrm{cm}}$ lang; in der Beugekante, welche $40^{\mathrm{mm}}$ vom Köppchen entfernt liegt, wird die Rippe am breitesten, nämlich $30^{\mathrm{mm}}$; sonst ist sie schmäler, also im Ganzen bedeutend schwächer als bei Halitherium; der Höcker ist, wie bei den andern rorderen Rippen gut ausgebildet und verhältnissmibsig hoch. Die zweite Rippe ist $24^{\mathrm{cm}}$ langr , die dritte $31 \mathrm{~cm}$; die folgenden ungefähr gleich lang mit

1) Auf Taf. VII Fig. 86 habe ich einen Knochen abbilden lassen, welcher jedenfalls zum Skelett des Halitberium gehört; ein ganz ebensolcher wurde mit dem Skelett gefunden, welches ron Ufthofen stammt und im Berliner Museum aufgestellt ist. Der Kuochen ist an der einen Seite 20-30 mm dick, abgerundet dreikantig; an der andern läuft er spitz zu. Mit dem dicken Ende scheint er an andern Knochen frei angesessen zu haben. Ich wüsste diesen Knochen nicht anders zu deuten, als dass er eine rudimentäre Rippe gewesen sei, welche etwa den letzten Halswirbeln angesessen hätte; solche rudimentären Rippen kommen, wenn auch selten, an den Halswirbeln des Manatus vor.

2) Steller sagt von der Structur der Rippen der Rhytina: scostae tam verae, quam spuriae omnes solidae, valde ponderosae et crassae sunt

$\left.{ }^{3}\right)$ Bei den meisten Säugethieren und auch beim Menschen ist die erste Rippe breiter als die andern (Meckel, 1. c. II. 2. pag. 301). Die erste Rippe sitzt mit ihrem Köpfchen stets in der Synchondrose hinter dem letzten Halswirbel und stützt ibren Höcker an den Querfortsatz des ersten Rückenwirbels; nur bei den Cetaceen liegt die Gelenkpfanne der ersten Rippe ganz am Körper des letzten Halswirbels, der Höcker aber am Querfortsatz des ersten Rüickenwirbels. 
$40-43^{\mathrm{cm}} \mathrm{im}$ äusseren Bogen uud $28-31^{\mathrm{cm}}$ in der Sehne gemessen. Der Querschnitt der Rippen ist elliptisch mit 15 auf $25^{\mathrm{mm}}$. Die vorletzte, 18. Rippe wird $35^{\mathrm{cm}}$, die letzte $30^{\mathrm{cm}}$ lang mit $27^{\mathrm{cm}}$ und $23^{\mathrm{cm}}$ Sehne. Die hinteren Rippen werden immer dünner: die 18, hat noch 10 auf $20 \mathrm{~mm}$; die letzte hat oben noch $20 \mathrm{~mm}$ sagittale Breite, rerschmälert sich nach unten auf $10^{\mathrm{mm}}$ und ist dabei nur $10^{\mathrm{mm}}$ dick. Diese Halicore ist allerdings ein noch nicht altes und wahrscheinlich ein weibliches Thier gewesen; bei alten mämnlichen Thieren werden die Rippen etwas länger und dicker sein; doch niemals erreichen die Rippen der Halicore die unförmliche Grösse derjenigen des Halitherium. Ausserdem biegen sich die Rippen der Halicore nur einfach convex nach aussen in der transversalen Ebene, sie wenden ihre Enden nicht zugleich nach hinten, wie bei Halitherium und Manatus. Der ganze Rippenkorb der Halicore hat eine transversale Breite von $46^{\mathrm{cm}}$, eine verticale Höhe von $25 \mathrm{~cm}$; des Halitherium $65-70^{\mathrm{cm}}$ und $40^{\mathrm{cm}}$; des Manatus australis $52^{\mathrm{cm}}$ und $23-24^{\mathrm{cm}}$.

Die Rippen des mir vorliegenden Manatus australis von $2^{\mathrm{m}} 46$ Länge des ganzen Skelettes sind wie gesagt platter, als die der andern Sirenen, ihre Flächen stehen sagittal, und ihre grösste Breite liegt in der Beugekante. Die erste Rippe ist 23 'm lang, dabei nicht breiter, als die übrigen Rippen, die zweite ist $29^{\mathrm{cm}}$, die dritte $34^{\mathrm{cm}}$, die folgenden $41-43^{\mathrm{cm}}$ lang; in der Mitte beträgt ihre sagittale Breite $40-50 \mathrm{~mm}$, ihre transversale Dicke $10-15 \mathrm{~cm}$. Diese Rippen sind ebenso doppelt gebogen, wie die des Halitherium und endigen spitz; nur die drei ersten heften sich mittelst Knorpelbändern an das Brustbein. Die drittletzte, 15 . Rippe ist $37 \mathrm{~cm}$ lang, die 16. ist $33 \mathrm{~cm}$ und die letzte $22^{\mathrm{rm}}$ lang. Die letzte ist gerade gestreckt, nach hinten gerichtet und besitzt kein tuberculum; ihr Köpfchen sitzt auf dem kurzen Querfortsatz des letzten Rückenwirbels ').

Rhyt in a besitzt nach Steller und von Nordmann 17 Rippen ${ }^{2}$ ), welche, wie der letztere pag. 26 hemerkt, denen der Halicore gleichen. Dic erste Rippe stïtzt ihr Köpfchen, wie wir gesehen haben, ebenso wie bei den andern Sirenen, zwischen den letzten Hals- und ersten Brustwirbel; sie hat einen dicken Hals und die Entfernung zwischen capitulum und tuherculum ist rerlültnissmässig geringer, als hei Halitherium. An dem jungen Slielett von 5 m 24 Länge, welches von Nordmann vorlag, wird die erste Rippe $300 \mathrm{~mm}$ lang und am Ende $78^{\mathrm{mm}}$ breit und $37^{\mathrm{mm}}$ dick; die zweite Rippe ist schlanker, als die erste, und wird $427^{\mathrm{mm}}$ lang. Die 11. Rippe ist die längste mit $820 \mathrm{~mm}$; ihr Ende wird $50^{\mathrm{mm}}$ breit und $35^{\mathrm{mm}}$ dick. Die letzte Rippe ist nur $676^{\mathrm{mm}}$ lang. Die Rippen der Rhytina gleichen auch darin den Halicore-Rippen, dass sie einfach nach abwïrts gekrümmt sind und nicht zugleich die zweite Biegung nach hinten zeigen; dabei strecken sich die letzten Rippen, wie gewöhnlich, im Ganzen etwas nach hinten; die letzte Rippe ist am wenigsten gekrimmt. Der Querschnitt der Rippen ist nicht so rund, wie derjenige der Rippen des Ialitherium, nicht so platt wie bei Manatus, sondern mehr elliptisch wie bei Halicore. Nach Steller legen sich fünf Paar Ripnen an das Brust-

3) Nach Krauss kommen bei Manatus australis neben meistens 17 auch 16 Rippen vor, und das weibliche Skelett, welches J. Murie vorlag, von Manatus australis besass deren 18.

3) 17 Rippen und demnach 17 Rückenwirbel kommen sicher der Rhytina zu; auch die Photopraphie des Stockholmer Skelettes weist 17 dicke, grosse Rippen auf. 
bein. Bei der Rhytina erscheinen die Rippen fast ebenso ungewöhnlich dick und gross, wie bei Halitherium; sie stehen auch ziemlich dicht bei einander; ihr Ende ist quer abgestumpft wie bei Halicore, nicht zugespitzt wie bei Halitherium und Manatus.

\section{Os hyoides.}

Das Zungenbein des Halitherium ist mir leider noch nicht bekannt geworden; es fehlte jedenfalls nicht, sowohl weil die lebenden Sirenen Zungenbeine besitzen, als weil die Bandansätze des Zungenbeins an der Schädelbasis des Halitherium vorhanden sind (siehe oben pag. 5). Das Zungenbein der Halicore ist normaler und complicirter als das des Manatus: ein verhältnissmässig kleiner, platter Körper trägt zwei lange und platte cornua majora und zwei schmächtige, kurze cornua minora; die grossen Hörner sind mittelst Knorpelbändern an dem processus jugularis ossis occipitis und processus mastoideus ossis temporum angeheftet. Dagegen fehlen dem Zungenbein des Manatus die kleinen Hörner; an dem Skelett des Manatus australis von $2^{\text {m }} 46$ Länge hat der Körper des Zungenbeins eine transversale Länge von $37^{\mathrm{mm}}$, eine Breite von in der Mitte $11 \mathrm{~mm}$, an den Enden $17^{\mathrm{mm}}$ und eine Dicke von $4-5^{\mathrm{mm}}$. Die durch kurze Knorpel mit dem Körper verbundenen cornua majora sind $88^{\mathrm{mm}}$ lang, unten platt und $15^{\mathrm{mm}}$ breit, oben rund mit $13-14^{\mathrm{mm}}$ Durchmesser. Das Zungenbein der Rhytina ist noch unbekannt, da weder Steller, noch Brandt, noch von Nordmann dasselbe erwähnen.

\section{Sternum.}

Ein vollständiges Brustbein des Halitherium haben wir Taf. VI Fig. 73-75 abgebildet. Dasselbe besteht aus drei gesonderten linochenstücken, welche in ihrer Form bei verschiedenen Individuen etwas variiren; ich habe daher das vordere Stuick des Brustbeines eines andern Thieres Fig. 63 und das eigenthümlich verbogene hintere Stuick Fig. 62 abzeichnen lassen. Das Brustbein findet sich in der Regel noch mit den übrigen Skelettheilen in den Meeressanden, da diese Knochen gross und schwer genug waren, um nicht fortgespïhlt zu werlen, und wohl auch, durch starke Knorpelbänder an den ersten vier Rippen befestigt, längere Zeit an diesen hängen blieben; nur das kleine mittlere Stück gelst zuweilen verloren.

Das vordere Stück des Brustbeines entspricht dem manubrium, das mittlere kleine dem corpus, das hintere lange schmale dem processus ensiformis hominis. Da sich bei Halitherium nur so wenig Rippen am Brustbein befestigen, nämlich woll nur vier, so ist der Körper in seiner Länge ausserordentlich reducirt; denn je mehr Rippen sich an dem Brustbein der Säugethiere anheften, um so länger wird der Körper, da er sich zusammensetzt aus einzelnen, hintereinander gereihten Stücken, von denen jedes das mittlere Schlusstück eines Rippenpaares bildet, also dem Körper des Zungenbeins homolog ist.

Am manubrium ist der ganze Rand des vorderen Theiles scharf und ohne Einschnitte von Rippenansätzen, sodass das erste Rippenpaar sich mittelst seiner Knorpelbänder erst $6-8^{\mathrm{cm}}$ hinter 
dem vorderen Ende des Brustbeins anheftete. Die nach innen und oben gekehrte Fläche ist ebener und glatter, als die äussere Fläche; die letztere trägt vorn immer eine mehr oder weniger stark vorspringende crista, welche an die crista sterni der Vögel erinnert ${ }^{1}$ ). Die crista ist am höchsten nahe der vorderen Spitze des Brustbeins und reicht verschieden weit herab: bei den Stiicken Fig. 75 und 63 etwa bis zur Mitte, bei andern ist sie zuweilen nur halb so lang. Am hinteren Theil des Seitenrandes des manubrium zeigt eine flache Auskerbung und rauhe, abgestumpfte Randflächen den Ansatz von Rippen-Bandmasse an, und zwar scheint der Ansatz für die erste Rippe, entsprechend dem breiten Ende derselben, eine ansehnlich lange gewesen zu sein. Der hintere Rand ist sehr rauh, hoch und breit; jedenfalls befestigte sich der Körper nicht direct an diese Fläche, sondern wie Halicore durch Knorpelmasse, ebenso wie der processus ensiformis an das corpus; daher passen die gegenstehenden Ränder nicht genau aneinander.

Die Dicke des manubrium ist bei verschiedenen Individuen ziemlich viel verschieden: die grösste verticale Dicke liegt meist in der crista, bei Fig. 63 mit $24^{\mathrm{mm}}$, wobei in der Regel sich die obere Fläche flach auskehlt. Der hintere Rand ist in der Mitte $20 \mathrm{~mm}$ dick; doch kommen auch weniger dicke manubria vor.

Das corpus (Fig. 74) ist ein oblong oder quadratisch gestaltetes Knochenstück mit abgerundeten Ecken von $15-18^{\mathrm{mm}}$ Dicke. Rippen-Ansïtze erscheinen nur an den Ecken, die Mitte der Seitenrïnder ist ohne Ansatzfliachen und glatt alggerundet. Der vordere und hintere Rand ist breit und sehr rauh und höckerig zum Ansatz von Bandmasse.

Der processus ensiformis wird verhältnissmässig sehr lang. Ansatzflächen für Rippenbänder zeigen sich nur an seinen beiden vorderen Ecken, und zwar je eine Fläche oder etwa zwei dicht neben einander liegende. Diher verbanden sich mit dem Brustbein wohl höchstens vier Paar Rippen mittelst Knorpelbändern: und zwar das erste Paar ganz mit dem hinteren Theil des manubrium, das zweite Paar zwischen manubrium und corpus, das dritte und vierte Paar dicht bei einander zwischen corpus und processus oder das vierte Par mit dem letzeren allein.

Der Schwertfortsatz biegt sich seiner Länge nach vom Vorderrande bis etwa in die Mitte flach nach unten convex aus und streckt sich dann mit seinem verschmälerten Ende gerade aus nach hinten; daher trägt die obere Fläche eine stumpfe Ecke auf der Mitte ihrer Länge. Kurz vor seinem Ende ist der processus nittelst eines länglichen Schlitzes durchbohrt; diese Oeffnung deutet wohl an, dass der Schwertfurtsatz ehemals gabelig endigte ${ }^{2}$ ). Die starke seitliche Verbiegung des processus ensiformis Fig. 62 ist eine natürliche; solche Verkrïmmungen kommen, wenn auch in geringerem Matasse, auch am Brustbein des. Manatus und der Rhytina vor (von Nordmann l. c. pag. 25).

Die Dicke des Schwertfortsatzes nimmt nach hinten allmählich ab: am vorderen rauhen Rande beträgt dieselbe $15-17^{\mathrm{mm}}$, in der mittleren Ecke gewinnt sie noch einmal $20^{\mathrm{mm}}$, das Ende

1) Eine crista sterni findet sich auch bei andern Såugethieren, z. B. bei dem Maulwurf, den Fledermäusen und den Guirtelthieren.

2) Am Ende des Schwertfortsatzes Fig. 73 ist die linke Ecke quer abgebrochen, sodass ein kleines Stück fehlt; bei Fig. 62 ist ein grösseres Stück bis vor die Durchbohrung abgebrochen. 
ist sehr dünn und scharf, kaum $2-3^{m m}$ dick. Die Seitenränder sind mit Ausnahme der vorderen Ecken glatt abgerundet.

Während das Brustbein des Halitherium aus drei Knochenstücken zusammengesetzt ist, besteht dasselbe bei Halicore und Rhytina aus zwei, bei Manatus nur aus einem Stïck.

Das Brustbein an dem mir vorliegenden Skelett von Halicore steht ziemlich steil nach vorn und oben, etwa in $45^{\circ}$ gegen die Horizontale aufgerichtet. Seine ganze sagittale Länge betrigt $21^{\mathrm{cm}}$ (gegen $34^{\mathrm{cm}}$ bei Halitherium). Das corpus scheint ganz verschwunden oder knorpelig geworden zu sein, da die beide Theile des Brustbeins durch ziemlich viel Knorpelmasse getrennt sind; das vordere Stüch scheint dem manubrium, das hintere dem processus ensiformis des Halitherium zu entsprechen. Das manubrium endigt nach vorn spitz, sodass sein vorderes Ende $27 \mathrm{~mm}$, sein hinteres aber zwischen den Rippenansätzen $60 \mathrm{~mm}$ transversale Breite besitzt. Die Knorpelbänder der vier wahren Rippen setzen sich zwar mehr an eine breite Knnorpelmasse zu Seiten der Kinochen als direct an diese selbst an, doch liegen die Ansätze der beiden ersten Rippen neben dem manubrium, der dritten und vierten neben den vorderen Ecken des Schrertfortsatzes. Das manubrium ragt noch etwa $6^{\mathrm{cm}}$ vor die ersten Rippenbänder nach oben, und ist im Ganzen $9^{\mathrm{cm}}$ lang; sein hinterer Rand ist ebenso, wie der vordere Rand des zweiten Stückes, halbkreisförmig abgerundet, sodass sich beide Stücke kaum in der Mitte ihrer Ränder berihren, in ührigen durch Knorpelmasse verbunden werden. Der processus ensiformis wird vorn zwischen den Rippenansätzen $40^{\mathrm{mm}}$, in der Mitte $20^{\mathrm{mm}}$ und am hinteren Ende $33 \mathrm{~mm}$ transversal breit: das Ende ist ganz kurz gegabelt; der Einschnitt zwischen beiden Stummeln hat nur $15^{\mathrm{mm}}$ Breite und $5 \mathrm{~mm}$ Tiefe. Bei Rhytina sind die Gabelzinken betrïchtlich länger und endigen spitz.

Das Brustbein der Halicore ist in der Mitte am Rande beider Theile $20 \mathrm{~mm}$ dick und schärft sich von hier aus sowohl nach vorn und hinten, als nach den Seiten gleichmässig zu.

Vom Brustbein der Rhytina sagt zwar Steller, dass das vordere Stück knorpelig und nur das hintere knöchern gewesen sei; doch scheint dies nicht richtig zu sein: denn das Brustbein am Skelett in Stockholm besitzt zwei lange, schmale Knnochenstiucke, welche abgesehen von ihrer Grösse einigermassen dem Brustbein der Halicore gleichen; das eine der beiden Stücke kennt auch von Nordmann schon (1. c. pag. 25 und Taf. V Fig. 5 und 6): es scheint mir das manubrium zu sein. Auf der Photographie des Stockholmer Skelettes kann ich nicht gentg vom Brustbein erkennen, um es zu beschreiben; das manubrium ist sehr lang, vorn nach oben aufgekrümmt; die Ansatzfläche der Rippen (nach Steller fünf Paare, was mir zu viel zu sein scheint, vielleicht nur vier) liegt auch am hinteren Seitenrande des manubrium und am vorderen des processus ensiformis; der letztere gabelt sich an seinem hinteren Ende.

Das Brustbein des Manatus weicht sehr stark in seiner Gestalt von den Brustbeinen der andern Sirenen ab; überhaupt zeigt das Brustbein der Sirenen grössere Verschiedenheiten bei den einzelnen Arten und Individuen, als andere Theile des Skelettes. Hervorzuheben ist, dass bei Manatus das Brustbein aus einem, nicht aus mehreren Stücken wie bei den meisten Säugethieren besteht; die mir bekannten Manatis wenigstens und die von den meisten Autoren beschriebenen zeigen einen einzigen Schildknochen. Nur Blainville, Ostéographie, Manatus pag. 52 sagt, das sternum 
des Manatus australis bestånde aus zwei Theilen: „un manubrium large aplati, comme tronqué carrément en avant, un xiphoïle étroit et non dilaté à l'extrèmité "; da Blainville's Zeichner aber Taf. V zwei Brustbeine aus einem einzigen Stiick bestehend abbildet, beruht jene Angabe für erwachsene Ianatis jedenfalls auf einem Irrthum; doch ist es möylich, ja sogar wahrscheinlich, dass das sternum bei ganz jungen Manatis noch aus zwei getrennten Stủcken besteht.

An dem mir vorliegenden Skelette des Manatus australis von $2^{\text {n }} 46$ Länge ist das Brustbein ein einziger breiter Schild-förmiger Knochen mit einem schmalen hinteren Fortsatz, den man als processus ensiformis zu betrachten hat. Die granze Lünge des Brustheins betrïgt $20^{\mathrm{cm}}$, des processus allein etwa $7,5^{\mathrm{cm}}$; die transversale Breite des vorderen Theiles $11^{\mathrm{cm}}$, des Fortsatzes an seinem Ende $4^{\mathrm{cm}}$. Der $11^{\mathrm{cm}}$ lange vordere Rand zeigt in der Yitte einen $5^{\mathrm{cm}}$ langen und $3,5^{\mathrm{cm}}$ tiefen Ausschnitt, sodass das Brustbein sich nach rorn in zwei breite kurze Fortsätze gabelt, an deren Enden Sehnen befestigt waren. Die Seitenränder des manubrium sind vorn glatt und flach eingebuchtet, hinten verlängern sie sich zu einem kurzen seitlichen Fortsatz, an welchem sich die Bänder dreier Rippen befestigen. Wiihrend also bei den andern Sirenen sich an der Ansatzstelle der Rippen Einschnitte im Rande des Brustbeines befinden, entstehen hier an derselben Stelle kurze Fortsätze. Erst hinter diesen processus costales zieht sich das Brustbein zusammen zu dem $40-45$ mm breiten und $75 \mathrm{~mm}$ langen processus ensiformis der an seinem hinteren Ende einen in der Mitte gekerbten Rand und an demselben den Ansatz zweier Sehnen zeigt. Auf der Unterseite des Brustbeius tritt eine niedrige crista hervor, welche vorn nahe dem Rande der vorderen Bucht am höchsten ist und nach hinten an Höhe abnimmt, aber noch auf der vorderen Hälfte des Schwertfortsatzes sichthar ist. Die Dicke des Brustbeins beträgt 3-5 $\mathrm{mm}$ und erreicht in der vorderen Ecke der crista $10 \mathrm{~mm}$.

Die beiden ersten Rippen stehen an diesem Skelette $16 \mathrm{~cm}$ weit auseinander und heften sich mit $40^{\mathrm{mm}}$ langen Bändern an das Brustbein; dieses steht zwischen den Rippen viel weniger steil von vorn oben nach hinten unten als bei Halicore.

Ganz anders gestaltet ist das Brustbein eines Manatus senegalensis vom Ogowe, das ich im Berliner Universitäts-Inseum kennen lernte. Dasselbe besteht auch aus einem einzigen, Schild-förmigen Stiicke; indessen ist das manubrium vorn nicht gabelig, sondern flach abgerundet mit nach vorn convexem Rande, ist schmäler und länger als beim amerikanischen Manatus, entbehrt der processus costales und trågt einen kiirzeren Schwertfortsatz als Manatus australis. Ausserdem ist dieses Brusthein der Länge nach in der Mitte durchhrochen mittelst vier länglichen Schlitzüftnungen, deren vordere drei im manubrium, die letzte und länste in processus ensiformis liegen; da der letztere zugleich nach hinten in zwei kurze Fortsätze gabelt, so sieht es gerade aus, als sei er der Länge nach aus zwei schmalen Stücken zusammengesetzt. Das ganze Brustbein ist $19^{\mathrm{em}}$ lang; das manubrium ist $67-98^{\mathrm{mm}}$ transversal breit; der processus ensiformis $30-40^{\mathrm{mm}}$ breit und etwa $55^{\mathrm{mm}}$ lang. Drei Rippen setzen sich an dem hinteren Seitenrand des manubrium in drei Ausschnitten an. Von der crista ist nur eine schwache Erhöhung in der Mitte der Unterfläche des manubrium uibrig geblieben. Der vorderste Schlitz beginnt $40 \mathrm{~mm}$ hinter dem vorderen Ende des Brustbeins und ist sagittal $30^{\mathrm{mm}}$ lang und bis $10^{\mathrm{mm}}$ breit; der zweite Schlitz ist $15 \mathrm{~mm}$, der dritte nur $8^{\mathrm{mm}}$ lang; der letzte liegt im Schwertfortsatz und ist $27^{\mathrm{mm}}$ lang, $4-5^{\mathrm{mm}}$ breit. Eine solche theilweise Längs- 
spaltung des Brustbeins ist eine bei den Süugethieren seltene Erscheinung, obschon die hinter einander liegenden Brustbeinstücke nicht selten aus paarigen Ossificationskernen entstehen; nur bei manchen Delphinen bleibt es vollstïndig lïngsgespalten; indessen solche Längs-Durchbrechungen wie an diesem Brustbein des Manatus senegalensis (eines sicherlich nicht mehr jungen Thieres) finden sich wohl bei keinem andern Säugethiere.

Wir sehen demnach, dass die Brustbeine der Sirenen sehr verschieden gestaltet sind; jedoch stehen sich auch in diesem Punkte, wie in so vielen andern, Halicore und Rhytina näher, als den andern beiden Sirenen, während wenigstens durch das Vorhandensein einer crista das Brustbein des Manatus auch in seiner stark reducirten Gestalt noch an dasjenige des Halitherium erinnert.

\section{Die rordere Extremitiit.}

Die vordere Extremität des Halitherium und der lebenden Sirenen besteht aus einem Schulterblatt, einem kurzen humerus, einer ulna, einem theilweise mit der ulna verwachsenen radius, und einer fünffingerigen vollständigen Hand; alle diese einzelnen Theile tragen die bei den Säugethieren gewöhnlich vorkommenden Fortsätze, sind mit Gelenken versehen und an einander (mit Ausnahme der uha und radius) beweglich. Es stellt daher die vordere Extremität der Sirenen einen wohlausgebildeten Arm dar, der sich von der vorderen Extremität anderer mit Händen versehenen Säugethiere durch die Kürze seiner gedrungenen Knochen unterscheidet. Die Finger waren von einer gemeinsamen Haut ungeben, damit die Hand zum Rudern im Wasser gebraucht werden konnte. Am Rande der Flossenhand des Manatus zeigen sich drei bis fünf rudimentäre Fingernägel; es ist daher wahrscheinlich, dass auch Halitheriun Fingernägel besass. Von den Handknochen des Halitherium Schinzi kennen wir bisher nur die beiden Mittelhandknochen Taf. VI Fig. 66 und 69 und die beiden Phalangen Fig. 67 und 68, von welchen die Knochen Fig. 66-68 ein und demselben Individuum, vielleicht ein und demselben Finger angehörten. Dagegen werden das Schulterblatt und die drei Armknochen gewöhnlich bei den Skeletten noch vorgefunden, und liegen mir deren eine grössere Anzahl vor.

Ein Schlüsselbein fehlt den Sirenen, wie ja auch alle Ungulaten und Cetaceen desselben vollständig entbehren.

\section{a. Scapula.}

Taf. VI Fig. 72.

Das Schulterblatt des Halitherium ist ein flach ausgebreiteter, platter Knochen von langgezogen dreiseitiger Gestalt; es besitzt einen dicken condylus mit concaver Gelenkgrube, einen niedrigen Schulterkamm mit kurzem acromion und einen kleinen processus coracoideus. Die abgebildete scapula ist eine rechte und liegt so auf dem Brustkorb, dass die lange, eingebogene Kante nach hinten gerichtet, die spina scapulae über die äussere Fläche zieht (Fig. 91). Das Schulterblatt streckt sich demnach mit seinem oberen Theile weit nach rückwärts; der kurze Rand, welcher 
über dem Schulterkamm und schief zu demselben gerichtet verläuft, liegt zunächst den ersten RückenWirbeln an und geht demnach sagittal und parallel der Gelenkfläche; dic rauhe Ecke am vorderen Ende dieser Wirbelkante entspricht dem oberen Winkel des menschlichen Schulterblattes, der hintere, flach ausgebreitete Theil dem unteren Winkel desselben. Rauhe Ansatzflïchen für Muskeln sieht man vorwiegend am hinteren und oberen Rande ${ }^{1}$ ); die Flächen des Schulterblattes sind ziemlich glatt, nur einige feine Lïngsstreifen machen sich auf beiden Seiten bemerkbar, welche wohl von den Muskelfasern herrühren.

Die spina scapulae ist nicht hoch und bildet eine flach abgerundete Kante, welche etwa halb so lang ist als das ganze Schulterblatt; sie beginnt mit dem wenig vorspringenden, etwas nach hinten übergebogenen acromion ${ }^{2}$ ), zieht ziemlich gerade nach oben, etwas mach hinten gerichtet und hört mit flacher Ecke $40-50 \mathrm{~mm}$ vor dem oberen Rande der scapula auf. Das acromion bleibt um $40^{\mathrm{mm}}$ von dem condylus entfernt. Eine fossa supraspinata kommt kaum zum Ausdruck, weil der Schulterkamm ganz flach nach vorn verläuft; dagegen fällt der letztere steil, im acromion concav nach hinten gegen die tiefeingefurchte fossa infraspinata $a b$.

Die incisura scapulae ist ein ganz flacher Ausschnitt des vorderen Randes und wird unten begrenzt durch den am Gelenkkopf mach vorn ragenden, kurzen processus coracoideus, welcher an seinem vorderen Ende eine sehr rauhe, zum Theil vertiefte Ansatzfläche für den musculus pectoralis trägt. Dor Schulterhaken steht dicht vorn an Rand der cavitas glenoidea und biegt sich zuweilen noch etwas nach unten herüber ̈̈ber den Rand derselben. Die Gelenkgrube ist rund oder elliptisch mit grösserer sagittaler Axe; ihre Ränder stehen allseits vor über der vertieften Grube und zeigen an verschiedenen Stellen rauhe Ansätze für die Gelenkbänder.

Das Fig. 75 abgebildete Schulterblatt ist noch nicht das grösseste mir vorliegende: ein anderes wird $305^{\mathrm{mm}}$ lang, in gerader Linie gemessen vom processus coracoideus bis zum hinteren Rande; die Gelenkgrube desselben ist elliptisch, sagittal $45^{\mathrm{mm}}$, transversal $38^{\mathrm{mm}}$ gross und bis $10^{\mathrm{mm}}$ tief. Die Dicke der scapula ist im Ganzen $10-15 \mathrm{~mm}^{\prime}$, in der spina $20 \mathrm{~mm}$, im acromion etwa $30 \mathrm{~mm}$, in condylus bis 38 mu. Die Fläche des Schulterblattes ist fast ganz ehen, nicht gewöllbt, nur der hinterste Theil biegt sich etwas nach aussen $a b$.

Das Schulterblatt der lebenden Sirenen ist in sagittaler Richtung viel kürzer, in seinen Flächen bewegter und trägt weit kräftigere Fortsätze, als das des Halitherium. Bei Manatus zieht sich das acromion zu einem langen und schmalen Fortsatz aus und biegt sich nach vorn iiber, statt nach hinten, wie bei den andern Sirenen. Die spina ist hoch und schmal und wird kaum halb so lang als das ganze Schulterblatt. Nur der processus coracoideus wächst nicht viel stïrker aus, als bei Halitherium. Der Hinterrand läuft ziemlich gerade nach oben hinten und bildet mit dem halbkreisförmigen Ober- und Vorderrand eine scharfe Ecke. Die Gelenkpfanne ist elliptisch, sagittal $50 \mathrm{~mm}$, transversal $40 \mathrm{~mm}$, bei ganzer Länge der scapula von $28 \mathrm{~cm}$.

1) Manatus besitzt wohlausgebildete musculi trapezius und rhomboideus; auch die musculi supra- und infraspinatus sind vorhanden. J. Murie 1. c. pag. 156. Taf. 21 Fig. 8 und Tat. 22 Fig. 13.

3) Die Spitze des acromion ist bei den mir vorliegenden Schulterblättern stets abgebrochen, auch bei Fig. 72. 
Das Schulterblatt der Halicore legt sich mit ziemlich starker Wölbung dem Brustkasten auf. Die hohe und diinne spina ist kurz und trägt ein nicht sehr starkes acromion, das sich nach hinten über die fossa infraspinata etwas iberkrümmt. Sehr kräftig entwickelt ist der processus coracoideus, welcher als selbstïndige Ossification bei jungen Thieren noch durch Naht vom Schulterblatt getrennt bleibt. Die Gelenkpfinne ist elliptisch und schmäler, als bei den andern Sirenen.

Die scapula der Rhytina gestaltet sich ähnlich derjenigen der Halicore nur wird sie am oberen Rande verhältnissmässig etwas breiter. Sie wölbt sich flach; die spina wird noch kürzer und besteht eigentlich nur noch aus dem hohen, krüftigen, nach hinten etwas übergebogenen acromion. Der äussere Rand des letzteren ist wulstig und rauh zum Ansatz von Muskeln. Das untere Ende des acromion rückt noch weiter ab vom condylus, als bei Halicore; die Rhytina besitzt daher ein längeres collum scapulae, als ihre Verwandten; doch bleibt der Hals dabei dick, denn die incisura schneidet auch hier nicht tief in das Schulterblatt ein. Die Gelenkgrube ist auffallend gross und in die Länge gezogen durch den starken processus coracoideus, welcher, wie bei Halicore, den condylus nach vorn verlängert und rauhe Ansatzflächen zeigt ${ }^{\text {'). }}$

\section{b. Humerus.}

Taf. VI Fig. 64.

Der Oberarmknochen des Halitherium zeichnet sich durch seine gedrungene Gestalt und seine kräftigen Fortsätze aus; im Gegensatz zum Oberarm der Cetaceen, zeigt der humerus der Sirenen eine charakteristische, durchgearbeitete Form, deren Hauptmomente mit den Oberarmknochen der höheren S:iugethiere ïbereinstimmen; besonders beweisen die wohlgebildeten Gelenkköpfe eine grosse Beweglichkeit des Oberarmes.

Der abgebildete humerus ist noch nicht einer der grössesten; doch sind seine Formen am besten erhalten, da seine Oberfläche nicht corrodirt ist. Ein anderer Oberarm wird noch um $30^{\mathrm{mm}}$ länger und ebenfalls dicker; er gehörte einem Skelett an, das wohl $3^{\mathrm{m}}$ lang war. Der humerus Fig. 64 stammt von einem etwa $2^{\text {m }} 55$ langen Skelette. Sein caput ist halbkugelig mit einem Durchmesser von $40^{\mathrm{mm}}$ und $15^{\mathrm{mm}}$ Höhe des Kugelabschnittes; die Oberfläche des Kopfes ist glatt und war sicherlich überknorpelt. Gegen den Hals setzt sich der Kopf mit etwas überstehendem Rande ab. An der dem tuberculum major zugekehrten Seite vertieft sich vom Rande her in die Oberfläche des caput eine $10^{\mathrm{mm}}$ lange, $5^{\mathrm{mm}}$ breite und $3-4^{\mathrm{mm}}$ tiefe fossa, welche sich auch bei Halicore und Manatus, doch reducirt vorfindet; sie diente wohl dem Ansatz von Gelenk-Bändern, welche sich zu dem gerade darüber liegenden processus coracoideus hiüber spannten. Der Gelenkkopf steht mit seiner Fläche hinten am dicken Oberrande des humerus und zwar schief um $45^{\circ}$ gegen die Lüngsaxe des Oberarmes gerichtet; es kounte daher der humerus nicht vertical zu Seiten

1) An dem von Nordmann abgebildeten Schulterblatt l. c. Taf. IV Fig. 1-3 fehlt die Epiphyse und der processus coracoideus. Das Stockholmer Skelett besitzt vollständige Schulterblätter. 
des Brustkorbes herunterhängen, sondern musste schräg nach hinten und unten gerichtet unter der seapula stehen.

Das tuberculum majus, welches vor dem caput steht, wird bei Halitherium sehr breit und dick, sodass es an dem abgebildeten Oberarm in transversaler Richtung $45^{\mathrm{mm}}$ lang, und sayittal 10-16 mn breit ist; sein oberer dicker Rand und seine Flächen sind rauh von Muskelansätzen. Das tuberculum minus ist auch energisch ausgebildet: es steht an der medialen Seite gerade nach oben gerichtet und hat einen runden Querschnitt von 20-25 mm Durchmesser; nach vorn spitzt es sich dick aus; seine obere Fläche ist rauh und wellig und trägt vorn und hinten je eine vertiefte fossa fiir den Sehnen-Ansatz der Schultermuskeln '). Der sulcus intertubercularis schneidet eine tiefe Furche zwischen die beiden Höcker ein; auch tuberculum majus ist breit getrennt vom caput, während der kleinere Höcker dicht an den Rand der Gelenkfläche stösst. Bei jungen Thieren trennt die Epiphysen-Naht noch :den Gelenkkopf und die heiden Höcker zusammen ab von dem andern Theil des Oberarms: auch zeigen abgewitterte, ältere humeri diese Naht. Das collum humeri ist allseits rauh vom Ansatz der Muskeln.

Auf dem kurzen Stiel des Oberarms zieht sich an der vorderen Seite eine energische Kante, angulus anterior, rom tuberculum majus hinab bis ïber die fossa anterior major und entwickelt in ihrem Verlauf zwei rauhe, kräftige Ecken, Kante und Ecken für den Ansatz der musculi teres major und deltoideus; lïngs der medialen Seite der Kante läuft eine seichte Furche herab. Die iibrigen Flächen des Stieles sind glatt abgerundet und tragen nur Längsfurchen der Muskelfasern.

Das untere Ende des Armbeins ist platt gedrückt von vorn nach hinten $50 \mathrm{~mm}$ transversal lang und 20-25 dick; es trägt die cylindrische, transversal gestellte Gelenkfläche fuir die Unterarmknochen, die beiden epicondyli und wird eingeschnïrt von der fossa olecrani und fossa anterior. Die Gelenkrolle wird durch eine flache Furche in die trochlea und in das capitulum getheilt; doch sind die Unterammknochen so gestellt, dass sowohl radius als unna auf beiden Theilen des processus cubitalis laufen. Die Gelenkfläche steht schräg gegen die Längsaxe des Oberarms nach vorn gerichtet; ihr (querschnitt betrïgt in der Mitte der Rolle mehr als $3 / 4$ Kreisumfang. Die fossa olecrani ist ziemlich tief, aber weniger breit als die auf der andern Seite eingegrabene fossa anterior. Der epicondylus medialis ist kräftig ausgebildet, legt sich stark nach hinten aus und trägt an seiner äusseren $25-30$ mm breiten Fläche rauhe und höckerige Vertiefungen zum Ansatz der UnterarmMuskeln; auf seiner glatten hinteren Fläche schneidet wenig tief ein sulcus ulnaris ein. Der epicondylus lateralis tritt weniger hervor und zeigt auf seiner äusseren Fläche ähnliche Vuskelansïtze.

Bei den lebenden Sirenen gleicht der Oberarmknochen des Manatus sehr dem des Halitherium; derjenige der Halicore verkürzt sich ansehnlich und entwickelt noch kräftigere Fortsätze; der humerus der Rhytina ist ebenfalls sehr kurz und dabei ausserordentlich dick.

Vom humerus des Manatus haben wir nur geringe Abweichungen vom Halitherium-Oberarm anzuführen: derselbe ist etwas schlanker gebaut, besonders das obere Ende nicht so dick und der

1) J. Murie beschreibt in seiner Anatomie des Manatus australis 1. c. pag. 156 ff, ausfubrlich die Schulter-, Arm- und Finger-Muskeln des Manatus und bildet dieselben Taf. 22 Fig. 13 ab. 
Gelenkkopf auf dïnnerem und längerem Halse weiter entfernt von den Höckern; der processus cubitalis ist kïrzer und die Theilungsfurche zwischen trochlea und capitulum tiefer, als bei Halitherium; dagegen sind die Epicondylen grösser, sodass die fossa olecrani und der Ellenbogen breiter wurden. Verhältnissmïssig ist auch der humerus des Manatus beträchtlich länger als bei der tertiären Sirene, wie wir ja iibcrhaupt bei den meisten andern linochen des Manatus-Skelettes eine Verlingerung im Verhältniss zu denen des Halitherium zu constatiren hatten.

Am Oberarmknochen der Halicore vergrössern sich die beiden Höcker bedeutend; das tuberculum majus wird ausserdem nach unten direct fortgesetzt durch starke Entwickelung eines scharf und weit nach vorn vorspringenden angulus anterior. Der Stiel wird noch kantiger durch einen scharfen angulus lateralis, der vom Halse unter dem caput bis auf den epicondylus lateralis zieht; auch ein angulus medialis zieht vom tuberculum minus zum epicondylus medialis, sodass der Querschnitt des Stieles scharf dreikantig ausgebildet ist.

Der humerus der Rhytina ist ein unförmig dicker, kurzer Knochen, welcher mehr dem Oberarmknochen der Halicore, als dem der andern beiden Sirenen gleicht, besonders in dem Auftreten der drei energischen Kanten des Mittelstückes. Am Oberarm der Rhytina sind die Fortsütze am knorrigsten, dicksten und deuten eine der Grösse des Thieres angemessene kräftige Entwickelung der Arm- und Schulter-Muskeln an.

\section{c. Ulna und radius.}

Taf. VI Fig. 65.

Die beiden Unterarmknochen sind am Skelett des Halitherium regelmässig mit einander verwachsen bis auf eine kurze, schmale Strecke, welche als ein Rest des spatium interosseum stets offen bleibt. Auf unserer Tafel haben wir den gut erhaltenen Unterarm abgebildet, welcher dem Oberarmknochen Fig. 64 zugehört; er zeigt noch am unteren Gelenkkopf die Spur der EpiphysenNalıt. Die beiden Unterarmknochen waren am Körper des Thieres so gerichtet, dass der radius vor der ulna sich befand. Der radius ist gerade gestreckt, die ulna ein wenig nach aussen gebogen, sodass der obere Gelenkkopf des radius etwas seitlich gerückt schief an demjenigen der ulna festgewachsen ist. Durch das spatium interosseum kann man auf der Zeichnung nicht hindurchsehen, es ist aber vorhanden, und zwar $30^{\mathrm{mm}}$ lang und $2-3 \mathrm{~mm}$ breit, etwas offener auf der lateralen, als auf der medialen Seite der Knochen.

Die obere Gelenkgrube der Unterarmknochen ist im Profil halbkreisförmig ausgehöhlt, indem sich der am olecranon gelegene Theil der fossa sigmoidea etwas nach vorn überkrümmt. Die Naht zwischen radius und ulna bleibt auch auf der Gelenkfläche siclitbar und ist hier $32 \mathrm{mn}$ lang. Eine flache Kante theilt die Gelenkgrube in eine rechte und linke Hälfte, da sie quer über radius und ulna wegläuft, und entspricht der Furche, welche den processus cubitalis humeri theilte; sie verhindert das seitliche Ausweichen der Armknochen im Ellenbogengelenk und findet sich am Gelenk der meisten Säugethiere.

Während die Längsaxe der fossa sigmoidea genau transversal zum Körper des Thieres stand, 
richtet sich die Gelenkrolle am unteren Ende des ulna-radius mehr sagittal und etwas schief von innen nach aussen gestellt, wodurch der Flossenhand eine solche Drehung gegeben wird, dass sie mit ilırer inneren Fläche medialwärts und nach hinten gewendet rudern kann. Die untere Gelenkrolle ist im Ganzen an dem Stück Fig. 65 an $35^{\mathrm{mm}}$ lang und $16-21^{\mathrm{mm}}$ breit; sie ist durch die Verwachsungsnaht zwischen ulna und radius zweigetheilt: die hintere Hälfte des Gelenkes steht am Ende der ulna und ist eine platte, cylindrische Rolle, deren Mitte flach concav eingebogen ist; sie liegt schief gegen die Lüngsaxe der ulna und etwas nach hinten gerichtet. Die vordere Hälfte des unteren Gelenkkopfes liegt an dem radius, ist nicht viel grösser, nur transversal etwas lïnger, und ist weniger stark gewölbt, als das ulna-Gelenk; eine hervorstehende, transversal gerichtete Kante theilt die Gelenkfläche des radius in zwei Theile, von denen der hintere grössere länger, als der kleine vordere Theil und concav eingebogen ist. Aus dieser Dreitheilung des Gelenkkopfes am unteren Ende der Unterarmknochen kam man schliessen, dass in der ersten Reihe des carpus drei Handwurzelknochen standen (wie bei Manatus), was ron Wichtigkeit ist, da wir die ossa carpi des Halitherium Schinzi noch niclit kennen.

Die ulna selbst ist, wie man auf der Abbildung sieht, kurz und kräftig gebaut; sie wird $16-20 \mathrm{~mm}$ dick. Das olecranon ist hoch und breit, 10-15 $\mathrm{mm}$ dick. Der Querschnitt der ulna ist elliptisch; ilre Flächen ziemlich glatt, einzelne Längsstreifen von Muskelfasern schneiden sich besonders gegen die rauhen Enden zu in die Flächen, und auf der lateralen Seite des unteren Endes der ulna liegt eine Hache, grössere Furche für die Einlagerung einer Muskelsehne. Ein processus styloideus fehit der ulna, ebenso wie das untere Ende des radius des gleichbenannten Fortsatzes entbehrt: der Wegfall dieser Fortsätze am unteren Ende der Unterarmlnnochen ist die erste Reduction, welche wir an der vorderen Extremität des Halitherium finden; dieselbe macht sich noch stärker geltend bei den lebenden Sirenen, bei denen besonders die Hand einigen Verånderungen durch Anpassung an ilhre Bestimmung als Flosse zu dienen sich unterziehen musste. Eine Beziehung zu dieser Bestimmung des Armes beim Halitherium liegt in der Verkürzung der Ober- und Unterarmknochen; ein kürzerer Arm kann effectvoller im Wasser rudern, als ein långerer. Auch die feste Verwachsung von ulna und radius ist in diesem Sinne einer besseren Arm-Function zu verstehen: denn beim Rudern ist es günstig, ja nothwendig, dass in der Längsaxe des Ruders keine Drehungen stattfindeu.

Der radius des Halitherium steht an der Vorderseite der ulna und ist plattgedrückt, derartig, dass seine breite Fläche transversal steht; er ist in der Mitte $19^{\mathrm{mm}}$ breit und $8^{\mathrm{mm}}$ dick, an den beiden Enden $30-32 \mathrm{~mm}$ breit und $15-17 \mathrm{~mm}$ dick. Die vordere Fläche des radius ist ein wenig concav eingebogen und trägt an der medialen Seite eine schwach vorgezogene Kante für den Ansatz dęs musculus pronator teres.

Die Unterarmknochen des Manatus sind im Ganzen denen des Halitherium ähnlich; nur ist das spatium interosseum breiter und länger, da radius und ulna sich nach den Seiten etwas auskrümmen, während beide gerade standen beim Halitherium. Auch bei Manatus verwachsen die oberen und unteren Enden von radius und ulna stets miteinander im Alter des Thieres; bei jungen Thieren sind sie oft noch getrennt und auch die Epiphysen noch nicht verwachsen. Es scheinen 
bei den Sirenen die Epiphysen aller Knochen der vorderen Extremität in etwas höherem Alter des Thieres, als es bei anderen Säugethieren der Fall ist, zu verknöchern und mit den Mittelstücken zu verwachsen ${ }^{1}$ ).

Das untere Ende der Unterarmknochen des Manatus weicht etwas mehr von dem gleichen des Halitherium ab: es ist breiter in sagittaler Richtung, seine Flächen sind noch glatter, als bei jenem, und tragen gar keine Fortsätze. Ausserdem ist die Gelenkrolle gerade nach unten gerichtet, steht nicht schief hinten am Ende der Unterarmknochen, wie bei Halitherium; die Gelenkffïchen sind ebenso dreitheilig, wie bei jenem und stützen drei Handwurzelknochen.

Am Unterarm der Halicore werden ulna und radius kürzer, als bei Halitherium; sie verwachsen an den Gelenken mit einander und lassen ein schnnäleres spatium interosseum zwischen sich, als bei Manatus, weil beide Knochen sich wenig nach aussen biegen. Wie bei Manatus verbreitert sich das untere Ende der ulna ansebnlich und stellt seine Fläche quer zum radius in sagittaler Richtung, als wollte es die Fläche der Ruderhand vergrössern. Die Gelenkflächen sind beiderseits gut ausgebildet und gleichen denen des Manatus; die untere steht auch gerade nach unten gerichtet und ist getheilt in zwei Flächen fiir die beiden Knöchelchen der ersten Carpal-Reihe.

Ulna und radius der Rhytina sind zwei ungefüge, dicke und kurze Knochen, welche dicht an einander liegen und nur einen geringen Zwischenraum übrig lassen. Wir kemen diese Kinochen nur durch die Abbildung von Nordmann (1. c. Taf. IV Fig. 8-13 und pag. 29); jedoch entbehren dieselben der Epiphysen, welche sich abgetrennt haben. Die Unterarmknochen der Rhytina weichen am meisten von denen des Halitherium in ihrer plumpen Gestalt ab und gleichen auch nicht denjenigen der beiden andern Sirenen; nur in ihrer Küirze stimmen sie überein mit denen der Halicore. Die Armknochen der Rhytina mussten eben ganz besonders stark gebaut sein und diese gedrungene Gestalt erhalten, um den 80 Centner schweren Körper im Wasser fortrudern zu können.

\section{d. Knochen der Hand.}

\section{Taf. VI Fig. $66-69$.}

Von den Handknochen des Halitherium sind uns, wie gesagt, nur erst die vier abgebildeten bekannt; wir können uns daher über dieselben kurz fassen. Dass die tertiäre Sirene zwei Reihen wohl ausgebildeter ossa carpi besessen hat, geht sowohl aus den gut entwickelten Gelenken an ulna, radius und metacarpus hervor, als daraus, dass die lebenden Sirenen eine vielgliedrige Handwurzel zeigen. Der Mittelhandknochen Fig. 66 ist noch weit vollkommener entwickelt, als die Metacarpalknochen der lebenden Sirenen: an seinen Enden liegen mehrflächige Gelenke und vor denselben rauhe Ansätze für die Handmuskeln. Das obere Ende des Knochens ist vierseitig mit rhombischem

1) Auch das Skelett der Rhytina, welehes Nordmann vorlag bei seiner Abhandlung, ist noch in dem Altersstadium begriffen, in welchem die Epiphysen der Armknochen unverwachsen sind, wie wir ja auch schon bemerkten, dass die Kürze des ganzen Skelettes ein jüngeres Thier andeutet. Wahrscheinlich verknöcherten auch die Phalangen der Rhytina verhältnissmässig spät und schreibt sich vielleicht daher Steller's Angabe, dass die Rhytina der Phalangen ganz entbehre. 
Querschnitt; die Epiphyse ist fast ganz verwachsen. Der Kopf zeigt eine glatte Gelenkflïche, welche halbcylindrisch von zwei Handwurzelknochen umfisst wurde; beiderseits stehen rauhere Gelenkflächen, welche an nebenliegende Metacarpal-Iínochen anstiessen; wahrscheinlich gehörte dieser linochen dem zweiten Finger an. Das untere Ende ist etwas abgeplattet, $17^{\mathrm{mm}}$ breit und $9^{\mathrm{mm}}$ dick; es stand wohl in der Richtung des unteren Rollengelenkes von ulna und radius, also schief von innen nach aussen gestellt, doch melnr sagittal als transversal. Die Breitseiten des Endes sind kantig begrenzt und sehr rauh, ein wenig vertieft durch Muskelansätze. Das capitulum wird durch seinen rings vorstehenden Rand etwas abgeschnürt vom Endstiick in der verwachsenen Epiphyse. Das Gelenk besteht aus zwei Flächen, die sich in ziemlich scharfer Kante in $104^{\circ}$ schneiden: die grössere liegt schief zur Innenfäche der Hand hin gerichtet, ist $17^{\mathrm{mm}}$ lang. und $6-7^{\mathrm{mm}}$ breit und ist ziemlich glatt; die kleinere steht nach aussen, ist mehr dreiseitig, wellig und nur $10^{\mathrm{mm}}$ lang und $4-6 \mathrm{~mm}$ breit. Das Mittelstück des Knochens zeigt glatte Flächen und plattet sich etwas ab mit runden Kanten, sodass der Querschnitt oval wird; an der dünsten Stelle beträgt die Breite $12^{\mathrm{mm}}$, die Dicke $8 \mathrm{~mm}$. Während dieser Vittelhandkuochen in seiner Längsaxe gerade gestreckt ist, biegt sich der andere Fig. 69 schwach nach innen, wie es die Metacarpalknochen der Halicore thuen; die äusseren Flïchen dieses Knochens sind etras corrodirt, sodass die IIuskelansätze und Kanten nicht mehr zu sehen sind.

Die Phalange Fig. 67 ist im Ganzen etwas abgeplattet, doch nicht so stark als bei Manatus, ihr Mittelstück ist $11-12 \mathrm{~mm}$ breit auf $6-7 \mathrm{~mm}$ Dicke. Das obere Ende ist dicker, nåmlich $14 \mathrm{~mm}$ breit und $11^{\mathrm{mm}}$ dick; es trägt eine viereckige, flach concave Gelenktläche von $8-9^{\mathrm{mm}}$ Seite; über derselben ragen jederseits rauhe Ecken zum Ansatz der Fingermuskeln hervor, und auch an der Aussenseite des Halses zeigen sich rauhe, etwas vertiefte Ansätze. Das untere Ende ist wenig verdickt und trïgt eine etwas schief nach innen hängende, schwach sattelförmige Gelenkfläche von 7 auf $9 \mathrm{~mm}$ Breite.

Die zweite Phalange Fig. 68 hat ein dickes oberes Ende mit einer viereckigen, etwas schief nach iunen abfallenden, schwach concaven Gelenkfläche von $10^{\text {mun }}$ Durchmesser; auch hier zeigen die etwas über die verwachsene Epiphyse vorragenden Ründer des Mittelstückes auf den Seiten und aussen neben der Gelenkfliache rauhe Muskelansïtze. Nach unten spitzt sich der Knochen etwas zu und trïgt am unteren Ende eine kleine, 5) auf $6 \mathrm{~mm}$ breite Gelenkfliiche, welche angibt, dass dieser Finger noch eine dritte, letzte Plalange besass, mit welcher wahrscheinlich ein Fingernagel in Verbindung stand. Die innere Fliche dieser kleinen Phalange zeigt mehrere scharfe Eiuschnitte, als wäre dieselbe bereits zwischen den spitzen Zähnen der Haifische gewesen, welche so zahlreich das rheinhessische Tertiärmeer berrolnten ').

1) Mancher Anthropologe würde vielleicht diese Einschnitte, welche sich nicht selten auf den Knochen des Halitherium fuden, für ein menschliches Erzeugniss balten, und daraus schliessen, dass zur oligocaenen Zeit bereits Menschen lebten und am Ufer des rheinhessischen Meeres sich das Fleisch der Sirenen trefflich schmecken liessen. Vergl. M. Farge. Sur un fragment d'os d'Halitherium portant des traces d'incisions. Bull. Soc. géolog. France. 1871. pag. 265. 
Die Handknochen des Manatus zeigen eine ziemlich starke Abplattung und Verbreiterung in der Richtung der Handläche, ein Umstand, welcher die Ruderfihigkeit der Hand erhöhen musste. Der Carpus besteht aus zwei Reihen von je drei Knöchelchen, und zwar stehen in der ersten Reihe unter dem radius ein sehr kleines Kahnbein und ein grösseres Nondbein, unter der ulna ein grosses und plattes Pyramidenbein, an dessen hinterem Ende eine bei jungen Thieren noch nicht gewachsene Apophyse unter dem fünten Finger das Erbsenbein angibt; in der zweiten Reihe stützt sich der schwache Daumen und die Hälfte des zweiten Fingers auf die zu einem Stuick verwachsenen Trapezund Trapezoidbeine, die hintere Ecke des zweiten Fingers und der dritte auf das Kopfbein, der vierte Finger auf das grosse Hakenbein, während der fünfte Finger seitlich an das Hakenbein stösst und hauptsächlich auf dem Pyramidenbein aufsteht. Das Trapezbein lenkt sich ein auf dem Kahnbein und halbem Iondbein; das Kopfbein auf der hinteren Gelenkfläche des letzteren; das Hakenbein auf dem Pyramidenbein, wobei es mit seiner vorderen Ecke noch an das Mondbein anstösst. Alle sechs Knöchelchen sind gegeneinander, mit ulna und radius und mit dem metacarpus in Gelenkflächen beweglich. Die fünf metacarpal-Knochen sind besonders an den Enden stark abgeplattet und verbreitert. Der Daumen besitzt eine runde, spitze Phalange; die Phalangen der andern Finger sind alle platt geschlagen und in Ganzen hreiter als die Vittelhandknochen: der zweite, dritte und vierte Finger bestehen je aus drei Phalangen, der fünfte aus zwei, von denen sich die zweite zuspitzt, wie die letzten Phalangen des zweiten und dritten Fingers, und sich, wie diese, dem Nebenfinger anlegt, sodass sich der ïussere Rand der Flossenhand auch in den Ḱnochenenden abrundet.

Die Hand der Halicore ist bedeutend kürzer, als die des Manatus; die einzelnen Knochen sind wenig abgeplattet; die Mittelhandknochen schwach nach innen concav gebogen. Im Carpus treten bei alten Thieren mehrere Verwachsungen ein: an der mir vorliegenden Hand einer jungen Halicore ist ein sehr kleines Kalnbein, ein grösseres Mondbein, ein grosses Pyramidenbein und ein kleines Erbsenbein vorhauden. Bei älteren Thieren wächst zunïchst das Erbsenbein als Apophyse an das Pyramidenbein, und der Rest des Kahnbeines an das Mondbein an. Endlich wachsen auch diese beiden zu einem langen Kinochen, der nun die ganze erste Reihe vertritt, zusammen; er behält oben und unten wohlausgebildete Gelenkflächen. In derselben Weise verwachsen beim alten Thiere die drei Knöchelchen der zweiten Reihe zu einem einzigen langen Knochen. Daher besteht der carpus der alten Dugongs nur aus zwei ïbereinander eingelenkten Ḱnochen. Ebenso wie durch die Verwachsung der una und radius, wird durch diese Verschmelzung der Caral-Knöchelchen eine Drebung der Hand parallel der Längsaxe vermieden, was für die Ruderbewegung ron Vortheil ist; dagegen bleiben die Gelenkverbindungen in horizontaler Richtung bestehen, um die nothwendige Scharnir-Bewegung der Hand zu ermöglichen.

Die Anzahl der Finger-Phalangen ist die gleiche, wie bei Manatus; nur sind die Phalangen bei Halicore iiberhaupt kleiner, und besonders bleiben die äussersten Phalangen sehr kleine Kinöchelchen. Fingernägel fehlen der Halicore vollståndig.

Von der Hand der Rhytina wissen wir nur, was uns Steller dariber berichtet, und das ist wenig: denn er sagt nur, dass ein carpus und metacarpus vorhanden gewesen seien, dagegen die Phalangen ganz fehlten. Die letztere Angabe dirfte zu bezweifeln sein: wir sehen bei Halicore und 
Manatus, dass die Epiphysen erst im Alter des Thieres verknöchern, und bei jüngeren Exemplaren die einzelnen knöchernen Mittelstïcke der kurzen Phalangen durch Knorpelbänder verbunden werden. Vielleicht hat nun Steller gerade die Hand eines jungen Thieres untersucht, dabei die Kunorpelbänder zwischen Metacarpal- und Fingerknochen durchgeschnitten und die kleinen Phalangen zwischen den Bändern der Hand übersehen. Es ist nicht wahrscheinlich, dass die sämmtlichen Phalangen der Hand fortfallen, ohne dass carpus und metacarpus reducirt und wesentlich verändert werden.

\section{Die hintere Extremität.}

Obwohl äusserlich am Körper der Jebenden Sirenen nichts von hinteren Extremitäten zu sehen ist, besitzen dieselben doch unter der Haut zwischen Muskeln und Sehnen eingespannt zwei Beckenknochen, welche nicht mit der Wirbelsäule verwachsen sind, sondern frei mittelst Bändern an den Querfortsïtzen eines Lendenwirbels hängen und untereinander mit einem Bande ${ }^{1}$ ) verbunden sind. Es ist nun zum Verständniss dieser abnormen Bildung bei den lebenden Sirenen von grosser Wichtigkeit, dass der Beckenknochen des Halitherium trotz seiner offenbar reducirten Gestalt noch eine Gelenkpfanne trägt und in derselben den kurzen Stummel eines rudimentären Schenkelbeines stützt ${ }^{2}$ ).

\section{a. Os coxae.}

Taf. VII Fig. $80-82.84,85$.

Es liegen mir einige zwanzig Hüftbeine des Halitherium vor, von denen keines dem andern gleicht; selbst die beiden Beckenknochen ein und desselben Individuums stimmen nicht ganz genau bis ins Einzelne mit einander überein. Die fün abgebildeten Hüftbeine sind von fünf verschiedenen Thieren und weichen daher in ihrer Gestalt unter einander nicht unwesentlich ab. Bei allen sehen wir einen längeren, meist keulenförmigen Theil und einen kürzeren, platt ausgebreiteten zweizipfeligen Theil, zwischen welchen beiden Stiicken an der äusseren Seite die Gelenkpfanne für den femur stets vorhanden ist. Wir stellen diesen Knochen mit seinem platten Ende nach vorn und etwas nach oben gewendet, mit dem grösseren seitlichen Fortsatz nach unten gerichtet, und zwar

1) Siehe J. Murie, pag. 140

2) Das Vorhandensein der Gelenkpfanne am os coxae constatirte bereits Kaup in seinen Beiträgen Heft 2. 1855 pag. 21 ; im 5. Heft derselben Beiträge 1861 Taf. V Fig. 5 und im Neuen Jahrb. für Min. 1858. Taf. 21 bildete Kaup das Stück eines Knochens als rudimentären femur ab, welcher mit dem Beckenknochen eines Halitherium in Flonheim gefunden sein soll; dabei ist zu bemerken, dass der mit dem angeblichen femur abgebildete Beckenknochen auf der Tafel im Neuen Jahrbuch ein andrer ist, als der mit demselben femur gezeichnete Beckenknochen in den Beiträgen. Leider ist das Original zu Kaup's Abbildung nicht mehr zu finden; einen:Gypsabguss dieses Knochens, von Kaup herrührend, sah ich im Berliner Universitäts-Museum an dem dort anfgestellten und in Uffhofen (nahe bei Flonheim) gefundenen Halitherium-Skelett. Dieser von Kaup als femur gedentete Knochen ist jedenfalls nicht der femur des Halitherium gewesen, wie man sich durch Vergleichung desselben mit den von mir abgebildeten Schenkelbeinen überzeugen kano. Dagegen sieht dieses Knochenstück, dessen unteres Ende abgebrochen ist, dem oberen Ende eines Metacarpal-Knochens vom Halitherium nicht unähnlich. 
stellen wir ihn desswergen so, weil diese Stellung derjenigen des Hüftbeines der Halicore, mit welchem jenes Hüfthein eine entfernte Aehnlichkeit hat, entspricht und dieselbe ïberhaupt der Gestalt des Knnochens, seiner Biegung und seinen Muskelansiitzen angemessen ist. Bei dieser Stellung sind die Figuren 81.82 und 85 linke, 80 und 84 rechte Hüftbeine. Obschon an den mir vorliegenden Beckenknochen des Halitherium nicht mit Sicherheit die Spur der Symphyse zu verfolgen ist, so dürfte das os coxae doch am hinteren Eude der Gelenkfläche aus zwei Stücken zusammengewachsen sein und demnach der vordere platte Theil dem os ilium, der hintere dicke Theil dem os puboischiadicum entsprechen; die Trennung beider Stücke durch eine Symphyse ist noch stets bei jungen Thieren der Halicore vorhanden; Manatus besitzt einen einfachen und zwar sehr reducirten Beckenknochen (Taf. VIII Fig. 88 und 89).

Die Länge des ganzen Hüftbeines beträgt $23-26^{\mathrm{cm}}$; bei jüngeren Thieren ist sie entsprechend geringer. Die Biegung desselben in sagittaler Richtung, welche auf den Abbildungen nicht sichtbar ist, geht nach aussen und erreicht in der Mitte eine Abweichung von der Horizontalen um 2-3 ${ }^{\mathrm{cm}}$, sodass also der Beckenknochen des Halitherium, wie eine nach hinten gerichtete Rippe, schräg von vorn oben ${ }^{1}$ ) nach hinten unten mit Wölbung nach aussen an den Querfortsätzen eines oder mehrerer Lendenwirbel hing, in gleicher Lage wie bei Halicore.

Der vordere platte Theil (os ilium) des Hüftbeins sendet ein längeres Stück (sein vorderes Ende) nach oben, welches wir pars anterior, einen Fortsatz nach unten, den wir processus inferior, und eine kleine, scharfe Apophyse am oberen Rande gelegen, die wir spina superior nennen wollen; endlich erhebt sich auf der medialen Fläche des Darmbeins nahe vor der verwachsenen Symphyse zum Schambein eine niedrige, rauhe Apophyse, processus medialis. Die Knorpelbänder, welche das Hüftbein mit den Querfortsätzen der Lendenwirbel verbanden, setzten jedenfalls an dem rauhen, mehr oder weniger stark verdickten Vorderrand der pars anterior an in einer Länge von $45-50 \mathrm{~mm}$. Denn diese Ansatzstelle ist die grösseste am os ilium; an die andern Ränder und Fortsätze desselben Beines hefteten sich wohl nur Yuskeln") an; auch hei Halicore heftet sich das ligamentum ilio-vertebrale an das vordere Ende des os ilium. Obwohl sich das Darmbein im Ganzen nach aussen convex auswöbt, wird der verdickte Vorderrand ron dem starken ilio-vertebral-Band loch häufig lateralwärts ungebogen, wie es bei den Hüftbeinen Fig. 52 und $\$ 4$ der Fall ist; bei diesen Beinen scheint es fast, als hätten sich am Vorderrand zwei Bänder befestigt, denn besonders die beiden Ecken zeigen rauhe Ansatzstellen, die Jitte des Randes zieht sich dümn zusammen; vielleicht ging das eine Band zum Querfortsatz des dritten, das andere zu dem des zweiten Lendenwirbels (siehe oben pag. 130). Die Umbiegung des Vorderrandes hängt offenbar mit der grossen Länge der Querfortsätze der Lenden-Wirbel zusammen.

1) In der Zeichnung Taf. VIII Fig. 91 richtet sich das Hüftbein fälschlich ganz horizontal; die Längsaxe des Knochens muss etwas schräg von vorn oben nach hinten unten gerichtet sein, mit einer Abweichung von der Horizontalen um etwa $15^{\circ}$.

2) Musculus rectus abdominis und m. transversus perinaei setzen sich an den vorderen Theil des Hüftbeines von Manatus. J. Murie 1. c. pag. 139, Taf. 26 Fig. 37. 50. 
Der in sagittaler Richtung lange, transversal dünne processus inferior zeigt eine sehr rauhe laterale Fläche, auf welcher sich wohl der musculus rectus abdominis inserirte. Dieser Fortsatz wird an verschiedenen Hüftbeinen verschieden weit nach unten ausgezogen (bei Fig. 84 ist er abgebrochen), meistens hat er eine dreiseitige Gestalt, mit der rauhen Spitze nach unten gekehrt. Die spina superior liegt am oberen, sonst glatten Rande des os ilium, bald melir nach vorn, bald mehr nach hinten geriickt, je nach der Lïnge der pars anterior; an der Aussenseite dieser $\Lambda$ pophyse sieht man die schräg nach oben und vorn gerichteten Fasereindrücke eines Muskels. Der processus medialis ist eine höckerige Apophyse nahe oberhalb des hinteren Endes des processus inferior gelegen, an welche sich vielleicht die Sehne des musculus transversus perinaei anheftete. Die übrigen Flächen des os ilium sind ziemlich glatt, einige feinverzweigte Gefässeindrücke und Längsstreifen ron Muskelfasern abgerechnet. Die Dicke dieses vorderen Theiles des Hüftheines ist $5-10^{\mathrm{mm}}$, erst zum Schambein hin wird es dicker und zeigt an der Symphyse einen fast kreisrunden Querschnitt von $24-26 \mathrm{~mm}$.

Das Vorhandensein dieser Symphyse schliesse ich daraus, dass an der Oberfäche am hinteren Ende der Gelenkpfanne an den besterhaltenen Hüftbeinen rings um den Knochen herum einige Vertiefungen und kleine Höcker auftreten, welche der Rest ron der Verknöcherung der Symphyse zu sein scheinen. Die Gelenkpfanne läge dann zum grösseren Theil noch am os ilium.

Die Pfanne für den femur ist von kreisrunder oder elliptischer Gestalt mit $15-20$ mm Durchmesser; die umfassenden Ränder stehen immer etwas vor, besonders auf der hinteren Seite; bei einigen Exemplaren sind die Ränder so erhaben, dass die sonst nur wenige mm tiefe Pfanne bis $10^{\mathrm{mm}}$ Tiefe erreicht. Die Fläche der Pfanne ist zum grösseren Theil glatt ausgehöhlt und wahrscheinlich ibberknorpelt gewesen; nur der untere Theil bleibt rauh, ist tiefer als die Gelenkfliche und bildet demnach eine Art fossa acetabuli. Der am besten erhaltene femur Fig. 83 gehört zu dem Hüftbein Fig. 85: sein glatter Gelenkkopf passt ganz genan auf den ghtten Theil der Gelenkpfanne des Hüftbeines und lässt die fossa acetabuli frei.

Der hintere Theil des Hüftbeines, das os pubo-ischiadicum ist einfach dick keulenförmig gestaltet ${ }^{1}$. Seine Längsaxe biegt sich stets in sagittaler Richtung nach innen flach concav; doch auch nach oben findet meist eine geringe Biegung statt (Fig, 84 und 85). Der Querschnitt des linochens ist ein ungefäh kreisrunder. am dicken Ende mehr elliptischer; die Länge des Durchmessers betrïgt an der Symphyse zum os ilium 25-30 run , verringert sich weiter hinten etwas und erreicht im keulenförmigen Ende $40-50 \mathrm{~mm}$. Die Flächen des Schambeines sind meistens ziemlich glatt, einige kleine Höcker auf der Innenseite ausgenommen; nur an der Keule und zwar auf dem hinteren Theile ihrer medialen und oberen Seite breitet sich eine grosse, rauhe, vertiefte Ansatzfliiche fuir eine Band- oder Muskelmasse aus. Da diese 30-40 rom grosse Ansatzfläche schräg nach innen und oben gerichtet ist, so dürte sich von ihr aus wohl ein Band zu den ersten Schwanzwirbeln, etwa zu den Hämapophysen hinüber gespannt haben; vielleicht ging von ihr auch ein ligamentum subpubicum aus zur Verbindung mit dem andern Hüftbein.

1) Die Keule des Hüftbeines Fig. 82 ist so dïnn, weil sie abgewittert ist. 
Unter den Hüftbeinen der lebenden Sirenen erinnert dasjenige der Halicore noch einigermassen an den Beckenknochen des Halitherium. Wir haben Taf. VIII Fig. 88 das Hüftbein einer jungen Halicore im Umriss gezeichnet, welches noch aus den beiden Theilen os ilium Fig. 88a und os pubo-ischiadicum Fig. 88h besteht; in der Symphyse sind beide Knochen fest durch Bandmasse miteinander verbunden und beginnen zu verknöchern. Dieses Hüfthein hängt mittelst eines $3^{\mathrm{em}}$ langen, $10^{\mathrm{mm}}$ breiten Bandes an dem Querfortsatz des Lendenwirbels fest, den wir als SacralWirbel bezeichneten. Seine Längsaxe ist ein wenig convex nach aussen gebogen, wie bei Halitherium; es richtet sich von vorn nach hinten, etwas nach unten herabhängend, sodass es die Richtung und Stellung der letzten Rippen nachahmt. Das os ilium ist ein diinner Knochenstab, welcher nach unten durch einen kleinen processus inferior verhreitert wird; seine transversale Dicke beträgt nur 5 mm, erst gegen die kreisrunde Symphyse wird er dicker, da die Fuge einen Durchmesser von 13-14 ${ }^{\text {mm }}$ hat. Zu beiden Seiten der Symphyse ist das Hüftbein aber auch an stärksten. Das os pubo-ischiadicum plattet sich wieder ab, ist 11-12 $\mathrm{mm}$ breit und $5-6^{\mathrm{mm}}$ dick; das hintere Ende verbreitert sich bis $20^{\mathrm{mm}}$ und verdickt sich bis auf $11 \mathrm{~mm}$. Am abgestutzten Ende setzt sich ein Ḱnorpelband an, welches wahrscheinlich zu dem ersten Hämapophysen-Paar hiniher sich spannte; doch ist es an unserm Exemplar abgeschnitten, während die Verbindung des vorderen Endes mit dem Querfortsatz des Sacral-Wirbels erhalten blieb. Ich brauche kaum hinzuzusetzen, dass an diesem Hüftbein keine Spur einer Gelenkfläche zu bemerken ist. Bei alten Thieren scheinen die beiden Knochen immer zu einem einzigen Knochenstabe zu verwachsen; Rüppell gibt für das aus einem Stiick bestehende Hüftbein des ron ihm untersuchten weiblichen Thieres eine Länge von $20 \mathrm{~cm}$ an (1. c. pag. 109); das unsrige eines jungen Thieres ist nur $13 \mathrm{~cm}$ lang. ${ }^{1}$ )

Bei der Rhytina ist ein Hüftbein vorhanden gewesen, welches nach Steller's Angabe demjenigen der Halicore am ehesten geglichen zu haben scheint; Steller sagt uber dasselbe: „loco ossis innominati coxae duo ossa, utrinque unum magnitudine et forma unam sceleti humani referentia, ac fortissimis ligamentis ex una parte vertebrae 35 (?25) ex altera ossi pubis junguntur." 2) Diese Worte lassen nicht klar erkennen, ob Rhytina zwei aneinander geheftete Beckenknochen jederseits besessen hat, von denen Steller das eine os innominatum, das andre os pubis nennt ${ }^{3}$ ), oder ob nur ein Knochen rorhanden war und Steller als os pubis etwa das erste Hämapophysen-Paar bezeichnete, weiches wahrscheinlich wie bei Halicore und Nanatus anders gestaltet war als die folgenden Hämapophysen. Der letzteren Annahme möchte ich mich anschliessen; denn falls das Hüftbein aus zwei Knochen bestanden hätte, wären dieselben wohl nicht so weit von einander entfernt gewesen, dass

1) Blainville gibt an, dass der Beckenknochen der Halicore aus zwei Stücken bestehe (Ostéogr. Man. pag. 63) und erwähnt nicht die Verwachsung derselben im Alter, obwohl neben dem zweitheiligen Hüftbein seiner Tafel VI ein einfaches gezeichnet ist; die Ërklärung zu den Tafeln ist eben eine mangelhafte und die einzelnen Figuren sind nicht mit Nummern versehen. Blainville starb, ehe er die letzte Redaction seines Werkes vornebmen konnte. Dieselben beiden Hüftbeine bildete wieder ab A. Gandry, Enchainements du Mlonde Animal etc. Paris 1878. pag. 37.

2) De bestiis marinis, autore Georg Wilhelm Steller. Novi commentarii academiae scientiarum imp. Petropolitanae. tom.11. 1751. Descriptio Manati sen vaccae marinae, occisae 12 Jul. 1742 in insula Beringij. pag. 320. $\left.{ }^{3}\right)$ In dieser Weise fasst offenbar Meckel 1. c.pag. 422 die Worte Steller's auf. 
Steller nur von einem os imominatum coxae jederseits berichtet und den zweiten Knochen nur ganz beiläufig als os pubis erwähnt hätte'). Dass Steller eine Aehnlichkeit des Hüftbeines der Rhytina mit der ulna des Menschen erkennt, soll wohl nur heissen, dass der Ḱnochen lang und dünn war, also wahrscheinlich ähnlich gestaltet dem Hïftbein der Halicore, welcher Sirene ja die Rhytina auch in den andern Skelettheilen am meisten gleicht. Anderen Forschern, als dem ungliicklichen Reisegefährten Berings, ist der Beckenknochen der Rhytina nicht bekannt geworden, anch Nordenskjöld's neueste Funde am Strande der Beringsinsel scheinen das Hüftbein nicht zu Tage gefördert zu haben ${ }^{2}$ ).

Das Hüftbein eines Manatus australis ist auf Taf. VIII Fig. 89 skizzirt: seine Gestalt ist vollständig verschieden von derjenigen der Hüftbeine der anderen Sirenen; eine unregelmässig viereckige Knochenplatte ron $4-15^{\mathrm{mm}}$ Dicke trägt an der einen Seite einen dimmen, schmalen Fortsatz; an diesem Stiel ist das Band angeheftet, welches zum Querfortsatz des Sacral-Wirbels aufsteigt (J. Murie 1. c. pag. 140). Uebrigens scheint die Gestalt des Beckenknochens bei verschiedenen Individuen nicht unwesentlich zu variiren und Verknöcherungen der ansetzenden Bänder die Hörner und Ecken desselben gelegentlich zu verlingern; doch zejgt keine der verschiedenen Gestalten mit derjenigen des Halitherium-Hüftbeines auch nur eine entfernte Aehnlichkeit.

Es ist nicht zu verwundern, dass der völlig rudimentäre Beckenknochen der Sirenen nicht allein bei den verschiedenen Gattungen, sondern anch bei den Individuen ein und derselben Art eine ganz besonders starke Verïnderlichkeit seiner Form zeigt; er hatte eben keine hestimmten und nothwendigen Functionen mehr zu versehen. Auch dass das Hüftbein der Halicore noch eine wenn auch greringe Aehnlichkeit mit dem des Halitherium zeigt, wïhrend das Hüftbein des Manatus, dessen Skelett im übrigen mehr als das der Halicore dem Skelett des Halitherium gleicht, gar nicht mehr dem Hiütbein des Halitherium ähnlich sieht, darf bei einem so reducirten línochen nicht auffallen.

\section{b. Femur.}

Taf. VII Fig. 76. 77. 79 a. b. 83 a. b. c.

Halitherium ist die einzige Gattung unter den Sirenen, deren femur bekannt ist. Von andern Orten ist meines Wissens nur hei Bordeatux ${ }^{3}$ ) ein femur des Halitherium gefunden worden, sodass die Alzeyer und Flonheimer Schenkelbeine mit jenem einen französischen bis jetzt noch die alleinigen Funde sind. Ausser den vier abgebildeten Schenkelbeinen liegt mir noch ein fünftes vor, welches dem gut erhaltenen femur Fig. $\$ 3$ gleicht, aber oberflichlich corrodirt ist; er gehört dem Skelett von $2^{\text {n }} 60$ Länge an, welches im Mainzer Museum aufgestellt ist.

1) Brandt. Symb. sirenolog. pag. 98 stellt in der Anmerkung die beiden oben angeführten Annahmen gleichwerthig nebeneinander.

2) In der kürzlich erschienenen 17. Lieferung der sUnsegelung Asiens und Europas auf der Vega* Leipzig 1881 gibt Nordenskjüld pag. 260 eine kurze Beschreibung der Rhytina Stelleri und pag. 267 die Abbildung eines von ihm gefundenen Skelettes, an welchem nur die Hände, Beckenknochen und die letzten Schwanzwirbel fehlen. Leider ist der Zeichnung kein Masstab beigefügt.

$\left.{ }^{3}\right)$ Siehe unten bei den fossilen Sirenen. 
Das Schenkelbein des Halitherium ist desswegen als rudimentär zu bezeichnen, weil es die Function eines solchen Knochens nicht mehr ausüben kann: sein unteres Ende liuft zugespitzt aus, trägt kein Kniegelenk und wurde von keinem andern Knochen der hinteren Extremität getragen. da der Unterschenkel und der Fuss dem Halitherium vollständig fehlten. Der femur Fig. 83 ist ein $93^{\mathrm{mm}}$ langer Knochenstab, dessen oberes verdicktes Ende in einem Winkel von $130^{\circ}$ kurz umgrebogen ist; sein unteres Ende biegt sich auch ein wenig nach der einen Seite (Fig. 83c); im uibrigen streclit er sich ziemlich gerade. Seine Flïchen sind schwach wellig gebogen, ihre Oberfläche glatt, nur an den Enden rauh. An seinem vorderen Ende trïigt der femur eine glatte Gelenkfliiche, welche halbkugelig ausgewölbt ist und eine Lünge von $15^{\mathrm{mm}}$, eine grösste Iireite von $10^{\text {num }}$ besitzt; diese Fläche passt wie gesagt genau in die Gelenkgrube des Hüftbeines Fig. 85. Der Gelenkkopf stelt mit seinen Rändern vor ïber den etwas abgeschnürten Hals. Das collum ist ringsum rauh und höckerig, offenbar rom Ansatz der Gelenkkapselbänder, welche sich an dem rorstehenden Rande der fossa articularis ossis coxae anhefteten.

Nach der Gelenkfläche zu urtheilen stand der femur im Körper ziemlich gerade nach unten gerichtet, etwas schief nach aussen mit seinem unteren Ende von der Verticalen abweichend; da das Hüftbein schräg von vorn oben noch hinten unten sich stellt, so sperrt sich der femur weit ab rom Beckenknochen nach unten und aussen ${ }^{1}$ ). Demnach ist der femur Fig. 83 ein linker, a stelit die vordere, $b$ die hintere, $\mathrm{c}$ die mediale Seite desselben dar. Gleich ausserlalb des Halses erhebt sich auf der Hinterseite eine rauhe Apophyse, welche sich schräg nach oben $15^{\mathrm{mm}}$ weit auf die Oberseite des umgebogenen dicken Endes längs des Halses hinzieht; in ihrer Lage entspricht diese Apophyse dem trochanter major wohlausgehildeter Schenkelbeine und darf daher trotz ihrer reducirten Gestalt als solcher gelten ${ }^{2}$ ). Eine zweite Apophyse steht an der lateralen Seite des femur, etwa $10^{\mathrm{mm}}$ unter dem trochanter major und kann wobl als Rest des trochanter minor betrachtet werden. Dieser niedrige Wulst hat eine rauhe Oberfläche von etwa $7^{\mathrm{mm}}$ Breite und $10^{\mathrm{mm}}$ Höhe; er steht gerade gegenïber der Hohlkehle, welche sich auf der medialen Seite des femur durch die Umbiegung des oberen Endes gebildet hat.

Nach unten spitzt sich das Schenkelbein zu und plattet sich etwas ab, sodass sein Querschnitt, der unter dem trochanter minor ungefähr kreisrund mit 13-14 ${ }^{\mathrm{mm}}$ Durchmesser war, im unteren Theile seitlich comprimirt ist. Das untere Ende trägt eine schräge Abschärfungr auf der medialen Seite; diese kleine Fläche ist rauh und scheint einen Bande zum Ansatz gedient zu hahen.

Das Schenkelbein Fig. 79a. b ist ein rechtes: dasselbe ist viel schlanker als das oben beschriebene; das umgebogene obere Ende ist kürzer, die glatte Gelenkfläche ist runder und etwas kleiner; der trochanter minor tritt weniger deutlich hervor; das untere Ende spitzt sich schärfer

3) Der femur war nach unten, nicht nach hinten gerichtet wie es auf der Zeichnung Fig. 91 fälschlich angegeben ist.

$\left.{ }^{2}\right)$ Man sieht den trochanter major Fig. 83c links oben neben dem Gelenkkopf und Fig. 83 b links neben dem Halse; den trochanter minor als vorspringende Ecke auf der lateralen Seite des oberen Endes in Fig. 83 a rechts, in Fig. $83 \mathrm{~b}$ links unter dem trochanter major. 
zu, obwohl es auch eine kleine rauhe Endfläche trägt. Die Abplattung des unteren Theiles ist ebenso wie bei jenem vorhanden. Im Ganzen ist dieses Schenkelbein oberflächlich etwas corrodirt, sodass es weniger stark bewegte Flächen, als das gut erhaltene andere Schenkelbein zeigt.

Die beiden femora Fig. 76 und 77 gehören $2 u$ ein und demselben Individuum; an beiden sind die unteren Enden abgebrochen. Die Bruchfliache an dem längeren, rechten Schenkelbein Fig. 76 beweist, dass der Knochen noch länger war und also auch länger, als die beiden Beine Fig. 79 und 83. Der untere Theil ist ebenso wie bei jenen seitlich comprimirt in transversaler Richtung. Der Gelenkkopf ist dicker und kürzer, als bei Fig. 83 , und die glatte Gelenkfläche ansehnlich breiter; die letztere ist am vorderen Rande eingebuchtet gerade gegeniber der fossa acetabuli des Hüftbeines. Der Hals trägt die rauhen Spuren der Bandansiitze; die beiden trochanter reduciren sich auf schwache Apophysen.

Die drei abgebildeten Schenkelbeine verschiedener Individuen zeigen demmach etwas verschicdene Gestalten; nur der oben erwähnte femur eines vierten Skelettes gleicht dem Schenkelbein Fig. 83. Uebrigens ist es nur natülich, dass ein so rudimentärer Knochen, wie der femur des Halitherium, bei verschiedenen Individuen in seiner Form variirt, um so mehr als die tertiären Gattungen die letzten in der Reihe der Sirenen waren, welche einen solchen Knochen besassen. Bei den lebenden Sirenen ist keine Spur eines Schenkelbeines mehr zu sehen. 


\section{Die fossilen Sirenen.}

Fossile Sirenen sind in verschiedenen Gegenden der alten und neuen Welt überall nur in tertiären Ablagerungen aufgefunden worden. Als der erste beschrieb G. Cuvier in Jahre 1809 die Reste einer fossilen Sirene aus Frankreich unter dem Namen eines fossilen Nanatus (Lamantin). Später wurden fossile Sirenen entdeckt im Mainzer Becken, im Elsass, in der Schweiz, in Oberschwaben, in Belgien, im Wiener Becken, in den drei französischen Tertiärbecken (Seine-Loire, Rhône, Garonne), in Nordböhmen, in Bessarahien, der Krym, in Oberitalien, auf Nalta, in Aegypten. in England und in Nordamerika. Alle diese Funde förderten aus dem Schoosse der Erde nur unvollständige Reste, oft nur aus wenigen Theilen des Skelettes, zuweilen nur in Zähnen bestehend; an keinem andern Orte sind so gut erhaltene Skelette gefunden worden, wie in Rheinhessen. Da ausserdem manchmal nur kurze Notizen, selten genauere Beschreibungen der fossilen Sirenen vorliegen, einige, z. B. die bei Boom in Relgien vor einigen Jabren gentachten Funde noch nicht publicirt sind, so wurde es mir oft schwer, die Reste ihrer Gattung und Art nach zu bestimmen und muss ich die gliucklichen Besitzer der Originalien um Entschuldigung bitten, wenn etwa in der folgenden Uebersicht der fossilen Sirenen verschiedener Lünder der eine oder andre Irrthum mit unterlaufen sollte.

\section{Aus dom Mainzer Becken.}

Halitherium Schinzi Kaup. 1838.

Neues Jahrb. Min. 1838. pag. 319 und pag. 536 .

syn. Pugmeodon Schinzi Kaup. 1834. ')

Verzeichniss der Gyps-Abgüsse von den urweltlichen Thierresten des Grossh. Museums zu Darmstadt von J. Kaup. 2. Aufl. 1834. pag. 16. Neues Jahrb. Min. 1838. pag. 319. Taf. II Fig. C 1.2.

Halitherium dubium Kaup. 1838.

Neues Jahrb. Min. 1838 pag. 319 Taf. II Fig. D 1.2.

Halianassa Studeri H. von Meyer. 1838.

Neues Jahrb. Min. 1838 pag. 667.

Halianassa Collinii H. von Meyer. 1846.

Neues Jahrb. Min. 1846 pag. 328

Diese Art findet sich in den mittel-oligocaenen Meeressanden, welche die untersten tertiären Schichten des Mainzer Beckens bilden und den Sandsteinen des oberen Rothliegenden, resp. den

3) Da Kaup selbst den älteren Namen Pugmeodon verliess, und zwar aus triftigen Gründen, wurde er auch von andern Autoren nicht wieder aufgegriffen. 
devonischen Grauwacken unmittelbar aufruhen ${ }^{1}$ ). Die reiche Fauna von marinen Mollusken dieser Schichten ist bekannt ${ }^{2}$ ); selı zahlreich sind Haifischzähne in den Sanden, häufig Reste einer Schildkröte. Von andern Säugethieren, als Halitherium, kamen bisher nur vor: die Unterkieferhälfte einer Phoca ${ }^{3}$ ) und Theile der hinteren Extremität eines Rhinoceros ${ }^{4}$ ), beirle in den Sandgruben von Flonheim bei Alzey in Rheinhessen gefunden ${ }^{5}$ ); alle andern Säugethierreste des Mainzer Beckens stammen aus jüngeren Schichten desselben.

Halitherium Schinzi findet sich häufig in den Meeressanden, meist freilich nur in Bruchstïcken von Rippen und Wirbeln, und zwar besonders längs der jetzigen Westgrenze des Mainzer Beckens von Alzey nach Kreuznach und Bingen. Vollständige Skelette sind bisher nur gefunden worden in den Simdgruben von Alzey, Flonheim, Utfhofen und Wendelsheim, rheinhessischen Orten, welche nahe bei einander um eine Rothliegende Erhebung herumliegen; wahrscheinlich war dort eine Rothliegende Insel im tertiären Meere, um welche herum die Halitherien in Heerden, wie die Rhytinen ehemals an der Küste der Behringsinsel, im seichten Meere das Seegras abweideten. Bei Bingen enthïlt der Meeressind des Rochusberges Reste des Halitherium. Nördlich der Nahe ist Kirn der westlichste Punkt, von dem mir Halitherien-Rippen bekannt wurden; dann am Südrande des Soonwaldes nördlich der Nahe hei Walıböckelheim, Langenlohnsheim und Stromberg, rechtsrheinisch auf dem Niederwald hei Rüdesheim. Auch sind neuerlings im oligocaenen Meeresthon (Septarien- oder Rupelthon) von Flürsheim am Main unterhalb Frankfurt Reste des Halitherium Schinzi entileckt worden. Endlich kommt Halitherium auch siidlich Alzey in den oligocaenen Meeressanden der Rheinpfalz z. B. zu Dürkheim an der Haardt vor ${ }^{6}$ ).

\section{Aus der Umgegend von Basel.}

Halitherium Schinzi Kaup.

In einem grobkörnigen tertiären Sandstein zu Rödersdorf bei Pfirt im Ober-Elsass wurde im Jahre 1830 ein Skelett ohne Kiopf gefunden, welches im Strassburger Museum aufbewahrt wird. Der Sandstein liegt bei Pfirt auf dem Jurakalk und gehört der étage tongrien Ch. Mayer (= mittel-

1) Diese marinen untersten Sande werden zuweilen verwechselt mit den obersten Schichten des Mainzer Beckens, den obermiocänen Land-Sanden, welche die bekannte reiche Fauna: Dinotherium giganteum, Mastodon longirostris, Acerotherium incisivum etc. enthalten; von den Fundorten dieser Landsäugethiere ist Eppelsheim, zwischen Worms und Alzey gelegen, der bekannteste. Bei Eppelsheim kann Halitherium nicht vorkommen, weil dort die untersten Meeressande nicht zu 'T'age treten; danach ist z. B. die Angabe de Blainville's, Ostẻogr. Manatus, pag. $98 \mathrm{zu}$ corrigiren.

3) Fr. Sandberger. Die Conchylien des Mainzer Tertiär-Beckens. Wiesbaden. 1858-63.

3) Befindet sich in der Heidelberger Universitäts-Sammlung.

*) Im Darmstädter Museum.

s) Squalodon wurde in den Meeressanden des Mainzer Beckens noch nicht entdeckt, obwohl dasselbe mit Halitherinm zusammen in den gleichaltrigen Meeressanden von Linz in Oestreich, von Belgien und Frankreich häufig gefunden wird.

6) Jahresbericht der Pollichia. Dürkheim. 1868. pag. 90. 
oligocaen) an, ist also gleichaltrig mit den rheinhessischen Meeressanden; er enthält zahlreiche marine Uuscheln, Haifischzähne und Schildkröten-Reste. Die vorhandenen Wirbel, Rippen und ein Stück des Hüftbeines weisen diesen Rumpf dem Halitherium Schinzi zu').

Desgleichen fanden sich Rippen und Wirbel des Halitherium in demselben oligocaenen Sandstein des Birsthales im Baseler Jura, zu Dornach, Develier, Brislach, und bei Basel selbst im Rheinbette nach den Angaben von Peter Merian und Gressly. Endlich entdeckte P. Merian im oligocaenen marinen Kalkstein zu Lörrach im Wiesenthal NO Basel neben Rippen und Wirbeln auch einen ersten Prämolaren des Unterkiefers; H. von Meyer bestimmte dieses Zähnchen $1838^{2}$ ) als zu Halitherium Schinzi gehörig und Kaup bildete es $a b^{3}$ ).

\section{Aus dem Aargau.}

In Betreff der übrigen Tief-Schweiz gibt H. von Meyer im N. Jahrb. Min. 1839 pag. 4 an, dass Ḱnochen und ein Oberkiefer-Fragment des Halitherium Schinzi in der Meeresmolasse von Mägenwiel bei Lenzburg im Kanton Aargau vorgekommen seien. Denselben Fund erwähnt Kaup in seinen Beiträgen, Heft 2 pag. 12. Nach K. Miller ${ }^{4}$ ) sind die schweren Rippen, die Wirbel und Zähne der Halianassa Studeri in den Steinbrichen des Molasse-Sandsteins des Aargau's nicht selten. Da indessen diese marine Molasse ein mittel-miocaenes Alter (étage helvétien Ch. Nayer) hat, möchte ich es dahin gestellt sein lassen, ob diese Reste, wie die folgenden aus den gleichen Schichten Oberschwabens wirklich zu Halitherium und nicht vielmehr zu dem miocaenen Yetaxytherium gehören: leider sind keine Abbildungen oder Beschreibungen dieser Reste vorhanden.

\section{Aus Oberschwaben.}

In der marinen Molasse der Steinbrüche von Baltringen bei Biberach SUlm sind häufig Reste des Halitherium gefunden worden. Jiger bildete bereits $1839^{5}$ ) eine Anzahl Rippen ab von glänzender, dichter, dunkelbrauner Knochensubstanz (pag. 3-10. Taf. I. 1-11 und Taf. IX Fig. 1-5), die er z. Th. für Wallross-Zähne hält, Wirbel Fig. 33. 34, einen ?Stosszahn Fig. 17, Felsenbein mit

1) Das Skelett von Rödersdorf wurde zuerst beschrieben als sune espèce de Lamantia von Duvernoy Compt. rend. Acad. Paris. 1836. tome III und Mém. Soc. d'Hist. nat. de Strasbourg. 1838. tome II. Blainville, Ostẻogr. Manatus. Taf. X bildet das Skelett ab. Peter Merian erwähnt dasselbe als Halianassa Studeri H. von Meyer, im 3. Bericht der Verhandl. naturf. Ges. in Basel. 1836-38. Denselben Namen gibt ihm Gressly in Lettres ẻcrites du Jura. Bern. 1850.

2) N. Jahrb. Min. 1838. pag. 77.

3) Kaup. Beiträge zur näheren Kenntniss der urweltlichen Såugethiere. Darmstadt, 1855. Heft 2. pag. 15 Taf. I Fig. 21 b.

4) K. Miller. Das Molassemeer in der Bodensee-Gegend. Lindau. 1877. pag. 71.

5) G. F. Jäger. Ueber die fossilen Säugethiere, welche in Würtemberg in verschiedenen Formationen aufgefunden worden sind. Stuttgart. 1839. 
Schnecke Fig. 23-25 etc. In einem späteren Werke ${ }^{1}$ ) erkannte Jäger diese Reste als der Gattung Halianassa H. von Meyer zugehörig und fügte noch einige weitere Funde hinzu. II. von Meyer hestimmte einige Rippen, Wirbel und Zähne von Baltringen und von Scheer an der Donau unterhalb Sigmaringen als Halitherium Schinzi (N. Jahrb. Min. 1835 pag. 68 und 1841 pag. 97 und 365). Später erhielt H. von Meyer von dort auch einen humerus und Unterarm desselben (N. Jahrb. Min. 1842. pag. 101). K. Yiller fiihrt in der erwihnten Ahhandlung auch Hausen am Andelshach S Sigmaringen als Fundort für Halianassa an. Indessen ist wie gesagt die Bestimmung dieser Sirenen-Reste aus der miocienen Meeresmolasse Schwabens noch nicht möglich.

\section{Von Linz an der Donau.}

Halitherium Schinzi Kaup.

syn. Halitherium Christolii Fitz. ${ }^{8}$ )

Halianassa Collinii (H. von Meyer) Ehrlich. ${ }^{3}$ )

Die Hügel W und SW der Stadt Linz in Oberöstreich bestehen aus marinen Sanden, welche nach Fitzinger von granitischen Bergen umschlossen und von Löss bedeckt werden. In den Sandlagern nahe der Stadt finden sich nicht selten die Reste von Halitherium Schinzi neben Squalodon Grateloupi H. von Meyer, Balänodon lentianum H. v. M., Haifischzähnen, Austern und zahlreichen Vlecresmuscheln; diese Santle gehören der untersten Stufe des oberöstreichischen Beckens an und dïften nach den genannten Fossilien wohl gleichaltrig mit den rheinhessischen, belgischen und französischen oligocaenen Ablagerungen sein ${ }^{4}$ ).

Der Unterkiefer, welchen Fitzinger abbildet, wurde 1839 aufgefunden; er gleicht vollkommen der oben beschriebenen mandibula des Halitherium des Mainzer Beckens: er hat eine Länge von $260 \mathrm{~mm}$ und im Gelenkkopf eine Höhe von $220^{\mathrm{mm}}$; er ist also etwas grösser, als der auf unsrer Taf. IV algebildete I"nterkiefer. Die rechte Kieferhälfte enthält den bereits angekanten $\mathrm{m}^{4}$, danm $\mathrm{m}^{3}$ und $\mathrm{m}^{2}$ und die beiden Wurzeln des $\mathrm{m}^{2}$; davor drei Alveolen der drei Prämolaren und undeutliche Alveolen in der Kinnfäche. An der linken Hälfte ist der letzte Molar mit dem Ast weggebrochen; $\mathrm{m}^{3}$ und $\mathrm{m}^{2}$ vollständig, $\mathrm{m}^{1}$ zur Hälfte erhalten. Alle diese Molaren sind zweiwurzeiig und stimmen nach den thbildungen vollständig mit denen des Mainzer Halitherium Schinzi überein. Es scheint, dass auch bei diesem Unterkiefer die beiden oben erwähnten (pag. 105) Alveolen vor dem

1) Uebersicht der fossilen Såugethiere Wïrtembergs. Acta Leopold. Acad, natur. 1850. vol. XXII. 2. pag. 781. Taf. 68 Fig. 3-6 und pag. 814.

2) Dr. L. Fitzinger. Bericht über die in den Sandlagern von Linz aufgefundenen fossilen Reste eines urweltlichen Säugers (Halitherium Christolii n. sp.). Im 6. Jahresbericht des Museum Francisco-Carolinum. Linz. 1842 pag. 67.

3) C. Ehrlich. Beiträge zur Palaeontologie und Geognosie von Oberösterreich und Salzburg. Linz. 1855. pag. 11 Halianassa Collinii H. von Meyer.

4) F. von Hauer, Geologie der östr. ung. Monarchie. Wien 1875. pag. 570, sieht zwar die Sande von Linz als eine marine Stufe der Neogenformation an. 
dritten Prämolaren am oberen Ende der rauhen Kinnfläche vorhanden sind, welche nur einem vierten Prämolaren und einem Eckzahn, beide friih ausfallend, zugeschrieben werden können ${ }^{1}$ ).

In späteren Jahren wurden aus den oligocaenen Sanden und Sandsteinen bei Linz häufiger Reste des Halitherium zu Tage gefördert. 1854 fanden sich noch mit einander vereinigt 17 Rückenund Lendenwirbel mit 24 Rippen, welche nach Ehrlich's Beschreibung und Abbildung völlig denen unsres Halitherium gleichen. Die Rippen sind ebenso dick und von so dichter Structur wie jene; von einem Rippenstück liess Ehrlich eine chemische Analyse ausführen, welche wir hier zur Vergleichung mit der unsrigen (pag. 137) wiedergeben wollen:

\begin{tabular}{lr} 
Phosphorsaurer Kalk mit Spuren von Fluorcalcium & 75,20 \\
Kohlensaurer Kalk & 17,34 \\
Phosphorsaure Magnesia & 0,78 \\
Kieselsäure & 1,10 \\
Alkalien & 0,92 \\
Organische Substanz & 3,94 \\
Spuren von $\mathrm{Fe}^{2} \mathrm{O}^{3}$ und Verlust & 0,72 \\
\hline & 100,00
\end{tabular}

Diese Analyse stimmt so ziemlich mit der unsrigen überein und beweist gleichfalls, dass die Ińnochensubstanz der Rippen des IIalitherium im Laufe der Zeiten noch kaum verändert worden ist.

Ausser weiteren Funden von Rippen und Wirbeln kamen auch Schädelfragmente und ein Schulterblatt aus den Sanden bei Linz zum Vorschein; soweit die scapula erhalten ist, gleicht sie derjenigen des Mainzer Halitherium.

Aus der ferneren Umgebung von Linz ist Wallsee an der Donau zu nennen, wo sich in einem wohl mit dem Linzer gleichaltrigen Sandsteine Reste unsrer Sirene vorfanden, und zwar 45 Rippen und 6 Wirbel (Ehrlich pag. 19). Von derselben Localität erhielt H. von Meyer einen Zahn seiner Halianassa Collinii (N. Jahrb. Min. 1847 pag. 578) und liegt ein Molar derselben im k. k. Hofmineraliencabinet in Wien; an dem letzteren constatirt Peters ${ }^{2}$ ) den Unterschied dieses Halitherium Schinzi von der miocaenen fossilen Sirene des Wiener Beckens.

\section{Aus dem Wiener Becken. \\ Metaxytherium sp.}

Im miocaenen Leithaconglomerat zu Hainburg an der Donau unterbalb Wien wurde im Jahre 1867 das Skelett einer fossilen Sirene aufgefunden, welches aus der Wirhelsäule, den Rippen. der vorderen Extremität und dem Hüftbein bestand; Zühne oder andre Theile des Schädels fehlten.

1) An einem neuerdings in Flonheim aufgefundenen Unterkiefer sind diese beiden Alveolen auf jeder Seite ebenso gut erhalten, wie in dem Unterkiefer unsrer Taf. IV Fig. 32 linke Seite, was ich oben (pag. 105) noch nicht berichten konnte.

2) Die in der folgenden Anmerkung citirte Abhandlung pag. 310. 
In der Besprechung dieses Skelettes hebt K. Peters ${ }^{1}$ ) mit richtigem Blicke hervor, dass zwar die Knochen des Stammes wenig, aber desto mehr die der Extremitäten Unterschiede in der Form von dem Halitherium von Linz und von Rheinhessen zeigen; indem Peters mit Recht zu derselben Sirene mehrere Molaren aus den gleichaltrigen Sanden von Neudorf bei Wien rechnet, kommt er zu dem Schlusse, dass diese Sirene des Wiener Beckens identisch sei mit der Miocaenspecies von Angers in der Touraine, Halitherium Cordieri de Christol sp. Wir werden unten die französische Art zu besprechen haben und sehen, dass derselben der Name Metaxytherium Cuvieri de Christol zukommt.

Metaxytherium unterscheidet sich von Halitherium am leichtesten durch den Nangel an Prämolaren, die Grösse der Stosszähne und die complicirtere Gestalt der Molaren-Kronen. Die drei von Peters abgebildeten Molaren von Neudorf (1. c. Taf. VII Fig. 1-3) beziehen sich auf einen grossen halb ahgekunten letzten (nicht wie Peters meint vorletzten) Molaren iles Unterkiefers (Fig. 1), dessen vordere Wurzel am Ende gespalten, die hintere selı kräftig ist; auf einen frischen Md m* mit offener Wurzel (Fig. 2. vergl. unsre Taf. IV Fig. 32a) und auf einen frischen letzten Molar des Oberkiefers (Fig. 3), nicht des Unterkiefers. An diesen drei Molaren sieht man, wie im Vergleich mit den nach den gleichen Grundplan gebauten Zihnen des Halitherium Schinzi die Nebenhöcker in den Thälern und in den Hauptzapfen-reihen ihre Anzahl vermehren, und der Schmelz viel tiefer in die Furchen eindringt, sodass die Krone derselben complicirter und zerschnittener wird. An Grösse nehmen die Molaren nicht zu.

Obwohl die scapula beschädigt ist, sind doch die Unterschiede mit der unsrer Abbildung Fig. 72 leicht zu erkennen: die spina ist viel länger und läuft bis zur oberen Ecke aus; das collum ist dünner und länger; der ganze Umriss ist anders gezogen, abgesehen davon, dass der hintere Theil der scipula abgebrochen ist. Besonders charakteristisch ist der humerus des Metaxytherium, welcher an dem Hainburger Skelett gut erhalten ist: wie diese Gattung überhaupt in der Gestalt der Knochen etwas mehr Halicore-artig ist als Halitherium, eriunert besonders der humerus an denjenigen der Halicore: er ist gedrungener, als der des Halitherium, das obere Ende ist dicker, der Raum zwischen caput und tuherculum majus breiter und besouders der angulus anterior durch den Muskelzug des teres major und deltoideus fast ebenso stark ausgebildet, wie bei Halicore. Die srösste Lïnge des humerus hetrïgt $21 \mathrm{~cm}$, die Dicke des oberen Endes $94 \mathrm{~mm}$. Die Unterarm-Kínochen sind weniger gut erhalten. Interessant ist das Vorhandensein von zwei Carpal-Knochen, welche vom Halitherium noch nicht bekannt wurden: es sind die beiden Knochen der ersten Reihe, sodass also, wie beim Dugong, das os pyramidale nit dem pisiforme zu einem längeren und das os lunatum mit dem scaphoideum zu einem kiurzeren Knochen verwachsen sind (Peters, Fig, 7a.b).

Das Hüftbein (Fig. 8) weicht weniger stark von dem gleichen des Halitherium Schinzi ab, wenn wir uns erinnern, wie bedeutende Verschiedenheiten die Hüftbeine der rheinhessischen Art aufweisen (oben pag. 154). Das vordere Ende des os ilium ist abgebrochen; seitlich der scharf aus-

1) Das Halitherium-Skelett von Hainburg. Jahrbuch der k. k. geol, Reichsanstalt. Wien. Bd. XVII. 1867. pag. 309. Siehe auch F. von Hauer's Ankündigung desselben Skelettes in den Verhandl. der k. k. Reichsanstalt. 1867. pag. 140 . 
geprägten Gelenkfläche für den rudimentiren femur steht ein bedeutend kleinerer processus inferior. Das hintere Ende des os pubo-ischiadicum ist seitlich comprimirt, etwas nach innen umgebogen und zeigt starke Rauheiten durch den Ansatz von Muskeln.

Die hervorgehobenen Unterschiede zwischen den Funden des Wiener und des Mainzer Beckens genuigen, um die miocaene Donau-Sirene nicht zur Gattung Halitherium zu rechnen, sondern der Gattung Metaxytherium de Clristol zuzuweisen. Doch reicht das Wiener Material nicht hin, um die Identificirung mit der französischen Art MI. Cuvieri de Christ. zu rechtfertigen; vielmehr zeigt z. B. der humerus bereits einige Abweichungen. Solange aber nicht die wichtigsten Schädeltheile des Metaxytherium im Wiener Becken aufgefunden worden sind, würde eine neue Species in der Luft schweben; ich habe daher diese Funde von Hainburg und Neudorf als Metaxytherium sp. aufgefuihrt.

Abgesehen davon, dass Reste von Sirenen noch von verschiedenen andern Orten in der Umgegend von Wien z. B. von Hernals citirt werden, finde ich von weiteren östreichischen Lokalitäten nur noch Leitmeritz und Theresienstadt an der Elbe in Nordböhmen als Fundort für einen fossilen Manatus bezeichnet ${ }^{1}$ ); doch sind wie es scheint die Knochen und Zähne von dort niemals beschrieben worden.

\section{Aus Bessarabien und der Krym.}

In der Nähe von Kertsch in der Krrym wurden Wirbel und Rippen einer fossilen Sirene gefunden, welche Eichwald ${ }^{2}$ ) zuerst mit dem Skelett von Rödersdorf im Elsass verglich; zweifelhaft ob zu derselben gehörig sind Schädelfragmente und eine Phalange von dort. Später brachte Hommaire de Hell aus den Steppen Südrusslands die Rippen einer fossilen Sirene mit nach Paris, von denen Blainville 1. c. Taf. $\mathrm{X}$ eine abbildet ("de Bessarabie", im 'Texte pag. 118 „de la crimée"). Eichwald benannte in seiner Lethaen rossica, Stuttgart 1853, pag. 344 Taf. XIII Fig. 38 einige Rippen aus Bessarabien Manatus maeoticus. Diesen Namen belielt von Nordmann bei in seiner Paläontologie Südrusslands pars IV 1866. jag. 330 für Rippen, Wirbel und zwei Schulterblätter einer fossilen Sirene, welche aus den Steinbrüchen von Kischinew in Bessarabien stammen. Zu welcher von den verschiedenen Gattungen diese fossile Sirene Suidrusslands zu rechnen ist, lässt sich nach dem bis jetzt vorliegenden Material nicht bestimmen; das Alter der Schichten, in welchen die Reste vorkamen, scheint ein miocaenes zu sein.

1) G. Cuvier. Sur l'ostéologie du Lamantin. Annal. du muséum d'hist. nat. tome 13. Paris 1809. pag. 303, Anmerkg.: „ II. Jean Meyer médicin de Prague dit bien (Mémoire d'une société privée de Bohême, tome 6 pag. 262) que l'on a trouvé à Leitmeritz et à Theresienstadt des os et des dents de Manatus; mais il ne donne point de figure et n'explique point de quelle manière ou est parrenu à les reconnaître pour telsc. Darauf bezieht sich die Anmerkg. bei Blainville. Ostéogr. Man. pag. 80.

2.) Ed. Eichwald. Ueber die Dinotherien und einige ihnen verwandte Thiere Russlands. Bull. Acad. st. Petersbourg. 1838. pag. 257. 


\section{Aus Belgion.}

In den oligocaenen Septarien-Thonen von Belgien scheinen Halitherien-Reste nicht selten zu sein. Herr Th. Lefèvre in Brüssel meldete mir auf Anregung von Dewalque in Lüttich vor zwei rahren, dass er im Besitz eines ziemlich vollständigen Skelettes von Halitherium Schinzi sei, welches zusammen mit Haifischzïhnen und zahlreichen Mollusken im oligocaenen Mceresthon (Rupelthon) bei 130om, zwischen Antwerpen und Mecheln gelegen, gefunden worden sei. ${ }^{1}$ ) Leider ist über dies Skelett noch nichts veröffentlicht, und konnte ich den genannten Herren auch nicht bewegen, mir Notizen ïber dieses Halitherium zı geben; nur eine kleine Photographie der scapula und der drei Armknochen sandte mir derselbe zu, welche allerdings, soweit es zu sehen ist, mit den gleichen Knochen der rheinhessischen Sirene übereinstimmen. Auch sind ja die Schichten ron Boom gleichaltrig mit den Meeressanden resp. mit den marinen Septarien-Thonen (Flörsheim am Main) des Mainzer Beckens und wurlen wahrscheinlich in einem mit dem Mainzer Veere zusammenhängenden Meere abgelagert.

Van Beneden bildete im Bull. de l'Acad. roy. de Belgique, tome 22. 1871 pag. 164 zwei Wirbel und ein Schïdelfragment einer Sirene ab, welche mit Squalodon-Resten im oligocaenen Septarien-Thon von Elsloo bei Maastricht gefunden wurden. Der Riickenwirbel Fig. 2 und ein vorderer Schwanzwirbel Fig. 3 stimmen in der Grösse mit denen des Halitherium Schinzi überein. Diese Wirbel gehören wohl kaum zu dem grossen Schädelfragment Fig. 1; dazu sind sie viel zu klein. Wenn dieses sehr verstümmelte Fragment der unteren Partie des Hinterhauptes überhaupt einer Sirene zuzuschreiben ist, so könnte es der bedeutenden Grösse und Dicke seiner Knochen nach etwa zur Gattung Felsinotherium Capp. ${ }^{2}$ ) gehören. Van Beneden gibt dieser zweifelhaften Sirene den neuen Namen Crassitherium robustum; es dürfte auf das so ungenügende Material eines schlecht erlaltenen Schädelfiagmentes wohl nicht gleich ein neues Genus und eine neue Species aufgestellt werden. Daselbst pag. 168 meldet auch van Beneden, dass zu Basel bei Rupelmonde nahe Boom im Pupelthon ein vollstindigeres Skelett eines Halitherium gefunden sei, welches beim Ausgraben leider vernichtet wurde.

\section{Aus Frankreich.}

\section{a. Loire-Becken.}

Metaxytherium Cuvieri, de Christol 1843.

Die erste fossile Sirene, welche überhaupt beschrieben wurde, ist der "Lamantin fossile" von Angers an der Loire, welchen G. Cuvier 1809 in den Amral. du Mus. d'hist. nat. de Paris. tome XIII pag. 303 Taf. 19 bespricht und abbildet. In seinen berühmten Ossemens fossiles tome V. 1. 1823 lässt G. Cuvier sowohl den Text als die Tafel jenes ersten Artikels wieder abdrucken mit einigen

${ }^{1}$ ) Den ersten Fund dieser Reste aus dem Rupelthon von Boom erwähnte Vicomte du Bus bereits im Bull. Acad. roy. de Belgique. 2. série. tome 26. 1868. pag. 20.

3) Felsinotherium ist bisher nur iu den pliocienen Schichten Oberitaliens gefunden worden (siehe unten). 
neuen Zusätzen am Ende des Kapitels üher die fossilen Lamantine (pag. 266 Taf. 19 Fig. 12 a.b und 19-29). Es waren diese ersten Reste: ein Schädeldach mit der squama ossis occipitis, dem os parietale, dem os frontis und os nasi ${ }^{1}$ ), alle Theile mehr oder weniger zerbrochen Fig. 22. 23; ein gut erhaltener atlas Fig. $12 \mathrm{a}, \mathrm{b}$, den ich oben pag. 124 Anmerkg. 3 erwähnte; die beiden Unterarm-Knochen Fig. 19-21 und das obere und untere Ende eines humerus Fig. 24-26 und 28. 29, welchen Cuvier fälschlich einer Phoca zuschreibt (pag. 233). Diese Reste stammten her aus einem muscheIreichen Grobkalk am Ufer des Flüsschens Layon, welches gegenuber Angers in die Loire mündet. Das Schädeldach stimmt in seiner Gestalt überein mit dem Metaxytherium Curieri de Christol, wie es am besten P. Gervais (Zool. et Paléont. franç. tome I Taf. 4-6) von Montpellier abgebildet hat, nur sind die cristae temporales etwas kräftiger und verschmälem die Obertiiche des Schädels etwas mehr. Von Halitherium weicht dieser Schädel sogleich durch die schmalen und langen processus orbitales ossis frontis ab. Die Grösse des Scliädels vom Metaxytherium ist etwa die gleiche wie bei Halitherium: dieses Schädeldach, welches Cuvier zuerst beschrieb, ist von der vorderen Ecke der eben genannten Fortsätze bis zur squama ossis occipitis $22^{\mathrm{cm}}$ lang. Der atlas ist hüher, schmächtiger und trïgt einen kleineren Querfortsitz, als derjenige des Halitherium Schinzi. Der humerus zeigt diejenigen Abweichungen, welche wir oben bei dem Hainburger Metaxytherium hervorhoben. Die zu dem Schädelfragment gehörigen Rippen hatten, wie Cuvier pag. 209 erwähnt, einen runden Querschnitt, eine Eigenschaft, welche den Rippen aller tertiären Sirenen zuzukommen scheint gegenüber den mehr abgeplatteten Rippen der lebenden Sirenen.

De Blainville erwähnt ausser diesen Cuvier'schen Stücken noch ein Fragment des os occipitis, einen Theil des 0 s frontis, einen vollständigen grossen lumerus, melırere Wirbel, Rippen und ein Schulterblatt aus der Umgegend von Angers (1. c. pag. 82-89) und bildet von diesen das Schulterblatt, den humerus und eine Rippe auf seiner Taf. X, Rückenwirbel auf Taf. VIII ab. Von allen diesen Resten weicht der humerus am meisten von dem des Halitherium Schinzi von Rheinhessen ab: er ist verhältnissmiäsig liüzer, dicker, hat ein stïrkeres tuberculum majus und eine viel grössere crista für den Ansatz des musculus deltoideus darunter; seine Ellenbogen-Gelenkrolle steht etwas schief, nicht in $90^{\circ}$ gegen die Lïngsaxe des humerus. Durch diese Nerkmale nähert sich die Gestalt des humerus mehr derjenigen des humerus der Halicore.

Nahe bei diesem Yorkommen wurde zu St. Michel-de-Chaisine bei Angers in einem Kalke das Unterkieferfragment gefunden, welches Cuvier, Oss. foss. I pag. 332 als Hippopotame moyen fossile beschreibt und Taf. VII Fig. a abbildet. Dasselbe Stiick findet sich hesser dargestellt bei Blainville, Manatus Taf. IX oben rechts. De Christol erkannte die Zugehörigkeit dieses Unterkiefers zu den Lamantins 1832, gebrauchte zuerst für denselben und für ähnliche Reste von Montpellier den Namen Halicore Cuvieri 1835 und stellte in der Sitzung des Institut de France vom 21. Sept. 1840 die

1) Die beiden kleinen Knochenstïcke, welche Cuvier als Nasenbeine beschreibt 1. c. pag. 268 und abbildet Taf. 19 Fig. $22 \mathrm{e}$ sind die Wurzelenden des os nasi; der Stirnrand ist fortgewittert mit dem vorderen breiten Ende der Nasenbeine. Blainville corrigirt Cuvier falsch, wenn er annimmt (Ostéogr. Man.pag. 83), es seien diese beiden Stücke c die Enden der processus frontales ossis incisivi; die Zwischenkieferenden blieben weiter vorn. Blainville bildet das von Cuvier beschriebene Schädeldach wieder ab auf seiner Taf. VIII links. 
Gattung Metaxytherium und 1843 (bei Blainville, Ostéogr. Man. pag. 130) die Arten M. Cuvieri und Cordieri auf; da beide Artnamen gleichzeitig entstanden, die französischen Autoren sich aber fast ausschliesslich des ersteren bedienen, habe auch ich den Artnamen M. Cuvieri für die französische miocaene Sirene beibehalten und den andern Namen fallen lassen. In diesem Unterkiefer stecken drei zweiwurzelige Molaren $\mathrm{m}^{2}-\mathrm{m}^{4} ; \mathrm{m}^{2}$ ist bis auf die Wurzeln abgekaut. $\mathrm{m}^{3}$ zeigt bei halber Abkauung die blumenblattartige Kaufläche, welche Cuvier bewog, diese Stücke dem Hippopotamus zuzuweisen. $\mathrm{m}^{3}$. ist bereits complicirter gebaut als $\mathrm{Md} \mathrm{m}^{3}$ des Halitherium Schinzi: die Schmelzlage zieht sich tiefer zwischen die heiden Hauptzapfen-Reihen hinein und der talon hinten theilt sich in zwei bis drei Zapfen; es erhält dadurch dieser Md $\mathrm{m}^{3}$ des Metaxytherium von Angers einige Aehnlichkeit mit dem Md $\mathrm{m}^{4}$ des Halitherium von Flonheim. Der letzte Molar complicirt seine Krone dadurch mehr als derjenige der rheinischen Art, dass in den heiden Querthälern Nebenhöcker entstehen, und die beiden Hauptzapfen jeder Reihe sich nicht mit deutlichen Querbriicken miteinander verbinden. Die Molaren des Metaxytherium verlieren durch die Vermehrung und unregelmässigere Stellung der Zapfen noch mehr als diejenigen des Halitherium die Jochform der Molaren ihrer Vorfahren und werden dadurch den Backzähnen der Suiden ähnlicher (vergl. Blainville pag. 85).

Zu derselben Sirenen-Art sind wohl die Armbeine zu rechnen, welche Blainville aus der Umgegend ron Rennes, Ille-et-Villaire, $\mathrm{N}$ Angers gelegen, pag. $\$ 9$ anfuihrt; einen derselben bildet Blainville auf Taf. $\mathrm{X}$ ab. Ebenso hemerkt Roualt ${ }^{1}$, dass sich in der Umgegend von Rennes, nämlich zu Dingé, St. Juvat und la Chaussairie Fragmente des Schädels, der Wirhel und Zähne des Halitherium medium ('uv. (= Metaxytherium Cuvieri de Christ.) gefunden hätten. Endlich erwähnt P. Gervais, Zool. et Paléont. générales. 1867-69 tome I pag. 183 ein Unterkiefer-Fragment eines Halitherium (? Metaxytherium) aus dem Grobkalk ron Blois an der Loire, ohne sich eingehender über dasselbe zu äussern.

Das Alter der Schichten, in welchen die genannten Reste des Metaxytherium Cuvieri an der unteren Loire vorkommen, wird von den iilteren Autoren nicht genauer angegeben. Gervais dagegen nennt die Allagerungen der angeführten Fundorte, also bei Angers, Doué, Rennes etc., „molasse miocène" (Zool. et Paléont. franç. tome I pag. 143). Wir werden sehen, dass die Gattung Metaxytherium auch an amleren Orten erst im Miocaen crscheint, während Halitherium auf die oligociene (und eocaene) Abtheilung des Tertiär beschränkt ist.

\section{b. Garonne-Becken.}

Halitherium Schinzi Kaup.

Die ersten Funde von Halitherien-Resten aus der Gegend von Bordeaux beziehen sich auf drei Rippen, welche G. Cuvier aus einem tertiären Grobkalk von Capians bei Bordeaux erwähnt (Ann. du mus. d'hist. nat. pag. 308): „pareilles à celles des environs d'Angers". Später erhielt

1) Compt. rend. Acad. sc. de Paris. 1858, tome 47. pag. 100. 
Cuvier drei vordere Molaren aus einem Kalkstein von Blaye ${ }^{1}$ ), nahe der Garonne-Müundung gelegen im dép. Gironde; Cuvier schrieb diese Zähne einem „Hippopotame fossile" zu (Oss. foss. tom. I. pag. 333 Taf. VII Fig. 12-20). Blainville bildet diese Zähne wieder ab, Man. Taf. IX, unter dem Namen Metaxytherium Cuvieri, welchen Namen de Christol den Halitherien-Resten von Montpellier gegeben hatte (Blains. Man. pag. 130). Es sind zwei dreiwurzelige Molaren des Oherkiefers, und zwar wie mir scheint $\mathrm{m}^{2}$ beider Seiten; dazu ein zweinurzeliger Molar des Unterkiefers, wohl auch $\mathrm{m}^{2}$, alle drei Zähne vielleicht von ein und demselben Schïdel. Diese drei Zähne zeigen keine Unterschiede von den gleichen des Halitherium von Rheinhessen.

Seit Cuvier's erster Beschreibung sind nun die Halitherien-Reste im Gironde-lépartement häufiger gefunden und im Museum zu Bordeaux angesammelt worden. Delfortrie, welcher 1872 einen Theil der Funde beschrieben hat ${ }^{2}$ ), gibt an, dass in den untermiocaenen (oligocaenen) Kalksteinen an rechten Lfer der Garonne oberhalb Bordeaux bis la Réole die Halitherien-Rippen ausserordentlich häufig seien. Leider sind Beschreibung und Abbildungen Delfortrie's ziemlich mangelhaft. Diese Reste bestehen aus mehreren Schädeldächern (Delfortrie pl. 18 Fig. 1-4 und pl. 19 Fig. 6), welche sich wie gewöhnlich aus squama ossis occipitis, os parietale, os frontis und Stücken des os nasi und os ethmoideum zusammensetzen; alle Theile sind mehr oder weniger verletzt. Die Länge des Schädeldaches von der vorderen Ecke des processus orbitalis ossis frontis bis zum Oberrand der squama ossis occipitis beträgt $20^{\mathrm{cm}}$, ist also dieselbe wie bei unserm Halitherium Schinzi. Die Formen und Fortsätze dieser Schädelknochen unterscheiden sich, soweit sie erhalten sind, in keiner Weise von denselben der rheinhessischen Sirene; die cristae temporales springen ebenso stark hervor und liegen in der Vitte des Schäldhaches so nahe heieinamler. wie hei dem spitzlöpfigen H. Schinzi; die protuberantia occipitis externa, die spina parietalis interna sind vorhanden; auch die Dicke der Schädelknochen und ihre Nahtverbindungen sind die gleichen, wie bei unserm Halitherium. Ein schlecht erhaltenes Stück der partes laterales ossis occipitis Fig. 5 mit einem condylus, Theile des processus zygomaticus ossis temporum Fig. 7.8, ein Theil des rechten Oberkiefers mit den drei letzten Molaren Fig. 12 sind ausser einigen Zähnen die einzigen Reste des Oberkopfes. Etwas vollständiger sind die beiden Unterkiefer Fig. 9-11, welche soweit sie erhalten sind, genau mit dem des Halitherium Schinzi übereinstimmen. Der eine Fig. 9 enthält noch den halbabgekauten letzten Molaren der linken Seite, del andre zeigt nach Delfortrie pag. 15 vier zweiwurzelige Alveolen für vier Molaren, davor zwei einzelne Alveolen für Prämolaren und vier Alveolen auf der Kinnfläche für rudimentäre Schneidezälıne.

Dieser Unterkiefer aus dem Kalk von Léognan wurde an P. Gervais nach Paris gesendet, welcher ihn als „Halithérium fossile de Léognan" erwähnt (Zool. et Paléont. génér. tom. I. pag. 182),

1) P. Gervais, Zool. et Paléont. franç. tome I. 1848-52. pag. 145 sagt von diesem Fundorte: sdépôt marin qui repond au calcaire grossier sous-gypseux de Paris*; es würde das schon eocaen sein; doch sind im Garonne-Becken auch die jitngeren Tertiär-Stufen vorhanden. Er erwähnt diese drei Zühne als Ialitherium dubium Cuv. sp.; jedoch hat Cuvier niemals diesen Artnamen gebraucht.

2) Etude sur les restes fossiles de Siréniens du genre Halitherium dans le bassin de la Garonne. Actes Soc. Linnéenne de Bordeanx. tome 28. 1872. mit fünf Tafeln. 
ohne ihn einer bestimmten Art zuzurechnen; Gervais meint, dass sich dieser Unterkiefer von dem des Halitherium Serresii Gervais (= Metaxytherium Cuvieri de Christ.) dadurch unterscheide, dass in der Lücke zwischen den Backenzähnen und der incisiven Kinnfläche Alveolen vorhanden seien; dies ist in der That ein Charakter, welcher dip ältere Gattung Halitherium von der jüngeren Metaxytherium unterscheidet: dem miocaenen Metaxỵtherium fehlen nämlich die Prämolaren (siehe unten) ${ }^{3}$ ).

Das Gebiss des Halitherium ron Bordeaux entspricht nach dem, was Delfortrie davon angibt, ganz genau dem des Halitherium Schinzi: Taf. 20 Fig. 12 stecken die drei letzten Molaren noch in dem rechten Oberkiefer; Fig. 13.14.15a sind Molaren des Oberkiefers, Fig. 15b.c des Unterkiefers. Wichtig ist der einwurzelige, noch nicht abgekaute Prämolar Fig. 15 D, welcher dem Zahn unsrer Tafel IV Fig. 28 ziemlich genau gleicht. Sowohl die Form der Kronen als die Grösse aller dieser Zähne ist dieselbe wie bei Halitherium Schinzi.

Die Fig. 17-19 stellen schwach gekrümmte breite Knochenstücke dar, welche Delfortrie als Zungenbein-Hörner bezeichnet: ich weiss nicht, ob diese Deutung die richtige ist; Fig. 18 scheint mir ein verbogener processus ensiformis sterni zu sein, wie unsre Fig. 62.

Die zahlreichen Wirbel, welche Delfortrie auf den Tafeln 20 und 21 darstellt, stimmen bis ins Detail und in der Grösse vollständig mit denen des rheinhessischen Halitherium Schinzi überein: der Fpistropheus Fig. 23 zeight dieselbe Grösse, denselben Zahn, dieselbe dicke Kippe im oberen Bogen und die Gelenkfächen, wie der unsre. Die Wirbel Fig. 31-35 scheinen mir nicht die Lendenwirbel, sondern erste Schwanzwirbel zu sein: denn ihre Querfortsïtze sind zwar lang und gross, haben aber noch nicht die Dicke, welche sie an den Lendenwirbeln des Halitherium Schinzi erreichen. Auch die Hälfte einer Hämapophrse billet Delfortrie Fig. $39 \mathrm{ab}$ : sie hat dieselbe Gestalt, wie an den Flonheimer Skeletten, muss aber umgekehrt stehen, das schmale Ende nach oben.

Die Rippen Taf. 22 haben dieselbe Grösse, dieselbe Krümmung, die Dicke, die runde Gestalt, die spitzen Enden, capitulum und tuherculum ebenso ausgebildet, wie bei der rheinhessischen Art. Von den Extremitäten ist nicht viel vorhanden: von der scapula Fig. 21.22 ist zu wenig erhalten, um sie vergleichen zu können. Ausserdem ist ein Metacarpal-Knochen Fig. 41 abgebildet, welcher mit dem unsrigen Fig. 66 übereinstimmt, wenn man berücksichtigt, dass sein Fingerende abgebrochen ist. Von grosser Wichtigkeit ist aber, dass der rudimentäre femur Fig. $40 a-c$ gefunden wurde, der einzige, welcher ausser den Flonheimer Schenkelbeinen bekannt geworden ist. Allerdings ist derselbe etwas corrodirt; man erkennt aher gut das umgebogene obere Ende mit dem Gelenklïppfchen und einem trochanter; das untere Ende ist zugespitzt und zeigt eine kleine, rertiefte Ansatzstelle für eine Sehne. Dieser femur ist $82^{\mathrm{mm}}$ lang, sein Gelenkkopf $10-12^{\mathrm{mm}}$ dick; er gleicht unsrer Fig. 79. Delfortrie hält diesen Knochen fälschlich für ein os penis, welches bekanntlich den Sirenen ganz fehlt und auch eines Gelenkkopfes nicht bedurft hätte.

1) Gervais gibt ebenso wie Delfortrie von diesem oligocaenen Unterkiefer von Léognan an, dass auf der incisiven Kinnfläche neben der Symphyse fünf Alveolen sichtbar seien; ausserdem eine weitere drüber in der - barre vor dem ersten Molaren. Indessen bleiben die Alveolen der Prämolaren und der früh ausfallenden Schneidezähne nicht immer sämmtlich erhalten, diejenigen der letzteren sind sogar meistens ganz verwachsen am Unterkiefer des Halitherium. Nach den besterhaltenen Stïcken kommen der Mandibula des Halitherium zu: $4 \mathrm{~m}$, 3 oder 4 p, $1 \mathrm{c}, 3$ (oder 4 ) $i$, wobei die letzteren jedenfalls rudimentär blieben und früb resorbirt wurden. 
Delfortrie nennt die von ihm beschriebene Sirene der Umgegend von Bordeaux Halitherium Cuvieri Kaup und behauptet zugleich, dass alle andern französischen und deutschen fossilen Sirenen dieser Species zugerechnet werden müssen. Abgesehen davon, dass Ľaup gar nicht diesen Artnamen aufgestellt hat, sondern de Christol für die fossilen Sirenen von Montpellier, diurfte wohl dieses Halitherium bei der vollständigen Uebereinstimmung aller bis jetzt vorliegenden Theile mit denen der rheinhessischen Art auch als Halitherium Schinzi zu bezeichnen sein. Die meisten von Delfortrie beschriebenen Reste stammen aus oligocaenen („miocène inférieur“) Schichten bei Bordeaux; nur bei dem Bruchstiick des os parietale und der squama ossis occipitis Fig. 4 und den Zïhnen Fig. 15 gibt Delfortrie "eocène" an; wir haben oben bemerkt, dass die Molaren Cuvier's von Blaye bei Bordeaux gleichfalls eocaenen Kalken angehören sollen. Auch in Ober-Italien wird Halitherium im Eocaen angegeben (sielie unten).

Aus derselben Gegend stammt auch der kaum angekaute zweite Molar des rechten Oberkiefers, welchen P. Gervais in der Zool. et Paléont. franç. tome I. 1848-52 pl. 41 Fig. 3 abbildet und als Backenzahn eines unbestimmten Halitherium pag. 144 bespricht. Gervais erhielt ihn aus dem marinen untermiocänen (oligocaenen) Grobkalk von Cénac bei Bordeaux; in den gleichen Kalken finden sich sehr häufig Halitherien-Ripnen. Auch dieser dreiwurzelige Zahn stimmt genau überein in seiner Grösse und der Form seiner Krone mit demselben des Halitherium Schinzi von Rheinhessen. Desgleichen ist der zweiwurzelige Zahn daselbst pag. 145 Taf. 41 Fig. 2, auf welchem P. Gervais die neue Sirenen-Gattung Trachytherium ${ }^{1}$ ) und die Art Raulinii begründet, ein letzter Molar des Halitherium Schinzi: er stammt aus demselben marinen Grobkalk des Garonne-Beckens und zwar yon La Réole oberhalb Bordeaux, woselbst, wie erwähnt, häufig Halitherien-Rippen gefunden werden.

Endlich bildet P. Gervais, Zool. et Paléont. franç. tome I Taf. 41 Fig. 1 einen Stosszahn mit etwas verkrümmter Wurzel ab, den er zweifelhaft für den unteren Schneidezahn einer Phoca hillt; dieser Zalhn kommt aus marinem Sandstein von Léognan bei Bordeaux, einem Hauptfundort für Halitherium. Nach seiner Grösse und der runden, kleinen Schmelzkrone scheint dieser Zahn der Stosszahn des Halitherium zu sein; der Schneidezahn einer Phoca müsste doch comprimirt und scharfkantig sein, z. B. wie der daselbst Taf. 8 Fig. 7 abgebildete. Dagegen dürften die beiden Zähne daselbst Taf. 3 Fig. 12 und Taf. 8 Fig. 8 aus dem Miocaen von Montpellier, welche Gervais pag. 140 gleichfalls zur Phoca stellt, die Stosszähne des Metaxytherium Cuvieri sein; sie sind beinahe doppelt so lang, als diejenigen des Halitherium.

1) P. Gervais stellte die Gattung Trachytherium mit der einzigen Art Raulinii allein nach diesem Zahn auf, zuerst in Compt. rend. de l'Acad. scienc. Paris 1849. tome 28. pag. 644; dann hier in der Zool. et Paléont. franç. Auch Lartet ist der Meinung, dass dieser Zahn oin Molar des Halitherium ist, in der Note sur deux nouveaux Siréniens fossiles des terrains tertiaires du bassin de la Garonne. Bull. soc. gẻol. France. 2. série tome 23. 1866. pag. 684. In dieser Abhandlung rechnet Lartet vier Stosszähne, welche aus dem obermiocaenen Kalk von Bournie bei Sos, Lot-et-Garonne, stammen, einer Halicore-artigen Sirene zu und nennt sie R y tiodus Capgrandi. Diese grossen, stark comprimirten Stosszähne gehören keinesfalls einer Sirene an; Sirenen-Stosszähne besitzen immer einen runden, nie einen so platten Querschnitt. Die Art der Abuutzung dieser Zähne zeigt, dass denselben andere Stosszähne im Unterkiefer gegeniiberstanden, sodass sie z. B. einem Hippopotamus angehüren künnten. 
c. Rhône-Becken.

\section{Metaxytherium Cuvieri de Christol.}

Fossile Sirenen sind in den marinen miocaenen Sandsteinen und Kalken (calcaire moëllon) des Languedoc und besonders in der Umgegend von Montpellier luäufig gefunden worden. Solche Reste erwähnte zuerst Marce] de Serres, welcher sie als Theile eines Lamantin (Manatus) und Dugong erkannte $^{1}$ ). Sie wurden dann von de Christol beschrieben: die Sirene von Montpellier namte er Metaxytherium Cuvieri, die von Beaucaire, an der Rhône oberhalb Mrles gelegen, Metaxytherium Beaumontii, während er gleichzeitig den Lamantin von der Loire als Metaxytherium Cordieri bezeichnete $^{2}$ ). Obwohl nun der Name Metaxytherium von allen späteren Autoren aufgegeben und dafür Kaup's Halitherium eingefïhrt wurde, glaube ich diese Gattung de Christol's wieder aufnehmen zu sollen, da die miocaene Sirene sich in wesentlichen Punkten, besonders im Gebiss, von der oligocienen Gattung Halitherium unterscheidet, wie wir sogleich an den Resten aus dem Miocaen des Languedoc sehen werden und wie wir bereits oben bei Besprechung der miocaenen Sirenen von Angers und aus dem Wiener Becken hervorhoben.

P. Gervais taufte die Sirene von Montpellier um in Halitherium Serresii. Zool. et Paléont. franç. tome I. 1848-52 pag. 143 und tome II, Explic. des planches 4-6. Daselbst bildet Gervais recht gut erhaltene Schädelfragmente $\mathrm{ab}$, die besten, welche wir vom Metaxytherium besitzen; sie werden ergänzt durch den Unterkiefer von Montpellier bei Blainville 1. c. Taf. IX.

Danach ist das Metaxytherium eine Sirene, welche sich hauptsïchlich in den folgenden wichtigen Punkten vom Halitherium unterscheidet: die Prämolaren fehlen; statt ihrer erscheint vor den Molaren ein scharfer Zahnrand („barre") ohne Alveolen. Die vier ${ }^{3}$ ) dreiwurzeligen Molaren compliciren ihre Schmelz-Líronen durch Vermehrung der Anzahl der Zapfen und durch tieferes Einschneiden der Quertläler und Furchen, obwohl der Grundplan der Kronen-Gestaltung für jeden Molaren derselbe bleibt wie bei Halitherium: nämlich in (h)erkiefer zwei Haupthöcker-Reihen, eine schmale vordere Nebenreihe und ein starker Talon an der Hinterseite; im Unterkiefer ebenso, nur ohne die vortere Vehenreihe. Die Vermehrung durch Nebenzapfen geschieht hauptsïchlich in ter Tiefe der Gruben und Thïler. Zugleich stellen sich die Zapfen weniger Querjoch-artig, wodurch die Zütme den Molaren der Suiden ähnlicher werden. Die Blumenblatt-Form der abgekauten Flächen wird ein wenig complicirter, als bei Halitherium, dadurch dass der Schmelz der Thäler und Furchen tiefer in die Krone einschneidet.

3) Annal. des scienc. nat. 2. série. tome 9. Paris 1838. pag. 280. Note sur les animaux des terrains tertiaires etc. des environs de Montpellier; und Annal. des sc. nat. 1841. tome 16. pag. 14.

2) Compt. rend. Acad. scienc. de Paris. 1840, tome 8. pag. 322. In der Sitzung des Institut vom 21. Sept. 1840 stellte de Christol für die Sirenen-Reste von Montpellier und Angers nur den Gattungsnamen Metaxytherium auf; siehe auch Annal. scienc. nat. 1841.2. série. tome 15. pag. 317. Die drei Artnamen entstanden erst 1843 in einem Briefe de Christol's an de Blainville, alle drei gleichzeitig (Blainv. Ostéogr. Man. pag. 130). Da nun die drei Arten identisch mit einander sind, fallen die Namen ML. Beaumontii und Cordieri fort.

$\left.{ }^{3}\right)$ Gervais, Zool. et Pal. franç. tome II Expl. gibt zwar fünf Backenzähne dem Metaxytherium, jedoch sind an seinen Stücken nur 2 oder 3 Molaren vorhanden und für den bereits abgestossenen vordersten, vierten die z. Th. verwachsenen Alveolen; vielleicht beachtete Gervais nicht, dass auch der erste Molar im Oberkiefer drei, nicht zwei Wurzeln besitzt. Auch aus den bei Blainville abgebildeten Stïcken folgen nur vier Molaren. Bruno gibt für sein Cheirotherium (= Metaxytherium siehe unten) auch vier Backenzähne an. Indessen war vielleicht ein früh ausfallender Prämolar vorhanden, dessen Spuren aber noch nicht nachgewiesen sind. 
Am auffallendsten ist die bedeutendere Grösse des Zwischenkiefers und der beiden Stosszähne; die letzteren haben eine kurze conische Schmelzkrone, eine lange dicke Wurzel und werden bis $16^{\mathrm{cm}} \operatorname{lang}^{1}$ ) (gegen $9^{\mathrm{cm}}$ bei Halitherium). Die Aeste des Zwischenkiefers sind dicker, kürzer und sind etwas stirker gebogen als bei jener Gattung. Die Nasenbeine sind etwas kleiner geworden, stossen aber noch in der Mittelnaht zusammen und werden zum Theil bedeckt von den Frontalenden der Zwischenkiefer-Aeste. Die Kinntläche des Unterliefers ist breiter und steiler geworden; sie trägt fünf Paar Alveolen für rudimentäre Zähne, von welchen wohl die drei unteren den Schneidezähnen, die beiden oberen dem Eckzahn und vierten Prämolaren zukommen.

Das Schädeldach verbreitert sich, indem die niedrigen cristae temporales weiter auseinander treten; die processus orbitales ossis frontis werden schmäler und linger, das Jochbein wird dicker und knorriger, als bei Halitherium. Die Länge des Schädels ist etwa die gleiche als bei jener Gattung, nämlich $37-40^{\mathrm{km}}$; auch die Molaren sind nicht grösser, als diejenigen des Halitherium.

In Ganzen sehen wir also, dass Metaxytherium in der Richtung zum Schädel-Typus der Halicore hin sich entwickelt und noch weiter sich von Manatus entfernt, als Halitherium: der grosse Zwischenkiefer mit seinen Stosszähnen, die Breite des Scheitels und der scharfe Zahnrand an Stelle der fehlenden Prämolaren sind Merkmale, welche zum Dugong hiniberfiihren, wenn auch Metaxytherium in anderen Beziehungen noch weit genug von Halicore entfernt und dem Halitherium nahe bleibt.

Von den übrigen Skelettheilen des Metaxytherium des Languedoc ist leider nichts beschrieben, obschon Gervais 1. c. pag. 143 ff. Wirbel und Rippen desselben erwähnt; nur Blainville bildet 1. c. Taf. X von Moutpellier einen Humerus ab, der genau dem von Angers gleicht, und ein Rippenstückchen von St. Paul-trois-Châteaux, im dép. Drôme auf dem linken Rhône-Ufer gelegen. Wir sind daher für den Rumpf noch auf das Metaxytherium von Hainburg an der Donau angewiesen, von welchem wir wissen, dass diese Sirenen-Giattung unter anderm auch einen rudimentären femur besass.

Als Fundorte für Reste dieses miocaenen Netaxytherium Cuvieri werden im Languedoc die folgenden angegeben: Montpellier, Beaucaire, Pézènas, Estres, St. Jean-de-Védas, Sommières, Castries, Vandargues, Gallargues und St. Paul-trois-Châteaux.

\section{d. Seine-Becken.}

Halitherium Schinzi Kaup.

Von den verschiedenen Halitherien-Funden bei Paris sind diejenigen die reichsten, welche zu Étrichy bei Étampes S Paris in mittel-oligocaenen (étage tongrien) Sanden gemacht wurden. Blainville widmet dem schönen Skelett seines Manatus Guettardi von Étrichy eine ganze Tafel (I. c. Taf. XI. pag. 109), auf welcher zahlreiche Theile des Oberkopfes (auch z. Th. die Ohrknöchelchen), der Unterkiefer mit je vier Molaren, 19 Paar Rippen und Theile der Wirbel dargestellt sind. P. Gervais ergänzt diesen früheren Fund durch weitere Reste von derselben Lokalitït in seiner Zool. et Paléont.

1) Gervais, Zool. et Paléont franç. Taf. 8 Fig. 8. Diese Figur ist in halber Grösse. Von den Figuren der Taf, 6 sagt Gervais im Texte der Explic. fälschlich, sie seien in halber Grösse gemacht; statt dessen sind dieselben in etwa $3 / 8$ natiirl. Grösse dargestellt, was man sogleich durch Messen mit den z. Th. in halber, z. Th. in ganzer Grössé gezeichneten Figuren der Tafeln 4 und 5 feststellen kann. Bei den Abbildungen sollte niemals der Maasstab auf der Tafel selbst fehlen. 
générales tome I pag. 183 Taf. 38, indem er eine Unterkiefer-Hälfte, os frontis mit einem Theil der Nasenmuscheln, Theile des Zwischenkiefers, des Oherkiefers, des os parietale und andre Stücke beschreibt und abbildet. In allen diesen Resten des Halitherium von Étrichy herrscht vollständige Uebereinstimmung mit dem Skelett des Halitherium Schinzi von Rheinhessen, sodass wir nicht weiter auf diese Funde einzugehen brauchen, um so mehr als sie unvollständiger sind als die unsrigen, wichtige Theile wie z. B. die Extremitäten noch fehlen. Schon Kaup hat daher den Manatus Guettardi Blainv. von Étrichy mit seinem Halitherium Schinzi vereinigt (Beiträgo Heft 2 pag. 11) und auch P. Gervais, Zool. et Pal. génér. pag. 185 ist nicht abgeneigt, die beiden Arten zu identificiren.

In der Umgegend von Paris scheint wach den Angaben von Blainville das Halitherium Schinzi nicht selten zu sein; er nennt Jeurre. Iongjumeiu, Marly und Belleville als weitere Fundorte. Ferner berichtet Belgrand, dass im Walde von Fontainebleau Rippen des Halitherium häufig seien'). Alle diese Orte im Seine-Becken sind bekanntlich typische Lokalitäten für die gleichen marinen mitteloligocaenen Sande, wie im Mainzer Becken.

Wir hätten demnach in der Tertiär-Formation von Frankreich nur zwei verschiedene Sirenen:

1. Halitherium Schinzi Kaup. 1838.

aus den oligocaenen Schichten der Umgegend von Paris und Bordeaux.

syn. Hippopotame fossile Cuv. Oss. foss. tome I. 1821. pag. 333. Taf. VII Fig. 12-20.

Hippopotamus dubius (Cuv.) Blainville. Ostéogr. Man. 1843. Taf. IX.

Metaxytherium Cuvieri (de Christ.) Blainv. ibid.

Manatus Guettardi Blainv. ibid. Taf. XI.

Halitherium Guettardi Gervais. Zool. et Paléont. franç. I. 1848-52. pag. 144.

Trachytherium Raulinii Gervais. Compt. rend. Acad. sc. de Paris. 1849. tome 28. pag. 644.

Halitherium Cuvieri Delfortrie. Act. Soc. Linné. de Bordeaux. tome 28. 1872.

2. Metaxytherium de Christol. 1840. Compt. rend. Acad. sc. de Paris. tome 8. pag. 332.

Metaxytherium Cuvieri de Christol. 1843. Bei Blainv. Ostéogr. Man. pag. 130. aus den miocaenen Schichten an der unteren Loire, besonders in der Gegend von Angers, und im Tertiärbecken der unteren Rhône, am häufigsten in der Umgegend von Montpellier.

syn. Metaxytherium Cordieri de Christol. 1843. Bei Blainv. Ostéogr. Man. pag. 130.

Metaxytherium Beaumontii de Christol. ibid. pag. 130.

Lamantin fossile G. Cuvier. Annales du Muséum d'hist. nat. Paris. 1809. tome XIII. pag. 303. Taf. 19. und Oss. foss. 1823. tome V. 2. pag. 266. Taf. 19.

Hippopotame moyen fossile. Cuv. Oss. foss. 1821. tome I. pag. 332. Taf. VII.

Hippopotamus medius (Cuv.) Blainville. 1843. Ostéogr. Man. Taf. IX.

Manatus fossilis (Cuv.) Blainville ibid. Taf. VIII.

Metaxytherium Cuvieri (Christ.) Blainville ibid. Taf. IX.

Halitherium Serresii Gervais. Zool. et Paléont. franç. tome I. 1848-52. pag. 143. Taf. 4-6.

Halitherium Beaumontii Gervais. ibid. pag. 144.

1) Bull. Soc. gẻol. France. 1871. pag. 268. 


\section{Aus Ober-Italien.}

a. Von Montiglio bei Turin.

\section{Metaxytherium subapenninum Bruno sp.}

Im Jahre 1828 wurde in einem blauen Thon bei Montiglio, einem Dorfe, gelegen in den Hügeln des Montferrato zwischen Turin und Casale, das Slielett einer fossilen Sirene ausgegraben; dasselbe bestand aus der Rückenwirbelsäule von etwa $1^{\text {ma }}$ Länge, den Rippen (auf der rechten Seite waren noch 18 vorhanden), dem Schulterblatt und dem Schädel, von welchem die Gesichtsknochen weggebrochen und nur die beiden Stosszähne erhalten waren. Dieses Skelett wurde 1838 von G. D. Bruno beschrieben, abgebildet und Cheirotherium subapenninum') benannt. Hlustrazione di un nuovo Cetaceo fossile. Memorie della reale Accademia delle scienze di Torino. Serie seconda. tomo I. 1839. pag. $143-160$. tav. $I^{2}$ ). Blainville hat die recht guten Abbildungen Bruno's copirt.

Bruno charakterisirt diese Sirene folgender Maassen (pag. 160): „capite breviore quam in Nanato; dentibus incisivis superioribus duobus longius quam in Halicore exertis; maxillaribus supra utrinque tribus vel duobus extrinsecus tuberosis, infra duobus, tribus vel quatuor, e tuberculis multifariam distributis compositis, sulcisque numerosioribus divisis; apparatu maxillari robustiori instructum." Die Grösse dieser Sirene war etwa die gleiche wie diejenige dles Halitherium Schinzi und des Metaxytherium Cuvieri.

Diese Sirene von Montiglio schliesst sich unmittelbar an das Metaxytherium Cuvieri des Rhône- und Loire-Beckens an, mit dem Unterschied, dass das Schädeldach wieder etwas verkürzt und verbreitert ist, die beiden spitz-conischen Stossziihne dicker geworden sind, da der eine, obschon nicht vollständig, $90 \mathrm{~mm}$ lang und am inneren Ende $30 \mathrm{~mm}$ breit ist, und die vier Molaren wieder die Anzahl ihrer Zapfen vermehrt und ihre Thäler tiefer eingeschnitten haben. Abgesehen von den Molaren wird also cliese Sirene von Montiglio in ihrem Schädel wieder um einen Grad Halicoreartiger, als Metaxytherium Cuvieri. Die Nasenbeine sind vorhanden und ebenso grosse Schildknochen, wie bei der französischen Art. Prämolaren fehlen. Die Stosszähne sind trotz Bruno's Bemerkung noch nicht von der Grösse, wie bei der Halicore ${ }^{3}$ ). Der Grundplan der Molaren ist noch derselbe, wie bei Halitherium: am besten erhalten sind Md $\mathrm{m}^{3}$ und $\mathrm{m}^{4}$, Bruno tav. I. Fig. 7 und 9. Der $\mathrm{m}^{3}$ hat zwei Haupthöckerreihen mit einem gekerbten starken Talon dahinter; nur die Anzahl der Zwischenhöcker vermelırt sich im Verhältniss zu Mil ms des Halitheriun Schinzi. Der letzte Molar des Unterkiefers Fig. 9 Bruno sieht in der Seitenansicht unserm Mr $\mathrm{m}^{4}$ Taf. IV 32 a ähnlich, da

2) de Blainville hat in Bruno's Abhandlung pag. 160 statt dieses Artnamen nur den Namen Brocchi gelesen und daher die Art Cheirotherium Brocchii Bruno daraus gemacht. Ostéogr. Man. pag. 103. Taf. IX und X.

${ }^{2}$ ) Ein guter und ausfibrlicher Auszug der Abhandlung von Bruno findet sich im N. Jahrb. für Min. 1840 pag. 496-501.

3) Es scheint, als wenu diese Stosszähne, wie bei Halicore, permanent fortwüchsen, da sie hohle Wurzeln haben; auch sieht es aus, als ob die kurze Schmelzkrone der Stosszähne des Metaxytherium und Halitherium fehlt, obwohl Bruno sagt pag. 148: whanno di fuori una corteccia di smalto*. Es wären dann diese Stosszähne so verschieden von denen des Metaxytherium Cuvieri, dass Bruno's Sirene fast eine neue Gattung repräsentiren dürfte. 
gleichfalls ein tiefes Querthal die erste Reihe starker Zapfen von der zweiten Reihe scheidet, während sich die Zapfen des hinteren Endes dichter an die zweite Reihe anschliessen; auch die WurzelBildung ist die gleiche. Dagegen schneiden hier die Furchen noch tiefer, als bei Metaxytherium Cuvieri, in die Krone ein; auch sieht man in der Ansicht von oben, um wie viel neue Höcker die Krone vermehrt ist.

Bei der nahen Verwandtschaft der Sirene von Montiglio zu dem Metaxytherium Cuvieri von Montprellier, welche schon Capellini') hervorhebt, darf dieselbe wohl als Metaxytherium suhapenninum Bruno sp. ${ }^{2}$ ) bezeichnet werden. Das Alter der Schichten, in welchen dieses Metaxytherium gefunden wurde, kann nach den vorhandenen Notizen nicht genau angegeben werden; doch ist ein miocienes Alter wahrscheinlicher, als ein pliocatenes (subapennin ${ }^{3}$ ), weil in ten pliocienen Schichten der Po-Ebene die jüngere Sirenen-Gattung Felsinotherium herrschte ${ }^{4}$ ).

\section{b. Die Gattung Felsinotherium.}

In Jahre 1872 stellte Capellini die Gattung Felsinotherium auf ${ }^{5}$ ) für die Reste einer sehr grossen Sirene, welche sich in den marinen pliocaenen Schichten von Riosto und Mongardino bei Bologna und im Val di Pugna bei Siena in Toscana vom Jahr 1865 an gefunden hatten; Capellini nannte die Bologneser Reste Felsinotherium Forestii, die von Siena F. Gervaisi; beide Arten sind aber derartig identisch, dass Capellini den schlecht erhaltenen Schädel von Siena auch in der Zeichnung nach jenem von Bologna ergänzt. Später beschrieb de Zign ${ }^{6}$ ) einen vorzüglich erhaltenen Schärtel und eine Rippe eines Felsinotherium, welches Cesare d'Ancona im pliocaenen Kalke der Hïgel von Brà, STurin gelegen, entdeckte; Prof. Cesare d'Ancona hatte die Güte, mir das Gypsmodell dieses schönen Schädels, welcher im Museum zu Florenz aufgestellt ist, zu übersenden. de Zigno nannte dieses Felsinotherium von Brà F. Gastaldi. Auch dieser Schädel ist kaum ver'schieden von denen von Bologna, nur dass er besser erhalten und weniger seitlich comprimirt ist, als der Bologneser Schädel, sodass diese drei Funde aus dem Pliocren Oberitaliens wohl unter dem einen Namen Felsinotherium Forestii Capellini vereinigt werlen können.

Nach den vortrefflichen Beschreibungen von Capellini und de Zigno ist dieses Felsinotherium eine Sirene, welche in der Gestalt ihres Schädels, ihrer grossen Stosszähne und des Zwischenkiefers der Halicore nahe steht, nur dass in jedem Kiefer vier oder fünf Molaren mit Zapfen-Kronen und

\footnotetext{
1) Sul Felsinoterio, Sirenoide halicoreforme Bologna. 1872. pag. 613.

2) Die Gattung Cheirotherium Bruno ist eingezogen worden, da der Name bereits für die Labyrinthodonten Fusspuren im Bunten-Sandstein vergeben war.

3) Wenn die Schichten nicht subapennine, sondern miocaene wären, würde eigentlich der von de Blain. ville fälschlich gegebene Artname Broccbii vorzuziehen sein.

4) Keinesfalls kann Bruno's Sirene von Montiglio zum Felsinotherium gezogen werden, wie es Capellini und de Zigno thuen; dann noch eher zu Halitherium. Ebensowenig darf man das französische Metaxytherium Cuvieri zu Felsinotherium rechnen, wie es jene beiden Autoren thuen.

5) Sul Felsinotherio sirenoide Halicoreforme dei depositi littorali pliocenici dell'antico bacino del Mediterraneo e del Mar nero. Mem. del prof. G. Capellini. Bologna. 1872.

-) Sopra un nuovo Sirenio fossile scoperto nelle colline di Brà in Piemonte. Mem. d. reale Accademia dei Lincei. Serie 3. Class. fis. mat. nat. vol. II. Roma. 1878.
} 
Schmelzbedeckung vorhanden sind. In der Grösse stand das Felsinotherium der Rhytina Stelleri kaum nach, da der Schädel von Bologna $54^{\mathrm{cm}}$, der von Brà nicht weniger als $62^{\mathrm{cm}}$ Länge erreicht; es war also eine Sirene ron beträchtlichen Dimensionen, iloppelt so wross als Halitherium, Iletaxytherium, Manatus und Halicore, fast eben so gross als Rhytina ${ }^{1}$ ).

Das Schädeldach ist platt und breit, aber noch nicht so verkïrzt, wie bei Halicorc. Die heiden starken Stosszälıne sind viel dicker, als bei der grössten Halicore, und besitzen $5-6^{\mathrm{cm}}$ Durchmesser bei $20^{\mathrm{cm}}$ Länge; der Zwischenkiefer ist in Folge dessen sehr gross und entwickelt eine breite, rauhe Fläche für eine Kauplatte in der vorleren Mundspalte. Damn folgt wie bei Metaxytherium und Halicore die lange Lücke der fehlenden Prämolaren mit scharfem Zahnrande. Die Molaren zeigen trotz ihrer Zapfenkronen darin eine Annäherung an die Form der Halicore-MLlaren, dass die Zapfen nicht mehr breit auseinander stehen und eine breite Kautläche bilden; wie bei Halitherium und Metaxytherium, sondern ihre Spitzen dicht an einander legen, sodass die Kronen der wenig abgekiuten Zähne etwas conisch nach oben zugehen. Diese Zuspitzung der Krone hatten wir bei den noch unverletzten Molaren der Halicore in noch höherem Maasse constatirt. Die Molaren des Oberkiefers haben drei, des Unterkiefers zwei grosse Wurzeln. Der Unterkiefer ist ebenfalls Halicore-artiger geworden in der bedeutenden Dicke les Kinntheiles und der breiten, steil nach vorn abfallenden, incisiven Kinnfläche, in welcher die Alveolen der rudimentären Schneidezähne sich an den bisher gefundenen Stiicken nicht erhalten haben.

Bei Bologna fanden sich auch Wirbel, Hämapophysen, Rippen, eine scapula und ein grosses Horn des Zungenbeins. Felsinotherium besass sieben unverwachsene Halswirbel, wie Halicore. Die Rippe von Brì ist eine der vordersten, da ilır tuberculum weit ab vom capitulum steht; sie hat eine Länge von $64^{\mathrm{cm}}$.

\section{c. Aus den venetianischen Alpen.}

Baron de Zigno hat in einer werthvollen Abhandlung iiber die Sirenii fossili trovati nel Veneto ${ }^{2}$ ) Schädeltheile aus dem miocaenen Sandstein von Belluno als Halitherium Bellunense, und aus eocaenen Schichten des Monte Zuello bei Ronca im Veronesischen einen ziemlich vollständigen Oberkopf und vershiedene Theile desselben als Halitherium Teronense ${ }^{3}$ ), angustifrons und curvidens besclirieben.

Von diesen Resten scheinen mir die Reste von Belluno einem Metaxytherium anzugehören: der Zwischenkiefer mit seinen starken processus frontales und die Stosszähne sind viel zu gross für ein Halitherium. Die drei vorhandenen Molaren des Oberkiefers sind wohl $\mathrm{m}^{1}-\mathrm{m}^{3}$, denn der letzte der drei Zähne zeigt nicht die vielen Nebenzapfen hinter der zweiten Reile, welche dem $\mathrm{m}^{4}$ zukommen, nur eine einfache Nebenreihe. Die tief einschneidenten Schmelzfurchen geben diesen Molaren den Charakter der Zähne des Metaxytherium, nur scheinen ihre Kronen etwas kegelförmiger gebaut zu sein (Taf. II Fig.6), als bei (len französischen Arten, obwohl zu bericksichtigen ist, dass

1) Wir haben oben (pag. 168) bemerkt, dass vielleicht das Schädelfragment von Mastricht in Belgien, welches van Beneden Crassitherium robustum nannte, zu Felsinotherium zu stellen wäre.

2) Mem. del'Istituto veneto. Vol. 18. Venezia 1875.

3) Gypsabgüsse des Schädels und zweier Hiiftbeine des Halitherium Veronense hatte Prof. Cesare d'Ancona in Florenz die Güte mir zu übersenden. 
die vorderen Molaren der französischen Stïcke und auch des Metaxytherium subapenninum Bruno stärker abgekaut sind als der noch ganz frische $\mathrm{m}^{3}$ von Belluno.

Die Sirenen-Reste des miocienen Sandsteins von Cavarzana im Valle delle Guglie bei Belluno dürften demnach als Metaxytherium Bellunense Zigno sp. bezeichnet werden.

Dagegen gehört der etwas verdrückte ziemlich vollständige Oberkopf, welchen de Zigno als Halitherium Veronense auf Taf. V abbildet, aus dem eocaenen Nummuliten-Kralk des Monte Zuello bei Ronca im Vicentinischen entschieden zur Gattung Halitherium: die Grösse des Schädels (37 cu Länge) und seine allgemeine Form stimmen überein mit dem rheinhessischen Halitherium. Dass die Alveolartheile des Zwischenkiefers bei Halitherium Schinzi nicht so kurz und klein waren, wie sie von Krauss angegeben wurden, haben wir oben gesehen. Das Schädeldach des Halitherium Veronense zeigt den schmaleu Scheitel und die starken cristae temporales der Gattung. Die Nasenbeine sind, soweit sie sich erhalten haben, breite, Schild-förmige Knochen. Vom Gebiss sind jederseits im Oberkiefer $\mathrm{m}^{2}$ bis $\mathrm{m}^{4}$ und links zwei einwurzelige Prämolaren $\mathrm{p}^{1}$ und $\mathrm{p}^{2}$ vorhanden; die Kronen dieser Zähne stimmen ziemlich genau mit den Zapfenkronen der rheinischen Art überein. Einen einzelnen Prämolaren mit langer, einfacher IVurzel bildet de Zigno Taf. V Fig. 6-9 ab; der eine grosse Zapfen mit den umliegenden Kranz von Nobnhö̈liern gleicht dem p' vom Halitherim Schinzi. Da seine Kaufläche schräg nach aussen hängt, ist es ein Prïmolar des Unterkiefers; mit der Wurzel ist er $30^{\mathrm{mm}}$ lang, die Krone allein ist $10^{\mathrm{mm}}$ hoch und $11 \mathrm{~mm}$ breit. Dagegen kann ich den Zahn, welchen de Zigno von demselben Fundorte des Monte Zuello in einer neueren Mittheilung ${ }^{1}$ ) Fig. 1-4 als einen Schneidezahn des Unterkiefers vom Halitherium Veronense angibt, nicht als einen solchen anerkennen; denn die Schneidezähne des Halitherium können nach der Natur der undeutlichen Alveolen in den incisiven Zahnrändern nur rudimentäre, sehr friih ausfallende Zälmchen, nicht Zähne mit runder, langer Wurzel und einer Zapfenkrone gewesen sein. Dieser Zahn ist jedenfalls ein Prämolar mit etwas grösseren Nebenhöckern als gewölmlich; ein ganz ähnlicher Prämolar liegt mir von Flonheim vor. Den andern seitlich comprimirten Zahn Fig. $5-8$ hält de Zigno auch für einen Schneidezahn des Unterkiefer: : ein solcher Ziahn ist mir heim Halitherim Schinzi nicht rorgekommen.

Aus denselben Schichten des Monte Zuello stammen 60 Wirbel und ebensoviel Rippen, eine scapula und andre Theile des Skelattes. De Zigno beschrieb von denselben das Schuiterblatt und die linke Hälfte cines Unterkiefers $\left.{ }^{2}\right)$ : das erstere besitzt eine bedeutend stärker vorspringende spina, als dasjenige des Halitherium Schinzi; an Unterkiefer haben wir bereits oben pag. 80 die eigenthümliche Apophyse in der Mitte des Hinterrandes des Astes erwähnt, welche sich am Unterkiefer des Halitherium Schinzi nur in geringem Maasse bemerkbar macht; auch der processus coronoideus ist bedeutend höher und zweizipfelig, wenn derselbe nicht etwa durch schlechte Erhaltung so anders als bei allen andern Sirenen gestaltet ist.

Prof. Cesare d'Ancona hat in einem Block Nummulitenkalkes, welcher zahlreiche Wirbel und Rippen des Halitherium Veronense enthielt, vom Monte scuffonaro bei Lonigo im Vicentinischen auch zwei Hüftbeine entdeclit, die noch nicht beschrieben sind: die mir vorliegenden Gypsabguisse der-

1) Annotazioni Paleontologiche. Nuove aggiunte alla Fauna eocena del Veneto. Memorie del'Istituto veneto. vol, 21. 1881. Taf. I Fig. 1-3 und Fig. 5-8.

2) Nuove osservazioni sull'Halitherium Veronense. Mem. del'Istituto reneto. vol. 21. 1880. 
selben zeigen die Form des Hüftbeines, wie wir eines auf Taf. VII Fig. 80 abgebildet haben, nur ist es kleiner und schmächtiger, nämlich nur $20 \mathrm{~cm}$ lang. Ausserdem tragen beide Beine je eine kleine Apophyse am Unterrande des os pubo-ischiadicum in der Mitte zwischen der Gelenkfläche für den femur und dem dicken Hinterende des Knochens; eine solche Apophyse habe ich bei keinem Hüftbein des Halitherium Schinzi bemerkt.

Wenn demnach eine grosse Aehnlichkeit zwischen dem vicentinischen Halitherium Veronense de Zigno und dem rheinhessischen Halitherium Schinzi besteht, so sind diese beiden Arten iloch in einigen Details verschieden von einander, wenn auch das vorliegende Material der italienischen Art noch unvollstïndig ist. Dagegen sind die Reste, welche de Zigno als Halitherium curvidens und angustifrons aus dem gleichen Kalke des. Monte Zuello beschreibt, loch zu geringfügig, um durch dieselben neue Arten zu begründen; dieselben diurfen wohl, solange nicht besseres Material vorliegt, als Theile des Halitherium Veronense angesehen werden.

Suess fuhrt in seiner bekannten Abhandlung über die Gliederung des vicentinischen Tertiärgebirges aus seiner zweiten Gruppe, welche für gleichaltrig mit dem Pariser Grobkalk (eocaen) gehalten wird, Rippen des Halitherium von Priabona an ${ }^{1}$ ). Dr. Th. Fuchs, Custos am k. k. Hofmineralien-Cabinet in Wien hatte die Guite, mir brietlich mitzutheilen, dass Prof. Suess auch aus den vicentimischen (astel' Gomberto-Schichten, welche oligocienen Alters sind, Halitherien-Reste mit nach Wien gebracht hat. Danach würde die Gattung Halitherium anch in Oberitalien, wie im Garonnebecken sowohl zur eocaenen als zur oligocaenen Zeit gelebt haben; die Sirenen-Gattungen Metaxytherium und Felsinotherium dagegen in der neogenen Tertiär-Zeit.

Wir hätten demnach aus Oberitalien die folgenden fossilen Sirenen kennen gelernt:

1. Halitherium Veronense de Zigno 1875.

Eocaen des Monte Zuello bei Ronca, des Monte Scuffonaro bei Lonigo und andrer Orte im Veronesischen; vielleicht auch oligocaen im Vicentinischen.

2. Metaxy therium Bellunense, de Zigno sp. 1875.

Miocaen von Cavarzana im Val delle Guglie bei Belluno.

3. Metaxy therium subapenninum, Bruno sp. 1838.

Miocaen (oder pliocien) von Montignlio im Montferrato.

4. Felsinotherium Foresti i, Capellini. 1872.

syn. Felsinotherium Gervaisi, Cap. 1872.

Felsinotherium Gastaldi, Zigno. 1878.

Pliocaen von Bologna, Siena und Brà.

\section{Aus England.}

Der einzige Fund einer fossilen Sirene in England ist das Schädelstück, welches Flower aus

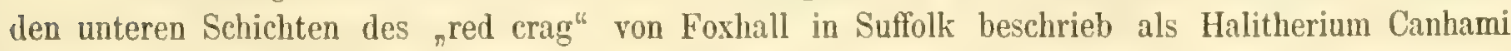
(Quarterly Journal of the geological Society of London. vol. 30. 1874. pag. 1 Taf. I). Dasselbe be-

$\left.{ }^{1}\right)$ Sitz. Ber. Wien. Acad. Wiss. Math. Classe. 58. Bd. 1. Abth. Jahrg. 1868. pag. 273. 
steht aus dem mittieren Theil eines Oberkopfes mit Theilen des os frontis, os nasi und des as maxillae, welch letzteres beiderseits mehrere Alveolen zeigt. Die Kanten der Knochen sind allseits abgerollt; in der Discussion der Vittheilung von Flower constatiren anch Prestwich, Ramsay und andere Fachmänner (daselbst pag. 7), dass sowohl dieses Stück als die Melırzahl der anderen Sảugethier-Reste in dem pliocaenen red crag sich auf secundärer Lagerstätte befänden und aus dem miocaen eingeschwemmt seien. Das Schädelfragment gehörte also einer miocaenen oder noch älteren Sirene an.

Leider ist an dem Stïcke wenig zu sehen; nur die Sirenen-Natur desselben ist unzweifelhaft. Wenn übrigens Flower aus den Alveolen auf sechs Backenzähne schliesst, zwei vordere einwurzelige, einen zwei- und drei letzte drei-rwurzelige, so möchte ich diese Annahme bezweifeln. Der ganze erhöhte Zahnrand des os maxillae ist abgewaschen, sodass das Gaumengewölbe in einer Höhc mit dem Alveolenrande steht; die Alveolen sind schlecht erhalten. Die Molaren des Oberkiefers aller fossilen Sirenen besitzen drei, niemals nur zwei Wurzeh. Doch scheinen die beiden vordersten Alveolen zwei einwurzelige Prämolare anzudeuten, sodass dieses Schälelfragment zur oligocaenen Gattung Halitherium, nicht zur miocaenen Metaxytherim zu rechnen wäre. Beziehmgen zu andern Sirenen sind nach diesem Reste kaum aufzustellen. Immerhin ist der Fund wichtig dadurch, dass er die Anwesenheit der Sirenen zur T'ertiärzeit in England nachweist.

\section{Aus Malta und Aegypten.}

Halitherium sp.

Das Vorkommen von Halitherium-Zähnen in einem tertiären Kalkstein der Insel Malta erwähnt L. Adams im Quart. Journ. of the geolog. Soc. of London. 1874. pag. 7, ohne weitere Angaben über dieselben zu machen. Jedenfalls gehört zum Halitherium auch der letzte Molar des Unterkiefers von der Insel Malta, welchen de Blainville als Sus? mastodontoideus, Ostéogr. Sus. pag. 217, Taf. IX erwiihnt und albildet, während das Unterkiefer-Fragment desselhen Namens, welchen Blainville ebendaselbst anfiihrt, aus dem alt-tertiären Siisswasserkalk des Bastberges bei Buxweiler in Elsass nicht hierher zu rechnen ist; dieser Meinung ist auch P. Gervais. Zool. et Paléont. franç. tome I. pag. 101 und 145.

Interessant ist der Steinkern des Gehirnraumes eines Halitherium aus dem cocaenen Nummulitenkalk von Mokattam bei Cairo in Aegypten, welchen R. Owen') unnöthiger Weise gleich mit einem neuen Gattungsnamen Eotherium aegyptiacum belegt. Owen sagt selbst (pag. 102), dass das Gehim dieses Eotherium in Breite und Länge mit dem des Halitherium übereinstimme. Und wenn wir uns unsrer obigen Beschreibung des Gehirnraumes und der denselben ungrenzenden Knochen bei Halitherium Schinzi erinnern (pag. 48. pag. $2 \mathrm{ff}$. etc.) und mit Owen's Angaben vergleichen, so sehen wir in der That keinen Grund, diesem Rest einen andern Gattungsnamen, als den des Halitherium beizulegen, während über die Beziehungen desselben zu den Arten dieser Gattung natürlich kaum etwas auszusagen ist.

1) Quarterly Journal of the geological Society of London. Vol.31. 1875. pag. 100. Taf. III. 


\section{Prorastomus sirenoïdes, Owen von Jamaica ${ }^{1}$ ).}

Der Schädel, welchen Owen aus einem alt-tertiären Kalkstein der Insel Jamaica beschreibt, zeigt uns den ältesten bisher bekannten Sirenen-Typus und ist durch seine bedentungsvollen Abweichungen von dem Schädel der fossilen Sirenen Europa's wohl der wichtigste aller fossilen Reste dieser Säugethier-Ordnung. Wenn es mir möglich gẹvesen wäre, dieses Stück selbst in Augenschein zu nehmen und mit dem Schädel des Halitherium zu vergleichen, so würde es wohl begrüindeter erscheinen, wenn ich einige Knochentheile an dem Jamaica-Schädel anders als Owen deuten möchte ${ }^{2}$ ). So kann ich nur aus Owen's Beschreibung einige für die Vergleichnng wichtige Punkte hervorheben.

Der Jochbogen und besonders der processus zygomaticus ossis temporum entspricht am Schïdel des Prorastonus in seiner (iestalt vielmehr dem normalen Sïugethier-Jochbogen, als bei allen andern Sirenen. Die elliptischen Angenhöhlen treten weniger weit auseinander, als bei Halitherium, weil die knö̈herne Nasenöffnung viel schmaler und kleiner ist und die Aeste des Zwischenkiefers nicht so weit auseinandersperren. Der Stirnrand ist zerbrochen, sodass die Gestalt der Nasenbeine nicht mehr zu erkennen ist. Die processus orbitales ossis frontis sind ähnlich geformt, wie bei Halitherium, breit und dick; indessen ist das Stimbein im Ganzen und der Gehirnraum vorn bedeutend schmäler. Die cristae temporales sind vorhanden, aber nicht so kräftig erhoben, wie bei Halitherium: sie schwingen sich im Bogen über das nach oben zugeschärfte Sehädeldach. Ein kleines, undurchbohrtes Thränenbein liegt zwischen dem vorderen Ende des processus orbitalis ossis zygomatici und dem gleichnamigen Fortsatz des Stimbeins eingeschaltet, wie bei Manatus. Das foramen intraorbitale ist fast ebenso gross wie bei Halitherium; aber der grosse, breite und platte processus zygomatico-orbitalis ossis maxillae aller andern Sirenen fehlt dem Prorastomus fast ganz, sodass der processus orbitalis des Jochbeins sich nahe ausserhalb der Backenzähne dem Oberkiefer anlegt: dies ist ein wesentlicher Unterschied, durch welchen Prorastomus sich dem normalen Säugethier-Schädel ganz bedeutend nähert; die Breite der Schädelbasis der andern Sirenen (vergl. unsre Fig. 96 und 99) ist, wie wir oben pag. 117 bemerkten, wesentlich bedingt durch die starke Verbreiterung des os maxillae.

Eine andere wichtige Abweichung von den andern Sirenen zeigt Prorastomus in der Gestalt des Unterkiefer's: derselbe ist beträchtlich länger im Verhältniss zu seiner Höhe, als selbst bei Manatus. Vor Allem aber ist der Kinntheil des Prorastomus ganz normal ausgebildet: die schräg nach vorn abfallende incisive Kinnfliche beiderseits der Symplyse, welche die mandibula aller andern Sirenen charakterisirt, fehlt der Jamaica-Gattung vollständig; statt dessen biegt sich das vordere

1) Quart. Journ. Geolog. Soc. London. vol. 11. 1855. pag.541 und vol. 31. 1875. pag. 559.

${ }^{2}$ ) Jedenfalls ist z. B. der Körper zwischen den Oefinungen der foramina lacera, den R. Owen nicht nur bei Prorastomus, sondern auch bei Manatus, Halicore und Rhytina pag. 560 zum os sphenoideum zieht, statt dessen zum os occipitis zu rechnen, und die verwachsene Naht zwischen den beiden Knochen nicht hinter, sondern vor dem Körper zu suchen. Sehr erschwerend für das Studium ist die willkürliche Benennung der einzelnen Knochentheile am Schädel und in der ganzen Anatomie der Körpertheile, wie sie Owen, Murie, Flower und andere Engländer handhaben; eine einheitliche Benennung ist zwar auch nicht bei den deutschen Autoren zu finden, wie ich oben im Vorwort pag. IV hervorhob, indessen ist sie doch nicht so zerfabren, wie die englische. Auch dass die englischen Forscher immer noch mit ihren sinches und wines messen, statt mit dew Metermaass, ist sehr zu bedauern. 
Ende des Unterkiefers in normaler Weise nach oben und enthielt nach Owen jederseits drei Schneidezälıne1). Das foramen mentale ist ebenso gross, wie bei Halitherium; die Gefässkanäle dieser Oeffnung sind nur nach oben vorn, nicht nach unten gerichtet. Trotz dieses normalen Kinntheiles der mandibula ist der Alveolartheil des Zwischenkiefers doch bereits ziemlich gross; durch Druck ist er an dem vorhandenen Schädel etwas noch oben gepresst, er zeigt aber seine Grösse, welche sogar diejenige des Manatus etwas übertrifft, wenn sie auch diejenige des Zwischenkiefers von Halitherium noch lange nicht erreicht.

Ganz besonders interessant ist das Gebiss: im Zwischenkiefer sind je drei Alveolen für Schneidezälne vorhanden; dann folgt in der Naht zum Oberkiefer die Alveole des Caninen. Nach einer Lücke von $33^{\text {min }}$ mit scharfem Zahnrand stehen hintereinander die Wurzeln zweier abgekauten Prämolaren schräg nach hinten und unten gerichtet; diese einfachen Wurzeln zeigen Lïngsfurchen, als wären sie aus zweien zusammengewachsen. Da im Unterkiefer die Wurzeln zweier Prämolaren unter der Lüicke von $33 \mathrm{~mm}$ im Oberkiefer stehen, nimmt Owen an, dass die beiden vordersten Prämolaren im Oberkiefer fehlen. Owen rechnet die Prämolaren von vorn nach hinten und benennt daher die beiden Prämolaren-Wurzeln im Oberkiefer $d^{3}$ und $d^{4}$. Es folgt ein Zahn mit erhaltener Schmelzkrone, welchen Owen als $d^{5}$ ansieht; die Krone ist $9^{\mathrm{mm}}$ lang, $5^{\mathrm{mm}}$ hoch und zeigt in der Mitte der lateralen Seite eine vertikale Furche, welche auf eine Einschnïrung der Krone hinweist gleich derjenigen der folgenden Molaren; wegen dieser Einschnïrung und weil dieser Zahn zwei Wurzeln zeigt und wahrscheinlich auf der medialen, verleckten Seite noch eine dritte Wurzel besitzt, möchte ich glauben, dass dieser Zahn der erste Molar $m^{1}{ }^{1}$ ist. Danach hätte Prorastomus vier Prämolaren (nicht fünf) und vier (nicht drei) Molaren, was mit Halitherium stimmen würde.

Die Molaren des Oberkiefers von Prorastomus sind in ihren Schmelzkronen noch vollständige Jochzähne: zwei einfache Querjoche werden getrennt durch ein tief einschneidendes Querthal. Wir hatten schon oben bei Betrachtung der Molaren des Halitherium und des Manatus stets darauf hingewiesen, dass dieselben sich auf eine bizygodonte Grundform zurückführen lassen. Hier beim Prorastomus sehen wir diese Grundform verwirklicht. Die Verwandtschaft der Sirenen mit den ältereu Ungulaten-Typen wird damit wieder bestätigt. Von Zapfen oder Höckern ist an den Jochkronen des Prorastomus noch nichts zu sehen; wahrscheinlich waren aber die Kämme der Joche bereits gekerbt, wie einzelne vorhandene Furchen an den abgekauten Jochen beweisen. Dem hinteren Joch schliesst sich hinten eine accessorische Schmelzfalte an, getrennt durch eine lateralwärts abfallende Furche; ans derselben entwickelt sich bei Halitherium die hintere Nebenreihe. An der Vorderseite der Molarenkrone ist durch eine schwache Querfurche eine vordere Schmelzfalte angedeutet. Die Krone des $\mathrm{m}^{2}$ hat eine Länge von $12^{\mathrm{mm}}$, des $\mathrm{m}^{2} 16^{\mathrm{mnx}}$, des $\mathrm{m}^{\mathrm{s}} 20^{\mathrm{mm}}$; die Kronen sind auf der lateralen Seite etwas länger als auf der medialen, wie bei Halitherium. Das Querthal sclmürt auch seitlich die Krone etwas ein, sodass die Joche breiter sind als die Nitte des Zahnes; die Joche sind bei $\mathrm{m}^{1} 13^{\mathrm{mm}}$ breit, bei $\mathrm{m}^{2} 16^{\mathrm{mm}}$, bei $\mathrm{m}^{3} 17^{\mathrm{mm}}$. Da alle drei Molaren mehr oder weniger abgekaut sind, zeigen die Kronen je zwei langgezogene quere Kauinseln und sind nur $3-5^{\mathrm{m} m}$ hoch. Bei den Molaren des Oberkiefers werden meist nur die beiden lateralen Wurzeln sichtbar, bei einem auch die mediale; ich weiss nicht, warum Owen trotzdem den Molaren des Oberkiefers je vier Wurzeln, statt drei wie bei Halitherium zuspricht.

I) Von denen übrigens nur die Wurzel des dritten vorhanden ist. 
Am Unterkiefer ist wie gesagt die Wurzel des dritten Schneidezahnes $\mathrm{i}^{3}$ und des Caninen vorhanden; nach einer Lücke von $20^{\mathrm{mm}}$ folgen zwei Wurzeln der beiden vorderen Prämolaren, welche Owen mit $d^{1}$ und $d^{2}$ bezeichnet. Dahinter ergïnzt Owen in der Lücke einen $d^{3}$, der nicht vorhanden ist. Danach folgen zwei einfache Wurzeln zweier weiterer Prämolaren: also vier Prämolaren im Ganzen wie bei Halitherium, nach Owen aber fünf. Von den drei oder vier Molaren des Unterkiefers sind auf der rechten Seite zwei, auf der linken drei zweiwurzelige erhalten; dahinter geht ein klaffender Bruch quer durch den Unterkiefer und den Schädel. Die Molaren des Unterkiefers sind einfache bizygodonte Zïhne. Die dunkelbrame Schmelzlage aller Zïlme des Prorastomus ist dick.

Die Zahnformel des Prorastomus ist nach Owen demnach: 3 i, 1 c, $5 \mathrm{p}, 3 \mathrm{~m}=48$ Zähne; nach meiner Ansicht aber: 3 i, 1 c, 4 p, $4 \mathrm{~m}=48$ Zähne. Der Ausspruch Owen's: „the Sirenia are essentially monophyodont" pag. 566 gilt nicht für die alttertiären Gattungen Prorastomus und Halitherium, welche sicher Milchzähne besassen; die neogenen und lebenden Sirenen sind allerdings monophyodont, muissen aber demnach als Ahiömmlinge einer diphyodonten Stammreihe angesehen werlen.

Owen vergleicht Prorastomus nicht mit Halitherium, sondern allein mit dem jüngeren, sehr abweichenden Felsinotherium, mit welchem sich natiolich weit weniger Vergleichungspunkte als mit Halitherium ergeben.

In Bezug auf das Gebiss constatirt Owen dass die Molaren des Halitherium und des Felsinotherium mehr denjenigen des Hippopotamus, die des Prorastomus mehr denen des Lophiodon und Tapir gleichen; indessen hahen wir oben gesehen, dass die Molaren des Halitherium eigentlich nur in der blumenblattartigen Zeichnung der Kautlächen den Molaren des Hippopotamus entfernt ähnlich sehen, während ihre Gestalt sich mehr den IIolaren der älteren Ungulaten anschliesst.

Owen bildet Taf. 29 Fig. 5 auch den atlas des Prorastomus ab: derselbe trägt bedeutend längere und breitere Querfortsätze, als der atlas der andern Sirenen.

Das Alter des harten grauen Kalksteins, in welchem sich diese Reste des Prorastomus auf Jamaica fanden, ist nach Owen's Angabe noch nicht festgestellt; nur ist gewiss, dass der Kalkstein unter miocaenen Schichten liegt. In Amerika zeigen sich ja auch in andern Säugethier-Ordnungen die Typen persistenter, als in der alten Welt; es wäre daher nicht unmöglich; dass Prorastomus sogar gleichzeitig mit dem Halitherium geleht hiitte, trotzdem derselbe einen bedeutend ailteren Typus der Sirenen-Stammreihe verwirklicht als das Halitherium. Jedenfalls weicht Prorastomus in allen Stiicken seiner bis jetzt bekannten Skelettheile weniger ron dem normalen Sängethier-Charakter und speciell von dem der illteren Typen der Ungulaten ab, als alle andern fossilen und lebenden Sirenen.

Neben Prorastomus ${ }^{1}$ ) werden aus Nord-America nur fossile Manatus, keine der fossilen europäischen Sirenen-Gattungen angeführt. Von dem Zahn-Fragment, welchem Cope den Namen Hemicaulodon effodiens zulegte, ist es nach Leidy's Urtheil sehr zweifelhaft, ob es einer Sirene zukommt; dasselbe stammt aus eocaenen (?) Schichten von Mommouth Co., New-Jersey ${ }^{2}$ ). Aus den

1) Prorastomus sirenoildes Owen wurde von Leidy Ischyrotherium antiquum genannt (Proc. Acad. nat. scienc. Philad. 1856 pag. 89) und von Cope Ischyrosaurns antiquus (Trans. Americ. Phil. Soc. 1869, vol. 14 pag. 38 ). Leidy bezweifelt die Sirenen-Natur des Prorastomus und hält ihn für ein Reptil, allerdings nur nach der ersten Notiz von Owen über Prorastomus 1855 (Leidy. The extinct mammalian fauna of Dakota and Nebraska. Journ. Acad. nat. scienc. Philad. vol. VII. 2. series. 1869 pag. 414).

2) Cope in Proc. Americ. Philos. Soc. 1869 pag. 191 und Leidy in der eben citirten Abhandlung pag. 440. 
„phosphate beds" der "post-pliocene formation" vom Ashley River, Süd-Carolina beschreibt Leidy den Molar des Unterkiefers von einem fossilen Manatus, der sich nach Leidy kaum von denselben Zähnen des lebenden Manatus der Florida-Kïiste unterscheidet; er nennt denselben Manatus inornatus ${ }^{1}$ ). An demselben Fundort Ashley River und in den gleichen post-pliocaenen Schichten wurden Ripyen und Wirbel eines fossilen Manatus gefunden, den Leidy Manatus antiquus namte ${ }^{2}$ ). Die ersten ManatusFunde in Nord-America erwähnt Harlan 1824 ${ }^{\mathrm{s}}$ ): „a cervical, a caudal vertebra and a rib of a gigantic species of fossil Manatus from the western shore of Maryland". Nach dieser Notiz citirt Pictet, Traité de Paléont. 1853 I pag. 372 den Manatus americanus fossilis, Harlan. Endlich bemerkt Leidy in den Ext. Mamm. Dak. Nebr. pag. 414: "I have seen fragments of ribs and vertebrae of a Manatus from the miocene and later formations of New-Jersey, Virginia, North-C'arolina and Florida. Prof. Cope recently noticed remains from the post-pliocene formation of Charles Co., Maryland."

Es scheinen demnach aus America bisher mit Sicherheit nur aus post-pliocaenen Schichten längs der Ostküste der Vereinigten Staten fossile Manatus bekannt geworden zu sein, welche dem lebenden Manatus sehr nahe stehen ${ }^{4}$ ). Es wäre interessant, wenn in America die Reihe der fossilen Formen zwischen dem alttertiären Prorastomus und dem lebenden Manatus in solcher Vollständigkeit entdeckt würde, wie sie in Europa vorliegt vom Halitheriunn zur Halicore und Rlyytina. Bemerkenswerth ist, dass Manatus, der wie alle Sirenen nur an den Küsten und in den Flussmündungen lebt, von America über den breiten Ocean nach der Westküste von Africa wandern konnte und zwar erst in später, wahrscheinlich diluvialer Zeit, da sich Manatus australis und senegalensis kaum von einander unterscheiden. Vielleicht bestand ehemals eine Landverbindung zwischen der neuen und alten Welt mitten durch den atlantischen Ocean hindurch; denn die Meeresströmungen dieses Oceans bewegen sich ja ungekehrt von Africa nach America hinüber.

\title{
III. Uebersicht der Gattungen und Arten der Sirenen.
}

\author{
Ordnung Sirenia Illiger 1811.
}

Im Wasser lebende, pflanzenfressende Sïugethiere mit einem $2,5-8^{\text {nis }}$ langen, horizontal ausgestreckten, walzenförmigen Körper. Kopf breit mit dicken, beborsteten Lippen, kleinelr, seitlich stehenden Augen, engen Nasenlöchern, sehr enger Ohrötfnung. Hals kurz und dick. Haut pachydermal mit schwacher Behaarung. Schwanztheil lang, endigt in eine horizontal gestellte Hautflosse. Die vordere Extremität ist ein kurzer Ruderarm mit Flossen-Hand; die hintere Extremität bleibt

1) Leidy, Contrib. Extinct Vertebrate Fauna of the IVestern Territories pag. 336 pl. 37 Fig. 16, 17. In Hayden. Report of the Unit. Stat. Geol. Survey of the Territories. Vol. I. Washington 1873.

2) Leidy, Proc. Acad. nat. scienc. 1856 pag. 165 und Holmes, Post-pliocene fossils of South-Carolina. 1860 pag. 117 Taf. 24 Fig. 5-7.

3) Harlan. Notice of the Plesiosaurus and other fossil reliquiae from the state of New-Jersey, im Journ. Acad. nat. scienc. Philad, vol. IV part II 1824 pag. 232.

*) Auch Marsh, Introd. and Success. of vertebrate life in America. 1877 pag. 29 sagt, dass sich die bisher in Nord-America gefundenen fossilen Manatus dem lebenden unmittelbar ansehliessen. 
rudimentär unter der Haut. - Herz und Magen zweitheilig; Darm sehr lang; Placenta vorhanden. Milchdrüsen brustståndig neben den Ellenbogen.

Sieben Gattungen: Prorastomus, Halitherium, Metaxytherium, Felsinotherium, Halicore, Rhytina und Manatus.

\section{a. Fossile Sirenen.}

\section{Gattung Prorastomus, Owen 1855.}

Aeltester Typus der Sirenen. Bekannt ist Schädel und Atlas. Schädel $28 \mathrm{~cm}$ lang. Scheitel rund. 'Zwischenkiefer und knöcherne Nasenöffnung kleiner als bei den andern Sirenen; die Aeste des Zwischenkiefers reichen bis zu den Nasenbeinen. Unterkiefer $25^{\mathrm{cm}} \mathrm{Iang}$, niedrig, schmal, im Kinntheil aufwärts gebogen. Schädel im Ganzen normaler als bei den iibrigen Sirenen gestaltet. Gebiss: 3 i , 1 c, 4 p , $4 \mathrm{~m}=48$ Zühne. Prämolaren einwurzelig, Molaren oben drei-, unten zweiwurzelig; die Schmelzkrone der Prämolaren einfach rund, diejenige der Molaren besteht aus zwei Querjochen mit einer vorderen und einer hinteren kleinen Schmelzfalte. - Atlas mit den grossen Querfortsätzen $12 \mathrm{~cm}$ breit und $5,5 \mathrm{~cm}$ hoch.

Einzige Art: Prorastomus sirenoïdes, Owen 1855.

Alttertiär der Insel Jamaica.

\section{Gattung Halitherium, Kaup 1838.}

Skelett fast vollständig bekannt, gegen $3^{\mathrm{m}}$ lang, besteht aus einem $36-40^{\mathrm{cm}}$ langen Schädel, 7 Hals-, 19 Riicken-, 3 Lenden- und 25 Schwanz-Wirbeln, einem dreitheiligen Brustbein, einer vollständigen vorderen Extremitï, einem rudimentïren Hüftbein uml rudimentïren Fentur. Der Schädel wird aus 13 dicken Kinochen zusammengesetzt. Olirapparat vollkommen; Felsenbein fest umfasst vom Schläfenbein. Scheitel scharfkantig, Stim hreit. Nasenbeine Schild-fürmig, stossen in langer Mittelnaht zusammen; Nasenöffnung weit, umfasst von den bis auf die Nasenbeine reichenden, langen Aesten des Zwischenkiefers; in dem grossen, vorn herabhängenden Alveolartheil des lełzteren sitzen zwei, 9-10 cm lange Stosszähne mit kurzem, rundem Schmelzkegel und langer, im Alter geschlossener Wurzel. Jochbogen stark und weit gespannt; Augenhöhle nicht geschlossen. Unterkiefer sehr gross, der dicke Kinntheil abwïrts gebogen. Gebiss: die Schneidezähne des Unterkiefers bleiben rudimentär; die Eckzähne und die vorderen Prämolaren fallen früh aus; zwei Milchbackenzähne. Zahnformel: $\frac{1}{(3)} \mathrm{i}, \frac{1}{1} \mathrm{c}, \frac{3}{4} \mathrm{p}, \frac{4}{4} \mathrm{~m}=42$ Zähne. Die Schmelzkrone der Prämolaren besteht aus einem kegelförmigen Hauptzapfen mit einem Krranz von Nebenzapfen; die Krone der Molaren aus zwei quer gestellten Hauptzapfenreihen, denen sich im Oberkiefer eine vordere und hintere Nebenreihe, in Unterkiefer ein hinterer starker Talon anschliesst. Die Kauflächen der Molaren sind blumenblatt-förmig. Die Prämolaren besitzen eine Wurzel, die Molaren des Oberkiefers drei, des Unterkiefers zwei Wurzeln.

Alter : Alttertiär.

Arten: Halitherium Schinzi, Kaup 1838.

Kommt vor in den oligocaenen Meeressanden von Rheinhessen, der Pfalz und der Gegend von Kreuznach an der Nahe. In der Ungegend von Basel; bei Linz an der Donau. In Belgien. In der Umgegend von Paris und von Bordeaux. 
Halitherium Veronense, de Zigno 1875.

Im eocaenen Nummulitenkalk bei Vicenza in Oberitalien.

Halitherium sp.

Im Aargau, in Oberschwaben. In Suffolk in England. Auf der Insel Malta. Bei Cairo in Aegypten.

\section{Gattung Metaxytherium, de Christol 1840.}

Das Skelett ist etwa von der Grösse des Halitherium, welchem diese Gattung iiberhaupt am nächsten steht. Der Schädel ist etwa $37^{\mathrm{cm}}$ lang. Unterschiede vom Halitherium: der Scheitel ist breiter und platter; der Zwischenkiefer ist stärker und enthält grössere Stosszähne; an Stelle der fehlenden Prämolaren erscheint ein scharfer Zahnnand; die vier Molaren sind complicirter durch Vermehrung der Zapfen und tiefer einschneidende Thäler und Furchen; zugleich werden die Kronen etwas conisch. Die schräg nach unten abfallende Kimnfäche neben der Symphyse des Unterkiefers ist breiter, der Kinntheil dicker, und zeigt fünf seichte Alveolen. Der humerus ist kräftiger gebaut und kürzer, als der des Halitherium. Das Hüfthein trïgt die Gelenkpfanne für einen Femur.

Alter: Miocaen.

Arten: Metaxytherium Cuvieri, de Christol 1843.

In den miocaenen Schichten des Languedoc: Montpellier, Beaucaire etc. und der unteren Loire, bei Angers, Rennes und Umgegend.

Metaxytherium subapenninum, Bruno sp. 1839. Montiglio im Montferrato bei Turin.

Metaxytherium Bellunense, de Zigno sp. 1875.

Cavarzana bei Belluno in den venetianischen Alpen.

Metaxytherium sp.

Leithakalk des Wiener Beckens, Hainburg, Neudorf u. a. 0.

4. Gattung Felsinotherium, Capellini 1872.

Sirene von grossen Dimensionen. Der Schädel wird $54-62 \mathrm{~cm}$ lang, enthält im grossen Zwischenkiefer zwei starke Stosszähne. Die Form des Schädels ist Halicore-artig: der breite Scheitel, die kräftigen Aeste des Zwischenkiefers, das knorrige Jochbein und die bedeutende Grösse und Schwere des Unterkiefers. Dagegen ist das șchädeldach länger und schmäler, die Nasenöffnung nicht so weit geöffnet und die Molaren andere, als bei Halicore. Die Schmelzkronen der vier Molaren bestehen noch aus Zapfen und Höckern, welche in ihrem Grundplane der Anordnung der Zapfen bei Halitherium folgen; die Furchen und Tläler schneiden nicht so tief ein, wie bei Metaxytherium und Halitherium; vielmehr legen sich die Zapfen dichter aneinander, sodass die Kronen noch conischer zulaufen, als bei Metaxytherium; durch diese verhältnissmässig geringe Breite der Zapfen-Oberflïchen und die bedentende Höhe der Kronen nilhert sich die Gestalt der Molaren des Felsinotherium derjenigen der frischen Molaren des Dugong. Die oberen Molaren besitzen drei, die unteren zwei Wurzeln. - Vom übrigen Skelett ist noch wenig bekannt. Sieben unverwachsene 
Halswirbel sind vorhanden. Die Grösse des Thieres wird derjenigen der Rhytina nahezu gleich gewesen sein.

Alter: Pliocaen.

Art: Felsinotherium Forestii, Capellini 1872.

Bologna. Brà bei Turin. Siena in Toscana.

\section{b. Lebende Sirenen.}

5. Gattung Halicore, Illiger 1811.

Körper $3-3,5^{\mathrm{m}}$ lang, Schwanzflosse gegabelt. Das Skelett besteht aus einem grossen, 37-44 ${ }^{\mathrm{cm}}$ langen Schädel, 7 Hals-, 19 Rüicken-, 5 Lenden- und 31 Schwanz-Wirbel. Armknochen gedrungener, als bei Halitherium; die fünffingerige Flossenhand ohne Nägel; das rudimentïre Hüftbein olme Femur. Im Schädelbau schliesst sich Halicore zunächst an Felsinotherium an: die grossen Zwischenkiefer gewimnen noch stärkere Aeste; Nasenbeine fehlen; Schädeldach platt, breit und sehr verkiirzt. Unterkiefer gross und plump grebaut. Gebiss: im Zwischenkiefer zwei grosse Stosszïhne, welche beim weiblichen Thiere in den Alveolen bleiben; daneben ein früh ausfallender zweiter Schneidezahn: in der breiten Kinnfl̈̈che des Lnterkiefers fünf rudimentäre Zähnchen, die früh resorbirt werden. Verhornte Kauplatten in der vorderen Mundsjalte. Scharfer, leerer Zahnrand an der Stelle der fehlenden Prämolaren. 5 bis 6 einwurzelige Molaren, stiftförmig, ohne Schmelzkrone; die nicht abgekante Krone hesteht aus dicht aneinnder liegenden Zatfen, welche beim Gebrauch bald verschwinden. Die rorderen Molaren schliessen im Alter ihre cylindrischen Wurzeln und fallen dann aus; nur die letzten beiden behalten offene Wurzeln und wachsen fortdauernd. Die Zahnformel: $\frac{2}{5} \mathrm{i} \frac{5-6}{5-6} \mathrm{~m}$ ist nach Analogie des Halitherium und Prorastomus vielleicht so zu deuten:

$\frac{2}{3} \mathrm{i}, \frac{0}{1} \mathrm{c}, \frac{1-2}{2-3} \mathrm{l} \frac{4}{4} \mathrm{~m}=34-38$ Zähne.

Einzige Art: Halicore Dugong, Daubenton sp. 1765. syn. Halicore tabernaculi, Rüppell 1832.

Lebt im Rothen Meer, an der Kü̈ste ron Mozambique, an der Insel Mauritius, im Malayischen Archipel, an den Philippinen und an der Nordkiiste ron Australien.

\section{Gattung Rhytina, Illiger 1811.}

Der 80 Centner schwere Körper wird bis $8^{\mathrm{m}}$ lang. Die dicke Haut ist bedeckt von einer durch Verfilzung der Haare und Verumreinigung entstandenen borkenartigen Aussenhaut. Die SchwanzHlosse gabelt. Der Bau des Skelettes schliesst sich zunächst an den der Halicore an. Das Skelett besteht aus einem 60-72 cm langen Schädel, 7 Hals-, 17 Riicken-, 2 Lenden- und 35 SchwanzWirbeln. Arm kurz; rudimentäres Hüftbein olne Femur. Zwischenkiefer ohne Stosszähne kleiner, als hei Halicore, doch mit lirüftigen Aesten, unter deren oberen Enden rudimentäre Yasenbeine liegen. Starker Jochbogen; breiter Hinterkopf; grosser, hoher Unterkiefer. In der vorderen Mundspaite je eine dicke und grosse Hornkauplatte mit groben Querrunzeln. Zähne fehlen vollständig.

Einzige Art: Rhytina Stelleri, Cuvier sp. 1509. syu. Rhytina borealis, Gmelin sp. 1788²).

Wurde im Jahre 1741 zum ersten Mal von Europäern an der Küste der Berings-Insel in

3) Die Rhytina müsste danach eigentlich borealis heissen: aber zu Ehren ihres unglücklichen Entdeckers wird sie allgemein Steller's Rhytina genannt. 
Heerden angetroffen, war dort bereits im Jahre 1768 vollständig ausgerottet. Lebte auch am Strande der Kupferinsel und wahrscheinlich an den Küsten von Kamschatka und Japan. Nach Nordenskjöld soll sie noch im Jahre 1780 und später gesehen worden sein; vielleicht lebt sie noch an den Küsten von Alaska.

7. Gattung Manatus, Rondelet 1558.

syn. Lamantin, Bution 1765.

Der Körper wird $2,5-3^{\mathrm{m}}$ lang, endigt in eine einfache, halbrunde Hautflosse. In der Haut am Rande der fünffingerigen Flossenhand 1-4 rudimentäre Fingernägel. Das Skelett bestelit aus einem 30-38 cm langen Schädel, aus 6 Hals-, 16-18 Rïcken-, 2-3 Lenden- und 24-26 SchwanzWirbeln. Die einzelnen Knochen des Skelettes sind langgestreckter, als bei Halicore. Der Schädel ist niedrig im Verhältniss zu seiner Länge und Breite. Der Jochfortsatz des Schläfenbeins schwillt stark an und wird schwammig; die Augenhöhle ist kreisrund, zuweilen ganz geschlossen. Zwischenkiefer kürzer und kleiner, als bei den andern Sirenen; seine Aeste sclımal, reichen niclit bis an die von einander getrennten, rudimentären Nasenbeine hinauf. Stirnrand kurz; Nasenöffnung lang und schmal. Unterkiefer lang und niedrig; Kinntheil bedeutend kleiner, als bei Halicore. In der vorderen Mundspalte verhornte Schleimhant-Flächen. Ohne Stosszihne: die Schmeidezähne beiben rudimentär und werden friih resorbirt. I'räimolaren fehlen beim erwachsenen Manatus vollständion (beim neugebornen ein Prämolar vorhanden). Die Schmelzkronen der 8-10 Molaren ordnen ihre Haupthöcker in zwei Querreihen an, denen sich im Oberkiefer eine vordere und hintere Sclmelzfalte, im Unterkiefer ein hinterer starker Talon anschliessen. Die Molaren des Oberkiefers haben drei, des Unterkiefers zivei Wurzeln.

Zwei Arten: Manatus australis, Gmelin 1788.

syn. Manatus americanus, autorum.

Manatus latirostris, Harlan 1824 ${ }^{\prime}$ ).

Die kleinste $\Lambda \mathrm{rt}$ unter den Sirenen; Schälel $30-36^{\mathrm{cm}}$ lang. 9 Nolaren. Lebt an den Küsten der Antillen, von Florida, Mexico, Venezuela und Nord-Brasilien; in den Orinoco, Amazonas und andre Flüsse dieser Küsten steigt die Art hoch hinauf.

Manatus senegalensis, Desmarest 1805.

Diese Art ist noch wenig bekannt; sie ist vielleicht etwas grösser, als die vorige Art; Schädel bis $38^{\mathrm{cm}}$ lang. Sie unterscheidet sich von der vorigen z. B. in einigen Schädeltheilen: der Zwischenkiefer ist etwas kürzer und die incisive Kinnfläche des Unterkiefers ist kileiner; der Jochfortsatz des Schläfenbeines wird grösser; der Stimrand ist liüzer; der Unterkiefer streckt sich gerader; der Zahnrand der Molaren ist lïnger, als beim amerikanischen Manatus. 10 Molaren. Das Brustbein ist ein in der Mittellinie mehrfach durchbrochener, schild-förmiger Knochen, wesentlich anders gestaltet als das Brusthein der amerikanischen Art.

Lebt an der Westküste des tropischen Afrika und findet sich in allen Flussmïndungen von Senegambien bis in den Meerbusen von Guimea.

1) Diesen Namen stellte Harlan auf nach zwei Schädeln des Manatus, der in den Flussmündungen von Ost-Florida lebt; die knöcherne Nasenöfinung wäre etwas breiter, als bei den andern Manatus-Arten. Journ. Acad. nat. scienc. Philadelphia. 1824. vol. III part II pag. 390 pl. XIII Fig. 1-3. 


\section{Die Stellung der Sirenen im zoologischen System.}

Wenn in den meisten zoologischen Handbiichern noch jetzt die Sirenen mit den Walen und Delphinen zusammen in einer Ordnung aufgeführt werden, so ist dies wesentlich der gewichtigen Autorität Cuvier's zuzuschreiben, welcher zuerst diese Thiergruppe als herbivore Cetaceen bezeichnete. Vor Cuvier wurden die Sirenen mit den Phocen verbunden (Linné, Buffon, Blumenbach), und Manatus direct als Trichechus bezeichnet. Seit Cuvier ist von den meisten Forschern, welche sich eingehender mit der Anatomie der Sirenen beschäftigten, hervorgehoben worden, dass die Sirenen nur eine sehr geringe oder gar keine Verwandtschaft mit den carnivoren Cetaceen besässen, vielmehr nach ihrer inneren Organisation den Ungulaten nahe ständen. Man kann die Gegensätze der früheren und jetzigen Anschauungen über die Stellung der Sirenen nicht besser wiedergeben, als mit den Worten Cuvier's und Flower's. Der erstere schliesst die Einleitung seiner Untersuchung der Lamantine mit einem Satze, welcher die ganze Unklarheit der damaligen Auffassung über die Verwandtschaft verschiedener Säugethiergruppen charakterisirt "): no terminerai par cette conclusion, que ces trois gemres (Manatus, Ilalicore, Rhytina) doivent constituer une famille separée, très-différente des phoques, et qui est à peu près aux cétacés ce que les pachydermes sont aux carnassiers." Und Flower ${ }^{2}$ ): „Die Thiere der Ordnung Sirenia, welche früher, aber ganz irrthümlich, zu den Cetaceen gerechnet wurden, haben Schädcl gebaut nach einem sehr eigenthümlichen Typus, wenn auch mit einiger Verwandtschaft sowohl zu den Ungulaten als zu den Proboscidiern. Viele der besonderen Veränderungen sind Anpassungen an ihre Lebensweise im Wasser, und nur in diesen allein zeigen sie einige Aehnlichkeit mit den Cetaceen".

Blainville erklärte sich in seiner Ostéographie des Lamantins ganz entschieden gegen die Zurechnung der Sirenen zu den Cetaceen ${ }^{3}$ ); er vereinigt die Sirenen mit den Elephanten zusammen als "Gravigrades".

J. Murie in seiner Anatomie des amerikanischen Manatus nähert die Sirenen den Pachydermen, ohne sie aber von den Cetaceen ganz zu trennen, und stellt seine Ansicht in folgenden Schema dar (1. c. pag. 190):

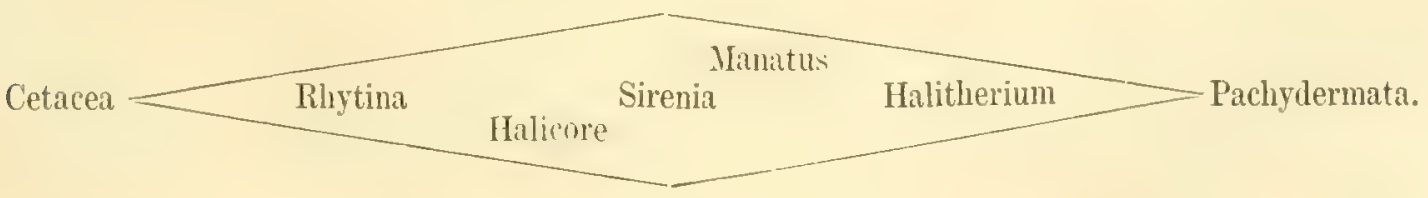

1) Annales du museum d'hist. nat. de Paris. tome XIII. 1809. pag. 282 und dieselben Worte in den Ossemens fossiles. tome V.1. 1823. pag. 242.

2) An introduction to the osteology of the Mammalia. by W. H. Flower. 2 ed. London 1876. pag. 198.

3) Ostéogr. Manatus 1843. pag. 31. Pander und d'Alton sprachen sich bereits 1826 in ihrem wichtigen Werke über die Skelette der Säugethiere gegen die Unterordnung der Lamantine unter die Cetaceen aus, obne die Sache weiter zu verfolgen, da die Systematik der Sängethiere nicht im Plane ibres Werkes lag. 
R. Owen hatte bereits im Jahre 1856 die Sirenen den Ungulaten untergeordnet ${ }^{1}$ ) und zwar hatte er sie gegeniiber den Ungulata typical (Artiodactyla und Perissodactyla) als Ungulata aherrantia zusammengefasst mit den Proboscidea und Toxodontia. Huxley theilt in seinem Handbuch der Anatomie der Wirbelthiere 1873 in „provisorischer" Weise die Abtheilung Monodelphia non-decidnata in die vier gesonderten Ordnungen: 1. Ungulata. 2. Toxodontia. 3. Sirenia. 4. Cetacea; und sagt daselbst von den Sirenen: „Früher wurden die Sirenen mit Walen und Delphinen als Cetacea herbivora vereinigt; aber ihre Organisation entfernt sich von der der Cetaceen fast in jeder Einzelheit, während sie den Ungulaten sehr nahe stehen."

Die Sirenen wurden demnach von den verschiedenen Forschern in nähere Beziehung gesetzt zu den Phocen, zu den Cetaceen, zu den Proboscidiern und Pachydermen und zu den Ungulaten; da die Gruppe der Pachydermata jetzt aufgelöst ist und die Proboscidier mit Recht den Ungulaten untergeordnet werden, so bleiben nur die Phocen, Cetaceen und Ungulaten zur Vergleichung mit den Sirenen bestehen.

Von diesen drei Gruppen haben ohme Zweifel die Phocen am wenigsten mit den Sirenen zu thun. Dieselben verhalten sich etwa zu den Carnivoren, wie die Sirenen zu den Ungulaten. Und in dieser Beziehung lieten sie einige Analogien zu den Sirenen: heide Thierfanilien sind rom Lande hinab in das Wasser. gestiegen und haben ihren Körper diesem neuen Lebenselement äusserlich angepasst. Beide brauchten ein Steuerruder beim Schwimmen: die Phocen benutzten dazu ihre hinteren Extremitäten, streckten dieselben mach hinten aus und legten sie möglichst dicht aneinander, sodass ihre Füsse die Function der Schwanzflosse der Fische iibernehmen konnten; gleichzeitig umgaben sie Hand und. Fuss mit einer Schwimmhat. Die Sirenen dagegen verwirklichen fitr dieselbe Function eine andre Möglichlieit; sie wandeln ihren Schwanz um zum Steuerruder, indem sie denselben verlingern und verstärken und ihn mit einer horizontal gestellten Hautflosse umgeben, welche sich bei Halicore und Rhytina dazu noch gabelt. Die vorderen Extremititen wurlen wie bei den Phocen die Ruder. Da auf diese Weise die hinteren Extremitiiten weder als Stener noch als Ruder benutzt wurden, verkümmerten sie durch Nicht-Gebrauch.

Die Borsten am Munde der Sirenen sind gelegentlich mit dem Schnauzbart des Walrosses verglichen worden; indessen bleiben dieselben ganz kurz und stehen, wie über den ganzen Körper, so auch auf den Lippen und sogar im Munde. J. Murie bemerkt daher (1. c. pag. 134), dass die Borsten auf den Lippen der Sirenen nicht denen der P'imnipedier, sondern eher denen des Hippopotamus gleichen. Dass die Pinnipedier ebenso wie die Sirenen ilhen Körper abrunden durch eine Fettlage unter der Haut, ist auch nur ein Lerkmal, welches auf ihr gemeinsames Leben im Wasser zuriickzuführen ist.

Eigentlich beruht die Zutheilung der Sirenen zu den Cetaceen auf ganz denselben Ursachen, wie diejenige zu den Phocen: die iussere Aehnlichkeit beider Thiergruppen ist ebenso nur die Folge von der Anpassung an das beiden gemeinsame Leben im Wasser; sie ist der einzige Grund dieser unnatürlichen Verbindung. Nur der Umstand, dass die Sirenen nicht wie die Phocen die Hinterbeine, sondern wie die Cetaceen ilren Schwanz zum Steuerruder umwandelten, macht die äussere Aehnlichkeit um einen Grad höher. Aber anch in der äusseren Gestalt der Sirenen und Cetaceen

1) Annales of natural history or Magazine of Zool. Bot. Geol. II. ser. vol. 19. pag. 66. 
treten bedentende Unterschiede hervor: ler Kopf der Cetaceen ist bedeutend grösser im Verhältniss zur Lïnge des Rumpfes, als bei den Sirenen; er ist schnabelförmig spitz nach vorn ausgezogen, hinten hoch und dick; bei den Sirenen dagegen ist der Kopf klein, niedrig, breit und vorn quer abgestutzt. Der Rachen der Cetaceen ist sehr weit bis binten an die Augen gespalten, liegt in Mitten des Gesichtes und ermangelt der Lippen, während der IIund der sirenen klein bleibt, am unteren Rande der Vorderseite des Kopfes liegt und umgeben ist ron starken, wulstigen Liphen. Die Nasenlöcher rücken bei den Cetaceen weit nach hinten zur Stirn hinauf, bei den Sirenen befinden sie sich nahe dem vorderen Ende des Kopfes. Die Augen der Cetaceen entbehren des dritten Augenlides, das den Sirenen zukommt; dieselben liegen so tief an der Seite des Kopfes dicht uiber den Mundwinkeln, dass sie in der Oberansicht des Kopfes nicht sichthar werten, während die Augen der Sirenen am oberen Rande der Kopfseite und weit entfernt vom Munde stehen.

Die Armflossen ragen bei den Cetaceen wegen der Kürze der Armknochen aus der Mitte der Körperseite hervor und sind bei der grossen Länge des Kopfes weiter nach hinten gerückt als bei den Sirenen, wo die Arme länger aus der Haut hervorstehen und mehr unten seitlich der flachen Brust sitzen. Die Armflosse der Cetaceen ist schmal und läuft spitz zu ohne jede Gliederung in Hand und Arm; die der Sirenen bleibt ein kurzer Arm und eine breite, platte Hand mit flach abgerundeter Endigung, an deren Rande bei Manatus rudimentïre Fingernïgel vorhanden sind. Eine Rückenflosse kommt bei den Sirenen niemals, bei den schuell beweglichen Cetaceen meistens vor.

Bei der geringeren Fettablagerung werden die Körper der Sirenen niemals so dick als die der Wale; besonders bleibt der Hals dünner und setzt sich mehr vom uibrigen Körper ab. Die Milchdrïsen liegen bei den Sirenen an der Brust zwischen den Armen, bei den Cetaceen neben den Genitalien. Die Haut der Wale ist dïnn, glatt ohne jede Behaarung; diejenige der Sirenen dick wie Elephantenbaut ${ }^{1}$ ), sehr runzelig, zwischen den Runzeln plattig äbnlich wie bei Rhinoceros, und spärlich behart mit Borsten und feineren Haaren.

Im Skelettbau unterscheiden sich beide Thiergruppen vollständig von einander bis in die Einzeltheile; wir wollen nur die wesentlichen Merkmale hervorheben. Der Schädel der Cetaceen zeigt einen ganz anderen Bau, als der der Sirenen: die hohe, kurze Schädelkapsel besteht aus selır dünnen, leichten Knochen; vor derselben steht schabelförmig lang ausgezogen, gerade nach vorn der Gesichtstheil. Das breite und dünne corpus ossis occipitis lässt keine foramina lacera an der Schädelbasis erscheinen; die noch übrige Oeffnung für das Gehör wird unterfangen von einer bulla 0ssea. Das foramen occipitale liegt bei den Cetaceen stets völlig in der Hinterwand des Schädels, nicht schrïig auf die Schädelunterseite ibbertretend. Die Condylen mehr unter als neben dem Hinterhaupts-Loche gelegen berühren sich häufig unten mit einander. Da die Wirbelsäule nur einfach convex nach oben ausgebogen, nicht S-fürmig doppelt gekrümmt ist, und die Halswirbel-Säule sich nicht nach oben aufrichtet, hängt der Schädel der Cetaceen nach vorn herunter am Atlas, und stehen die Condyli mit ihren Flächen nicht schräg nach unten vorn, sondern vertical oder sogar schri̊g nach oben vorn gerichtet. Diese Stellung des Kopfes und Lage des Hinterhauptsloches kommt unter allen Säugethieren nur den Cetaceen zu; sie erinnern in dieser Beziehung an die

1) Aus der Haut des Manatus schneiden die Eingebornen von Senegambien dieselben bekannten Kameelsresp. Sklaven-Peitschen, wie aus der Elephantenhaut. 
Reptilien. Die Sirenen dagegen tragen ihren Kopf aufrecht auf der nach oben vorn gerichteten Haiswirbelsäule.

Die squama ossis occipitis ist am Schädel der Cetaceen sehr gross, dünn und biegt sich weit nach vorn auf die Oberseite des Schädels; das Hinterhaupt ist glatt abgerundet ohne Kanten und Wülste. Die Nähte der vier'Stücke des os occipitis verwachsen sehr früh vollständig; sie zeigen vor der Verwachsang die den Schädelknochen der Cetacen eigenthimliche sutura foliacea. Allerdings breitet sich das IInterhauptshein am fütalen Schiidel z. B. (les Viligewales ${ }^{1}$ ) noch nicht so bedeutend aus, wie am Schädel der erwachsenen Wale; vor demselben liegt noch eine breite Interparietal-Schuppe, welche später von der squama ossis occipitis fast vollständig iberdeckt wird. Die Hinterwand ist am fötalen Schädel noch steiler, weniger abgerundet, und wird seitlich begrenzt vom os temporum, welches später vom os occipitis ganz nach vorn und unten gedrängt wird.

Die Scheitelbeine bleiben bei den Cetaceen meistens ganz auf die Seitenwände des Schädels beschränlit, indem sie ron der Occipital-Schnpe und dem Zwickelbein auseinander gedrängt werlen. Die Stimbeine erscheinen im Scheitel nur als ein schmaler Streifen, zum grösseren Theil bleiben sie seitlich mit bedeutender Ausbreitung der processus orbitales. Durch diese Reduction der Scheitelund Stimbeine im Scheitel geselieht es, dass die weit aufsteigenden Stirniste des (Oher- und Zwischenkiefers und die Nasenbeine fast in Perïhrung treten mit dem Vorderrand der Oecipital-Schupe. Am fötalen Schïdel ist diese starke Verkiirzung des Scheitels noch nicht vorhanden, erst späiter schieben sich die Knochen der Schädelkapsel derartig ïbereinander.

Das Schläfenbein, welches bei den Sirenen mit seinen Fortsätzen einen so bedeutenden Antheil an der Zusanmensetzung der Seitenwïnde des Schädels nimmt, wird am Schädel der Cetaceen durch die umliegenden Knochen sehr reducirt und ganz an die Schädelbasis gerückt: die Schuppe geht fast ganz verloren, es bleibt die pars mastoidea als Gelenkfortsatz für den Unterkiefer mit kurzem processus zygomaticus, und die Pyramide. Bei den Delphinen löst sich die letztere bei der Naceration ganz yom Warzentheil ab, bei den Bartenwalen wird sie durch einen bakenförmigen Fortsatz der pars mastoidea festgehalten; indessen ist auch diese Verbindung der beiden Hälften des os temporum niemals eine so innige und feste, wie bei den Sirenen. Dass der Ohrapparat der Cetaceen ganz anders gestaltet ist, als derjenige der Sirenen, dass eine bulla ossea bei den Cetaceen vorhanden, dass die bedeutenden Erweiterungen der Paukenhöhle und der Eustachischen Röhre im CetaceenSchädel den Sirenen gänzlich abgehen, haben wir oben hei Besprechung des Sirenen-Ohres erwähnt. Das Jochbein, welches sich bei den Sirenen zu einem kräftigen Knochen entwickelte, wird bei den Cetaceen meist ein dïnner Knochenstab.

Die Nasenhöhle hat bei den Cetaceen durch den Mangel eines nervus olfactorius ihre Function als Riechorgan vollständig verloren und dient nur zum Ein- und Ausathmen der Luft. Daher ist die Siehplatte wenig, zuweilen gar nicht durchhohrt, die Muscheln sind gänzlich verkiummert. Die

1) Siehe Eschricht, Zoolog. Anatom. Physiologische Untersuchungen über die nordischen Wallthiere. Leipzig 1849. Eine Vergleichung des fötalen Schådels vom Vaagewal bei Eschricht und des fötalen Nanatus. Schädels bei Vrolik und Murie erweist manche Aehnlichkeiten beider, aber nur solche, welche sich nicht über die allgemeine Aehnlichkeit verschiedener Säugethier-Schädel erheben. Der fütale Cetaceen-Schädel zeigt eben eine viel grössere Uebereinstimmung mit dem Schädel anderer Såugethiere, als der ausgewachsene Cetaceen-Schädel; dasselbe gilt für den Sirenen-Schädel. 
Nasenbeine sind bei den Walen noch Schildknochen über der Nasenhöhle, bei den Delphinen reduciren sie sich auf kurze Knochenstuicke, welche hinter der Nasenöffnung am Rande vor dem Stirnbein stecken. Bei den Walen verlaufen auch die Nasengänge normaler, von den Choanen schräg nach oben vorn, bei den Delphinen aber direct nach oben, sodass bei diesen auch die äussere Nasenöffinung dicht vor dem Scheitel und weit nach hinten von der Schnauzenspitze entfernt mündet.

Rauhe Apophysen und wulstige Flächen für den Ansatz von IIuskeln sind am Schällel der Cetaceen nicht zu bemerken: die Knochen ¿des Kopfes sind im Gegensatz zu den ganz besonders schweren Schädelknochen der Sirenen leicht, diunn und zum Theil hohl, der Kopf im Nacken zugleich unbeweglich und die Kiefer nicht zum Zermahlen, sondern nur zum Ergreifen der Beute eingerichtet, sodass es starker Muskeln zur Berregung des Kopfes und des Unterkiefers nicht bedarf.

Die Kiefer sind bei den Cetaceen ganz anders gestaltet, als bei den Sirenen: an Stelle der grossen, plumpen Knochen der letzteren sind es schmale, lange Röhrenknochen, weiche der Schädelkapsel wie ein Vogelschnabel vorgesetzt sind. Die Zwischenkiefer liegen ganz zwischen den Oberkiefern und parallel denselben, sodass sie von der Umgrenzung der Mundspalte fast ausgeschlossen sind, während sie bei den Sirenen einen hervorragenden Antheil beim Zermahlen der Nahrung übernehmen. Sie endigen vorn spitz olme Zähne, nach hinten strecken sie sich bis zur Nasenöffuung herauf und umfassen dieselbe mit schmalen Aesten, welche bei den Walen wie bei den meisten Sirenen bis an das Stirnbein reichen. Der Oberkiefer legt sich hinten breit und platt auf das Stirnbein auf. Jede Unterkiefer-Hälfte ist ein einfach lang gestreckter schmaler Knochen, zum Theil hohl, ohne aufsteigenden Ast, und das Gelenk liegt am hinteren Ende des Körpers.

Das Gebiss der Cetaceen bestelt bekanntlich aus einer grossen Menge kleiner Kegelzähne, welche bei den Bartenwalen nur am fötalen Schädel vorhanden sind, bei den Delphinen zu spitzen Fangzähnen auswachsen. Alle Zähne gleichen einander und werden bei den lebenden Cetaceen nicht gewechselt (monoplyyodont). Diese Zähne der Cetaceen erinnern an diejenigen einiger Reptilien, sind völlig verschieden von den wohl entwickelten Mahlzähnen der Sirenen; auch die zweiwurzeligen 'Zähne der ausgestorbenen Zeuglodonten mit ihrer mehrzackigen Schmelzkrone können in keiner' Weise mit den Zähnen der Sirenen verglichen werden. Noch weniger haben die Stosszähne des Narwales etwas zu thun mit den Stosszïhnen der Sirenen, da sich diese im Zwischenkiefer, jene im Oberkiefer entwickeln. Das Gebiss der Cetaceen hat so bedeutende Umwandlungen erfahren, dass es kaum möglich ist, dasselbe in Beziehung zu setzen mit dem anderer Säugethiere; am ehesten kann noch eine Aehnlichkeit der Zeuglodonten-Zähne mit denen einiger Phocen herausgefunden werden. Cetaceen und Phocen sind beide Fleischfresser, die Sirenen sind wie alle Ungulaten Pflanzenfresser. Die Barten der Wale sind zwar ebenso epidermale Gebilde wie die Hornkauplatten der Sirenen; dieselben entwickeln sich aber nur am Oberkiefer, bei den Sirenen am Zwischen- und Unterkiefer und ergeben sehr verschiedene Producte.

Auch das Rumpfskelett der Cetaceen hat mit dem der Sirenen keine anderen Aelnlichkeiten, als diejenigen, welche aus der gleichartigen Reduction und Umwandlung der Extremitäten durch die Bewegung im Wasser folgen; im Einzelnen sind die Knochen der Wirbelsäule und der Extremitäten ganz verschieden gestaltet. Die Reduction der Knochen des Rumpfes ist ebenso wie bei den Schädeltheilen bedeutend weiter vorgeschritten bei den Cetaceen, als bei den Sirenen. Nur die Phalangen der fünffingerigeu Flossenhand vermehren ilhre Anzahl bei manchen Walen in einer Weise, welche erimnert an die aus vielen kleinen Knöchelchen zusammengesetzten Fingerstrahlen der juras- 
sischen Meeressaurier. An den Armknochen der Sirenen fanden wir stets wohlausgebildete Gelenke; bei den Cetaceen ist nur das Schultergelenk vorhanden, die übrigen Gelenke fehlen, sodass sich die einzehnen Knochen mehr oder weniger fest mit einander verbinden. Arm und Hand ermangeln daher meistens ganz der Muskeln, nur an der Schulter sind Muskeln ausgebildet. Dazu sind die Armknochen bedeutend kürzer und schmächtiger, als bei den Sirenen, und ohne jede Apophyse.

Ein Beckenrudiment aus parigen Knochen bestehend ist auch bei den Cetaceen vorhanden, aber anders gestaltet als bei den Sirenen. Als rudimentïrer Femur wird bei den Bartwalen ein neben dem Hüfthein erscheinendes Kü̈chelchen gedentet, ohne dass dasselbe an Hüfthein eingelenkt ist oder irgend an die Gestalt eines Schenkelbeines erinnert. Bei den fossilen Cetaceen ist noch nicht ein ebenso gut entwickelter Femur nachgewiesen, wie bei dem Halitherium.

Die sieben Halswirbel der Cetaceen bilden eine ganz kurze Säule und verwachsen in der Regel zu melireren oder sämmtlich mit einander; unter den Sirenen kommt nur dem Manatus die Verwachsung des zweiten und dritten Halswirbels zu, welche sich gelegentlich auch bei Halitherium zeigt. Dem epistrophens der Cetaceen fehlt der Zahn. Der Brustkorb derselben ist kurz, sodass eine starke Vermehrung der Lendenwirbel gegenuiber den Riickenwirbeln eintritt. Die Wirbelsäule der Cetaceen ist durch dicke intervertebrale Knorpelscheiben viel beweglicher als diejenige der Sirenen.

Im Ganzen ist also der Körper der Cetaceen noch vollkommener eingerichtet fuir das Leben und die Bewegung in Wasser, als derjenige der Sirenen und dies ist im wesentlichen durch eine viel bedeutendere Reduction und Umwandlung des Skelettes erreicht, als es bei den Sirenen der Fall ist. Die Cetaceen als Fleischfresser müssen eine grössere Beweglichkeit entwickeln, als die ptlanzenfressenden Sirenen, welche behaglich am Orte die Seegras-Wiesen abweiden.

Bei der ganzen obigen Beschreibung des Skelettes der Sirenen haben wir für die meisten Knochentheile die Bezeichnungen anwenden können, wie sie von der Topographie des menschlichen Skelettes auf das Skelett der löheren Süugethiere leicht bis ins Einzelne zu übertragen sind. Schon dieser Unstand weist darauf hin, dass wir es bei den Sirenen mit Säugethieren zu thun haben, welche verhältnissmåssig wenig vom allgemeinen Typus der Säugethiere abweichen, und keineswegs die bedeutenden Reductionen der Skelettheile aufweisen, welche eine Vergleichung der höheren Sïugethiere mit den Cetaceen erschwert.

Es ist, wie wir oben bemerkt haben, ron den meisten Anatomen der neueren. Zeit hervorgehoben worden, dass die Sirenen ihrer inneren Organisation nach am nächsten den Ungulaten stehen. Wir haben im Verlauf der Beschreibung wiederholt Gelegenheit gehabt auf diese Beziehungen der Sirenen zu den Ungulaten hinzuweisen und zwar haben wir ihre Verwandtschaft gerade zu den älteren Typen der Ungulaten betont, während die jüngeren Typen derselben z. B. Boviden, Cerviden, Oviden durch neuere Erwerbungen ibrer Skelettheile sich weiter von den Sirenen entfernen. Vor allen erweist der persistenteste Typus unter den Ungulaten, der Tapir, dessen älteste Arten der Tertiäzeit kaum wesentliche I'nterschiede von den lebenden zejgen, eine nähere Beziehung zu den Sirenen, besonders in der Schädelbildung.

Der Schädel des Tapirus indicus z. B. bietet uns viele Vergleichungspunkte mit demjenigen der Sirenen, speciel des Halitherium: der Schädel des Tapir ist lang und schmal, nur verbreitert. durch den Jochbogen, welcher nicht viel weniger kräftig entwickelt ist, wie bei Halitherium; der 
processus aygomaticus ossis temporum und das Jochbein gleichen auffallend denselben Finochen am Halitherium-Schädel sowohl in ihrer Gestalt und ihren Fortsätzen als in der Art ihrer Verbindung mit den andern Schädelknochen. Der Körper des Jochbeins ist ebenso rhombisch, wie bei Halitherium, und entsendet nach hinten unter den Jochfortsatz des Schlïfenbeins einen spitzen processus malaris, nach vorn um die Orbita unten herumbiegend einen schmalen processus orbitalis. Auch beim Tapir ist Schläfen- und Augenhöhle nicht getrennt, da das Jochbein ebenso weit wie bei Halitherium vom Stirnbeinfortsatz entfernt bleibt. Erst bei den jüngeren Typen der Ungulaten, so beim Pferde, tritt die Verbindung des Jochbeins mit dem Stirnbein auf, gerade wie solche beim Manatus gelegentlich vorkommt.

Das Schädeldach des Tapirus indicus gleicht sehr dem des Halitherium: zwei cristae temporales schwingen sich von der scharfen Oberkante der Hinterwand über den Scheitel und verlieren sich nach vorn in den weit vorspringenden processus orbitales ossis frontis; zwischen diesen Kanten bleibt auf dem Scheitel eine plane Fläche, welche sich vorn zur Stirn erweitert. Die Nasenbeine sind etwas länger als beim Halitherium; dafür stecken sie mit zèrfaserter Wurzel weniger tief im Stirnrand. Die beiden Nasenbeine stehen Schild-förmig über der weiten Nasenöffnung, welche nicht viel enger ist als bei Halitherium. Da der Tapir lieine Stosszilme im Zwisehenkiefer entwickelt, liegt kein Grund vor, die Aeste des Zwischenkiefers zur besseren Stütze hoch hinauf zu schieben bis auf die Nasenbeine, wie bei den Sirenen; nur bei Manatus, welcher die Stosszähne verloren oder nie besessen hat, tritt die Rückbildung ein, dass die aufsteigenden Aeste des os incisivum sich vom Stirnrande wieder nach vorn weit zuriickziehen. Beim Tapir wird daher nur der vordere Theil der knöchernen Nasenhöhle von den Zwischenkiefer-Aesten, der grössere Theil vom Oberkiefer umfasst. Die Muscheln der Nase entwickeln beim Tapir zahlreiche Blätter; bei den Sirenen haben wir bei der älteren Gattung Halitherium noch ausgehildete Inschelwiilste gefumlen, bei den jüngeren Sirenen verkümmern sie mehr und mehr. Der Vomer des Tapirs und des Manatus sind einander sehr ähnlich; beide reichen mit dünner, langer Spitze von der weit in die Nase zurückgezogenen lamina perpendicularis bis an das foramen incisivum vor. Das foramen infraorbitale liegt beim Tapir an der gleichen Stelle wie bei Halitherium, und ist ebenfalls grösser, als bei andern Säugethieren, wemn es auch nicht entfernt die Weite wie am Halicore-Schädel erreicht.

Auch die Hinterwand des Tapir-Schädels gleicht der des Halitherium, nur bleibt sie viel schmäler als bei diesem: sie ist ebenso steil und vertical gestellt; wird oben umrandet von einer sehr liräftigen linea nuchae superior, unter welcher sich die Ansätze der Nackenmuskeln tief einsenken; in der Mitte springt eine protuberantia externa und von ihr aus nach unten eine linea nuchae mediana vor. Die Nähte der squama ossis occipitis gegen die partes laterales verlaufen ebenso wie bei Halitherium; die Schuppe ist bei beiden ausgeschlossen von der Umrandung des dreiseitigen foramen occipitale. Seitlich der partes laterales erscheinen an der Hinterwand des TapirSchädels neben dem processus jugularis der Warzentheil des Schläfenbeins und ein Streifen des Felsenheins mit dem foramen mastoideum daríber.

An der Schädelbasis öffnen sich beim Tapir ebenso wie bei Halitherium neben dem schmalen und langen corpus ossis occipitis zwei grosse foramina lacera, zum Theil ausgefüllt durch die Pyramide des Schläfenbeins: Paukenring und Lahyrintheil sind beim Tapir ganz ähnlich gestaltet, nur schmächtiger als bei Halitherium, und haben die gleiche Lage. Unter den schräg über die Beuge- 
kante des os occipitis stehenten Condylen erscheint an derselben Stelle wie an Halitherium-Schïdel ein canalis hypoglossi. Das os sphenoideum am Schädel des Tapir ist bis in die Einzelheiten gestaltet wie bei Halitherium, nur ist es wie ïberhaupt der Tapir zierlichere Knochen besitzt als dieses und kleiner ist, auch in allen Theilen schwächer gebaut; nur der canalis vidianus fehlt den Sirenen. So ist der Körper des Wespenbeins in derselben Weise getrennt von den Flügeln; der sulcus caroticus und der canalis rotundus schneiden wie bei Halitherium nur in den hinteren Rand der Fligelwurzel, olne geschlossen zu sein. Das Gaumengewölbe des Tapirs ist etwas breiter und kürzer, als bei den Sirenen; eine Gaumenspalte fehlt: dieselbe drang bei Halitherium weit nach vorn vor, bei den lebenden Sirenen ist sie stark verkürzt. Der Oberkiefer verbreitert sich zum Jochbein hin bei den meisten Sirenen in ungewöhnlich starkem Maasse, nur bei der ältesten Gattung Prorastomus nicht: gerade die beiderseitige Befestigung des Jochbogens vorn am Oberkiefer, hinten an der Schläfenschuppe fanden wir bei Prorastomus normaler, als bei den andern Sirenen, und sie ist daher auch älnlich derjenigen an Tapir-Schädel. Die Gestalt des Unterkiefers von Prorastomus grleicht ebenfalls derjenigen des Tapir, wïhrend die Unterkiefer der jüngeren Sirenen durch die breiten Aeste und das Herunterbiegen des Kinntheiles sich sehr fremdartig gestalten.

In Betreft des Gebisses haben wir bereits oben bemerkt, dass dasselbe gerade am wenigsten geeignet ist, der vergleichenden Anatomie zu dienen, weil die 'Zähne diejenigen Theile des Sảugethier-Körpers sind, welche sich am schnellsten umwandeln. Sehen wir allein die Gruppe der Sirenen an, so beobachten wir wie grosse Verschiedenheiten die Zähne der einzelnen Gattungen zeigen; ebenso bei den echten Ungulaten entwickeln sich neben den conservativen älteren Typen mit einfachen bizygodonten Molaren eine grosse Nenge jüngerer Gattungen, welche gerade in ihrem Zahnbau am meisten von einander abweichen. Ebenso wie die neueren Untersuchungen bewiesen haben, dass die Backenzähne der verschiedenen Ungulaten sich zurückführen lassen auf einfache bizygodonte Zahmkronen, wie sie bei Lophiodon und Tapir verwirklicht sind, so haben wir auch für die Sirenen erkannt, dass die Molaren des Prorastomus jene einfache bizygodonte Form besitzen, dass dieselbe noch scharf hervortritt in den Molaren des Manatus und dass erst vom Halitherium an die Zertheilung der Querjoche in einzelne Höcker und Zapfen beginnt, bei Metaxytherium fortschreitet, und bei Felsinotherium und Halicore durch Verwachsung der Höcker zugleich mit der Jochform gänzlich verschwindet. Auch in der Beziehung haben wir in der Zahnentwicklung der Sirenen Analogien mit den Ungulaten gefunden, dass die Zähne der älteren Typen nur aus Schmelz und Dentin bestehen, die Ziilme der juingeren Typen das ('ement hinzu erwerben und dass sie endlich die Eigenschaft gewinnen, mit hohlen Wurzeln permanent fortzuwachsen.

Auch die Wurzelstellung der Molaren des Tapir und des Halitherium ist die gleiche im Ober- und Unterkiefer. Dass die Prämolaren der Sirenen aus zwei- zu ein-wurzeligen Zähnen reducirt sind, beweist der Fund eines zweiwurzeligen Prämolars des Halitherium, beweist der zweiwurzelige Prämolar des Manatus-Fötus, welchen Stannius beschreibt ${ }^{1}$ ), und beweist die Furchung der Prämolaren-Wurzel bei Prorastomus. Die Stosszähne der Sirenen endlich waren noch bei Prorastomus einfache Schneidezälne. So zeigen sich selbst bei den scheinbar so verschiedenen

\footnotetext{
3) Beitr. zur Kenntniss des amerik. Manatus. 1845 pag. 14 Taf. II Fig. 6.
} 
Gebissen der Sirenen und Ungulaten nicht unwichtige Analogien, welche auf verwandtschaftliche Beziehungen beider Thiergrtupen hinweisen.

In dem Rumpfskelett weichen die für das Leben im Wasser umgestalteten Sirenen natürlich am meisten von den Land-bewohnenden 'Tapiren ab; hier iberwuchern die durch Anpassung erworbenen Eirgenschaften so vollständig die überkommenen Formen, dass eine Vergleichung der Knochen des Stammes und besonders der Extremitäten kaum angebracht ist. Nur das eine will ich erwähnen, dass die Wirbel des Tapirs in ihrer Gestalt und ihren Fortsätzen etwas denen der Sirenen gleichen, dass besonders die Lendenwirbel desselben ebenso ungewöhnlich grosse Querfortsätze tragen, wie diejenigen der Sirenen, und dass dem Tapir auch 18-19 grosse Rippen zukommen. Endlich ragt das manubrium des Brustbeines vom Tapir in ähnlicher Weise wie bei Halitherium über den Ansatz des ersten Rippenpaares empor und trïgt auch auf der Unterseite eine crista.

Wuirden wir die Skelettheile der Sirenen in ihren conservativen Elementen noch mit anderen Gruppen der Ungulaten vergleichen, so könnten wir überall ähnliche Beziehungen finden, wie mit den 'Tapiren, bei keiner Ungulaten-Gattung aber so weitreichende Aehnlichkeiten im Schädelban, als bei diesen, weil die Tapire wie gesagt zu den persistentesten Vertretern der Ungulaten gehören. Blainville hat eine besoudere Terwanltschaft der Sirenen zu den Elephanten finden wollen; gehen wir die Punkte durch, in welchen sich hier Achnlichkeiten zeigen, so beziehen sich dieselben zumeist auf die allgemeine Verwandtschaft der Proboscidier zu den Ungulaten, speciel zu den pachydermalen Ungulaten. Nur die besonderen Umwandlungen des Schädels durch die Stosszähne, Umwandlungen, welche bekanntlich bei den Elephanten viel bedeutender sind, als bei den Sirenen, bringen einige specielle Aelnnlichkeiten vor allem in der Bildung der Zwischenkiefer mit sich; auf diese Analogie kann aber keine nähere verwandtschaftliche Beziehung begrïndet werden, da bei den Proboscidiern wie bei den Sirenen die Stosszähne erst erworben, nicht ererbt wurden. Auch wird zuweilen angefiilnt, dass die letzten Molaren des Halitherium ein verkleinertes Bild der Molaren des Mastodon darstellten, oder dass die Kaufächen der ersteren denen des Hippopotamus glichen; beide Beziehungen erheben sich nicht ïber eine äusserliche Aehnlichkeit, begrinden keinerlei Homologie.

Wir wïrlen demnach zu dem Schlusse gelangen, dass die Sirenen in keiner Weise mit den Cetaceen, dagegen offenbar mit den Ungulaten eine nähere Verwandtschaft zeigen und dass sie unter diesen den ältesten Typen, wie den Tapiren, am meisten gleichen, wenigstens in den conservativen Eigenschaften ihrer Skelettheile. Unter den verschiedenen Sirenen-Gattungen bieten wieder die ältesten, nämlich Prolastomus und Halitherium die meisten Vergleichungspunlite mit den Ungulaten dar; lem alttertiären Prorastomus schliesst sich zunichst die lebende Gattung Manatus an, an dessen vorderen Extremitäten noch die Rudimente der Cngulaten-Nägel zurückbliehen. Ein anderer Zweig der Sirenen entwickelt sich von dem alttertiären Halitherium aus durch das miocaene Metaxytherium zum pliocaenen Felsinotherium hin und endigt in der lebenden Gattung Halicore und der ausgerotteten Rhytina. Die verwandtschaftlichen Beziehungen der Sirenen zu den Ungulaten und der verschiedenen Sirenen-Gattungen unter einander lassen sich daher etwa in folgender Weise darstellen: 


\section{Ungulata}

I. Ungulata terrestria:

1. Perissodactyla

2. Artiodactyla

3. Proboscidea

II. Ungulata natantia:

4. Sirenia

$\begin{array}{ll}\text { Halitherium } & \text { Prorastomus } \\ \text { Metaxytherium } & \text { Manatus } \\ \text { Felsinotherium } & \\ \text { Halicore } & \\ \text { Rhytina. } & \end{array}$




\section{Erklärung der Tafeln.}

Die Originale der Abbildungen befinden sich sämmtlich im Grossherzoglichen Museum zu Darmstadt. Nur auf Taf. X Fig. 96 sind die Prämolaren der linken Zahnreihe nach einem Schädel des Heidelberger Universitäts-Museum ergänzt, und die drei Ansichten der Rhytina auf Taf. X Fig. 98-100 sind gezeichnet nach Photographien, deren Originale in Stockholm aufgestellt sind.

Alle Kuochen sind zuerst in ganzer oder in halber Grösse mittelst Zeichen-Apparates und Diopter aufgezeichnet worden, sodass die Umrisse absolut genau sind. Wo keine gegentheilige Angabe gemacht ist, sind die Knochen in natürlicher Grösse gezeichnet.

\section{'Taf. I.}

Fig. 1. Halitherium Schinzi aus dem oligocaenen Meeressande von Alzey in Rheinhessen. Schädel von oben, ohne die Gesichtsknochen.

Fig. 2. Derselbe Schädel von unten. Diese beiden Abbildungen zeigen die Art und Weise der Erhaltung, in welcher gewöhnlich diese fossilen Schädel in den Meeressanden des Mainzer Beckens gefunden werden: der Ober- und Zwischenkiefer sind vom Stimbein abgebrochen; der Ohrapparat fehlt, die dicken Knochen der Schädelkapsel selbst sind häufig durchgebrochen.

\section{Taf. II.}

Fig. 3. Derselbe Schädel, wie auf Taf. 1 von der Seite. Der Jochfortsatz des Schläfenbeins zeigt seine bedeutende Grösse.

Fig. 4. Stirnbein vom Gehirn aus gesehen mit dem Siebbein darin, von einem andern Thier von Alzey. Die Zeichnung steht aus Versehen auf dem Kopf. Die untere Hälfte der Siebplatte ist abgebrochen und die Muschelwuilste mit der perpendiculären Platte erscheinen.

Fig. 5. Der vordere Theil des Stimbeins und die äussere Nasenöffnung eines noch jungen Thieres von Flonheim. Der Ansatz des Oberkiefers an der inneren Seite des processus orbitalis des Stirnbeins und am Nasenbein ist zu sehen; feruer die rauhe Fläche und die Rinne, auf welchen der Stirnfortsatz des Zwischenkiefers aufliegt. Das obere Horn des Labyrinthes des Siebbeins schaut ein wenig unter dem Nasenbein vor. Auf der Nasentläche des linken Oberkiefers liegt die eine Hälfte des Vomer. Zwei Zahuwurzeln haben den Oberkiefer durchbohrt.

Fig. 6. Linke Pyramide und Warzentheil des Schläfenbeins von demselben Schädel, wie Fig. 5. Paukentheil, Hammer und Ambos, Steigbügel und Labyrinththeil des Felsenbeins von vorn gesehen und so gedreht, dass der Paukentheil, statt horizontal, vertikal gerichtet steht.

Fig. 7. Dasselbe Stück wie Fig. 6 von hinten gesehen und in demselben Sinne gedreht. Das Felsenbein sitzt fest im Warzentheil.

Fig. 8. Labyrinththeil, Hammer, Ambos und Steigbügel von demselben Stuick, wie Fig. 6 und 7 im Umriss. 
Fig. 9. Paukentheil, Hammer und Ambos von demselben Stück im Umriss.

Fig. 12. Paukentheil und Hammer durch den processus longus mallei verbunden und Paukentheil mit der vorderen Ecke des Felsentheils verwachsen; zwischen beiden Ansätzen die fissura Glaseri. Umriss des Gehörs vom Stiick Fig. 6 und 7.

Fig. 10. Rechtes Schläfenbein, zu demselben Schädel wie Fig. 4 gehörig, vom Gehirnraum aus gesehen. Von der Schuppe siebt man die rauhen Nahtflächen zum Scheitelbein, vorn die tiefe Nahtgrube für den Temporalfliigel des Wespenbeins und dahinter den oben kurz abgebrochenen Jochfortsatz; links kommt der processus mastoideus unter dem Felsentheil heraus und trägt den Fuss des hinteren Hornes des abgebrochenen Paukentheils. Der Felsentheil ruht in der Schuppe und zeigt den Labyrinthwulst und den Hammer.

Fig. 13. Linkes Schläfenbein von dem gleichen Schädel, wie Fig. 10 und 4, von unten gesehen. Auf der breiten Brücke zum Jochfortsatz erscheint die Gelenktläche für den Unterkiefer. Der Paukentheil spanut sich uiber den Hammer, mit dem Fuss seines hinteren Hornes etwas vom processus mastoideus abstehend.

Fig. 11. Coprolith mit dem Halitherium Taf. I zusammen gefunden und wohl zu ihm gehörig.

Taf. III.

Oberkiefer, Zwischenkiefer und Jochbein vom Halitherium.

Fig. 14. Zwischenkiefer von einem Schädel von Flonheim, von oben gesehen. Die obere Hälfte der Stirnnähte ist weggebrochen.

Fig. 15 und 16. Zwischenkiefer von der Seite gesehen mit beiden Stosszähnen. Der Alveohartheil und der Stimast sind verletzt. Die Gefässkanäle zur Ernährung der Stosszähne sind zum Theil erhalten.

Fig. 17. Linkes Jochbein vom Schädel Fig. 5, a von aussen, b von innen, c von unten gesehen. Ein Stiickchen von dem Jochfortsatz des Oberkiefers haftet innen an.

Fig. 18. Oberkiefer zu dem Schädel Fig. 5 eines noch jungen Thieres gehörig. Auf der linken Seite sind alle vier dreiwurzeligen Backenzähne erhalten, auf der rechten nur drei und die Alveolen des ersten; die beiden vierten Backenzähne Fig. $8 \mathrm{a}$ und b) waren noch nicht hervorgebrochen, denn sie sind gar nicht angekaut. Zwei Alveolen der einwurzeligen Prämolaren sind sichthar.

Fig. 19. Der dritte, rechte Backenzahn von einem noch jüngeren Thier, noch nicht angekaut.

Fig. 20. Der vierte, linke Backenzahn eines andern Thieres, nicht abgekaut.

Fig. 21. Oberkiefer eines alten Thieres von Flonheim, von oben gesehen. Der Stirnfortsatz mit der runzeligen Oberfläche für den Ansatz des Zwischenkiefers ragt über dem foramen infraorbitale empor.

Fig. 2.2. Oberkiefer eines alten Thieres von Alzey. Jederseits ist der zweite, dritte und vierte (letzte) Backenzahn, stark abgekaut erhalten; davor die dreiwurzelige Alveole des ersten Backenzahnes. Auf der rechten Seite sitzt noch die eine Wurzel des zweiten Prämolaren.

Fig. 23. Erster (hinterster), rechter Prümolar des Oberkiefers.

Fig. 24. Vierter, rechter Holar, wenig abgekaut. 
Figr. 25. Erster, linker Prämolar, a von oben, b von der Seite.

Fig. 26. Vierter, linker Molar, wenig abgekaut.

Taf. IV.

Unterkiefer vom Halitherium.

Fig. 27. 28. 29. Einzelne, ausgefallene Prämolaren des Unterkiefers.

Fig. 30. Unterkiefer von Flonheim, rechte Hälfte von innen gesehen. Der letzte, vierte Backenzahn sitzt noch im Knochen. Die Prämolaren und der erste Molar sind bereits ausgefallen.

Fig. 31. Derselbe Unterkiefer, linke Hälfte von aussen gesehen. Der erste Molar ist stark abgekaut und steht schon auf schwachen Wurzeln. Die foramina mentalia sind sichtbar.

Fig. 32. Die beiden Hälften desselben Unterkiefers von oben gesehen. Man sieht mehrere einwurzelige Alveolen der Prämolaren und die absteigende raube Fläche davor.

Fig. 32 a. Der vierte, linke Backenzahn des Unterkiefers Fig. 32 aus der Alveole herausgenommen und von der inneren Seite, b von oben gesehen.

Fig. 33. Zweiter, rechter Backenzahn des Unterkiefers, halb abgekaut.

Fig. 34. Dritter, rechter Backenzahn des Unterkiefers, kaum erst abgekaut, von einem jungen Thiere.

Fig. 35. Vierter, linker Backenzahn des Unterkiefers, halb abgekaut.

Fig. 36. Dritter, linker Backenzahn des Unterkiefers, mehr als halb abgekaut.

Taf:. V.

Auf dieser Tafel sind die einzelnen Schädelknochen des Halitherium, von einander losgetrennt, in halber Grösse dargestellt, und Quer- und Längsschnitte des Schädels gezeichnet, damit die Fortsätze und Theile der Kopflnochen möglichst klar vor Augen liegen. Es empfahl sich diese dem technischen Zeichnen entnommene Methode ganz besonders für die Darstellung dieser complicirten Organe. Die Umrisse wurden, wie auf den übrigen Tafeln, sämmtlich mit dem Zeichen-Apparat und dem Storchschnabel genommen. Die schräge Schraffirung giebt die Schnittflächen durch die Knochen an.

Fig. 37. Mx Os maxillae, Schnitt nach Fig. 38, a-b, von vorn gesehen.

Pf processus frontalis.

Fi foramen infraorbitale.

Pzo processus zygomatico-orbitalis.

$\mathrm{Sz}$ sutura zygomatica.

$m^{2}$ dens molaris secundus.

$\mathrm{p}^{3} \quad$ dens praemolaris tertius.

Fig. 38. Mx Os maxillae, linke Hälfte.

lf processus frontalis.

Sl sulcus lacrymalis.

IL locus ossis lacrymalis.

$\mathrm{Sz}$ sutura zygomatica.

Sin sutura incisiva.

Pra processus alveolaris. 
$\mathrm{m}^{2}, \mathrm{~m}^{3}, \mathrm{~m}^{4}$ dentes molares $\mathrm{II}-\mathrm{IV}$.

$\mathrm{m}^{3}$ dens praemolaris tertius.

Fig. 39. T Os temporum.

$\mathrm{Pz}$ processus zygomaticus.

Sst sutura sphenoidalis alate temporalis.

Psq pars squamosa.

Ipr incisura parietalis.

Cp cavum pyramidis.

Mtg margo tympanicus.

Prm processus mastoideus.

Fig. 39a. T Os temporum, Schnitt nach Fig. 39a-b. Die Bezeichnungen sind dieselben, wie in der vorigen Figur.

Fig. 40. Z Os zygomaticum.

Po processus orbitalis.

$\mathrm{Pm}$ processus malaris.

$\mathrm{Tm}$ tuberositas malaris.

Sm sutura maxillaris.

x Fläche für die Auflagerung des Jochfortsatzes des Schläfenbeins.

Fig. 41. Py Pyramis.

Ply pars labyrinthica.

Pt pars tympanica.

Mai meatus acusticus internus.

Av aquaeductus vestibuli.

Fig. 42. Stapes.

Fig. 43. Incus.

Fig. 44. Malleus.

Mm manubrium mallei.

Fig. 45. Py Pyramis.

Ppet pars petrosa.

Pt pars tympanica.

Mn manubrium mallei.

Fec fenestra cochleae.

Fig. 46. I Os incisivum.

Pal processus alveolaris.

ii dentes incisivi.

Pfr processus frontalis.

Fig. 47. V Vomer.

Av alae vomeris.

$\mathrm{Pm}$ processus maxillaris.

Fig. 48. N Os nasi. Schnitt nach Fig. 49a-b. 
Fig. 49. N Os nasi.

$r$ radices nasales.

1 sutura ossis frontis externa.

3 sutura ossis frontis interna.

2 sutura processus frontalis ossis incisivi.

Fig. 50. F Os frontis.

Ff facies frontalis.

Sfr sutura frontalis.

Pn processus nasalis.

Sn sutura ossis nasi.

Po processus orbitalis.

Sc sutura coronalis.

Fig. 51. $\operatorname{Pr}$ Os parietale.

Prp processus parietalis.

Lt linea temporalis.

In os interparietale.

Fig. 52 und 53. 0 Os occipitis.

C corpus ossis occipitis.

Pc processus condyloideus.

Ppm processus jugularis s. paramastoideus.

Ch canalis hypoglossi.

Fo foramen occipitale.

P] partes laterales.

Fm foramen mastoideum.

Lnm linea nuchae mediana.

Sq squama ossis occipitis.

Poe protuberantia occipitis externa.

Fig. 54. I Os incisivum, Schnitt nach Fig. 46a-b.

Pfr processus frontalis.

Sim sutura incisiva mediana.

Si sinus incisivus.

Pal processus alveolaris.

Din dens incisivus.

Fig. 55. F Os frontis, Ansicht von vorn.

E os ethmoideum.

Cs concha superior ossis ethmoidei.

Lpe lamina perpendicularis ossis ethmoidei.

$\mathrm{N}$ os nasi.

Mx processus frontalis ossis maxillae.

I processus frontalis ossis incisivi.

Po processus orbitalis ossis frontis. 
Fig. 56. Schnitt nach Fig. 58c-d.

F os frontis.

Prp processus parietalis ossis parietalis.

E os ethmoideum.

Lc lamina cribrosa ossis ethmoidei.

Cn conchae ossis ethmoidei.

S os sphenoideum.

Fig. 57. S Os sphenoideum.

At ala temporalis.

St sutura temporalis.

Sa spina angularis.

Fo foramen ovale.

Fos fissura orbitalis superior.

Ao ala orbitalis.

Co canalis opticus.

Ppt processus pterygoideus.

Ssp spina sphenoidalis.

Fig. 58. E Os ethmoideum.

Lc lamina cribrosa.

$\mathrm{Cg}$ crista galli.

Cn conchae.

Cs cornu conchae superioris.

$\mathrm{N}$ os nasi.

$\mathrm{F}$ os frontis.

Po processus orbitalis ossis fronitis.

$\operatorname{Pr}$ os parietale.

Sc corpus ossis sphenoidei.

Fig. 59. Schnitt nach Fig. 58 a-b.

E os ethmoideum.

Cn conchae ossis ethmoidei.

$\mathrm{N}$ os nasi.

F os frontis.

S os sphenoideum.

Ao ala orbitalis ossis sphenoidei.

Fig. 60. Querschnitt des Schädels mitten durch den Gehirnraum nach Fig. 61 a-b. S os sphenoideum.

At ala temporalis ossis sphenoidei.

Fos fissura orbitalis superior interna.

Ppt processus pterygoideus ossis sphenoidei.

$\mathrm{T}$ os temporum. 
Pcz processus zygomaticus ossis temporum.

$\mathrm{Sq}$ squama ossis occipitis.

Fo foramen occipitale.

$\operatorname{Pr}$ os parietale.

Spp spina parietalis interna.

Fig. 61. Längsschnitt der Schädelkapsel.

Oc corpus ossis occipitis.

Opc processus condyloidei ossis occipitis.

Osq squama ossis occipitis.

Poe protuberantia occipitis externa.

$\operatorname{Pr}$ os parietale.

Spp spina parietalis interna.

F 0 os frontis.

Fpo processus orbitalis ossis frontis.

$\mathrm{N}$ os niasi.

Spe lamina perpendicularis ossis ethmoidei.

At ala temporalis ossis sphenoidei.

Ppt processus pterygoideus ossis sphenoidei.

Py pyramis ossis temporum.

Ppet pars petrosa pyramidis.

\section{Taf. VI.}

Fig. 62. Verbogener unterer Theil des Brustbeins vom Halitherium, innere Seite.

Fig. 63. Oberer Theil des Brustbeines, äussere Seite.

Fig. 64. Oberarmknochen.

Fig. 65. Unterarmknochen, radius und ulna mit einander verwachsen.

Fig. 66 und 69. Mittelhandknochen.

Fig. 67 und 68. Phalangen.

Fig. 70 a und b. Gelenkköpfchen der ersten Rippe, abgebrochen vom Körper.

Fig. 71. Letzte Rippe.

Fig. 72. Schulterblatt eines alten Thieres.

Fig. 73 unteres, 74 mittleres, 75 oberes Stück des Brustbeines eines ausgewachsenen Thieres.

\section{Taf. VII.}

Beckenknochen, Oberschenkel und Rippen des Halitherium.

Fig. 76 und 77 rechter und linker rudimentärer Femur ein und desselben Thieres von Alzey; die unteren Enden beider Knochen sind abgebrochen.

Fig. 78. Erste Rippe, bedeutend breiter als die übrigen Rippen.

Fig. $79 \mathrm{a}$ und b. Ein und derselbe rudimentäre Femur eines Thieres von Alzey, Ansicht von beiden Seiten; dieser Knochen ist vollständig erhalten, nur die Obertläche etwas abgewittert. 
Fig. $83 \mathrm{a}, \mathrm{b}$ und c. Rudimentärer Femur eines Thieres von Flonheim, von drei Seiten gesehen, vollständig und gut erhalten. Caput, collum, trochanter major und minor sichtbar; das untere Ende des Schenkels ist zugeschärft und olne Gelenkfläche.

Fig. 86. Wahrscheinlich eine rudimentäre Rippe vom letzten Rückenwirbel.

Fig. 80, 81, 82, 84 und 85. Beckenknochen, verschieden gestaltet von verschiedenen Thieren von Alzey und Flonheim. Jeder Knochen zeigt die Gelenkpfanne für den rudimentären Fenur. Vergleiche damit die Beckenknochen von Halicore und Manatus auf der nächsten Tafel.

\section{Taf. VIII.}

Fig. 87. Schädel und Unterkiefer eines alten Halitherium von Alzey, von der Seite gesehen, in halber Grösse.

Fig. 88 a und b. Umriss des rudimentären Beckenknochens von Halicore Dugong ans dem rothen Meer. Von einem vollständigen Skelett.

Fig. 89. Umriss des rudimentären Beckenknochens von Manatus australis aus Surinam. Von einem vollständigen Skelett.

Fig. 90. Schiddel von Halicore Dugong aus dem rothen Meer, Seitenansicht in halber Grösse. Von einem alten und sehr grossen Thiere.

Fig. 91. Wiederherstellung des Skelettes von Halitherium Schinzi, vervollständigt nach Kaup's Zeichnung, im Maasstab $1: 6$.

\section{Taf. $\mathbf{I X}$.}

Fig. 92. Schädel des Halitherium Schinzi von Alzey, von oben gesehen und in halber Grösse gezeichnet. Der Vomer und der Zwischenkiefer sind unvollständig, alle andern Knochen vollständig erhalten.

Fig. 93. Schiadel einer Halicore Dugong aus dem rothen Meere, von einem jüngeren und kleineren Thier, als Fig. 90; von oben gesehen und in halber Grösse gezeichnet.

Fig. 94. Schädel des Manatus austrilis von Surinam, von der Seite und in halber Grösse gezeichnet.

Fig. 95. Derselbe Schädel wie Fig. 94 von oben gesehen und in halber Grösse gezeichnet.

'Taf. $x$.

Fig. 96. Schädel von Halitherium Schinzi von Flonheim, fast vollständig erhalten, von unten gesehen, ohne den Unterkiefer, und in halber Grösse gezeichnet. Die drei Prämolaren der linken Zahnreihe sind nach einem Schädel von Flonheim, der sich im Heidelberger UniversitätsMuseum befindet, ergänzt.

Fig. 97. Hinterwand des Schädels Fig. 96, in halber Grösse gezeichnet.

Fig. 96. 99 und 100. Abbildung eines Schädels von Rhytina Stelleri, gezeichnet nach Photographien, welche nach den Originalen in Stockholm genommen wurden. Diesen Schädel fand Nordenskjöld mit mehreren Skeletten im Jahre 1880 auf seiner Umsegelung Asiens in den Sanden am Strande der Berings-Insel bei Kamschatka. 




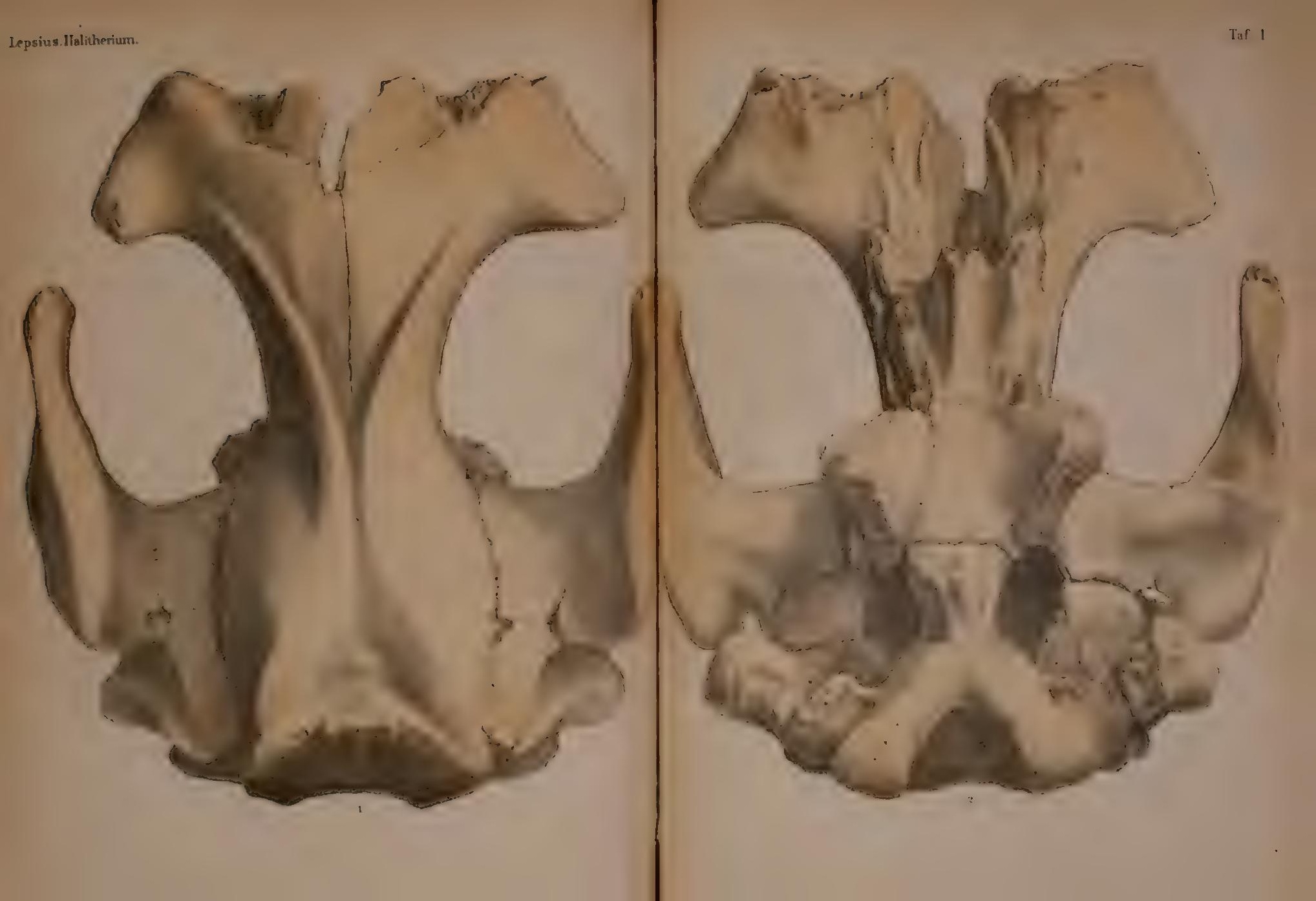







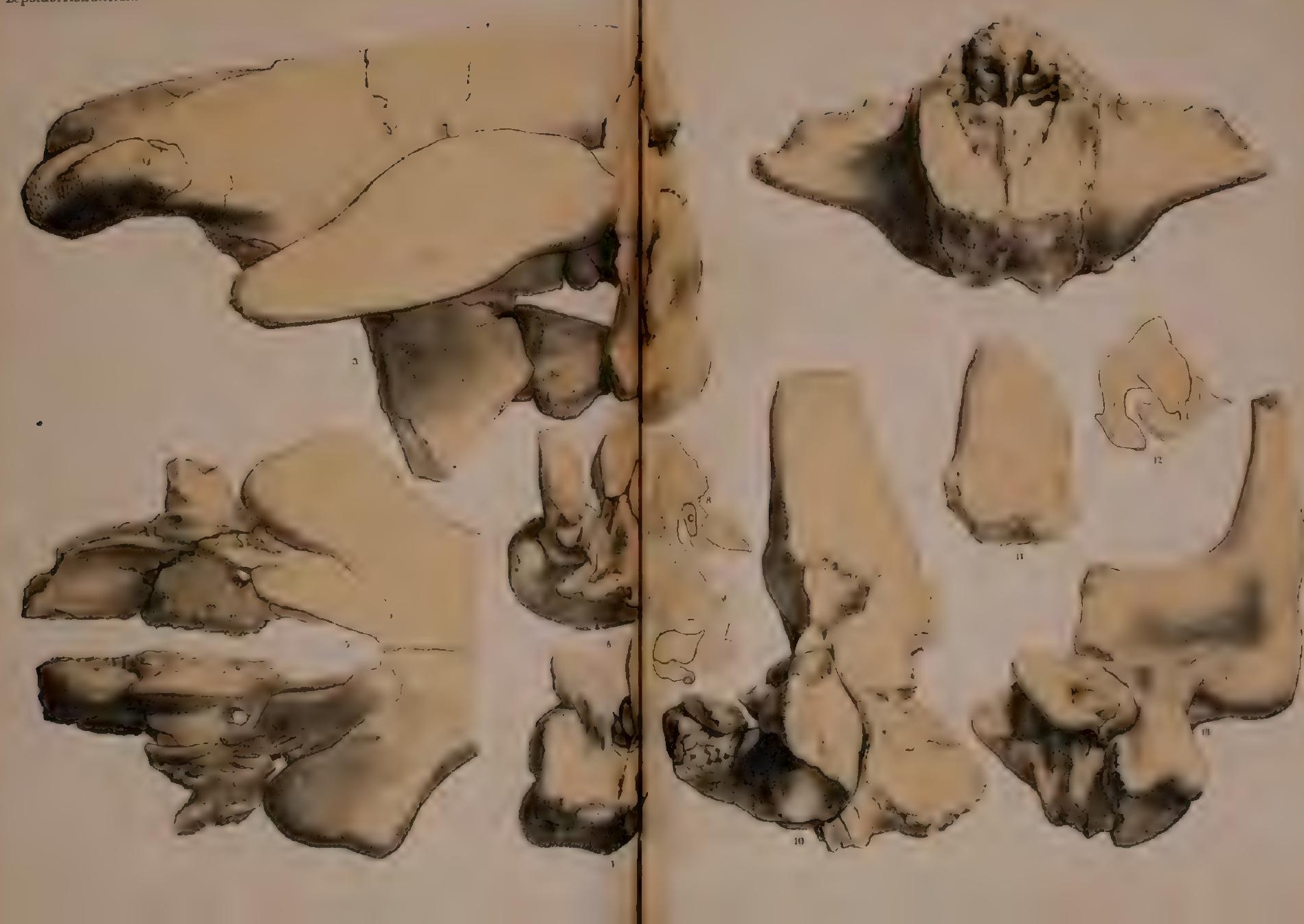







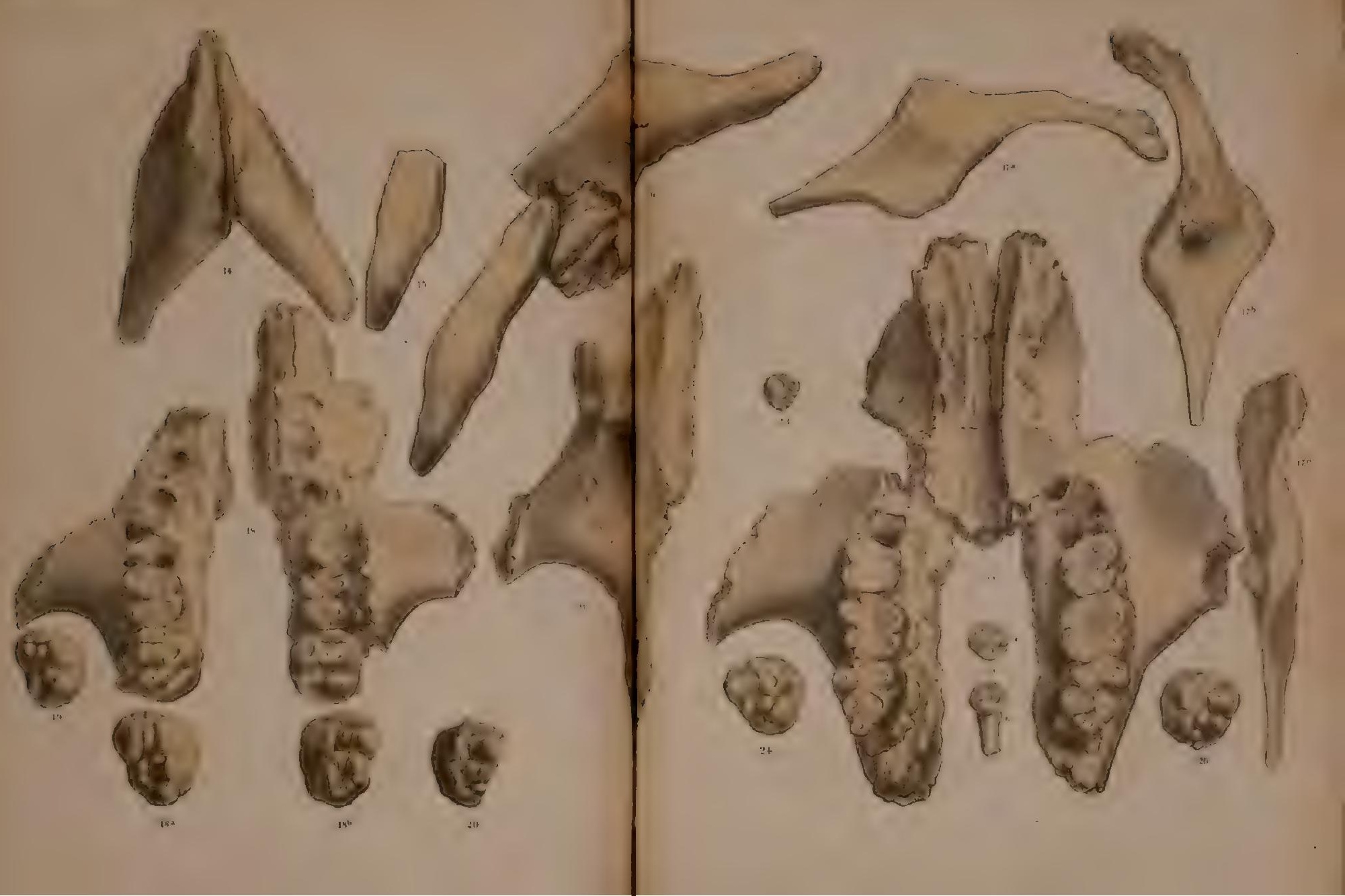







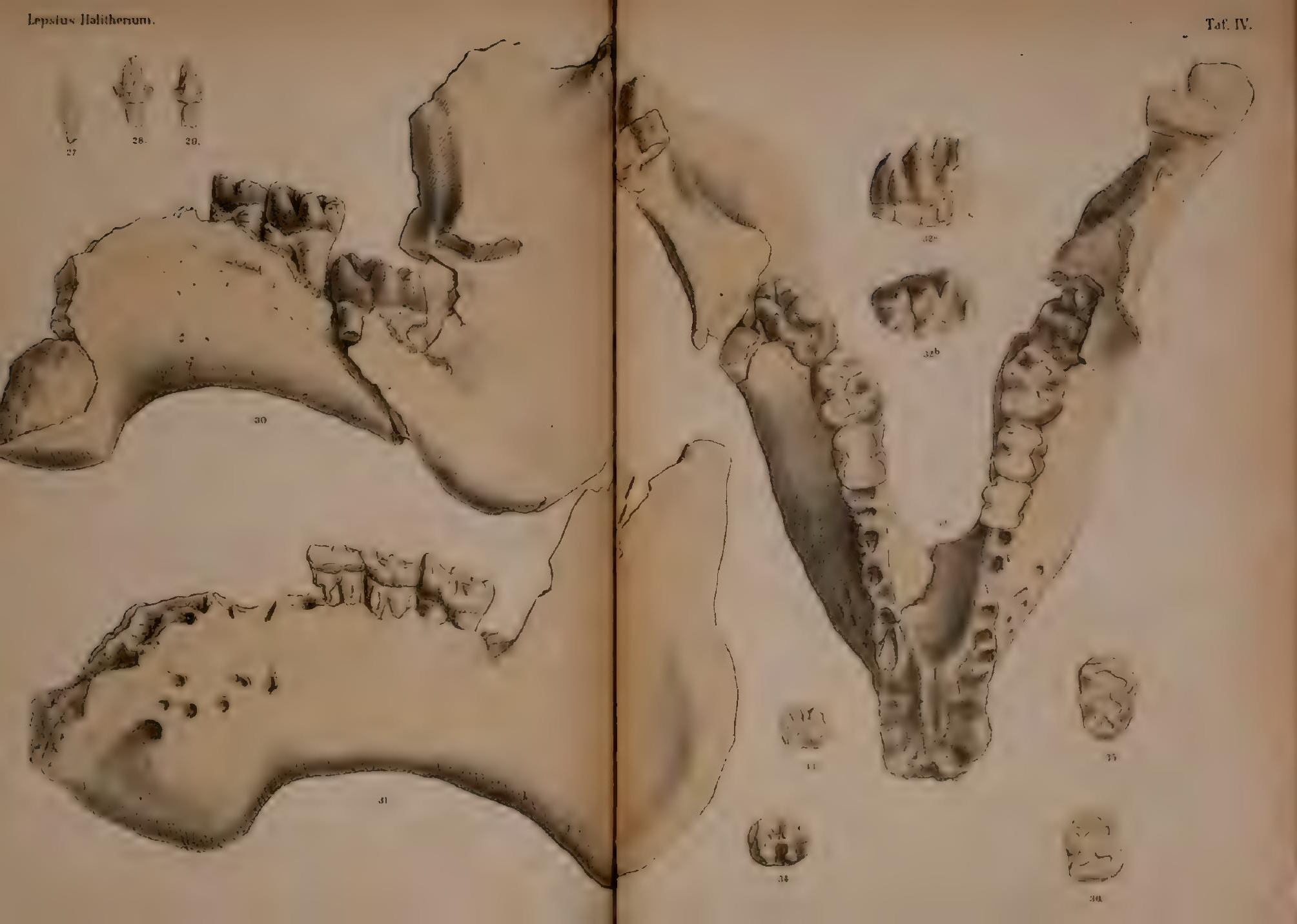



. 




epsius. Halitherium-

TarlT

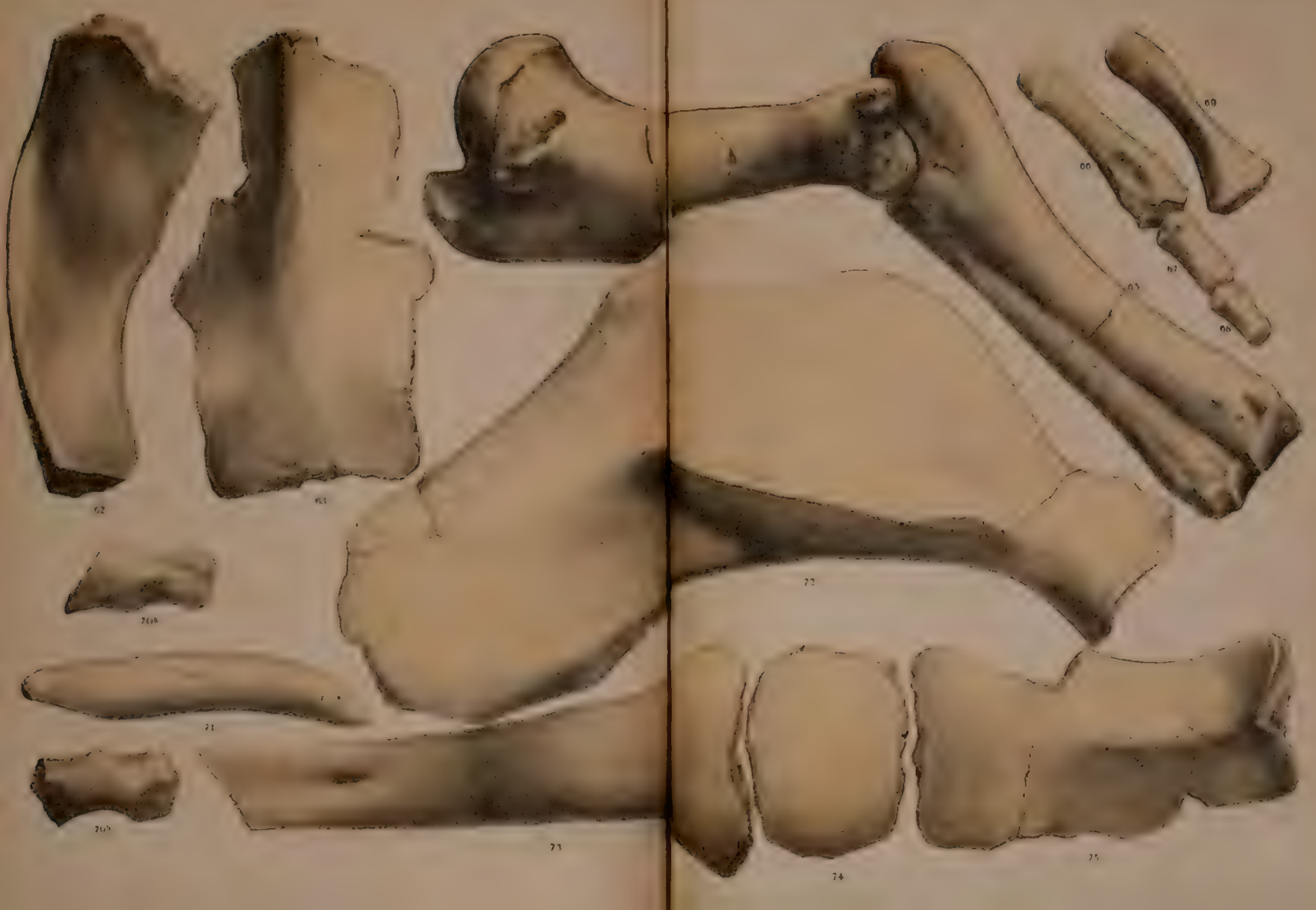

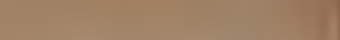

$1-5$

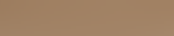

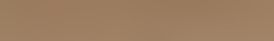
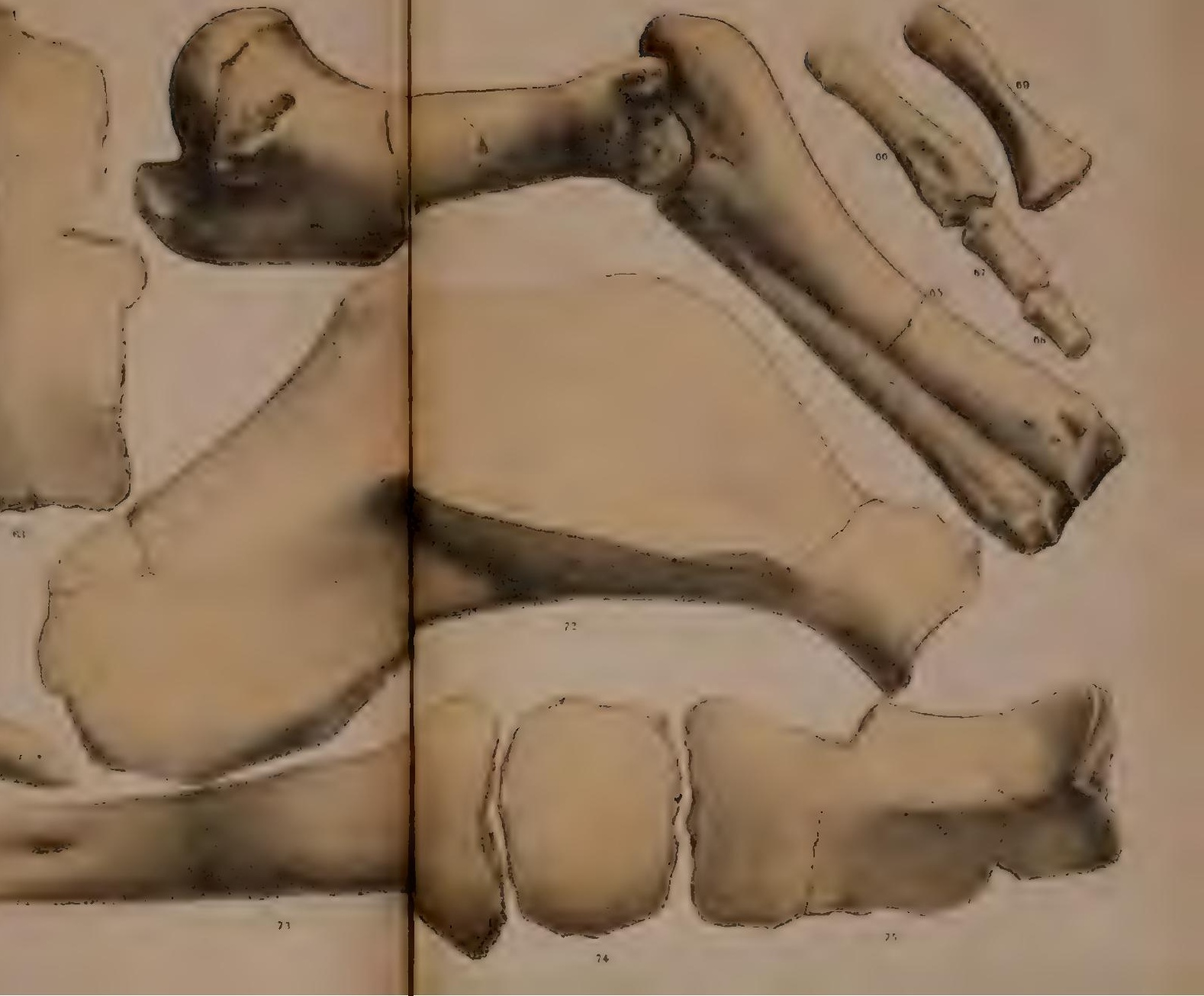

. 









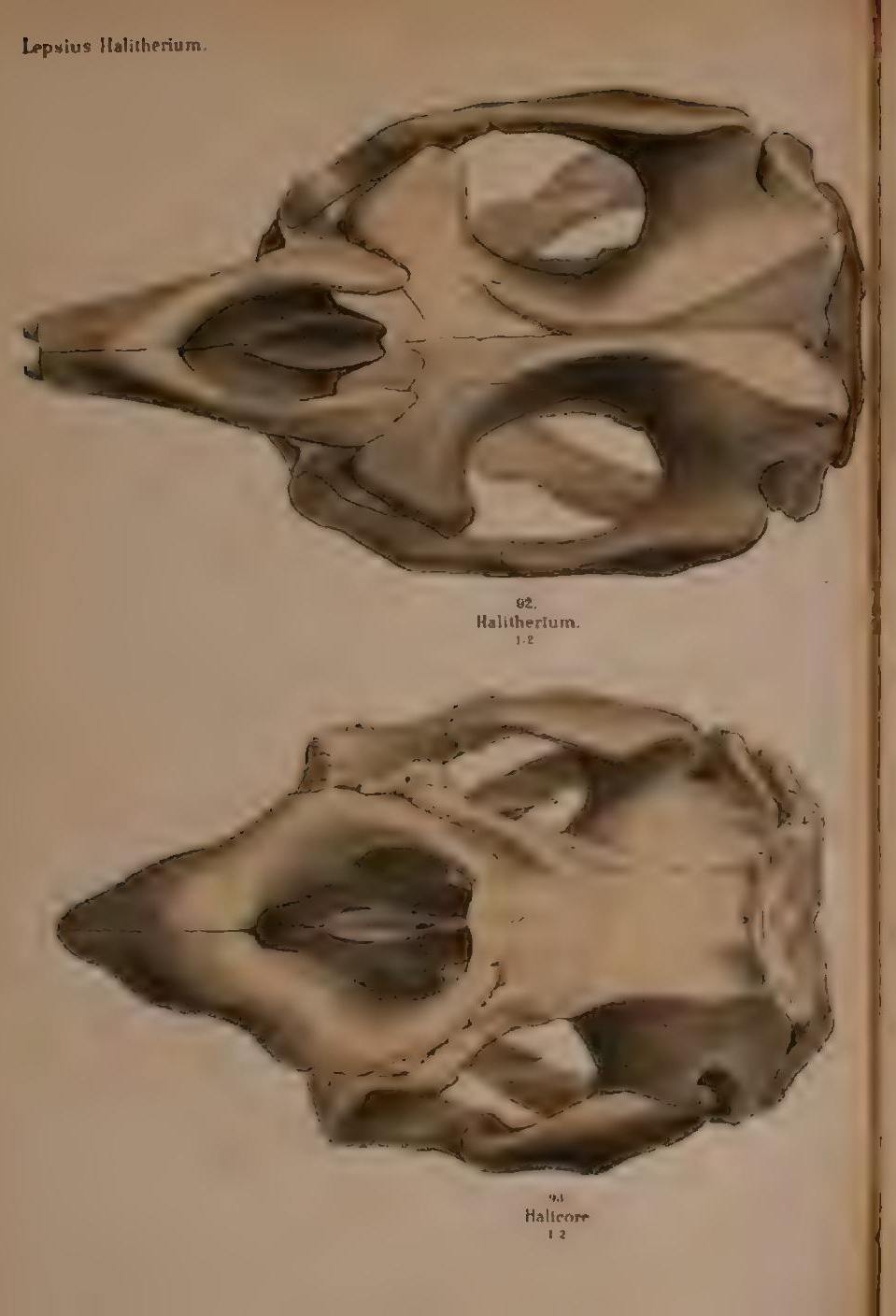

Taf. IX.
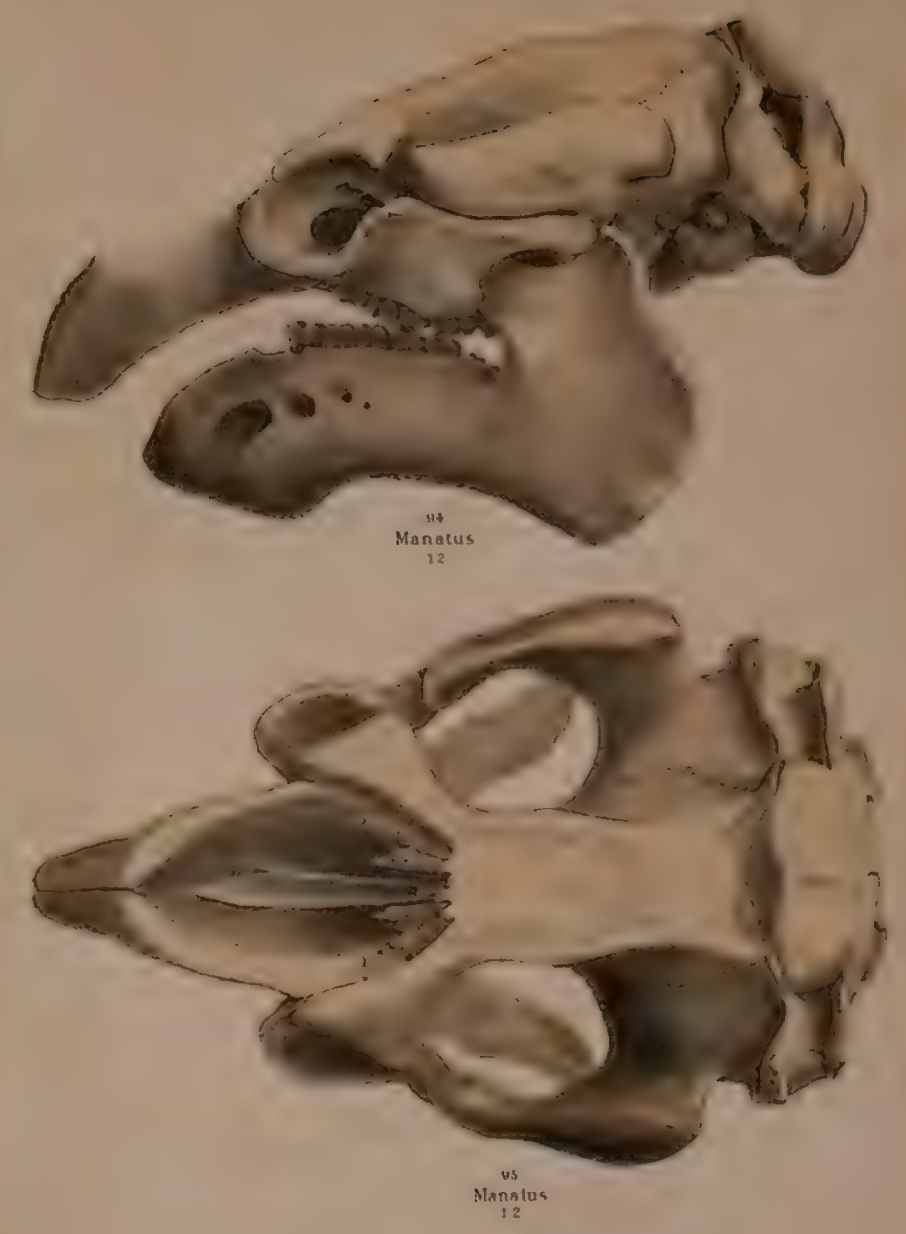



Lepsius. Halıtherrum.

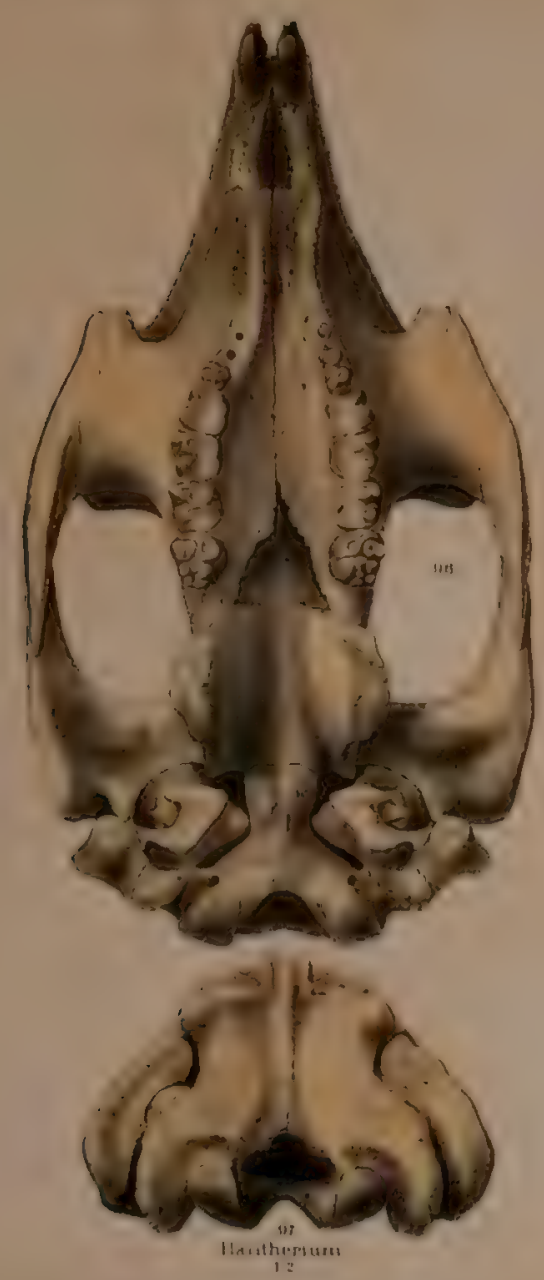

Taf: $\mathrm{x}$
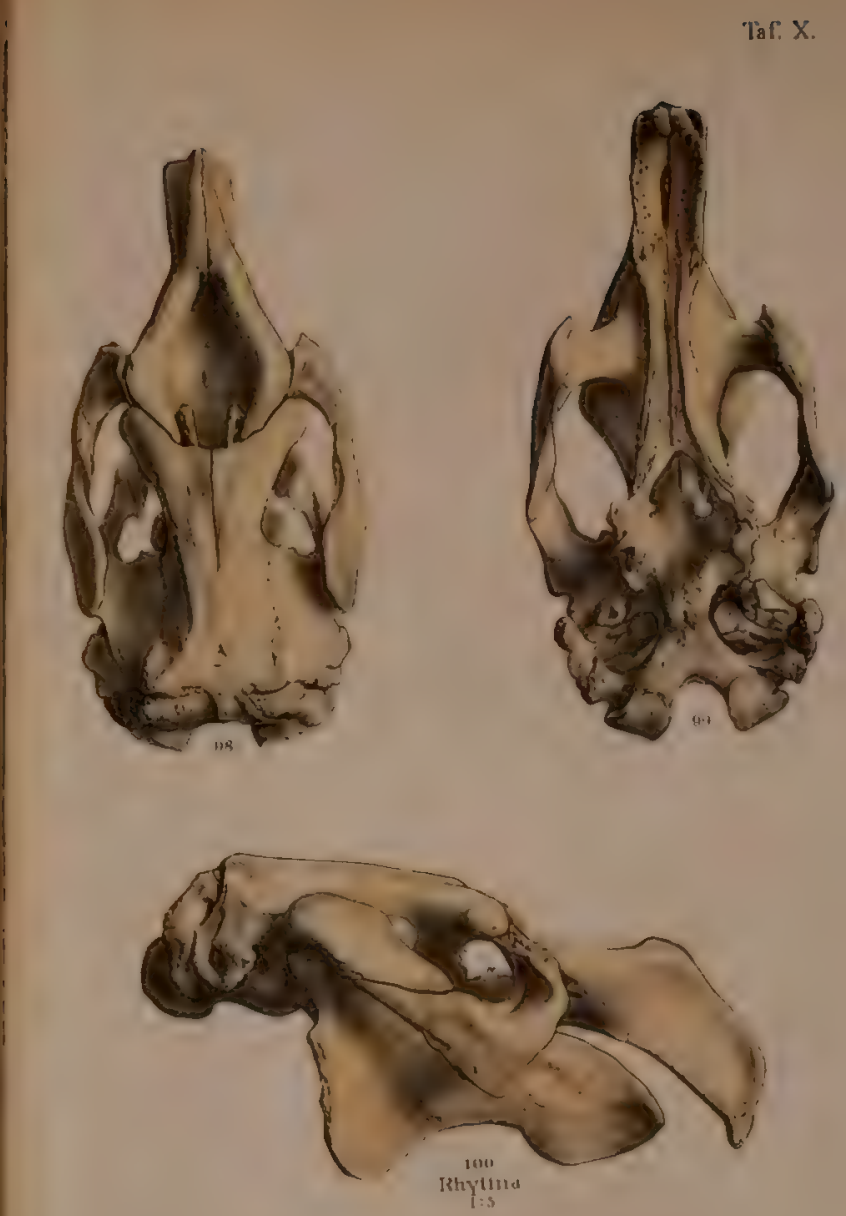



